\author{
Universidade de São Paulo \\ Instituto de Física
}

\title{
Estudo teórico de complexos polipiridínicos de Ru-Aqua/Oxo em solução aquosa
}

\section{Leandro Rezende Franco}

Orientador(a): Prof ${ }^{\mathrm{a}}$. Kaline Coutinho

Tese de doutorado apresentada ao Instituto de Física da Universidade de São Paulo, como requisito parcial para a obtenção do título de Doutor em Ciências.

Banca Examinadora:

Prof ${ }^{\mathrm{a}}$. Dr ${ }^{\mathrm{a}}$. Kaline Rabelo Coutinho - Orientador (IFUSP)
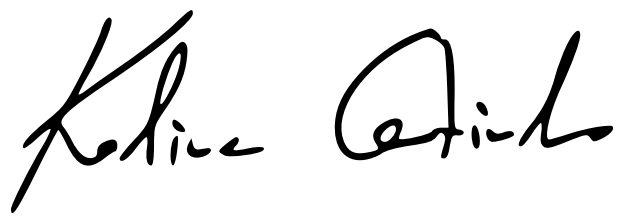

Prof. Dr. Adriano Mesquita Alencar (IFUSP)

Prof. Dr. Ataualpa Albert Carmo Braga (IQUSP)

Prof. Dr. Willian Ricardo Rocha (UFMG)

Prof. Dr. Gustavo Troiano Feliciano (UNESP) 
FICHA CATALOGRÁFICA

Preparada pelo Serviço de Biblioteca e Informação do Instituto de Física da Universidade de São Paulo

\section{Franco, Leandro Rezende}

Estudo teórico de complexos polipiridínicos de Ru-Aqua/Oxo em solução aquosa. São Paulo, 2020.

Tese (Doutorado) - Universidade de São Paulo. Instituto de Física, Depto. de Física Geral.

Orientador: Profa. Dra. Kaline Rabelo Coutinho

Área de Concentração: Física Molecular

Unitermos: 1. Fluídos Complexos; 2. Física Computacional; 3. Estrutura eletrônica. 
University of São Paulo

Physics Institute

\section{Theoretical study of Ru-Aqua/Oxo polypyridine complexes in aqueous solution}

\section{Leandro Rezende Franco}

Supervisor: Profa. Kaline Coutinho

Thesis submitted to the Physics Institute of the University of São Paulo in partial fulfillment of the requirements for the degree of Doctor of Science.

Examining Committee:

Prof $^{\mathrm{a}}$. Dr ${ }^{\mathrm{a}}$. Kaline Rabelo Coutinho - Supervisor (IFUSP)

Prof. Dr. Adriano Mesquita Alencar (IFUSP)

Prof. Dr. Ataualpa Albert Carmo Braga (IQUSP)

Prof. Dr. Willian Ricardo Rocha (UFMG)

Prof. Dr. Gustavo Troiano Feliciano (UNESP) 

Em memória de minha querida mãezinha lolanda 



\section{Agradecimentos}

Agradeço à Profa . Kaline Coutinho por ter me aceito em seu grupo de pesquisa, e por ter me orientado durante o período de doutorado. Agradeço por toda dedicação e tempo despendidos ao meu lado, com o objetivo de me ajudar a crescer como cientista. Sou muito grato por todo conhecimento e experiência compartilhados. Para onde eu for, levarei comigo um eterno sentimento de gratidão por tudo que recebi. Em nome do Prof. Sylvio Canuto, agradeço a todos os integrantes do grupo de Física Molecular e Modelagem, por todos os momentos de aprendizagem e socialização que compartilhamos nos seminários do grupo, nos cafés de sexta-feira e nas confraternizações. Aqui aproveito para agradecer ao carinho de um trio especial de mulheres que abrilhantam o DFGE: Fátima \& Bianca \& Edineusa. Agradeço ao meu amigo Danillo Valverde, que sempre esteve presente na minha jornada de pesquisa em São Paulo. Agradeço por todas as discussões científicas que tivemos, pela companhia e amizade fora da academia, aonde se fez também presente a sua esposa Sueny Valverde, a quem estendo esse agradecimento. Agradeço a amizade e companhia de muitas outras pessoas maravilhosas, que tornaram a minha jornada em São Paulo um dos melhores momentos da

minha vida. Agradeço em especial a 10 amigos da pós-graduação, que foram muito presentes nos últimos anos: Adriana Valerio, Alexsander Vendite, Ana Camila, Arthur Prado, Henrique Musseli, Marcelo Cadernuto, Matheus Lazarotto, Peter Park, Ricardo de Lima, Tárcius Ramos. Reforço aqui que sou muito grato pelo carinho, amizade e apoio que recebi de todos vocês. Agradeço também a minha querida amiga carioca Thayx de Lima, pela amizade preservada desde os tempos de graduação, quando eu ainda estava aprendendo a nadar. Agradeço a minha querida amiga baiana Elaine de Jesus pela amizade, carinho e tempo compartilhados. Agradeço também as minhas amigas Daniela Sidrim, Bárbara Peluzo, Gelaysi Moreno e Ana Paula pela amizade e apoio. Do lado de fora da universidade, eu sou muito grato ao amor da minha família, meus pais Adinaldo \& lolanda e meu irmão Adinael. Sou também muito grato aos meus tios Jorge \& Maria Helena, que se fizeram de ponte para que eu pudesse chegar até a USP.

Agradeço ao suporte financeiro do Instituto Nacional de Ciência e Tecnologia de Fluidos Complexos (INCT-FCx) com o CNPq grant 141260/2017-3 e FAPESP grant 2014/50983-3 e da agência FAPESP com o grant 2017/11631-2. Agradeço aos recursos computacionais disponibilizados pelo Centro de computação HPC-USP; Agradeço aos recursos humanos e infraestrutura disponibilizados pelo Instituto de Física da USP.

O presente trabalho foi realizado com apoio da Coordenação de Aperfeiçoamento de Pessoal de Nível Superior - Brasil (CAPES) - Código de Financiamento 23038.004630/2014-35. 

"Não morre aquele que deixou na terra a melodia de seu cântico na música de seus versos." 



\section{Resumo}

FRANCO, L. R. Estudo teórico de complexos polipiridínicos de Ru-Aqua/Oxo em solução aquosa. 2020. 252 p. Tese de Doutorado - Instituto de Física, Universidade de São Paulo, São Paulo, 2020.

Avanços recentes no desenvolvimento da fotossíntese artificial demonstraram a capacidade fotocatalítica de compostos polipiridínicos à base de rutênio $(R u)$ em reações de clivagem da água. A partir da clivagem da água pode-se obter gás hidrogênio, uma fonte de energia renovável, inesgotável e não poluente. Compostos com um único centro metálico e uma única coordenação aquosa se destacam por sua simplicidade de síntese e alta eficiência catalítica. Nesta tese, trazemos um estudo teórico das propriedades estruturais e eletrônicas de 5 complexos de $R u$-Aqua/Oxo mono nucleares em solução aquosa, com diferentes estados de oxidação, protonação e spin: $\left[R u^{I I}\left(\mathrm{H}_{2} \mathrm{O}\right)(\mathrm{py})(\mathrm{bpy})_{2}\right]^{2+} ;\left[R u^{I I I}\left(\mathrm{H}_{2} \mathrm{O}\right)(\mathrm{py})(\mathrm{bpy})_{2}\right]^{3+} ;\left[R u^{I I}(\mathrm{OH})(\mathrm{py})(\mathrm{bpy})_{2}\right]^{1+}$; $\left[R u^{I I I}(O H)(p y)(b p y)_{2}\right]^{2+}$ e $\left[R u^{I V}(O)(p y)(b p y)_{2}\right]^{2+}$, onde $p y=$ piridina e bpy =bipiridina. Utilizando uma abordagem multiescala que combina métodos de mecânica quântica e mecânica molecular (QM/MM), estudamos os efeitos do solvente, e da troca de prótons e elétrons entre os complexos e a solução na estrutura conformacional e eletrônica dos complexos. Investigamos a estrutura do solvente no entorno dos complexos e o papel das interações específicas soluto/solvente nas suas propriedades eletrônicas. Investigamos de forma explícita o papel do solvente nas excitações eletrônicas de elétrons de camadas de valência (espectroscopia UV-Vis) e de camadas profundas (espectroscopia fotoeletrônica de raios X - XPS). Investigamos a aplicação de diferentes metodologias na predição teórica dos pKa e potenciais redox de várias reações químicas envolvendo a troca de prótons e elétrons, de forma isolada e acoplada. Os complexos estudados tem uma estrutura conformacional bastante rígida. Os efeitos da solvatação, oxidação ou desprotonação são notados principalmente entre os átomos coordenados e o centro metálico. Na interface água/vácuo, a posição desses complexos encontra-se correlacionada com suas cargas totais: quanto menor a carga, mais próximo da superfície. Em geral, há a formação de uma primeira camada de solvatação completa com aproximadamente 70 moléculas de água, e dependendo do complexo, os grupos Aqua/Oxo realizam entre 1 a 3 ligações de hidrogênio com a solução, com tempos de vida longos. Os complexos tem orbitais de fronteira do tipo $d$ em $R u$ (HOMO ou SOMO) e $\pi^{*}$ nas bipiridinas (LUMO), que são desestabilizados em solução. Nas camadas de valência, as excitações eletrônicas ocorrem principalmente de orbitais $d$ do metal para orbitais $\pi^{*}$ dos ligantes polipiridínicos, no visível e ultravioleta, e entre orbitais $\pi$ e $\pi^{*}$ dos grupos ligantes polipiridínicos, no ultravioleta. Nas camadas eletrônicas de caroço, $R u(3 d)$ e $C(1 s)$, a energia de ligação dos elétrons sofre deslocamentos que são governados principalmente pela interação soluto-solvente até a primeira camada de solvatação. O tratamento quântico do complexo e de toda a sua primeira camada de solvatação leva a uma correta descrição dos picos de XPS. Os pKa e potenciais redox desses complexos são sensíveis ao modelo de solvente e sua polarização, e diferentes combinações de métodos QM e MM levam a valores acurados dessas propriedades. Portanto, neste trabalho, demonstramos a importância do tratamento explícito do ambiente molecular no estudo de complexos de $R u$-Aqua/Oxo, pelo qual elucidamos a estrutura e dinâmica de soluções aquosas desses complexos e os diversos processos físico/químicos envolvidos na catálise de reações de clivagem da água, desde a absorção de luz até a troca de prótons e elétrons com a solução.

Palavras-chaves: Complexos polipiridínicos de $R u$-Aqua/Oxo. Efeito Solvente. Espectroscopia UV-Vis. Espectroscopia XPS. Eletroquímica. Fotossíntese Artificial. 



\section{Abstract}

FRANCO, L. R. Theoretical study of Ru-Aqua/Oxo polypyridine complexes in aqueous solution. 2020. 252 p. Ph.D. Thesis - Instituto de Física, Universidade de São Paulo, São Paulo, 2020.

Recent advances in the development of artificial photosynthesis have demonstrated the photocatalytic capacity of ruthenium-based polypyridine compounds $(R u)$ in water cleavage reactions. Hydrogen gas can be produced from the water cleavage, a renewable, unlimited, and non-polluting energy source. Compounds with a single metallic center and single aqueous coordination stand out for their simplicity of synthesis and high catalytic efficiency. In this thesis, we present a theoretical study of the structural and electronic properties of $5 \mathrm{Ru}$-Aqua/Oxo mononuclear complexes in aqueous solution, with different states of oxidation, protonation, and spin: $\left[\mathrm{Ru}^{I I}\left(\mathrm{H}_{2} \mathrm{O}\right)(\mathrm{py})(\mathrm{bpy})_{2}\right]^{2+} ;\left[\mathrm{Ru}^{I I I}\left(\mathrm{H}_{2} \mathrm{O}\right)(\mathrm{py})(\mathrm{bpy})_{2}\right]^{3+} ;\left[\mathrm{Ru} \mathrm{u}^{I I}(\mathrm{OH})(\mathrm{py})(\mathrm{bpy})_{2}\right]^{1+}$; $\left[R u^{I I I}(O H)(p y)(b p y)_{2}\right]^{2+}$ e $\left[R u^{I V}(O)(p y)(b p y)_{2}\right]^{2+}$, where $p y=$ pyridine and $b p y=$ bipyridine. Using a multiscale approach that combines quantum mechanics and molecular mechanics $(\mathrm{QM} / \mathrm{MM})$ methods, we studied the effects of the solvent and the proton/electron transfer between the complexes and the solution in the conformational and electronic structure of the complexes. We investigated the structure of the solvent around the complexes and the role of specific solute/solvent interactions in their electronic properties. We explicitly investigated the role of the solvent in the electron excitations of valence shells (UV-Vis spectroscopy) and core shells (X-ray photoelectronic spectroscopy - XPS). We investigated the application of different methodologies in the theoretical prediction of pKa and redox potentials of various chemical reactions involving proton/electron transfer, in an isolated and coupled way. The studied complexes have a very rigid conformational structure. The effects of solvation, oxidation, or deprotonation are noted mainly between the coordinated atoms and the metal center. At the water/vacuum interface, the position of these complexes is correlated with their total charges: the lower the charge, the closer to the surface. In general, there is the formation of a first complete solvation shell with approximately 70 water molecules, and depending on the complex, the Aqua/Oxo groups make between 1 to 3 hydrogen bonds with the solution, with long lifetimes. The complexes have frontier molecular orbitals of the type $d$ in $R u$ (HOMO or SOMO) and $\pi^{*}$ in the bipyridines (LUMO), which are destabilized in solution. In the valence shells, electronic excitations occur mainly from metal $d$ orbitals to $\pi^{*}$ orbitals of the polypyridine ligands in the visible and ultraviolet spectrum range, and between the $\pi$ and $\pi^{*}$ orbitals of the polypyridine ligands in the ultraviolet range. In the electronic core shells, $R u(3 d)$ and $C(1 s)$, the electron binding energy undergoes redshifts that are governed mainly by the solute-solvent interaction up to the first solvation shell. The quantum mechanics treatment of the complex and all of its first solvation shell leads to a correct description of the XPS peaks. The pKa and redox potentials of these complexes are sensitive to the solvent model and its polarization, and different combinations of QM and MM methods can lead to accurate values of these properties. Therefore, in this work, we have demonstrated the importance of the explicit treatment of the molecular environment in the study of $R u$-Aqua/Oxo complexes, by which we have elucidated the structure and dynamics of aqueous solutions of the studied complexes and the various physical/chemical processes involved in the catalysis of water cleavage reactions, from the absorption of light to the proton/electron transfer with the solution.

Key-words: Ru-Aqua/Oxo polypyridine complexes. Solvent Effect. UV-Vis Spectroscopy. XPS Spectroscopy. Electrochemistry. Artificial Photosynthesis. 



\section{Lista de figuras}

Figura 1.1 - Estrutura orbital da piridina. . . . . . . . . . . . . . . . . . . . . 28

Figura 1.2 - Estrutura molecular dos 6 possíveis isômeros de bipiridina. . . . . . . . . . . . 29

Figura 1.3 - Conformação molecular da molécula 2,2'-bipiridina isolada e coordenada a um átomo metálico em modo bidentado. Conformação molecular da molécula 2,2':6',2"'-terpiridina isolada e coordenada a um átomo metálico em modo tridentado.

Figura 1.4 - Ligação $\sigma$ e ligação $\pi$ reversa, formadas entre um átomo de nitrogênio da piridina e um átomo metálico.

Figura 1.5 - Diagrama das transições eletrônicas e orbitais envolvidos em sistemas polipiridínicos octaédricos e com metal de transição.

Figura 1.6 - Diagrama de Jablonski para complexos polipiridínicos de rutênio, no estado singleto. . . . . . . . . . . . . . . . . . . 31

Figura 1.7 - Diagrama de Latimer para a água. . . . . . . . . . . . . . . . . . . . . . . 33

Figura 1.8 - Representação esquemática de uma célula solar de combustível baseada em fotossíntese artificial. . . . . . . . . . . . . . . . . 34

Figura 1.9 - Complexos polipiridínicos de $R u \ldots \ldots$. . . . . . . . . . . . . . 35

Figura 1.10-Complexo 2,6-di(1,8-naftiridin $-2-i l)$ piridina . . . . . . . . 35

Figura 1.11-Mecanismo catalítico proposto para o complexo 2,6 -di $(1,8$-naftiridin2 -il)piridina. . . . . . . . . . . . . . 36

Figura 1.12-Consumo de energia por fontes, no mundo. Emissão global de $\mathrm{CO}_{2}$, por ano, de 1960 a 2016. Estimativa anual da temperatura média do ar na superfície da Terra, de 1960 a 2019 . . . . . . . . . . . . . . . . . . . 38

Figura 1.13-Mapa de recursos solares: soma média diária/anual da irradiação horizontal

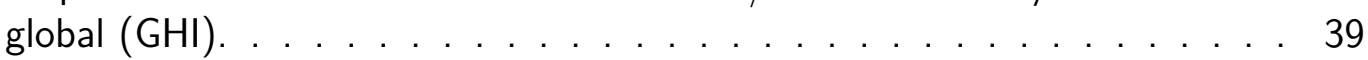

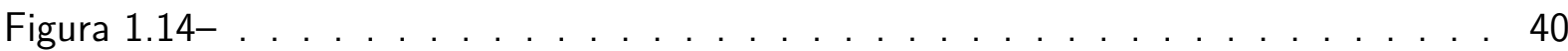

Figura 1.15-Ilustração em 3D dos complexos de $R u$-Aqua/Oxo. . . . . . . . . . . . . . . 44

Figura 3.1 - Representação esquemática das condições de contorno periódicas. . . . . . 70

Figura 3.2 - Ilustração dos três termos da equação 3.22 . . . . . . . . . . . . . . . . . 71

Figura 3.3 - Ilustração da cavidade PCM para o complexo $R u^{I I}\left(H_{2} O\right)$. . . . . . . . . 73

Figura 3.4 - Ilustração de uma configuração média ASEC para a molécula N,N-dimetilindoanilina em solução de acetonitrila. . . . . . . . . . . . . . . . . . . . . .775

Figura 3.5 - Representação bidimensional da estrutura de um líquido homogêneo. . . . . 77

Figura 3.6 - Representação de uma ligação de hidrogênio entre duas moléculas de água. 78

Figura 3.7 - Ciclo termodinâmico utilizado para o cálculo do pKa de uma molécula em solução. . . . . . . . . . . . . . . . . . . . . . . . 82 
Figura 3.8 - Ciclo termodinâmico de Born-Haber utilizado para o cálculo do potencial redox de uma molécula em solução. . . . . . . . . . . . . . . . . . . . 83

Figura 4.1 - Caixa de simulação contendo 1 complexo e 4000 moléculas de água. . . . . 88

Figura 4.2 - Ciclos termodinâmicos utilizados nos cálculos de $p K a$ e $V^{o x}$ dos complexos de $R u$-Aqua/Oxo em solução aquosa. . . . . . . . . . . . . . . . . . 98

Figura 5.1 - Ilustração em 3D da estrutura molecular do complexo $R u^{I I}\left(H_{2} O\right)$. . . . . 100

Figura 5.2 - llustração da estrutura molecular dos complexos $\mathrm{Ru}^{I I}\left(\mathrm{H}_{2} \mathrm{O}\right)$ e $\mathrm{Ru}^{I I} \operatorname{Tris}\left(2,2^{\prime}-\right.$ bpy). . . . . . . . . . . . . . . . . . . 101

Figura 5.3 - Superposição das geometrias otimizadas em vácuo e em solução. . . . . . . 104

Figura 5.4 - Distâncias $R u-N$ e $R u-O$ para os cinco complexos de $R u$-Aqua/Oxo em solução. . . . . . . . . . . . . . . . . . . . . . . . . . . . . 108

Figura 5.5 - Cargas atômicas dos complexos de $R u$-Aqua/Oxo, calculadas com o método CHELPG no vácuo e em solução aquosa. . . . . . . . . . . . . . . . . . 110

Figura 5.6 - Potencial de interação água/complexo no complexo $R u^{I I}\left(H_{2} O\right) \ldots \ldots$

Figura 5.7 - Densidades de spin dos complexos de $R u$-Aqua/Oxo de camada aberta. . . 117

Figura 6.1 - Funções de distribuição de mínima distância (MDDF) entre os complexos de $R u$-Aqua/Oxo e as moléculas de água da solução. . . . . . . . . . . . 120

Figura 6.2 - llustração da primeira camada de solvatação do complexo $R u^{I I}\left(H_{2} O\right)$. . . 121

Figura 6.3 - Funções de distribuição radial de pares, $g(r)$, dos complexos $R u$-Aqua em solução. . . . . . . . . . . . . . . . . . . . . . . . . . . . 122

Figura 6.4 - Funções de distribuição radial de pares, $g(r)$, dos complexos $R u$-Hidróxido em solução. . . . . . . . . . . . . . . . . . . . . . . . . . . 123

Figura 6.5 - Funções de distribuição radial de pares, $g(r)$, do complexo $R u$-Óxido em solução. . . . . . . . . . . . . . . . . . . . . . . . . . . . . . 124

Figura 6.6 - llustração de ligações de hidrogênio nos complexos $R u$-Aqua/Oxo. . . . . . 126

Figura 6.7 - Distribuições de distâncias, ângulos e energias das ligações de hidrogênio entre os complexos de Ru-Aqua/Oxo e o solvente.

Figura 6.8 - Distribuições de distância, ângulo e energia das ligações de hidrogênio entre os complexos de Ru-Hidróxido e o solvente. . . . . . . . . . . . . . . . . 128

Figura 6.9 - Funções de auto correlação das ligações de hidrogênio envolvendo os complexos de $R u$-Aqua/Oxo e a solução, e envolvendo as moléculas de água que compõem primeira camada de solvatação.

Figura 6.10-Deslocamento quadrático médio (MSD) do complexo $R u^{I I}\left(\mathrm{H}_{2} \mathrm{O}\right)$ em solução aquosa. . . . . . . . . . . . . . . . . . . . . . . . . . . . . . . 134

Figura 6.11-llustração do sistema $R u^{I I}\left(H_{2} \mathrm{O}\right)$ na interface água/vácuo. . . . . . . . . 136

Figura 6.12-Funções de distribuição de mínima distância (MDDF) entre os complexos de $R u$-Aqua/Oxo e as moléculas de água da solução, na interface água/vácuo.137

Figura 6.13-Perfis de densidade das soluções de Ru-Aqua/Oxo na interface água/vácuo. 138

Figura 6.14-Coordenada $z$ das posições dos átomos de $R u$ e $O$, e ângulo entre o vetor que liga $R u$ a $O$ e o eixo de coordenadas $z$, nas simulações dos complexos de $R u$-Aqua em solução.

Figura 6.15-Coordenada $z$ das posições dos átomos de $R u$ e $O$, e ângulo entre o vetor que liga $R u$ a $O$ e o eixo de coordenadas $z$, nas simulações dos complexos de $R u$-Hidróxido em solução.

Figura 6.16-Coordenada $z$ das posições dos átomos de $R u$ e $O$, e ângulo entre o vetor que liga $R u$ a $O$ e o eixo de coordenadas $z$, nas simulações dos complexos de $R u$-Óxido em solução.

Figura 7.1 - Diagrama de energia dos orbitais de fronteira dos complexos de Ru-Aqua/Oxo, no vácuo e em solução aquosa. 
Figura 7.2 - Orbitais moleculares HOMO-2 ao LUMO+2 dos complexos de Ru-Aqua/Oxo.145

Figura 7.3 - Espectros de absorção UV-Vis experimentais dos complexos de $R u$-Aqua/Oxo em solução aquosa. . . . . . . . . . . . . . . . . . . . . . . . . . . . . 149

Figura 7.4 - Espectro de absorção UV-Vis teórico do complexo $R u^{I I}\left(H_{2} \mathrm{O}\right)$ em solução aquosa obtido por diferentes métodos. . . . . . . . . . . . . . . . . 151

Figura 7.5 - Espectros de absorção UV-Vis teóricos dos complexos $\mathrm{Ru}\left(\mathrm{H}_{2} \mathrm{O}\right)$ no vácuo e em solução aquosa, por diferentes aproximações da interação soluto solvente.155

Figura 7.6 - Espectros de absorção UV-Vis teóricos dos complexos de $R u(O H)$ no vácuo e em solução aquosa, por diferentes aproximações da interação soluto solvente. 156

Figura 7.7 - Espectros de absorção UV-Vis teóricos dos complexos de $R u(O)$ no vácuo e em solução aquosa, por diferentes aproximações da interação soluto solvente.157

Figura 7.8 - Espectro de absorção UV-Vis teórico do complexo $R u^{I I}\left(H_{2} \mathrm{O}\right)$ em solução aquosa, utilizando Dinâmica Molecular. . . . . . . . . . . . . . . . . . 159

Figura 7.9 - Espectros de absorção UV-Vis teóricos dos complexos de Ru-Aqua/Oxo em solução aquosa e mapa das contribuições MC, MLCT, LMCT, LLCT e LC das excitações eletrônicas. . . . . . . . . . . . . . . . . . . . .

Figura 7.10-Espectro de absorção UV-Vis teórico do complexo de $R u^{I V}(O)$ em solução
aquosa e mapa das contribuições MC, MLCT, LMCT, LLCT e LC das

Figura 7.10-Espectro de absorção UV-Vis teórico do complexo de $R u^{I V}(O)$ em solução
aquosa e mapa das contribuições MC, MLCT, LMCT, LLCT e LC das excitações eletrônicas.

Figura 7.11-Mapa detalhado das contribuições MC, MLCT, LMCT, LLCT e LC das
excitações eletrônicas dos complexos $R u^{I I}\left(\mathrm{H}_{2} \mathrm{O}\right)$ e $R u^{I I I}\left(\mathrm{H}_{2} \mathrm{O}\right)$ em solução

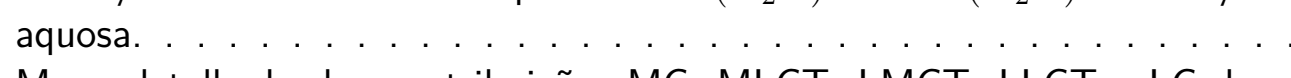

Figura 7.12-Mapa detalhado das contribuições MC, MLCT, LMCT, LLCT e LC das excitações eletrônicas dos complexos $R u^{I I}(O H)$ e $R u^{I I I}(O H)$ em solução aquosa. . . . . . . . . . . . . . . . . . . . . . . 165

Figura 7.13-Mapa detalhado das contribuições MC, MLCT, LMCT, LLCT e LC das excitações eletrônicas do complexo $R u^{I V}(O)$ em solução aquosa. . . . . . . 166

Figura 7.14-Espectro de XPS experimental e teórico (no vácuo e em solução aquosa) dos complexos de $R u$-Aqua/Oxo. . . . . . . . . . . . . . . . . 168

Figura 7.15-Deconvolução dos espectros experimentais dos complexos $R u^{I I I}\left(\mathrm{H}_{2} \mathrm{O}\right)$ e $R u^{I I I}(O H)$. . . . . . . . . . . . . . . . . . 169

Figura 7.16-Espectro de XPS do orbital $R u\left(3 d_{5 / 2}\right)$ no vácuo, incluindo apenas as moléculas de água que realizam ligações de hidrogênio com os complexos e incluindo todas as moléculas de água que compõem a primeira camada de solvatação. . . . . . . . . . . . . . . . . . . . . .

Figura 8.1 - Caminhos de reação para a transferência de prótons e elétrons dos complexos de $R u$-Aqua/Oxo em solução aquosa. . . . . . . . . . . . . . . . . . . 174

Figura 8.2 - Função de distribuição radial entre o átomo de $R u$ dos complexos e o átomo de $N$ das moléculas de $\mathrm{KNO}_{3}\left(G(r)^{R u-N\left(\mathrm{NO}_{3}\right)}\right)$. . . . . . . . . . . . 180

Figura 8.3 - Erro quadrático médio relacionado ao cálculo dos pKa e potenciais redox dos complexos de $R u$-Aqua/Oxo em solução aquosa, utilizando diferentes combinações de métodos e conjuntos de funções base. 



\section{Lista de tabelas}

Tabela 5.1 - Comparação estrutural entre a geometria otimizada de vácuo do complexo $R u^{I I}\left(H_{2} \mathrm{O}\right)$ e a geometria cristalográfica do complexo $\mathrm{Ru}^{I I} \operatorname{Tr} i s\left(2,2^{\prime}-\right.$ bpy $) .101$

Tabela 5.2 - Comparação estrutural entre as geometrias otimizadas no vácuo (VAC) e em solução (SOL) dos complexos de Ru-Aqua/Oxo . . . . . . . . . . . 103

Tabela 5.3 - Principais mudanças estruturais nos complexos de $R u$-Aqua/Oxo devido a processos de oxidação e desprotonação, em solução aquosa. . . . . . . . . 107

Tabela 5.4 - Cargas atômicas dos complexos de $R u$-Aqua/Oxo, calculadas com o método CHELPG no vácuo e em solução aquosa. . . . . . . . . . . . . . . . . . . 111

Tabela 5.5 - Variações das cargas atômicas dos complexos de $R u$-Aqua/Oxo em solução devido a processos de oxidação e desprotonação. . . . . . . . . . . . . . 113

Tabela 5.6 - Parâmetros LJC para o átomo de $R u$ em simulações MM. . . . . . . . . . . 115

Tabela 6.1 - Número médio, distância, ângulo e energia das ligações de hidrogênio realizadas pelos complexos de $R u$-Aqua/Oxo em solução . . . . . . . . . . 129

Tabela 6.2 - Tempo de vida das ligações de hidrogênio envolvendo os complexos de $R u$-Aqua/Oxo e a solução e envolvendo as moléculas de água que compõem a primeira camada de solvatação.

Tabela 6.3 - Coeficientes de difusão médios calculados a partir do ajuste linear das curvas de MSD dos complexos de Ru-Aqua/Oxo em solução. . . . . . . . . . . . 134

Tabela 6.4-Distâncias características dos perfis de densidade das soluções de $R u$ Aqua/Oxo na interface água/vácuo. . . . . . . . . . . . . . . . . 137

Tabela 7.1 - Energias dos orbitais HOMO ou SOMO e LUMO dos complexos de $R u$ Aqua/Oxo, no vácuo e em solução aquosa . . . . . . . . . . . . . . . 146

Tabela 7.2 - Potencial químico e dureza química dos complexos $R u^{I I}\left(\mathrm{H}_{2} \mathrm{O}\right)$ e $R u^{I I}(\mathrm{OH})$ no vácuo e em solução. . . . . . . . . . . . . . . . . . . . . . . . . . . 148

Tabela 7.3 - Valor do comprimento de onda $\lambda(\mathrm{nm})$ do pico de absorção da banda em menor energia do complexo $R u^{I I}\left(H_{2} \mathrm{O}\right)$ em solução aquosa, utilizando o funcional B3LYP e diversos conjuntos de funções base.

Tabela 7.4 - Valor do comprimento de onda $\lambda(\mathrm{nm})$ dos picos de absorção UV-Vis dos complexos de $R u$-Aqua/Oxo no vácuo e em solução aquosa, utilizando $\mathrm{B} 3 \mathrm{LYP} /($ aug)-cc-pVDZ/(PP-Ru) e diferentes aproximações para a interação soluto-solvente (PCM, PC, HB+PC)

Tabela 7.5 - Percentual das contribuições MC, MLCT, LMCT, LC e LLCT por grupos de excitações eletrônicas (1-30 e 31-50). . . . . . . . . . . . . . . . 162

Tabela 7.6 - Valores experimentais e teóricos (no vácuo e em solução aquosa) de BE dos orbitais $R u\left(3 d_{5 / 2}\right)$ nos complexos de $R u$-Aqua/Oxo. 
Tabela 8.1 - Valores experimentais de $p K a$ e $V^{o x}$ relacionados às reações de transferência de prótons e elétrons dos complexos de $R u$-Aqua/Oxo em solução aquosa. 174

Tabela 8.2 - Variação da energia livre de vácuo $\left(\Delta G_{v a c}\right)$ em reações de troca de prótons e elétrons dos complexos de $R u$-Aqua/Oxo, utilizando diferentes médodos QM. . . . . . . . . . . . . . . . . . . . . 175

Tabela 8.3 - Variação da energia livre de vácuo $\left(\Delta G_{v a c}\right)$ em reações de troca de prótons e elétrons dos complexos de $R u$-Aqua/Oxo, utilizando o funcional B3LYP e diferentes conjuntos de funções base. . . . . . . . . . . . . . . 176

Tabela 8.4 - Energia livre de solvatação $\left(\Delta G_{\text {solv }}\right)$ dos complexos de $R u$-Aqua/Oxo, por diferentes métodos QM e MM.

Tabela 8.5 - Variação da energia livre de solvatação $\left(\Delta \Delta G_{\text {solv }}\right)$ em reações de troca de prótons e elétrons dos complexos de $R u$-Aqua/Oxo, utilizando diferentes métodos. . . . . . . . . . . . . . . . . . . . 178

Tabela 8.6 - Cargas atômicas de $R u, N$ e $O$ do complexos de $R u$-Aqua/Oxo, utilizando diferentes métodos. . . . . . . . . . . . . . . . . . 179

Tabela 8.7 - Energia de polarização da função de onda B3LYP/(aug)-cc-pVDZ/(PP-Ru) utilizando PCM e ASEC e energia relacionada à mudança de geometria de vácuo para solução.

Tabela $8.8-p K a$ e potenciais redox $(V)$ em reações de troca de prótons e elétrons dos complexos de $R u$-Aqua/Oxo, utilizando diferentes métodos.

Tabela A.1 - Comprimento de onda e intensidade $I$ das 50 primeiras excitações eletrônicas dos complexos de $R u$-Aqua/Oxo na oxidação $I I$. . . . . . . . . . . . . . 214

Tabela A.2 - Comprimento de onda e intensidade $I$ das 50 primeiras excitações eletrônicas dos complexos de $R u$-Aqua/Oxo na oxidação $I I I \ldots . . . .215$

Tabela A.3-Comprimento de onda e intensidade $I$ das 50 primeiras excitações eletrônicas

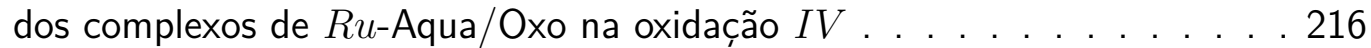




\section{Lista de abreviaturas e siglas}

\begin{tabular}{ll} 
Ru & Rutênio \\
py & Piridina \\
bpy & Bipiridina \\
MC & Metal Centrado \\
LC & Ligante Centrado \\
MLCT & Transferência de Carga do Metal para o Ligante \\
LMCT & Transferência de Carga do Ligante para o Metal \\
QM & Mecânica Quântica \\
MM & Mecânica Molecular \\
MC & Monte Carlo \\
MD & Dinâmica Molecular \\
DFT & Teoria do Funcional de Densidade \\
TD-DFT & Teoria do Funcional de Densidade Dependente do Tempo \\
HF & Método de Hartree Fock \\
ECP & Potencial Efetivo de Caroço \\
BSSE & Erro de Superposição de Bases \\
VAC & Vácuo \\
SOL & Solução \\
RMSD & Raiz Quadrada Média do Deslocamento \\
PCM & Modelo Contínuo Polarizável \\
SMD & Modelvão Eletrostática Média do Solvente \\
MSE & Conte Baseado na Densidade \\
\hline
\end{tabular}




\begin{tabular}{ll} 
HFD & Método Hirsfeld \\
CPG & Método CHELPG \\
LJ & Lennard Jones \\
LJC & Lennard Jones Coulomb \\
PME & Método Particle Mesh Ewald \\
NVT & Ensemble Canônico \\
NPT & Ensemble Isotérmico-Isobárico \\
FEP-MC & Perturbação de Energia Livre por Monte Carlo \\
BAR-MD & Raio de Aceitação de Bennet por Dinâmica Molecular \\
MSD & Deslocamento Quadrático Médio \\
XPS & Espectroscopia de Fotoelétrons de Raios X \\
UV-Vis & Ultra Violeta Visível \\
BE & Energia de Ligação \\
HOMO & Orbital Molecular Ocupado mais Alto \\
SOMO & Orbital Molecular Singularmente Ocupado \\
LUMO & Orbital Molecular não Ocupado mais Baixo \\
\hline
\end{tabular}




\section{Sumário}

INTRODUÇÃO . . . . . . . . . . . . . . . . . . . 27

$1.1 \quad$ Complexos de $R u$ polipiridínicos . . . . . . . . . . . . . . . . . . . 27

$1.1 .1 \quad$ Absorção e emissão de luz . . . . . . . . . . . . . . . . . . . . . 30

1.2 Motivação: aplicação em fotossíntese artificial . . . . . . . . . . . 32

1.2.1 Justificativa: apelo ambiental . . . . . . . . . . . . . . . 38

1.3 Simulação atomística de compostos de $\boldsymbol{R u}$ - Literatura . . . . . . . . 40

1.4 Complexos de $R u$-Aqua/Oxo investigados . . . . . . . . . . . . . . . . 43

1.5 Objetivos e organização do texto . . . . . . . . . . . . 45

2 ESTRUTURA ELETRÔNICA MOLECULAR . . . . . . . . . . 47

2.1 Separação de Born-Oppenheimer . . . . . . . . . . . . . 47

2.2 Determinante de Slater . . . . . . . . . . . . . . . . . . . . 48

$2.3 \quad$ Método de Hartree-Fock . . . . . . . . . . . . . . . . . . . . . 49

2.3.1 Correções perturbativas . . . . . . . . . . . . . . . . . 51

$2.4 \quad$ Teoria do funcional de densidade . . . . . . . . . . . . . . . 52

2.4.1 Teoria do Funcional de Densidade Dependente do Tempo . . . . . . . . . . 54

$2.5 \quad$ Modelo de estado de transição de Slater-JanaK . . . . . . . . . . . 57

$2.6 \quad$ Conjuntos de funções base . . . . . . . . . . . . . . . . . . . 58

2.6.1 Bases com potencial central efetivo . . . . . . . . . . . . . 59

2.6.2 Erro de superposição de bases . . . . . . . . . . . . . . . . . 59

$2.7 \quad$ Cargas atômicas . . . . . . . . . . . . . . . . . . 60

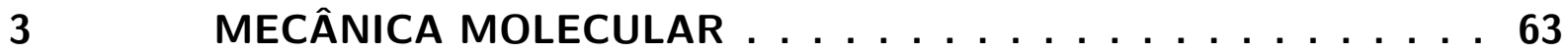

$3.1 \quad$ Simulação clássica . . . . . . . . . . . . . . . . . 63

3.1.1 Método de Monte Carlo . . . . . . . . . . . . . . . . 63

3.1.2 Dinâmica Molecular . . . . . . . . . . . . . . . . . . 65

3.1.3 Condições de contorno periódicas . . . . . . . . . . . . . . . . 69

3.1.4 Correções de longo alcance . . . . . . . . . . . . . . . . . . . . 69

$3.2 \quad$ Potencial de interação molecular . . . . . . . . . . . . . . 70

$3.3 \quad$ Efeitos de polarização do meio . . . . . . . . . . . . . . . . 72

3.3.1 Modelos contínuos de solvente . . . . . . . . . . . . . . 73

3.3.2 Modelo discreto - ASEC . . . . . . . . . . . . . . . . . . . . . . . . . . . . . . . . .

3.3.3 Difusão de massa . . . . . . . . . . . . . . . . . . . . 76

3.3.4 Distribuição radial de pares . . . . . . . . . . . . . . . . . 76

3.3.5 Ligações de hidrogênio . . . . . . . . . . . . . . . . . . . . 77

$3.4 \quad$ Energia livre de solvatação f . . . . . . . . . . . . . . . . 78

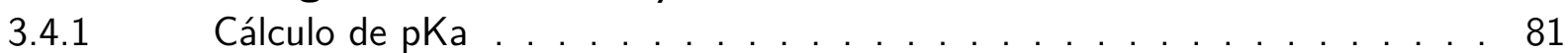

3.4.2 Cálculo de potencial redox . . . . . . . . . . . . . . 83

$3.5 \quad$ Métodos QM/MM . . . . . . . . . . . . . . . . 84 
METODOLOGIA ................... 87

$4.1 \quad$ Geometria dos complexos . . . . . . . . . . . . . . . 87

$4.2 \quad$ Simulações de Monte Carlo . . . . . . . . . . . . . . . . . . . . 87

$4.2 .1 \quad$ Simulações MC na interface água/vacuo . . . . . . . . . . . . . . . 89

$4.3 \quad$ Simulações de Dinâmica Molecular . . . . . . . . . . . . . . . . . 89

4.3.1 Coeficiente de difusão . . . . . . . . . . . . . . . . . . . . 89

4.3.2 Tempo de vida de ligações de hidrogênio . . . . . . . . . . . . . . . . . 90

$4.4 \quad$ Obtenção de parâmetros para as simulações MM . . . . . . . . . . 90

4.4.1 Parâmetros não-ligados . . . . . . . . . . . . . . . . . . . . . 90

$4.4 .2 \quad$ Parâmetros ligados . . . . . . . . . . . . . . . . . . . . . . . 91

$4.5 \quad$ Energia livre de solvatação . . . . . . . . . . . . . . . . . . . 91

$4.5 .1 \quad$ Procedimento via FEP-MC . . . . . . . . . . . . . . . . . . 92

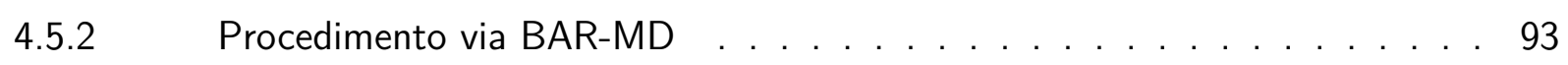

$4.5 .3 \quad$ Procedimento via DFT . . . . . . . . . . . . . . . . . . . . . 94

$4.6 \quad$ Excitações eletrônicas . . . . . . . . . . . . . . . . . . . . . . . . . . 94

4.7 Energia de ligação de elétrons de camadas profundas . . . . . . . 96

$4.8 \quad$ pKa e potencial redox . . . . . . . . . . . . . . . 97

5 GEOMETRIA, POLARIZAÇÃO, E CAMPO DE FORÇA . . . . . 99

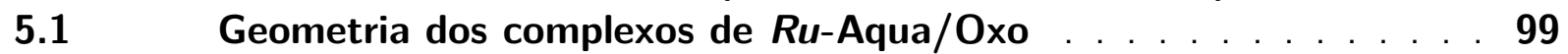

5.1.1 Comparação com dados de cristalografia . . . . . . . . . . . . . . . 100

$5.1 .2 \quad$ Efeitos da solvatação . . . . . . . . . . . . . . . . . . . . . . . . . . . . . . . . . . .

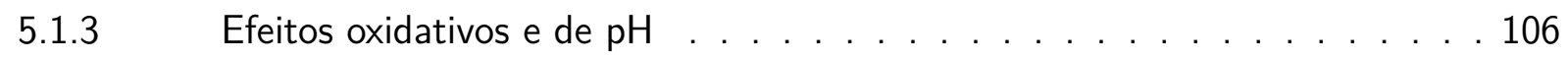

$5.1 .3 .1 \quad$ Efeito trans . . . . . . . . . . . . . . . . . . 108

5.2 Cargas atômicas . . . . . . . . . . . . . . . . 109

5.2.1 Efeitos da solvatação . . . . . . . . . . . . . . . . . . . . 109

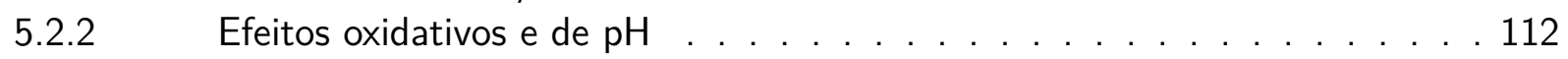

$5.3 \quad$ Campo de força para o átomo de $R u \ldots \ldots$

5.3.1 Breve revisão da literatura . . . . . . . . . . . . . . . . . . . . 114

5.3.2 Uma nova proposta de parâmetros LJC para $R u$. . . . . . . . . . . . . 115

6 ESTRUTURA E DINÂMICA EM SOLUÇÃO . . . . . . . . . . . 119

$6.1 \quad$ Estrutura do solvente . . . . . . . . . . . . . . . 119

$6.2 \quad$ Ligações de hidrogênio intermolecular . . . . . . . . . . . . . 125

6.2 .1 Tempo de vida das ligações de hidrogênio . . . . . . . . . . . . . . . . . . . . . . . . . . . . . . . . . . . . . . . . . . .

6.3 Difusão de massa . . . . . . . . . . . . . . . . . . . . . . . 133

$6.4 \quad$ Simulações na interface água/vácuo . . . . . . . . . . . . . . 134

7 PROPRIEDADES ELETRÔNICAS . . . . . . . . . . . . . 143

$7.1 \quad$ Orbitais de fronteira . . . . . . . . . . . . . . . . 143

$7.1 .1 \quad$ Reatividade eletrônica . . . . . . . . . . . . . . . . 147

$7.2 \quad$ Espectroscopia de absorção UV-Vis . . . . . . . . . . . . . . . . . 148

7.2.1 Espectros UV-Vis experimentais . . . . . . . . . . . . . . . . . . 149

7.2.2 Efeitos da escolha do método QM e do conjunto de funções base na descrição teórica dos espectros UV-Vis . . . . . . . . . . . . . . . . . . . . . . . . 150

7.2.3 Espectros UV-Vis teóricos e efeitos do solvente . . . . . . . . . . . . . . 154

7.2.4 Caracterização das excitações eletrônicas . . . . . . . . . . . . . 160

7.3 Espectroscopia de fotoelétrons de raios-X (XPS) . . . . . . . 165 
8 PROPRIEDADES ELETROQUÍMICAS . . . . . . . . . . 173

8.1 Eletroquímica dos complexos de $R u$-Aqua/Oxo . . . . . . . . . 173

$8.2 \quad$ Energia livre de vácuo . . . . . . . . . . . . . . . . . 174

8.3 Energia livre de solvatação . . . . . . . . . . . . . . 176

$8.4 \quad$ Energia de polarização e de mudanças geométricas . . . . . . . . . 181

$8.5 \quad$ pKa e potencial redox . . . . . . . . . . . . . . . . 182

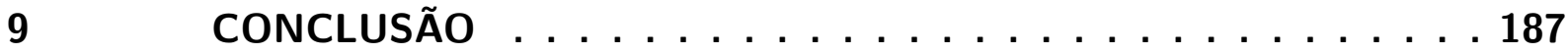

REFERÊNCIAS . . . . . . . . . . . . . . . . . . 191

$\begin{array}{ll}\text { APÊNDICES } & 211\end{array}$

A - EXCITAÇÕES ELETRÔNICAS DOS COMPLEXOS DE RU-AQUA/OXO EM SOLUÇÃO AQUOSA. . . . . . . . . . . . . . . . . . . 213

B - GEOMETRIAS OTIMIZADAS E CARGAS ATÔMICAS POLARIZADAS EM SOLUÇÃO AQUOSA (VIA PCM), E PARÂMETROS DE LJ DOS COMPLEXOS DE $R u$-AQUA/OXO . . . . . . . . . 217

C - EXEMPLOS DE INPUTS PARA SIMULAÇÕES DE DINÂMICA MOLECULAR NO GROMACS . . . . . . . . . . . . . . . 223

D - EXEMPLOS DE INPUTS PARA SIMULAÇÕES DE MONTE CARLO NO DICE . . . . . . . . . . . . . . . . . . 237

E - EXEMPLOS DE INPUTS PARA CÁLCULOS DE MECÂNICA QUÂNTICA NO GAUSSIAN . . . . . . . . . . . . . . . . . . 241

$\begin{array}{ll}\text { ANEXOS } & 249\end{array}$

A - PRODUÇÃO CIENTÍfICA DURANTE O DOUTORADO . . . . 251

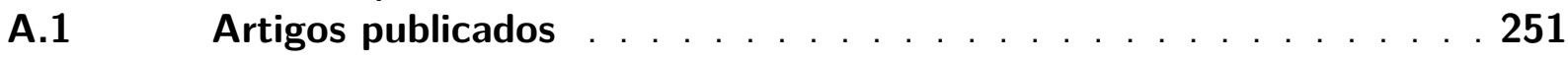

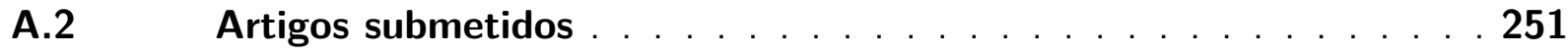

A.3 Manuscritos em preparação . . . . . . . . . . . . . . . . 252 



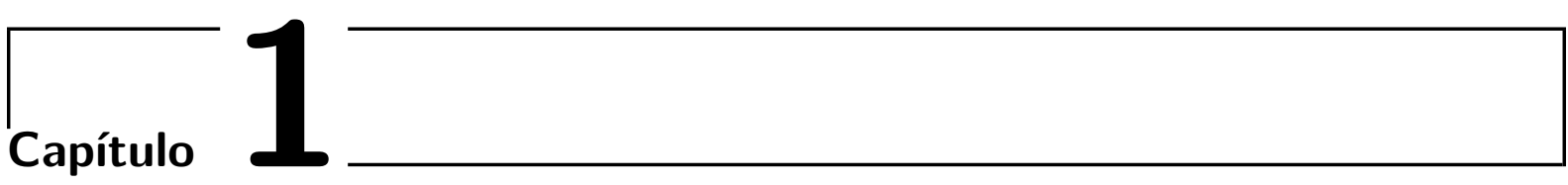

\section{Introdução}

O Rutênio é um metal de transição pertencente ao grupo 8 da tabela periódica. É conhecido por formar o chamado grupo da platina (platina - $P t$, paládio - $P d$, íridio - $I r$, ósmio - $O s$, ródio - $R h$ e rutênio - $R u$ ). Foi descoberto por Klaus, em 1844, em Tartu, na Estônia. Pode ser considerado um metal único devido à sua capacidade de formar complexos que cobrem a gama mais ampla de estados de oxidação permitidos teoricamente para um metal de transição: de 8 em $\left[\mathrm{RuO}_{4}\right]$ até -2 em $\left[\mathrm{Ru}(\mathrm{CO})_{4}\right]$, que correspondem as configurações eletrônicas $d^{0} \mathrm{e}$ $d^{10}[1]$

Os complexos de rutênio são estudados profundamente em diferentes campos da ciência, e tem aplicações tecnológicas diversas. Eles atraem a atenção em várias áreas de pesquisa devido a facilidade de terem suas propriedades moleculares modificadas sinteticamente. Existe uma forte correlação entre as propriedades fotofísicas, fotoquímicas e de óxido redução de complexos de $R u$ e a natureza dos grupos ligantes. Alterando-se os grupos na esfera de coordenação do $R u$ é possível otimizar complexos para diferentes finalidades. Complexos caracterizados por apresentar grande delocalização eletrônica tem aplicações em óptica não linear, ${ }^{[2,3]}$ magnetismo, ${ }^{[4,5]}$ cristais líquidos ${ }^{[6,7]}$ e sensores moleculares. ${ }^{[8,9]}$ Complexos coordenados com sulfóxidos podem ser utilizados em quimioterapia para o tratamento do câncer. ${ }^{[10]}$ Complexos com ligantes heterocíclicos podem ser usados como agentes de clivagem do DNA para fins terapêuticos, ${ }^{[11]}$ como fotossensibilizadores em células solares ${ }^{[12-16]}$ e como fotocatalisadores em reações de clivagem de moléculas de água em fotossíntese artificial ${ }^{[17]}$.

\subsection{Complexos de Ru polipiridínicos}

A química de coordenação do rutênio com ligantes de polipiridina é relativamente nova. Entre os anos de 1940 e 1960, o químico australiano P. Dwyer e seus colaboradores publicaram uma série de trabalhos sobre a síntese de complexos polipiridínicos de rutênio. ${ }^{[18]} \mathrm{Em}$ meados dos anos 1960, Meyer iniciou estudos sistemáticos nesses complexos, chamando a atenção para as suas propriedades reativas, acessíveis em estados excitados com longo de tempo de vida, e 
nos estados de oxidação de II a IV. Alguns dos trabalhos mais importantes nessa área foram publicados na década de 1970, e estão referenciados em: ${ }^{[19-21]}$.

A molécula de piridina (py), bloco fundamental em polipiridinas, é um composto orgânico heterocíclico de seis membros, com cinco carbonos e um nitrogênio. Todos os átomos do anel apresentam hibrização $s p^{2}$ e formam uma núvem eletrônica $\pi$ de seis elétrons delocalizada sobre o anel. O nitrogênio participa da estrutura eletrônica $\pi$ do anel usando seu orbital $p$ não-hibridizado, e projeta para fora do anel, no mesmo plano que as ligações $\sigma$, um par de elétrons isolados em um orbital $s p^{2}$. A piridina é uma molécula planar assim como o benzeno, entretanto, devido a presença do nitrogênio, apresenta uma densidade eletrônica não uniforme sobre o anel.

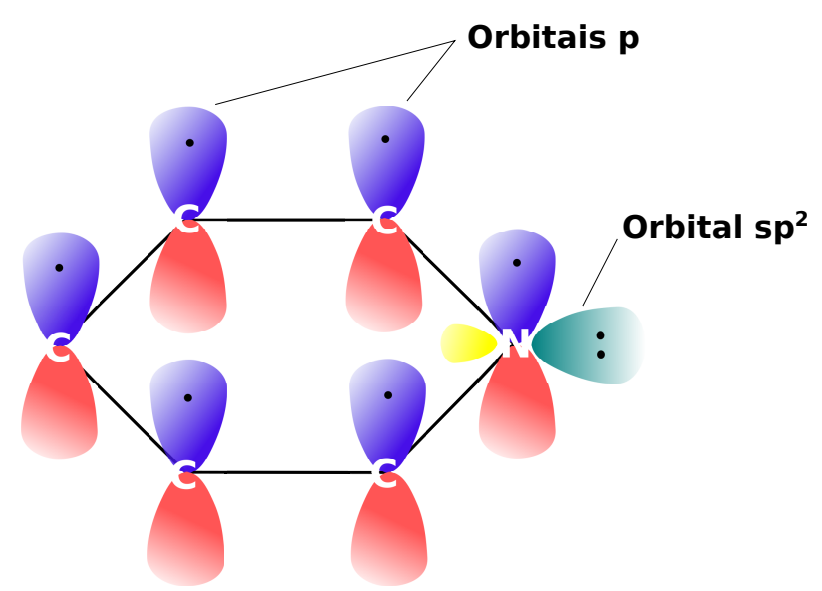

Figura 1.1 - Estrutura orbital da piridina.

Moléculas como bipiridinas (bpy) e terpiridinas (tpy) são formadas a partir da junção de piridinas por meio de uma ligação simples entre as diferentes posições de carbono das piridinas. E portanto, estruturas com mais de uma piridina podem dar origem a diversos isômeros. Para exemplificar, apresentamos na figura 1.2 os seis possíveis isômeros de bipiridina.

A principal aplicação de compostos aromáticos heterocíclicos contendo nitrogênio envolve a formação de complexos com um ou mais centros metálicos. ${ }^{[22,23]}$ As moléculas 2,2'-bipiridina e $2,2^{\prime}: 6^{\prime}, 2^{\prime \prime}$-terpiridina, por exemplo, podem ser coordenadas a um único centro metálico, como ilustrado na figura 1.3. Quando isoladas, essas moléculas preferem conformações planares do tipo trans, (a) e (c) na figura 1.3, de modo a minimizar a repulsão entre os elétrons isolados dos nitrogênios pirimidínicos. Entretanto, quando coordenadas a um centro metálico, nos modos bidentado e tridentado, (b) e (d) na figura 1.3, prefererem uma conformação planar cis, com a formação de um ou dois anéis estáveis de cinco membros com o metal, respectivamente.

Podemos descrever a interação do nitrogênio da piridina com um átomo metálico em termos de duas componentes. Na primeira componente temos a doação de dois elétrons do par isolado do nitrogênio a um orbital $d$ não ocupado do metal, dando origem a uma ligação $\sigma$ entre $N$ e o metal. Essa doação de elétrons torna o metal mais rico em elétrons e, para compensar essa densidade eletrônica aumentada, um orbital $d$ ocupado do metal interage com o orbital 


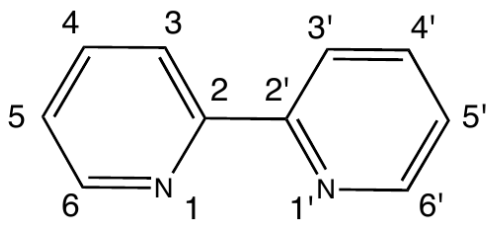

2,2'-bipiridina

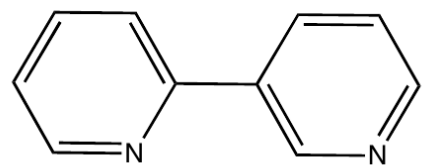

2,3'-bipiridina

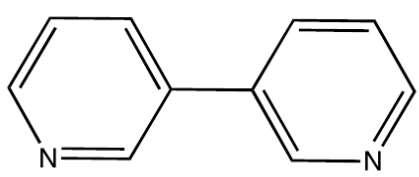

3,3'-bipiridina

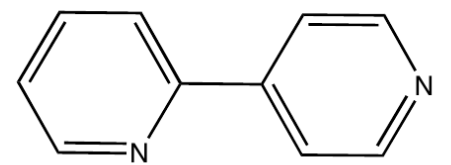

2,4'-bipiridina

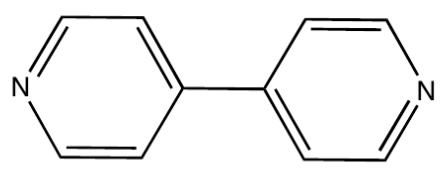

4,4'-bipiridina

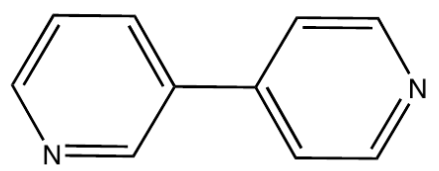

3,4'-bipiridina

Figura 1.2 - Estrutura molecular dos 6 possíveis isômeros de bipiridina.

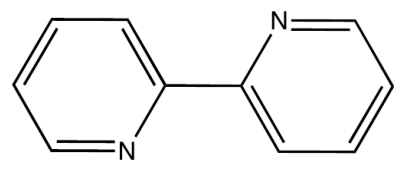

(a)<smiles>c1ccc(-c2cccc(-c3ccccn3)n2)nc1</smiles>

(c)

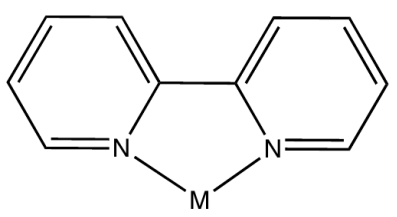

(b)<smiles></smiles>

(d)

Figura 1.3 - Conformação molecular da molécula 2,2'-bipiridina isolada (a) e coordenada a um átomo metálico em modo bidentado (b). Conformação molecular da molécula $2,2^{\prime}: 6^{\prime}, 2^{\prime \prime}$-terpiridina isolada (c) e coordenada a um átomo metálico em modo tridentado $(\mathrm{d})$.

$\pi^{*}$ não ocupado do ligante. Essa ligação $\pi$ por compensação é também conhecida por ligação reversa (retrodoação, " $\pi$-backbonding"). As duas componentes da interação metal-nitrogênio tem um caráter sinérgico. Quanto mais forte for a doação $\sigma$, mais forte se torna a interação $\pi$-backbonding. As duas componentes são mostradas de forma ilustrativa na figura 1.4.

Dada a diversidade de átomos metálicos listados na tabela periódica, em seus possíveis estados de oxidação e de spin. Dada a diversidade de grupos polipiridínicos (piridinas, bipiridinas, terpiridinas, fenantrolinas, etc.) em suas diversas conformações isoméricas. Dada a possibilidade de se coordenar a um ou mais centros metálicos grupos químicos projetados. A química de coordenação em complexos metálicos polipiridínicos é muito rica e muito vasta. Nesta seção apenas introduzimos o tema, e para mais detalhes sugerimos como leitura a referência. ${ }^{[24]}$ 


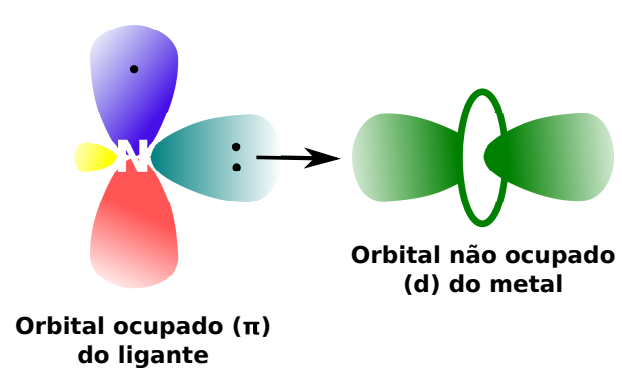

(Ligação $\sigma)$

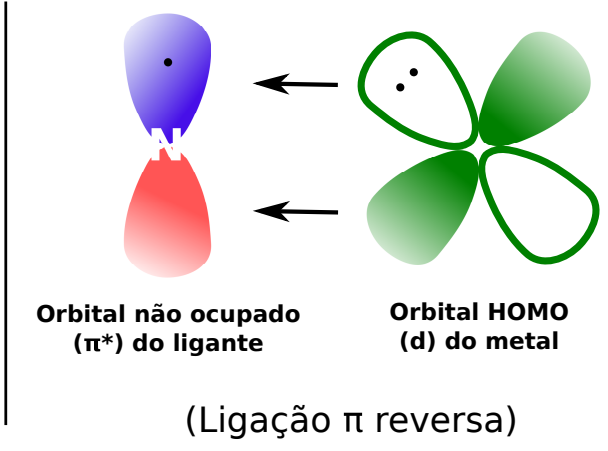

Figura 1.4 - Ligação $\sigma$ e ligação $\pi$ reversa, formadas entre um átomo de nitrogênio da piridina e um átomo metálico.

\subsubsection{Absorção e emissão de luz}

As transições eletrônicas, em camadas de valência, de complexos polipiridínicos com metal de transição são geralmente descritas a partir de uma nomenclatura que damos aos orbitais envolvidos nos processos fotoquímicos. ${ }^{[25]}$ Os cinco principais tipos de transições eletrônicas, que podem ser encontrados na química de coordenação, são os seguintes:

- Excitações centradas no metal (MC), como por exemplo transições eletrônicas $d-d$. Essas são, em princípio, estritamente proibidas pelas regras de Laporte em ambientes centrossimétricos, mas parcialmente permitidas devido aos acoplamentos vibrônicos e spin-órbita e, portanto, costumam exibir coeficientes de extinção geralmente mais baixos em comparação com as transições de transferência de carga (CT). A Regra de Laporte estabelece que as transições eletrônicas que conservam a simetria ou assimetria em relação a um centro de inversão são proibidas.

- Excitações de transferência de carga do metal para ligante (MLCT). Essas transições envolvem excitações de orbitais $d$ do metal para orbitais vazios localizados nos ligantes, tipicamente de caráter $\pi^{*}$. Eles são esperados no regime de baixa energia, quando o metal é fácil de oxidar e o ligante é fácil de reduzir.

- Excitações de transferência de carga do ligante para o metal (LMCT). Essas envolvem a promoção de elétrons de orbitais ocupados dos grupos ligantes para a camada $d$ parcialmente vazia do metal. Essas excitações são facilitadas quando os grupos ligantes são faceis de oxidar e o metal é fácil de reduzir.

- Transições centradas nos ligantes (LC) são aquelas que envolvem a excitação entre orbitais que estão localizados no mesmo ligante.

- Estados de transferência de carga de ligante para ligante (LLCT). Essas transições envolvem orbitais localizados em diferentes ligantes, tipicamente do tipo $\pi-\pi^{*}$. 
No diagrama da figura 1.5 ilustramos algumas das possibilidades de transição eletrônica para um complexo polipiridínico de Rutênio.

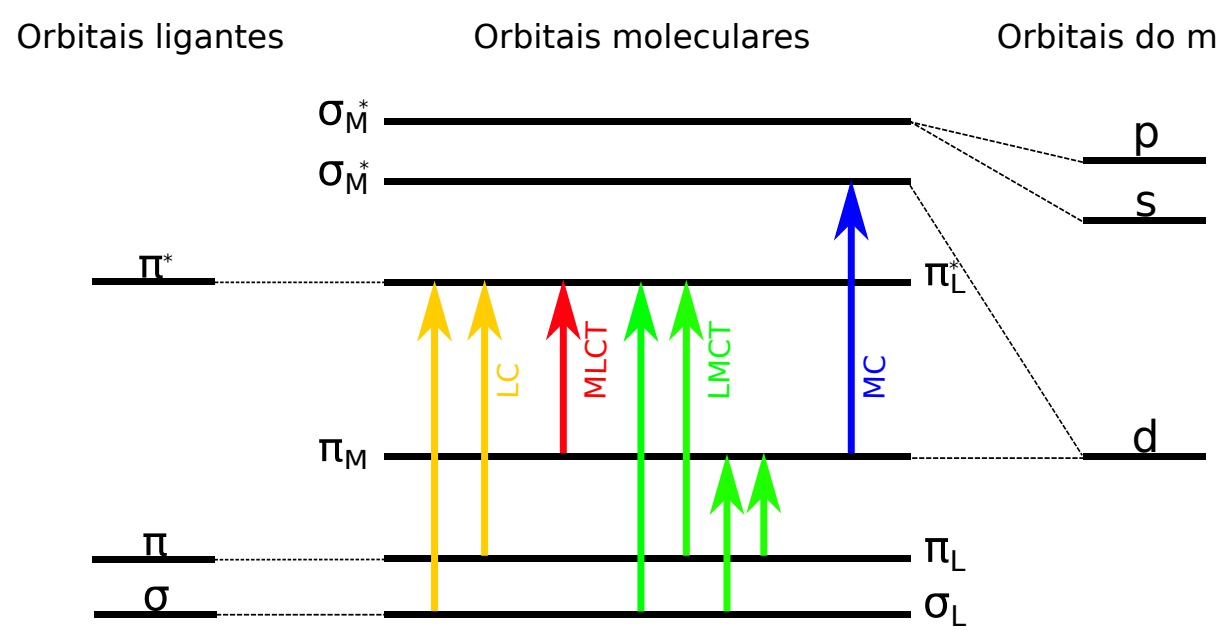

Figura 1.5 - Diagrama das transições eletrônicas e orbitais envolvidos em sistemas polipiridínicos octaédricos e com metal de transição. Fonte: Diagrama reproduzido a partir da referência ${ }^{[26]}$.

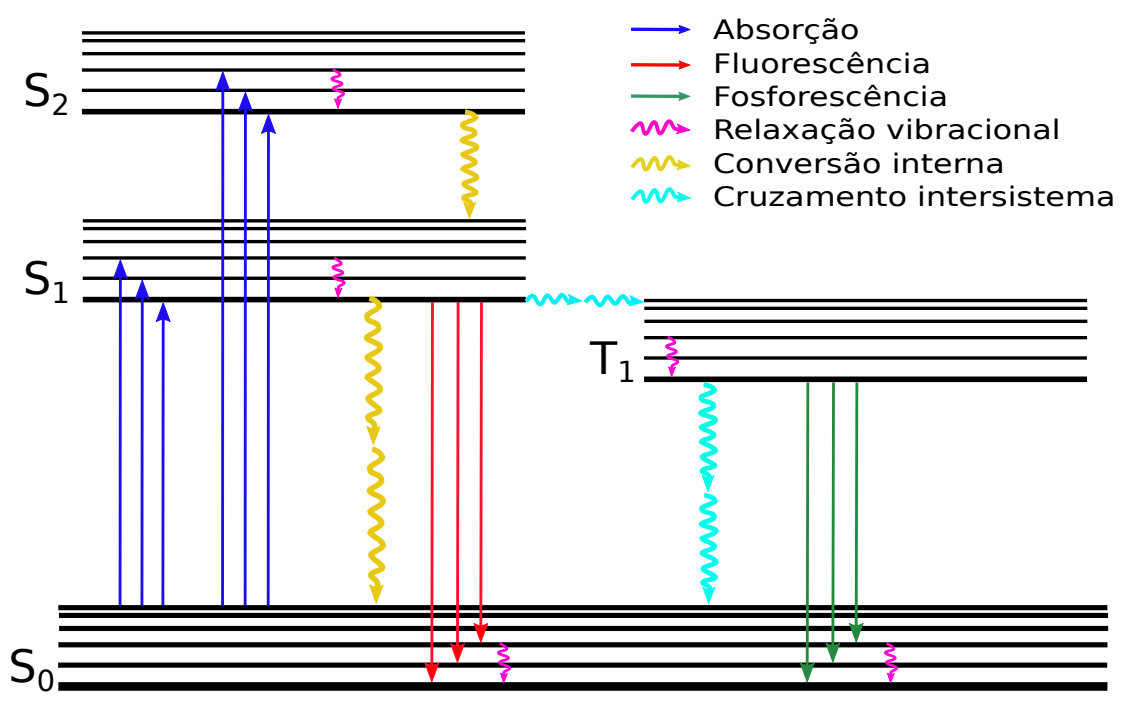

Figura 1.6 - Diagrama de Jablonski para complexos polipiridínicos de rutênio, no estado singleto. Fonte: Elaborada pelo autor.

O processo de desexcitação eletrônica em grande parte dos complexos polipiridínicos com metal de transição, no estado singleto, pode ser descrito por meio de um diagrama de Jablonski, como o da figura 1.6. No diagrama, os estados excitados S1 e T1 criam uma rota pela qual elétrons excitados para S2 ou S1 podem voltar para o estado fundamental com ou sem a emissão de fótons.

Em um complexo singleto, um elétron pode ser promovido do seu estado fundamental para o estado excitado S1, S2, ou estados de maior energia, sem sofrer alteração de spin. Apesar da existência de estados tripletos de mais baixa energia, esses estados não podem ser acessados primariamente via absorção de luz. ${ }^{[25]}$ Mas podem ser populados por elétrons 
previamente promovidos ao S1. Em uma das possibilidades apresentadas no diagrama de Jablonski, o elétron excitado ao S1 decai para T1, via cruzamentos intersistema que surgem devido ao alto acomplamento spin-órbita, inerente a complexos com metais de transição. ${ }^{[27]} \mathrm{A}$ partir daí o decaimento eletrônico para o estado fundamental pode ocorrer por meio radiativo (fosforescência) ou não radiativo.

A existência de estados tripletos de baixa energia é bastante comum em complexos bipiridínicos. ${ }^{[28]}$ Em sistemas com ligantes diferentes, por exemplo em complexos com terpiridinas, a sistemática de desescitação pode ser bastante diferente. Em complexos de rutênio terpiridínicos, nenhum processo radiativo é detectado na temperatura ambiente. ${ }^{[27]}$ Nesse caso, cruzamentos de níveis eletrônicos entre o estado excitado singleto, estados tripletos T2 e T1 intermediários e o estado fundamental, permitem o retorno do complexo para o estado fundamental sem a emissão de luz. Já em temperaturas mais baixas, as interseções cônicas entres as hipersuperfícies dos estados excitados podem se tornar menos acessíveis, tornando esse mecanismo ineficiente e fazendo com que parte da desexcitação eletrônica passe a ocorrer de forma radiativa. ${ }^{[27]}$

\subsection{Motivação: aplicação em fotossíntese artificial}

O termo fotossíntese artificial engloba todos os processos que utilizam a radiação solar, e tão somente ela, como fonte de energia para produzir e armazenar outros tipos de energia. ${ }^{[29]}$ Em suma, trata-se de uma tentativa de imitar a fotossíntese natural das plantas, que convertem dióxido de carbono e água em carboidratos e oxigênio, utilizando a luz do sol. Nesse contexto, a separação fotocatalítica da água em oxigênio e hidrogênio é um importante tópico de pesquisa em fotossíntese artificial. Ao contrário dos combustíveis fósseis, o hidrogênio gerado a partir de fontes renováveis de energia é um combustível sustentável, atraente e que não contribui para o aquecimento global. Dentre os processos utilizados para produção de hidrogênio, a clivagem da água é um método tradicional, e que pode ser conduzido usando eletricidade (eletrólise da água) ou energia solar (fotossíntese artificial). Esse processo ocorre por meio de duas reações químicas: uma reação de oxidação (equação 1.1), que resulta na produção de $\mathrm{O}_{2}$, e uma reação de redução (equação 1.2) que resulta na produção de $H_{2}$. Nas equações 1.1 a 1.3 mostramos como duas moléculas de água podem dar origem a duas moléculas de $H_{2}$ e a uma molécula de $\mathrm{O}_{2}$.

$$
\begin{gathered}
2 \mathrm{H}_{2} \mathrm{O} \rightarrow \mathrm{O}_{2}+4 \mathrm{H}^{+}+4 e^{-} \\
4 \mathrm{H}^{+}+4 e^{-} \rightarrow 2 \mathrm{H}_{2} \\
2 \mathrm{H}_{2} \mathrm{O} \rightarrow 2 \mathrm{H}_{2}+\mathrm{O}_{2}
\end{gathered}
$$

A oxidação da água é um processo termodinamicamente desfavorável e que conduz a uma variedade de espécies, de acordo com o número de elétrons que são removidos. Para se ter uma 
ideia, a oxidação de 1 elétron em uma molécula de água é proibida por uma barreira energética de $2.5 \mathrm{~V}(57.65 \mathrm{kcal} / \mathrm{mol})$ em $\mathrm{pH} 1.0$, figura $1.7 .{ }^{[30]} \mathrm{Na}$ natureza, o que se observa em fotossistemas como o PSII (oxiduretase água-plastoquinona) é a redução desse custo energético aliado a uma múltipla transferência de elétrons. O PSII realiza o processo apresentado na equação 1.1 por um custo energético de $0.94 \mathrm{~V}(21.68 \mathrm{kcal} / \mathrm{mol})$ em pH 1.0. ${ }^{[30]}$ A pergunta que se faz é: que tipo de sistema artificial seria capaz de mimetizar o PSII?

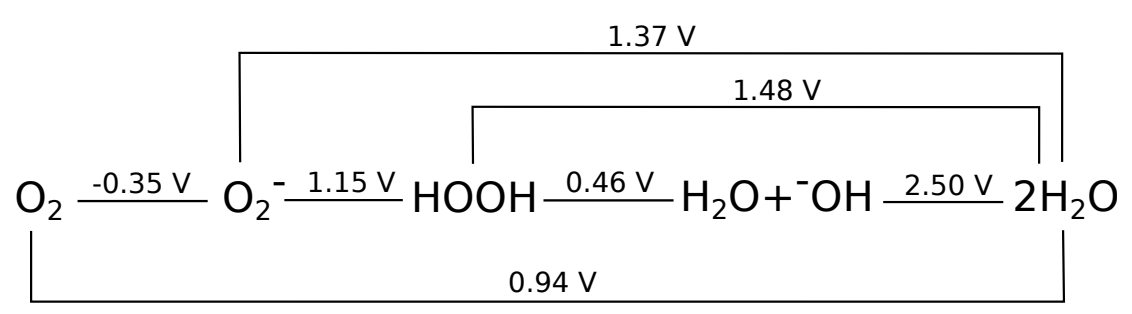

Figura 1.7 - Diagrama de Latimer para a água. Os números representam os potenciais redox em $\mathrm{pH}$ 1.0. Fonte: Elaborada pelo autor, com base em informações da referência. ${ }^{[30]}$

Em um aparato convencional de fotossíntese artificial, figura 1.8, um catalisador de água (WOC - do inglês Water Oxidation Catalyst) e um fotossensibilizador (PS - do inglês Photosensitizer) são conectados nessa ordem à superfície de um material semicondutor, de dióxido de titânio, por exemplo. Primeiro, o fotossensibilizador coleta a luz do sol e excita 1 elétron para um estado de separação de carga (MLCT). Se esse estado excitado tiver um tempo de vida suficientemente longo, então PS poderá transferir o elétron excitado para a banda de condução do semicondutor e se regenerar abstraindo 1 elétron de WOC. Depois de quatro separações de carga sucessivas e abstrações de elétrons concomitantemente, o catalisador encontrar-se-á em um alto estado de oxidação (IV), que o levará a oxidar moléculas de água na sua vizinhança, formando por conseguinte moléculas de $\mathrm{O}_{2}$. Os elétrons abstraídos da água são transferidos por meio de circuito externo até um catalisador de redução (HEC - do inglês Hydrogen Evolution Catalyst), que irá mediar a redução dos prótons gerados a partir da oxidação da água para a produção de gás hidrogênio, por exemplo.

Na natureza, tanto a oxidação de $H_{2}$ quanto a redução de prótons em $H_{2}$ são realizadas pelas enzimas hidrogenase, que são compostas por ferro e/ou níquel. ${ }^{[31]}$ Essas reações ocorrem em soluções aquosas em $p H$ neutro e em frequências extremamente altas, cerca de 100 a 10000 mols de $H_{2}$ podem ser produzidos por mol de catalisador por segundo. ${ }^{[32]}$ A redução de prótons em $\mathrm{H}_{2}$ tem uma grande barreira de ativação, e por isso é necessário usar um catalisador para diminuir essa barreira e permitir a produção eficiente de $\mathrm{H}_{2}$. Complexos à base de platina provaram ser excelentes catalisadores para a redução de prótons. ${ }^{[33]}$ No entanto, a escassez e o alto custo associado à platina limitam seu uso em aplicações de grande escala. Outros catalisadores baseados em metais de transição incluem cobalto ${ }^{[34]}$ e níquel ${ }^{[35]}$.

A primeira etapa em um aparato fotossintético é a absorção de luz solar por um fotossensibilizador, que deve ser excitado para um estado eletrônico com tempo de vida suficientemente longo para criar um estado de separação de carga. Um dos primeiros fotossensibilizadores tes- 


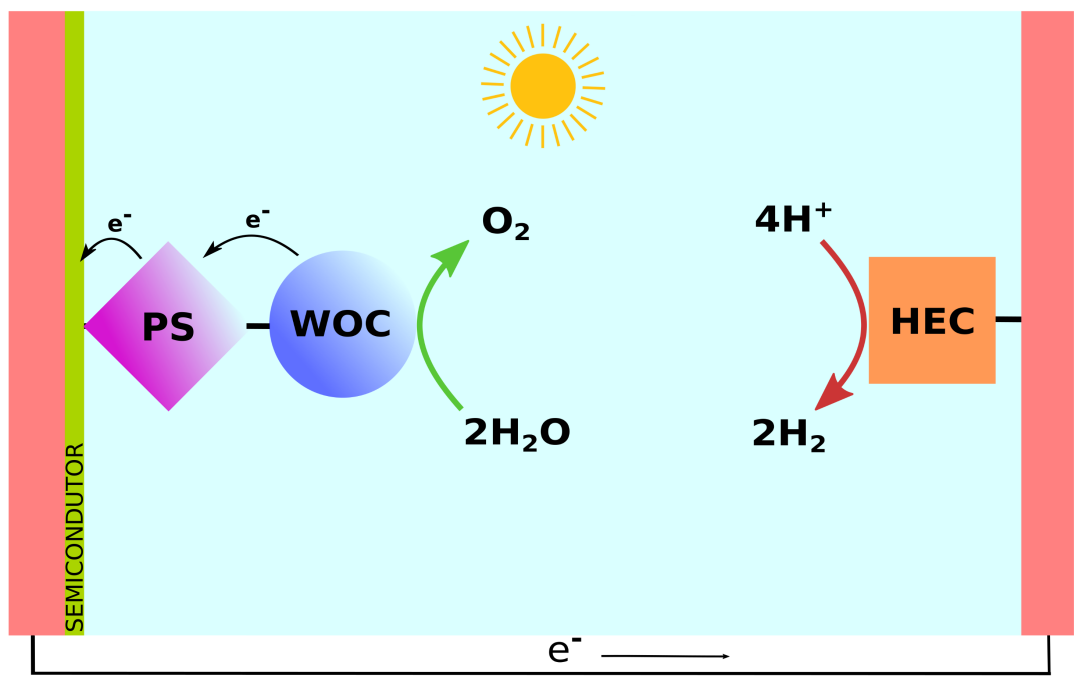

Figura 1.8 - Representação esquemática de uma célula solar de combustível baseada em fotossíntese artificial. PS é o fotossensibilizador, WOC é o catalisador para oxidação da água, HEC é o catalisador para geração de $H_{2}$.

tado com sucesso, ainda na década de 70 , para esse propósito, foi o complexo $\left[R u(b p y)_{3}\right]^{2+[25]}$, figura 1.9-a. Quando esse complexo absorve radiação na faixa dos $450 \mathrm{~nm}$, um elétron é excitado do orbital $d$ do metal para um orbital $\pi^{*}$ centrado no ligante bpy (transição MLCT), dando origem a um estado singleto ${ }^{1}\left[R u(b p y)_{3}\right]^{2+*}$. Esse estado tem um tempo de vida muito curto, e logo decai por cruzamentos intersistesma para um estado tripleto ${ }^{3}\left[R u(b p y)_{3}\right]^{2+*}$, que tem um longo tempo de vida. Nesse estado, o centro metálico do complexo encontra-se formalmente foto-oxidado a $R u^{I I I}$ ligado à bipiridinas agora reduzidas por 1 elétron, o que pode ser denotado pela configuração eletrônica ${ }^{3}\left[(d \pi)^{5}\left(\pi_{b p y}{ }^{*}\right)^{1}\right]$. Esse estado fotoexcitado tem a capacidade de ser mais oxidante e mais redutor do que o estado fundamental de $\left[R u(b p y)_{3}\right]^{2+}$, e essa natureza dual do estado excitado permite que ele possa atuar tanto como agente oxidante, como também redutor. Essa propriedade única de complexos do tipo $\left[R u(b p y)_{3}\right]^{2+}$ juntamente com sua estabilidade química, estado excitado triplelo com longo tempo de vida, e sua flexibilidade sintética os tornam altamente versáteis e atraentes no campo da foto-oxidação e foto-redução. Artigos de revisão sobre fotocatálise podem ser encontrados nas referências: $[25,36-39]$.

Em 1982, Meyer e colaboradores reportaram o primeiro complexo capaz de realizar a oxidação da água (WOC) gerando 4 elétrons e 4 prótons. ${ }^{[40]}$ Esse complexo é conhecido na literatura como Dímero Azul, e trata-se de um complexo de $R u$ bi-nuclear (cis, cis $\left.\left[(b p y)_{2}\left(\mathrm{H}_{2} \mathrm{O}\right) \mathrm{Ru}(\mu-\mathrm{O}) \mathrm{Ru}\left(\mathrm{H}_{2} \mathrm{O}\right)(\mathrm{bpy})_{2}\right]^{4+}\right)$, figura 1.9-b. O número de mols de substrato que um mol de catalisador pode converter antes de se tornar inativado é definido na literatura como TON (do inglês turn-over number) e a taxa TON/por unidade de tempo é definida como TOF (do inglês turn-over frequency). O Dímero Azul apresenta TON $=13.2^{[41]} \mathrm{e}$ $\mathrm{TOF}=4.2 \times 10^{-3} \mathrm{~s}^{-1[42]}$, que são considerados valores bastante modestos para fotossíntese artificial atualmente. Apesar de não ser um potente catalisador, esse complexo inspirou o 

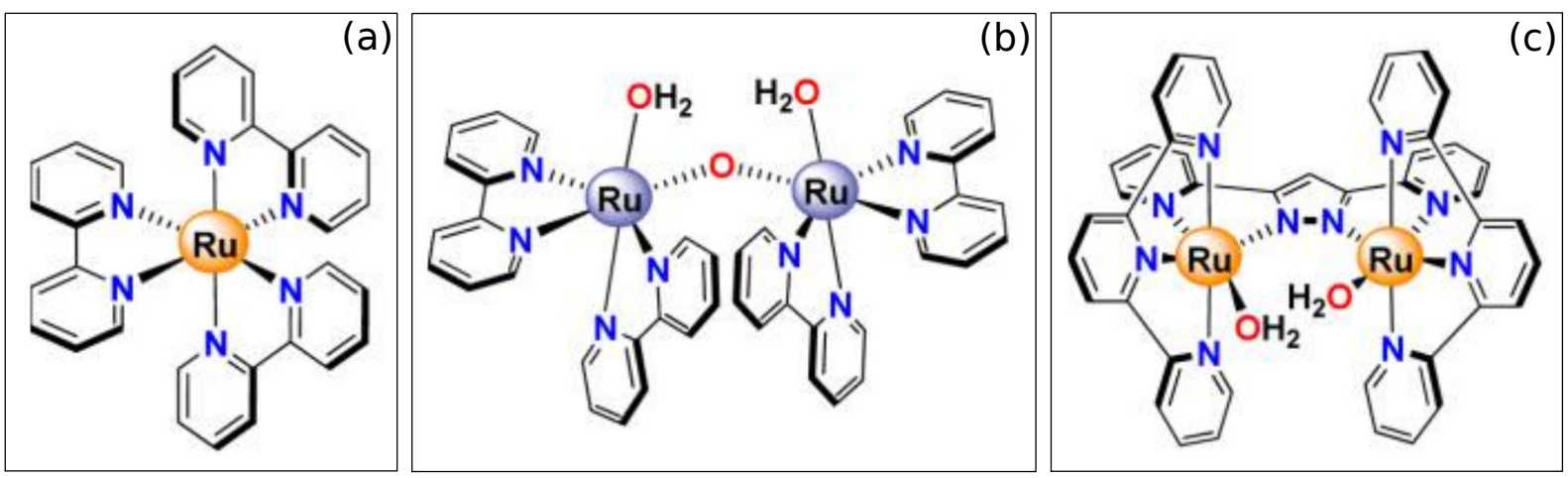

Figura 1.9 - Complexos polipiridínicos de $R u$ : (a) $\left[R u(b p y)_{3}\right]^{2+}$; (b) (cis, cis $\left.\left[(b p y)_{2}\left(\mathrm{H}_{2} \mathrm{O}\right) \mathrm{Ru}(\mu-\mathrm{O}) \mathrm{Ru}\left(\mathrm{H}_{2} \mathrm{O}\right)(\mathrm{bpy})_{2}\right]^{4+}\right)$, conhecido como Dímero Azul; (c) $\mathrm{Ru}-\mathrm{Hbpp}\left[\mathrm{Ru}_{2}\left(\mathrm{OH}_{2}\right)_{2}(\mathrm{bpp})(\mathrm{tpy})_{2}\right]^{2+}$.

desenvolvimento de muitos outros complexos de $R u$ binucleares como catalizadores da oxidação da água. O mecanismo de oxidação do Dímero Azul foi explicado por Meyer e colaboradores em $2008^{[43]}$. Numa primeira etapa, ocorrem 4 eventos de oxidação/desprotonação acoplados, que leva cada átomo de $R u$ ao estado de oxidação $V$ e coordenado com um íon óxido. A partir daí, uma molécula de água se liga entre os íons óxidos (mecanismo designado por WNA - do inglês Water Nucleophilic Attack) e dá se início a uma sequência de troca de prótons e elétron entre os reagentes que conduz à completa oxidação da água e produção de $\mathrm{O}_{2}$.

Outro WOC bastante estudado é o $\mathrm{Ru}-\mathrm{Hbpp}\left[\mathrm{Ru} u_{2}\left(\mathrm{OH}_{2}\right)_{2}(b p p)(t p y)_{2}\right]^{2+}$, figura 1.9-c. Esse complexo foi primeiramente reportado por Benet-Buchholz e colaboradores no ano de $2004{ }^{[44]}$ Esse foi o primeiro complexo bi-nuclear de $R u$ sem a junção $R u-O-R u$ e capaz de oxidar a água. Vários estudos demonstraram que a formação da ligação $O-O$ durante a oxidação da água, em contraste com o "Dímero Azul", acontece exclusivamente por meio da interação de duas unidades metálicas, mecanismo I2M (do inglês interaction of two metaloxo units ${ }^{[45]}$. Esse complexo apresenta um valor de TON bem próximo do Dímero Azul $(\mathrm{TON}=18.6)^{[44]}$ e um TOF 3 vezes maior $\left(\mathrm{TOF}=0.014 \mathrm{~s}^{-1}\right)^{[44]}$.

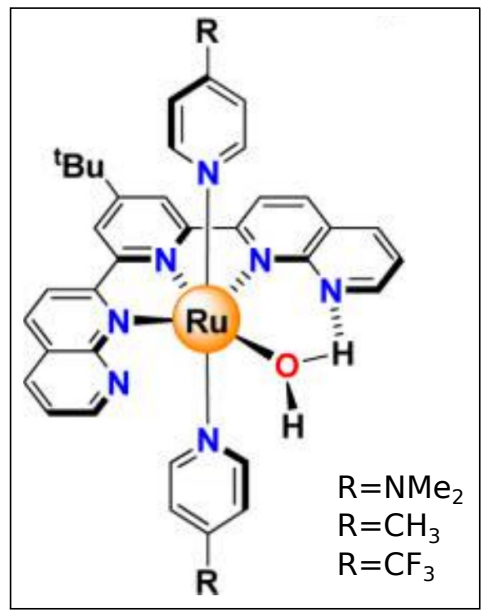

Figura 1.10 - Complexo 2,6 - di(1,8-naftiridin $-2-i l)$ piridina. 
Durante muito tempo acreditou-se que para realizar a reação de oxidação da água seria necessário que o composto tivesse pelo menos dois centros metálicos, para lidar com o acúmulo de elétrons provenientes da reação. A primeira prova real de que a oxidação de quatro elétrons de uma molécula de água poderia ser catalizada por complexos de 1 único sítio metálico só foi fornecida em 2005, por Thummel ${ }^{[46]}$. Eles investigaram alguns compostos constituídos por um ligante polipiridínico do tipo tridentado, 2,6 - di(1,8 - naftiridin - 2-il)piridina, com nitrogênios de naftiridina não coordenados, figura 1.10. Ficou demonstrado que os nitrogênios não coordenados interagem com a molécula de água coordenada ao centro metálico através de ligações de hidrogênio, estabilizando assim os complexos aquosos de 1 único sítio metálico. Os valores de TON e TOF alcançados por esse complexo são: TON $=20$ e TOF $=0.0015 \mathrm{~s}^{-1}$ para $R=N \mathrm{Ne}_{2}{ }^{[47]}, \mathrm{TON}=260$ e TOF $=0.014 s^{-1}$ para $R=\mathrm{CH}_{3}{ }^{[47]}, \mathrm{TON}=35$ e TOF $=0.0033 \mathrm{~s}^{-1}$ para $R=C F_{3}{ }^{[47]}$. Alguns anos mais tarde, em 2011, foi apresentado o mecanismo catalítico desse composto, baseado no ataque nucleofílico de uma molécula de água (WNA) ${ }^{[48]}$, figura 1.11 .

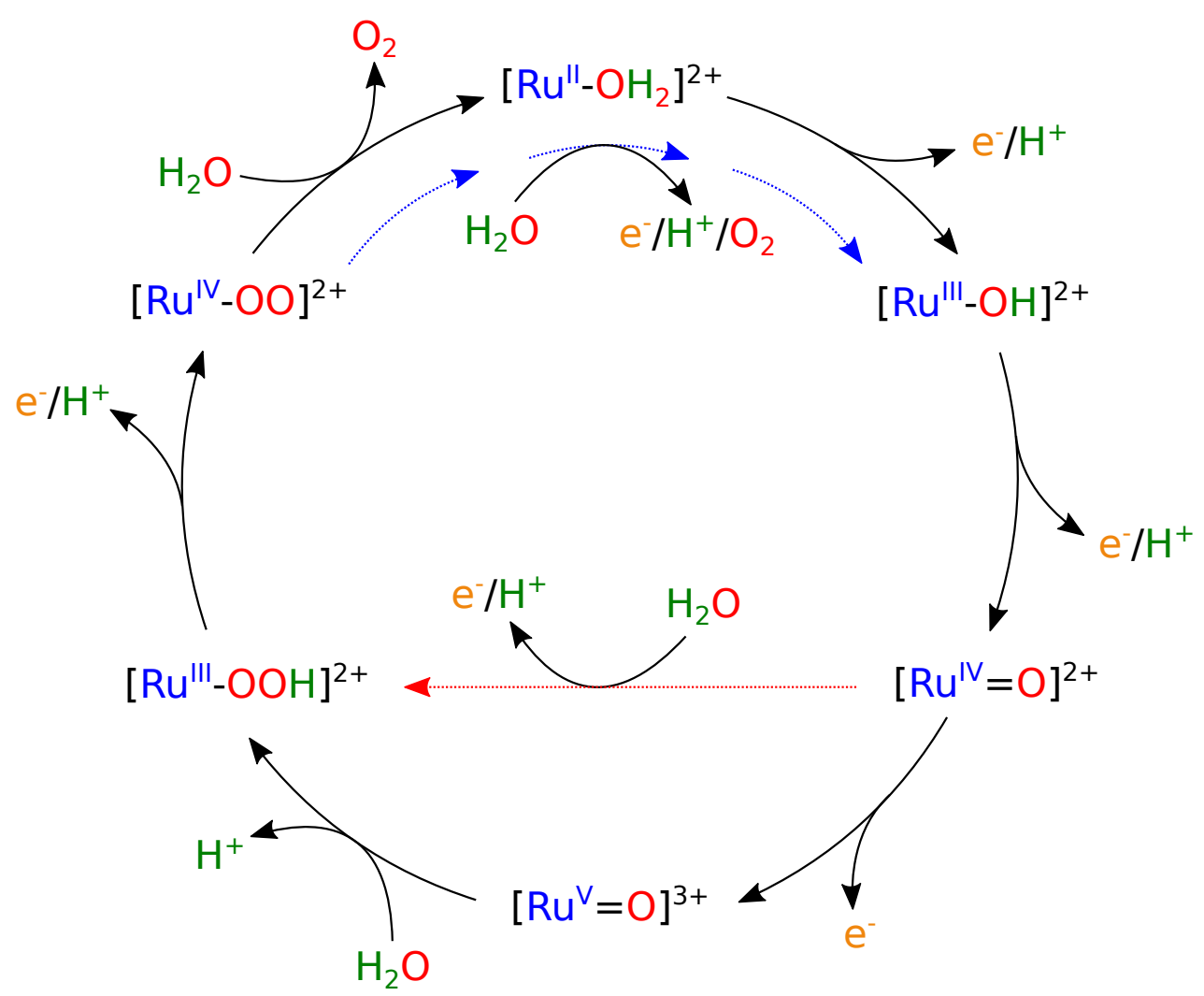

Figura 1.11 - Mecanismo catalítico proposto para o complexo 2,6 - di(1,8 - naftiridin $2-i l)$ piridina. ${ }^{[48]}$

A demonstração da viabilidade dos complexos mono-metálicos como WOC representou um avanço nessa área de pesquisa, uma vez que a síntese de compostos mononucleares é mais simples de ser realizada. ${ }^{[30]}$ Atualmente existe uma variedade de catalisadores mono-metálicos que podem mediar a oxidação de quatro elétrons da água. Em 2011, foi proposto um WOC mono-metálico a base de $R u^{[49]}$ capaz de gerar TON $=55419$ e TOF $=232 s^{-1}$, os valores mais 
altos encontrados na literatura até o momento. 


\subsubsection{Justificativa: apelo ambiental}

Dentre as mais variadas aplicações de complexos de $R u$, a sua utilização na produção de energia limpa e sustentável é certamente uma das grandes motivações para o desenvolvimento de pesquisas científicas nessa área. A produção sustentável de energia limpa constitui um dos

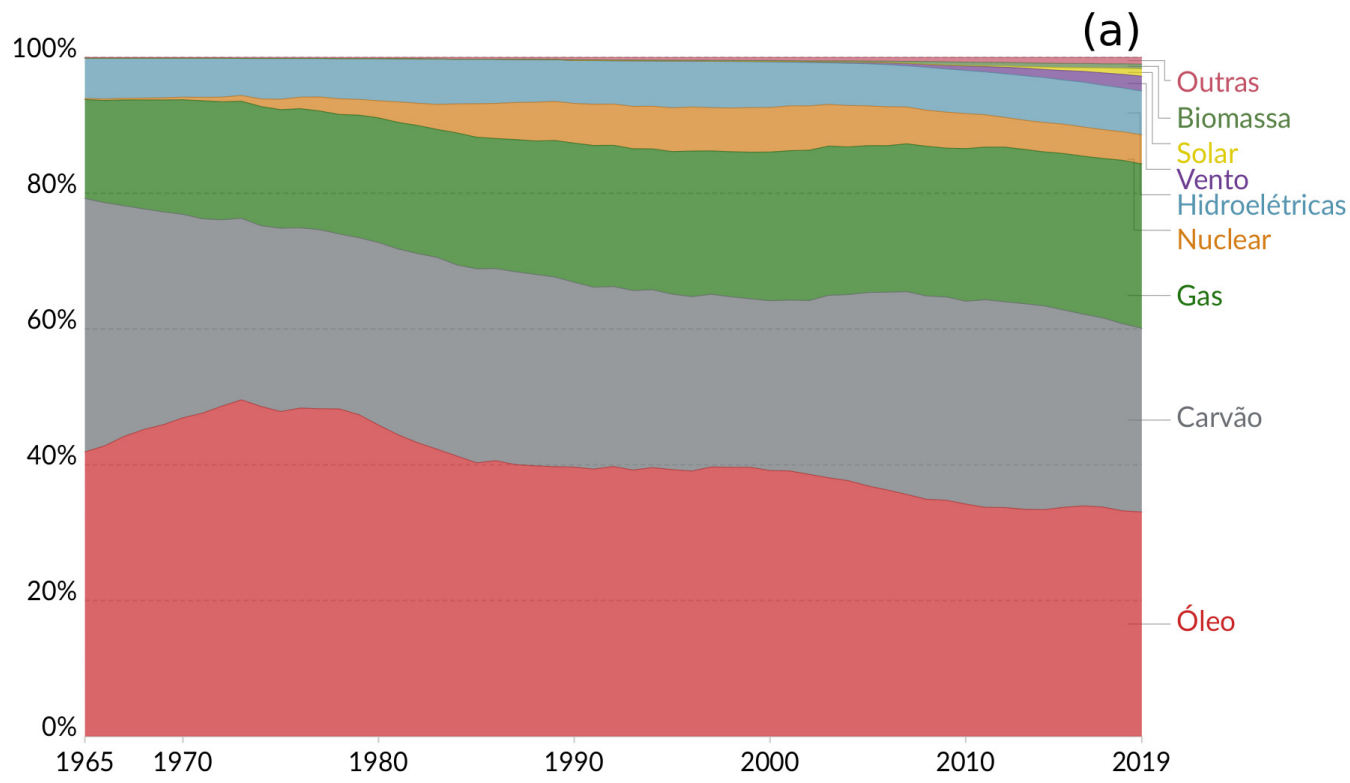

(b)

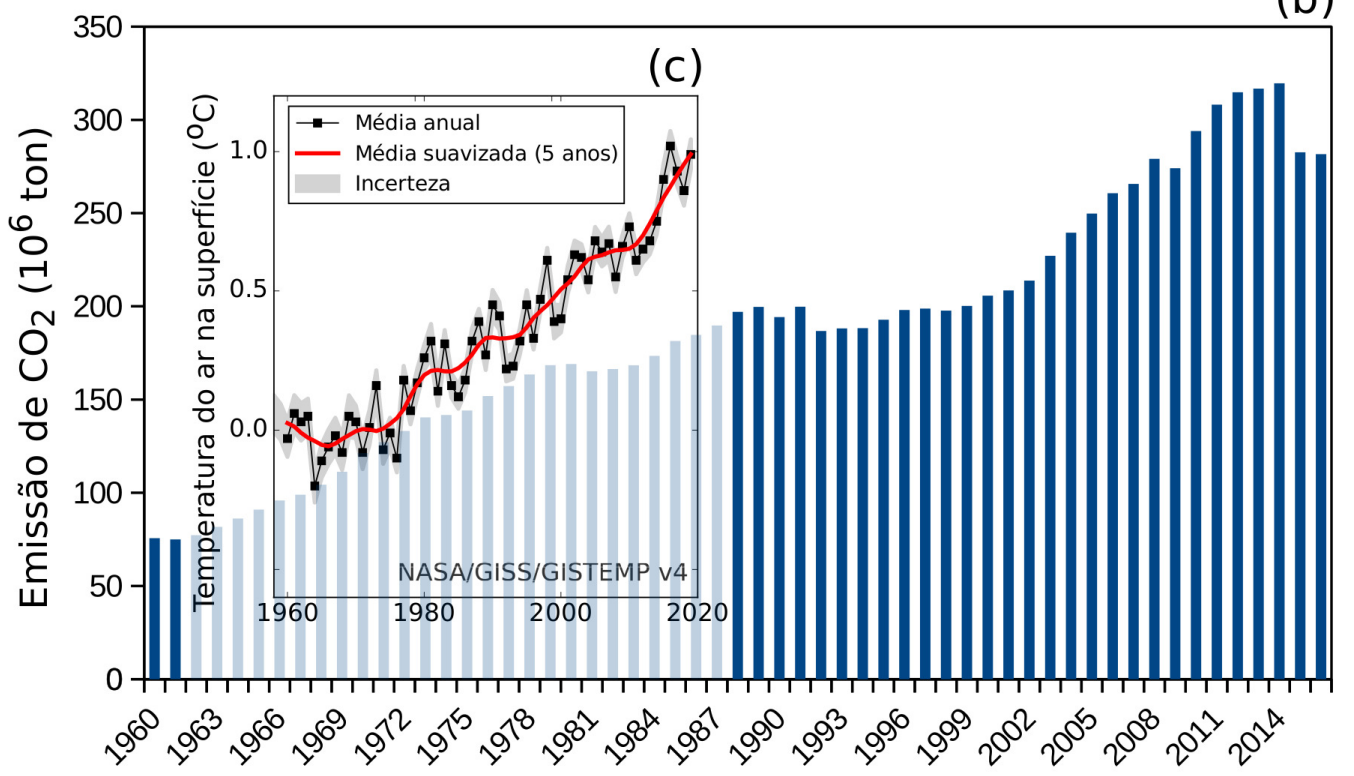

Figura 1.12 - (a) Consumo de energia por fontes, no mundo. Fonte: BP Statistical Review of World Energy (disponível em https://ourworldindata.org/energy) (b) Emissão global de $\mathrm{CO}_{2}$, por ano, de 1960 a 2016. Fonte: Carbon Dioxide Information Analysis Center, Environmental Sciences Division (dados disponibilizados pelo Banco Mundial em https://data.worldbank.org/). (c) Estimativa anual da temperatura média do ar na superfície da Terra, de 1960 a 2019. Fonte: America's Space Agency (disponível em https://data.giss.nasa.gov/gistemp). 
desafios científicos mais importantes do século 21. Atualmente, a maior parte do suprimento global de energia é fornecida por fontes de energia baseadas no carbono (óleo, carvão e gás), figura 1.12-a, que estão conectadas a graves questões ambientais, como poluição do ar e aumento da temperatura global, figura 1.12-c. O aumento da temperatura é causado principalmente pela elevação dos índices de $\mathrm{CO}_{2}$ na atmosfera ${ }^{[50]}$, que tem aumentado gradativamente nas últimas décadas. Segundo dados disponibilizados pelo Banco Mundial, figura 1.12-b, alcançamos a taxa de 200 milhões de toneladas de $\mathrm{CO}_{2}$ por ano no início deste século, e ultrapassamos a taxa de 300 milhões em menos de 1 década. Consequentemente, existe uma forte demanda por alternativas limpas e ecologicamente corretas, livres de carbono, e que tenham o potencial de atender às necessidades das gerações presentes e futuras.

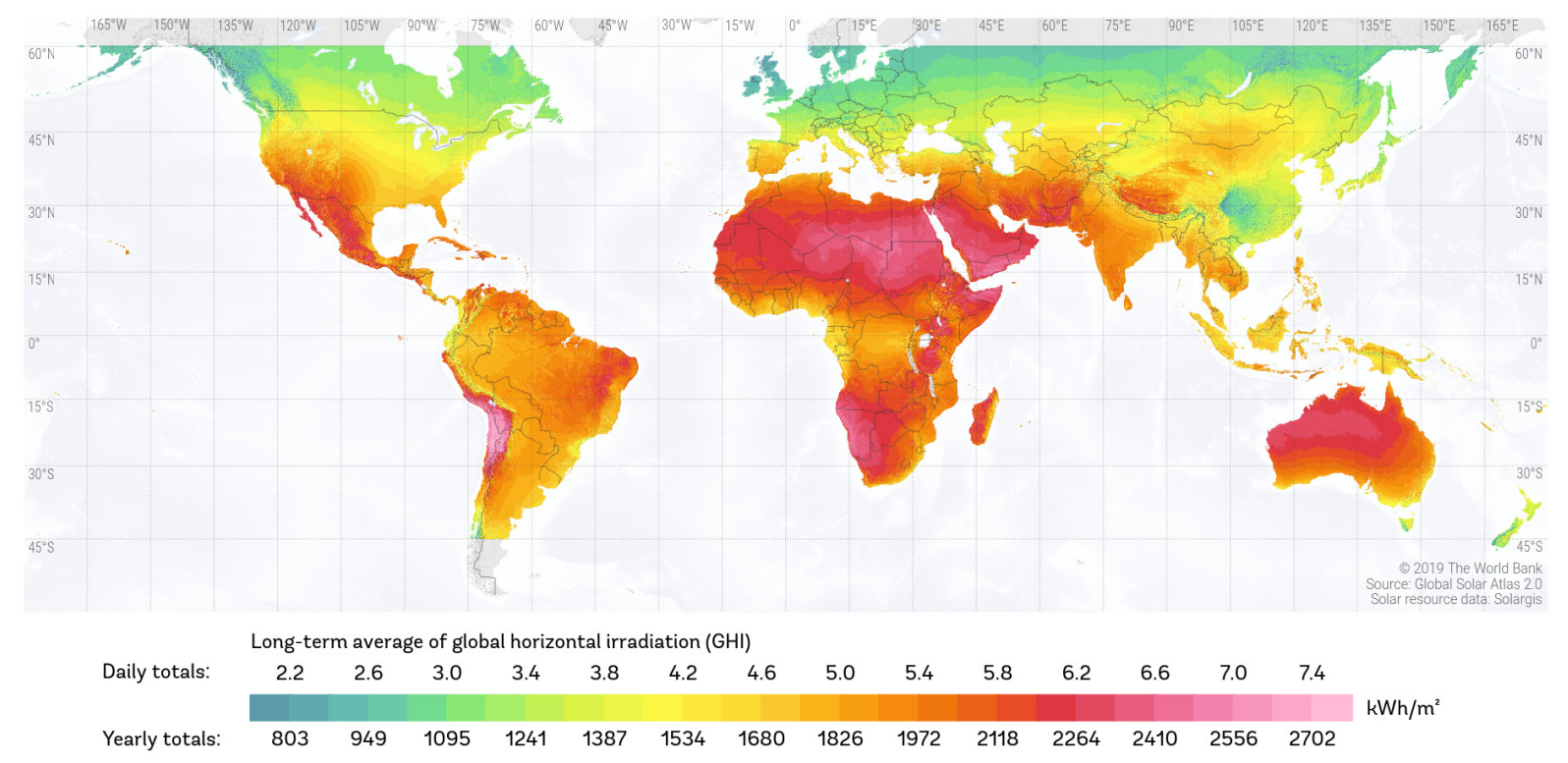

Figura 1.13 - Mapa de recursos solares: soma média diária/anual da irradiação horizontal global $(\mathrm{GHI})$. Fonte: Mapa publicado pelo Banco Mundial usando dados do Global Solar Atlas (GSA) (disponível em: https://globalsolaratlas.info/download/world).

A exploração da energia solar é uma das alternativas mais promissoras. A radiação solar pode ser aproveitada de diferentes formas, sendo que a fotovoltaica e a térmica são as mais conhecidas. Medidas da irradiação global (GHI)* (do inglês Global horizontal irradiation) do planeta Terra, figura 1.13, demonstram o enorme potencial energético a ser explorado por meio de tecnologias baseadas na absorção de luz solar para produção de energia elétrica. Em quase todo o planeta, o GHI é superior a $1500 \mathrm{kWh} / \mathrm{m}^{2}$ na média anual. Apesar do crescimento no consumo de energia solar na última década, ainda existem grandes desafios a serem superados quanto ao aproveitamento dessa energia, dentre eles: a produção de gás hidrogênio em escala industrial por meio de fotossíntese artificial.

\footnotetext{
* O GHI consiste na soma das componentes da irradiação direta e difusa recebidas por uma superfície horizontal. É dado em unidades de $k W h / m^{2}$ e permite comparar as condições naturais de implementação de tecnologias fotovoltaicas.
} 


\subsection{Simulação atomística de compostos de $R u$ - Literatura}

A pesquisa científica sobre o rutênio e seus compostos, para aplicações diversas, cresceu bastante nas últimas décadas. No banco de dados do Web of Science (WoS)*, encontramos entre 139 e 140 mil trabalhos (teóricos e experimentais) publicados, considerando as palavras chave "Ru"e "Ruthenium", na série histórica de 1864 a 2020. Esses trabalhos se enquadram nas áreas da Química (em torno de 70\%), Física (em torno de 20\%), Engenharia, Ciência dos materiais e Bioquímica molecular. Desse total, 113 trabalhos, figura 1.14-b, utilizaram algum tipo de simulação atomística (clássica, quântica ou híbrida), tratando o composto e/ou o solvente explicitamente. Um número modesto, se comparado ao número de trabalhos teóricos que aplicaram, por exemplo, a teoria do funcional de densidade (DFT), 5751 trabalhos, figura 1.14-a.

(a)

(b)
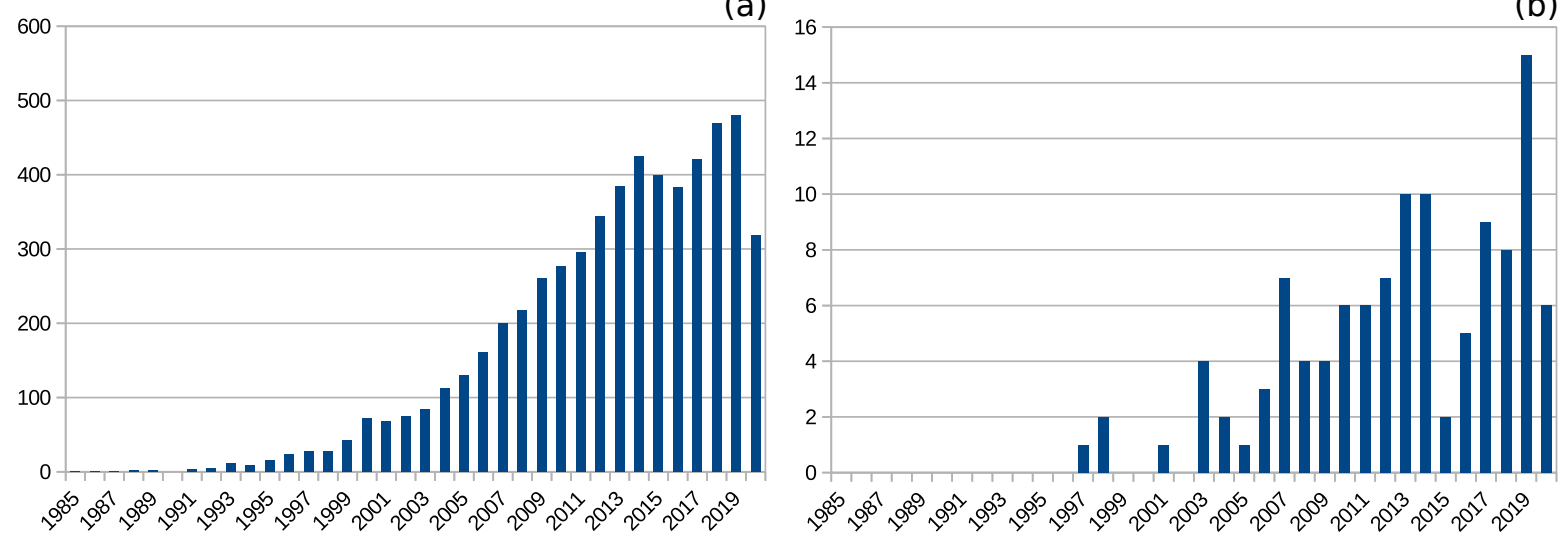

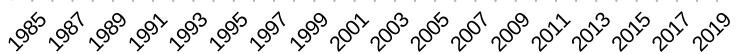

Figura 1.14 - Número de trabalhos publicados sobre $R u$ e compostos de $R u$ segundo o banco de dados do Web of Science (WOS, CCC, DIIDW, KJD, RSCI, SCIELO e ZOOREC), de 1964 a 2020, considerando as diretivas de busca: (a) $A B=(R u$ OR Ruthenium) $A N D A B=(D F T$ OR "density functional theory"); (b) $A B=(R u$ OR Ruthenium) $A N D A B=$ ("atomistic simulation" OR "molecular simulation" OR "molecular mechanic" OR "molecular dynamic" OR "QM/MM" OR "explicit solvent").

Dentre os 113 trabalhos teóricos que aplicaram algum tipo de simulação atomística, apenas 19 deles (publicados entre 2010 e 2020) tratam de temas como: catálise de reações, oxidação e clivagem da água. Encontramos estudos sobre complexos de $R u$ com capacidade de oxidar e clivar moléculas de água, com apenas 1 centro metálico ${ }^{[51-55]}$ e com 2 ou mais centros metálicos ${ }^{[56-58]}$. Encontramos estudos sobre a aplicação de complexos de $R u$ na desidrogenação catalítica de metanol ${ }^{[59-61]}$ e metano ${ }^{[62]}$ para produção de gases $C O$ e $H_{2}$. Encontramos estudos sobre a redução de $N_{2}$ para produção de $N_{3}{ }^{[63,64]}$ e hidrogenação de 2-butanona para produção de 2-butanol ${ }^{[65]}$. Adicionalmente, encontramos também estudos teóricos de 
propriedades redox em solução ${ }^{[66-68]}$ e sobre espectroscopia de fotoelétrons de raios-X (XPS) ${ }^{[69]}$, em que nós colaboramos.

A aplicação de complexos de $R u$ na clivagem da água ou na catálise de outros tipos de reações químicas só é possível em meio a algum solvente. A modelagem correta dos efeitos do ambiente é de suma importância para se reproduzir corretamente as propriedades dos complexos em solução. A correta descrição das interações soluto-solvente é essencial para se compreender: eventos acoplados de oxidação e desprotonação; excitação e desexcitação eletrônica; regeneração eletrolítica; adsorção de complexos em superfícies semicondutoras; etc.

Por uma lado, as simulações por mecânica quântica (QM) de complexos com metal de transição em solução poderia contribuir efetivamente na compreensão físico-química de todos esses processos, entretanto, a modelagem QM de sistemas moleculares tão grandes é uma tarefa extremamente custosa computacionalmente, e às vezes infactível. Dentre os complexos de $R u$-Aqua/Oxo mais conhecidos, por exemplo, a maior parte deles são formados por mais de 50 átomos, com 1 ou 2 centros metálicos. Uma sistema molecular formado por 1 complexo de 50 átomos e 4000 moléculas de água, por exemplo, corresponderia à uma simulação com mais de 12 mil átomos. Mesmo que uma simulação desse porte fosse factível à nível QM, não seria possível alcançar a escala de nano segundos, o que limita o alcance dessa modelagem ao estudo de propriedades que ocorrem até a escala de alguns pico segundos. Além do mais, a presença de metais de transição em um simulação QM pode ser decisiva sobre a sua factibilidade. Dependendo do estado de oxidação do metal, o estado de spin do sistema será não nulo, exigindo assim a aplicação de métodos quânticos ainda mais custosos computacionalmente.

Por outro lado, as simulações por mecânica molecular (MM) permitem que sistemas moleculares com mais de 30 mil átomos sejam estudados na escala de micro segundos. ${ }^{[70]}$ À primeira vista, isso pode nos levar a pensar que um sistema com pouco mais de 12 mil átomos seria então facilmente modelado à nível atomístico, entretanto, a presença do metal de transição no sistema torna essa modelagem um problema um tanto mais desafiador. Em uma simulação MM de complexos com metal de transição, todos os parâmetros do campo de força são altamente sensíveis: ao estado de oxidação e de spin do metal; à natureza dos grupos ligantes que se coordenam com o metal; aos efeitos de microsolvatação em regiões potencialmente doadoras ou aceitadoras de prótons; aos efeitos globais da solvatação dos complexos, em diferentes solventes. A definição do campo de força do metal e do complexo como um todo representa assim um grande desafio.

Dentre os trabalhos encontrados na literatura, e citados acima, sobre a aplicação de complexos de $R u$ para a catálise de reações, oxidação e clivagem da água, há 8 trabalhos que utilizaram simulações de dinâmica molecular quânticas DFT/MD $[52,53,59,61,62,64,65,68]$ e outros 7 trabalhos que utilizaram métodos híbridos, combinando mecânica molecular e mecânica quântica $(\mathrm{QM} / \mathrm{MM})^{[51,56-58,63,66,67]}$, onde o complexo de $R u$ é tratado quanticamente durante a modelagem. Outros 3 trabalhos, utilizaram apenas dinâmica molecular clássica $[54,55,60]$, para os complexos e seu ambiente. A opção pela modelagem quântica apenas de parte do 
sistema soluto mais ambiente, no caso os complexos de $R u$, ou mesmo a modelagem quântica de todo o sistema, são opções que podem garantir o tratamento adequado das interações intra e inter moleculares. Mas, novamente, o alto custo computacional dessas técnicas impõe restrições à sua utilização apenas em simulações de sistemas moleculares com poucos átomos e por um curto intervalo de tempo.

Neste trabalho, adotamos uma abordagem híbrida, onde combinamos cálculos de mecânica molecular, Monte Carlo (MC) ou Dinâmica Molecular (MD) e cálculos de mecânica quântica sequencialmente, método S-QM/MM ${ }^{[71]}$, para estudar as propriedades eletrônicas de 5 complexos polipiridínicos de $R u$-Aqua/oxo em solução aquosa. Nessa abordagem, todo o sistema (soluto + solvente) é inicialmente simulado utilizando apenas mecânica molecular, permitindo assim que o espaço de configurações (nas simulações MC) ou o espaço de fases (nas simulações MD) sejam amplamente explorados, em simulações longas e computacionalmente baratas. Na sequência, configurações estatisticamente descorrelacionadas são extraídas das simulações para compor os cálculos quânticos das propriedades de interesse. Os cálculos quânticos, por sua vez, podem também ser realizados dentro de um esquema $Q M / M M$, onde o soluto, e até parte do solvente, são tratados quanticamente, e as moléculas remanescentes podem ter suas contribuições computadas apenas em nível eletrostático, por exemplo.

Em se tratando de complexos contendo metais de transição, uma das etapas cruciais para a correta aplicação do S-QM/MM é sem dúvidas a escolha do campo de força para as simulações MM. Como não há na literatura proposta de campo de força para $R u$ em complexos polipiridínicos de $R u$ com coordenação aquosa*, nos dedicamos inicialmente no desenvolvimento de parâmetros não-ligados para o átomo de $R u$ nos diversos estados de oxidação e de spin, a fim de descrever corretamente as interações entre o grupo Aqua/Oxo e o complexo. Ademais, este é o primeiro trabalho com aplicação do método S-QM/MM à complexos de $R u$-Aqua/Oxo em solução. Este estudo se destaca por trazer uma investigação detalhada das propriedades eletrônicas, estruturais e físico-químicas de um conjunto de complexos de $R u$-Aqua/Oxo modelo, em solução aquosa, utilizando modelos realísticos de solvente. Os complexos estudados são apresentados na próxima seção, e podem ser considerados uns dos precursores na aplicação de complexos polipiridínicos de metais de transição em fotossíntese artificial.

\footnotetext{
*É até comum encontramos propostas para complexos polipiridínicos de $R u$, mas que não tem coordenação como grupos Aqua/Oxo ${ }^{[72]}$
} 


\subsection{Complexos de Ru-Aqua/Oxo investigados}

No começo dos anos 1980, Meyer e seus colaboradores apresentaram alguns complexos polipiridínicos de rutênio coordenados com uma molécula de água, e capazes de promover a perda combinada de dois prótons e dois elétrons em autos estados de oxidação. Um exemplo desses complexos é o composto $\left[\mathrm{Ru}^{\mathrm{II}}\left(\mathrm{H}_{2} \mathrm{O}\right)(\mathrm{py})(\mathrm{bpy})_{2}\right]^{2+}$ (bpy = 2,2'-bipiridina; py = piridina), que foi apresentado por Meyer e Moyer em 1981. ${ }^{[73]}$ Esse complexo mostrou-se capaz de realizar a perda combinada de dois prótons e dois elétrons em autos estados de oxidação, com um custo para a transferência de dois hidrogênios e dois elétrons estimado em 0.95 V. ${ }^{[73]}$ Dependendo do $p H$ da solução, a molécula de água coordenada pode se transformar em um íon hidróxido $\left(O H^{-}\right)$ou óxido $\left(\mathrm{O}^{2-}\right)$. Adicionalmente, o átomo de $R u$ pode ainda apresentar diferentes estados de oxidação. Neste trabalho, estudamos cinco possíveis formações desse complexo:

(1) $\left[R u^{I I}\left(H_{2} O\right)(p y)(b p y)_{2}\right]_{S}^{2+}$

(2) $\left[R u^{I I I}\left(\mathrm{H}_{2} \mathrm{O}\right)(\mathrm{py})(\mathrm{bpy})_{2}\right]_{D}^{3+}$

(3) $\left[R u^{I I}(O H)(p y)(b p y)_{2}\right]_{S}^{1+}$

(4) $\left[R u^{I I I}(O H)(p y)(b p y)_{2}\right]_{D}^{2+}$

(5) $\left[R u^{I V}(O)(p y)(b p y)_{2}\right]_{T}^{2+}$

O primeiro e terceiro complexos são sistemas singletos, o segundo e quarto são sistemas dubletos, e o último é um sistema tripleto. Na figura 5.1 apresentamos uma ilustração da estrutura molecular de cada complexo. Por simplicidade, adotaremos no texto uma nomenclatura menos carregada para nos referirmos a cada complexo, e os denominaremos por: $R u^{I I}\left(H_{2} O\right)$; $R u^{I I I}\left(H_{2} \mathrm{O}\right) ; R u^{I I}(\mathrm{OH}) ; \mathrm{Ru}^{I I I}(\mathrm{OH}) ; \mathrm{Ru}^{I V}(\mathrm{O})$.

Na literatura, encontramos apenas o trabalho experimental de Meyer e Moyer, de 1981, sobre esses complexos de $R u$. E mais recentemente, em 2019, foi reportado um estudo teórico/experimental do XPS desses complexos em solução aquosa, que será discutido nos resultados deste trabalho. ${ }^{[69]}$ Além desses 2 trabalhos, não encontramos informações adicionais na literatura. Em contrapartida, existe um outro complexo muito similar ao $\left[\mathrm{Ru}^{\mathrm{II}}\left(\mathrm{H}_{2} \mathrm{O}\right)(\mathrm{py})(\text { bpy })_{2}\right]^{2+}$, e mais estudado. Troca-se uma bipiridina e a piridina por uma terpiridina e obtém-se o complexo: $\left[\mathrm{Ru}^{\mathrm{II}}\left(\mathrm{H}_{2} \mathrm{O}\right)(\text { tpy })(\text { bpy })\right]^{2+}$. Em 2008, Meyer e colaboradores utilizaram esse complexo para responder a uma pergunta seminal na época. Ainda pairava no ar a dúvida se os complexos metálicos capazes de oxidar a água, com base em $R u, M n$ e $I r$, deveriam acomodar 2 ou mais centros metálicos. Na ocasião, os autores demonstraram que esse complexo mono-metálico é capaz de promover a oxidação da água. ${ }^{[74]}$ Mais tarde, em 2010, Berlinguette e colaboradores reportaram a eficiência de 10 variantes desse complexo para oxidar a água, variando 4 ligantes $(\mathrm{OMe}, \mathrm{H}, \mathrm{Cl}, \mathrm{COOH})$ em três posições fixas na terpiridina e na bipiridina, ${ }^{[75]}$ alcançando eficiências entre 60 e 480 TON. 

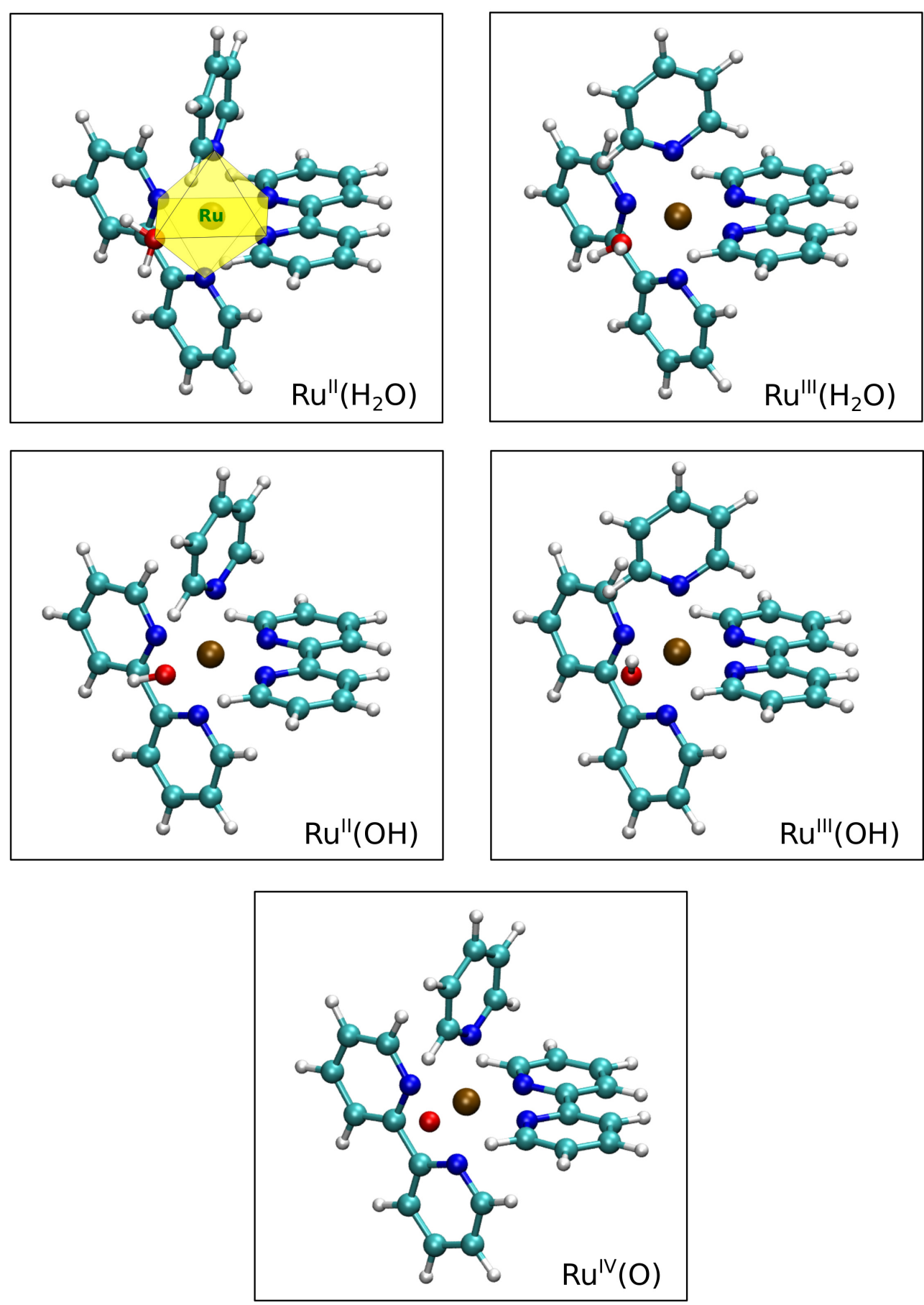

Figura 1.15 - Ilustração em 3D dos complexos de Ru-Aqua/Oxo. Geometrias obtidas a partir de otimização por mecânica quântica $(Q M)$ no vácuo, utilizando Teoria do Funcional da Densidade (DFT), com funcional B3LYP e conjunto de funções base aug-cc-pVDZ (PP para $R u$ ). Observa-se que os átomos de nitrogênio e oxigênio encontram-se espacialmente distribuídos nos vértices de uma estrutura octaédrica não regular, com o átomo de $R u$ no centro da base do octaedro. 


\subsection{Objetivos e organização do texto}

Este trabalho tem por objetivo trazer uma elucidação em nível atomístico de propriedades eletrônicas, estruturais e físico-químicas de um conjunto de complexos de $R u$-Aqua/Oxo modelo em solução aquosa, abordando: (1) os efeitos do solvente e de reações de troca de prótons e elétrons (entre os complexos e o solvente) na estrutura conformacional e eletrônica dos complexos; (2) a estrutura e dinâmica do solvente no entorno dos complexos; (3) as excitações eletrônicas dos complexos nas regiões do visível e ultra-violeta; (5) a energia de ligação de elétrons de camadas profundas de átomos dos complexos; (6) os valores das constantes eletroquímicas $p K a$ e potencial redox em várias reações químicas envolvendo a troca de prótons e elétrons. Ao longo do texto, esses objetivos são alcançados na ordem:

(i) Nos capítulos 2 e 3, apresentamos uma breve revisão sobre os métodos teóricos que foram aplicados nos cálculos de mecânica quântica e de mecânica molecular. No capítulo 4, apresentamos a metodologia utilizada para a realização dos cálculos e análises.

(ii) Nos capítulos 5 e 6, investigamos os efeitos do solvente e de processos de oxidação e desprotonação na estrutura conformacional e eletrônica dos complexos. Apresentamos uma nova proposta de parâmetros não-ligados para o átomo de $R u$ em diferentes estados de oxidação, utilizados para realizar as simulações de mecânica molecular. A partir das simulações, investigamos os detalhes atomísticos da interação dos complexos de $R u$-Aqua/Oxo com o solvente, e nos aprofundamos nos temas: estrutura do solvente no entorno dos complexos; formação de ligações de hidrogênio intermolecular; difusão de massa dos complexos; comportamento dos complexos na interface água/vácuo.

(iii) Em seguida, no capítulo 7, utilizamos um protocolo que combina cálculos de mecânica quântica e de mecânica molecular sequencialmente (S-QM/MM) para estudar diversas propriedades eletrônicas. Investigamos os efeitos do solvente nas energias dos orbitais de fronteira. Estudamos a espectroscopia de absorção UV-Vis e também a espectroscopia de fotoelétrons de raios-X dos complexos. No capítulo 8 , tratamos da predição teórica da energia livre de solvatação e de propriedades eletroquímicas dos complexos de $R u$-Aqua/Oxo em solução aquosa, $p K a$ e potencial redox, a partir da aproximação de ciclos termodinâmicos.

Considerações finais são apresentadas no capítulo 9, e apêndices diversos seguem em anexo. Em todo o texto, utilizaremos o ponto como separador decimal, ao invés da vírgula usualmente adotada no Brasil. 



\section{Capítulo}

\section{Estrutura eletrônica molecular}

Este capítulo traz a apresentação de alguns tópicos de Física Atômica e Molecular que darão o suporte teórico mínimo aos cálculos de mecânica quântica realizados neste estudo. Iniciaremos com a separação de Born-Oppenheimer e a função de onda como determinante de Slater. Passaremos ao método de Hartree-Fock e correções perturbativas para a inclusão de correlação eletrônica. Apresentaremos a Teoria do Funcional de Densidade e sua versão dependente do tempo, utilizada no cálculo de excitações eletrônicas. Em seguida, apresentaremos o modelo de estado de transição de Slater-JanaK, utilizado no cálculo da energia de ligação de elétrons de camadas profundas. Discorreremos sobre conjuntos de funções base, funções base com potencial central efetivo e erro de superposição de bases. Finalizaremos com o tema métodos de cálculo de cargas atômicas.

\subsection{Separação de Born-Oppenheimer}

As propriedades quânticas de uma molécula podem ser obtidas a partir da resolução de uma equação de Schrödinger independente do tempo, na forma

$$
\hat{H}(\vec{r}, \vec{R}) \Psi(\vec{r}, \vec{R})=E \Psi(\vec{r}, \vec{R})
$$

onde o operador $\hat{H}(\vec{r}, \vec{R})$ representa as energias cinética $\hat{T}(\vec{r}, \vec{R})$ e potencial $\hat{V}(\vec{r}, \vec{R})$ dos $M$ núcleos (localizados por $\vec{R}$ ) e $N$ elétrons (localizados por $\vec{r}$ ) da molécula. Em termos de $\hat{T}$ e $\hat{V}$, e em unidades atômicas, $\hat{H}$ pode ser reescrito como:

$$
\hat{H}(\vec{r}, \vec{R})=-\sum_{i=1}^{N} \frac{1}{2} \nabla_{i}^{2}-\sum_{A=1}^{M} \frac{1}{2 M_{A}} \nabla_{A}^{2}-\sum_{i=1}^{N} \sum_{A=1}^{M} \frac{Z_{A}}{r_{i A}}+\sum_{i=1}^{N-1} \sum_{j>i}^{N} \frac{1}{r_{i j}}+\sum_{A=1}^{M-1} \sum_{B>A}^{M} \frac{Z_{A} Z_{B}}{R_{A B}} .
$$

O primeiro termo corresponde à energia cinética dos elétrons $\left(\hat{T}_{e}\right)$; o segundo à energia cinética do núcleos $\left(\hat{T}_{n}\right)$; o terceiro à energia potencial devido à interação elétron-núcleo $\left(\hat{V}_{e n}\right)$; o quarto à energia potencial de interação elétron-elétron $\left(\hat{V}_{e e}\right)$; e o último termo à energia potencial de interação núcleo-núcleo $\left(\hat{V}_{n n}\right)$. 
Para sistemas eletrônicos de muitos elétrons, a equação de Schrödinger não é separável e precisa de aproximações para ser resolvida. A primeira aproximação consiste em fazer a separação dos movimentos nuclear e eletrônico: a Aproximação de Born-Oppenheimer. A função de onda $\Psi(\vec{r}, \vec{R})$ é escrita como o produto de duas funções de onda,

$$
\Psi(\vec{r}, \vec{R})=\Psi_{e}(\vec{r} ; \vec{R}) \Psi_{n}(\vec{R})
$$

A primeira, $\Psi_{e}(\vec{r} ; \vec{R})$, uma função que descreve o estado quântico eletrônico e depende parametricamente das coordenadas nucleares. A segunda, $\Psi_{n}(\vec{R})$, uma função que descreve o estado quântico nuclear e sem dependências paramétricas. Substituindo a expressão (2.3) na equação (2.1), e escrevendo o operador $\hat{H}$ em termos dos operadores de energia cinética e potencial $\left(\hat{T}_{e}, \hat{T}_{n}, \hat{V}_{e n}, \hat{V}_{e e}, \hat{V}_{n n}\right)$, resulta:

$$
\left(\hat{T}_{e}+\hat{T}_{n}+\hat{V}_{e n}+\hat{V}_{e e}+\hat{V}_{n n}\right) \Psi_{e}(\vec{r} ; \vec{R}) \Psi_{n}(\vec{R})=E \Psi_{e}(\vec{r} ; \vec{R}) \Psi_{n}(\vec{R}) .
$$

A segunda aproximação é conhecida por aproximação adiabática ${ }^{[76]}$. Considera-se que os elétrons possuem massa muito menor que os núcleos e se adaptam quase que instantaneamente a qualquer disposição nuclear, de modo que a cinética nuclear pode ser desprezada no cálculo eletrônico. Fisicamente, isso implica dizer que o operador de energia cinética dos núcleos não atua sobre a função de onda eletrônica, levando a equações separadas para elétrons e para núcleos:

$$
\begin{gathered}
\left(\hat{T}_{e}+\hat{V}_{e n}+\hat{V}_{e e}+\hat{V}_{n n}\right) \Psi_{e}(\vec{r} ; \vec{R})=\hat{H}_{e} \Psi_{e}(\vec{r} ; \vec{R})=E_{e}(\vec{R}) \Psi_{e}(\vec{r} ; \vec{R}) \\
{\left[\hat{T}_{n}+E_{e}(\vec{R})\right] \Psi_{n}(\vec{R})=\hat{H}_{n} \Psi_{n}(\vec{R})=E \Psi_{n}(\vec{R}) .}
\end{gathered}
$$

A resolução da equação (2.5) permite obter a energia eletrônica $E_{e}(\vec{R})$ para diferentes valores fixos da coordenada $\vec{R}$.

\subsection{Determinante de Slater}

Em Mecânica Quântica, o estado físico de um sistema, em um instante de tempo $t$, é representado por um vetor de estado $|\psi(t)\rangle$, que contém toda a informação que pode ser obtida do sistema. Projetando-o no espaço das posições, obtêm-se a função de onda do sistema, $\psi(\vec{r})$, também chamada de orbital espacial molecular, no caso de moléculas. A probabilidade de que um elétron $i$ descrito por $\psi_{i}(\vec{r})$ seja encontrado dentro de um volume $\overrightarrow{d r}$ é dada por $\left|\psi_{i}(\vec{r})\right|^{2} \overrightarrow{d r}$. Mas, para descrever um elétron é necessário mais do que um orbital espacial, é necessário explicitar também o seu estado de spin. Para isso, faz-se um produto da função orbital por uma função de spin, gerando-se um spin-orbital. O conjunto completo e ortonormal de funções de spin é dado por $\{\alpha(\omega), \beta(\omega)\}$, onde a primeira função representa "spin para cima"e a segunda "spin para baixo". Logo, obtêm-se um conjunto de coordenadas espaço-spin que pode 
ser denotado por $\vec{x}=\{\vec{r}, \omega\}$. A partir de um orbital espacial $\psi_{i}$ constrói-se 2 spin-orbitais: $\chi_{j}(\vec{x})=\psi_{i}(\vec{r}) \alpha(\omega)$ e $\chi_{k}(\vec{x})=\psi_{i}(\vec{r}) \beta(\omega)$.

Uma primeira aproximação para a função de onda de $N$ elétrons é o Produto de Hartree. Nesse produto os elétrons são considerados partículas não interagentes e a função de onda total pode ser escrita como o produto dos spin-orbitais de cada elétron. Não são considerados os princípios da indistinguibilidade dos elétrons e da antissimetria da função de onda com relação à troca de coordenadas espaço-spin entre os spin-orbitais. É uma função de onda descorrelacionada, donde a probabilidade de se encontrar um elétron nas imediações de uma posição fixa do espaço independe das posições dos outros elétrons. Por meio de um processo de antissimetrização ${ }^{[7]}$ do Produto de Hartree, obtém-se uma função de onda na forma de um determinante, conhecido por Determinante de Slater.

$$
\Psi\left(\vec{x}_{1}, \vec{x}_{2}, \ldots, \vec{x}_{N}\right)=\frac{1}{\sqrt{N !}}\left|\begin{array}{cccc}
\chi_{1}\left(\vec{x}_{1}\right) & \chi_{2}\left(\vec{x}_{1}\right) & \cdots & \chi_{N}\left(\vec{x}_{1}\right) \\
\chi_{1}\left(\vec{x}_{2}\right) & \chi_{2}\left(\vec{x}_{2}\right) & \cdots & \chi_{N}\left(\vec{x}_{2}\right) \\
\vdots & \vdots & & \vdots \\
\chi_{1}\left(\vec{x}_{N}\right) & \chi_{2}\left(\vec{x}_{N}\right) & \cdots & \chi_{N}\left(\vec{x}_{N}\right)
\end{array}\right| .
$$

Resolve-se assim o problema da indistinguibilidade e da antissimetria e, em partes, o da correlação. A função de onda passa a ter correlação de troca entre elétrons com spins paralelos, entretanto não é considerada nenhuma correlação entre elétrons de spins anti-paralelos. Apesar dos problemas, é a função de onda antissimétrica mais simples, que pode ser usada para descrever o estado fundamental de um sistema de muitos elétrons.

\subsection{Método de Hartree-Fock}

Segundo o Princípio Variacional, dada uma função de estado aproximada, bem comportada e normalizada $|\varphi\rangle$, que satisfaça as condições de contorno de um sistema físico com operador hamiltoniano $\hat{H}$, o valor esperado da energia $\varepsilon$ calculado a partir desta função,

$$
\varepsilon=\langle\varphi|\hat{H}| \varphi\rangle
$$

será sempre um limite superior da energia exata $E_{0}$ do estado fundamental $\left|\varphi_{0}\right\rangle$ desse sistema,

$$
\langle\varphi|\hat{H}| \varphi\rangle \geq E_{0}
$$

A flexibilidade variacional da função de onda eletrônica, $\Psi_{0}(\vec{r}, \vec{R})$, escrita como um determinante de slater, está na escolha dos spin-orbitais. A idéia por trás da obtenção das equações de Hartree-Fock está justamente em minimizar a energia eletrônica e assim determinar os spin-orbitais $\chi_{i}$ que melhor representam a aproximação para a energia do estado fundamental com apenas um determinante. 
Com a função de onda eletrônica na forma de um único determinante de Slater, a energia $E_{0}=\left\langle\Psi_{0}\left|H_{e}\right| \Psi_{0}\right\rangle$ é um funcional dos spin-orbitais $\left\{\chi_{a}\right\}$ e deve ser minimizada com a restrição de que os spin-orbitais permaneçam ortonormais. Definindo-se os operadores de Coulomb, $J_{b}(1)$, e de Exchange, $K_{b}(1)$, a partir de suas atuações sobre um spin-orbital $\chi_{a}(1)$ :

$$
\begin{aligned}
& J_{b}(1) \chi_{a}(1)=\left[\int d \overrightarrow{x_{2}} \chi_{b}^{*}(2) r_{12}^{-1} \chi_{a}(2)\right] \chi_{a}(1), \\
& K_{b}(1) \chi_{a}(1)=\left[\int d \overrightarrow{x_{2}} \chi_{b}^{*}(2) r_{12}^{-1} \chi_{a}(2)\right] \chi_{b}(1),
\end{aligned}
$$

considerando o operador de 1 elétron $h \hat{(i)}$ como

$$
\hat{h}(i)=-\frac{1}{2} \nabla_{i}^{2}-\sum_{A=1}^{M} \frac{Z_{A}}{r_{i A}},
$$

e realizando a minimização da energia eletrônica $E_{0}$, conforme demonstrado em ${ }^{[77]}$, obtem-se a expressão canônica para as equações de Hartree-Fock:

$$
f\left|\chi_{a}\right\rangle=\sum_{b=1}^{N} \epsilon_{b a}\left|\chi_{b}\right\rangle,
$$

onde o operador de Fock $f$ fica definido como

$$
f=\left[h(1)+\sum_{b=1}^{N} J_{b}(1)-K_{b}(1)\right]
$$

Dado um novo conjunto de spin-orbitais $\left\{\chi_{a}^{\prime}\right\}$ obtido a partir de um conjunto já conhecido $\left\{\chi_{a}\right\}$ via uma transformação unitária $U^{\dagger}=U^{-1}$, pode-se mostrar que os autovalores de uma função de onda na forma de um determinante único é invariante sob essa transformação unitária dos spin-orbitais que a compõem. Como o operador de Fock $f$ e os multiplicadores de lagrange $\epsilon_{b a}$ são também invariantes sob uma transformação unitária arbitrária dos spin-orbitais ${ }^{[8]}$, então a equação (2.13) pode ser colocada na forma de uma equação de autovalor para um conjunto particular de spin-orbitais. Ou seja, deve existir um conjungo de spin-orbitais $\left\{\chi_{a}^{\prime}\right\}$ para os quais os multiplicadores de Lagrange são diagonais. Assim, as equações de Hartree-Fock podem ser colocadas na forma: $f\left|\chi_{a}\right\rangle=\epsilon_{a}\left|\chi_{a}\right\rangle$.

Na aproximação de Hartree-Fock o problema de muitos elétrons é trocado por um problema de um elétron em que a repulsão eletrônica é tratada de forma média. O operador de Fock $f$ é um operador de um elétron. O somatório da diferença entre os operadores de Coulomb e de Troca em $f$ constitui o potencial médio experimentado por um elétron $i$ devido à presença dos outros elétrons, e depende portanto dos spin-orbitais dos outros elétrons. A dependência do operador de Fock com os spin-orbitais é responsável pela sua não linearidade, e portanto, as equações de Hartree-Fock devem ser resolvidas de forma iterativa.

Os spin-orbitais que compõe o estado de um sistema molecular podem ser organizados em duas classes: spin-orbitais restritos, que possuem a mesma função espacial $\psi_{i}$ para funções de 
spin $\alpha(\omega)$ e $\beta(\omega)$; e spin-orbitais não restritos, que tem funções espaciais diferentes para $\alpha(\omega)$ e $\beta(\omega)$. Sistemas que possuem um número par de elétrons, com todos os orbitais espaciais duplamente ocupados, são denominados sistemas de camada fechada. E sistemas que possuem elétrons desemparelhados, ocupando orbitais espaciais diferentes, recebem o nome de sistemas de camada aberta. A descrição de sistemas de camada aberta é realizada a partir da Teoria de Hartree-Fock não restrita. Já os sistemas de camada fechada são tratados com a Teoria de Hartree-Fock restrita.

\subsubsection{Correções perturbativas}

Por não levar em conta a correlação eletrônica entre elétrons de spins anti-paralelos, a aproximação de Hartree-Fock fornece um valor superestimado da energia do estado fundamental. Para contornar esse problema, e construir uma função de onda mais acurada, existem métodos chamados "pós-Hartree-Fock", e, dentre os mais conhecidos: métodos de Interação de Configuração (FCI, CIS, CID, CISD); métodos Couple-Cluster (CCS, CCSD, CCSD(T), etc.), métodos perturbativos (MP2, MP3, MP4, MP5 e MP6), entre outros.

No contexto dos métodos pós-Hartree-Fock, a Teoria de Perturbação de Rayleigh-Schrödiger (TPRS), amplamente discutida em ${ }^{[79]}$, é uma ferramenta útil para a inclusão de correlação na função de onda eletrônica. O hamiltoniano $H$ pode ser particionado na soma do hamiltoniano de Hartree-Fock $H_{0}$ a um termo perturbativo $V$,

$$
H=H_{0}+V
$$

onde

$$
\begin{aligned}
& H_{0}=\sum_{i} f(i)=\sum_{i}\left[h(i)+v^{\mathrm{HF}}(i)\right], \\
& V=\sum_{i<j} r_{i j}^{-1}-\sum_{a=1}^{N}\left(J_{a}(i)-K_{a}(i)\right),
\end{aligned}
$$

Como autovalores associados a $V$ são em geral muito menores que autovalores associados a $H_{0}$, para uma função de onda arbitrária, a TPRS é aplicável e as correções para os autoestados de $H$ e para as energias $E_{n}$ podem ser obtidas no nível desejado. Nesses moldes, a TPRS recebe a denominação de teoria de perturbação de Moller-Plesset (TPMP).

Em primeira ordem, a correção para a energia do estado fundamental é dada por

$$
E_{0}^{1}=\left\langle\phi_{0}\left|\left(\sum_{i>j}^{N} \frac{1}{r_{i j}}-\sum_{i}^{N} \nu^{\mathrm{HF}}(i)\right)\right| \phi_{0}\right\rangle=\left\langle\phi_{0}\left|\sum_{i>j}^{N} \frac{1}{r_{i j}}\right| \phi_{0}\right\rangle-\left\langle\phi_{0}\left|\sum_{i}^{N} \nu^{\mathrm{HF}}(i)\right| \phi_{0}\right\rangle .
$$

Pelas regras de Condon-Slater, $E_{0}^{1}$ se resume a

$$
E_{0}^{1}=-\frac{1}{2} \sum_{i, j}^{N}\langle i j \mid i j\rangle-\langle i j \mid j i\rangle=-\frac{1}{2} \sum_{i, j}^{N}\langle i j \| i j\rangle .
$$


A energia do sistema no estado fundamental corrigida até primeira ordem via TPMP é igual a energia de Hartree-Fock, indicando que somente a partir da segunda ordem de perturbação é que realmente haverá correção perturbativa.

$$
E^{\mathrm{HF}}=E_{0}^{0}+E_{0}^{1}=\sum_{i} e_{i}-\frac{1}{2} \sum_{i, j}^{N}\langle i j \| i j\rangle .
$$

Em segunda ordem, a correção na energia é dada por ${ }^{[80]}$

$$
E_{0}^{2}=\sum_{a<b} \sum_{r<s} \frac{|\langle a b|| r s\rangle|^{2}}{\epsilon_{a}+\epsilon_{b}-\epsilon_{r}-\epsilon_{s}} .
$$

$\mathrm{Na}$ TPMP correções de segunda ordem na energia são normalmente designadas pela sigla MP2, correções de terceira ordem por MP3, e assim por diante. Expressões para correções em ordens superiores estão disponíveis em ${ }^{[80]}$. Correções na função de onda de HF normalmente não são necessárias, pois muitas das propriedades eletrônicas de interesse podem ser obtidas por meio da Energia.

\subsection{Teoria do funcional de densidade}

Em 1964, Hohenberg e Kohn ${ }^{[81]}$ demonstraram, através de dois teoremas, que a partir da densidade eletrônica de um sistema no seu estado fundamental é possível obter a energia do estado fundamental de maneira exata. Isso representou o início do desenvolvimento da Teoria do Funcional de Densidade (DFT), na qual a densidade eletrônica $n(\vec{r})$ do sistema é a variável fundamental, e a partir dela todos os outros observáveis podem ser calculados. A grande vantagem em relação a métodos como Hartree-Fock, MP2, CCSD, entre outros, está na redução do custo computacional. Para um sistema arbitrário qualquer descrito por $n$ funções base, o esforço computacional em DFT aumenta da ordem de $n^{3}$, enquanto que para os métodos Hartree-Fock aumenta em $n^{4}$ ou $n^{5[82]}$.

O primeiro teorema de Hohenberg e Kohn ${ }^{[81]}$ estabelece que a densidade de carga $n(\vec{r})$ do estado fundamental de um sistema de muitos elétrons é determinada de maneira unívoca a partir do potencial externo $v_{\text {ext }}(\vec{r})$. O segundo teorema diz que a energia do estado fundamental corresponde ao mínimo do funcional de energia $E_{0}[n(\vec{r})]$, obtido a partir da densidade exata do estado fundamental $n_{0}(\vec{r})$. Qualquer densidade diferente $n^{\prime}(\vec{r}) \neq n_{0}(\vec{r})$ conduzirá a uma energia $E\left[n^{\prime}(\vec{r})\right]$ maior do que a energia do estado fundamental, $E\left[n^{\prime}(\vec{r})\right]>E_{0}\left[n_{0}(\vec{r})\right]$.

Na aproximação de Born Oppenheimer, a energia $E$ de um sistema de $N$ elétrons é escrita como um funcional da densidade eletrônica na forma:

$$
E[n]=T[n]+U[n]+U_{\text {ext }}[n]
$$

onde $T[n]$ é a energia cinética, $U[n]$ é a energia de interação entre elétrons e $U_{\text {ext }}[n]$ é a energia devido a interação com os núcleos e outros entes externos que possam existir (um 
campo magnético, por exemplo). O termo de energia $U_{\text {ext }}[n]$ é uma soma exata das energias de interação $u_{\text {ext }}(\vec{r})$ de cada elétron em $\vec{r}$

$$
U_{\text {ext }}[n]=\int n(\vec{r}) u_{\text {ext }}(\vec{r}) d \vec{r}
$$

Já as energias $T[n]$ e $U[n]$ devem ser obtidas aproximadamente.

Uma das primeiras aproximações bem sucedidas para esses termos foi a aproximação de

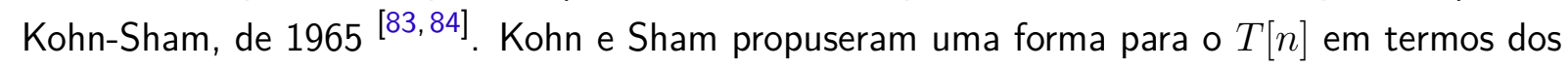
orbitais $\phi_{i}$ de um gás de elétrons não interagentes e de densidade $n$

$$
T[n] \approx T_{S}[n]=-\frac{1}{2} \sum_{i=1}^{N} \int \phi_{i}^{*}(\vec{r}) \nabla^{2} \phi_{i}(\vec{r}) d \vec{r},
$$

onde

$$
n(\vec{r})=\sum_{i=1}^{N} \int \phi_{i}^{*}(\vec{r}) \phi_{i}(\vec{r}) d \vec{r} .
$$

A aproximação em $T S[n]$, para $T[n]$, se baseia na suposição de que a densidade $n(r)$ é aproximadamente constante num volume $d r$ e portanto despreza a correlação instantânea entre os elétrons. Dentro do formalismo de partícula independente:

$$
E_{0}[n]=T_{S}[n]+U_{H}[n]+U_{\mathrm{ext}}[n]+E_{\mathrm{XC}}[n]
$$

onde $E_{\mathrm{XC}}[n]$ é o termo que contém a correção da energia cinética $T[n]-T_{S}[n]$ e da energia de Hartree $U[n]-U_{H}[n]$, sendo portanto definido como:

$$
E_{\mathrm{XC}}[n]=\left(T[n]-T_{S}[n]\right)+\left(U[n]-U_{H}[n]\right) .
$$

Pela aproximação de Kohn-Sham, minimizando o funcional energia $E_{0}[n]$ em relação a densidade com o vínculo do número de partículas constante, obtêm-se as equações que descrevem o estado do sistema, as equações de Kohn-Sham:

$$
\left(-\frac{\nabla^{2}}{2}+V_{\text {ef }}\right) \phi_{i}=\epsilon_{i} \phi_{i}
$$

onde

$$
V_{\mathrm{ef}}=\int \frac{n(\vec{r} \prime)}{|\vec{r}-\vec{r} \prime|} d \vec{r} \prime+u(\vec{r})+\frac{\delta E_{\mathrm{XC}}[n]}{\delta n},
$$

$\epsilon_{i}$ e $\phi_{i}$ são os autovalores e autofunções de Kohn-Sham. Essa minimização é equivalente a resolver uma equação do tipo Schrödinger com um potencial efetivo $V_{\text {ef }}$. As equações de Kohn-Sham devem ser resolvidas de forma autoconsistente, pois o potencial efetivo depende da densidade eletrônica que depende das autofunções de Kohn-Sham.

A perda da correlação e da anti-simetria das funções de onda devido à aproximação de partículas independentes é considerada no termo da energia de troca-correlação como um funcional de densidade. A dependência desse termo com a densidade não é conhecida exatamente, e deve ser tratada por meio de aproximações. A aproximação mais simples é 
chamada Aproximação da Densidade Local ${ }^{[85]}$ (LDA) (do inglês Local Density Approximation). A aproximação LDA consiste em expressar a energia de troca-correlação por elétron $\epsilon_{\mathrm{XC}}$ em um ponto $r$ do espaço como a de um gás de elétrons homogêneo que tenha a mesma densidade $n(r)$ em $r$. Essa aproximação é viável para sistemas cujas densidades eletrônicas não variam rapidamente dentro de um pequena região. Para casos em que a densidade eletrônica varia no espaço de forma menos suave, inclui-se a dependência da primeira derivada espacial da densidade, na Aproximação do Gradiente Generalizado ${ }^{[86]}$ (GGA).

$$
E_{\mathrm{XC}}^{\mathrm{GGA}}[n]=\int f(n(\vec{r}), \vec{\nabla} n(\vec{r})) d^{3} \vec{r}
$$

Na GGA, a energia de troca-correlação por elétron é substituída por uma função local da densidade eletrônica e do gradiente de densidade. Com o termo do gradiente da densidade eletrônica presente no funcional de troca-correlação, obtêm uma melhor descrição dos sistemas não homogêneos. Para além de métodos convencionais como LDA, GGA ou M-GGA ${ }^{[87]}$ ), existem funcionais que utilizam uma mistura de DFT e energias de troca de Hartree-Fock para obter uma aproximação para o termo $E_{\mathrm{XC}}[n]$, esses são os funcionais híbridos.

Os funcionais híbridos incluem uma parte de troca proveniente da teoria de Hartree-Fock e uma parte de troca e correlação de outras fontes (ab initio ou empírica). Existem diversos funcionais híbridos, e dois bem conhecidos são o B3LYP e o CAM-B3LYP. O B3LYP é formado pela combinação do funcional híbrido de troca-correlação de Becke ${ }^{[88]}$ e o funcional de correlação não-local de Lee, Yang e Parr ${ }^{[89]}$. Esse funcional usa um esquema que envolve três parâmetros de troca (representados pelo sub-índice $X$ ) e dois parâmetros de correlação (sub-índice $C$ ):

$E_{\mathrm{XC}}=0,2 \cdot E_{X}(\mathrm{HF})+0,8 \cdot E_{X}(\mathrm{LSDA})+0,72 \cdot E_{X}(\mathrm{~B} 88)+0,81 \cdot E_{C}(\mathrm{LYP})+0,19 \cdot E_{C}(\mathrm{VWN})$.

O funcional CAM-B3LYP ${ }^{[90]}$ adiciona correções de longo alcance ao B3LYP ${ }^{[91]}$. Foi demonstrado que esse método fornece valores das energias de ligação com qualidade similar à que pode ser alcançada pelo B3LYP e apresenta um bom desempenho para excitações de transferência de carga em um modelo de dipeptídeo, para o qual B3LYP subestima enormemente. Uma amostra maior de funcionais híbridos e não híbridos pode ser encontrada na referência ${ }^{[92]}$.

\subsubsection{Teoria do Funcional de Densidade Dependente do Tempo}

Em 1994, Runge-Gross ${ }^{[93]}$ demonstraram que: dado um sistema de elétrons preparados em um estado inicial $\left|\Phi\left(t_{0}\right)\right\rangle$, há uma correspondência biunívoca entre o potencial externo dependente do tempo $v_{\text {ext }}(\vec{r}, t)$ e a densidade eletrônica dependente do tempo $n(\vec{r}, t)$,

$$
n(\vec{r}, t) \leftrightarrow v_{\text {ext }}(\vec{r}, t) .
$$

Essa é uma generalização do teorema fundamental de Hohenberg e Kohn para cálculos DFT com dependência temporal, que mais tarde ficou conhecida por Teoria do Funcional da Densidade Dependente do Tempo (TD-DFT). 
Em virturde do teorema de Runge-Gross, um esquema artificial de Kohn-Sham pode ser introduzido pela consideração inicial de que um sistema de elétrons não interagentes está sujeito a um potencial externo $v_{\mathrm{KS}}(\vec{r}, t)$ que reproduz a densidade dependente do tempo $n(\vec{r}, t)$ do sistema interagente. Essa densidade é obtida propagando-se um conjunto de equações do tipo Schrödinger, as equações de Kohn-Sham dependentes do tempo (TD-KS), onde todos os efeitos de muitos corpos são incluídos por meio de um potencial de correlação e troca dependente do tempo. As equações TD-KS são da forma:

$$
i \frac{\partial}{\partial t} \varphi_{i}(\vec{r}, t)=\left[-\frac{\nabla^{2}}{2}+v_{\mathrm{KS}}[n](\vec{r}, t)\right] \varphi_{i}(\vec{r}, t)
$$

A densidade do sistema interagente pode ser obtida a partir dos orbitais de Kohn-Sham dependentes do tempo

$$
n(\vec{r}, t)=\sum_{i}\left|\varphi_{i}(\vec{r}, t)\right|^{2}
$$

O potencial de Kohn-Sham é convenientemente separado em três partes:

$$
v_{\mathrm{KS}}(\vec{r}, t)=v_{\mathrm{ext}}(\vec{r}, t)+v_{H}(\vec{r}, t)+v_{\mathrm{XC}}(\vec{r}, t)
$$

O primeiro termo é algum potencial externo, o segundo termo é um potencial de Hartree que leva em conta as interações eletrostáticas clássicas entre os elétrons do sistema, e o terceiro termo inclui todos os efeitos não triviais de muitos corpos. No caso independente do tempo, o potencial $v_{\mathrm{XC}}$ é derivado como funcional da energia, o que não é válido para o caso dependente do tempo, pois em sistemas quânticos com dependência temporal, a energia total não é uma constante de movimento ${ }^{[94]}$. Uma quantidade análoga à energia e que se conserva no tempo é a ação quântica:

$$
A[\Psi]=\int_{t_{0}}^{t_{1}} d t\left\langle\Psi(t)\left|i \frac{\partial}{\partial t}-\hat{H}(t)\right| \Psi(t)\right\rangle
$$

Utilizando a ação quântica, Runge e Gross derivaram as equações de Kohn-Sham, mostrando que o potencial $v_{\mathrm{XC}}$ poderia ser escrito na forma

$$
v_{\mathrm{XC}}=\frac{\delta A_{\mathrm{XC}}}{\delta n(\vec{r}, t)},
$$

onde $A_{\mathrm{XC}}$ incluiria todas as contribuições não triviais da ação $A$. No entanto, descobriu-se mais tarde que essa formulação não respeitava ao princípio da causalidade de funções resposta do tipo $f_{\mathrm{XC}}\left(\vec{r}, t, \vec{t}^{\prime}, t^{\prime}\right)=\delta v_{\mathrm{XC}}(\vec{r}, t) / \delta n\left(\vec{r}^{\prime}, t^{\prime}\right)$. Esse e outros problemas foram resolvidos com a introdução do formalismo de Keldish e de uma nova ação quântica. ${ }^{[94]}$

Propriedades como polarizabilidade dinâmica e energias de excitação podem ser obtidas a partir da resposta do sistema a pequenas pertubações temporais $\delta w(\vec{r}, t)$. Essas perturbações induzem mudanças na densidade $\delta n(\vec{r}, t)$ que são relacionadas ao potencial perturbativo por:

$$
\delta n(\vec{r}, \omega)=\int \chi_{\mathrm{KS}}\left(\vec{r}, \vec{r}^{\prime}, \omega\right) \delta v_{\mathrm{KS}}\left(\vec{r}^{\prime}, \omega\right) d \vec{r}^{\prime}
$$


onde a função $\delta v_{\mathrm{KS}}$ inclui tanto o potencial de Hartree quanto os potenciais de correlação e troca. Em termos de $f_{\mathrm{XC}}$,

$$
\delta v_{\mathrm{KS}}(\vec{r}, \omega)=\delta \omega(\vec{r}, \omega)+\int \frac{\delta n\left(\vec{r}^{\prime}, \omega\right)}{\left|\vec{r}-\vec{r}^{\prime}\right|} d \vec{r}^{\prime}+\int f_{\mathrm{XC}}\left(\vec{r}, \vec{r}^{\prime}, \omega\right) \delta n\left(\vec{r}^{\prime}\right) d \vec{r}^{\prime}
$$

A função de resposta de Kohn-Sham $\chi_{\mathrm{KS}}\left(\vec{r}, \vec{r}^{\prime}, \omega\right)$ é a função resposta de um sistema não interagente. Aplicando a teoria de perturbação Rayleigh-Schodinger em primeira ordem às equações de Kohn-Sham, $\chi_{\mathrm{KS}}\left(\vec{r}, \vec{r}^{\prime}, \omega\right)$ pode ser expressa em termos das autofunções $\psi_{i} \mathrm{e}$ autovalores $\epsilon_{i}$ do estado fundamental de Kohn-Sham:

$$
\chi_{\mathrm{KS}}\left(\vec{r}, \vec{r}^{\prime}, \omega\right)=\sum_{i j}\left(f_{i}-f_{j}\right) \frac{\psi_{i}(\vec{r}) \psi_{j}^{*}(\vec{r}) \psi_{j}\left(\vec{r}^{\prime}\right) \psi_{i}^{*}\left(\vec{r}^{\prime}\right)}{\omega-\omega_{i j}+i \eta}
$$

onde $\omega_{i j}=\left(\epsilon_{i}-\epsilon_{j}\right)$ e $f_{i}$ é o número de ocupação dos orbitais de Kohn-Sham. Combinando as equações 2.38 e 2.39 , chega-se nas equações de Dyson, recentemente revisitadas em ${ }^{[95]}$, para a função resposta. Utilizando esse formalismo pode-se chegar a uma equação de autovalores (não linear) que determina as energias de excitação através dos orbitais de Kohn-Sham ${ }^{[96]}$. Considerando apenas a resposta linear da densidade (LR TD-DFT), esse problema de autovalor pode ser escrito como:

$$
\left(\begin{array}{ll}
A & B \\
B & A
\end{array}\right)\left(\begin{array}{l}
X^{I} \\
Y^{I}
\end{array}\right)=E^{I}\left(\begin{array}{cc}
1 & 0 \\
0 & -1
\end{array}\right)\left(\begin{array}{l}
X^{I} \\
Y^{I}
\end{array}\right)
$$

As matrizes $A$ e $B$ são chamadas de orbitais de rotação Hessianos ${ }^{[97]}$ e dependem das diferenças e integrais sobre os operadores de Coulomb de dois elétrons e sobre o operador de troca. Resolvendo-se essa equação, obtêm-se a energia de excitação $E^{I}$ e também o vetor resposta $\left(X^{I}, Y^{I}\right)$. O vetor $X^{I}$ corresponde às excitações de orbitais ocupados para orbitais virtuais, por exemplo, o elemento vetorial $X_{i a}^{I}$ é o coeficiente correspondente a uma excitação de um orbital ocupado $i$ para um orbital virtual $a$. O vetor $Y^{I}$ corresponde a desexcitações de orbitais virtuais para orbitais ocupados. Essas desexcitações, que decorrem da derivação das equações LR TD-DFT, não possuem um significado físico claro e geralmente são descartadas nas discussões. A desconsideração dessas desexcitações é conhecida como aproximação de Tamm-Damcoff (TDA), ${ }^{[98]}$ e pode ser escrita na forma:

$$
A X^{I}=E^{I} X^{I}
$$

A aproximação TDA é freqüentemente aplicada no TD-DFT por razões de eficiência computacional, pois substitui um problema de autovalor não-hermitiano por um problema de autovalor hermitiano de metade do tamanho. Ainda mais, foi apontado que a aproximação TDA às vezes leva a melhores resultados, evitando instabilidades de tripletos para funcionais híbridos ${ }^{[99]}$. 


\subsection{Modelo de estado de transição de Slater-JanaK}

Em 1978 ${ }^{[100]}$ JanaK desenvolveu uma extenção da DFT a partir da introdução de números de ocupação aos orbitais de Kohn-Sham na equação de densidade

$$
n(\vec{r})=\sum_{i} \eta_{i}\left|\psi_{i}(\vec{r})\right|^{2}
$$

onde $\eta_{i}$ são os números de ocupação $\left(0 \leq \eta_{i} \leq 1\right)$ dos orbitais $\psi_{i}$. Com a inclusão dos números de ocupação $\eta_{i}$, JanaK demontrou que é possível obter um conjunto de equações de Kohn-Sham modificadas, que poderiam ser resolvíveis até mesmo para números de ocupação fracionários. A introdução dos números de ocupação no formalismo DFT levaria a um funcional de energia total diferente do funcional de energia do DFT, mas JanaK também demonstrou que se os números de ocupação $\eta_{i}$ respeitassem a distribuição de Fermi-Dirac, então esses funcionais de energia seriam numericamente iguais.

O teorema de Janak estabelece que, independente da forma do termo de troca-correlação, a derivada em primeira ordem do funcional de energia $E$ em relação ao número de ocupação $\eta_{i}$ é igual a energia $\epsilon_{i}$ do orbital $i$ :

$$
\frac{\partial E}{\partial \eta_{i}}=\epsilon_{i}
$$

Integrando-se essa equação é possível fazer a conexão entre os estados fundamentais de sistemas com $N$ e $N+1$ partículas, por meio da inserção de $\eta$ elétrons no nível de energia desocupado mais baixo:

$$
E_{N+1}-E_{N}=\int_{0}^{1} \epsilon_{i}\left(\eta_{i}\right) d \eta_{i}
$$

Essa integral pode ser identificada como a energia de ligação $-E_{i}$ do elétron de valência mais externo. Se o auto-valor de energia $\epsilon_{i}$ depende linearmente do número de ocupação $\eta_{i}$, então essa integral pode ser reescrita como

$$
E_{N+1}-E_{N} \approx \epsilon_{i}(1 / 2) \approx \epsilon_{i}(0)+\frac{1}{2}\left[\epsilon_{i}(1)-\epsilon_{i}(0)\right]
$$

Nessa equação, a primeira igualdade fornece uma maneira muito útil de se calcular a energia de ligação de um elétron, conhecida por estado de transição de Slater-Janak. A avaliação "no ponto médio"pode ser realizada numericamente de maneira relativamente fácil, assumindo que o estado central em particular esteja apenas meio ocupado. Para manter a neutralidade da carga do sistema, aumenta-se correspondentemente o número de ocupação dos elétrons de valência na mesma metade de um elétron. Desde a sua proposição, o teorema de Janack tem sido amplamente discutido e aplicado no cálculo da energia de ligação de elétrons em sistemas moleculares ${ }^{[101-104]}$. 


\subsection{Conjuntos de funções base}

Seja na resolução das equações de Hartree-Fock ou na resolução das equações de KohnSham, é necessário fazer a escolha de um conjunto de funções base para descrever os orbitais moleculares. Se fosse possível escolher um número infinito de funções de base então a energia total do sistema seria igual à energia obtida pelo princípio variacional. No entanto, o aumento no custo computacional (da ordem de $k^{4}$, sendo $k$ o número de orbitais) inerente à escolha do conjunto de funções de base, exige que seja feita uma escolha de um número limitado de funções base.

As funções do tipo gaussianas, introduzidas por Boys em $1960^{[105]}$, são as mais empregadas em cálculos de Mecânica Quântica. Em coordenadas cartesianas assumem a forma:

$$
\theta(x, y, z, \alpha)=N_{i j k}\left(x-x_{0}\right)^{i}\left(y-y_{0}\right)^{j}\left(z-z_{0}\right)^{k} e^{-\alpha\left|\vec{r}-\vec{r}_{0}\right|^{2}}
$$

onde $N_{i j k}$ é uma constante de normalização, $(x, y$ e $z)$ são as coordenadas eletrônicas, $\left(x_{0}\right.$, $y_{0}$ e $z_{0}$ ) são as coordenadas do centro da função gaussiana, e $\alpha$ é um expoente positivo. Os expoentes $i, j, k$ são números inteiros positivos que estão associados à simetria da função, ou seja: quando $i+j+k=0$, a gaussiana é do tipo $s$; quando $i+j+k=1$, a gaussiana é do tipo $p$, quando $i+j+k=2$, a gaussiana é do tipo $d$, e assim por diante. Devido a dependência quadrática no termo exponencial, as funções gaussianas não descrevem bem os orbitais atômicos quando $\left|\vec{r}-\vec{r}_{0}\right| \rightarrow 0$ ou $\left|\vec{r}-\vec{r}_{0}\right| \rightarrow \infty$. Para solucionar esse problema costuma-se gerar funções gaussianas contraídas a partir da combinação linear de $n$ funções gaussianas centradas no mesmo núcleo atômico, e tão logo os orbitais moleculares podem ser expressos em termos da combinação linear de funções gaussianas contraídas.

Em um conjunto de funções base mínimo utiliza-se apenas uma função de base para descrever cada orbital atômico ocupado. As bases STO- $n \mathrm{G}$ são exemplos de bases mínimas, onde $n$ é o número de funções gaussianas primitivas combinadas para formar uma gaussiana contraída. Duplicando-se, triplicando-se etc. o número de funções gaussianas primitivas para cada orbital atômico ocupado obtêm-se o que é conhecido por conjuntos de funções base estendidos, que oferecem uma melhor descrição da densidade eletrônica já que impõem uma menor restrição à localização dos elétrons. Esse aumento no número de gaussianas primitivas pode ser dar apenas para os elétrons de valência, e nesse caso tem-se o que é conhecido por conjuntos de funções base estendidos com valência separada. Adicionalmente, para tratar os efeitos de polarização dos orbitais atômicos com momento angular superir àqueles de valência é possível adicionar funções base de polarização. E no caso de átomos carregados é comum também adicionar funções gaussianas extras com valores de expoente $\alpha$ menores, permitindo assim uma melhor descrição da densidade eletrônica em regiões mais afastadas do núcleo, essas são chamadas funções difusas. 


\subsubsection{Bases com potencial central efetivo}

Os potenciais centrais efetivos (ECPs) são usados para substituir os elétrons internos (centrais) de átomos com muitos elétrons, tais como metais de transição. Elimina-se assim a necessidade das funções de base próximas ao núcleo atômico, que geralmente exigem um grande conjunto de gaussianas. Além do mais, os ECPs podem ser usados para representar efeitos relativísticos, escalares e não escalares, que são amplamente confinados ao núcleo.

Tomando o rutênio como exemplo, no cálculo de todos os elétrons trata-se todos os 44 elétrons explicitamente (com distribuição eletrônica $1 s^{2} 2 s^{2} 2 p^{6} 3 s^{2} 3 p^{6} 3 d^{10} 4 s^{2} 4 p^{6} 4 d^{7} 5 s^{1}$ ). Utilizando o conjunto de funções base aug-cc-pVDZ-PP, ${ }^{[106]}$ subtitui-se os 28 elétrons de caroço dos orbitais $1 s^{2} 2 s^{2} 2 p^{6} 3 s^{2} 3 p^{6} 3 d^{10}$, nas camadas $\mathrm{K}, \mathrm{L}$ e $\mathrm{M}$, por um potencial efetivo com correções relatísticas de Douglas-Kroll-Hess, e os demais elétrons são tratados explicitamente.

Os ECPs têm pelo menos três vantagens principais na química quântica: (1) reduzem o custo dos cálculos diminuindo o tamanho do conjunto de bases necessário para uma determinada precisão; (2) permitem a inclusão de efeitos relativísticos escalares sem usar um tratamento relativístico da função de onda; (3) permitem uma redução nos erros de superposição dos conjuntos de funções base, por diminuírem a quantidade de funções superpostas. ${ }^{[107]}$

\subsubsection{Erro de superposição de bases}

O erro de superposição de bases (BSSE) (do inglês Basis Set Superposition Error) pode ser identificado no cálculo da energia de interação entre dois monômeros $A$ e B. Define-se a energia de interação do dímero A-B como sendo a diferença da energia total do dímero $E_{A B}$ pela soma das energias de cada monômero separadamente $\left(E_{A}+E_{B}\right)$ :

$$
E_{A B}^{i n t}=E_{A B}-\left(E_{A}+E_{B}\right) .
$$

Ocorre que no dímero, o conjunto de funções base do monômero $A$ atua como um conjunto de funções base difuso no monômero $B$, e vice versa. Isso leva a uma superestimação da energia de ligação do dímero, se calculada como na equação acima.

Uma das estratégias bastante utilizada para corrigir o BSSE é conhecido como método de counterpoise ${ }^{[108]}$. Esse método estabelece que a energia de ligação excessiva do dímero é dada pela quantidade em que o monômero $A$ é estabilizado pelas funções de base de $B$ no dímero, mais a quantidade em que o monômero $B$ é estabilizado pelas funções de base de $A$ no dímero, ou seja

$$
E_{B S S E}=\left(E_{A}(A B)-E_{A}(A)\right)+\left(E_{B}(A B)-E_{B}(B)\right) .
$$

onde os símbolos entre parêntesis denotam o conjunto de funções base utilizado. Portanto, calcula-se a energia de cada monômero na presença do conjunto de funções base do dímero 
como um todo. No cálculo de $E_{A}(A B)$, por exemplo, o conjunto de funções base do monômero $B$ são levados em conta, mas sem a presença dos núcleos e elétrons do monômero $B$. É importante notar que, o excesso de base no cálculo de $E_{A}(A B)$ faz com que $E_{A}(A B)<E_{A}(A)$, e também $E_{B}(A B)<E_{B}(B)$. A correção BSSE da energia, $E_{B S S E}$, é portanto um número negativo. Subtraindo $E_{A B}^{i n t}$ de $E_{B S S E}$ obtêm-se a energia de ligação corrigida.

\subsection{Cargas atômicas}

O conceito de cargas atômicas é amplamente utilizado para descrever propriedades químicas em sistemas moleculares. No entanto, como não existe uma maneira única de se obter cargas atômicas a partir de um cálculo de mecânica quântica, já que não existe um operador QM cujo valor esperado produza as cargas atômicas da molécula, ${ }^{[09]}$ existem diferentes esquemas propostos na Literatura para o cálculo de cargas atômicas. Alguns métodos se baseiam no particionamento da densidade eletrônica (Mulliken ${ }^{[110]}$ e Hirshfeld ${ }^{[111]}$, por exemplo), outros se baseiam no ajuste de potencial eletrostático (Merz-Singh-Kollman ${ }^{[12]}$ e ChelpG ${ }^{[113]}$, por exemplo).

O método Hirshfeld é baseado no particionamento da densidade eletrônica total $\rho_{t o t}(\vec{r})$ em contribuições atômicas $\rho_{A}(\vec{r})$ em cada ponto do espaço $\vec{r}$ de acordo com funções peso $W_{A}(\vec{r})$ :

$$
\rho_{A}(\vec{r})=\rho_{t o t}(\vec{r}) \frac{W_{A}(\vec{r})}{\left.\sum_{i} W_{i}(\overrightarrow{(r})\right)} .
$$

As cargas atômicas $q_{A}$ são calculadas pela integração das contribuições atômicas em todo o espaço:

$$
Q_{A}=Z_{A}-\int \rho_{A}(\vec{r}) d^{3} \vec{r}
$$

onde $Z_{A}$ é a carga nuclear do átomo $A$. Na sua versão padrão, $W_{A}(\vec{r})$ é definido como a densidade eletrônica do átomo $A$ calculada por algum método de mecânica quântica apropriado e $\sum_{i} W_{i}(\vec{r})$ fornece a densidade total da molécula. As cargas de Hirshfeld são conhecidas por serem insensíveis ao conjuntos de bases e quimicamente consistentes. O termo $W_{A}(\vec{r})$ fornece uma significativa flexibilidade no cálculo das cargas atômicas, e mais recentemente, muitas maneiras diferentes de particionar a densidade molecular de elétrons foram propostas dentro da abordagem de Hirshfeld: ISA ${ }^{[114]}, \mathrm{CM5}^{[115]}$, DDEC ${ }^{[116]}, \mathrm{PC}$ stockholder ${ }^{[117]}$, entre outras. O modelo CM5, por exemplo, foi parametrizado usando cinco métodos de estrutura eletrônica (a saber, os cinco funcionais de densidade M06- ${ }^{[118]}, \mathrm{M} 06^{[118]}, \mathrm{M} 06-2 \mathrm{X}^{[118]}$, B3LYP ${ }^{[88,89]}$, e mPW1PW52 ${ }^{[119]}$, para um conjunto de treinamento de 614 moléculas constituídas pelos elementos H-Ca, Zn, Ge-Br e I.

No método ChelpG, as cargas atômicas são obtidas a partir de um ajuste por mínimos quadrados do potencial eletrostático calculado em um grande número de pontos em torno da molécula. Os pontos são selecionados em uma malha cúbica com pontos regularmente espaçados $(0.3 \AA)$. Os pontos incluídos são aqueles que estão entre 0 e $2.8 \AA$ além da superfície 
de Van der Waals da molécula, e o método de multiplicadores de Lagrage é empregado para ajustar as cargas atômicas ao potencial eletrostático molecular. O método ChelpG utiliza uma distribuição de cargas pontuais e dipolos atômicos colocados sobre as posições nucleares, capaz de produzir um potencial elétrico $E\left(\overrightarrow{r_{p}}\right)$, em um ponto $P$ do espaço, como descrito na equação 2.52 .

$$
E\left(\overrightarrow{r_{p}}\right)=\sum_{k}^{N}\left(\frac{q_{k}}{\left|\vec{r}_{p}-\vec{R}_{k}\right|}+\frac{\vec{m}_{k} \cdot \vec{r}_{p}}{\left|\vec{r}_{p}-\vec{R}_{k}\right|^{3}}\right)
$$

onde $q_{k}$ e $m_{k}$ são respectivamente a carga pontual e o dipolo elétrico posicionados no ponto $R_{k}$, correspondente à posição do núcleo k, e o somatório é feito sobre todos os $\mathrm{N}$ núcleos. 



\section{Capítulo}

\section{Mecânica molecular}

Este capítulo traz a apresentação de alguns tópicos de simulação molecular clássica que darão o suporte teórico mínimo às simulações moleculares e suas análises realizadas neste estudo. Abordaremos os aspectos fundamentais dos métodos de Monte Carlo e de Dinâmica Molecular, e comentaremos sobre potencial de interação molecular. Trataremos dos efeitos de polarização do meio, por modelos contínuo e discreto de solvente. Falaremos sobre o cálculo de coeficientes de difusão, sobre funções de distribuição radial de pares e ligações de hidrogênio. Passaremos à descrição teórica da energia livre de solvatação e os cálculos de pKa e potencial redox. E por fim comentaremos sobre métodos híbridos, combinando mecânica molecular e mecânica quântica.

\subsection{Simulação clássica}

A simulação clássica de sistemas atômicos (moléculas, proteínas, líquidos iônicos, etc.) pode ser realizada por meio de duas técnicas bem conhecidas: o método de Monte Carlo (MC) e a Dinâmica Molecular (MD). O primeiro é um método estocástico, que permite acessar apenas o espaço de configurações, não admitindo assim a evolução temporal do sistema simulado. O segundo é um método determinístico, que segue as leis clássicas da mecânica newtoniana, permitindo assim que se acesse o espaço de fase do sistema. Nesta seção iremos apresentar os aspectos básicos das duas técnicas.

\subsubsection{Método de Monte Carlo}

O método de Monte Carlo pode ser visto como um método numérico universal para resolver problemas utilizando amostragem aleatória. Esse método foi formalizado em 1949, por meio do artigo "The Monte Carlo Method" escrito por Nicholas Metropolis e S. Ulam ${ }^{[120]}$. O nome Monte Carlo é uma referência ao distrito de Monte Carlo, localizado no Principado de Mônaco (França), que é um local famoso pelo cassino de Monte Carlo. Esse método foi muito 
utilizado na década de 50 na simulação de nêutrons em processos de fissão nuclear no projeto Manhattam, com o objetivo de desenvolver a primeira bomba atômica.

O método MC é reconhecidamente útil na solução de integrais multidimensionais e um exemplo clássico de sua aplicação é a solução de integrais termodinâmicas. Dada uma certa propriedade termodinâmica $f$ para um sistema de $N$ partículas interagentes num volume $V$ e a uma temperatura $T$, a média configuracional de $f$ será dada por:

$$
\langle f\rangle_{N V T}^{c o n f}=\frac{\int f(\vec{r}) e^{\frac{-U(\vec{r})}{k_{B} T}} d \vec{r}}{\int e^{\frac{-U(\vec{r})}{k_{B} T}} d \vec{r}},
$$

onde $U(\vec{r})$ representa a energia de interação das $\mathrm{N}$ partículas e $k_{B}$ é a constante de Boltzman. Desde que exista uma função densidade de probabilidade $\rho$ que governe a escolha de configurações do sistema, a média $\langle f\rangle_{N V T}^{c o n f}$ pode ser reescrita como

$$
\langle f\rangle_{N V T}^{\operatorname{conf}}=\frac{\int \frac{f(\vec{r}) \rho_{N V T}}{\rho} \rho d \vec{r}}{\int \frac{\rho_{N V T}}{\rho} \rho d \vec{r}} .
$$

onde

$$
\rho_{N V T}=e^{\frac{-U(\vec{r})}{k_{B} T}}
$$

E no limite em que $k \rightarrow \infty$, essas integrais podem ser colocadas na forma de somas:

$$
\langle f\rangle_{N V T}^{\operatorname{conf}}=\frac{\frac{1}{k}\left[\sum_{i=1}^{k}\left(\frac{f\left(\vec{r}_{i}\right) \rho_{N V T}}{\rho}\right)\right]_{\rho}}{\frac{1}{k}\left[\sum_{i=1}^{k}\left(\frac{\rho_{N V T}}{\rho}\right)\right]_{\rho}}
$$

onde $\vec{r}_{i}$ é a i-ésima configuração do sistema.

Num procedimento padrão, o método de Monte Carlo estabelece que a solução dessas somas pode ser obtida tomando-se aleatorimante pontos do espaço de configurações $\left(\vec{r}_{i}\right)$ que obedecem a distribuição de probabilidades $\rho$. A tomada aleatória de pontos para se avaliar o valor médio de integrais multidimensionais torna o procedimento de solução muito mais barato computacionalmente. Todavia, tratando-se do cálculo médio de propriedades termodinâmicas, tal como a propriedade $f$, é necessário fazer algumas considerações adicionais.

Na equação 3.1 , o termo $e^{-U(\vec{r}) / k_{B} T} \approx 0$ para muitas e muitas tentativas. A escolha de $\rho$ como uma distribuição uniforme, por exemplo, seria uma opção extremamente ineficiente. Nesse caso, uma amostragem preferencial é a melhor escolha. Em 1953, Metropolis ${ }^{[121]}$ sugeriu, no caso do ensemble $N V T$, a escolha $\rho=\rho_{N V T}$, de modo que o valor médio de $f$ pode ser obtido a partir de uma média arimética simples:

$$
\langle f\rangle_{N V T}^{\text {conf }}=\langle f\rangle_{\rho_{N V T}}
$$

Além disso, para gerar números aleatórios que satisfizessem a uma distribuição de probabilidades do tipo $\rho_{N V T}$, Markov também propôs que as configurações geradas não fossem obtidas de forma totalmente independente umas das outras, já que isso poderia levar a geração de muitas 
configurações de alta energia e portanto desprezíveis para o cálculo da média de $f$. Metropolis propôs que as configurações do sistema fossem obtidas segundo uma cadeia de Markov. ${ }^{[122]} \mathrm{Em}$ uma cadeia de Markov, as configurações são geradas sequencialmente, mas cada configuração acessada depende apenas da configuração anterior. Em um conjunto de configurações $i, j, k$ geradas sucessivamente, a configuração $k$ não guarda nenhuma informação sobre a configuração $i$, apenas de $j$.

Para gerar uma cadeia Markoviana, Metropolis propos a construção de uma matriz de probabilidade de transição $\pi$ que satisfaz algumas condições especiais:

$$
\left\{\begin{array}{l}
\pi_{i j} \geq 0 \\
\sum_{i} \pi_{i j}=1 \quad \text { para todo } j \\
\rho_{i} \pi_{i j}=\rho_{j} \pi_{i j}
\end{array}\right.
$$

Em termos das energias $U_{i}$ e $U_{j}$ de duas configurações $i$ e $j$ geradas sequencialmente, a matriz de transição sugerida por Metropolis respeita os seguintes critérios:

$$
\left\{\begin{array}{rlrl}
\pi_{i j} & =1 & & \text { se } U_{j} \geq U_{i} \text { para } i \neq j \\
\pi_{i j}=\frac{e^{-U_{j} / k_{B} T}}{e^{-U_{i} / k_{B} T}} & \text { se } U_{j} \geq U_{i} & \text { para } i \neq j \\
\pi_{i j}=1-\sum_{i \neq j} e^{-\Delta U / k_{B} T} & & \text { para } i \neq j
\end{array}\right.
$$

Na prática, dado um sistema molecular, representado por uma célula de referência contendo $N$ moléculas rígidas na densidade desejada e em uma dada configuração inicial $i$, uma nova configuração $j$ pode ser gerada e testada segundo os critérios do algoritmo de Metropolis. No ensemble $N V T$, a geração da nova configuração se dá a partir do sorteido de 3 números aleatórios responsáveis por provocar mudanças nas coordenadas de translação $x, y, z$ da molécula, e mais 2 números para a definição de um eixo e de um ângulo para a rotação da molécula. Se na configuração $j$ o sistema tem uma energia menor que na configuração $i$, então o movimento é aceito e uma nova configuração é gerada. Se na configuração $j$, o sistema tem uma energia maior que em $i$, então gera-se um número aleatório $p$ pertencente ao intervalo $(0,1)$ e testa se $p<e^{-\beta \Delta U}$. Caso $p$ satisfaça essa condição, a configuração gerada é aceita, caso contrário uma nova configuração deve ser gerada. Dessa forma, um conjunto de configurações escolhidas com o peso estatístico correto são acumuladas em um banco de configurações, e as propriedades termodinâmicas do sistema podem então ser calculadas como médias aritméticas nesse espaço de configurações. Uma descrição detalhada do método de Monte Carlo aplicado a sistemas moleculares pode ser encontrada nas referências ${ }^{[123,124]}$.

\subsubsection{Dinâmica Molecular}

O método de Dinâmica Molecular (MD) passou a ser desenvolvido a partir de 1950 . Cientistas como Fermi, Ulam (também desenvolvedor do método de Monte Carlo) entre 
outros, contribuíram para o seu avanço. Em 1964 Rahman publicou um dos primeiros trabalhos utilizando $\mathrm{MD}^{[125]}$, no qual realizou simulações de argônio líquido. Semelhantemente ao método de Monte Carlo, a Dinâmica Molecular também permite que se explore a hipersuperfície de energia potencial de sistemas moleculares, mas com a diferença de ser um método determinístico. Assim, propriedades como escoamento e difusão, que dependem de uma evolução no tempo, e que não podem ser simuladas por Monte Carlo, são facilmente obtidas via MD.

Uma simulação MD pode ser realizada apenas aplicando o formalismo Newtoniano. Dado um potencial total $V(\vec{r})$, que pode incluir efeitos internos e externos ao sistema, calcula-se para cada partícula $i$ do sistema a força resultante $\vec{F}_{i}$, dada por $\vec{F}_{i}=-\vec{\nabla} V$. Aplicando-se a $2^{\text {a }}$ Lei de Newton

$$
\vec{F}_{i}=m_{i} \cdot \vec{a}_{i}
$$

calcula-se a aceleração $\vec{a}_{i}$. Integrando-se a aceleração $\vec{a}_{i}$ no tempo $t$ obtêm-se a velocidade $\vec{v}_{i}$ e integrando-se a velocidade $\vec{v}_{i}$ obtêm-se a posição $\vec{r}_{i}$ da partícula $i$.

Uma vez obtidas as velocidades $\vec{v}(t)$ e posições $\vec{r}(t)$ para todas as partículas do sistema na configuração inicial, faz-se a evolução do sistema para um novo ponto no espaço de fases $(\vec{v}(t+d t), \vec{r}(t+d t))$, para um tempo $d t$ significativamente pequeno. Essa integração temporal permite a evolução do sistema de forma determinística, e pode ser obtida a partir de diferentes algoritmos, entre os mais conhecidos estão: Predictor Corrector, Verlet, Leap Frog, Velocit Verlet.

$\mathrm{Na}$ integração de Leapfrog, por exemplo, as equações para atualização de posição e velocidade são:

$$
\begin{gathered}
\vec{v}_{i+1 / 2}=\vec{v}_{i-1 / 2}+\vec{a}_{i} \Delta t \\
\vec{r}_{i+1}=\vec{r}_{i}+\vec{v}_{i+1 / 2} \Delta t
\end{gathered}
$$

onde $\vec{r}_{i}$ é a posição no passo $i, \vec{v}_{i+1 / 2}$ é a velocidade no passo $i+1 / 2, \vec{a}_{i}$ é a aceleração no passo $i$ e $\Delta t$ é o intervalo de tempo do passo. Essas equações podem também ser expressas para $\vec{v}_{i}$ em intervalos inteiros de tempo:

$$
\begin{aligned}
& \vec{v}_{i+1}=\vec{v}_{i}+\frac{1}{2}\left(\vec{a}_{i}+\vec{a}_{i+1}\right) \Delta t, \\
& \vec{r}_{i+1}=\vec{r}_{i}+\vec{v}_{i} \Delta t+\frac{1}{2} \vec{a}_{i} \Delta t^{2} .
\end{aligned}
$$

De forma sincronizada, um ciclo de integração Leapfrog é dado pelos passos:

$$
\begin{cases}(1) & \vec{v}_{i+1 / 2}=\vec{v}_{i}+\vec{a}_{i} \frac{\Delta t}{2} \\ (2) & \vec{r}_{i+1}=\vec{r}_{i}+\vec{v}_{i+1 / 2} \Delta t \\ (3) & \vec{v}_{i+1}=\vec{v}_{i+1 / 2}+\vec{a}_{i+1} \frac{\Delta t}{2}\end{cases}
$$

Uma das vantagens do algoritmo de Leapfrog é a reversibilidade temporal, ou seja, é possível integrar $n$ passos para a frente e, em seguida, inverter a direção da integração e integrar 
$n$ passos para trás, voltanto à mesma posição inicial. Além do mais é um algoritmo que apresenta excelente conservação da energia, mesmo para intervalos de tempo $\Delta t$ razoavelmente grandes. $^{[126]}$

A definição do intervalo de integração $\Delta t$ deve levar em conta os objetivos da simulação, mas em geral tende a ser de no máximo $5 \mathrm{fs}$. A utilização de restrições em comprimentos de ligação e ou ângulos de uma molécula permite aumentar o intervalo $\Delta t$ e tão logo gerar uma grande redução no custo computacional da simulação. Em modelagens típicas onde o movimento oscilatório de hidrogênios é importante, o intervalo de integração $\Delta t$ deve ser de no máximo $0.2 f s$. Mas, se essa oscilação for desprezível, pode-se aplicar restrições aos comprimentos de ligação que envolvem átomos de hidrogênio, e o tempo $\Delta t$ pode ser aumentado em até 10 vezes. Desprezando-se movimentos vibracionais relacionados a ângulos, $\Delta t$ pode chegar a até $5 f s$. Algoritmos como Links ${ }^{[127]}$ (para ligações) e o Shake ${ }^{[128,129]}$ (para ligações e ângulos) são os mais conhecidos atualmente.

A Dinâmica Molecular clássica gera configurações inerentemente pertencentes ao ensemble microcanônico NVE. Contudo, em simulações de sistemas moleculares é quase sempre desejável reproduzir as condições dos ensembles $N V T$ ou $N P T$, e por isso surge a necessidade de se controlar a temperatura e também a pressão durante uma simulação MD. Existem vários métodos que tentam adaptar a dinâmica molecular ao ensemble canônico $N V T$. Dentre os mais utilizados, o método velocity rescaling ${ }^{[130]}$ se destaca. Em sua formulação mais simples, esse método consiste em multiplicar as velocidades de todas as partículas do sistema pelo mesmo fator $\alpha$, calculado com a imposição de que a energia cinética total do sistema $K$ deve ser igual à energia cinética média na temperatura alvo $K^{\prime}=N_{f} / 2 \beta$, onde $N_{f}$ é o número de graus de liberdade e $\beta$ é o inverso da temperatura. Assim, o fator de reescalonamento $\alpha$ para as velocidades é obtido como $\alpha=\sqrt{\frac{K^{\prime}}{K}}$. Essa operação é geralmente realizada em uma frequência predeterminada durante a simulação, ou quando a energia cinética excede os limites de um intervalo centrado em torno do valor alvo. Entretanto, essa abordagem não gera as propriedades termodinâmicas corretas do ensemble canônico. Considerando o limite no qual as velocidades são redimensionadas a cada intervalo de tempo, a energia cinética permanecerá constante no tempo, com flutuação zero. Um resultado incorreto, já que conforme a mecânica estatística, o ensemble canônico diz que $\sigma_{k}^{2}=3 / 2\left(N K_{B}^{2} T^{2}\right)$. Em outras palavras, o reescalonamento de velocidade não captura as flutuações corretas de energia cinética. Além desse problema, o efeito do cubo de gelo voador (do inglês the flying ice cube effect) é um artefato de simulação de dinâmica molecular relacionado ao uso de termostatos com redimensionamento de velocidade, que às vezes causam a violação do teorema da equipartição, afetando tanto as propriedades estruturais quanto dinâmicas. Para contornar problemas como esses, G. Bussi e coloboradores ${ }^{[131]}$ desenvolveram uma versão modificada do velocity rescaling, com o objetivo de realizar simulações de dinâmica molecular que satisfaçam o ensemble canônico. Este novo esquema é conhecido na literatura como CSVR (do inglês canonical sampling through velocity 
rescaling), e é definido como:

$$
d K=\left(K_{0}-K\right) \frac{d t}{\tau_{T}}+2 \sqrt{\frac{K K_{0}}{N_{f}}} \frac{d W}{\sqrt{\tau_{T}}}
$$

onde $K$ é a energia cinética, $N_{f}$ é o número de graus de liberdade, $d W$ é um processo estocástico de Wiener e $\tau_{T}$ é uma contante temporal de acoplamento. Portanto, trata-se de uma formulação derivada de uma modificação do reescalonamento da velocidade padrão com um fator aleatório corretamente escolhido e com uma formulação que se assemelha ao termostato de Berendsen.

Outra opção são os termostatos estocásticos, que se baseiam na aplicação de fricção nas velocidades das partículas para reproduzir o ensemble canônico. Isso é realizado a partir de modificações no algoritmo de integração. Recentemente, uma versão estocástica do algoritmo Leapfrog foi proposta na literatura ${ }^{[132]}$, e implementada no programa GROMACS ${ }^{[133]}$. O algoritmo é denominado Impulsive Langevin Leap-Frog, e se baseia na aplicação de fricção e ruídos nas velocidades, a cada passo de integração. No artigo de referência ${ }^{[132]}$ os autores demonstram que esse algoritmo reproduz o ensemble $N V T$ de forma robusta: a temperatura do sistema decai automaticamente para a temperatura de referência, e a distribuição de velocidades evolui para o ensemble canônico com uma distribuição Maxwelliana. Esse algoritmo de integração é sugerido pelo programa GROMACS para a realização de cálculos de energia livre de solvatação, por ser capaz de gerar uma amostragem mais satisfatória do sistema durante as etapas de criação ou aniquilação do soluto.

Para simular no ensemble isotérmico-isobárico NPT é preciso dar uma passo além e fazer o acoplamento de um barostato ao sistema, a fim de equilibrar a pressão. Para essa finalidade, o método de acoplamento fraco de Berendsen ${ }^{[134]}$ é bastante utilizado. Nesse barostato, uma renormalização é aplicada às coordenadas cartesianas das partículas que compõem o sistema e nas dimensões da caixa de simulação, em cada passo de simulação ou num intervalo de tempo específico. O barostato de Berendsen é definido através da equação diferencial

$$
\frac{d P}{d t}=\frac{1}{\tau}\left(P_{0}-P\right)
$$

que conduz a um fator de normalização, para sistemas isotrópicos, dado por:

$$
\eta=\left(1-\frac{\Delta t}{\tau} \lambda\left(P_{0}-P\right)\right)^{\frac{1}{3}}
$$

onde $\lambda$ é a compressibilidade isotérmica do sistema e o termo $\Delta t \lambda / \tau$ é o fator de acoplamento efetivo.

Portanto, conhecendo-se o conjunto de posições iniciais do sistema e a forma do potencial de interação atuante, aplica-se a $2^{a}$ Lei de Newton à todas as particulas do sistema e calcula-se as acelerações, velocidades e posições num intante de tempo $t$. Aplicando-se um método de integração temporal, faz-se a evolução determinística do sistema para instantes sucessivos de tempo nas condições do ensemble NVE, obtendo-se assim uma trajetória. Caso seja acoplados 
ao sistema um termostato e um barastato, a trajetória pode ser obtida nas condições de temperatura e pressão desejadas. Para o estudo de MD sugiro a referência ${ }^{[135]}$.

\subsubsection{Condições de contorno periódicas}

Seja numa simulação MC ou MD, o sistema simulado deve ser confinado a uma caixa de simulação. Essa caixa pode ter várias formas, sendo a mais simples a forma cúbica. Com a delimitação espacial do sistema surge o problema do efeito de borda: as moléculas na superfície da caixa de simulação sentem um ambiente diferente daquele que é sentido pelas moléculas que se encontram no interior, e isso produz artifatos que podem comprometer a simulação. A solução para esse problema é conhecida como condição de contorno periódica, que equivale a uma replicação da caixa real em todas as direções, como ilustrado na figura 3.1. Logo, tudo o que acontece com uma molécula na caixa real é imitado por suas réplicas nas caixas virtuais, garantindo assim que todas as moléculas na caixa real sintam o mesmo ambiente. Mas, a replicação da caixa real, por sua vez, introduz um efeito indesejável: a periodicidade na interação entre as moléculas. A solução para esse problema está na utilização de um artifício chamado convenção da mínima imagem. Uma molécula alvo dentro da caixa real poderá interagir com todas as moléculas ao seu redor, sejam elas reais ou virtuais, desde que se encontrem dentro da região limitada por uma caixa mínima, de tamanho igual ao da caixa de simulação, mas agora centrada na molécula alvo. Adicionalmente, costuma-se definir um raio de corte de interação igual a metade da aresta da caixa de simulação, limitando assim as interações dentro de uma esfera de raio $\mathrm{L} / 2$ centrada na molécula alvo.

\subsubsection{Correções de longo alcance}

Como a caixa de simulação não pode ter tamanho infinito, e ainda existe uma raio de corte imposto para gerar redução no custo computacional, ao longo dos desenvolvimentos da MD foram desenvolvidos diferentes tipos de correções de longo alcance para recuperar a energia de interação perdida nessas limitações. A correção de campo de reação[136], por exemplo, é um tipo de correção de longo alcance. Ao redor de um dada molécula da simulação, além de um certo raio de corte, considera-se a existência de um meio com constante dielétrica uniforme e definida para reproduzir as propriedades do meio simulado. A molécula induz polarização nesse dielétrico, que, por sua vez, cria um campo de reação, que pode ser então contabilizado na dinâmica.

Uma opção mais sofistica e robusta é o método Particle mesh Ewald (PME), que é um caso especial da soma de Poisson ${ }^{[137]}$. Nesse método, o potencial de interação é dado pela soma de dois termos, um de curto alcance $\left(\phi_{s r}(r)\right)$ e outro de longo alcance $\left(\phi_{l r}(r)\right)$, e a ideia básica por trás do método está em substituir a soma direta da energia de interação entre as 


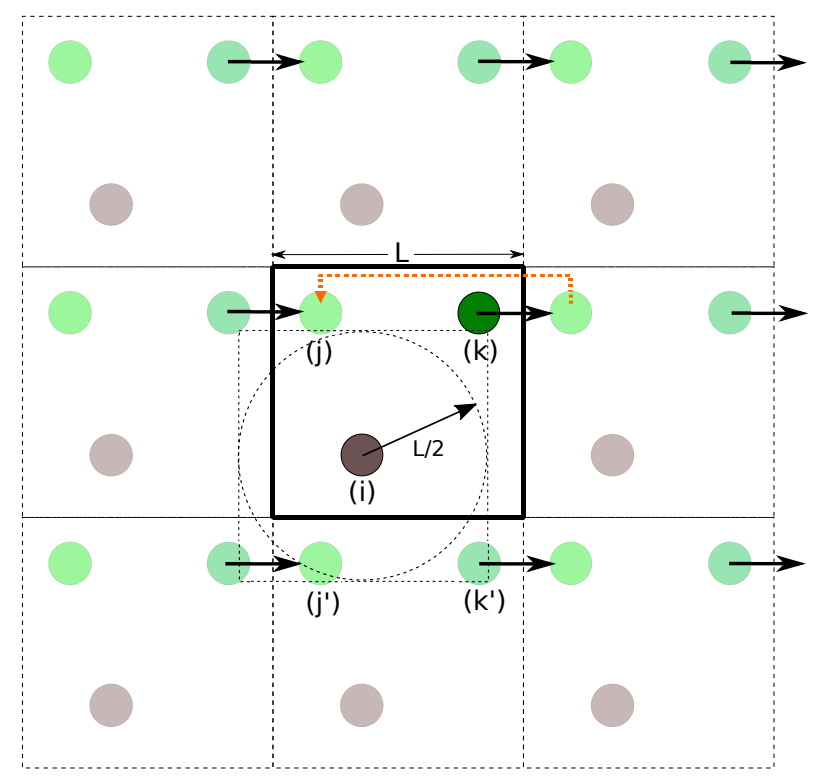

Figura 3.1 - Representação esquemática das condições de contorno periódicas. A caixa real contem as moléculas (i), (j) e (k), e encontra-se rodeada por 8 caixas imagem. Tudo o que acontece com uma molécula na caixa real é imitado por suas réplicas nas caixas virtuais. A molécula (i) dentro da caixa real interage apenas com a molécula $\left(j^{\prime}\right)$ na caixa imagem logo abaixo, obedecendo assim à convenção da mínima imagem e o limite imposto pelo raio de corte. A molécula ( $\left.k^{\prime}\right)$ obedece à convenção da mínima imagem, entretanto não se encontra dentro do raio de corte, e portanto não pode interagir com (i).

partículas do sistema

$$
E_{\text {total }}=\sum_{i, j} \phi\left(\overrightarrow{r_{j}}-\overrightarrow{r_{i}}\right)=E_{s r}+E_{l r}
$$

por duas somas, uma soma direta $E_{s r}$ do potencial de curto alcance no espaço real

$$
E_{s r}=\sum_{i, j} \phi_{s r}\left(\overrightarrow{r_{j}}-\overrightarrow{r_{i}}\right)
$$

e uma soma no espaço de Fourier $E_{l r}$ do potencial de longo alcance

$$
E_{l r}=\sum_{k} \Phi_{l r}(\vec{k})|\rho(\vec{k})|^{2} .
$$

$\Phi_{l r}$ e $\rho$ representam as transformadas de Fourier do potencial e da densidade de carga. Para avaliar a transformada de Fourier $\rho$ de forma eficiente, usa-se a aproximação rápida (Fast Fourier transform), que requer que o campo de densidade seja avaliado em uma malha de pontos no espaço, e daí provêm a denominação de mesh, que significa malha.

\subsection{Potencial de interação molecular}

O potencial de interação molecular pode ser escrito como a soma de dois termos:

$$
V(r)=\sum_{i} u_{1}\left(r_{i}\right)+\sum_{i} \sum_{j>i} u_{2}^{\mathrm{eff}}\left(r_{i j}\right)
$$


onde o potencial de uma partícula $u_{1}$ representa as interações do sistema com algum campo externo e o potencial efetivo de pares $u_{2}^{\text {eff }}$ representa uma aproximação para todas as interações de muitos corpos ${ }^{[138]}$. Considerando que não há nenhum campo externo agindo sobre o sistema, o potencial $V$ pode ser dividido em duas partes clássicas: uma intramolecular e outra intermolecular:

$$
V(r)=V_{\text {intra }}+V_{\text {inter }}
$$

A parte intramolecular pode ser separada em termos que descrevem o estiramento das ligações $\left(V_{b}\right)$, os ângulos $\left(V_{a}\right)$ e os diedros $\left(V_{d}\right)$ :

$$
V_{\text {intra }}=\sum_{b} E_{r}\left(r_{i j}-r_{e q}\right)^{2}+\sum_{a} E_{\theta}\left(\theta_{i j}-\theta_{e q}\right)^{2}+\sum_{d} \frac{E_{n}}{2}\left[1+\cos \left(n \phi_{i j}-\delta\right)\right] .
$$

O primeiro termo descreve a variação na distância entre dois átomos ligados por uma mola de constante elástica $E_{r}$ e distância de equilíbrio $r_{e q}$. O segundo termo descreve a flexão angular entre três átomos, com uma constante elástica $E_{\theta}$ e ângulo de equilíbrio $\theta_{e q}$. $O$ último termo descreve a rotação do diedro $\phi$ envolvendo 4 átomos ligados. Os três termos encontram-se ilustrados na figura 3.2 .

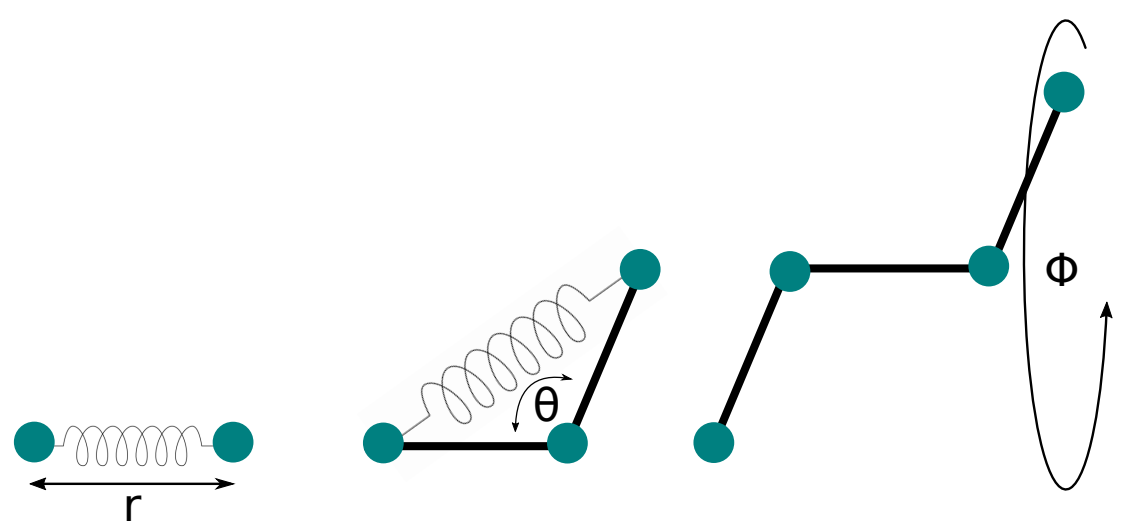

Figura 3.2 - Ilustração dos três termos da equação 3.22 .

O potencial de interação intermolecular pode ser representado por meio do somatório dos potenciais atômicos (os potenciais de sítios que descrevem a molécula). A interação entre duas moléculas $a$ e $b$ é descrita pela equação 3.23:

$$
V_{\text {inter }}^{a b}=\sum_{i}^{\text {em }} \sum_{j}^{a \text { em } b} V\left(r_{i j}\right) .
$$

onde os elementos $i$ são os sítios da molécula $a, j$ são os sítios da molécula $b$ e $r_{i j}$ é a distância entre os sítios $i$ e $j$.

O potencial de Lennard-Jones $(\mathrm{LJ})^{[139]}$ combinado ao potencial de Coulomb é um dos potenciais intermoleculares mais conhecidos na literatura:

$$
V_{i n t e r}^{L J C}\left(r_{i j}\right)=4 \varepsilon_{i j}\left[\left(\frac{\sigma_{i j}}{r_{i j}}\right)^{12}-\left(\frac{\sigma_{i j}}{r_{i j}}\right)^{6}\right]+\frac{q_{i} q_{j}}{r_{i j}}
$$


os termos $\varepsilon_{i j}$ e $\sigma_{i j}$ são os parâmetros LJ, $q_{i}$ é a carga do sítio $i, q_{j}$ é a carga do sítio $j$ e $r_{i j}$ é a distância entre os sítios $i$ e $j$. O potencial LJ tem a forma típica de basicamente todos os potenciais interatômicos: atrativo a longas distâncias e repulsivo a curtas distâncias. Dada a sua simplicidade analítica, é um potencial bastante utilizado em simulações moleculares. Os dois parâmetros livres do potencial LJ, $\epsilon$ e $\sigma$ podem ser ajustados para reproduzir propriedades do sistema simulado. O termo $\varepsilon$ é a profundidade do poço de potencial, $\sigma$ é a distância finita na qual o potencial entre partículas é zero, e $r$ é a distância entre as partículas. O potencial atinge um mínimo, de profundidade $\varepsilon$, quando $r=2^{1 / 6} \sigma$.

Existem diferentes regras de combinação para os parâmetros $\varepsilon$ e $\sigma$. As mais conhecidas são as regras de Lorentz ${ }^{[140]}$ (equação 3.25) e Good-Hope ${ }^{[141]}$ (equação 3.26) para $\sigma$ :

$$
\begin{gathered}
\sigma_{i j}=\frac{\sigma_{i i}+\sigma_{j j}}{2}, \\
\sigma_{i j}=\sqrt{\sigma_{i i} \sigma_{j j}} .
\end{gathered}
$$

E a regra de Berthelot ${ }^{[142]}$ (equação 3.27) para $\varepsilon$ :

$$
\varepsilon_{i j}=\sqrt{\varepsilon_{i i} \varepsilon_{j j}} .
$$

As regras de Good-Hope e Berthelot, por exemplo, são adotadas no programa GROMACS e tendem a deixar os cálculos mais rápidos. O programa Amber adota as regras de Lorentz e Berthelot. Já o programa Dice ${ }^{[143]}$ permite as duas combinações.

\subsection{Efeitos de polarização do meio}

Em simulações MM convencionais, baseadas no potencial LJC, não existe a possibilidade de que o solvente polarize o soluto ou de que o soluto polarize o solvente. Não é possível que se faça a contabilização de nenhum movimento de carga durante a simulação, que conta com parâmetros LJC fixos. Entretanto, no processo de obtenção de parâmetros para a simulação, no cálculo das cargas atômicas, é possível se fazer a inclusão de efeitos de polarização do solvente adotando-se algum modelo simplificado de solvente. Isso pode ser feito utilizando modelos contínuos como o $\mathrm{PCM}^{[144,145]}$ e o $\mathrm{SMD}^{[146]}$, com a constante diélétrica ajustada para o solvente desejado, e pode também ser feito utilizando modelos mais sofisticados como o ASEP ${ }^{[147]}$ e o ASEC ${ }^{[148]}$. Esses modelos tanto podem ser usados para se polarizar as cargas atômicas utilizadas na simulação MM, como podem também ser diretamente adotados nos cálculos de propriedades quânticas, representando diretamente a interação soluto-solvente. Esta seção traz uma breve apresentação dos modelos PCM e ASEC. 


\subsubsection{Modelos contínuos de solvente}

Nos modelos contínuos de solvente, o sistema de interesse é colocado no interior de uma cavidade que separa duas regiões de constantes dielétricas distintas, dentro (constante dielétrica do vácuo) e fora da cavidade (constante dielétrica do solvente $-\epsilon$ ). No modelo PCM, essa cavidade é gerada a partir da junção de cavidades esféricas, centradas em cada átomo, com raios de 1.2 do raio atômico de van der Waals, como ilustrado na figura 3.3. O ambiente líquido simulado é isotrópico, homogêneo, infinito e caracterizado por $\epsilon$.
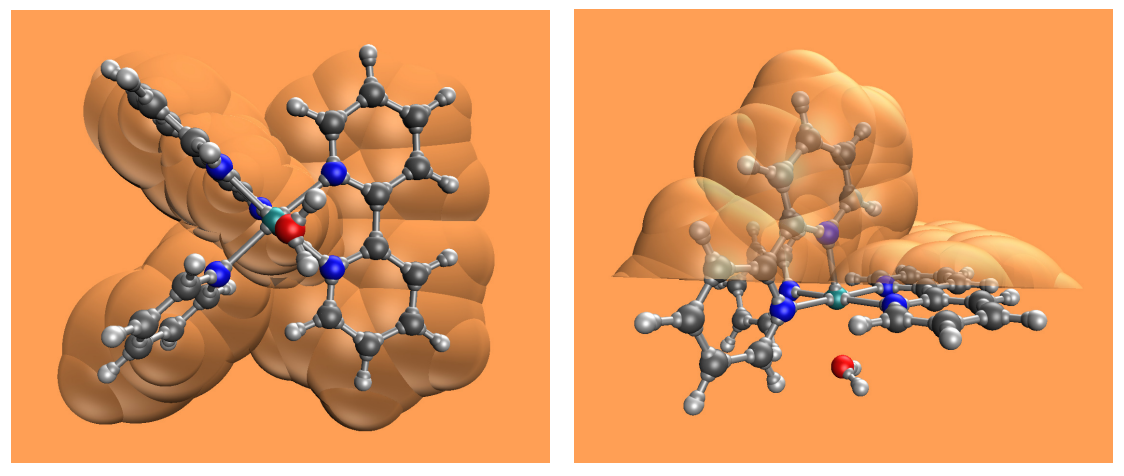

Figura 3.3 - Ilustração da cavidade PCM para o complexo $R u^{I I}\left(H_{2} O\right)$. Cavidade gerada no programa IQmol, e cortada ao meio para facilitar a visualização. Vista inferior à esquerda e vista lateral à direita. IQmol é um software livre e pode ser baixado em http://iqmol.org/downloads.html.

A distribuição de carga do soluto $\rho_{M}$ polariza a cavidade dielétrica, induzindo o aparecimento de cargas de polarização na superfície da cavidade, e essas cargas superficiais polarizam de volta o soluto. No modelo PCM, as cargas induzidas na superfície da cavidade são obtidas por meio do método de Cargas Superficiais Aparentes ${ }^{[149]}$. Utilizando-se o modelo PCM, primeiro resolve-se uma equação de Poisson do tipo:

$$
\varepsilon \nabla^{2} V(\vec{r})=-4 \pi \rho_{M}(\vec{r})
$$

que pode ser reescrita para as regiões interna e externa da cavidade sob a forma:

$$
\nabla^{2} V(r)=\left\{\begin{array}{cr}
-4 \pi \rho_{M}(r) & \text { Dentro da cavidade } \\
0 & \text { Fora da cavidade }
\end{array}\right.
$$

onde $V$ é o potencial eletrostático $V_{M}$ gerado pela distribuição de carga $\rho_{M}$ e o potencial de reação $V_{R}$ gerado pela polarização do meio dielétrico.

O conjunto de equações 3.29 é resolvido com algumas condições de contorno, apresentadada em ${ }^{[150]}$. Dentre elas, destaca-se: a continuidade do potencial $V$ através da superfície e a continuidade da componente perpendicular do vetor deslocamento elétrico na superfície. Uma vez obtido o potencial $V(\vec{r})$, a densidade de carga na superfície da cavidade é dada por:

$$
\sigma(s)=-\frac{\varepsilon-1}{4 \pi \varepsilon} \frac{\partial V}{\partial \vec{n}}
$$


onde $\vec{n}$ é um vetor unitário normal à superfície da cavidade. Logo, o termo perturbativo $V_{R}$ será dado por uma integral da densidade $\sigma$ :

$$
V_{R}=\int_{S} \frac{\sigma\left(\vec{r}^{\prime}\right)}{\left|\vec{r}-\vec{r}^{\prime}\right|} d \vec{r}^{\prime}
$$

A distribuição de carga é integrada sobre toda a superfície, e $\left|\vec{r}-\vec{r}^{\prime}\right|$ é a distância entre uma carga na superfície da cavidade, em $\vec{r}^{\prime}$, e um ponto dentro da mesma, em $\vec{r}$. Esse termo perturbativo pode ser inserido no hamiltoniano do soluto, dando início a um processo auto-consistente que deve ser resolvido de forma iterativa, até a convergência dos parâmetros desejados.

Os modelos contínuos permitem um tratamento puramente quântico da interação solutosolvente. Todavia, se esbarram na incapacidade de fornecer um tratamento correto de interações específicas, como ligações de hidrogênio entre o soluto e o solvente. Além do PCM, mais recentemente, o modelo SMD (Solvation Model based on Density) ${ }^{[146]}$ tem ganhando bastante espaço. O modelo SMD foi parametrizado para um grande conjunto de moléculas, neutras e carregadas, e em diferentes solventes (acetonitrila, metanol, dimetilsulfóxido e água). Os elementos presentes nas moléculas testadas foram: $\mathrm{H}, \mathrm{C}, \mathrm{N}, \mathrm{O}, \mathrm{F}, \mathrm{Si}, \mathrm{P}, \mathrm{S}, \mathrm{Cl}$ e $\mathrm{Br}$.

\subsubsection{Modelo discreto - ASEC}

O modelo ASEC (Average Solvent Electrostatic Configuration) é uma aproximação para a interação soluto-solvente de caráter puramente eletrostático. Foi proposto em 2007 por K. Coutinho et. al. ${ }^{[148]}$ e tem sido amplamente utilizado desde sua proposição. A sua construção pode ser dividida em 4 passos:

- (1) Faz-se uma simulação clássica MM mantendo a estrutura molecular do soluto rígida.

- (2) Seleciona-se de 1 a 4 centenas de configurações estatisticamente descorrelacionadas.

- (3) Aplica-se operações de translação e rotação nas configurações selecionadas para que todas elas tenham o soluto nas mesmas coordenadas cartesianas.

- (4) Gera-se uma configuração média, superpondo as configurações selecionadas.

- (5) Define-se um raio de corte específico para computar as interações soluto-solvente.

- (6) Reescalona-se as cargas do solvente dentro desse raio de corte pelo número de configurações.

- (7) Insere-se esse conjunto de cargas pontuais no Hamiltoniano QM do soluto, e calcula-se a propriedade QM desejada. 
Figura 3.4 - llustração de uma configuração média ASEC para a molécula N,Ndimetilindoanilina em solução de acetonitrila.

O modelo ASEC segue a filosofia do QM-MM sequencial (S-QM/MM) ${ }^{[71,151]}$, mais barato computacionalmente que o $\mathrm{QM} / \mathrm{MM}$ convencional e mais sofisticado que os modelos contínuos baseados em constante dielétrica. Com essa aproximação é possível contabilizar interações específicas entre o soluto e o solvente, a partir de uma descrição atomística da interação eletrostática. O modelo ASEC permite que se troque o problema de resolver centenas ou até milhares de cálculos quânticos (via $\mathrm{QM} / \mathrm{MM}$ convencional), para se obter a média de uma propriedade $\mathrm{QM}$ de uma molécula em solução, pelo problema de resolver um único cálculo quântico numa configuração média do solvente. Dada a economia no número de cálculos QM, utilizando o ASEC é possível realizar o cálculo quântico da propriedade desejada com um método QM de alto nível. Uma ressalva importante é que esse método só pode ser aplicado quando a flexibilidade interna do soluto não é importante no cálculo da propriedade desejada.

Mais recentemente, o modelo ASEC foi adotado no desenvolvimento de um sofisticado método para a otimização de geometria de moléculas em solução, o ASEC-FEG ${ }^{[152]}$. O método gradiente de energia livre (FEG) foi proposto em 1998, por M. Nagaoka e colaboradores, como um método de otimização em uma superfície de energia livre multidimensional (FES). ${ }^{[153]}$ Análogo ao método para a superfície de energia potencial de Born Oppenheimer, o método FEG depende da força e da Hessiana em FES, que podem ser calculadas adiabaticamente utilizando-se métodos de mecânica molecular, e alguma estratégia para se incluir o potencial externo médio gerado pelo solvente no Hamiltoniano eletrônico do soluto, tal como o ASEC ou o ASEP [147]. O primeiro trabalho de aplicação do ASEC-FEG foi desenvolvido por $\mathrm{H}$. C. 
Georg e S. Canuto ${ }^{[154]}$ e versou sobre as propriedades da água em ambiente líquido. Em 2016, publicamos um trabalho sobre as propriedades espectroscópicas da molécula Phenol Blue em solução, ${ }^{[155]}$ o qual tive a oportunidade de desenvolver durante a minha pesquisa de Mestrado, sob a orientação de H. C. Georg. Desde então, muitos outros estudos foram desenvolvidos, dentre os quais um segundo trabalho, de minha co-autoria, sobre propriedades elétricas do Phenol Blue em solução. [156]

\subsubsection{Difusão de massa}

Existem duas maneiras bem conhecidas de se obter o coeficiente de difusão de massa de partículas, a partir de uma simulação MD. A mais simples utiliza apenas informações configuracionais do sistema, a outra depende de informações do espaço de fases. Teoricamente, ambos os métodos devem produzir o mesmo resultado.

A obtenção do coeficiente de difusão a partir das posições foi proposto por Einstein, e relaciona o coeficiente de difusão de uma partícula ao seu deslocamento quadrático médio (MSD) em função do tempo. Segundo Einstein, o deslocamento quadrático médio de uma partícula é proporcional ao tempo de observação no limite em que o tempo de observação vai para o infinito. A constante de proporcionalidade que relaciona o MSD ao tempo de observação é o coeficiente de difusão da partícula. A expressão matemática do coeficiente de difusão, $D_{i}$, para uma partícula $i$ fica então definido como:

$$
D_{i} \equiv \frac{1}{2 d} \lim _{t \rightarrow \infty} \frac{\left\langle\left[\vec{r}_{i}\left(t_{0}+t\right)-\vec{r}_{i}\left(t_{0}\right)\right]^{2}\right\rangle}{t}
$$

onde $\vec{r}_{i}$ é a posição da partícula, $t_{0}$ é o tempo no instante de tempo inicial, $t$ é o tempo da simulação e $d$ é a dimensão do espaço em que a partícula se move ( $d=3$ para o espaço tridimensional). De outra forma, conhecendo-se a velocidade da partícula durante a simulação, é possível obter o coeficiente de difusão da partícula por meio da integração da função de autocorrelação de velocidade, utilizando-se o que é conhecido por relações de Green-Kubo. ${ }^{[157]}$

\subsubsection{Distribuição radial de pares}

A função de distribuição radial de pares, $G(r)$, representa a probabilidade de que um dado sítio de interação do sistema seja encontrado em relação a outro sítio radialmente disposto a uma distância $r$ do primeiro. Dividindo o espaço em camadas esféricas de espessura $d r$ e centradas num sítio de referência, é possível computar o número de sítios $d n(r)$ até uma distância $r+d r$ da referência como sendo o produto $\rho G(r) 4 \pi r^{2} d r$, onde $\rho$ representa a densidade do sistema. A intregral em $d r$ desse produto até uma certa distância $r$ fornece o número de sítios de interação $n(r)$ que se distribuem ao redor do sítio de referência dentro de uma esfera de raio $r$ centrada no mesmo, Equação 3.33. Na Figura 3.5 está uma representação 
da distribuição espacial de sítíos de interação em um líquido homogêneo.

$$
n(r)=4 \pi \rho \int_{0}^{r} G(r) r^{2} d r
$$

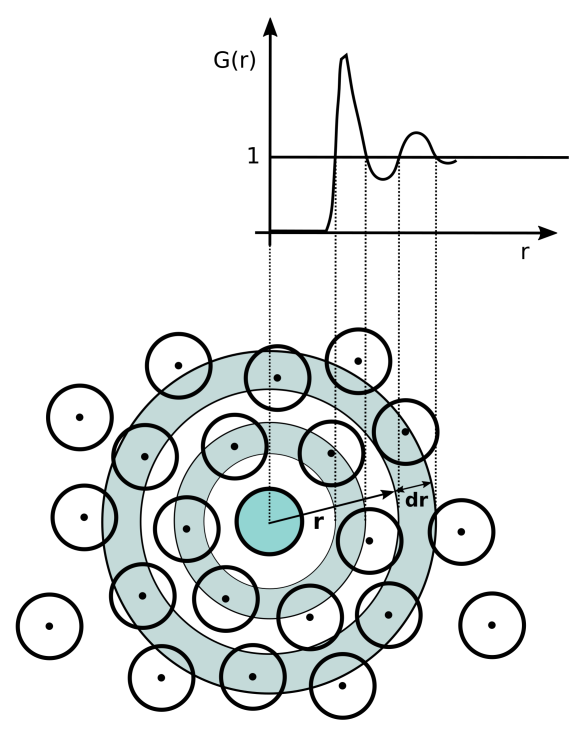

Figura 3.5 - Representação bidimensional da estrutura de um líquido homogêneo.

A função $G(r)$ pode ser obtida tanto teoricamente quanto experimentalmente. Teoricamente a $G(r)$ é uma medida da correlação entre as partículas de um sistema de muitos corpos. Escolhendo-se arbitrariamente uma das partículas como a origem, temos que o número médio de partículas entre uma distância $r$ e $r+d r$ é de $\rho g(r) d r$, onde $g(r)$ é a função de distribuição radial de pares. Experimentalmente, há duas técnicas bem conhecidas que podem ser utilizadas para a obtenção da RDF, são elas: difração de nêutrons e difração de raios- $X^{[158]}$.

\subsubsection{Ligações de hidrogênio}

As ligações de hidrogênio são interações específicas intermoleculares ou intra-moleculares que ocorrem quando um átomo de hidrogênio é atraído ao mesmo tempo por dois átomos eletronegativos, fazendo uma ligação química covalente com o átomo mais pŕximo e uma ligação mais fraca (ligação de hidrogênio) com o átomo mais distante. Os átomos eletronegativos podem ser átomos de oxigênio, nitrogênio, flúor, cloro, bromo, etc. A intensidade da ligação de hidrogênio é muito dependente da distância entre o átomo de hidrogênio e o átomo eletronegativo que recebe a ligação. ( $d_{D A}$ na figura 3.6).

Em simulação computacional, a caracterização de ligaç̃̃es de hidrogênio em solução costuma ser feita sob três critérios: (i) A distância entre o átomo eletronegativo doador e o átomo eletronegativo que recebe a ligação $\left(d_{D A}\right)$; (ii) $\mathrm{O}$ ângulo formado entre o átomo aceitador (A), o átomo doador (D) e o átomo de hidrogênio (ângulo $\Omega$ na figura 3.6); (iii) 


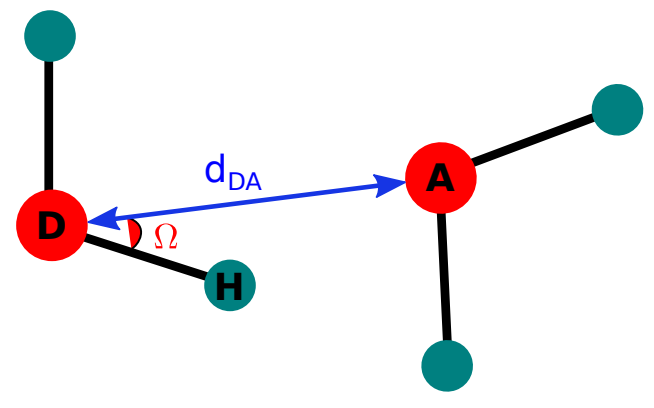

Figura 3.6 - Representação de uma ligação de hidrogênio entre duas moléculas de água.

A energia de interação da ligação $\left(E_{H B}\right)$. Normalmente se considera ligação de hidrogênio aquela interação que apresenta $d_{D A}<3.5 \AA, \Omega<40$ graus, e $E_{H B}<0$. [159]

O vínculo formado por uma ligação de hidrogênio é dinâmico, geralmente quebrado e restaurado numa escada de tempo de picossegundos. O tempo de duração entre a formação da ligação e sua primeira ruptura é conhecido como tempo de vida. Esse tempo pode ser mensurado a partir da função de autocorrelação das ligações de hidrogênio. Dada uma função de autocorrelação $C(\tau)$ do tipo

$$
C(\tau)=\left\langle s_{i}(t) s_{i}(t+\tau)\right\rangle
$$

onde $s_{i}(t)=\{0,1\}$ para a ligação de hidrogênio $i$ no tempo $t$, numa primeira aproximação o tempo de vida $\left(\tau_{H B}\right)$ de uma ligação de hidrogênio $i$ será dado por:

$$
\tau_{H B}=\int_{0}^{\infty} C(\tau) d \tau
$$

Em algumas abordagens mais sofisticadas faz-se ajustes multi-exponenciais da função de autocorrelação para obter o tempo de vida, tal como na proposta de Luzar e Chandler. ${ }^{[160]}$

\subsection{Energia livre de solvatação}

Em termodinâmica, a energia livre é uma função de estado, assim como a energia interna, a entalpia e a entropia. Supondo um sistema termodinâmico fechado, à pressão e temperatura constantes, a energia livre de Gibbs é definida como $G=H-T S$, onde $\mathrm{H}$ é a entalpia, $\mathrm{T}$ é a temperatura e $\mathrm{S}$ é a entropia. $H=U+p V$, onde $U$ é a energia interna, $p$ é a pressão e $V$ é o volume. Um processo termodinâmico que envolve uma variação de $\Delta G$ negativa é considerado um processo irreversível e espontâneo.

Define-se por energia livre de solvatação $\left(\Delta G_{\text {solv }}\right)$ a mudança de energia livre de Gibbs associada à transferência de uma molécula de sua fase gasosa para um solvente qualquer, a uma certa temperatura e pressão constantes. Quando o solvente em questão é a água, costuma-se designá-la por energia livre de hidratação $\left(\Delta G_{h y d}\right)$. A energia livre de solvatação informa o quanto uma molécula prefere uma fase à outra, como também fornece informações sobre como o solvente se comporta em diferentes ambientes. Entre muitas aplicações, a partir do cálculo 
de $\Delta G_{\text {solv }}$ é possível mensurar, por exemplo, o valor de propriedades de grande relevância em eletroquímica, como pKa e potencial redox.

A variação na energia livre de solvatação de uma molécula pode ser calculada por diferentes métodos. Existem propostas na literatura para a obtenção dessa energia utilizando modelos contínuos de solvente, como PCM (polarizable continuum model) ${ }^{[144,145]}$ e SMD (solvation model density $)^{[146]}$. E há métodos baseados em simulação molecular, tais como: Integração Termodinâmica (TI - Thermodynamic Integration), Teoria de Perturbação Termodinâmica (FEP - Free Energy Perturbation), e a Taxa de Aceitação de Bennett (BAR - Bennett Acceptance Ratio).

Nos métodos FEP ${ }^{[161]}$, TI[162] e BAR ${ }^{[163]}$ usa-se vários estados intermediários definidos por um parâmetro de acoplamento $\lambda$ para calcular a diferença de energia livre entre dois estados extremos $\mathrm{A}$ e $\mathrm{B}$. As hamiltonianas dos estados intermediários são definidas pela combinação das hamiltonianas dos estados extremos $H_{A}$ e $H_{B}$. Em linhas gerais, dados os estados $A$ e $B$ e suas respectivas hamiltonianas $H_{A}(\vec{r}, \vec{p}, \lambda)$ e $H_{B}(\vec{r}, \vec{p}, \lambda)$, define-se

$$
H(\vec{r}, \vec{p}, \lambda)=f(\lambda) \cdot H_{A}(\vec{r}, \vec{p}, \lambda)+g(\lambda) \cdot H_{B}(\vec{r}, \vec{p}, \lambda)
$$

onde $f(\lambda)$ e $g(\lambda)$ são funções de $\lambda$ utilizadas para misturar as hamiltonianas dos estados extremos $A$ e $B$. Comumentemente, $H=H_{A}$ para $\lambda=0$ e $H=H_{B}$ para $\lambda=1$, e os vetores $\vec{r}$ e $\vec{p}$ representam as posições e momentos do sistema.

A maneira mais direta de alternar entre estados é o caminho linear

$$
H(\vec{r}, \vec{p}, \lambda)=(1-\lambda) \cdot H_{A}(\vec{r}, \vec{p}, \lambda)+\lambda \cdot H_{B}(\vec{r}, \vec{p}, \lambda)
$$

Para obter as hamiltonianas intermediárias, no intervalo de discretização de $\lambda, 0<\lambda<1$, faz-se o reescalonamento das cargas atômicas $\{q\}$ e dos parâmetros de van der Walls $\{\varepsilon, \sigma\}$ do sistema de interesse, como segue:

$$
\begin{aligned}
& q_{\lambda}=\lambda q_{B}+(1-\lambda) q_{A} \\
& \varepsilon_{\lambda}=\lambda \varepsilon_{B}+(1-\lambda) \varepsilon_{A} . \\
& \sigma_{\lambda}=\lambda \sigma_{B}+(1-\lambda) \sigma_{A}
\end{aligned}
$$

Na prática, o cálculo de $\Delta G_{A B}$ é normalmente separado em duas etapas. Na primeira calcula-se a variação de energia livre devido às interações coulombianas, $\Delta G_{A B}^{\text {coul }}\left(0<\lambda_{\text {coul }}<1\right)$ e na segunda calcula-se a variação de energia livre devido às interaç̃oes de van der Walls, $\Delta G_{A B}^{v d w}$ $\left(0<\lambda_{v d w}<1\right)$. Logo, $\Delta G_{A B}$ fica dado por:

$$
\Delta G_{A B}=\Delta G_{A B}^{c o u l}+\Delta G_{A B}^{v d w}
$$

Apesar de simples, a interpolação linear de $\lambda_{v d w}$ pode ser difícil de ser realizada por conta de instabilidades numéricas. No potencial LJ, por exemplo, as forças repulsivas são modeladas por um termo de $1 / r^{12}$, e portanto, para valores muito pequenos de $\sigma$, os valores de $\Delta G$ podem ser imprecisos. Para contornar essas instabilidades numéricas são utilizados caminhos de 
interpolação alternativos, com a utilização de potenciais de interação de "núcleo-mole"(soft core potentials). Uma expressão comum para o potencial de Lennard-Jones entre duas partículas $i$ e $j$ é

$$
U_{i j}^{L J}\left(r_{i j}, \lambda\right)=\lambda^{n} 4 \varepsilon_{i j}\left(\frac{1}{\left[\alpha(1-\lambda)^{m}+\left(r_{i j} / \sigma_{i j}\right)^{6}\right]^{2}}-\frac{1}{\left[\alpha(1-\lambda)^{m}+\left(r_{i j} / \sigma_{i j}\right)^{6}\right]}\right),
$$

onde $\alpha, m$ e $n$ são números positivamente definidos e com valores tipicamente ajustados entre 0.5 e 1.0. ${ }^{[164,165]}$ Como a energia livre é uma função de estado, não depende do caminho pelo qual é calculada, e portanto a utilização de potenciais com correções de soft core não influencia no valor absoluto de $\Delta G$.

Pelo método $\mathrm{TI}$, a variação de energia livre $\Delta G_{A B}$ é calculada via integração do parâmetro $\lambda$ :

$$
\Delta G_{A B}=\int_{\lambda=0}^{\lambda=1}\left\langle\frac{\partial H}{\partial \lambda}\right\rangle_{\lambda} d \lambda
$$

A notação $\langle\cdots\rangle$ indica uma média de ensemble para um valor particular de $\lambda$. A TI é considerado um método acurado para o cálculo de $\Delta G$, entretanto, por uma questão de custo computacional, a integral deve ser transformada em uma soma finita para os valores simulados de $\lambda$. Logo, surgem duas possíveis fontes de erro: (1) a amostragem não satisfatória para cada $\lambda$; (2) a integração para poucos valores de $\lambda$. Para garantir que esses erros sejam evitados é importante que a fragmentação de $\lambda$, no intervalo de 0 a 1 , seja grande o suficiente para que 0 valor final de $\Delta G_{A B}$ encontre-se convergido.

Pelo método FEP, também conhecido na literatura como método da Média Exponencial (EXP - Exponencial Averaging), a variação de energia livre entre dois estados $i$ e $j, \Delta G_{j i}^{F E P}$ é dada por:

$$
\Delta G_{j i}^{F E P}=-k_{B} T \ln \left\langle e^{-\frac{1}{k_{B} T}\left[H_{j}\left(\vec{r}, \vec{p}, \lambda_{j}\right)-H_{i}\left(\vec{r}, \vec{p}, \lambda_{i}\right)\right]}\right\rangle_{j i}
$$

Logo,

$$
\Delta G_{A B}^{F E P}=\sum_{i=1}^{n-1} \Delta G_{i+1, i}^{F E P} .
$$

No caso da FEP, o espaçamento entre os valores de $\lambda$ deve ser pequeno o bastante para que haja uma sobreposição entre os espaços de configuração correpondentes a $\lambda_{i}$ e $\lambda_{i+1}$. Essa é uma condição necessária para que $\Delta G_{A B}$ seja calculado com precisão. ${ }^{[166]}$

Pelo método BAR, a diferença de energia entre dois estados $i$ e $j$ pode ser calculada de acordo com:

$$
\Delta G_{j i}^{B A R}=k_{B} T\left(\ln \frac{\left\langle f\left(H_{i}-H_{j}+C\right)\right\rangle_{j}}{\left\langle f\left(H_{j}-H_{i}+C\right)\right\rangle_{i}}\right)+C,
$$

onde $f$ é a função de Fermi

$$
f(x)=\frac{1}{1+\exp \left(\frac{x}{k_{B} T}\right)},
$$

com $k_{B}$ sendo a constante de Boltzmann, $T$ a temperatura, $H_{i}$ e $H_{j}$ as hamiltonianas dos estados $i$ e $j$. O valor da constante $C$ é determinado de forma iterativa satisfazendo a condição 
$\left\langle f\left(H_{i}-H_{j}+C\right)\right\rangle_{j}=\left\langle f\left(H_{j}-H_{i}+C\right)\right\rangle_{i}$. Logo, o valor de $\Delta G_{j i}^{B A R}$ é simplificado para:

$$
\Delta G_{j i}^{B A R}=-k_{B} T \ln \left(\frac{N_{j}}{N_{i}}\right)+C
$$

onde $N_{i}$ e $N_{j}$ representam o número de configurações obtidas das simulações do sistema com hamiltoninas $H_{i}$ e $H_{j}$, respectivamente. Logo, o valor de $\Delta G_{A B}^{B A R}$ é dado por:

$$
\Delta G_{A B}^{B A R}=\sum_{i=1}^{n-1} \Delta G_{i+1, i}^{B A R} .
$$

Em estudos recentes, o método BAR foi avaliado como a maneira mais eficiente e acurada de se calcular a energia livre de solvatação $\Delta G_{i, i+1}$ entre dois estados adjacentes $i$ e $i+1$, utilizando a sobreposição dos ensembles de $i$ e $i+1 .{ }^{[167,168]}$

\subsubsection{Cálculo de pKa}

O $p K a$ é uma constante de equilíbrio químico definida como o negativo do $\log _{10}$ da constante de dissociação de um ácido $(K a)$ :

$$
p K a=-\log _{10} K a \text {. }
$$

Para uma reação química de desprotonação

$$
X H \rightleftharpoons X^{-}+H^{+}
$$

a constante $K a$ indica o equilíbrio das concentrações dos componentes $X^{-}, H^{+}$e $X H$ :

$$
K a=\frac{\left[X^{-}\right]\left[H^{+}\right]}{[X H]} .
$$

Logo,

$$
p K a=-\log _{10} K a=\log _{10} \frac{[X H]}{\left[X^{-}\right]\left[H^{+}\right]} .
$$

As quantidades entre colchetes representam as concentrações de cada espécie em equilíbrio.

Portanto, o $p K a$ é uma medida quantitativa de quão facilmente ou com que rapidez um ácido perde prótons em solução e, portanto, serve como uma medida da "força" do ácido. Ácidos fortes têm um pKa pequeno ou negativo $(p K a<<7)$ e ácidos fracos têm um pKa grande $(p K a>>7)$. A relação entre $p K a$ e $p H$ é representada pela equação de HendersonHasselbach mostrada abaixo, onde $\left[X^{-}\right]$representa a concentração da forma desprotonada do ácido e $[X H]$ representa a concentração da forma protonada do ácido na solução.

$$
p H=p K a+\log \frac{\left[X^{-}\right]}{[X H]} .
$$

Uma solução para esta equação pode ser obtida tomando-se a igualdade $p H=p K a$. Nesse caso, $\log ([X-] /[X H])=0$ e $[X-] /[X H]=1$. Isso significa que quando o $p H$ é igual ao $p K a$, existem quantidades iguais de formas protonadas e desprotonadas do ácido. 
O $p K a$ de uma molécula pode ser calculado utilizando a aproximação de ciclo termodinâmico. $\mathrm{O}$ ciclo termodinâmico mais simples, também conhecido como método direto, considera a dissociação de uma espécie ácida $X H$ em sua base conjugada $X^{-}$e um próton $H^{+}$, de acordo com a figura 3.7. Partindo de $X H$ em solução, o primeiro passo consiste na dessolvatação de $X H$, depois $X H$ é desprotonada na fase gasosa produzindo a base conjugada $X^{-}$e o próton isolado $H^{+}$. Finalmente, os produtos resultantes $X^{-}$e $H^{+}$são solvatados para completar o ciclo. De acordo com esse ciclo termodinâmico, a energia livre de desprotonação em solução $\left(\Delta G_{\text {sol }}\right)$ é obtida conforme a equação 3.53:

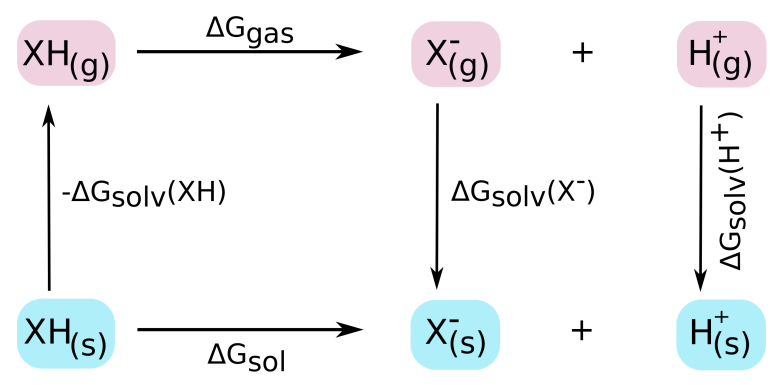

Figura 3.7 - Ciclo termodinâmico utilizado para o cálculo do pKa de uma molécula em solução.

$$
\Delta G_{\text {sol }}=\Delta G_{v a c}+\Delta \Delta G_{\text {solv }}+\Delta G_{\text {solv }}\left(H^{+}\right)
$$

onde

$$
\begin{gathered}
\Delta G_{v a c}=G_{v a c}\left(X^{-}\right)-G_{v a c}(X H)+G_{v a c}\left(H^{+}\right), \\
\Delta \Delta G_{\text {solv }}=\Delta G_{\text {solv }}\left(X^{-}\right)-\Delta G_{\text {solv }}(X H) .
\end{gathered}
$$

O ciclo termodinâmico envolve vários termos que correspondem às fases de gás e solução. A energia livre do próton, $G_{v a c}\left(H^{+}\right)$, e sua energia livre de solvatação, $\Delta G_{\text {solv }}\left(H^{+}\right)$, em fase gasosa, tem valores conhecidos na literatura: $G_{v a c}\left(H^{+}\right)=5.4 \pm 0.2 \mathrm{kcal} / \mathrm{mol}^{[169]} \mathrm{e}$ $\Delta G_{\text {solv }}\left(H^{+}\right)=-265.9 \pm 0.2 \mathrm{kcal} / \mathrm{mol}^{[170]}$. As energias livre das espécies $X H$ e $X^{-}$, em fase gasosa, podem ser obtidas quanticamente, a partir da soma da energia eletrônica às correções térmicas para a energia livre de Gibbs (correções térmicas de translação, rotação, e vibração). $\mathrm{E}$ as energias livre de solvatação das espécies $X H$ e $X^{-}$podem ser obtidas utilizando qualquer um dos médodos discutidos anteriormente: modelos contínuos PCM ou SMD; métodos TI, FEP ou BAR em simulações moleculares; etc.

Dentro da aproximação de ciclo termodinâmico, o $p K a$ pode ser calculado a partir da razão:

$$
p K a=\frac{\Delta G_{\text {sol }}}{R T \ln 10},
$$

onde $R$ é a constante universal do gas ideal $(R=0.001986 \mathrm{kcal} / \mathrm{mol} \cdot K)$ e $T$ a temperatura $(\mathrm{em} K)$. 


\subsubsection{Cálculo de potencial redox}

Assim como o $p H$ representa a facilidade com que prótons podem ser transferidos entre espécies diferentes em solução, o potencial redox representa o análogo, mas para elétrons. A tendência de transferência de elétrons entre espécies químicas ou entre as espécies químicas e o eletrodo determina o potencial redox da solução. De maneira análoga ao cálculo do $p K a$, é possivel utilizar a aproximação de ciclo termodinâmico para obter teoricamente o potencial redox em reações de perda ou ganho de elétrons. Existem muitas propostas na literatura para a predição teórica do potencial redox, ${ }^{[171,172]}$ e o ciclo de Born-Haber, na figura 3.8, é um dos mais utilizados.

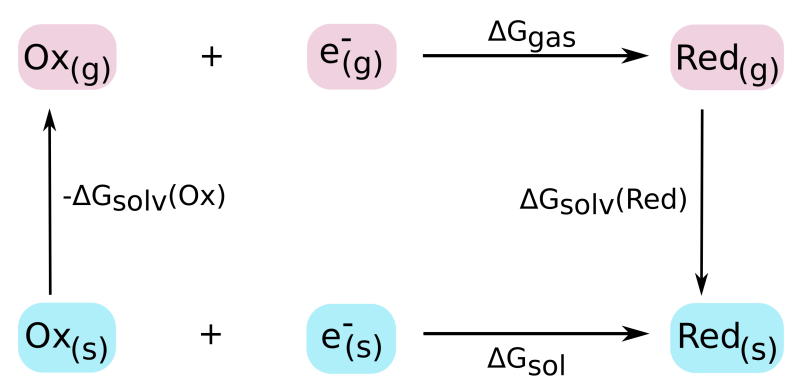

Figura 3.8 - Ciclo termodinâmico de Born-Haber utilizado para o cálculo do potencial redox de uma molécula em solução.

Partindo da molécula oxidada $O x$ em solução, o primeiro passo consiste na dessolvatação de $O x$, depois $O x$ ganha um elétron na fase gasosa produzindo o par reduzido Red, que é então solvatado para completar o ciclo. No ciclo de Born-Haber a solvatação do elétron, e sua energia livre em fase gasosa, são desprezadas. De acordo com esse ciclo termodinâmico, a energia livre de oxidação em solução $\left(\Delta G_{s o l}\right)$ é obtida conforme a equação 3.57 :

$$
\Delta G_{\text {sol }}=\Delta G_{v a c}+\Delta \Delta G_{\text {solv }}
$$

onde

$$
\begin{gathered}
\Delta G_{v a c}=G_{v a c}(R e d)-G_{v a c}(O x), \\
\Delta \Delta G_{\text {solv }}=\Delta G_{\text {solv }}(R e d)-\Delta G_{\text {solv }}(O x) .
\end{gathered}
$$

Assim como no cálculo do $p K a$, as energias livre das espécies $O x$ e Red, em fase gasosa, podem ser obtidas quanticamente, a partir da soma da energia eletrônica às correções térmicas para a energia livre de Gibbs. E as energias livre de solvatação dessas espécies podem ser obtidas utilizando qualquer um dos médodos discutidos anteriormente: modelos contínuos PCM ou SMD; métodos TI, FEP ou BAR em simulações moleculares; etc.

O valor de $\Delta G_{\text {sol }}$ obtido no ciclo termodinâmico de Born-Haber pode ser relacionado ao potencial redox a partir da equação de Nernst, que tem o papel de conectar a termodinâmica 
com a eletroquímica:

$$
V_{a b s}^{o x}=\frac{-\Delta G_{\text {sol }}}{n F}
$$

onde $n$ é o número de elétrons transferidos na reação de óxido-redução, $F$ é a constante de Faraday (96.48kJ mol $\mathrm{m}^{-1} V^{-1}$ ), e $V_{a b s}^{o x}$ é o potencial redox absoluto (em unidades de voltz).

Para comparar o potencial redox calculado com o redox experimental, o valor calculado deve ser fornecido em relação a algum eletrodo de referência $\left(V^{o x}\right)$. O eletrodo padrão de hidrogênio (SHE) ou o eletrodo de Calomel saturado (SCE) são frequentemente usados como eletrodos de referência.

$$
V^{o x}=V_{a b s}^{o x}-V_{r e f}^{o x}
$$

onde $V_{a b s}^{o x}$ é o valor absoluto do potencial calculado e $V_{r e f}^{o x}$ é o valor absoluto do potencial do eletrodo de referência. Em artigos anteriores, que tratam do cálculo de potenciais redox em solução aquosa, os valores usuais de 4.36 e $4.43 \mathrm{~V}$ tem sido adotados como potenciais de referência para o eletrodo SHE. ${ }^{[173,174]}$ Como o potencial do eletrodo SCE é de $+0.24 \mathrm{~V} / \mathrm{SHE}$ a $298 K^{[175]}$ então, na referência de Calomel os valores usuais são de 4.60 e $4.67 \mathrm{~V}$.

\subsection{Métodos QM/MM}

A proposta dos métodos híbridos que combinam as mecânicas quântica e molecular (QM/MM) consiste em tratar uma parte do sistema molecular de interesse utilizando mecânica quântica (QM) e outra parte utilizando mecânica molecular ( $M M)$. Esses métodos são normalmente empregados em situações onde não se pode abrir mão por completo do tratamento quântico de pelo menos uma parte do sistema. Em um reação química, por exemplo, essa descrição quântica pode ser imprescindível, mas apenas para os produtos e reagentes envolvidos, e talvez para as moléculas do solvente nas primeiras camadas de solvatação. Moléculas mais distantes, e que não participam ativamente da reação, podem muitas vezes receber um tratamento menos sofisticado, por mecânica molecular, por exemplo.

Em um esquema $\mathrm{QM} / \mathrm{MM}$, a energia potencial total é dada pela soma de três contribuições: (1) as interações entre os átomos na região QM; (2) entre os átomos na região $\mathrm{MM}$; (3) e as interações entre os átomos que se encontram nas regiões QM e MM. As duas primeiras dependem apenas das interações entre os átomos nas regiões QM e MM isoladamente, e as interações entre os dois subsistemas podem ser computadas de diferentes formas. As abordagens propostas para descrever as interações entre as regiões QM e MM podem ser divididas em duas categorias: esquemas de acoplamento subtrativo e aditivo.

No esquema subtrativo, a energia $\mathrm{QM} / \mathrm{MM}$ é dada por:

$$
V_{Q M / M M}=V_{M M}(M M+Q M)+V_{Q M}(Q M)-V_{M M}(Q M)
$$

onde $V_{M M+Q M}$ é a energia $\mathrm{MM}$ do sistema completo, $V_{Q M}$ é a energia QM do subsistema $\mathrm{QM}$ isolado e $V_{M M}(Q M)$ é a energia MM do subsistema $\mathrm{QM}$. Esse esquema é chamado de 
subtrativo justamente porque a energia MM da região QM é subtraída da energia total para que a energia QM dessa região possa ser contabilizada, sem duplicidade. A principal vantagem desse esquema é que nenhuma comunicação é necessária entre os cálculos $Q M$ e $M M$, o que torna a implementação mais simples. A maior desvantagem é que é necessário determinar um campo de força para a região QM, e isso nem sempre é possível ou desejável. Outra desvantagem, não menos importante, é a ausência de polarização da região $Q M$ pela região $\mathrm{MM}$, o que pode ser problemático em situações em que os efeitos de polarização do meio afetam a densidade eletrônica na região QM.

No esquema aditivo, a energia $\mathrm{QM} / \mathrm{MM}$ é dada por:

$$
V_{Q M / M M}=V_{Q M}(Q M)+V_{M M}(M M)+V_{Q M-M M}(Q M+M M)
$$

onde $V_{Q M}$ é a energia $\mathrm{QM}$ do subsistema $\mathrm{QM}$ isolado, $V_{M M}(M M)$ é a energia $\mathrm{MM}$ da parte $\mathrm{MM}$ e $V_{Q M-M M}(Q M+M M)$ é a energia de interação entre as partes QM e MM. No esquema aditivo, a energia de interação $V_{Q M-M M}(Q M+M M)$ é tratada explicitamente. Numa primeira aproximação, a parte QM recebe um tratamento quântico de forma isolada, sem contabilizar efeitos de polarização da parte MM. Em seguida, as interações entre as regiões QM e MM são computadas apenas no nível MM. Interações ligadas entre átomos das duas regiões podem ser contabilizadas por potenciais mecânicos responsáveis por modelar estiramentos de ligações químicas, deformações angulares e rotações. Interações não-ligadas são modeladas por algum potencial não-ligado como o de Lennard-Jones-Coulomb.

Um primeiro aprimoramento da abordagem aditiva se dá quando os efeitos de polarização da parte MM são computados na função de onda eletrônica da parte QM. A aproximação conhecida por banho eletrostático permite que os efeitos de polarização da região MM sejam contabilizados à nível eletrostático no Hamiltoniano da parte QM. Os átomos MM são tratados como cargas pontuais, e entram no Hamiltoniano QM como operadores de 1 elétron. Outro aprimoramento ocorre quando os efeitos de polarização da região $\mathrm{MM}$ devido a região $\mathrm{QM}$ são também considerados. Isso pode ser obtido a partir da utilização de campos de força polarizáveis.

As abordagens QM/MM subtrativa e aditiva são comumente adotadas em simulações QM/MM tradicionais. No caso de uma dinâmica molecular, por exemplo, as energias das regiões QM, MM e da interação entre essas regiões são calculadas e derivadas no tempo a cada passo de simulação, para se obter as forças que atuam em cada átomo do sistema, permitindo assim a evolução temporal nas condições termodinâmicas pré-definidas. Dessa maneira, explora-se o espaço de fases do sistema por um intervalo de tempo finito, e calcula-se propriedades de interesse para cada passo de simulação ou num intervalo de tempo específico. Normalmente são realizados da ordem de centenas de milhares de cálculos quânticos durante uma simulação QM/MM tradicional.

Uma abordagem alternativa ao QM/MM convencional é o QM/MM sequencial (S-QM/MM) ${ }^{[71,151]}$. Nessa abordagem faz-se inicialmente o tratamento puramente clássico de todo o sistema, a partir de simulações por mecânica molecular, até que se atinja o ensemble de equilíbrio nas 
condições de temperatura e pressão desejadas. Em seguida, seleciona-se configurações estatisticamente relevantes, e apenas nessas configurações realiza-se os cálculos quânticos desejados. Poupa-se assim um grande tempo de processamento, sem necessariamente se incorrer na perda de qualidade dos resultados obtidos. Nas configurações selecionadas, pode-se ainda separar um conjunto específico de átomos para serem tratados explicitamente via $Q M$, enquanto que os demais átomos podem ser tratados como cargas pontuais, dentro da aproximação de banho eletrostático. Por depender da simulação MM do sistema como um todo, o S-QM/MM pode não ser uma boa opção quando não se tem a definição de um campo de força adequado para a região QM. Além disso, o S-QM/MM não permite estudar reações químicas. Aplicações recentes do S-QM/MM tem demonstrado um grande sucesso dessa metodologia na combinação de simulações de Monte Carlo com cálculos quânticos em diferentes níveis. ${ }^{[154,155,176-178]}$ 


\section{Capítulo}

\section{4}

\section{Metodologia}

Neste capítulo, apresentaremos a metodologia utilizada para a realização deste trabalho. Trataremos de detalhes sobre os cálculos quânticos, métodos e conjuntos de funções base adotados, desde os cálculos de otimização de geometria até os cálculos de propriedades como excitações eletrônicas, pKa e potencial redox. Trataremos das simulações clássicas de Monte Carlo e de Dinâmica Molecular, trazendo informações sobre os campos de força adotados, condições termodinâmicas das simulações, e obtenção de propriedades relacionadas à estrutura e dinâmica da solução.

\subsection{Geometria dos complexos}

As estruturas moleculares dos complexos de $R u$-Aqua/Oxo foram obtidas a partir de otimizações de geometria no vácuo e em solução aquosa, utilizando a teoria do funcional de densidade (DFT). Nas otimizações, adotamos o funcional de densidade híbrido B3LYP ${ }^{[88,89]}$ combinado ao conjunto de funções base: aug-cc-pVDZ ${ }^{[179]}$ para os átomos de carbono, oxigênio e nitrogênio; cc-pVDZ ${ }^{[179]}$ para os átomos de hidrogênio; e a base com potencial efetivo aug-cc-pVDZ/PP ${ }^{[106]}$ para o átomo de rutênio. Por simplicidade, utilizaremos a partir de agora a notação (aug)-cc-pVDZ/(PP-Ru) para indicar esse conjunto de funções base em específico. Para levar em conta efeitos do solvente, na otimização geométrica, utilizamos o modelo contínuo polarizável $\operatorname{PCM}^{[144,145]}$. Adicionalmente, cálculos de frequências vibracionais foram realizados, no mesmo de nível de cálculo da otimização, para atestar a ausência de qualquer frequência imaginária. Esses cálculos foram realizados no programa Gaussian 09 ${ }^{[92]}$. As geometrias otimizadas em solução encontram-se disponíveis no apêndice B.

\subsection{Simulações de Monte Carlo}

As simulações de Monte Carlo ( $M C$ ) foram realizadas para uma molécula de soluto (qualquer complexo na geometria otimizada em solução) inserida em uma caixa cúbica, com 
aproximadamente $50 \AA$ de lado, contendo $N=4000$ moléculas de água (figura 4.1). Utilizamos a técnica de amostragem de Metropolis e procedimentos padrões, tais como: método da mínima imagem, condições de contorno periódicas e correção de longo alcance. ${ }^{[180]}$ Todas as interações foram computadas dentro de um raio de corte de aproximadamente $23 \AA$. Nos limites desse raio de corte, computamos interações soluto/solvente da ordem de $-0.02 \pm 0.4 \mathrm{kcal} / \mathrm{mol}$ para o complexo de maior carga (3+), e portanto, não foi necessário adicionar contra-íons, ou mesmo correções de longo alcance eletrostáticas. Correções de longo alcance para o termo de van der Waalls foram adotadas utilizando a distribuição uniforme, ou seja, $G(r) \neq 1$. As simulações foram realizadas no ensemble $N P T$, com $P=1 \mathrm{~atm}$ e $T=298 \mathrm{~K}$. Para cada complexo em solução, um total de $2.0 \times 10^{5}$ ciclos MC foram realizados no processo de termalização, e $4.0 \times 10^{5}$ ciclos MC foram realizados nas simulações de equilíbrio. Em cada ciclo MC, sorteia-se $N$ moléculas do sistema e, uma a uma, faz-se uma tentativa de mudança de posicionamento, que inclui rotação e translação. O programa Dice ${ }^{[143]}$ foi utilizado para realizar as simulações MC neste trabalho.

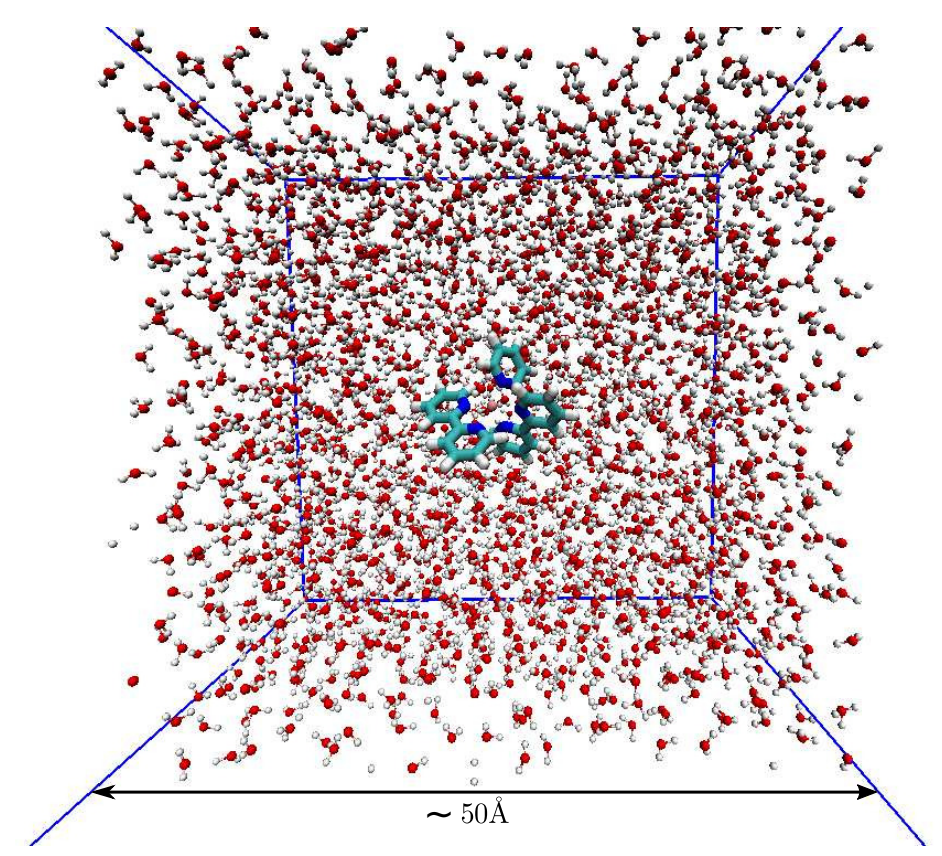

Figura 4.1 - Caixa de simulação contendo 1 complexo e 4000 moléculas de água.

Durante as simulações $\mathrm{MC}$, o soluto e as moléculas do solvente não sofreram deformações intramoleculares, ou seja, foram tratadas como moléculas rígidas. Nas simulações dos complexos de $\mathrm{Ru}$-Aqua/Oxo coordenados com uma molécula de água, $\mathrm{Ru} u^{I I} \mathrm{H}_{2} \mathrm{O}$ e $\mathrm{Ru} u^{I I I} \mathrm{H}_{2} \mathrm{O}$, tratamos a molécula de água coordenada como parte do solvente, e portanto, a mesma esteve livre para se movimentar durante as simulações. Nos outros casos, tratamos os grupos coordenados $\mathrm{OH}^{-}$ e $O^{2-}$ como parte do soluto, preservando assim as características geométricas dos sistemas de camada aberta e com delocalização de spin entre os átomo $R u$ e $O$. 


\subsubsection{Simulações MC na interface água/vacuo}

Para simular nas condições de interface, criamos um caixa cúbica com aproximadamente $50 \AA$ de lado, contendo 4000 moléculas de água. Na direção de $z$, criamos duas caixas vazias com as mesmas dimensões da caixa com água, e as posicionamos nas partes superior $(+z)$ e inferior da caixa com água $(-z)$. Nessa montagem, o complexo de $R u$ (na geometria otimizada em solução) foi centralizado dentro da caixa vazia em $+z$ e deslocado até as proximidades da interface com a caixa de água (até aproximadamente $5 \AA$ ). As simulações foram então realizadas no ensemble $N V T$, na temperatura $T=298 \mathrm{~K}$. Realizamos um total de $1.0 \times 10^{5}$ ciclos MC na etapa de termalização, mantendo o complexo fixo na posição inicial, e $20.0 \times 10^{6}$ ciclos MC da etapa de produção, sem qualquer restrição de posição.

\subsection{Simulações de Dinâmica Molecular}

Assim como nas simulações MC, o sistema simulado foi composto por um soluto (qualquer complexo na geometria otimizada em solução) cercado por 4000 moléculas de água, dentro de uma caixa cúbica. Para neutralizar a caixa de simulação utilizamos íons de cloro, na quantidade necessária para cada complexo. As simulações foram realizadas no ensemble NPT a uma pressão de $P=1 \mathrm{~atm}$ e a uma temperatura de $T=298 \mathrm{~K}$. Para manter o sistema nessas condições utilizamos o termostato Velocity Rescaling ${ }^{[130,131]}$ para o controle de temperatura, com uma constante de acoplamento de 0.1 ps, e o barostato de Berendsen ${ }^{[134]}$ para o controle de pressão, com uma constante de acoplamento de $2 \mathrm{ps}$. Todas as interações foram calculadas dentro de um raio de corte de $14 \AA$. Interações eletrostáticas de longo alcance foram tratadas com o método Particle Mesh Ewald (PME) ${ }^{[181]}$ com interpolação cúbica e espaçamento de grid de $14 \AA$. As equações de movimento foram integradas com o algoritmo Leapfrog ${ }^{[126]} \mathrm{em}$ intervalos de tempo de $2 f s$, usando restrições para as ligações $H$ pelo algoritmo LINCS $^{[127]}$. O movimento do centro de massa do sistema soluto/solvente foi removido linearmente a cada $200 \mathrm{fs}$. Para cada complexo, realizamos $5 \mathrm{~ns}$ de termalização e $10 \mathrm{~ns}$ de produção. Todas as simulações MD deste trabalho foram realizadas com o pacote de programas GROMACS 5.1.4. ${ }^{[133]}$

\subsubsection{Coeficiente de difusão}

Os coeficientes de difusão $D$ foram calculados a partir da relação de Einstein que relaciona o deslocamento quadrático médio (MSD) (do inglês Mean Square Displacement) de uma partícula ao seu coeficiente de difusão, equação 3.32. ${ }^{[182]}$ Para cada complexo em solução, obtivemos 5 curvas de MSD do centro de massa do complexo em 5 simulações independentes. Cada MSD foi gerado a partir de $5 \cdot 10^{4}$ configurações igualmente espaçadas por um $\Delta t=0.2 \mathrm{ps}$. Fazendo-se o ajuste linear pelo método dos mínimos quadrados de cada curva, em seu regime 
linear, em torno de 0 e $5 \mathrm{~ns}$, calculamos um coeficiente de difusão para cada curva. E o coeficiente de difusão do complexo foi então obtido como uma média aritmética simples dos 5 valores obtidos nessas simulações independentes. As curvas de MSD e os valores de $D$ foram obtidos usando o comando gmx msd disponível no pacote GROMACS 5.1.4.

\subsubsection{Tempo de vida de ligações de hidrogênio}

O tempo de vida de ligações de hidrogênio foi calculado integrando-se a função de autocorrelação das ligações de hidrogênio. ${ }^{[160,183,184]}$ Para esse propósito realizamos simulações MD curtas, de apenas $1 n s$, com passo de simulação de $2 f s$, e salvamos todas as configurações geradas. Em seguida calculamos o tempo de vida das ligações de hidrogênio na primeira camada de solvatação, entre moléculas de água da solução. E calculamos o tempo de vida entre os complexos e a solução. Esse cálculos foram realizados utilizando as ferramentas gmx trjorder e gmx hbond do pacote GROMACS 5.1.4.

\subsection{Obtenção de parâmetros para as simulações MM}

\subsubsection{Parâmetros não-ligados}

Para representar as interações de van der Walls e as interações eletrostáticas dos complexos em solução, adotamos o potencial clássico de Lennard-Jones-Coulomb (LJC) com as regras de combinação de Berthelot ${ }^{[185]}$ e de Good-Hope ${ }^{[186]}$. Os parâmetros de Lennard-Jones $\{\epsilon, \sigma\}$ para os átomos $C, O, H$ e $N$ foram retirados do campo de força OPLS-AA ${ }^{[187]}$, sendo que para a molécula de água coordenada e demais moléculas de água da solução utilizamos o modelo TIP3P ${ }^{[188]}$. Já os parâmetros de Lennard-Jones do átomo de $R u$ foram ajustados para reproduzir a energia de interação quântica da molécula de água nos complexos com graus de oxidação II e III num intervalo de distância $R u-O$ de 1.73 a $2.73 \AA$ A. As cargas atômicas do soluto foram obtidas quanticamente por meio do ajuste de cargas CHELPG, ${ }^{[189]}$ para reproduzir o potencial eletrostático nas vizinhanças atômicas. Os cálculos de carga foram também realizados com o funcional B3LYP e conjunto de funções base (aug)-cc-pVDZ/(PP-Ru). As cargas atômicas foram obtidas para o estado de vácuo, e também em solução, com a inclusão de efeitos de polarização provenientes do modelo contínuo PCM. Para os ajustes CHELPG utilizamos os raios atômicos de Breneman (1.5 $\AA$ para $C, 1.7 \AA$ para $O$ e N, $1.45 \AA$ para $\mathrm{H}$ ), valores padrões do programa Gaussian 09, e utilizamos o raio atômico de $1.0 \AA$ para $R u$. A escolha do raio atômico para $R u$ se deu após testes que mostraram valores de cargas para $R u$ compatíveis com a literatura ${ }^{[190]}$.

No ajuste dos parâmetros de Lennard-Jones para o átomo de $R u$, exploramos nos complexos $R u^{I I}\left(H_{2} \mathrm{O}\right)$ e $R u^{I I I}\left(H_{2} \mathrm{O}\right)$ a superfície de energia potencial QM rígida entre a molécula de 
água e o átomo de $R u$, no vácuo. Em cada complexo, na geometria otimizada de vácuo, calculamos a energia de interação da molécula de água coordenada a $R u$ em diferentes posições em torno do ponto de equilíbrio, traçando assim curvas de energia de interação água/complexo. Para corrigir erros de superposição de base (BSSE), empregamos a correção Counter Poise ${ }^{[108,191]}$. Realizamos os cálculos com o funcional B3LYP e o conjunto de funções base (aug)-cc-PVDZ/(PP-Ru). Uma vez traçadas as curvas quânticas de interação, passamos ao refinamento dos parâmetros $\mathrm{LJ}\{\epsilon, \sigma\}$ para $R u$ a fim de reproduzir melhor o perfil quântico de interação água/complexo em $R u^{I I}\left(H_{2} O\right)$ e $R u^{I I I}\left(H_{2} O\right)$. Os parâmetros $\epsilon$ e $\sigma$ obtidos para $R u^{I I}\left(\mathrm{H}_{2} \mathrm{O}\right)$ e $\mathrm{Ru} u^{I I I}\left(\mathrm{H}_{2} \mathrm{O}\right)$ foram adotados para os complexos $R u^{I I}(\mathrm{OH})$ e $R u^{I I I}(\mathrm{OH})$ respectivamente. Para o complexo $R u^{I V}(O)$ optamos por manter a parametrização obtida para o complexo $\mathrm{Ru}^{I I}\left(\mathrm{H}_{2} \mathrm{O}\right)$. Do ponto de vista quântico, existe uma limitação para o levantamento da curva de energia de interação do hidróxido $O H^{-}$no complexo $R u^{I I I}(O H)$ e do oxigênio $O^{2-}$ no complexo $R u^{I V}(O)$. A limitação consiste no fato de que a densidade de spin nesses complexos, que tem elétrons desemparelhados, encontra-se delocalizada entre o átomo de $R u$ e o átomo de oxigênio. $\mathrm{O}$ cálculo regular de energia de complexação de duas moléculas requer a definição prévia do estado de spin e de carga das partes que irão interagir. Como a densidade de spin encontra-se delocalizada entre $R u$ e $O$, é quanticamente inconsistente considerar o spin de cada parte separadamente. Como veremos no capítulo de resultados, a densidade de spin nos complexos de camada aberta, $R u^{I V}(O)$ e $R u^{I I I}(O H)$, encontra-se delocalizada em orbitais de $R u$ e $O$, o que inviabiliza o levantamento do perfil quântico de interação das partes $\mathrm{O}^{2-}$ e $O H^{-}$nesses complexos. $\mathrm{O}$ mesmo não ocorre no caso do complexo $\mathrm{Ru}^{I I I}\left(\mathrm{H}_{2} \mathrm{O}\right)$, que apesar de ser um dubleto, tem a sua densidade de spin localizada apenas no átomo $R u$. Todos os parâmetros não ligados utilizados nas simulações encontram-se disponíveis no apêndice $B$.

\subsubsection{Parâmetros ligados}

Nas simulações de Dinâmica Molecular, as geometrias dos complexos foram tratadas de forma flexível. As geometrias otimizadas em solução foram adotadas como estruturas de equilíbrio. As constantes de força da ligações e dos ângulos, e os parâmetros de ligação dos diedros, foram extraídos do campo de força UFF, utilizando o gerador de topologias OBGMX ${ }^{[192]}$. As topologias utilizadas nas simulações MD encontram-se disponíveis no apêndice C.

\subsection{Energia livre de solvatação}

A energia livre de solvatação de uma molécula em solução $\left(\Delta G_{\text {solv }}\right)$ é formalmente definida como sendo igual à energia livre de criação do soluto imerso no solvente, ou ao negativo da energia livre de aniquilação do soluto em solução ${ }^{[169,193-195]}$. A energia livre de criação/aniquilação

pode ser calculada ligando/desligando o potencial do soluto em várias simulações $\mathrm{MM}^{[169,195]}$, e o valor final de $\Delta G_{\text {solv }}$ pode ser obtido utilizando-se métodos como BAR ${ }^{[163]}$ (Bennet 
Acceptance Ratio) ou FEP (Free Energy Perturbation) ${ }^{[193,194]}$. Utilizamos as duas técnicas, combinando os métodos MD e BAR (BAR-MD), e, MC e FEP (FEP-MC). Todas as simulações MM foram realizadas para 1 complexo de $R u$-Aqua/Oxo embebido em 4000 moléculas de água, numa caixa de simulação cúbica, na temperatura de $298 \mathrm{~K}$ e pressão de $1 \mathrm{~atm}$. Geralmente, os valores experimentais de $\Delta G_{\text {solv }}$ são apresentados no estado de $1 \mathrm{~mol} / L$, ou seja, $P=24.46 \mathrm{~atm}$ e $T=298.15 \mathrm{~K}$ para o gás ideal. Portanto, para levar a energia livre calculada por simulações na condição de $1 \mathrm{~atm}$ para o estado padrão de $1 \mathrm{~mol} / \mathrm{L}$ é necessário somarmos ao valor final de $\Delta G_{\text {solv }}$ o termo - $R T \ln (24.46)$ responsável pela correção do estado padrão ${ }^{[196]}$. Adicionalmente, também realizamos cálculos de energia livre utilizando DFT.

\subsubsection{Procedimento via FEP-MC}

Para obter $\Delta G_{\text {solv }}$ dos complexos utilizando o método FEP, calculamos a energia livre de aniquilação do soluto em várias simulações $M C^{*}$. Dividimos o processo de aniquilação do soluto em três etapas, onde reescalonamos separadamente os três parâmetros do potencial LJC $\left(q_{i}, \varepsilon_{i}\right.$ e $\left.\sigma_{i}\right)$. Na primeira etapa, desligamos o potencial de Coulomb a partir do gradual reescalonamento das cargas atômicas até zerá-las. Os fatores de escala utilizados foram $\lambda=$ $1.00,0.95,0.90,0.85,0.80,0.75,0.70,0.65,0.60,0.50,0.40,0.30,0.20,0.10$ e 0.0 . Utilizando a técnica de dupla amostragem (double-wide) ${ }^{[194]}$, as cargas atômicas foram perturbadas simultaneamente para $\lambda_{i-1}$ e $\lambda_{i+1}$, e portanto realizamos simulações apenas para $\lambda_{i}=0.95$, $0.85,0.75,0.65,0.50,0.30$ e 0.10 . Na segunda etapa, desligamos quase que por completo o termo atrativo do potencial LJ a partir do gradual reescalonamento dos parâmetros $\varepsilon_{i}$ até próximo de zero. Os fatores de escala utilizados foram $\lambda=1.00,0.90,0.80,0.70,0.60$, $0.50,0.40,0.30,0.20,0.10$ e 0.01 . Novamente, aplicamos a técnica de dupla amostragem, de modo que realizamos simulações apenas para $\varepsilon_{i}=0.90,0.70,0.50,0.30$ e 0.10 . Na terceira e última etapa, desligamos por completo o termo repulsivo do potencial LJ a partir do gradual reescalonamento dos parâmetros $\sigma_{i}$ até zero, sem dupla amostragem ${ }^{\dagger}$. Os fatores de escala utilizados foram $\lambda_{i}=1.00,0.80,0.60,0.40,0.20$, e 0.00 . O valor final de $\Delta G_{\text {solv }}$ foi obtido como sendo o negativo da soma das energias de aniquilação do potencial de Coulomb $\left(\Delta G_{\text {solv }}^{\text {ele }}=-G_{r^{-1}}^{\text {annih }}\right)$, do termo atrativo do potencial LJ $\left(\Delta G_{\text {solv }}^{v d W}=-G_{r^{-6}}^{a n n i h}\right)$ e do termo repulsivo do potencial LJ $\left(\Delta G_{\text {solv }}^{\text {cav }}=-G_{r^{-12}}^{\text {annih }}\right)$. A soma dos dois últimos termos é chamado de termo não eletrostático, $\Delta G_{\text {solv }}^{\text {nele }}=\Delta G_{\text {solv }}^{v d W}+\Delta G_{\text {solv }}^{\text {cav }}$. O valor total da energia livre de solvatação foi obtido como: $\Delta G_{\text {solv }}=\Delta G_{\text {solv }}^{\text {ele }}+\Delta G_{\text {solv }}^{\text {nele }}$.

Cada simulação MC foi iniciada a partir de uma configuração pré-termalizada, com parâmetros LJC íntegros, e consistiu de uma fase de termalização com $2.0 \times 10^{5}$ ciclos MC e produção com $5.0 \times 10^{5}$ ciclos MC. Utilizamos a técnica de amostragem de Metropolis e procedimentos

\footnotetext{
* Simulações realizadas para uma molécula de soluto e 4000 moléculas de água em uma caixa cúbica com aproximadamente $50 \AA$ de lado, a uma pressão $P=1 \mathrm{~atm}$ e temperatura de $T=298 \mathrm{~K}$.

† Neste caso, a dupla amostragem não é utilizada, realizamos perturbações apenas para reduzir $\sigma_{i}$, para evitar variações de energia muito grandes, que levam a termos divergentes no cálculo de $\Delta G_{s o l v}$.
} 
padrões, tais como: método da mínima imagem, condições de contorno periódicas e correção de longo alcance. ${ }^{[180]}$ Todas as interações foram computadas dentro de um raio de corte de aproximadamente 23 Angstrom. Durante as simulações, o soluto e as moléculas do solvente foram tratadas como moléculas rígidas. Nas simulações dos complexos de $R u$-Aqua/Oxo coordenados com uma molécula de água, $\mathrm{Ru}^{I I} \mathrm{H}_{2} \mathrm{O}$ e $\mathrm{Ru} u^{I I I} \mathrm{H}_{2} \mathrm{O}$, tratamos a molécula de água coordenada como parte do soluto, na geometria otimizada em solução. Informações adicionais sobre os campos de força adotados encontram-se descritas na seção 4.4.

\subsubsection{Procedimento via BAR-MD}

Para obter $\Delta G_{\text {solv }}$ dos complexos utilizando o método BAR, calculamos a energia livre de criação do soluto em várias simulações MD*. Primeiro, parametrizamos as energias de interação não-ligadas entre o soluto e o solvente por um fator de reescalonamento $\lambda(0<\lambda<1)$, onde $\lambda=0$ significa interações totalmente desligadas e $\lambda=1$ significa interações totalmente ligadas. Ao todo, usamos 20 fatores $\lambda$ para reduzir as interações coulombianas $(\lambda=0.05,0.1,0.15$, $0.2,0.25,0.3,0.35,0.4,0.45,0.5,0.55,0.6,0.65,0.7,0.75,0.8,0.85,0.9,0.95,1.0)$ e 10 fatores $\lambda$ para reduzir as interações de van der Waals $(\lambda=0.1,0.2,0.3,0.4,0.5,0.6,0.7$, $0.8,0.9,1.0)$. Para calcular o valor da energia livre de solvatação, utilizamos as diferenças de energia potencial entre cada simulação com fatores $\lambda$ vizinhos como valores de entrada para o método Bennet Acceptance Ratio ${ }^{[163]}$ (BAR). Da variação de energia livre calculada a partir da redução das interações coulombianas obtivemos a contribuição eletrostática para a energia livre de solvatação $\Delta G_{\text {solv }}^{\text {ele }}$. Da variação de energia livre calculada a partir da redução das interações de van der Walls obtivemos a contribuição não-eletrostática para a energia livre de solvatação $\Delta G_{\text {solv }}^{\text {nele }}$. Somando essas contribuições, obtivemos a energia livre de solvatação total $\Delta G_{\text {solv }}=\Delta G_{\text {solv }}^{\text {ele }}+\Delta G_{\text {solv }}^{\text {nele }}$. O método BAR foi aplicado usando o comando gmx bar disponível no pacote GROMACS 5.1.4.

Para cada fator $\lambda$, partimos de uma configuração pré-termalizada, com parâmetros LJC íntegros, e realizamos $1 \mathrm{~ns}$ de termalização $\mathrm{MD}$ e $3 \mathrm{~ns}$ de produção MD. Utilizamos o barostato de Berendsen ${ }^{[134]}$ com constante de acoplamento de 2 ps, para o controle da pressão. Computamos as interações não-ligadas dentro de um raio de corte de $17 \AA$, e aplicamos correções de longo alcance com o método Particle Mesh Ewald (PME) ${ }^{[181]}$, com interpolação cúbica e espaçamento de grid de $14 \AA$ A. Adotamos a versão estocástica do integrador Leapfrog ${ }^{[197]}$, designada no programa GROMACS 5.1.4 pela sigla sd, e, dadas as condições de funcionamento desse integrador, desativamos a função do termostato. Integramos as equações de movimento em intervalos de tempo de $2 f s$, usando restrições para as ligações $H$ pelo algoritmo LINCS $^{[127]}$. Removemos os movimentos do centro de massa do sistema soluto/solvente linearmente a cada $200 \mathrm{fs}$. Durante as simulações, a molécula de água coordenada em $\mathrm{Ru} u^{I I} \mathrm{H}_{2} \mathrm{O}$ e $\mathrm{Ru}{ }^{I I I} \mathrm{H}_{2} \mathrm{O}$ foi tratada como parte do soluto, na geometria otimizada em solução. Informações adicionais

\footnotetext{
* Simulações realizadas para uma molécula de soluto e 4000 moléculas de água em uma caixa cúbica com aproximadamente $50 \AA$ de lado, a uma pressão $P=1 \mathrm{~atm}$ e temperatura de $T=298 \mathrm{~K}$.
} 
sobre os campos de força adotados encontram-se descritas na seção 4.4.

Todos os cálculos envolvidos no procedimento BAR-MD foram repetidos em três condições adicionais: (1) utilizando novas cargas atômicas, calculadas com o método CHELPG mas considerando os efeitos de polarização do solvente pelo método atomístico ASEC ${ }^{[148]}$; (2) utilizando novas cargas atômicas, calculadas com o método de Hirshfeld $\mathrm{CM}^{[111,115]}$, e considerando os efeitos de polarização do solvente pelo modelo PCM; (3) Adicionando uma concentração de 0.1 molar de Nitrato de Potássio nas simulações padrões, em que adotamos as cargas CHELPG polarizadas por PCM. A configuração ASEC, de cada complexo, foi gerada a partir da superposição de 200 configurações estatisticamente descorrelacionadas das simulações MC. Para atingir a concentração de 0.1 molar, adicionamos 7 pares $K^{+} \mathrm{NO}_{3}^{-}$para cada 4000 mil moléculas de água. Obtivemos a geometria otimizada de $\mathrm{NO}_{3}^{-}$à nivel MP2/cc-pVTZ, cargas atômicas CHELPG com polarização PCM em água, e adotamos os parâmetros ligados e não-ligados (LJ) do campo de força UFF. Para o $K^{+}$, adotamos o modelo proposto por Smith e Dang ${ }^{[198]}$.

\subsubsection{Procedimento via DFT}

Num primeiro momento, obtivemos $\Delta G_{\text {solv }}$ dos complexos por mecânica quântica, utilizando o método de Hartree Fock, funcionais DFT (B3LYP, MO5-2X ${ }^{[199]}$ ), e os modelos contínuos de solvente PCM e SMD ${ }^{[146]}$. Realizamos três tipos de cálculo: (1) Utilizando o método Hartree Fock com o conjunto de funções base $6-31+\mathrm{G}(\mathrm{d}),{ }^{[200]}$ e aug-cc-pVDZ/PP para $R u$, e o modelo contínuo PCM com a cavidade do soluto gerada segundo os raios atômicos UAHF ${ }^{[201]}$ (United Atom for Hartree-Fock); (2) Método B3LYP com o conjunto de funções base 6-31G*[200], e aug-cc-pVDZ/PP para Ru e o modelo contínuo SMD; Método M05-2X ${ }^{[199]}$ com o conjunto de funções base 6-31G*, e aug-cc-pVDZ/PP para $R u$, e o modelo contínuo SMD.

\subsection{Excitações eletrônicas}

Os cálculos de excitações eletrônicas foram realizados utilizando-se a teoria do funcional de densidade dependente do tempo (TD-DFT). Num primeiro momento, realizamos um pequeno estudo de benchmark para verificar os efeitos que a escolha de funcional e conjunto de funções base acarretariam nos cálculos das excitações eletrônicas, e tão logo na descrição dos espectros de absorção UV-Vis experimentais. Realizamos esse estudo comparativo apenas para o complexo $R u^{I I}\left(\mathrm{H}_{2} \mathrm{O}\right)$ em solução aquosa (via PCM), utilizando o conjunto de funções

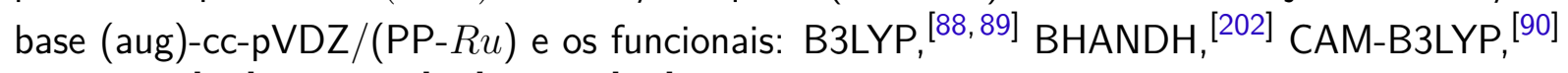
LC-wPBE, ${ }^{[203]}$ M06-2X, ${ }^{[118]}$ PBE0. ${ }^{[204]}$ Adicionalmente, realizamos o cálculo de excitações eletrônicas via TD-(Hartree Fock) ${ }^{[205]}$ e via o método de interação de configurações simples (CIS ${ }^{[206]}$ - Configuration Interaction Singles). Desse estudo, definimos o funcional B3LYP para os cálculos subsequentes. 
Fixando o funcional B3LYP, testamos vários conjuntos de funções base, novamente apenas para o complexo $\mathrm{Ru}^{I I}\left(\mathrm{H}_{2} \mathrm{O}\right)$ em solução aquosa (via PCM). As bases testadas podem ser classificadas em três categorias: (1) all-electron/ECP, onde todos os elétrons de átomos de $C$, $O, N$ e $H$ são tratados explicitamente e os elétrons do atómo de $R u$ são em parte tratados por um potencial efetivo de caroço (ECP - Effective Core Potential; (2) all-electron, onde todos os elétrons são tratados explicitamente; (3) all-electron $D K H$, onde todos os elétrons são tratados explicitamente, por funções base que receberam correções relativísticas do tipo DouglasKroll-Hess (DKH). Nos cálculos que envolveram correções DKH, também fizemos a adição da correção DKH de ordem zero no hamiltoniano do soluto ${ }^{[207,208]}$. Segue a lista de bases testadas: (1) cc-pVDZ/(PP-Ru $)^{[106,179]}$, cc-pVTZ/(PP-Ru ${ }^{[106,209]}$, cc-pVQZ/(PP-Ru $)^{[106,210]}$, (aug)cc-pVDZ/(PP-Ru $)^{[106,179]}$, (aug)-cc-pVTZ/(PP-Ru ${ }^{[106,209]}$, LANL2DZ $^{[211]}$, DEF2TZVP ${ }^{[212]}$,

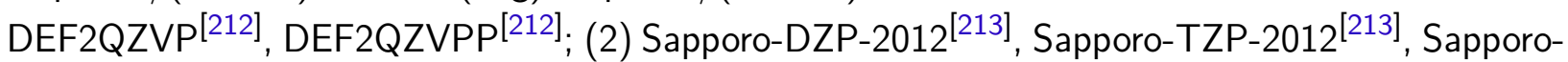
QZP-2012 ${ }^{[213]}$; (3) Jorge-ADZP ${ }^{[214]}$, Jorge-ATZP ${ }^{[214]}$, Jorge-AQZP ${ }^{[214]}$, ANO-RCC-VDZP ${ }^{[215]}$. Na notação adotada, (aug) significa que funções difusas foram adicionadas apenas aos átomos pesados $(C, O, N, R u)$ e (PP- $R u)$ significa que o potencial efetivo cc-pVXZ/PP (X $=\mathrm{D}, \mathrm{T}, \mathrm{Q})$, com ou sem funções difusas, foi adotado para o átomo $R u$. Para qualquer um dos potenciais efetivos adotados, o número de elétrons tratados implicitamente é de 30 $\left(1 s^{2} 2 s^{2} 2 p^{6} 3 s^{2} 3 p^{6} 4 s^{2} 3 d^{10}\right)$. De todos esses testes, definimos a combinação B3LYP/(aug)-ccpVDZ/(PP-Ru) como sendo a ideal para os cálculos subsequentes. Os resultados de todos esses testes encontram-se apresentados na figura 7.4 e tabela 7.3.

Utilizando o método B3LYP e o conjunto de funções base (aug)-cc-pVDZ/(PP-Ru), realizamos os cálculos das excitações eletrônicas dos 5 complexos de $R u$-Aqua/Oxo, na condição de vácuo e em solução. Para cada complexo, calculamos as 50 primeiras excitações eletrônicas. Para tratar os efeitos do solvente utilizamos 3 abordagens diferentes, as quais denominaremos por PCM, PC e $\mathrm{HB}+\mathrm{PC}$ :

- PCM - Aqui utilizamos simplesmente o modelo contínuo polarizável PCM para tratar as interações soluto-solvente, com o soluto na geometria otimizada em solução aquosa (via PCM). Realizamos portanto 5 cálculos TD-B3LYP com a base (aug)-cc-pVDZ/(PP-Ru).

- PC - Nessa abordagem, selecionamos uma centena de configurações do sistema solutosolvente, estatisticamente descorrelacionadas, segundo a função de auto-correlação da energia, na fase de produção das simulações de MC (ou MD). Utilizando o critério de mínima distância entre o soluto e as moléculas do solvente, selecionamos em cada configuração, o soluto e as 500 primeiras moléculas de água mais próximas do soluto ( $r=12 \AA$ na MDDF soluto/solvente), incluindo assim efeitos do solvente além das duas primeiras camadas de solvatação. Para cada configuração (soluto +500 moléculas de $\mathrm{H}_{2} \mathrm{O}$ ) realizamos o cálculo das 50 primeiras excitações eletrônicas, tratando o soluto quanticamente e as moléculas do solvente como cargas pontuais interagentes. É comum a referência à essa aproximação pela expressão "banho eletrostático"do soluto. Realizamos portanto $5 \times 100$ cálculos TD-B3LYP com a base (aug)-cc-pVDZ/(PP-Ru). 
- $\mathrm{HB}+\mathrm{PC}$ - Assim como na abordagem PC, selecionamos uma centena de configurações do sistema soluto-solvente, estatisticamente descorrelacionadas, segundo a função de auto-correlação da energia, na fase de produção das simulações de MC (ou MD). E utilizando o critério de mínima distância entre o soluto e as moléculas do solvente, selecionamos em cada configuração, o soluto e as 500 primeiras moléculas de água mais próximas do soluto ( $r=12 \AA$ na MDDF soluto/solvente). Para cada configuração realizamos o cálculo das 50 primeiras excitações eletrônicas, tratando o soluto e as moléculas do solvente que realizam ligações de hidrogênio com o soluto quanticamente, e as demais moléculas do solvente como cargas pontuais interagentes. Logo, realizamos outros $5 \times 100$ cálculos TD-B3LYP com a base (aug)-cc-pVDZ/(PP-Ru).

As estratégias de inclusão de efeitos do solvente $\mathrm{PC}$ e $\mathrm{HB}+\mathrm{PC}$ seguem o protocolo do método S-QM/MM (ver seção 3.5). Faz-se inicialmente a simulação clássica de todo o sistema, obtêm-se um ensemble de equilíbrio, seleciona-se configurações estatisticamente relevantes, e faz-se os cálculos quânticos das propriedades de interesse nesse conjunto de configurações. Para o cálculo de espectros de absorção, a abordagem S-QM/MM é uma poderosa ferramenta, já que permite desde a descrição do posicionamento dos picos de absorção como também do alargamento homogêneo e não-homogêneo das bandas.

\subsection{Energia de ligação de elétrons de camadas profundas}

As energias de ligação (BE - Binding Energy) dos elétrons de camada profunda dos complexos de Ru-Aqua/Oxo foram calculadas usando a teoria de estado de transição de SlaterJanaK ${ }^{[100]}$, descrita na seção 2.5. Esses cálculos foram realizados no vácuo e em solução aquosa (seguindo um protocolo S-QM/MM). Das simulações de MC, extraímos 20 configurações representativas do sistema soluto-solvente para serem utilizadas nos cálculos de BE em solução. Nessas configurações selecionamos o soluto e as 70 moléculas de água mais próximas do soluto (primeira camada de solvatação completa), por um critério de mínima distância. Para essas configurações, e tratando-se todas as moléculas quanticamente, calculou-se as energias de ligação dos elétrons dos orbitais $3 d_{3 / 2}$ e $3 d_{5 / 2}$ do átomo de $R u$, e dos orbitais $1 s$ dos átomos de carbono. Considerando que cada complexo tem 25 átomos de carbono e 1 átomo de rutênio, foram feitos $20 \times 25$ cálculos de BE para átomos de carbono e $20 \times 2$ cálculos de BE para o átomo de rutênio, para cada complexo em solução. Adicionalmente, para contabilizar os efeitos apenas das ligações de hidrogênio nas energias de ligação BE, repetiu-se esses cálculos excluindo, em cada configuração, as moléculas de água além da camada de micro-solvatação.

A teoria de Slater-Janak foi aplicada utilizando-se o funcional $\mathrm{PBE}^{[216]}$ e o método Projected Augmented Wave (PAW) ${ }^{[217]}$, no programa Vienna Ab-initio Simulation Package (VASP) ${ }^{[218]}$. É importante deixar claro que os cálculos de BE foram realizados pelo Dr. Jose Luis Silva sob a orientação do Prof. C. Moyses Araujo, ambos do Departamento de Física e Astronomia da Universidade de Uppsala. 


\section{8 $\mathrm{pKa}$ e potencial redox}

As propriedades $p K a$ e potencial redox $\left(V^{o x}\right)$ foram calculadas dentro da aproximação de ciclos termodinâmicos, utilizando a expressão que relaciona o $p K a$ com a energia livre em solução (equação 3.56) e utilizando a equação de Nerst (equação 3.60) para calcular $V^{o x}$. Os ciclos termodinâmicos utilizados encontram-se apresentados na figura 4.2. Investigamos as reações de oxidação (1) e (2); as reações de desprotonação (3) e (4); e as reações acopladas de oxidação e desprotonação (5) e (6); apresentadas a seguir.

- (1) $\left[R u^{I I}\left(H_{2} O\right)\right]^{2+} \rightarrow\left[R u^{I I I}\left(H_{2} O\right)\right]^{3+}+1 e^{-}$

- (2) $\left[R u^{I I}(O H)\right]^{1+} \rightarrow\left[R u^{I I I}(O H)\right]^{2+}+1 e^{-}$

- (3) $\left[R u^{I I}\left(H_{2} O\right)\right]^{2+} \rightarrow\left[R u^{I I}(O H)\right]^{1+}+1 H^{+}$

- (4) $\left[R u^{I I I}\left(H_{2} O\right)\right]^{3+} \rightarrow\left[R u^{I I I}(O H)\right]^{2+}+1 H^{+}$

- (5) $\left[R u^{I I}\left(H_{2} O\right)\right]^{2+} \rightarrow\left[R u^{I I I}(O H)\right]^{2+}+1 H^{+}+1 e^{-}$

- (6) $\left[R u^{I I I}(O H)\right]^{2+} \rightarrow\left[R u^{I V}(O)\right]^{2+}+1 H^{+}+1 e^{-}$

A fim de compreender os efeitos da escolha do método QM e do conjunto de funções base na energia livre de vácuo $\left(G_{v a c}\right)$, fizemos dois testes preliminares: $(1)$ calculamos as variações de energia livre de vácuo nas reações de oxidação e desprotonação apresentadas acima, com vários métodos: M06-2X, ${ }^{[118]}$ PBE0, ${ }^{[204]} \mathrm{B} 3 \mathrm{LYP},{ }^{[88,89]} \mathrm{MP} 2,{ }^{[219,220]} \mathrm{MP} 4(\mathrm{SDQ})^{[221]}$; (2) fixamos o funcional B3LYP e calculamos as variações de energia eletrônica para diferentes conjuntos de funções base: (aug)-cc-pVDZ/(PP-Ru) ${ }^{[106,179]}$, (aug)-cc-pVTZ/(PP-Ru) ${ }^{[106,209]}$, (aug)cc-pVQZ/(PP-Ru $)^{[106,210]}$, DEF2-QZVPP ${ }^{[212]}$, ANO-RCC-VDZP $^{[215]}$, Jorge-AQZP ${ }^{[214]}$. Para $\Delta G_{\text {solv }}$, utilizamos todos os valores obtidos com os métodos PCM, SMD, FEP-MC e BAR-MD. Tal como encontra-se descrito na seção 4.5.

Para o íon $H^{+}$calculamos $G_{v a c}$ utilizando a reação de equilíbrio $\mathrm{H}_{2} \mathrm{O} \rightarrow \mathrm{OH}^{-}+\mathrm{H}^{+}$, em que $\Delta G_{v a c}\left(H_{2} O \rightarrow O H^{-}+H^{+}\right)=G_{v a c}\left(O H^{-}\right)+G_{v a c}\left(H^{+}\right)-G_{v a c}\left(H_{2} O\right)$. Otimizamos as moléculas $\mathrm{H}_{2} \mathrm{O}$ e $\mathrm{OH}^{-}$em nível $\operatorname{CCSD}(\mathrm{T})^{[222]}$ com o conjunto de funções base augcc-pV5Z ${ }^{[223]}$, e calculamos as correções de ponto zero, correções térmicas e entálpicas no mesmo nível de cálculo. Logo, determinamos o valor de $G_{v a c}$ do íon $H^{+}$, em $-4.45 \mathrm{kcal} / \mathrm{mol}$, utilizando o valor experimental $\Delta G_{v a c}\left(H_{2} O \rightarrow O H^{-}+H^{+}\right)=385.6 \pm 0.2 \mathrm{kcal} / \mathrm{mol}^{[224,225]}$. Da literatura, extraímos também $\left.\Delta G_{\text {solv }}\left(H^{+}\right)=-265.9 \mathrm{kcal} / \mathrm{mol}\right)^{[226]}$. Para o elétron, adotamos valores nulos para $G_{v a c}\left(e^{-}\right)$e $\Delta G_{\text {solv }}\left(e^{-}\right)$.

Adicionalmente, incluímos em $\Delta G_{\text {solv }}$ a energia relativa às mudanças geométricas $\left(\Delta E_{\text {geom }}\right)$ e a energia relativa à polarização da função de onda $\left(\Delta E_{p o l}\right)$, do vácuo para a solução, como sugerido na referência ${ }^{[169]}$, isto é: $\Delta G_{\text {solv }}=\Delta G_{\text {solv }}^{\text {ele }}+\Delta G_{\text {solv }}^{\text {nele }}+\Delta E_{\text {geom }}+\Delta E_{\text {pol }} . \Delta E_{\text {geom }}$ foi obtida apenas subtraindo as energias eletrônicas (de vácuo) dos complexos nas geometrias 


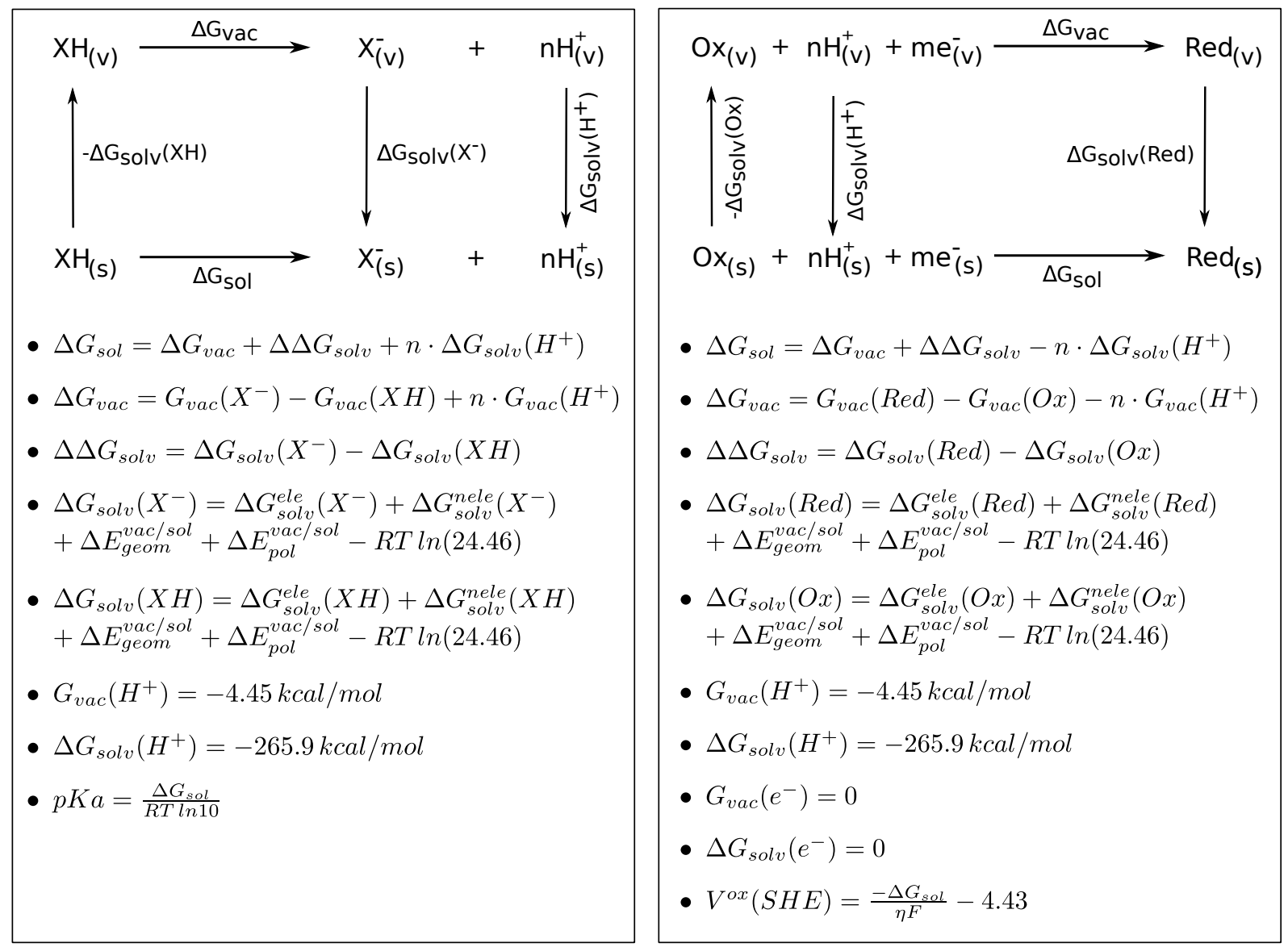

Figura 4.2 - Ciclos termodinâmicos utilizados nos cálculos de $p K a$ (à esquerda) e $V^{o x}$ (à direita) dos complexos de $R u$-Aqua/Oxo em solução aquosa. As letras $n$ e $m$ representam o número de prótons e elétrons trocados nas reações, respectivamente.

otimizadas no vácuo e em solução. $\Delta E_{\text {pol }}$ foi obtida como a diferença da energia eletrônica com a função de onda polarizada em água $\left(\Psi_{\text {pol }}\right)$ e da energia eletrônica com a função de onda de vácuo $\left(\Psi_{v a c}\right), \Delta E_{p o l}=\left\langle\Psi_{p o l}\left|H_{0}\right| \Psi_{p o l}\right\rangle-\left\langle\Psi_{0}\left|H_{0}\right| \Psi_{0}\right\rangle$, onde $H_{0}$ é o Hamiltoniano do soluto isolado. 


\section{Capítulo}

\section{Geometria, polarização, e campo de força}

Neste capítulo apresentaremos resultados sobre estrutura conformacional, polarização, e campo de força para $R u$ nos complexos de $R u$-Aqua/Oxo. Exploraremos os efeitos do solvente e de processos de oxidação e desprotonação nas geometrias dos complexos e nas suas distribuições de cargas atômicas. Discorreremos sobre o desenvolvimento de campos de força para o átomo de $R u$ em ambientes de coordenação Aqua/polipiridínicos, e apresentaremos uma proposta de parametrização baseada no potencial de Lennard-Jones-Coulomb (LJC) para o átomo de $R u$ em diferentes estados de oxidação (II, III e IV).

\subsection{Geometria dos complexos de Ru-Aqua/Oxo}

Os complexos de $R u$-Aqua/Oxo estudados neste trabalho apresentam uma geometria octaédrica, com um átomo de $R u$ hexa-coordenado à seis átomos eletronegativos. Na figura 5.1 ilustramos o complexo $\mathrm{Ru} u^{I I}\left(\mathrm{H}_{2} \mathrm{O}\right)$. Os átomos de nitrogênio das bipiridinas (bpy 1 e bpy2) e da piridina $(p y)$ juntos ao oxigênio de uma molécula de água podem ser visualizados nos vértices de um octaedro não regular. Os átomos $O, N_{11}, N_{3}$ e $N_{19}$ encontram-se posicionados nos vértices da base do octaedro, com $O$ diagonalmente oposto a $N_{11}$ e $N_{3}$ diagonalmente oposto a $N_{19}$. Adicionalmente, o átomo $N_{45}$ da piridina e o átomo $N_{25}$ do grupo bpy2 encontram-se posicionados nos demais vértices opostos do octaedro.

Essa conformação octaédrica, com um centro metálico positivo hexa-coordenado com nitrogênios de polipiridinas, confere estabilidade estrutural aos complexos de $R u$-Aqua/Oxo, fazendo com que apresentem uma estrutura molecular pouco flexível. No entanto, a solvatação dos complexos, a perda de prótons e, ou, a perda de elétrons, podem provocar mudanças estruturais importantes. Essas mudanças afetam principalmente o posicionamento dos átomos ligantes na esfera de coordenação do átomo de $R u$. Nesta seção iremos discutir as mudanças estruturais dos complexos de Ru-Aqua/Oxo devido a: solvatação dos complexos em água; oxidação do átomo de $R u$; desprotonação da molécula de água coordenada a $R u$. 


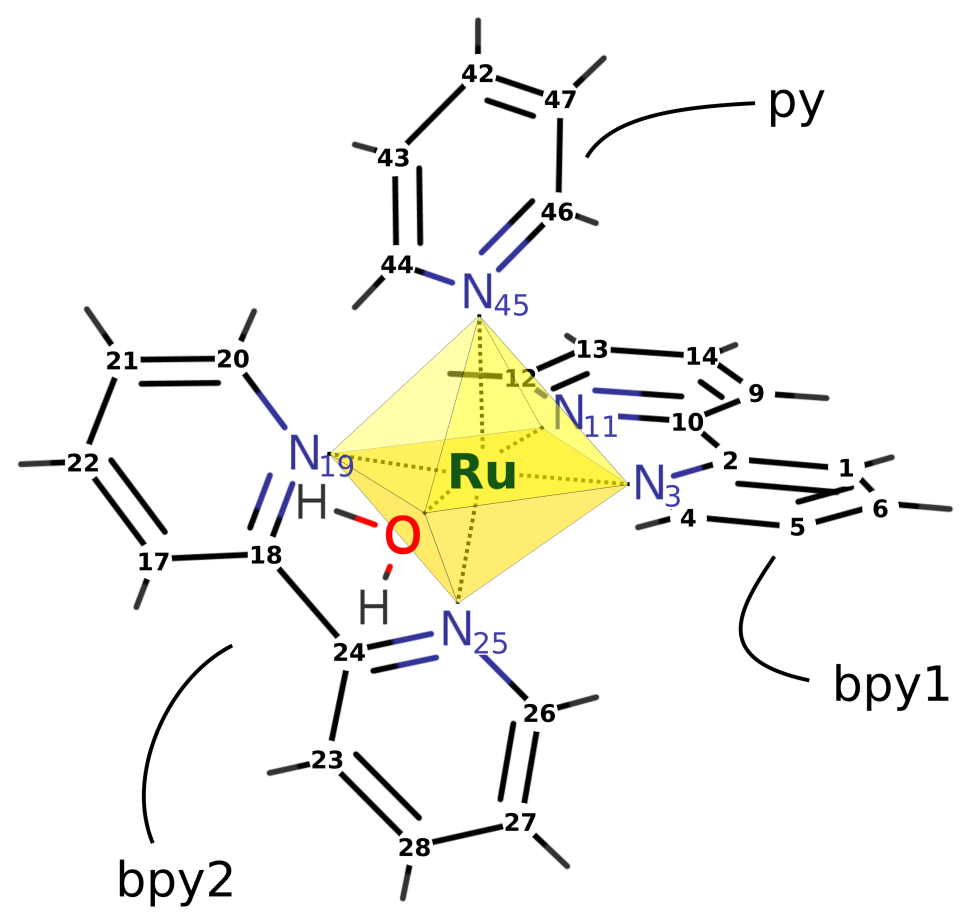

Figura 5.1 - Ilustração em 3D da estrutura molecular do complexo $R u^{I I}\left(H_{2} O\right)$. Os átomos $N_{3}, N_{11}, N_{19}$ e $O$ encontram-se no mesmo plano, e a composição desses átomos com os nitrogênios $N_{25}$ e $N_{45}$ dão forma a um octaedro não regular.

\subsubsection{Comparação com dados de cristalografia}

Os complexos de $R u$-Aqua/Oxo aqui estudados apresentam semelhanças com um outro complexo de $R u$ bastante estudado na literatura, o $R u^{I I} \operatorname{Tris}\left(2,2^{\prime}-b p y\right) .{ }^{[227-230]}$ Subtituindo a molécula de água e o grupo piridina no complexo $R u^{I I}\left(H_{2} O\right)$ por uma bipiridina, obtemos o complexo $\operatorname{Ru}{ }^{I I} \operatorname{Tris}\left(2,2^{\prime}-b p y\right)$, ilustrado na figura 5.2. Dadas as semelhanças, e dado que encontra-se disponível na literatura informações cristalográficas sobre o complexo $R u^{I I} \operatorname{Tris}\left(2,2^{\prime}-b p y\right),{ }^{[231]}$ podemos então iniciar a nossa discussão fazendo uma comparação estrutural entre a geometria otimizada no vácuo do complexo $R u^{I I}\left(\mathrm{H}_{2} \mathrm{O}\right)$ e a geometria cristalográfica do composto $\operatorname{Ru}{ }^{I I} \operatorname{Tr} i s\left(2,2^{\prime}-b p y\right)$.

Apresentamos na tabela 5.1 os comprimentos de ligação e ângulos relacionados ao posicionamento dos 6 átomos coordenados ao centro metálico, em cada complexo. No caso do complexo $R u^{I I}$ Tris $\left(2,2^{\prime}-b p y\right)$, todos os átomos que se coordenam com $R u$ são nitrogênios de bipiridina, mas no caso do complexo $R u^{I I}\left(H_{2} O\right)$, temos 4 nitrogênios de bipiridina, um nitrogênio de piridina, e um átomo de oxigênio de uma molécula de água. Destacamos com um asterísco na tabela 5.1 as distâncias e ângulos que não são exatamente equivalentes nos dois complexos comparados. 

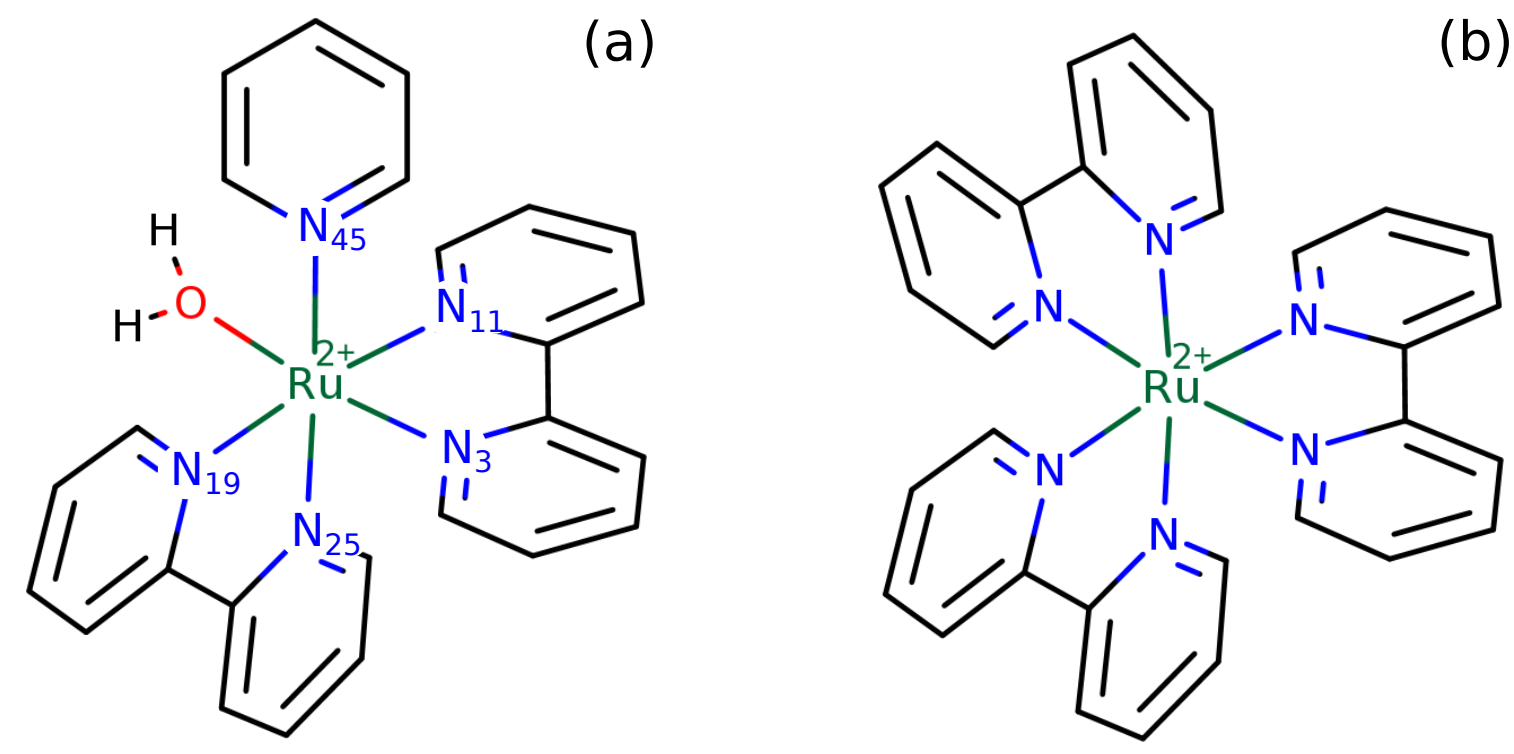

Figura 5.2 - llustração da estrutura molecular dos complexos $R u^{I I}\left(H_{2} O\right)$ (a) e $R u^{I I} \operatorname{Tris}\left(2,2^{\prime}-b p y\right)$ (b).

Tabela 5.1 - Comparação estrutural entre a geometria otimizada de vácuo do complexo $R u^{I I}\left(\mathrm{H}_{2} \mathrm{O}\right)$, usando a aproximação B3LYP/aug-cc-pVDZ(PP), e a geometria cristalográfica do complexo $\operatorname{Ru}{ }^{I I} \operatorname{Tr} i s\left(2,2^{\prime}-b p y\right)$. Distâncias $(r)$ em $\AA$ e ângulos (a) em graus. O parâmetro $|\Delta|$ representa o módulo da diferença dos parâmetos (par) nos dois complexos, ou seja $|\Delta|=\left|\operatorname{par}^{R u^{I I} \operatorname{Tris}\left(2,2^{\prime}-b p y\right)}-\operatorname{par}^{R u^{I I}\left(H_{2} O\right)}\right|$.

\begin{tabular}{cccc}
\hline par & $R u^{I I}\left(H_{2} O\right)$ & $\mathrm{Ru}^{I I}$ Tris(2,2'-bpy $)$ & $|\Delta|$ \\
\hline$r\left(R u-N_{11}\right)$ & 2.043 & $2.056(3)$ & 0.013 \\
$r\left(R u-N_{3}\right)$ & 2.084 & $2.056(3)$ & 0.028 \\
$r\left(R u-N_{19}\right)$ & 2.107 & $2.059(3)$ & 0.048 \\
$r(R u-O)$ & 2.242 & $2.059(3)^{*}$ & 0.183 \\
$r\left(R u-N_{25}\right)$ & 2.088 & $2.060(3)$ & 0.028 \\
$r\left(R u-N_{45}\right)$ & 2.149 & $2.060(3)^{*}$ & 0.089 \\
$a\left(N_{11}-R u-N_{3}\right)$ & 78.9 & $78.7(2)$ & 0.2 \\
$a\left(N_{11}-R u-N_{19}\right)$ & 99.1 & $97.9(1)$ & 1.2 \\
$a\left(N_{11}-R u-O\right)$ & 174.2 & $172.6(1)^{*}$ & 1.6 \\
$a\left(N_{11}-R u-N_{25}\right)$ & 90.4 & $92.0(1)$ & 1.6 \\
$a\left(N_{3}-R u-N_{25}\right)$ & 97.8 & $94.9(1)$ & 2.9 \\
$a\left(N_{19}-R u-N_{25}\right)$ & 78.1 & $78.5(1)$ & 0.4 \\
$a\left(O-R u-N_{19}\right)$ & 86.5 & $86.3(1)$ & 0.2 \\
$a\left(N_{19}-R u-N_{45}\right)$ & 97.5 & $94.8(1)^{*}$ & 2.7 \\
$a\left(N_{25}-R u-N_{45}\right)$ & 175.4 & $171.0(1)^{*}$ & 4.4 \\
\hline
\end{tabular}


Apesar das diferenças nos grupos ligantes, notamos que a estrutura octaédrica da geometria otimizada do complexo $R u^{I I}\left(H_{2} O\right)$ e da geometria cristalográfica de $\operatorname{Ru} u^{I I} \operatorname{Tris}\left(2,2^{\prime}-b p y\right)$ são parecidas. Conforme mostrado na tabela 5.1, as distâncias e ângulos envolvendo $R u$ e os nitrogênios de bipiridina se diferenciam em no máximo $0.048 \AA$ e 2.9 graus.

\subsubsection{Efeitos da solvatação}

Os efeitos da solvatação na estrutura conformacional dos complexos de $R u$-Aqua/Oxo podem ser investigados a partir da simples comparação de parâmetros geométricos (comprimentos de ligação, ângulos e diedros) antes e após a solvatação. Utilizando a teoria DFT dentro da aproximação B3LYP/aug-cc-pVDZ(PP), otimizamos as geometrias dos complexos de $R u$-Aqua/Oxo no vácuo e em solução aquosa, com as interações soluto-solvente tratadas por meio do modelo contínuo PCM. Na tabela 5.2, apresentamos os valores de uma seleção de parâmetros geométricos que mapeiam as mudanças estruturais mais relevantes, e na figura 5.3 apresentamos uma visão global da superposição das geometrias otimizadas no vácuo (VAC) e em solução (SOL), para cada complexo.

Observando as geometrias superpostas na figura 5.3, notamos que a solvatação causa um ligeiro reposicionamento da molécula de água ou do íon hidróxido, e também do grupo piridina, nos complexos de $R u$ com estados de oxidação II e III. No canto superior esquerdo, para cada conjunto de geometrias superpostas, apresentamos o valor do desvio da raiz quadrada média $\mathrm{RMSD}^{\mathrm{VAC} / \mathrm{SOL}}$ (do inglês Root-mean-square deviation). Na ordem, temos RMSD $\mathrm{VAC} / \mathrm{SOL}$ de $0.16,0.14,0.11,0.09$ e 0.01 para os complexos $R u^{I I I}\left(H_{2} O\right), R u^{I I}(O H), R u^{I V}(O)$, $R u^{I I I}(\mathrm{OH})$ e $R u^{I I}\left(\mathrm{H}_{2} \mathrm{O}\right)$, respectivamente. Portanto, da análise de RMSD, observamos que o complexo $\mathrm{Ru}^{I I}\left(\mathrm{H}_{2} \mathrm{O}\right)$ sofre as menores mudanças conformacionais devido aos efeitos do solvente e que o complexo de maior carga, $R u^{I I I}\left(H_{2} O\right)$ com carga $3+$, sofre as maiores mudanças conformacionais. Do ponto de vista eletrostático, era esperado que o complexo de maior carga viesse a apresentar maiores mudanças conformacionais, já que as interações eletrostáticas entre soluto e solvente são mais intensas. Nessa linha de raciocínio, poderíamos esperar que o complexo de $R u$ de menor carga total, $R u^{I I}(O H)$ com carga $1+$, apresentasse o menor RMSD $\mathrm{VAC} / \mathrm{SOL}$, entretanto não é isso que observamos. Conforme elencamos logo acima, após o complexo $R u^{I I I}\left(H_{2} \mathrm{O}\right)$, o complexo $R u^{I I}(\mathrm{OH})$ é o que apresenta o maior $\mathrm{RMSD}^{\mathrm{VAC} / \mathrm{SOL}}$. Esse resultado nos indica que as tendências nas mudanças geométricas dos complexos não seguem as cargas totais dos mesmos. 
Tabela 5.2 - Comparação estrutural entre as geometrias otimizadas no vácuo (VAC) e em solução (SOL) dos complexos de Ru-Aqua/Oxo, usando a aproximação B3LYP/aug-cc-pVDZ(PP) e o modelo contínuo PCM para tratar efeitos do solvente. Distâncias $(r)$ em $\AA$, ângulos $(a)$ e diedros $(d)$ em graus. O parâmetro $\Delta$ representa a diferença entre os parâmetros (par) geométricos das geometrias otimizadas no vácuo e em solução, ou seja $\Delta=p a r^{S O L}-p^{V A C}$. Na parte de baixo da tabela encontra-se uma legenda para todos os parâmetros geométricos apresentados. Os números dos átomos seguem a numeração apresentada na figura 5.1.

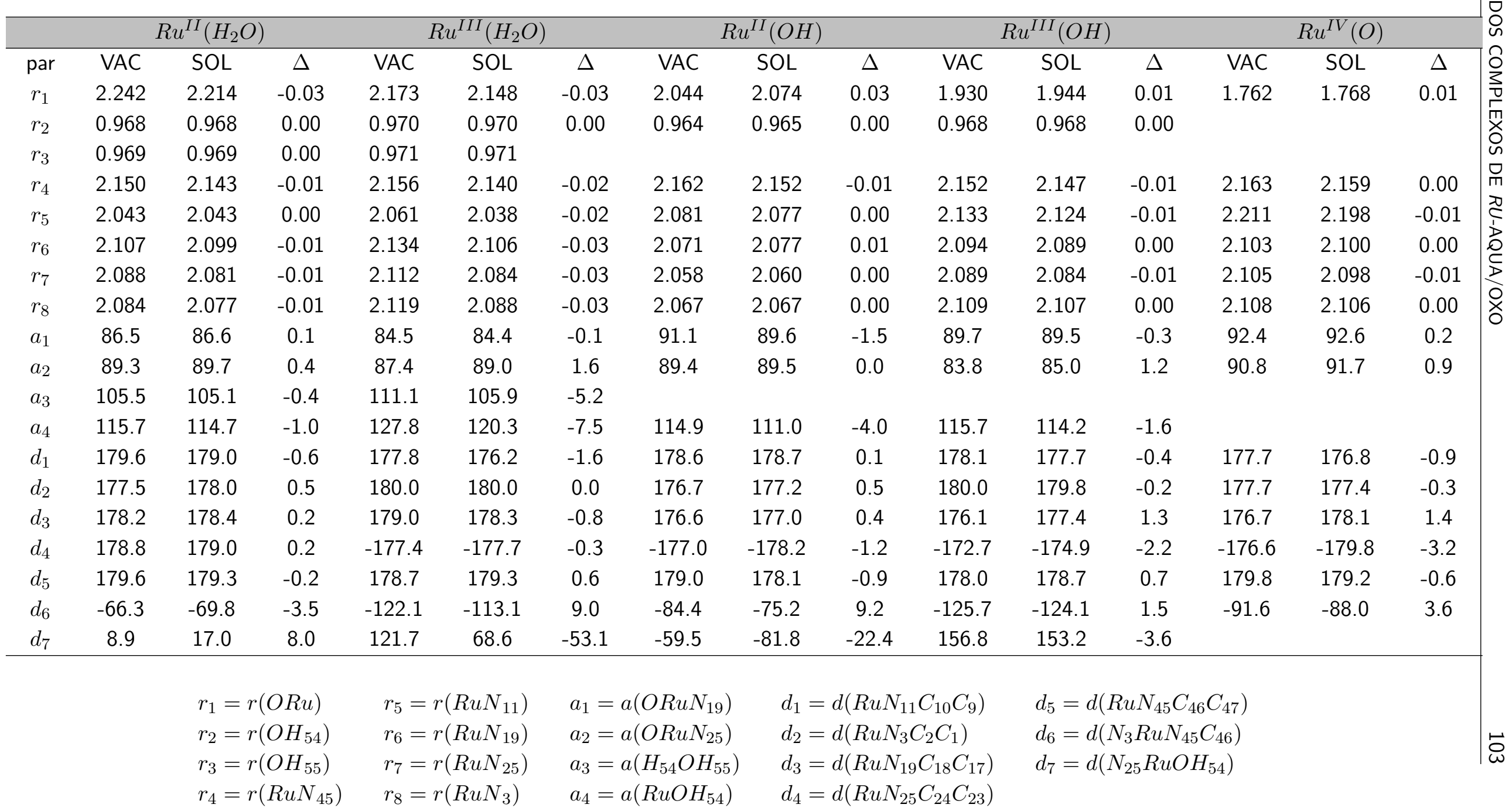



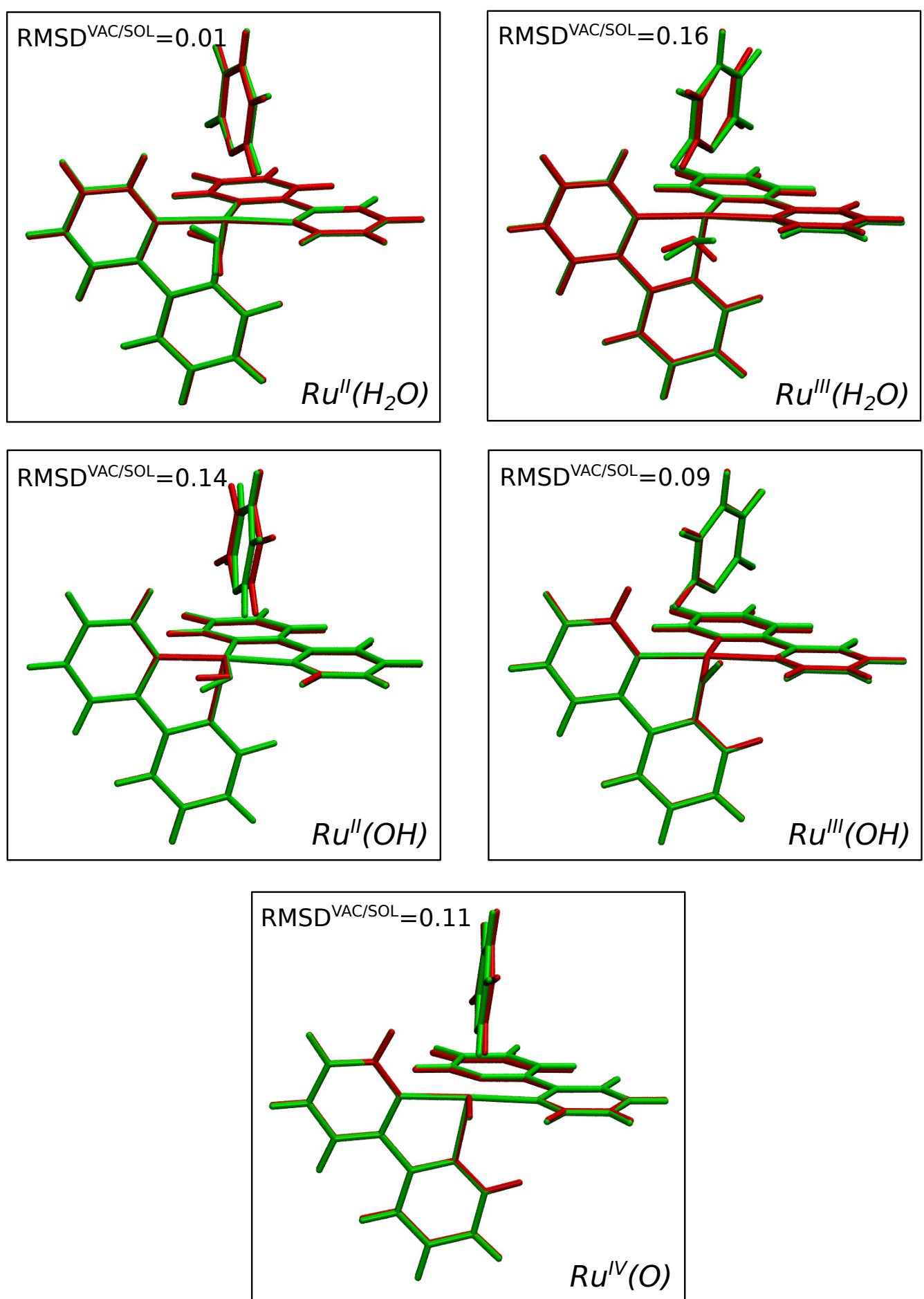

Figura 5.3 - Superposição das geometrias otimizadas em vácuo (verde) e em solução (vermelho). O RMSD $\mathrm{VAC} / \mathrm{SOL}$ é apresentado para cada complexo.

Na tabela 5.2, apresentamos os comprimentos de ligação ( $r$ ), ângulos (a) e diedros (d) que consideramos mais relevantes para se observar os efeitos do solvente nas geometrias. Para cada complexo, apresentamos o parâmetro $\Delta$, que representa a diferença entre os parâmetros geométricos para as geometrias otimizadas no vácuo e em solução, definimos $\Delta=$ par $^{\mathrm{SOL}}-$ par $^{\mathrm{VAC}}$. Portanto, valores negativos de $\Delta$ indicam um diminuição do parâmetro 
geométrico observado e valores positivos de $\Delta$ indicam um aumento do parâmetro geométrico observado.

As principais mudanças geométricas provocadas pelo solvente afetam principalmente o posicionamento relativo dos átomos próximos à esfera de coordenação do centro metálico. Observa-se uma tendência de redução das distâncias $R u-N\left(r_{4}\right.$ a $r_{8}$ na tabela 5.2) em quase todos os complexos, sendo que no caso do complexo $R u^{I I I}\left(H_{2} O\right)$ esse é um comportamento generalizado. Observa-se um redução na distância $R u-O\left(r_{1}\right.$ na tabela 5.2) nos complexos coordenados com uma molécula de aǵua, $R u^{I I}\left(\mathrm{H}_{2} \mathrm{O}\right)$ e $R u^{I I I}\left(\mathrm{H}_{2} \mathrm{O}\right)$, mas nos outros observase o contrário. As distâncias $R u-N$ e $R u-O$ são mais afetadas no complexo $R u^{I I I}\left(H_{2} O\right)$, onde $\Delta$ chega a ser em torno de $0.03 \AA$, enquanto que nos demais, em torno de $0.01 \AA$.

Olhando para as mudanças angulares, notamos que os ângulos e diedros que envolvem o grupo piridina ( $d_{5}$ e $\left.d_{6}\right)$, ou que envolvem a molécula de água coordenada $\left(a_{3}, a_{4}, d_{7}\right)$, ou o íon hidróxido $\left(a_{4}, d_{7}\right)$, são os mais afetados pelos efeitos do solvente. Mais uma vez, o complexo de maior carga, $R u^{I I I}\left(\mathrm{H}_{2} \mathrm{O}\right)$, sofre as maiores mudanças e, seguindo a tendencia observada nos valores de $\mathrm{RMSD}^{\mathrm{VAC} / \mathrm{SOL}}$, o complexo $R u^{I I}(O H)$ é o segundo sistema mais afetado. Nos complexos $R u^{I I I}\left(\mathrm{H}_{2} \mathrm{O}\right)$ e $R u^{I I}\left(\mathrm{H}_{2} \mathrm{O}\right)$, o efeito solvente provoca uma reorientação em torno de 8 e 53 graus $\left(d_{7}\right)$ da molécula de água coordenada, respectivamente. Já no complexo $R u^{I I}(O H)$, observamos uma reorientação em torno de 22 graus do íon hidróxido. Demais ângulos envolvendo ou não o centro metálico são pouco afetados. Os grupos bipiridinas apresentam mudanças angulares $\left(d_{1}\right.$ a $\left.d_{4}\right)$ de no máximo 3.2 graus, demonstrando a rididez dos complexos.

Para termos uma noção da proporção dessas mudanças geométricas, consideremos o comparativo que segue. Uma ligação química típica C-C possui comprimento de aproximadamente $1.5 \AA$ e um ligação típica $C=C$ possui comprimento de aproximadamente $1.3 \AA$. Dessa maneira, uma variação de $0.2 \AA$ no comprimento de uma ligação química entre carbonos pode ser interpretada como uma mudança geométrica drástica, já que seria suficiente para converter completamente uma ligação química simples em dupla. Portanto, uma variação de 0.02 Å num comprimento de ligação qualquer pode ser contabilizado como $10 \%$ do que seria necessário para que ocorresse uma mudança drástica de um comprimento de ligação típico. Para ângulos, podemos utilizar como referência o isomerismo conformacional devido ao efeito Gauche, onde mudanças conformacionais drásticas são observadas devido a rotações de 60 graus. Nesse caso, uma mudança angular de 6 graus pode ser contabilizada como $10 \%$ da rotação que seria necessária para se popular diferentes rotâmeros. Nesse sentido, acreditamos que merecem mais atenção as mudanças geométricas superiores a $0.02 \AA \AA$ ou 6 graus. É claro que essa é apenas uma possível referência, sendo que é importante ter em mente que para determinadas propriedades, mudanças conformacionais menores que essas podem ainda assim ter bastante relevância. 


\subsubsection{Efeitos oxidativos e de $\mathrm{pH}$}

Assim como a solvatação modifica a estrutura conformacional dos complexos, a oxidação do átomo de $R u$ ou a desprotonação da molécula de água coordenada também produz efeitos dessa natureza. Esses processos podem fazer com que o átomo de $R u$ passe a interagir de maneira totalmente diferente com os seus ligantes, levando a reestruturações geométricas significativas. Nesta seção, abordaremos as mudanças estruturais nos complexos de $R u$ causadas por reações de oxidação e desprotonação, em solução aquosa. Investigaremos as reações de oxidação 5.1 e 5.2, as reações de desprotonação 5.3 e 5.4, e a reação acoplada de oxidação e desprotonação 5.5 .

$$
\begin{gathered}
{\left[R u^{I I}\left(\mathrm{H}_{2} \mathrm{O}\right)\right]^{2+} \rightarrow\left[R u^{I I I}\left(\mathrm{H}_{2} \mathrm{O}\right)\right]^{3+}+1 e^{-}} \\
{\left[R u^{I I}(\mathrm{OH})\right]^{1+} \rightarrow\left[R u^{I I I}(\mathrm{OH})\right]^{2+}+1 e^{-}} \\
{\left[R u^{I I}\left(\mathrm{H}_{2} O\right)\right]^{2+} \rightarrow\left[R u^{I I}(O H)\right]^{1+}+1 H^{+}} \\
{\left[R u^{I I I}\left(H_{2} O\right)\right]^{3+} \rightarrow\left[R u^{I I I}(O H)\right]^{2+}+1 H^{+}} \\
{\left[R u^{I I I}(O H)\right]^{2+} \rightarrow\left[R u^{I V}(O)\right]^{2+}+1 H^{+}+1 e^{-}}
\end{gathered}
$$

As mudanças conformacionais mais relevantes são observadas na esfera de coordenação do átomo de $R u$, e principalmente na região de microsolvatação dos complexos. Na tabela 5.3 apresentamos as principais mudanças estruturais causadas pelas reações de oxidação e de desprotonação destacadas acima.

Nas reações de mono-oxidação do tipo $R u^{I I} \rightarrow R u^{I I I}$ (reações 5.1 e 5.2), observamos um distanciamento entre $R u$ e os nitrogênios de polipiridinas $\left(\Delta r_{4}\right.$ a $\left.\Delta r_{8}\right)$, principalmente na reação que envolve os complexos $R u^{I I}(O H)$ e $R u^{I I I}(O H)$ (reação 5.2). Nesse caso em particular, a oxidação leva a um aumento signicativo na distância entre $R u$ e os nitrogênios $N_{11}$ e $N_{3}\left(\Delta r_{5}\right.$ a $\left.\Delta r_{8}\right)$, de 0.05 e $0.04 \AA$, respectivamente. Por outro lado, observamos que a distância entre $R u$ e $O$ reduz drasticamente. Na reação que envolve os complexos coordenados com uma molécula de água (reação 5.1) essa redução $\left(\Delta r_{1}\right)$ é computada em $0.07 \AA ̊$ e na reação que envolve os complexos coordenados com um íon hidróxido (reação 5.2), em $0.13 \AA$. Além do mais, notamos também que o grupo piridina sofre rotações acima de 40 graus após reações de mono-oxidação, mapeadas na tabela 5.3 pelo parâmetro $\Delta d_{6}$.

Nas reações de desprotonação, observamos que as distâncias entre $R u$ e os nitrogênios nem sempre aumentam, já que há exceções como as distâncias entre $R u$ e os nitrogênios $N_{19}$ 
Tabela 5.3 - Principais mudanças estruturais nos complexos de $R u$-Aqua/Oxo devido a processos de oxidação e desprotonação, em solução aquosa. Variações de distâncias $(\Delta r)$ em $\AA$, e de diedros $(\Delta d)$ em graus. Na parte de baixo da tabela encontra-se uma legenda para todos os parâmetros geométricos analisados. Os números dos átomos seguem a numeração apresentada na figura 5.1.

\begin{tabular}{cccccc}
\hline & $R u^{I I}\left(\mathrm{H}_{2} \mathrm{O}\right)$ & $R u^{I I}(\mathrm{OH})$ & $R u^{I I}\left(\mathrm{H}_{2} \mathrm{O}\right)$ & $R u^{I I}\left(\mathrm{H}_{2} \mathrm{O}\right)$ & $R u^{I I I}(\mathrm{OH})$ \\
& $-e \downarrow$ & $-e \downarrow$ & $\downarrow-H^{+}$ & $\downarrow-H^{+}$ & $-e \downarrow-H^{+}$ \\
& $R u^{I I I}\left(H_{2} O\right)$ & $R u^{I I}(\mathrm{OH})$ & $R u^{I I}(\mathrm{OH})$ & $R u^{I I I}(\mathrm{OH})$ & $R u^{I V} O$ \\
\hline$\Delta r_{1}$ & -0.07 & -0.13 & -0.14 & -0.20 & -0.18 \\
$\Delta r_{4}$ & 0.00 & 0.00 & 0.01 & 0.01 & 0.01 \\
$\Delta r_{5}$ & 0.00 & 0.05 & 0.03 & 0.09 & 0.07 \\
$\Delta r_{6}$ & 0.01 & 0.01 & -0.02 & -0.02 & 0.01 \\
$\Delta r_{7}$ & 0.00 & 0.02 & -0.02 & 0.00 & 0.01 \\
$\Delta r_{8}$ & 0.01 & 0.04 & -0.01 & 0.02 & 0.00 \\
$\Delta d_{1}$ & -2.8 & -1.1 & -0.3 & 1.5 & -0.9 \\
$\Delta d_{2}$ & 1.9 & 2.6 & -0.8 & -0.2 & -2.3 \\
$\Delta d_{3}$ & -0.1 & 0.4 & -1.4 & -0.9 & 0.8 \\
$\Delta d_{4}$ & 3.0 & 3.3 & 3.0 & 2.8 & -4.9 \\
$\Delta d_{5}$ & -0.1 & 0.7 & -1.3 & -0.5 & 0.5 \\
$\Delta d_{6}$ & -43.3 & -48.9 & -5.4 & -11.1 & 36 \\
\hline
\end{tabular}

$$
\begin{array}{lll}
r_{1}=r(O R u) & r_{7}=r\left(R u N_{25}\right) & d_{3}=d\left(R u N_{19} C_{18} C_{17}\right) \\
r_{4}=r\left(R u N_{45}\right) & r_{8}=r\left(R u N_{3}\right) & d_{4}=d\left(R u N_{25} C_{24} C_{23}\right) \\
r_{5}=r\left(R u N_{11}\right) & d_{1}=d\left(R u N_{11} C_{10} C_{9}\right) & d_{5}=d\left(R u N_{45} C_{46} C_{47}\right) \\
r_{6}=r\left(R u N_{19}\right) & d_{2}=d\left(R u N_{3} C_{2} C_{1}\right) & d_{6}=d\left(N_{3} R u N_{45} C_{46}\right)
\end{array}
$$

$N_{25}$ e $N_{3}$ para a reação de desprotonação que envolve os complexos $R u^{I I}\left(H_{2} O\right)$ e $R u^{I I}(O H)$ (reação 5.3). Todavia, a redução na distância $R u-O$ é ainda assim observada em todos os casos, e chega a ser de $0.14 \AA$ na reação que envolve os complexos com estado de oxidação II (reação 5.3) e de $0.20 \AA$ na reação que envolve os complexos com estados de oxidação III (reação 5.4). O grupo piridina também passa por uma reorientação espacial, rotacionando entre 5 e 10 graus aproximadamente, a depender da reação de desprotonação em questão, como mostrado na tabela 5.3.

De outra parte, considerando a oxidação do complexo e a desprotonação do íon hidróxido, como uma reação acoplada de perda de 1 elétron e 1 próton (reação 5.5), reconstituímos o mesmo cenário observado nas reações de mono-oxidação. A perda acoplada de 1 elétron e 1 próton, faz com que o átomo de $R u$ e os nitrogênios das polipiridinas se afastem e o átomo de oxigênio se aproxime de $R u$. Por vez, observamos também que o grupo piridina sofre uma rotação de 36 graus, tão grande quanto as rotações observadas nos casos em que consideramos apenas a perda de 1 elétron. Esse resultado indica que o grupo piridina é dinamicamente mais 
estável à reações de desprotonação e menos estável à reações de oxidação.

De um modo geral, a perda de prótons ou elétrons altera minimamente os diedros associados aos grupos bipiridínicos $\left(\Delta d_{1}\right.$ a $\left.\Delta d_{4}\right)$. Isso demonstra que esses grupos são eletronicamente estáveis não só aos efeitos da solvatação, mas também à mudanças drásticas de pH e à processos internos de oxidação do centro metálico. Outra vez, é importante frisar duas mudanças geométricas que ocorrem nos complexos estudados quando esses sofrem oxidação, desprotonação ou ambos: a redução na distância $R u-O$ e o aumento da distância Ru- $\mathrm{N}_{11}$. $\mathrm{O}$ átomo $\mathrm{N}_{11}$ é encontrado na posição diametralmente oposta ao átomo de oxigênio, e, depois da distância $R u-O$, a distância $R u-N_{11}$ é a que mais sofre os efeitos de oxidação e desprotonação. Discutiremos esse fenômeno na próxima seção.

\subsubsection{Efeito trans}

No contexto de complexos de metal de transição, é conhecido na literatura que a coordenação com um grupo oxigenado $\left(\mathrm{H}_{2} \mathrm{O}, \mathrm{OH}^{-}\right.$ou $\left.\mathrm{O}^{2-}\right)$ causa perturbações maiores na ligação química diametralmente oposta ao átomo de oxigênio. Tiago et. al. reportaram recentemente esse efeito para um complexo de $R u$ binuclear, ${ }^{[232]}$ e mostraram que a ligação química $R u-N$ diametralmente oposta a ligação química $R u-O$ é significativa maior que as demais ligações químicas $R u-N$ do complexo. Denominaremos esse fenômeno por efeito trans.

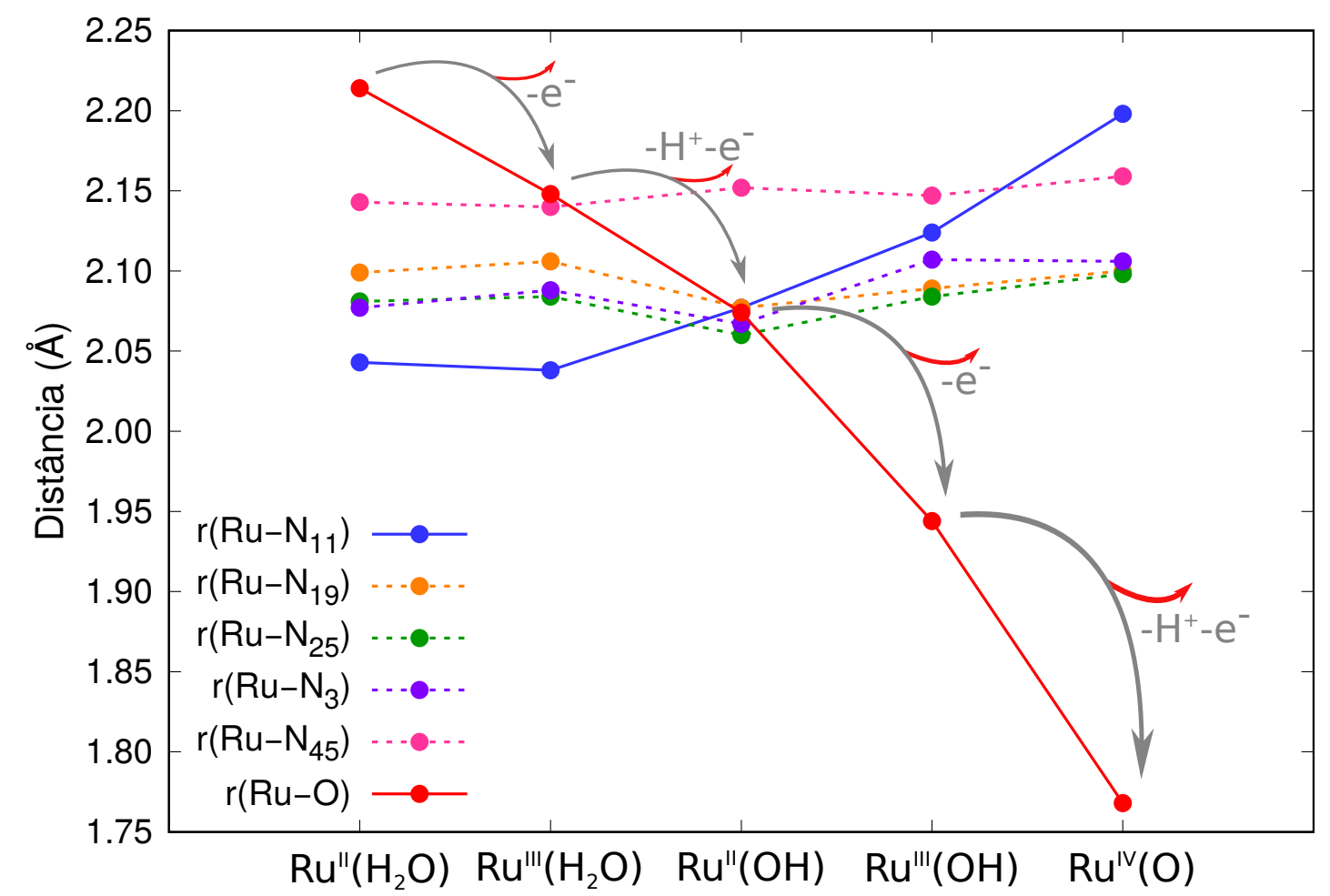

Figura 5.4 - Distâncias $R u-N$ e $R u-O$, em $\AA$, para os cinco complexos de $R u$-Aqua/Oxo em solução.

Na figura 5.4 apresentamos graficamente as distâncias $R u-N$ e $R u-O$ para os cinco 
complexos de $R u$-Aqua/Oxo aqui estudados. Por fins didáticos, apresentamos o valor das distâncias por complexo seguindo a ordem de decrescimento da ligação $R u-O$. Na ordem, temos que a ligação $R u-O$, tanto no vácuo como também em solução, é maior no complexo $R u^{I I}\left(\mathrm{H}_{2} \mathrm{O}\right)$ e segue diminuindo para $R u^{I I I}\left(H_{2} \mathrm{O}\right), R u^{I I}(\mathrm{OH}), R u^{I I I}(O H)$ e $R u^{I V}(\mathrm{O})$.

Dessa maneira, podemos visualizar claramente o efeito trans na ligação química $R u-N_{11}$ devido a perda de elétrons e prótons. Enquanto as demais ligações Ru-N sofrem apenas flutuações, observamos um aumento gradativo de $R u-N_{11}$, conforme a ligação $R u-O$ se encurta. A única exceção observada ocorre na mono-oxidação do complexo $R u^{I I}\left(H_{2} O\right)$, já que a ligação $\mathrm{Ru}-\mathrm{N}_{11}$ é ligeiramente menor em $\mathrm{Ru} u^{I I I}\left(\mathrm{H}_{2} \mathrm{O}\right)$.

\subsection{Cargas atômicas}

Processos como a solvatação, e a troca de prótons e elétrons entre soluto e solvente são fenômenos que podem causar grande perturbação na distribuição da densidade eletrônica do soluto. Utilizando o método CHELPG, calculamos as cargas atômicas que reproduzem o potencial eletrostático molecular dos complexos de $R u$-Aqua/Oxo no vácuo e em solução. Nesta seção discutiremos os efeitos de polarização devido ao solvente e de processos de oxidação e desprotonação na distribuição de cargas atômicas dos complexos.

\subsubsection{Efeitos da solvatação}

Na tabela 5.4 apresentamos as cargas atômicas calculadas para o átomo de $R u$ e para os átomos a esse coordenados $\left(N_{3}, N_{11}, N_{19}, N_{25}, N_{45}\right.$ e $\left.O\right)$. Adicionalmente, apresentamos também os valores de carga total por grupos, considerando apenas os nitrogênios $\left(\sum N\right)$, e considerando todos os átomos que compõem os grupos bpy1, bpy2 e py, apontados na figura 5.1. De forma mais ilustrativa, apresentamos também o diagrama da figura 5.5, apenas para os átomos de $R u, N$ e $O$.

Pelo diagrama, a primeira observação que fazemos é que existe uma separação nítida entre as cargas do átomo de $R u$, mais positivas e próximas de $1 e$; dos nitrogênios, que em geral tem cargas negativas entre aproximadamente -0.5 e $0.0 e$; e dos oxigênios, com cargas negativas menores que aproximadamente $-0.5 \mathrm{e}$. Vale observar nesse diagrama que a ordem escolhida para os complexos, de (a) a (e), segue a mesma ordem que utilizamos para discutir a influência dos processos de oxidação e desprotonação nas distâncias $R u-N$ e $R u-O$, na figura 5.4. Tão logo, notamos que nessa ordem não existe uma tendência de aumento ou redução das cargas atômicas dos complexos, seja no vácuo ou em solução. Por outro lado, apesar de não observarmos uma correspondência direta entre os valores absolutos da carga de $N_{11}$ e as distâncias entre $R u$ e $N_{11}$ ou entre $R u$ e $O$, notamos que, em solução, a carga do nitrogênio $N_{11}$ se destaca. Entre todos os nitrogênios, em solução, a carga de $N_{11}$ é sempre a mais 


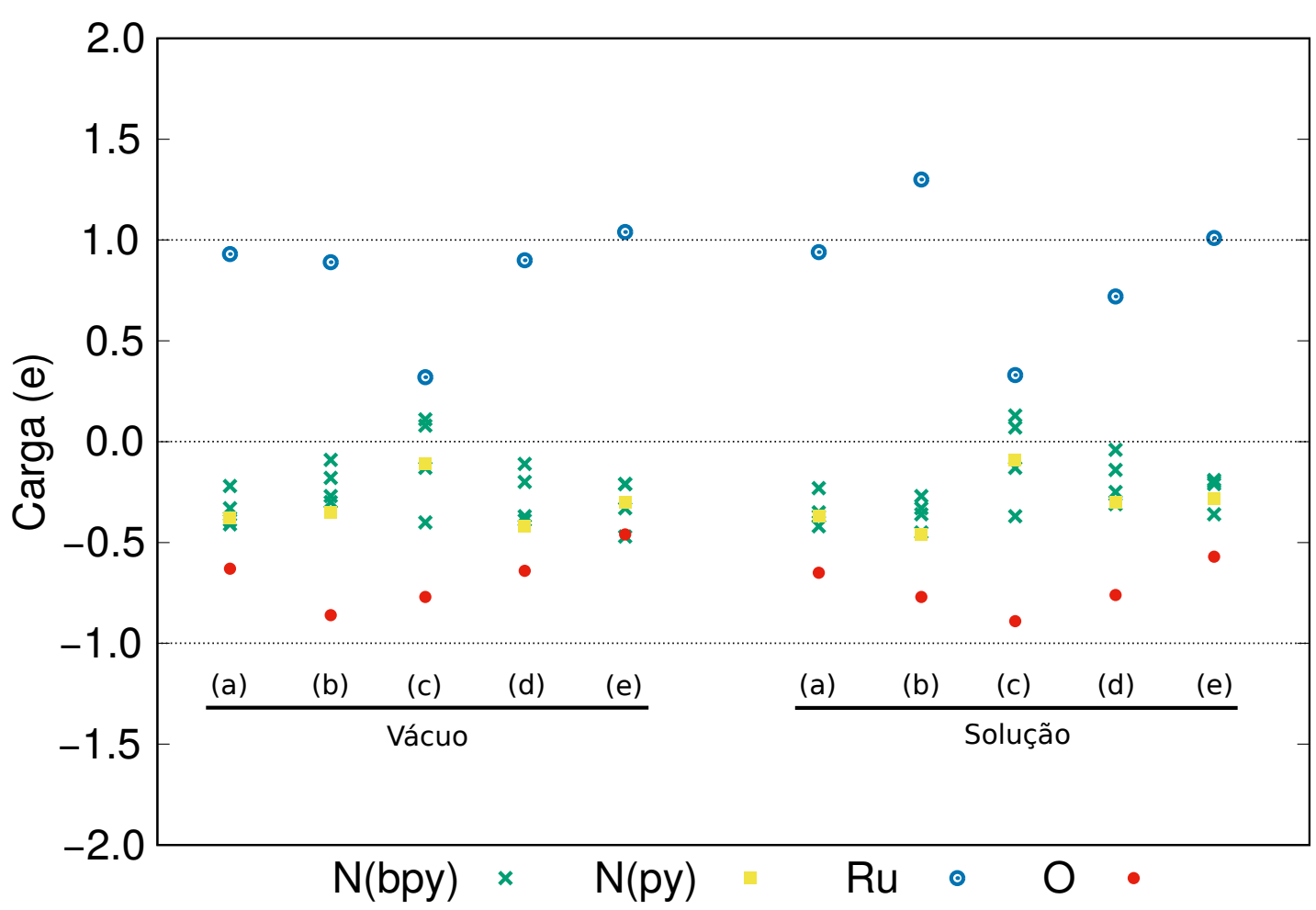

Figura 5.5 - Cargas atômicas (em unidades atômicas) dos complexos de Ru-Aqua/Oxo, calculadas com o método CHELPG no vácuo (VAC) e em solução aquosa (SOL), utilizando o modelo contínuo PCM. Os complexos estão representados pelas letras: (a) $R u^{I I}\left(\mathrm{H}_{2} \mathrm{O}\right)$; (b) $R u^{I I I}\left(\mathrm{H}_{2} \mathrm{O}\right)$; (c) $R u^{I I}(\mathrm{OH})$; (d) $R u^{I I I}(\mathrm{OH})$; (e) $R u^{I V}(O)$.

negativa nos complexos com carga +1 e +2 , e a menos negativa no complexo de carga +3 . E portanto, essa é uma observação do efeito trans devido a polarização dos complexos em solução. Isso pode ser conferido na tabela 5.4 .

Os principais efeitos de polarização do solvente nas cargas atômicas dos complexos de $R u$-Aqua/Oxo são observados na região central dos complexos, compreendendo o átomo de $R u$ e seus primeiros vizinhos. Analisando os valores de carga apresentados na tabela 5.4, podemos fazer algumas considerações:

i) O átomo de $R u$ é mais positivo em solução por $0.01,0.41$ e 0.01 nos complexos $R u^{I I}\left(H_{2} O\right)$, $R u^{I I I}\left(\mathrm{H}_{2} \mathrm{O}\right)$ e $R u^{I I}(\mathrm{OH})$, respectivamente; e mais negativo por -0.18 e -0.03 em $R u^{I I I}(\mathrm{OH})$ e $R u^{I V}(O)$, respectivamente. E portanto, o centro metálico demonstra ser mais vulnerável à polarização do meio quando encontra-se no estado de oxidação III, tornando-se mais positivo quando coordenado a uma molécula de água, e mais negativo quando coordenado a um íon hidróxido.

ii) $\mathrm{O}$ átomo de $O$ é mais positivo em solução por 0.09 apenas no complexo $R u^{I I I}\left(H_{2} O\right)$; e mais negativo por -0.02, -0.12, - 0.12 e -0.11 em $R u^{I I}\left(H_{2} O\right), R u^{I I}(O H), R u^{I I I}(O H)$ e $R u^{I V}(O)$, respectivamente. E portanto, não notamos uma correlação entre as variações nas cargas do átomo de $R u$ e do átomo de $O$ devido aos efeitos de polarização do meio. 
Tabela 5.4 - Cargas atômicas (em unidades atômicas) dos complexos de Ru-Aqua/Oxo, calculadas com o método CHELPG no vácuo (VAC) e em solução aquosa (SOL), utilizando o modelo contínuo PCM.

\begin{tabular}{|c|c|c|c|c|c|c|c|c|c|c|c|c|c|}
\hline & & $R u$ & $O$ & $N_{3}$ & $N_{11}$ & $N_{19}$ & $N_{25}$ & $N_{45}$ & $\sum N$ & bpy1 & bpy2 & py & Aqua \\
\hline \multirow{3}{*}{$R u^{I I}\left(H_{2} \mathrm{O}\right)$} & VAC & 0.93 & -0.63 & -0.22 & -0.33 & -0.39 & -0.41 & -0.38 & -1.74 & 0.46 & 0.33 & 0.19 & 0.10 \\
\hline & SOL & 0.94 & -0.65 & -0.23 & -0.42 & -0.37 & -0.35 & -0.37 & -1.75 & 0.39 & 0.36 & 0.18 & 0.13 \\
\hline & $\Delta q$ & 0.01 & -0.02 & -0.01 & -0.09 & 0.02 & 0.06 & 0.01 & -0.01 & -0.07 & 0.03 & -0.01 & 0.03 \\
\hline \multirow{3}{*}{$R u^{I I I}\left(\mathrm{H}_{2} \mathrm{O}\right)$} & VAC & 0.89 & -0.86 & -0.18 & -0.27 & -0.09 & -0.30 & -0.35 & -1.20 & 0.81 & 0.82 & 0.37 & 0.12 \\
\hline & SOL & 1.30 & -0.77 & -0.36 & -0.27 & -0.33 & -0.45 & -0.46 & -1.87 & 0.68 & 0.58 & 0.28 & 0.16 \\
\hline & $\Delta q$ & 0.41 & 0.09 & -0.18 & 0.00 & -0.24 & -0.15 & -0.11 & -0.67 & -0.13 & -0.24 & -0.09 & 0.04 \\
\hline \multirow{3}{*}{$R u^{I I}(O H)$} & VAC & 0.32 & -0.77 & 0.08 & -0.40 & 0.11 & -0.13 & -0.11 & -0.47 & 0.37 & 0.55 & 0.25 & -0.50 \\
\hline & SOL & 0.33 & -0.89 & 0.08 & -0.37 & 0.13 & -0.13 & -0.09 & -0.39 & 0.43 & 0.58 & 0.27 & -0.61 \\
\hline & $\Delta q$ & 0.01 & -0.12 & 0.00 & 0.03 & 0.02 & 0.00 & 0.02 & 0.07 & 0.06 & 0.03 & 0.02 & -0.11 \\
\hline \multirow{3}{*}{$R u^{I I I}(O H)$} & VAC & 0.90 & -0.64 & -0.20 & -0.39 & -0.11 & -0.37 & -0.42 & -1.49 & 0.53 & 0.65 & 0.22 & -0.30 \\
\hline & SOL & 0.72 & -0.76 & -0.14 & -0.31 & -0.04 & -0.25 & -0.30 & -1.03 & 0.63 & 0.74 & 0.27 & -0.37 \\
\hline & $\Delta q$ & -0.18 & -0.12 & 0.06 & 0.08 & 0.07 & 0.12 & 0.12 & 0.46 & 0.10 & 0.09 & 0.05 & -0.07 \\
\hline \multirow{3}{*}{$R u^{I V}(O)$} & VAC & 1.04 & -0.46 & -0.21 & -0.47 & -0.21 & -0.33 & -0.30 & -1.52 & 0.51 & 0.63 & 0.28 & -0.46 \\
\hline & SOL & 1.01 & -0.57 & -0.20 & -0.36 & -0.21 & -0.19 & -0.28 & -1.24 & 0.58 & 0.68 & 0.30 & -0.57 \\
\hline & $\Delta q$ & -0.03 & -0.11 & 0.01 & 0.11 & 0.00 & 0.14 & 0.02 & 0.28 & 0.07 & 0.05 & 0.02 & -0.11 \\
\hline
\end{tabular}

iii) Os átomos de $N$, em geral, tornam-se mais positivos nos complexos que tem coordenação com os íons hidróxido e óxido. Já nos complexos que tem coordenação com um molécula de água, temos duas situações distintas. No complexo $R u^{I I I}\left(\mathrm{H}_{2} \mathrm{O}\right)$, observa-se, quase que por unanimidade, os átomos de $N$ tornarem-se mais negativos; e já no complexo $R u^{I I}\left(H_{2} O\right)$, os nitrogênios $N_{3}$ e $N_{11}$ do grupo bpy tornam-se mais negativos enquanto que os nitrogênios dos grupos bpy2 e py ficam mais positivos. No mesmo sentido, a variação $(\Delta q)$ da soma das cargas dos nitrogênios, na coluna $\sum N$, mostra que a carga total dos nitrogênios torna-se mais negativa nos complexos que tem coordenação com uma molécula de água, e mais positiva nos complexos que tem coordenação com os íons hidróxido ou óxido.

iv) Olhando para um cenário mais global, analisando agora a soma das cargas atômicas nos grupos bpy 1 , bpy 2 e py, notamos as mesmas tendências observadas nas variações de carga dos nitrogênios. Os grupos polipiridínicos tornam-se menos positivos nos complexos que tem coordenação com uma molécula de água, e mais positivos nos complexos que tem coordenação com os íons hidróxido ou óxido. Portanto, em resposta aos efeitos do solvente concluímos que: quando temos uma molécula de água coordenada ao complexo, o átomo de $R u$ atua 
como um doador de densidade eletrônica e os grupos polipiridínicos atuam como aceitadores; e quando temos um íon hidróxido ou óxido, o átomo de $R u$ atua como um aceitador de densidade eletrônica e os grupos polipiridínicos atuam como doadores.

Como mostraremos nos próximos capítulos, todas essas mudanças na distribuição de cargas atômicas dos complexos de $R u$-Aqua/Oxo, devido aos efeitos de polarização do meio, traduzirse-ão em mudanças na estrutura do solvente em torno dos complexos e nas propriedades eletrônicas dos mesmos, em solução aquosa. Na ordem de carga total, o complexo $R u^{I I}(O H)$ tem carga +1 , os complexos $R u^{I I}\left(H_{2} O\right), R u^{I I I}(O H)$ e $R u^{I V}(O)$ apresentam carga +2 e o complexo $\mathrm{Ru}^{I I I}\left(\mathrm{H}_{2} \mathrm{O}\right)$ tem carga +3 , a maior de todas. Nessa análise de efeitos da polarização nas cargas atômicas, é importante perceber que é justamente no complexo de maior carga atômica que contabilizamos os maiores efeitos. Nesse complexo, a carga do átomo de $R u$ sobe em 0.41 e a soma das cargas dos nitrogênios é mais negativa em -0.67 .

Por outro lado, orientando-se pela carga do átomo de $R u$, temos, em ordem crescente da carga de $R u$ e na condição de vácuo: $R u^{I I}(O H)$ (0.32), $R u^{I I I}\left(H_{2} O\right)(0.89), R u^{I I I}(O H)$ (0.90), $R u^{I I}\left(H_{2} O\right)$ (0.93) e $R u^{I V}(O)$ (1.04). Já em solução, temos: $R u^{I I}(O H)$ (0.33), $R u^{I I I}(\mathrm{OH})$ (0.72), $R u^{I I}\left(\mathrm{H}_{2} \mathrm{O}\right)$ (0.94), $R u^{I V}(\mathrm{O})$ (1.01) e $R u^{I I I}\left(\mathrm{H}_{2} \mathrm{O}\right)$ (1.30). O que há de diferente nas duas situações é a posição em que aparece o complexo $R u^{I I I}\left(H_{2} O\right)$, que tem a maior carga. Na condição de vácuo, temos que a carga do átomo de $R u$ nesse complexo é intermediária às cargas dos complexos de carga +1 e +2 , mas em solução essa ordem muda, e obtemos no complexo de $\mathrm{Ru}^{I I I}\left(\mathrm{H}_{2} \mathrm{O}\right)$ a maior carga calculada para o átomo de $\mathrm{Ru}$ entre todos os complexos.

\subsubsection{Efeitos oxidativos e de $\mathrm{pH}$}

Nesta seção, abordaremos as mudanças nas cargas atômicas dos complexos de $R u$-Aqua/Oxo causadas por reações de oxidação e desprotonação (reações 5.1 a 5.5) em solução aquosa. Na tabela 5.5 apresentamos as reações estudadas e as respectivas variações de cargas atômicas. Por simplificação, apresentamos apenas as mudanças nas cargas atômicas de $R u$ e $O$ e nos grupos atômicos $\left(\sum N\right.$, bpy 1, bpy 2, py $)$ previamente definidos.

Nas reações de mono-oxidação do tipo $R u^{I I} \rightarrow R u^{I I I}$, observamos que o átomo de $R u$ torna-se mais positivo em 0.36 na reação que envolve os complexos coordenados com uma molécula de água, e em 0.39 na reação que envolve os complexos coordenados com um íon hidróxido. Localmente, observamos que o átomo de $O$ torna-se mais negativo na primeira reação (em -0.12), mas mais positivo na segunda (em 0.13). Enquanto isso, a soma das cargas dos nitrogênios é sempre mais negativa, em -0.12 e -0.63, na primeira e segunda reações, respectivamente. De um ponto de vista global, tanto o centro metálico como os grupos polipiridínicos $(b p y 1, b p y 2, p y)$ sentem a perda eletrônica, e ficam mais positivos, mas, átomo por átomo, o átomo de $R u$ é o mais afetado.

Nas reações de desprotonação, observamos que o átomo de $R u$ torna-se menos positivo 
Tabela 5.5 - Variações das cargas atômicas (em unidades atômicas) dos complexos de $R u$ Aqua/Oxo em solução devido a processos de oxidação e desprotonação.

\begin{tabular}{cccccc}
\hline & $R u^{I I}\left(\mathrm{H}_{2} \mathrm{O}\right)$ & $R u^{I I}(\mathrm{OH})$ & $R u^{I I}\left(\mathrm{H}_{2} \mathrm{O}\right)$ & $R u^{I I I}\left(\mathrm{H}_{2} \mathrm{O}\right)$ & $R u^{I I I}(\mathrm{OH})$ \\
& $-e \downarrow$ & $-e \downarrow$ & $\downarrow-H^{+}$ & $\downarrow-H^{+}$ & $-e \downarrow-H^{+}$ \\
& $R u^{I I I}\left(\mathrm{H}_{2} \mathrm{O}\right)$ & $R u^{I I}(\mathrm{OH})$ & $R u^{I I}(\mathrm{OH})$ & $R u^{I I I}(\mathrm{OH})$ & $R u^{I V} \mathrm{O}$ \\
\hline$R u$ & 0.36 & 0.39 & -0.61 & -0.58 & 0.29 \\
$O$ & -0.12 & 0.13 & -0.24 & 0.01 & 0.19 \\
$\sum N$ & -0.12 & -0.63 & 1.35 & 0.84 & -0.21 \\
$b p y 1$ & 0.29 & 0.20 & 0.04 & -0.05 & -0.05 \\
$b p y 2$ & 0.22 & 0.16 & 0.22 & 0.16 & -0.06 \\
py & 0.10 & 0.00 & 0.09 & -0.01 & 0.03 \\
Aqua & 0.03 & 0.61 & -0.74 & -0.53 & -0.20 \\
\hline
\end{tabular}

em -0.61 na reação que envolve os complexos com estado de oxidação II e menos positivo em -0.58 na reação que envolve os complexos com estado de oxidação III. No primeiro caso o átomo de $O$ também absorve um parte da densidade eletrônica, -0.24 , e a soma das cargas dos nitrogênios torna-se mais positiva em 1.35 . No segundo caso o átomo de $O$ torna-se levemente menos negativo, em apenas 0.01 , e a soma das cargas dos nitrogênios torna-se mais positiva em 0.84 . Nessas reações, o grupo bpy 2 sempre perde parte de sua densidade, ficando mais positivo. Os grupos bpy1 e py tornam-se mais positivos nas reações para o estado de oxidação III, e mais negativas nas reações para o estado de oxidação II.

Considerando agora a oxidação do complexo e a desprotonação do íon óxido, como uma reação acoplada de perda de 1 elétron e 1 próton, temos uma situação mista. Apesar da desprotonação, o átomo de $R u$ fica agora mais positivo, em 0.29 . O átomo de $O$ perde parte de sua densidade eletrônica e também fica mais positivo. Num movimento compensativo, os nitrogênios absorvem parte da densidade eletrônica, de modo que a soma total de suas cargas torna-se mais negativa em -0.21 . Quanto aos grupos polipiridínicos, observamos que as bipiridinas (bpy 1 e bpy2) encontram-se mais negativos, em - 0.11 , e a piridina ( $p y$ ) mais positiva, em 0.03 .

\subsection{Campo de força para o átomo de $R u$}

Conforme apresentamos no capítulo de metodologia, as simulações clássicas dos complexos de $R u$-Aqua/Oxo em solução foram realizadas utilizando o potencial clássico de LennardJones-Coulomb (LJC). As cargas atômicas foram calculadas utilizando a análise populacional CHELPG ${ }^{[189]}$, com efeitos de polarização do solvente tratados pelo modelo contínuo PCM. Os parâmetros de Lennard-Jones para os átomos não metálicos $\{\epsilon, \sigma\}$ foram retirados do campo de força OPLS-AA ${ }^{[187]}$, e os parâmetros de Lennard-Jones para o átomo de $R u$ 
foram desenvolvidos para reproduzir a energia de interação quântica da molécula de água nos complexos com graus de oxidação II e III. Nesta seção discutiremos sobre a parametrização do átomo de $R u$. Faremos uma breve revisão da literatura, e em seguida apresentaremos a nossa proposta de parametrização, comparando-a às propostas já existentes na literatura.

\subsubsection{Breve revisão da literatura}

Encontramos na literatura algumas propostas de conjuntos de parâmetros não ligados $\{\varepsilon, \sigma$ e $q\}$ para a simulação clássica de compostos de $R u$, segundo o campo de força LJC. Allinger et al. ${ }^{[233]}$, Adlhart et al. ${ }^{[234]}$ e Rappé et al. ${ }^{[235]}$ apresentam conjuntos de parâmetros LJ para $R u$ sem mencionar seu estado de oxidação, e Šebesta et al. ${ }^{[190]}$ foram recentemente os primeiros a propor diferentes conjuntos de parâmetros LJC para $R u^{I I}$ e $R u^{I I I}$. Esses parâmetros encontram-se apresentados na tabela 5.6 da próxima seção.

O trabalho de Allinger et al. ${ }^{[233]}$ é bastante geral e compreende mais de 100 átomos da tabela periódica, incluindo o átomo de $R u$. Os autores apresentam um amplo conjunto de parâmetros LJ desenvolvidos para o campo de força MM3. Adlhart et al. ${ }^{[234]}$ apresentam parâmetros LJ para $R u$ a partir de uma versão modificada do campo de força sybyl/tripos $5.2^{[236]}$. Como mencionado pelos autores, os parâmetros LJ foram desenvolvidos para serem usados em um estudo QM/MM da reação de metátese de olefinas catalisada por complexos de $R u$ carbeno. Rappé et al. ${ }^{[235]}$ são os desenvolvedores do famoso campo de força universal (UFF), e, nessa referência, os autores apresentam parâmetros LJ para todos os átomos da tabela periódica. É importante mencionar que nesses trabalhos encontramos apenas parâmetros LJ.

No trabalho mais recente, Šebesta et al. ${ }^{[190]}$ trouxeram o primeiro estudo de parametrização para o átomo de $R u$, levando em consideração dois estados de oxidação diferentes (II e III). Os autores empregaram a aproximação supermolecular ${ }^{[237]}$ para ajustar os parâmetros LJC para vários metais de transição. Eles consideraram um complexo metálico neutro e uma molécula "teste". Como complexos neutros, eles adotaram estruturas nas formas $M\left(\mathrm{NH}_{3}\right)_{x} \mathrm{Cl}_{y}$ e $\mathrm{MH}_{2} \mathrm{O}_{x}(\mathrm{SH})_{y}$, em que $\mathrm{M}$ é um metal de transição e $x$ ou $y$ significam um número variável de ligantes. Como moléculas de teste, eles adotaram $\mathrm{NH}_{3}, \mathrm{CH}_{4}$ e $\mathrm{H}_{2} \mathrm{O}$. Assim, Os parâmetros não ligados para $R u$ foram obtidos a fim de fornecer a melhor descrição das energias de interação quântica metal-ligante. E nesse caso, os autores obtiveram todos os parâmetros para o campo de força LJC.

Embora Šebesta et al. tenham proposto diferentes conjuntos de parâmetros para vários metais de transição em diferentes estados de oxidação, o procedimento de parametrização usado pelos autores não levou em consideração os metais em um ambiente de coordenação polipiridínico. De fato, não encontramos na literatura nenhuma proposta de parâmetros para átomos de $R u$ coordenados com polipiridinas e interagindo adicionalmente com moléculas de água ou mesmo íons hidróxido ou óxido. Esse tipo especial de coordenação oxigenada pode 
modificar completamente a estrutura eletrônica do complexo. É importante considerar explicitamente a interação do centro metálico com o ligante oxigenado para obter adequadamente os parâmetros não ligados necessários para as simulações clássicas.

\subsubsection{Uma nova proposta de parâmetros LJC para $R u$}

Em nossa proposta de parâmetros não ligados para o átomo de $R u$, baseamos-nos na descrição precisa do perfil quântico da energia de interação entre o complexo de $R u$ e a molécula de água coordenada, em um ambiente de coordenação polipiridínico. Exploramos nos complexos $\mathrm{Ru}^{I I}\left(\mathrm{H}_{2} \mathrm{O}\right)$ e $\mathrm{Ru}^{I I I}\left(\mathrm{H}_{2} \mathrm{O}\right)$ a superfície de energia potencial QM rígida (rPES) entre a molécula de água e o átomo de $R u$, no vácuo. Em cada complexo, na geometria otimizada de vácuo, calculamos a energia de interação da molécula de água coordenada a $R u$ em diferentes posições em torno do ponto de equilíbrio, traçando assim curvas de energia de interação água/complexo. Uma vez traçadas as curvas quânticas de interação, passamos ao refinamento dos parâmetros $\{\epsilon, \sigma\}$ do átomo de $R u$ a fim de reproduzir via potencial LJC o perfil quântico da interação água/complexo em $R u^{I I}\left(\mathrm{H}_{2} \mathrm{O}\right)$ e $\mathrm{Ru}^{I I I}\left(\mathrm{H}_{2} \mathrm{O}\right)$. Os parâmetros obtidos encontram-se apresentados na tabela 5.6, juntamente aos parâmetros encontrados na literatura. Na Figura 5.6, mostramos os perfis de energia LJC da água ligante nos complexos $R u^{I I}\left(H_{2} \mathrm{O}\right)$ e $R u^{I I I}\left(H_{2} \mathrm{O}\right)$, obtidos a partir dos parâmetros apresentados na tabela 5.6. Para comparação, também mostramos o perfil de energia QM calculado no nível B3LYP/aug-cc-pVDZ(PP).

Tabela 5.6 - Parâmetros LJC para o átomo de $R u$ em simulações MM.

\begin{tabular}{cccc}
\hline Sets & $\varepsilon(\mathrm{kcal} / \mathrm{mol})$ & $\sigma(\AA)$ & $q(\mathrm{e})$ \\
\hline Allinger et al. (MM3) ${ }^{[233]}$ & 0.438 & 2.08 & - \\
Adlhart et al. ${ }^{[234]}$ & 0.560 & 2.64 & - \\
Rappé et al. (UFF) ${ }^{[235]}$ & 0.056 & 2.64 & - \\
Šebesta et al. $\left(R u^{I I}\right)^{[190]}$ & 0.418 & 2.618 & 0.872 \\
Šebesta et al. $\left(R u^{I I I}\right)^{[190]}$ & 1.644 & 2.523 & 0.790 \\
Nossa proposta para $R u^{I I}$ & 0.400 & 1.80 & 0.94 \\
Nossa proposta para $R u^{I I I}$ & 0.400 & 2.00 & 1.30 \\
Nossa proposta para $R u^{I V}$ & 0.400 & 1.80 & 1.01 \\
\hline
\end{tabular}

Em nosso estudo, obtivemos valores iguais de $\varepsilon$ para $R u^{I I}$ e $R u^{I I I}$. Obtivemos um valor de $\sigma 0,2 \AA$ maior para $R u^{I I I}$ do que $R u^{I I}$. Calculamos uma carga mais positiva para $R u^{I I I}$ do que $R u^{I I}$. Embora a carga de $R u$ deva ser mais positiva após uma monoxidação, como obtivemos, os parâmetros propostos por Šebesta et al. não seguem essa tendência. O valor da carga que eles ajustaram para $R u^{I I I}$ é menos positivo que para $R u^{I I}$, um resultado incoerente.

Da literatura, o conjunto de parâmetros propostos por Allinger et al. é o que fornece os perfis de energia LJC mais próximos dos perfis obtidos por mecânica quântica, mas com uma 

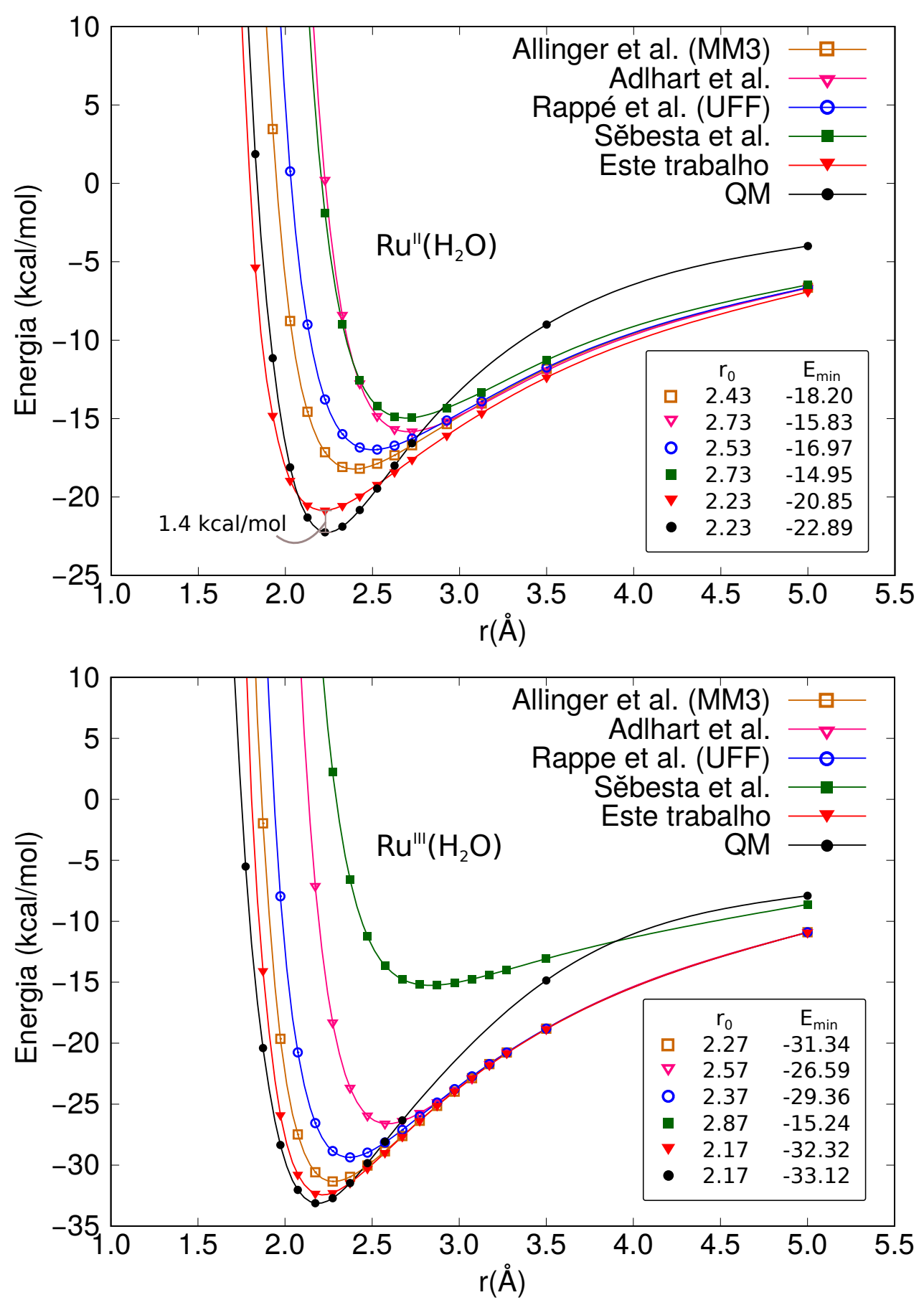

Figura 5.6 - Potencial de interação água/complexo no complexo $R u^{I I}\left(H_{2} O\right)$. Os pontos na curva quântica QM foram calculados em nível B3LYP/aug-cc-pVDZ(PP para $\mathrm{Ru}$ ), no vácuo. Os pontos da curva clássica, na cor azul, foram calculados com

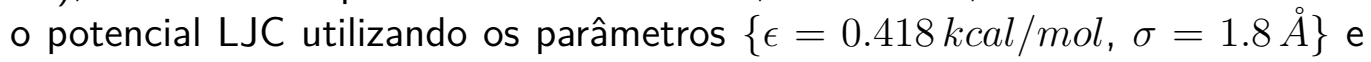
$q=0.94$ e para $R u$.

energia de mínimo $E_{0}$ menos negativa (em 4,7 kcal $/ \mathrm{mol}$ para $R u^{I I}$; em 1,8 $\mathrm{kcal} / \mathrm{mol}$ para $R u^{I I I}$ ), alem de valores distorcidos para a distância de equilíbrio $r_{0}$ (em $0,2 \AA$ para $R u^{I I}$, em $0,1 \AA$ para $R u^{I I I}$ ). Além disso, o conjunto de parâmetros propostos por Šebesta et al. é o que fornece os perfis de energia LJC mais distantes dos perfis QM, com $E_{0}$ ainda menos negativos (em 1,9 kcal/mol para $R u^{I I}$, em $17,9 \mathrm{kcal} / \mathrm{mol}$ para $R u^{I I I}$ ) e valores de $r_{0}$ ainda 
mais distorcidos (em $0,5 \AA$ para $R u^{I I}$, em $0,7 \AA$ para $R u^{I I I}$ ). Com as parametrizações propostas por Rappé et al. e Adlhart et al., obtemos perfis de energias LJC entre os perfis LJC de Allinger et al. e de Šebesta et al.

Por fim, nosso conjunto de parâmetros LJC fornece a melhor concordância entre os perfis de energia LJC e QM, com uma excelente descrição do mínimo de energia $E_{0}$ e distância de equilíbrio $r_{0}$, para ambos $R u^{I I}$ e $R u^{I I I}$. Alcançamos um desvio energético de apenas 1,4 e 0,8 $\mathrm{kcal} / \mathrm{mol}$ na descrição das energias quânticas de mínimo para $R u^{I I}$ e $R u^{I I I}$ respectivamente. Além disso, ajustamos exatamente a distância mínima QM em ambos os estados de oxidação.

Os parâmetros $\epsilon$ e $\sigma$ obtidos para $R u^{I I}\left(\mathrm{H}_{2} \mathrm{O}\right)$ e $R u^{I I I}\left(\mathrm{H}_{2} \mathrm{O}\right)$ foram extendidos para os complexos $R u^{I I}(O H)$ e $R u^{I I I}(O H)$, respectivamente. Para o complexo $R u^{I V}(O)$ optamos por manter a parametrização obtida para o complexo $R u^{I I}\left(H_{2} O\right)$. Do ponto de vista quântico, existe uma limitação para o levantamento da curva de energia de interação do íon hidróxido no complexo $R u^{I I I}(O H)$ e do íon óxido no complexo $R u^{I V}(O)$. A limitação consiste no fato de que a densidade de spin nesses complexos, que tem elétrons desemparelhados, encontra-se delocalizada entre o átomo de $R u$ e $O$. Não é possível calcular rigorosamente a energia de interação de duas partes que não podem ter seus estados de spin bem definidos.

Dentre os cinco complexos de $R u$-Aqua/Oxo, três deles apresentam momento angular de spin maior que zero. Os complexos $R u^{I I I}\left(\mathrm{H}_{2} \mathrm{O}\right)$ e $R u^{I I I}(\mathrm{OH})$ apresentam um elétron desemparelhado no subnível eletrônico $4 \mathrm{~d}$, e o complexo $R u^{I V}(O)$ tem dois elétrons desemparelhados em 4 d. Na figura 5.7 mostramos um plot da densidade de spin em cada um desses complexos.

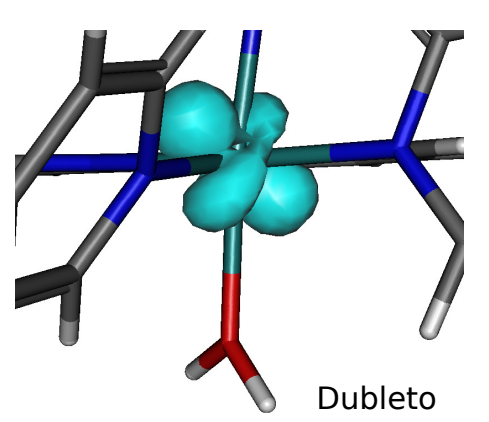

$\mathrm{Ru}^{\mathrm{III}}\left(\mathrm{H}_{2} \mathrm{O}\right)$

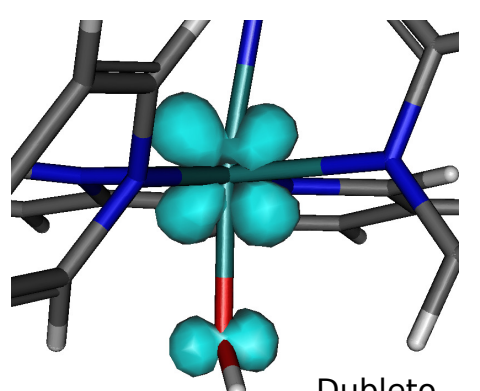

$\mathrm{Ru}^{\prime \prime \prime}(\mathrm{OH})$

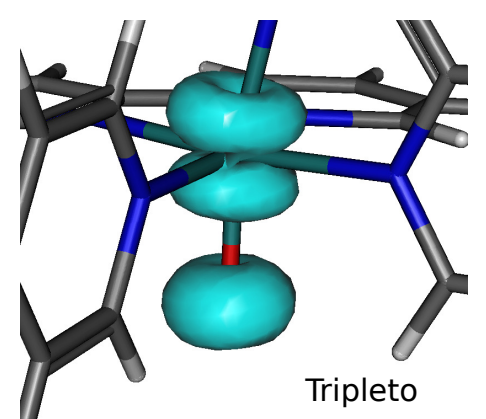

$\mathrm{Ru}^{\mathrm{IV}}(\mathrm{O})$

Figura 5.7 - Densidades de spin dos complexos de Ru-Aqua/Oxo de camada aberta. Densidades calculadas utilizando o funcional B3LYP e conjunto de funções base aug-cc-pVDZ(PP).

No complexo $R u^{I I I}\left(\mathrm{H}_{2} \mathrm{O}\right)$, o elétron desemparelhado encontra-se localizado em um orbital d do $R u$. Já nos complexos $R u^{I I I}(O H)$ e $R u^{I V}(O)$, temos uma delocalização da densidade eletrônica de spin num orbital $d$ do átomo de $R u$ e num orbital $s$ do átomo de oxigênio. Essa densidade de spin delocalizada é maior no átomo de oxigênio do complexo $R u^{I V}(O)$, que tem o átomo de $R u$ em um auto estado de oxidação IV e o átomo de oxigênio com um excesso de dois elétrons. 
O cálculo regular de energia de complexação de duas moléculas requer a definição prévia do estado de spin e de carga das partes que irão interagir. Como a densidade de spin encontra-se delocalizada entre o átomo de $R u$ e o átomo de $O$, é quanticamente inconsistente considerar o spin de cada parte separadamente. Como a densidade de spin nos complexos de camada aberta, $R u^{I V}(O)$ e $R u^{I I I}(O H)$, encontra-se delocalizada em orbitais dos átomos de $R u$ e $O$, isso inviabiliza o levantamento do perfil quântico de interação dos íons óxido e hidróxido nesses complexos. O mesmo não ocorre no caso do complexo $R u^{I I I}\left(H_{2} O\right)$, que apesar de ser um dubleto, tem a sua densidade de spin localizada apenas no átomo de $R u$. 


\section{Capítulo}

\section{Estrutura e dinâmica em solução}

Neste capítulo apresentaremos resultados sobre propriedades estáticas e dinâmicas de soluções aquosas de complexos de $R u$-Aqua/Oxo, a partir de análises das simulações por mecânica molecular, realizadas com os métodos de Monte Carlo e Dinâmica Molecular. O objetivo principal consiste em compreender os detalhes atomísticos da interação dos complexos de $R u$-Aqua/Oxo com o solvente. Abordaremos temas como: a estrutura do solvente no entorno dos complexos; a formação de ligações de hidrogênio intermolecular; a difusão de massa dos complexos; efeitos de superfície na interface água/vácuo.

\subsection{Estrutura do solvente}

Para compreender de forma global a estrutura do solvente no entorno dos complexos, calculamos as funções de distribuição de mínima distância (MDDF) ${ }^{\dagger}$ entre os complexos de $R u$-Aqua/Oxo e as moléculas de água da solução, apresentadas na figura 6.1.

Os primeiros picos na região de $r<2$ se referem à região de microsolvatação dos complexos, devido a formação de ligações de hidrogênio, que detalharemos adiante. Independentemente do complexo, percebe-se a formação de uma primeira camada de solvatação com pico e mínimo de probabilidade em aproximadamente 2.7 e $4.1 \AA$, respectivamente; e uma segunda camada de solvatação com pico variando entre 5.5 e $5.7 \AA$, e mínimo aparentemente próximo dos $7 \AA$. Integrando-se qualquer uma das MDDFs, de zero até $2.7 \AA$, indendentemente do complexo em questão, encontramos aproximadamente 25 moléculas de água; e integrando-se até $4.1 \AA$ encontramos um total de 70 moléculas de água, formando a primeira camada de solvatação. Para a segunda camada, considerando que seu mínimo esteja em aproximadamente $7 \AA$, na maioria dos complexos, estimamos que essa camada contenha até 220 moléculas de água. $\mathrm{Na}$

\footnotetext{
${ }^{\dagger}$ As funções de distribuição radial de pares foram calculadas a partir da superposição de histogramas de contagem gerados a cada 10 passos de MC, na etapa de produção. Isso significa que, nas simulações de bulk, cada função $G(r)$ foi gerada a partir da estatística de 50 mil configurações do sistema soluto/solvente. As funções de distribuição radial de pares de mínima distância (MDDF - Minimum Density Distribution Function $)^{[238,239]}$ foram geradas com a mesma estatística.
} 
figura 6.2, apresentamos uma ilustração da primeira camada de solvatação para o complexo $\mathrm{Ru}^{I I}\left(\mathrm{H}_{2} \mathrm{O}\right)$.

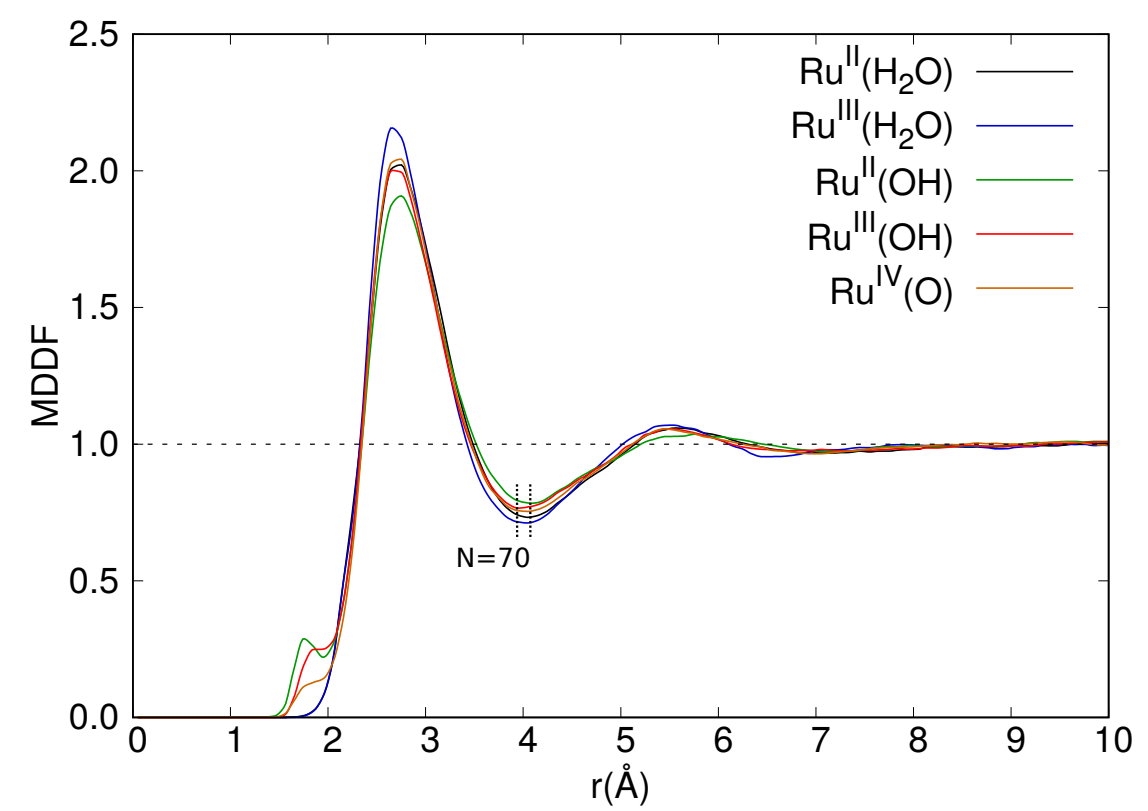

Figura 6.1 - Funções de distribuição de mínima distância (MDDF) entre os complexos de $R u$ Aqua/Oxo e as moléculas de água da solução. Em destaque, a primeira camada de solvatação contém aproximadamente 70 moléculas de água, independente do complexo. Funções obtidas a partir das simulações de MC.

Nas figuras 6.3, 6.4 e 6.5 apresentamos as funções $g(r)$ entre o átomo de $R u$ e os atómos de oxigênio, $g(r)^{R u-O w}$, e de hidrogênio, $g(r)^{R u-H w}$, da solução (os rótulos $O w$ e $H w$ serão utilizados para denotar os oxigênios e hidrogênios de moléculas de água da solução); e entre o átomo de oxigênio dos ligantes água, hidróxido e óxido e os atómos de oxigênio, $g(r)^{O-O w}$, e de hidrogênio, $g(r)^{O-H w}$, da solução. Na figura 6.3, os gráficos apresentados referem-se aos complexos $R u^{I I}\left(\mathrm{H}_{2} \mathrm{O}\right)$ e $R u^{I I I}\left(\mathrm{H}_{2} \mathrm{O}\right)$; na figura 6.4, aos complexos $R u^{I I}(O H)$ e $R u^{I I I}(O H)$; e, na figura 6.5, ao complexo $R u^{I V}(O)$. Para comparação, as distâncias características que demarcam o começo de cada $g(r)$, a posição do primeiro pico e a posição do primeiro vale, encontram-se sumarizadas nos gráficos pelas distâncias $r_{0}, r_{1}$ e $r_{2}$, respectivamente.

O posicionamento relativo entre os primeiros picos das $g(r)^{R u-O w}$ e $g(r)^{R u-H w}$ ou das $g(r)^{O-O w}$ e $g(r)^{O-H w}$ nos mostra como o solvente se organiza nas vizinhanças do centro metálico. O fato de observarmos um pico anterior ou posterior ao outro, em $g(r)$ diferentes, indica uma distribuição preferencial de oxigênios ou hidrogênios nessa micro região de solvatação dos complexos. Nos complexos $R u^{I I}\left(\mathrm{H}_{2} \mathrm{O}\right)$ e $\mathrm{Ru} u^{I I I}\left(\mathrm{H}_{2} \mathrm{O}\right)$, figura 6.3, as $g(r)$ que envolvem oxigênios de moléculas de água da solução apresentam o primeiro pico anterior ao primeiro pico das $g(r)$ que envolvem hidrogênios. Nos demais complexos, figuras 6.4 e 6.5 , observa-se o contrário. Isso acontece devido aos diferentes tipos de ligações de hidrogênio que são formadas entre os complexos e as moléculas de água da solução, tema que será discutido na próxima seção. 


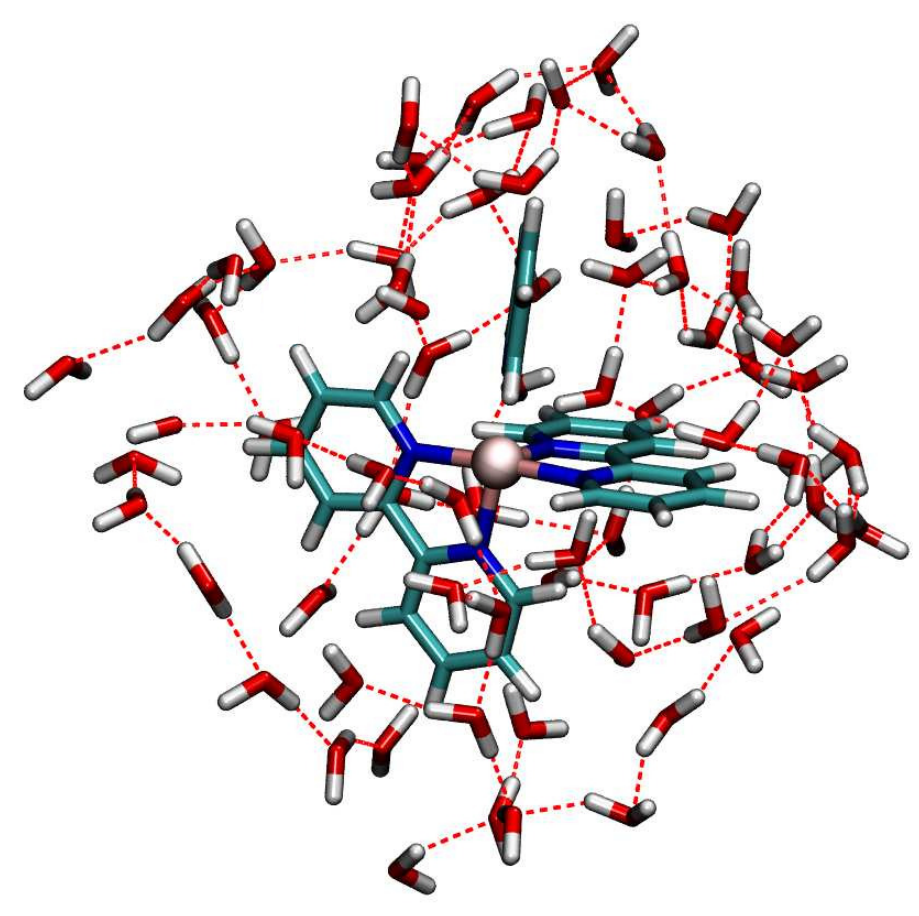

Figura 6.2 - Ilustração da primeira camada de solvatação do complexo $R u^{I I}\left(H_{2} O\right)$. As linhas tracejadas representam as ligações de hidrogênio entre as moléculas de água da solução. Configuração gerada a partir da simulação de MC do complexo em solução.

Nos complexos $R u^{I I}\left(\mathrm{H}_{2} \mathrm{O}\right)$ e $R u^{I I I}\left(\mathrm{H}_{2} \mathrm{O}\right)$, até uma distância de $r \approx 3.6 \AA$, os picos observados nas $g(r)$ envolvendo $R u$, referem-se apenas à molecula de água coordenada ao complexo. Em outras palavras, a integral da função $g(r)^{R u-O w}$ ou da função $g(r)^{R u-H w}$, até essa distância, é exatamente igual a 1 . Isso significa dizer que apenas a molécula de água coordenada é encontrada interagindo diretamente com o átomo de $R u$. Essa é uma observação importante, já que tanto nas simulações por $M C$ quanto por $M D$, a molécula de água coordenada interage com o restante do complexo apenas por interações do tipo não-ligadas, segundo o potencial de Lennard Jones Coulomb. Adicionalmente, a posição do pico na $g(r)^{R u-O w}$ reflete a distância entre $R u$ e $O$ na geometria otimizada em solução, mas agora com a presença explícita de solvente. Na geometria otimizada em solução, em que utilizamos modelo implícito de solvente (PCM), obtivemos as distâncias de $2.214 \AA 2.148$ $\AA$ entre $R u$ e $O$ nos complexos de $R u^{I I}\left(H_{2} O\right)$ e $R u^{I I I}\left(H_{2} O\right)$, nessa ordem. Em ambos os complexos, a posição do primeiro pico na $g(r)^{R u-O w}$ é observado em $r=2.3 \AA$ A. A princípio, essa informação indica-nos que as interações explícitas com o solvente, na região de micro solvatação desses complexos tem um papel predominante no posicionamento da molécula de água coordenada, independentemente do estado de oxidação do átomo de $R u$.

De um modo geral, a estrutura do solvente no entorno dos complexos de $R u$ coordenados com uma molécula de água é semelhante. Uma rápida inspeção na forma, e intensidade das 
(a)
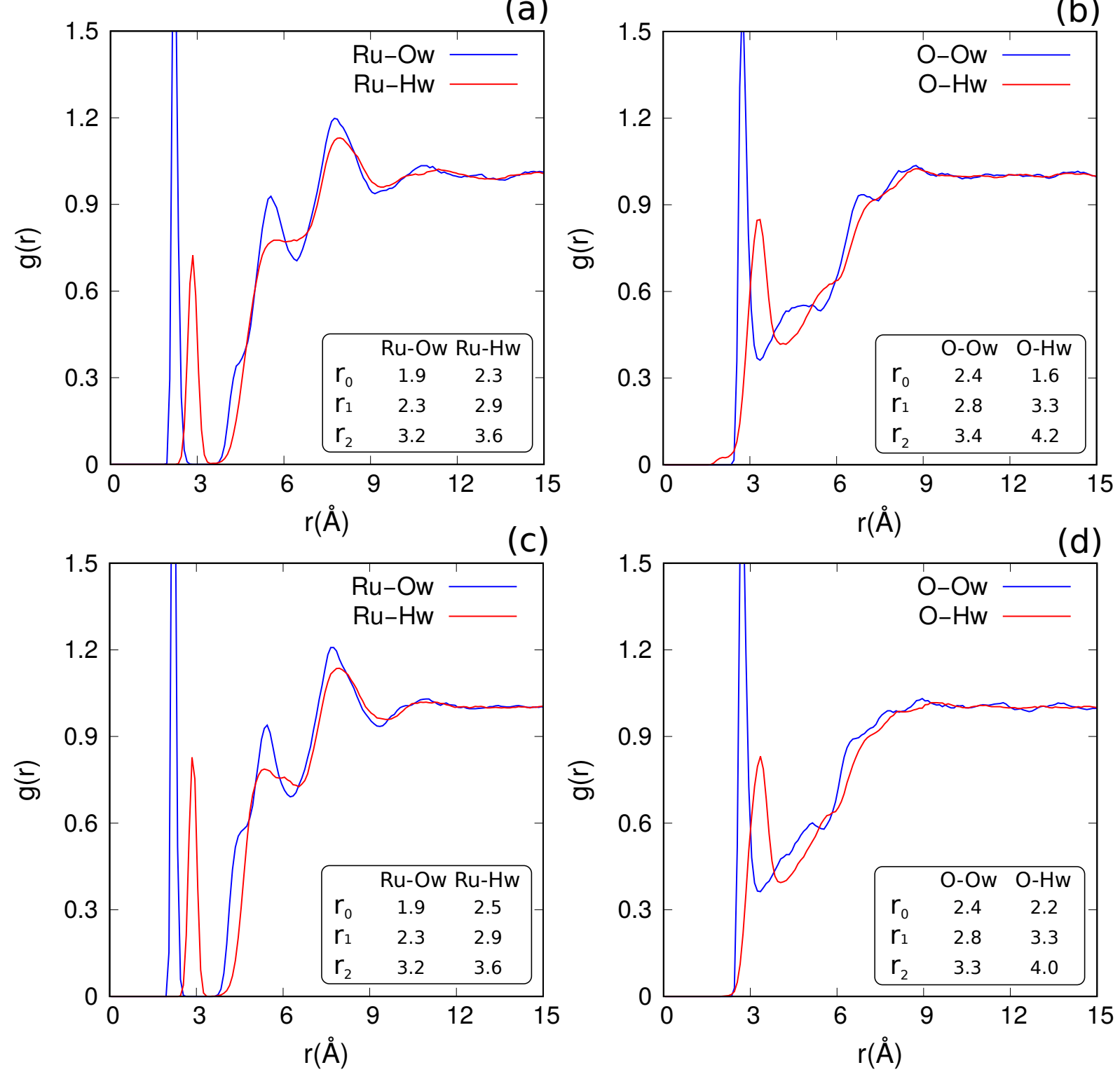

Figura 6.3 - Funções de distribuição radial de pares, $g(r)$, dos complexos $R u$-Aqua em solução: $R u^{I I}\left(\mathrm{H}_{2} \mathrm{O}\right)$ em (a) e (b), e $R u^{I I I}\left(\mathrm{H}_{2} \mathrm{O}\right)$ em (c) e (d). Os rótulos $\mathrm{Ow}$ e $H w$ representam oxigênios e hidrogênios de moléculas de água da solução, incluindo aquela que se coordena ao átomo de $R u$. O rótulo $O$ serve apenas para identificar o oxigênio da molécula de água coordenada, nas $g(r)$ entre essa molécula e as demais moléculas do solvente. As distâncias características que demarcam o começo de cada $g(r)$, a posição do primeiro pico e a posição do primeiro vale, encontram-se sumarizadas nos gráficos pelas distâncias $r_{0}, r_{1}$ e $r_{2}$, nessa ordem. Funções calculadas a partir das simulações de MC.

funções $g(r)$ e nos números apresentados nos gráficos da figura 6.3 revela grande similaridade na estrutura do solvente no entorno dos complexos $R u^{I I}\left(\mathrm{H}_{2} \mathrm{O}\right)$ e $R u^{I I I}\left(\mathrm{H}_{2} \mathrm{O}\right)$. Existe apenas uma diferença bastante notória nessa comparação, o valor de $r_{0}$ nas $g(r)^{O-H w}$, que vale 1.6 $\AA$ no complexo com oxidação II e $2.2 \AA$ no complexo com oxidação III. Esse resultado indica que existe uma pequena probabilidade de que para o complexo $R u^{I I}\left(H_{2} O\right)$, seja encontrada 
alguma molécula de água do solvente doando um próton numa possível ligação de hidrogênio com a molécula de água coordenada. Essa probabilidade é de fato bem pequena, dado a baixa intensidade da banda que se observa em $r \approx 2 \AA$ na $g(r)^{O-H w}$.

(a)
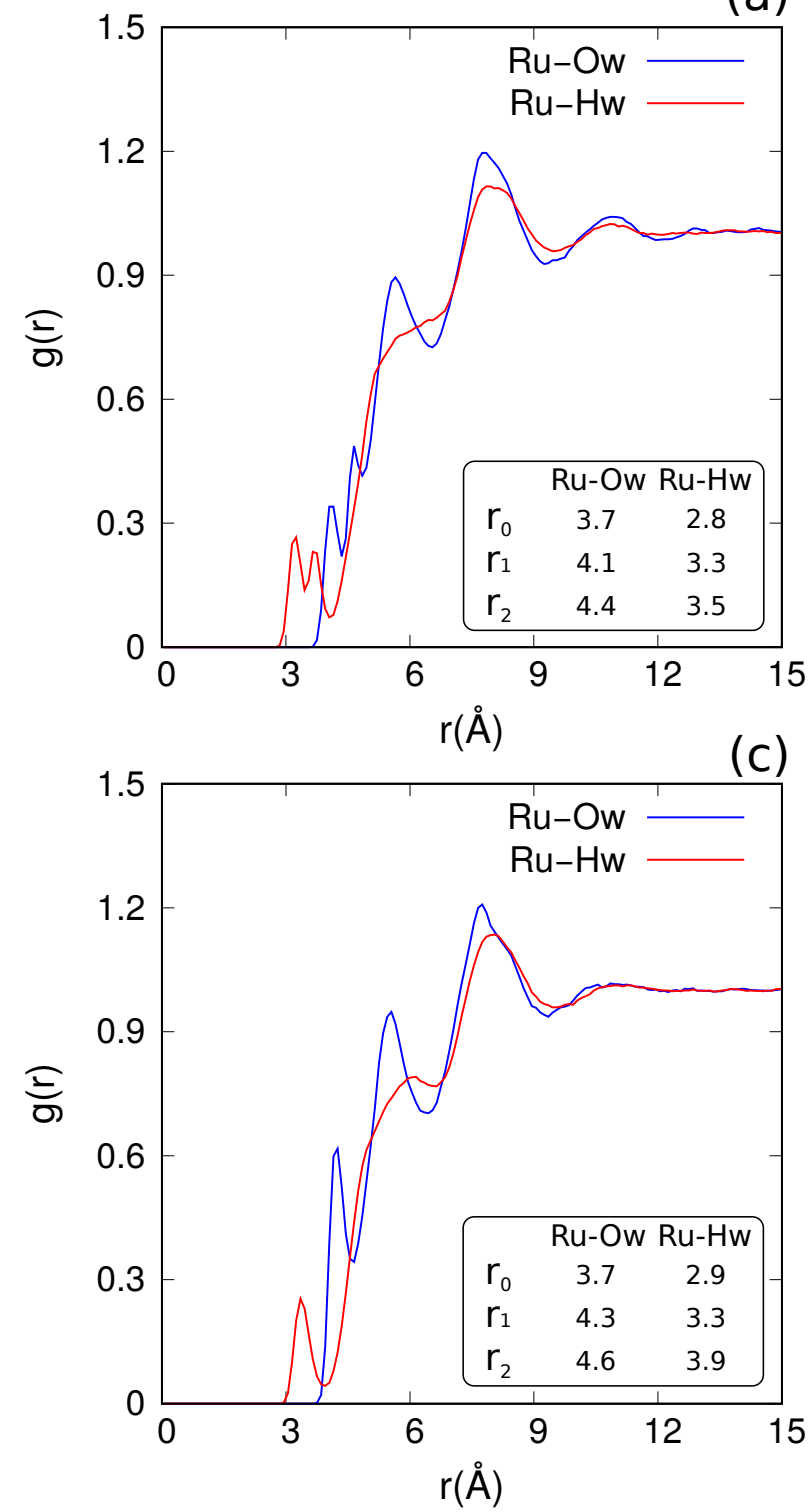

(b)
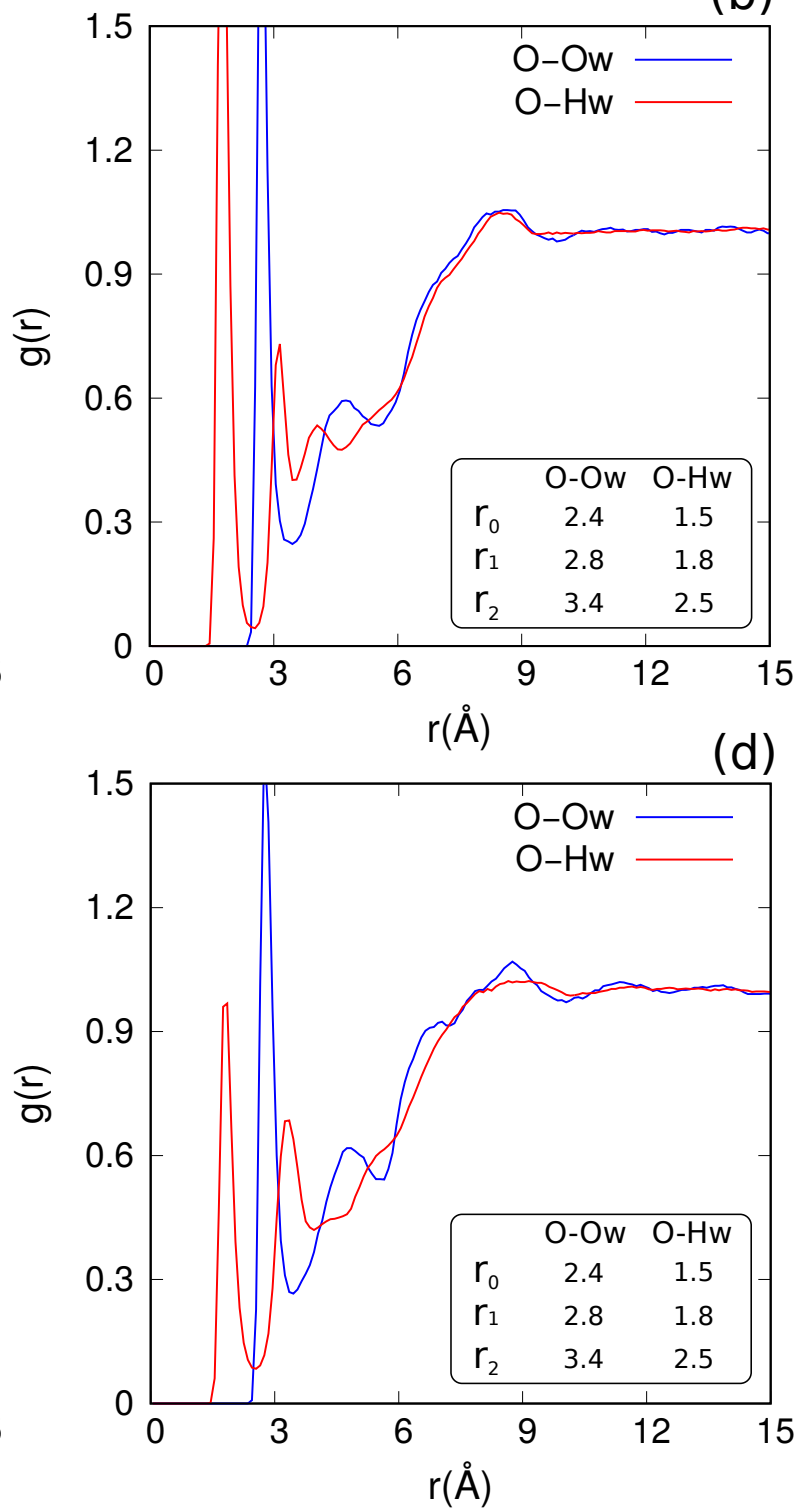

Figura 6.4 - Funções de distribuição radial de pares, $g(r)$, dos complexos $R u$-Hidróxido em solução: $R u^{I I}(O H)$ em (a) e (b), e $R u^{I I I}(O H)$ em (c) e (d). Os rótulos $O, O w$ e $H w$ representam o oxigênio do grupo hidróxido, e os oxigênios e hidrogênios das moléculas de água da solução, respectivamente. As distâncias características que demarcam o começo de cada $g(r)$, a posição do primeiro pico e a posição do primeiro vale, encontram-se sumarizadas nos gráficos pelas distâncias $r_{0}, r_{1}$ e $r_{2}$, nessa ordem. Funções calculadas a partir das simulações de MC.

Na figura 6.4, apresentamos as $g(r)^{R u-O w}, g(r)^{R u-H w}, g(r)^{O-O w}$ e $g(r)^{O-H w}$ para os complexos de $R u$ com a coordenação de um íon hidróxido, $R u^{I I}(O H)$ e $R u^{I I I}(O H)$. Como nesses complexos, o íon hidróxido foi tratado como parte do soluto, não contabilizamos os átomos de oxigênio e hidrogênio presentes nesse íon nas $g(r)^{R u-O w}$ e $g(r)^{R u-H w}$. De início, 
uma inspeção visual nas $g(r)$ calculadas para os dois complexos, revela também uma grande semelhança na estrutura do solvente no entorno desses complexos. Dentro dos limites de precisão adotados, o posicionamento dos primeiros picos nas $g(r)^{O-O w}$ e $g(r)^{O-H w}$, são idênticos para esses complexos. Identificados pelas posições $r_{0}, r_{1}$ e $r_{2}$ nos gráficos, notamos por exemplo que o máximo de intensidade desses picos, $r_{1}$, são observados em 2.8 e $1.8 \AA$ nas $g(r)^{O-O w}$ e $g(r)^{O-H w}$, respectivamente, para ambos os complexos. Todavia, indo além das similaridades, é perceptível que a intensidade do primeiro pico na $g(r)^{O-H w}$ é menor no complexo $R u^{I I I}(O H)$. Isso indica que no estado de oxidação $I I I$, esse complexo atrai uma menor densidade de hidrogênios de moléculas de água para as proximidades do íon hidróxido. Como veremos na próxima seção, isso ocorre porque o complexo $R u^{I I}(O H)$ realiza um número maior de ligações de hidrogênio, como aceitador de prótons, que o complexo $R u^{I I I}(O H)$.

(a)
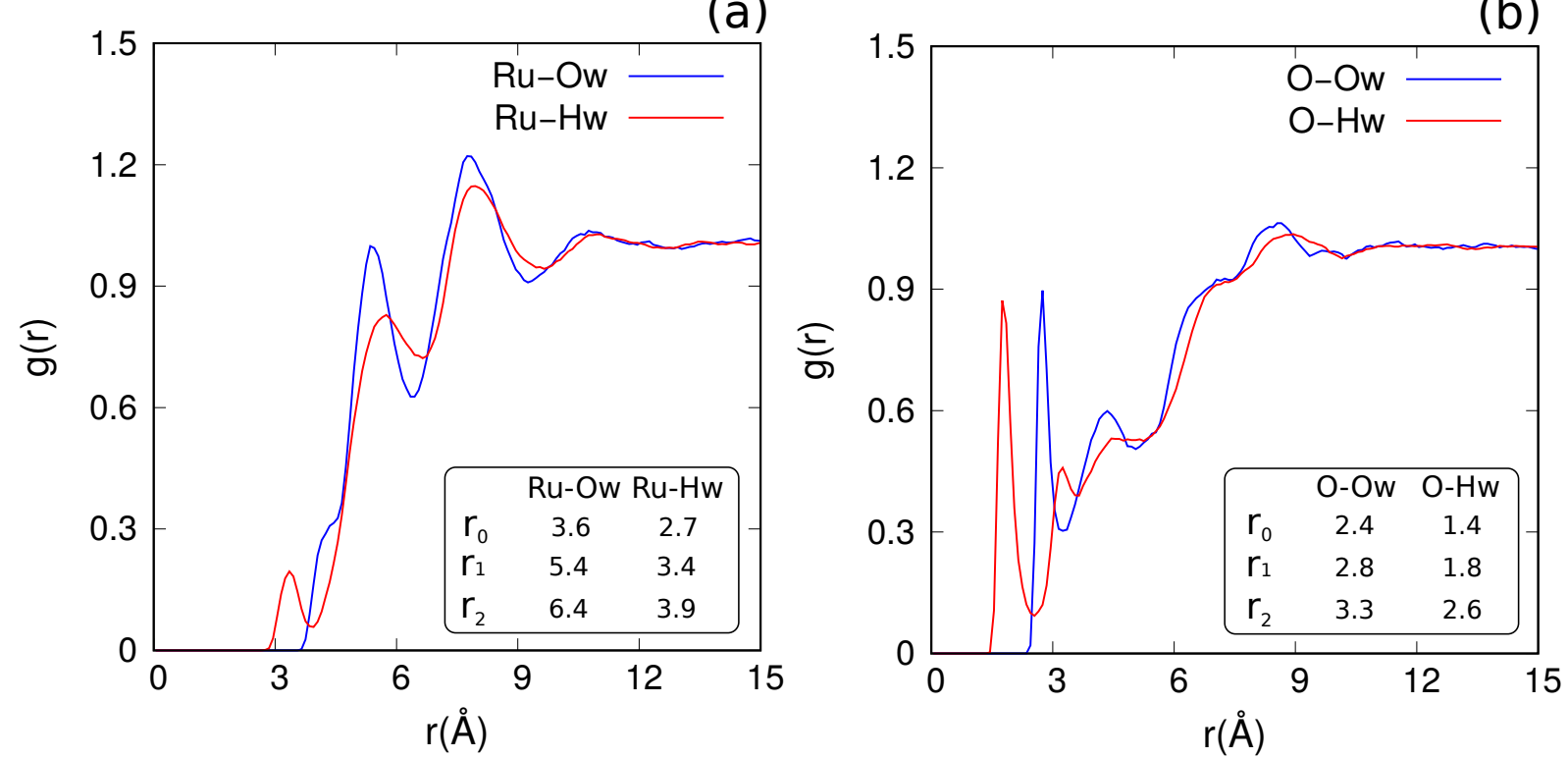

Figura 6.5 - Funções de distribuição radial de pares, $g(r)$, do complexo $R u$-Óxido em solução: $R u^{I V}(O)$ em (a) e (b). Os rótulos $O, O w$ e $H w$ representam o oxigênio do íon óxido coordenado à $R u$, e os oxigênios e hidrogênios das moléculas de água da solução, respectivamente. As distâncias características que demarcam o começo de cada $g(r)$, a posição do primeiro pico e a posição do primeiro vale, encontramse sumarizadas nos gráficos pelas distâncias $r_{0}, r_{1}$ e $r_{2}$, nessa ordem. Funções calculadas a partir das simulações de MC.

No tocante ao complexo $R u^{I V}(O)$, apresentamos na figura 6.5, as funções $g(r)^{R u-O w}$, $g(r)^{R u-H w}, g(r)^{O-O w}$ e $g(r)^{O-H w}$. Como antes, o íon óxido também foi tratado como parte do soluto, e portanto, não o contabilizamos na $g(r)^{R u-O w}$. A observação mais importante a ser feita está no posicionamento relativo do primeiro pico das $g(r)^{O-O w}$ e $g(r)^{O-H w}$. O posicionamento do primeiro pico na $g(r)^{O-H w}, r_{1}=1.8$, é anterior ao posicionamento do primeiro pico na $g(r)^{O-O w}, r_{1}=2.8$. Esse é um resultado intuitivo, já que o íon óxido possui uma carga negativa que necessariamente atrai os prótons da solução. Mas, adicionalmente, podemos extrair das $g(r)^{R u-O w}$ e $g(r)^{R u-H w}$ a informação de que nenhuma molécula de água da solução consegue se aproximar do centro metálico, positivamente carregado. A micro camada 
de solvatação que se forma nesse complexo, é preferencialmente constituída por moléculas de água que doam um próton para formar ligação de hidrogênio com o íon óxido.

Salientamos que não foram observadas diferenças significativas entre as $g(r)$ calculadas nas configurações geradas por MC ou por MD, e por isso, descartamos comparações entre os dois métodos.

\subsection{Ligações de hidrogênio intermolecular}

Nos complexos de $R u$-Aqua/Oxo, o centro metálico encontra-se protegido pelos seus ligantes de realizar interações específicas com as moléculas de água da solução. Por um lado, os ligantes bipiridina e piridina são grupos moleculares cujos átomos expostos ao solvente apresentam cargas atômicas pequenas, e que portanto interagem fracamente com o solvente. Por outro lado, os ligantes água, íon hidróxido, e íon óxido são aptos a realizar ligações de hidrogênio intermoleculares com as moléculas de água da solução. Para contabilizar o número de ligações de hidrogênio formadas em cada complexo, utilizamos dois critérios geométricos e um critério energético. Adotamos os critérios $r<3.5 \AA$ e $\theta<40$ graus para a distância máxima entre os átomos eletronegativos $X$ e $Y$ que participam da ligação, e o ângulo $X Y H$ de formação da ligação. Adicionalmente adotamos um critério energético segundo o qual só são consideradas ligações de hidrogênio aquelas que possuem uma energia de interação de pelo menos $-0.01 \mathrm{kcal} / \mathrm{mol}$. Com esses critérios, e para um conjunto de 20000 configurações da solução, igualmente espaçadas, e obtidas das simulações de $\mathrm{MC}$, computamos o número médio de ligações de hidrogênio realizado por cada complexo de $R u$-Aqua/Oxo, e investigamos as distribuições de distância, ângulo e energia dessas ligações.

Nos complexos coordenados com uma molécula de água, observamos principalmente a formação de ligações de hidrogênio do tipo $O-H \cdots O w$, onde a molécula de água coordenada ao complexo doa prótons para formar ligações de hidrogênio com até duas moléculas de água da solução. Nos complexos coordenados com um íon hidróxido, podemos ter a formação de ligações de hidrogênio do tipo $O-H \cdots O w$, mas também do tipo $O \cdots H w-O w$. Nesse segundo tipo, o oxigênio do íon hidróxido aceita prótons doados por moléculas de água do solvente. O complexo $R u^{I V}(O)$ é o único incapaz de doar prótons para formar ligações de hidrogênio, e portanto só realiza ligações de hidrogênio do segundo tipo, $O \cdots H w-O w$. Na figura 6.6, apresentamos uma ilustração das ligações de hidrogênio realizadas por cada complexo.

Na figura 6.7, apresentamos as distribuições de distância $r(\AA)$, ângulo $\theta$ (graus) e energia $\mathrm{E}(\mathrm{kcal} / \mathrm{mol})$ das ligações de hidrogênio entre os complexos de $R u$-Aqua/Oxo e o solvente. Conforme os critérios adotados para contabilizar essas ligações, as distribuiç̃ões respeitam os critérios de $r<3.5 \AA$, $\theta<40$ graus e $\mathrm{E}<-0.01 \mathrm{kcal} / \mathrm{mol}$. As distribuições de distância são em geral unimodais e apresentam grandes semelhanças entre si. Variam de aproximadamente 2.4 a $3.5 \AA$, com valores médios entre 2.8 e $2.9 \AA$, e valores de mediana ou moda entre 2.7 e 
$2.9 \AA$. As distribuições de ângulo também apresentam a característica unimodal, e os valores médios também são relativamente parecidos. Nos complexos $R u^{I I}\left(H_{2} O\right)$ e $R u^{I I I}\left(H_{2} O\right)$, o ângulo médio fica em torno de 14 graus e a mediana em torno de 12 graus. Nos complexos $R u^{I I}(O H)$ e $R u^{I I I}(O H)$, o ângulo médio fica em torno de 12 graus e a mediana em torno de 10 graus. Isso representa um deslocamento de 2 graus para baixos ângulos em relação aos complexos coordenados com uma molécula de água. Já no complexo $R u^{I V}(O)$, o ângulo médio se desloca para 16 graus e a mediana para 14 graus. Concluímos assim, que os complexos com a coordenação de 1 íon hidróxido oferecem uma pequena resistência à formação de ligações de hidrogênio em altos ângulos.
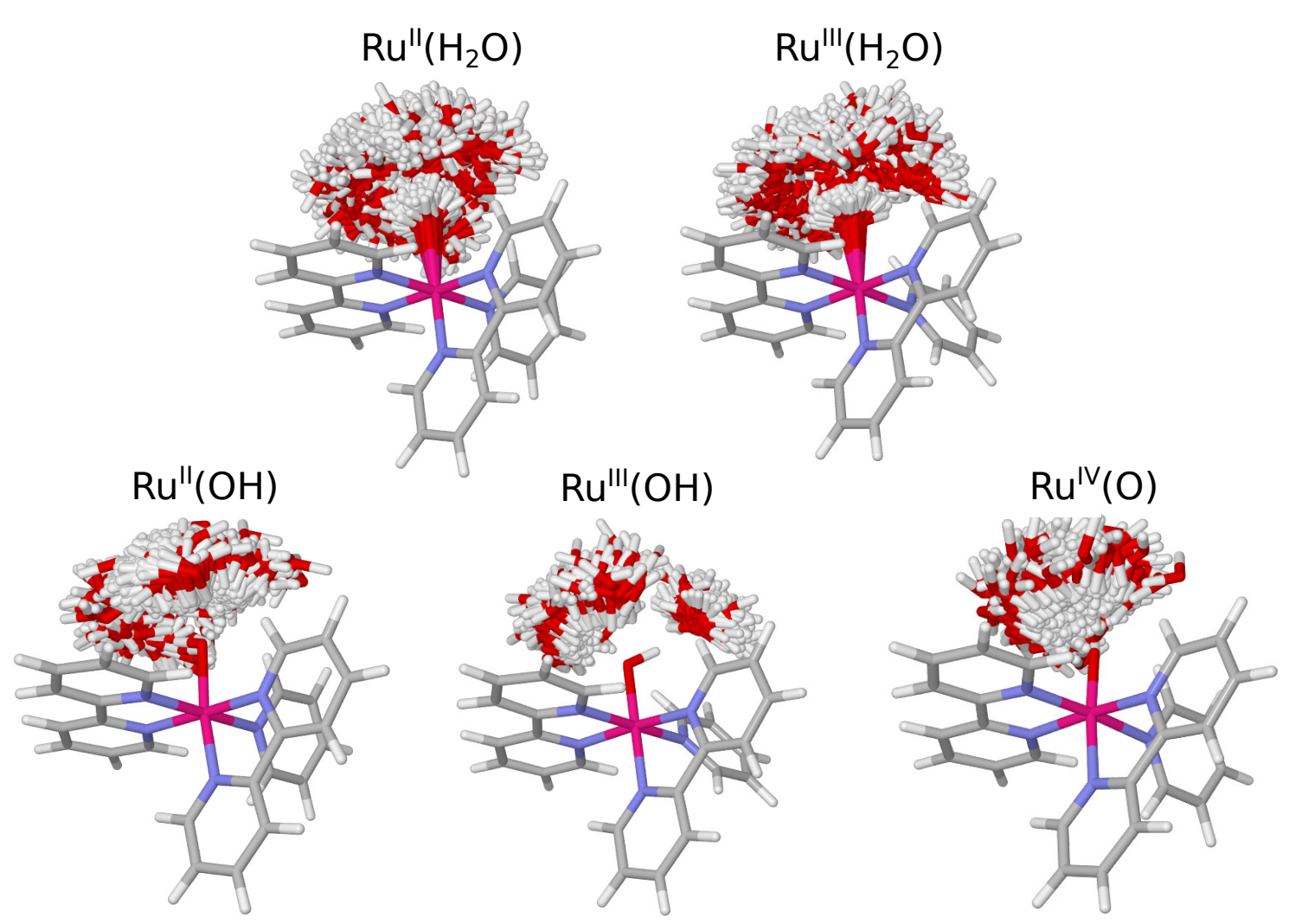

Figura 6.6 - Ilustração de ligações de hidrogênio nos complexos Ru-Aqua/Oxo. Encontram-se superpostas um total de 100 configurações, estatisticamente descorrelacionadas, do sistema soluto + moléculas de água que realizam ligações de hidrogênio, obtidas das simulações de MC.

No que diz respeito às distribuições de energia, temos um cenário mais diversificado. Observamos que as distribuições de energia tem um caráter unimodal para os complexos $R u^{I I}\left(H_{2} O\right), R u^{I I I}\left(H_{2} O\right)$ e $R u^{I V}(O)$, e bimodal para os complexos $R u^{I I}(O H)$ e $R u^{I I I}(O H)$. Essa característca bimodal presente nesses complexos se deve a capacidade desses de realizar ligações de hidrogênio tanto como aceitadores como doadores de prótons. $E$ as energias relativas às ligações dos tipos $O-H \cdots O w$ e $O \cdots H w-O w$ apresentam distribuições diferentes, e por isso a distribuição total de energia perde o caráter unimodal.

Considerando a princípio as distribuições totais de energia, observamos que o complexo 


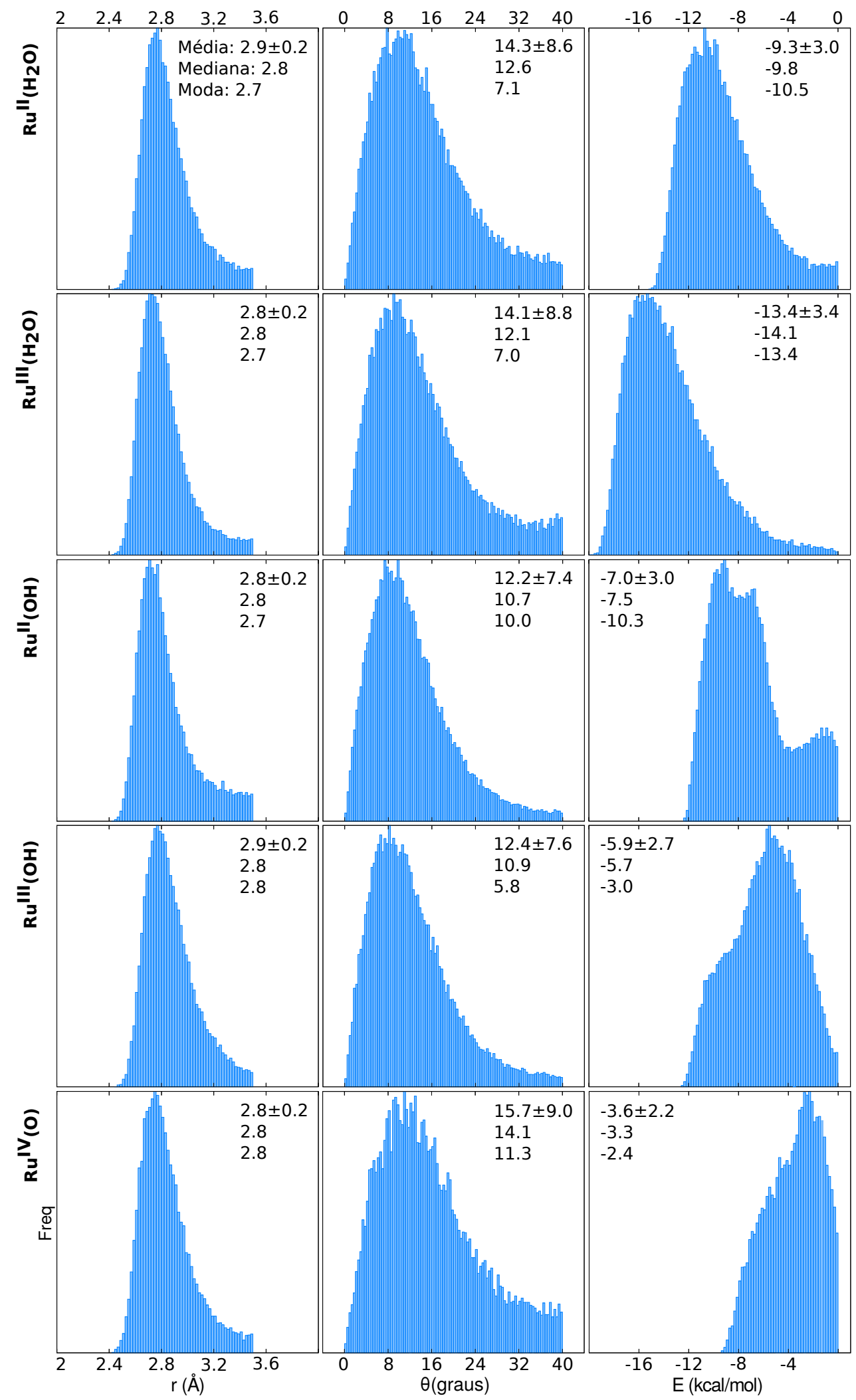

Figura 6.7 - Distribuições de distância $r(\AA)$, ângulo $\theta$ (graus) e energia $E(\mathrm{kcal} / \mathrm{mol})$ das ligações de hidrogênio entre os complexos de $R u$-Aqua/Oxo e o solvente. Distribuições geradas a partir das simulações de MC. 


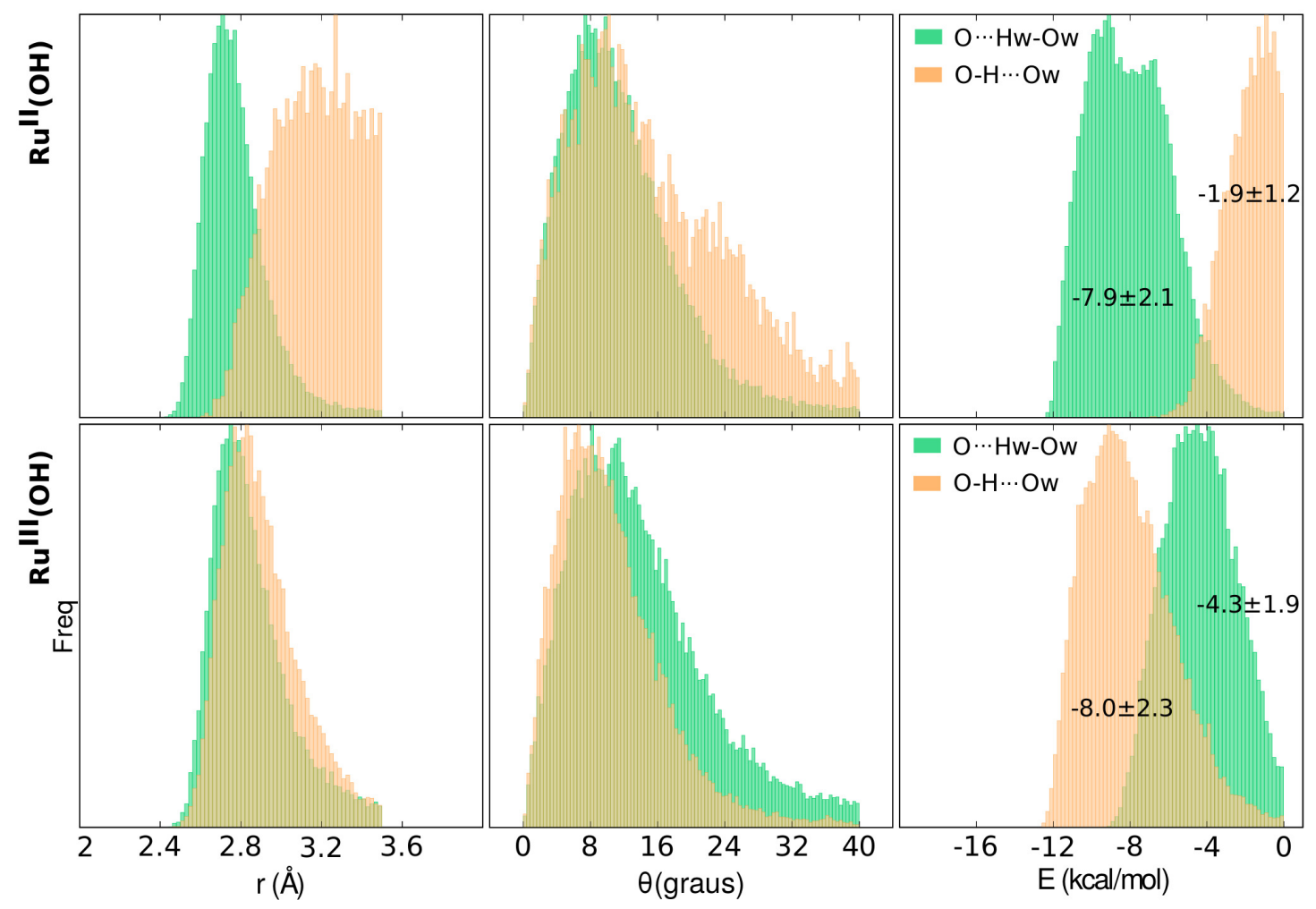

Figura 6.8 - Distribuições de distâncias $r(\AA)$, ângulos $\theta$ (graus) e energias $E(\mathrm{kcal} / \mathrm{mol})$ das ligações de hidrogênio entre os complexos de $R u$-Hidróxido e o solvente. Nas cores verde e amarelo, temos as distribuições relativas às ligações de hidrogênio dos tipos $O \cdots H w-O w$ e $O-H \cdots O w$, respectivamente. Distribuições geradas a partir das simulações de MC.

$R u^{I I I}\left(H_{2} \mathrm{O}\right)$ estabelece com o solvente as ligações de hidrogênio mais intensas, de -13.4 $\mathrm{kcal} / \mathrm{mol}$ na média, seguido pelo complexo $R u^{I I}\left(\mathrm{H}_{2} \mathrm{O}\right)$, com energia média de $-9.3 \mathrm{kcal} / \mathrm{mol}$. As ligações de hidrogênio mais fracas são realizadas pelo complexo $R u^{I V}(O)$, com energia média em torno de $-3.6 \mathrm{kcal} / \mathrm{mol}$.

Dado o caráter bimodal das distribuições de energia das ligações de hidrogênio realizadas por $R u^{I I}(O H)$ e $R u^{I I I}(O H)$, separamos para esses complexos, as distribuições de distância, ângulo e energia segundo os tipos de ligações de hidrogênio. Na figura 6.8, apresentamos nas cores amarelo e verde as distribuições relativas às ligações de hidrogênio dos tipos $O-H \cdots O w$ e $O \cdots H w-O w$, nessa ordem. Nas distribuições de energia, distinguimos os dois tipos de ligações, e notamos ainda que no complexo $R u^{I I}(O H)$, as ligações do tipo $O-H \cdots O w$ apresentam valores de energia menos negativos que as ligações do tipo $O \cdots H w-O w$, enquanto que para o complexo $R u^{I I I}(O H)$, temos o inverso disso. As ligações do tipo $O-H \cdots O w$ apresentam valores médios de energia de $-1.9 \mathrm{kcal} / \mathrm{mol}$ em $R u^{I I}(O H)$ e -8.0 $\mathrm{kcal} / \mathrm{mol}$ em $R u^{I I I}(O H)$. As ligações do tipo $O \cdots H w-O w$ apresentam valores médios de energia de $-7.9 \mathrm{kcal} / \mathrm{mol}$ em $R u^{I I}(O H)$ e $-4.3 \mathrm{kcal} / \mathrm{mol}$ em $R u^{I I I}(O H)$. A explicação para esse resultado pode ser encontrada nas distribuições de distância e ângulo dessas ligações. No caso do complexo $R u^{I I}(O H)$, verificamos que as ligações de hidrogênio do tipo $O-H \cdots O w$ 
são formadas à distâncias e ângulos, na média, $0.4 \AA$ e 4 graus, maiores que nas ligações $O \cdots H w-O w$. No caso do complexo $R u^{I I I}(O H)$, não verificamos grande mudança nas distâncias de formação das ligações de hidrogênio, e portanto uma possível justificativa a se considerar é que as ligações do tipo $O-H \cdots O w$ são formadas à ângulos, na média, 3 graus menores que nas ligações $O \cdots H w-O w$. Está claro que um aumento na distância de formação das ligações de hidrogênio leva a uma diminuição na energia de interação dos átomos envolvidos na ligação, já as mudanças angulares de apenas 3, 4 graus devem ser consideradas com cuidado.

Na tabela 6.1, apresentamos o número médio de ligações de hidrogênio $(N)$ e seus respectivos valores médios de distância $(r)$, ângulo $(\theta)$ e energia $(E)$, segundo os complexos de $R u$-Aqua/Oxo e os tipos de ligações, $O-H \cdots O w$ e $O \cdots H w-O w$.

Tabela 6.1 - Número médio $(N)$, distância $(r)$, ângulo $(\theta)$ e energia $(E)$, das ligações de hidrogênio realizadas pelos complexos de $R u$-Aqua/Oxo em solução, segudo os tipos de ligações, $O-H \cdots O w$ e $O \cdots H w-O w$. Propriedades obtidas a partir das simulações de MC.

\begin{tabular}{ccccccccc}
\hline & \multicolumn{4}{c}{$O-H \cdots O w$} & \multicolumn{4}{c}{$O \cdots H w-O w$} \\
& $N$ & $r(\AA)$ & $\theta$ (graus) & $E(\mathrm{kcal} / \mathrm{mol})$ & $N$ & $r(\AA)$ & $\theta($ graus $)$ & $E(\mathrm{kcal} / \mathrm{mol})$ \\
\hline$R u^{I I}\left(\mathrm{H}_{2} O\right)$ & 2.0 & $2.9 \pm 0.2$ & $14.9 \pm 8.8$ & $-9.2 \pm 3.0$ & 0.03 & $3.1 \pm 0.2$ & $20.5 \pm 11.1$ & $-0.9 \pm 0.7$ \\
$R u^{I I I}\left(H_{2} O\right)$ & 2.1 & $2.8 \pm 0.2$ & $14.0 \pm 8.8$ & $-13.5 \pm 3.4$ & 0.01 & $3.3 \pm 0.1$ & $33.9 \pm 5.3$ & $-2.5 \pm 1.7$ \\
$R u^{I I}(O H)$ & 0.4 & $3.2 \pm 0.2$ & $15.2 \pm 9.1$ & $-1.9 \pm 1.2$ & 2.0 & $2.8 \pm 0.2$ & $11.6 \pm 6.9$ & $-7.9 \pm 2.1$ \\
$R u^{I I I}(O H)$ & 1.0 & $2.9 \pm 0.2$ & $10.4 \pm 6.3$ & $-8.0 \pm 2.3$ & 1.3 & $2.9 \pm 0.2$ & $13.8 \pm 8.0$ & $-4.3 \pm 1.9$ \\
$R u^{I V}(O)$ & 0.0 & 0 & 0 & 0 & 1.1 & $2.8 \pm 0.2$ & $15.7 \pm 9.0$ & $-3.7 \pm 2.2$ \\
\hline
\end{tabular}

Seja para o complexo $R u^{I I}\left(\mathrm{H}_{2} \mathrm{O}\right)$ ou $R u^{I I I}\left(\mathrm{H}_{2} \mathrm{O}\right)$, observamos em média a formação de duas ligações de hidrogênio, em que dois prótons são doados para duas moléculas de água da solução. Apesar da semelhança no número de ligações, como já destacamos anteriormente, as ligações realizadas por $R u^{I I}\left(H_{2} \mathrm{O}\right)$ são na média $70 \%$ menos intensas que as ligações realizadas por $\mathrm{Ru}^{I I I}\left(\mathrm{H}_{2} \mathrm{O}\right)$. Fato esse que se justifica pela maior carga total do complexo no estado de oxidação $I I I$. Apesar da possibilidade desses complexos realizarem ligações de hidrogênio do tipo $O \cdots H w-O w$, os números apresentados na tabela nos garantem que esse é um evento muito raro para ambos os complexos. Na oxidação II computamos 0.03 ligações desse tipo, e na oxidação $I I I$ computamos 0.01 . Esses números significam que das 20 mil configurações analisadas, observamos 600 configurações em que o complexo na oxidação $I I$ foi capaz de formar uma ligação de hidrogênio com a solução aceitando um próton, e, 200 configurações na oxidação $I I I$. São números pequenos, comparados a quantidade observada de ligações de hidrogênio do tipo $O-H \cdots O w$, entretanto, essa pequena probabilidade de se observar um hidrogênio da solução participando de uma ligação de hidrogênio com esses complexos, foi sinalizada anteriormente na $g(r)^{O-H w}$ do complexo $R u^{I I}\left(H_{2} O\right)$, figura 6.3 (b). 
O complexo $R u^{I I}(O H)$ realiza em média 0.4 ligações de hidrogênio como doador de prótons, e 2 ligações de hidrogênio como aceitador. Enquanto que o complexo $R u^{I I I}(O H)$ realiza em média 1 ligação de hidrogênio como doador de prótons, e outras 1.3 ligações de hidrogênio como aceitador. Donde concluímos que existe uma preferência pela formação de ligações de hidrogênio do tipo $O \cdots H w-O w$ por esses complexos. Ademais, o complexo $R u^{I V}(O)$ realiza, na média, 1.1 ligações de hidrogênio como aceitador de prótons.

De um modo geral, a interação coulombiana tem um papel fundamental na formação de ligações de hidrogênio em soluções. Pequenas alterações nas cargas atômicas de uma molécula podem modificar completamente as características das ligações de hidrogênio formadas por essa molécula e a solução. Nos complexos que apresentam coordenação com um íon hidróxido, por exemplo, conseguimos justificar o número de ligações de hidrogênio dos tipos $O-H \cdots O w$ e $O \cdots H w-O w$, olhando apenas para as cargas atômicas dos átomos de oxigênio e hidrogênio do íon hidróxido. As cargas atômicas do oxigênio valem -0.89 e 0.76 , e do hidrogênio valem 0.29 e 0.39, para o complexos nas oxidações $I I$ e $I I I$, respectivamente. Assim, entendemos porque o número de ligações de hidrogênio do tipo $O \cdots H w-O w$ é maior na oxidação $I I$, e do tipo $O-H \cdots O w$ é maior na oxidação $I I I$. Notadamente, a carga de $O$ é maior na oxidação $I I$ e logo atrai mais prótons da solução, e a carga de $H$ é maior na oxidação $I I I$, e logo atrai mais oxigênios da solução. Além disso, o número de ligações de hidrogênio do tipo $O \cdots H w-O w$, realizadas pelos complexos que se coordenam com os íons hidróxido e óxido cresce com a carga de $O$, que vale -0.57, -0.76 e -0.89 em $R u^{I V}(O), R u^{I I I}(O H)$ e $R u^{I I}(O H)$, respectivamente.

\subsubsection{Tempo de vida das ligações de hidrogênio}

À título de compreender a dinâmica das ligações de hidrogênio nas soluções de complexos de $R u$-Aqua/Oxo, calculamos o tempo de vida médio das ligações de hidrogênio envolvendo os complexos e a solução e envolvendo as moléculas de água na primeira camada de solvatação. Para comparação, calculamos também o tempo de vida médio das ligações de hidrogênio da água pura. Conforme detalhado no capítulo de métodos, o tempo de vida médio de uma ligação de hidrogênio pode ser obtido a partir da integral da função de auto correlação das ligações de hidrogênio. Na figura 6.9, apresentamos as funções de auto correlação calculadas para as ligações de hidrogênio entre os complexos e a solução (a), entre as moléculas de água na primeira camada de solvatação (b), e entre moléculas de água em solução pura (linha tracejada em a ou b).

Os valores calculados de tempo de vida são apresentados na tabela 6.2. Definimos por $\tau_{L I G}$ o tempo de vida das ligações de hidrogênio entre os complexos e a solução, e por $\tau_{1 C S}$ o tempo de vida das ligações de hidrogênio entre moléculas de água na primeira camada de solvatação. Uma ressalva importante: para os complexos $R u^{I I}\left(\mathrm{H}_{2} \mathrm{O}\right)$ e $R u^{I I I}\left(\mathrm{H}_{2} \mathrm{O}\right)$, optamos por excluir a molécula de água coordenada das análises na primeira camada de solvatação. Assim, o 
(a)

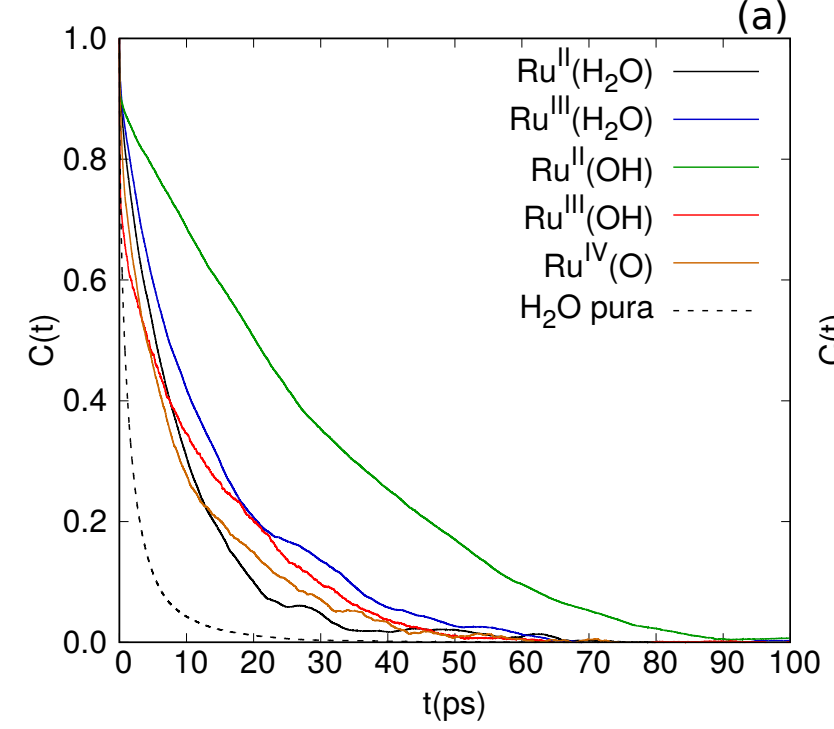

(b)

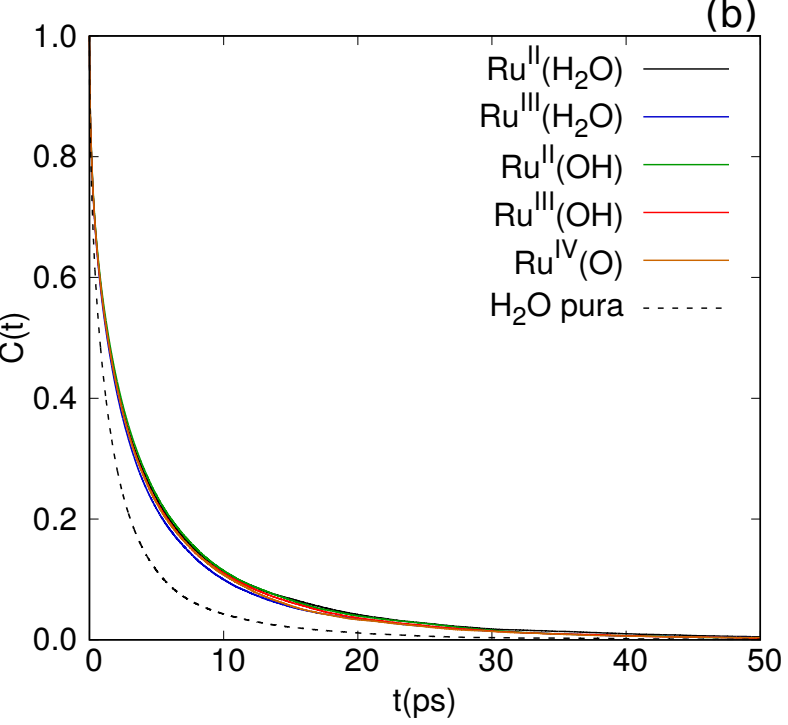

Figura 6.9 - Funções de auto correlação $(C(t))$ das ligações de hidrogênio envolvendo os complexos de $R u$-Aqua/Oxo e a solução, e envolvendo as moléculas de água que compõem a primeira camada de solvatação. Para os complexos $R u^{I I}\left(H_{2} O\right)$ e $R u^{I I I}\left(H_{2} \mathrm{O}\right)$, a molécula de água coordenada é desprezada nos cálculos. Funções calculadas a partir das simulações de MD.

tempo de vida calculado para as ligações de hidrogênio na primeira camada de solvatação não é diretamente afetado pela dinâmica das ligações de hidrogênio na região de microsolvatação dos complexos.

Analisando os valores apresentados na tabela 6.2, observamos que as ligações de hidrogênio realizadas entre os complexos e a solução apresentam um tempo de vida longo. Na primeira coluna da tabela, $\tau_{L I G}$ varia de aproximadamente $8 \mathrm{ps}$ até $31 \mathrm{ps}$. As ligações de hidrogênio entre moléculas de água na primeira camada de solvatação também apresentam um tempo de vida relativamente longo, com $\tau_{1 C S}$ em torno de $4.6 \mathrm{ps}$. Para comparação, o tempo de vida de ligações de hidrogênio entre moléculas de água numa solução pura foi calculado em $2.7 \mathrm{ps}$. O tempo de vida para ligações de hidrogênio é muito dependente do campo de força adotado. Para água pura, Antipova e Petrenko (2012) ${ }^{[240]}$ calcularam, por Dinâmica Molecular, tempos de vida igual a $3.04 \mathrm{ps}, 2.24 \mathrm{ps}$ e $3.70 \mathrm{ps}$ adotando os modelos de água SPC, ${ }^{[241]}$ TIP3P e TIP4P, ${ }^{[242]}$ respectivamente.

O longo tempo de vida observado nas ligações de hidrogênio entre os complexos e a solução revela-nos que a mobilidade das moléculas de água do solvente na região de microsolvatação dos complexos é muito menor que na água pura. De um ponto de vista de interação coulombiana, até conseguimos entender por exemplo, o porquê de o complexo $R u^{I I}(O H)$ realizar ligações de hidrogênio com um tempo de vida mais longo, de $31 \mathrm{ps}$. Nesse caso em específico, o oxigênio do íon hidróxido possui uma carga atômica mais negativa (-0.89) que a carga atômica de um oxigênio de uma molécula de água (-0.86), logo, tem a capacidade de formar ligações de hidrogênio mais estáveis que a solução. Mas, mesmo para esse complexo, é difícil acreditar que uma variação de apenas -0.03 na carga do oxigênio, já seria capaz de produzir um efeito 
Tabela 6.2 - Tempo de vida (em ps) das ligações de hidrogênio envolvendo os complexos de $R u$-Aqua/Oxo e a solução $\left(\tau_{L I G}\right)$, e envolvendo as moléculas de água que compõem a primeira camada de solvatação $\left(\tau_{1 C S}\right)$. Para os complexos $R u^{I I}\left(H_{2} O\right)$ e $R u^{I I I}\left(\mathrm{H}_{2} \mathrm{O}\right)$, a molécula de água coordenada é desprezada nos cálculos de $\tau_{1 C S}$. Tempos de vida calculados a partir das simulações de MD.

\begin{tabular}{ccc}
\hline & $\tau_{L I G}(p s)$ & $\tau_{1 C S}(p s)$ \\
\hline$R u^{I I}\left(H_{2} O\right)$ & $8.86 \pm 0.44$ & $4.44 \pm 0.17$ \\
$R u^{I I I}\left(H_{2} O\right)$ & $14.02 \pm 1.12$ & $4.45 \pm 0.17$ \\
$R u^{I I}(\mathrm{OH})$ & $31.00 \pm 2.73$ & $4.67 \pm 0.17$ \\
$R u^{I I I}(\mathrm{OH})$ & $13.69 \pm 1.35$ & $4.69 \pm 0.18$ \\
$R u^{I V}(\mathrm{O})$ & $8.55 \pm 0.96$ & $4.74 \pm 0.13$ \\
$\mathrm{H}_{2} \mathrm{O}$ pura & \multicolumn{2}{c}{$2.70 \pm 0.04$} \\
\hline
\end{tabular}

tão grande no tempo de vida de uma ligação de hidrogênio. No complexo $R u^{I V}(O)$, o íon óxido (carga -0.57) é bem menos competitivo que um oxigênio de uma molécua de água, e ainda assim observamos um longo tempo de vida das ligações de hidrogênio realizadas entre esse complexo e a solução, $\tau_{L I G}=8.55 \mathrm{ps}$.

Em uma solução de água pura, uma molécula de água realiza em média 4 ligações de hidrogênio. Cada molécula de água é assim disputada por outras 4 moléculas de água na sua primeira vizinhança. Essa competitividade eleva a probabilidade de que determinadas ligações de hidrogênio sejam desfeitas e outras sejam formadas. Quando temos uma molécula de água, ou íons hidróxido ou óxido, coordenados a um complexo de $R u$, encontramos uma situação atípica: esses ligantes só conseguem realizar ligações de hidrogênio por umas das faces do complexo a que se coordenam; e por estarem fortemente ligados ao centro metálico, passam a depender da dinâmica do complexo como um todo para fazer ou desfazer ligações de hidrogênio com a solução. Conforme veremos na próxima seção, o coeficiente de difusão dos complexos de $R u$-Aqua/Oxo é quase 3 vezez menor que o coeficiente de difusão de uma molécula de água em solução pura. Em partes, isso justifica os tempos de vida mais longos das ligações de hidrogênio na região de microsolvatação dos complexos.

Por outro lado, na primeira camada de solvatação, as ligações de hidrogênio também apresentam tempos de vida mais longos que em água pura. Nesse caso, podemos buscar uma explicação analisando a estrutura formada por essas ligações de hidrogênio no entorno dos complexos. É conhecido na literatura que moléculas apolares tendem a apresentar um caráter hidrofóbico, o que induz a formação de "jaulas"aquáticas no entorno da molécula. Essas "jaulas", também conhecidas por clatratos, são mantidas por ligações de hidrogênio entre as moléculas de água que as formam. Do ponto de vista termodinâmico, a formação de uma estrutura organizada em solução, como é o caso dos clatratos, causa uma redução na entropia do sistema. Uma variação $d G$ na energia livre de um sistema termodinâmico em equilíbrio, à pressão e temperatura constantes, pode ser expressa como: $d G=d U+p d V-T d S$, onde $\mathrm{p}, \mathrm{V}, \mathrm{T}, \mathrm{U}$ e $\mathrm{S}$ representam pressão, volume, temperatura, energia interna, e entropia. Se 
considerarmos que a formação do clatrato é um evento de natureza espontânea, então $d G$ deve ser negativo. Mas, como a formação do clatrato causa uma redução de entropia, isto é $d S<0$, então só é possível termos $d G<0$ se $d U$ ou $p d V$ forem negativos. Como já assumimos $p$ contante e a variação de volume devido a formação do clatrato é um temo positivo, então a variação na energia interna do sistema deve ser menor que zero. Isso significa dizer que as ligações de hidrogênio que formam o clatrato devem apresentar uma energia de interação mais negativa, sendo portanto mais estáveis. Mas ora, isso então justifica a observação de ligações de hidrogênio com tempos de vida mais longos na primeira camada de solvatação dos complexos de $R u$-Aqua/Oxo. Apesar de não estamos calculando a energia de interação entre as moléculas de água que formam o clatrato, o tempo de vida das ligações de hidrogênio é uma propriedade de natureza dinâmica que está intimamente relacionada à energia de interação entre os átomos participantes. Energias de interação mais negativas implicam em ligações de hidrogênio com tempos de vida mais longos, explicando assim os resultados obtidos.

\subsection{Difusão de massa}

A mobilidade de moléculas carregadas em solução é tema de interesse tanto na físicoquímica orgânica quanto inorgânica. Os processos que envolvem a fotossíntese artificial também dependem de fatores como a mobilidade dos complexos na solução, por exemplo, nas reações que levam à formação de dímeros. Para investigar a mobilidade dos complexos na solução, calculamos os coeficientes de difusão de massa dos complexos a partir do ajuste linear dos deslocamentos quadráticos médios (MSD). À guisa de exemplificação, apresentamos na figura 6.10, as curvas de MSD calculadas para o complexo $R u^{I I}\left(H_{2} O\right)$, para 5 simulações independentes (com condições iniciais diferentes), de $10 \mathrm{~ns}$ cada.

Entre 0 e 2 ns observamos que as curvas de MSD são lineares, e como é do caráter estatístico do MSD, após um longo tempo de simulação, observamos uma perda de linearidade. Conforme detalhado no capítulo de métodos, o coeficiente de difusão $D$ pode ser calculado em termos do coeficiente angular da curva de MSD, na região em que essa se comporta de maneira linear. Utilizando então o método dos mínimos quadrados, ajustamos retas no intervalo de 0 a 2 ns e calculamos o coeficiente de difusão dos complexos de Ru-Aqua/Oxo. Como critério estatístico, realizamos 5 simulações independentes de $10 \mathrm{~ns}$ para cada um dos complexos, e obtivemos o coeficiente de difusão como uma média sobre os coeficientes calculados para cada simulação. Os valores obtidos são apresentamos na tabela 6.3.

Os coeficientes de difusão calculados são similares entre os complexos de $R u$-Aqua/Oxo. Dentro da margem dos desvios padrões calculados, podemos afirmar que os complexos apresentam a mesma mobilidade em solução. Os valores obtidos para $D$ variam entre $0.69 \times 10^{-5}$ $\mathrm{cm}^{2} / \mathrm{s}$ e $0.84 \times 10^{-5} \mathrm{~cm}^{2} / \mathrm{s}$. À titulo de comparação, o coeficiente de difusão de íons de cálcio e magnésio em solução aquosa, em diluição infinita e na temperatura ambiente, valem: $D_{C a^{2+}}$ $=0.79 \times 10^{-5} \mathrm{~cm}^{2} / \mathrm{s}^{[243]}$ e $D_{M g^{2+}}=0.71 \times 10^{-5} \mathrm{~cm}^{2} / \mathrm{s}^{[243]}$. Já o coeficiente de difusão de 


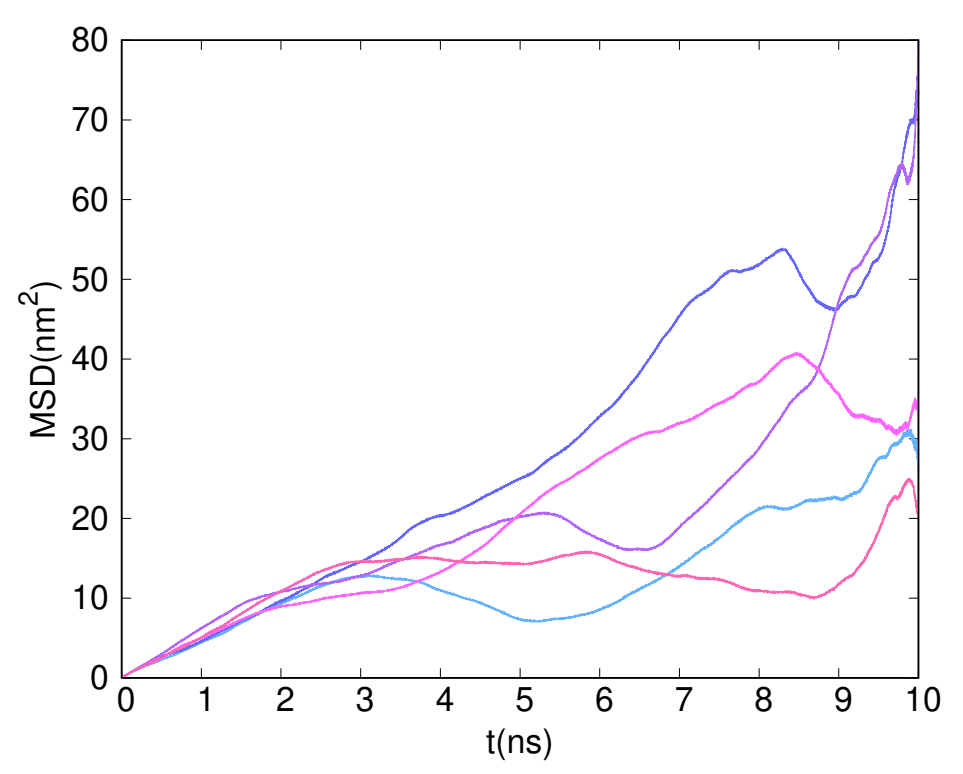

Figura 6.10 - Deslocamento quadrático médio (MSD) do complexo $R u^{I I}\left(H_{2} \mathrm{O}\right)$ em solução aquosa. São apresentadas 5 curvas de MSD, obtidas de 5 simulações independentes (com condições iniciais diferentes), de 10 ns cada. MSD obtidos a partir das simulações de MD.

Tabela 6.3 - Coeficientes de difusão $(D)$ médios calculados a partir do ajuste linear das curvas de MSD dos complexos de $R u$-Aqua/Oxo em solução. Coeficientes calculados a partir das simulações de MD.

\begin{tabular}{cc}
\hline Complexos & $D\left(10^{-5} \mathrm{~cm}^{2} / \mathrm{s}\right)$ \\
\hline$R u^{I I}\left(\mathrm{H}_{2} \mathrm{O}\right)$ & $0.84 \pm 0.09$ \\
$R u^{I I}\left(\mathrm{H}_{2} \mathrm{O}\right)$ & $0.74 \pm 0.19$ \\
$R u^{I I}(\mathrm{OH})$ & $0.83 \pm 0.18$ \\
$R u^{I I I}(\mathrm{OH})$ & $0.72 \pm 0.16$ \\
$R u^{I V}(\mathrm{O})$ & $0.69 \pm 0.11$ \\
\hline
\end{tabular}

uma molécula de água da solução vale $D_{H_{2} O}=2.30 \times 10^{-5} \mathrm{~cm}^{2} / s^{[244]}$.

\subsection{Simulações na interface água/vácuo}

No estudo de complexos de $R u$ em solução, algumas técnicas experimentais são aplicadas em condições específicas, tal como na interface entre a solução e o vácuo. A espectroscopia de fotoelétrons de raios-X (XPS), também conhecida como espectroscopia de elétrons para análise química (ESCA), é uma dessas técnicas de análise usada para obter informações químicas sobre as superfícies de materiais sólidos ou líquidos. Tanto a composição quanto o estado químico dos constituintes da superfície podem ser determinados até alguns nanômetros de profundidade. O XPS é uma técnica sensível à superfície porque apenas os elétrons gerados 
perto da superfície escapam e podem ser detectados. Devido a colisões inelásticas na estrutura atômica da amostra, os fotoelétrons de interesse possuem energia cinética relativamente baixa, e fotoelétrons originários a mais de $10 \mathrm{~nm}$ abaixo da superfície tendem a não escapar com energia suficiente para serem detectados.

Do ponto de vista experimetal, observar o sistema de interesse próximo da interface solução/vácuo pode ser uma boa notícia, já que viabiliza a aplicação de técnicas como o XPS. Já do ponto de vista teórico, isso pode representar um desafio a mais na modelagem e predição das propriedades eletrônicas do sistema. Modelos simplificados de solvente, tais como os modelos contínuos baseados na constante dielétrica do meio, tendem a falhar na descrição de ambientes químicos de natureza interfacial. Nesse caso, apenas uma modelagem mais realística da solução, na condição de interface, pode permitir a correta descrição do ambiente, e tão logo de propriedades eletrônicas, incluindo o XPS. Dentre as propriedades eletrônicas exploradas neste trabalho, investigamos o efeito solvente no cálculo do XPS dos complexos de $R u$-Aqua/Oxo. Conforme detalhado no capítulo de metodologia, realizamos simulações de MC dos 5 complexos na interface água/vácuo, objeto de estudo desta seção.

Na figura 6.11 apresentamos uma ilustração do complexo $R u^{I I}\left(H_{2} O\right)$ na interface água/vácuo. $\mathrm{Na}$ fase de termalização, o complexo foi mantido parado em sua posição original, e as moléculas de água, previamente termalizadas no ensemble $N P T(N=4000, P=1$ atm e $\mathrm{T}=298 \mathrm{~K})$ foram retermalizadas na presença do complexo. Nessa fase, notamos uma curiosidade, $\mathrm{O}$ complexo de $R u$ foi colocado acima da superfície de água, e com o centro metálico sem a coordenação de uma molécula de água. Quase no final da fase de termalização, observamos uma movimento colaborativo entre as moléculas de água a fim de que uma delas pudesse acessar o átomo $R u$ e se coordenar ao complexo. E de fato, ao fim da termalização, uma das moléculas de água conseguiu se coordenar ao complexo, e manteve essa coordenação durante toda a fase de produção. A figura 6.11 também mostra que ao final da fase de produção, o complexo de $R u$ ficou totalmente solvatado, mas ainda próximo da superfície.

Dado que temos 5 complexos, com diferentes estrututas moleculares e diferentes distribuições de carga, algumas das perguntas fundamentais a serem respondidas são: (1) quão solvatado encontra-se cada complexo nessa situação de interface?; (2) quão próximo da interface água/vácuo cada complexo se encontra; (3) Existe alguma correlação entre a posição dos átomos $R u$ e $O$ e a superfície; (4) Existe uma orientação angular preferencial dos complexos?

Para começar a responder a essas perguntas, calculamos as funções de distribuição de mínima distância (MDDF) entre os complexos de $R u$ e as moléculas de água da solução, apresentada na figura 6.12. Tão logo, observamos que essas novas MDDFs são semelhantes àquelas calculadas na condição de "bulk". Novamente, observamos a formação de uma primeira camada de solvatação com pico e mínimo de probabilidade em aproximadamente 2.7 e 4.1 $\AA$, respectivamente. Com exceção do complexo $R u^{I I}(O H)$, encontramos aproximadamente 70 moléculas de água formando a primeira camada de solvatação nos demais complexos, e considerando o mínimo da segunda camada em aproximadamente $7 \AA$, estimamos novamente 


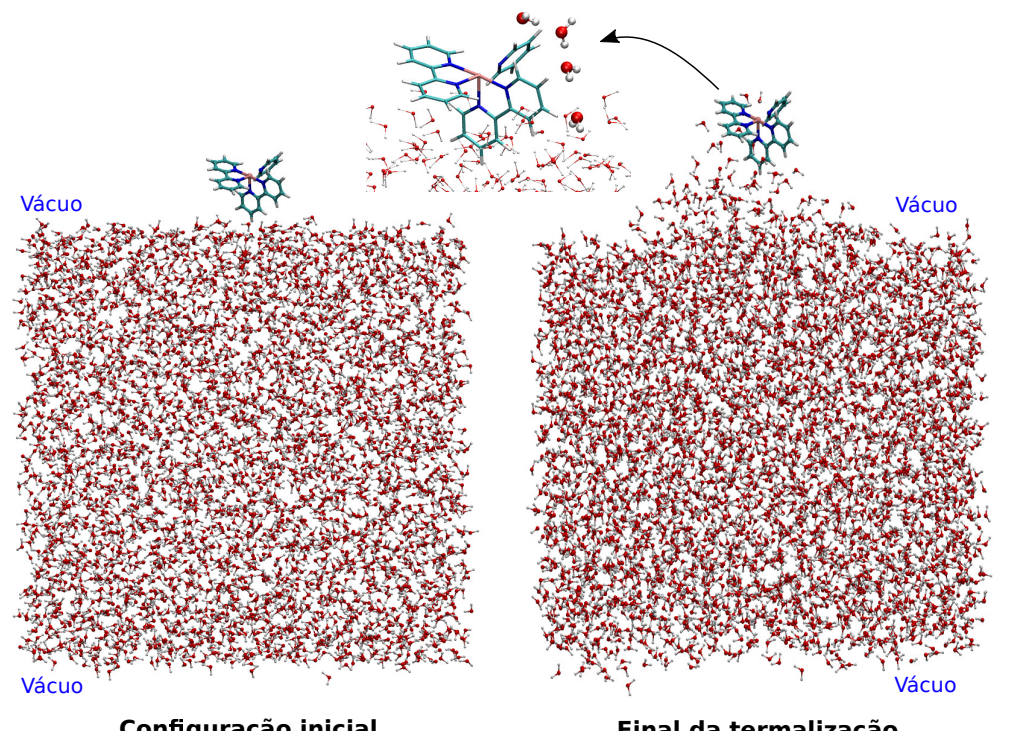

Configuração inicial

Final da termalização

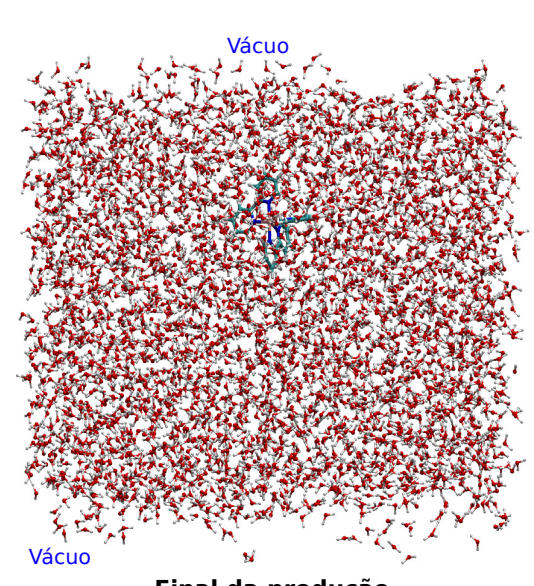

Final da produção

Figura 6.11 - Ilustração do sistema $R u^{I I}\left(H_{2} \mathrm{O}\right)$ na interface água/vácuo. Do lado esquerdo, a configuração inicial, com o complexo de $R u$ nas proximidades da superfície de água. No centro, a configuração do sistema após a fase de termalização. Do lado direito, a configuração do sistema após o término da simulação, mostrando que o complexo de $R u$ ficou totalmente solvatado, mas ainda próximo da superfície. A seta central indica para uma ilustração do movimento cooperativo entre as moléculas de água para que uma delas se coordene com o centro metálico durante a fase de termalização. Simulações realizadas com o método de MC.

que essa contenha aproximadamente 220 moléculas de água. O complexo $R u^{I I}(O H)$ sofre uma redução no número de moléculas de água nas suas camadas de solvatação, sendo que na MDDF desse complexo, até $4.1 \AA$ contabilizamos aproximadamente 50 moléculas de água, e até $7 \AA$ contabilizamos 150 moléculas de água. Isso representa uma redução importante na solvatação desse complexo próximo à interface água/vácuo.

Na figura 6.13, mostramos os perfis de densidade dos complexos de $R u$ e de toda a caixa de simulação preenchida por moléculas de água. Esses perfis foram traçados a partir da segunda metade da produção de equilíbrio, perfazendo 1 milhão de passos de MC. À meia altura, as distribuições relativas ao solvente apresentam uma largura similar, em torno de 42 a $43 \AA$. As distribuições em geral são mais alargadas na base e mais estreitas no topo. Em partes, isso é um efeito da presença do complexo, mas também um efeito da própria interface, aonde observamos comumentemente a evaporação de algumas moléculas de água. Apesar de não notarmos diferenças na solvatação dos complexos de $R u$, em relação à condição de bulk, observamos que para alguns complexos, existe uma maior afinidade pela interface.

Na tabela 6.4, sumarizamos os principais parâmetros que nos permitem inferir a proximidade dos complexos da interface água/vácuo. Apresentamos a posição do pico da distribuição do soluto, a posição na meia altura da distribuição do solvente, e, subtraindo esses dois valores, mensuramos a distância em que o soluto se encontra em relação à interface (profundidade). 


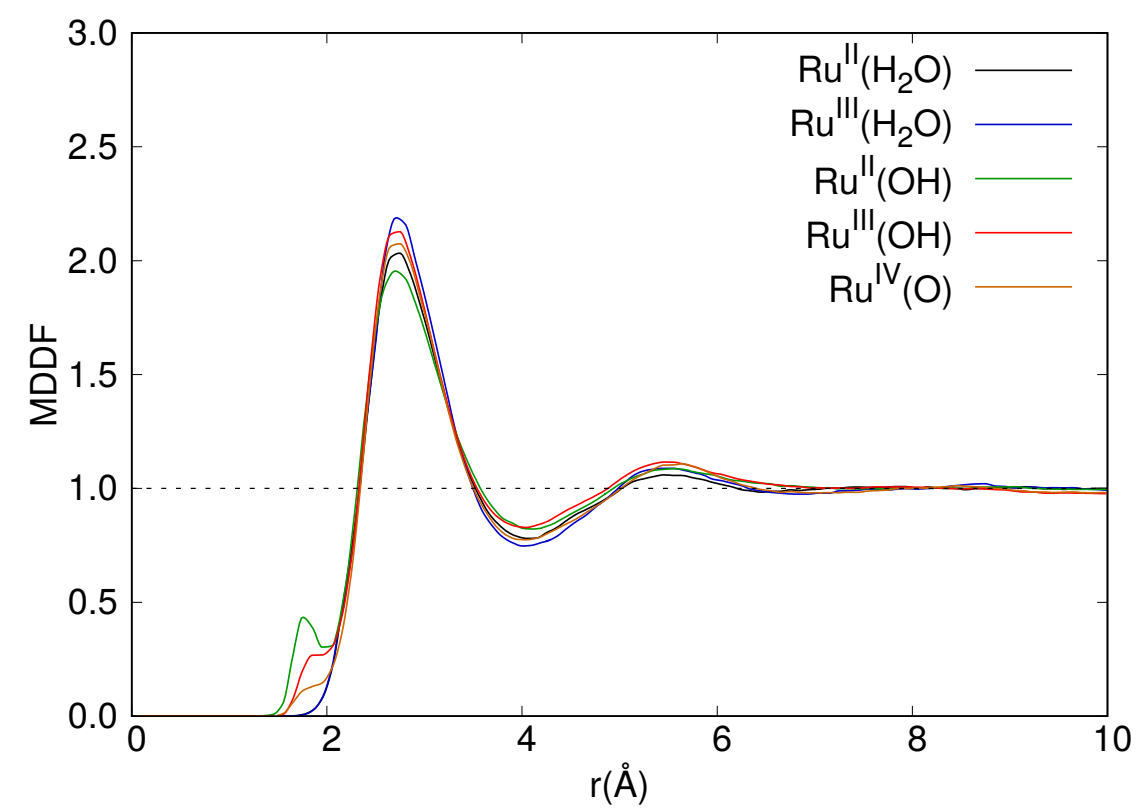

Figura 6.12 - Funções de distribuição de mínima distância (MDDF) entre os complexos de $R u$-Aqua/Oxo e as moléculas de água da solução, na interface água/vácuo.

Tabela 6.4 - Distâncias características dos perfis de densidade das soluções de $R u$-Aqua/Oxo na interface água/vácuo.

\begin{tabular}{cccccc}
\hline & $R u^{I I}\left(\mathrm{H}_{2} \mathrm{O}\right)$ & $R u^{I I I}\left(\mathrm{H}_{2} \mathrm{O}\right)$ & $R u^{I I}(\mathrm{OH})$ & $R u^{I I I}(\mathrm{OH})$ & $R u^{I V}(\mathrm{O})$ \\
\hline Pico (Soluto) & 81 & 81 & 82 & 79 & 81 \\
Meia altura (Solvente) & 92 & 94 & 84 & 92 & 91 \\
Profundidade (Soluto) & 11 & 13 & 2 & 13 & 10 \\
Largura meia altura (Solvente) & 42 & 42 & 42 & 43 & 43 \\
\hline
\end{tabular}

O complexo $R u^{I I}(O H)$ é o sistema com maior afinidade pela interface água/vácuo, com o pico da sua distribuição de densidade à aproximadamente $2 \AA$ da superfície. Por um lado, a apolaridade dos carbonos e hidrogênios dos grupos piridina e bipiridina, favorece aos complexos a permanência em regiões menos polares que a água, mas por outro lado, o centro metálico e seu ligante oxigenado preferem interagir com a água. Essa competição é guiada principalmente pela interação eletrostática entre os átomos do complexo e as moléculas de água da solução. Nesse sentido, as cargas atômicas dos complexos, adotadas nas simulações tem um papel fundamental no comportamento de cada complexo nessa condição de interface. Essas, por sua vez, refletem a estrutura eletrônica do complexo e efeitos de polarização. O complexo $R u^{I I}(O H)$ apresenta um spin total nulo (camada fechada) e a menor carga total entre todos os complexos $(+1)$, o que justifica a sua preferência pela região de interface. Os demais complexos são encontrados mais distantes da superfície, em profundidades que variam de 10 $\AA$, para $R u^{I V}(O)$, até $13 \AA$, para $R u^{I I I}\left(H_{2} O\right)$ e $R u^{I I I}(O H)$. Assim respondemos a segunda pergunta, sobre o quão próximo da interface água/vácuo cada complexo se encontra.

A terceira e a última perguntas dizem respeito às possíveis correlações entre as posições dos 

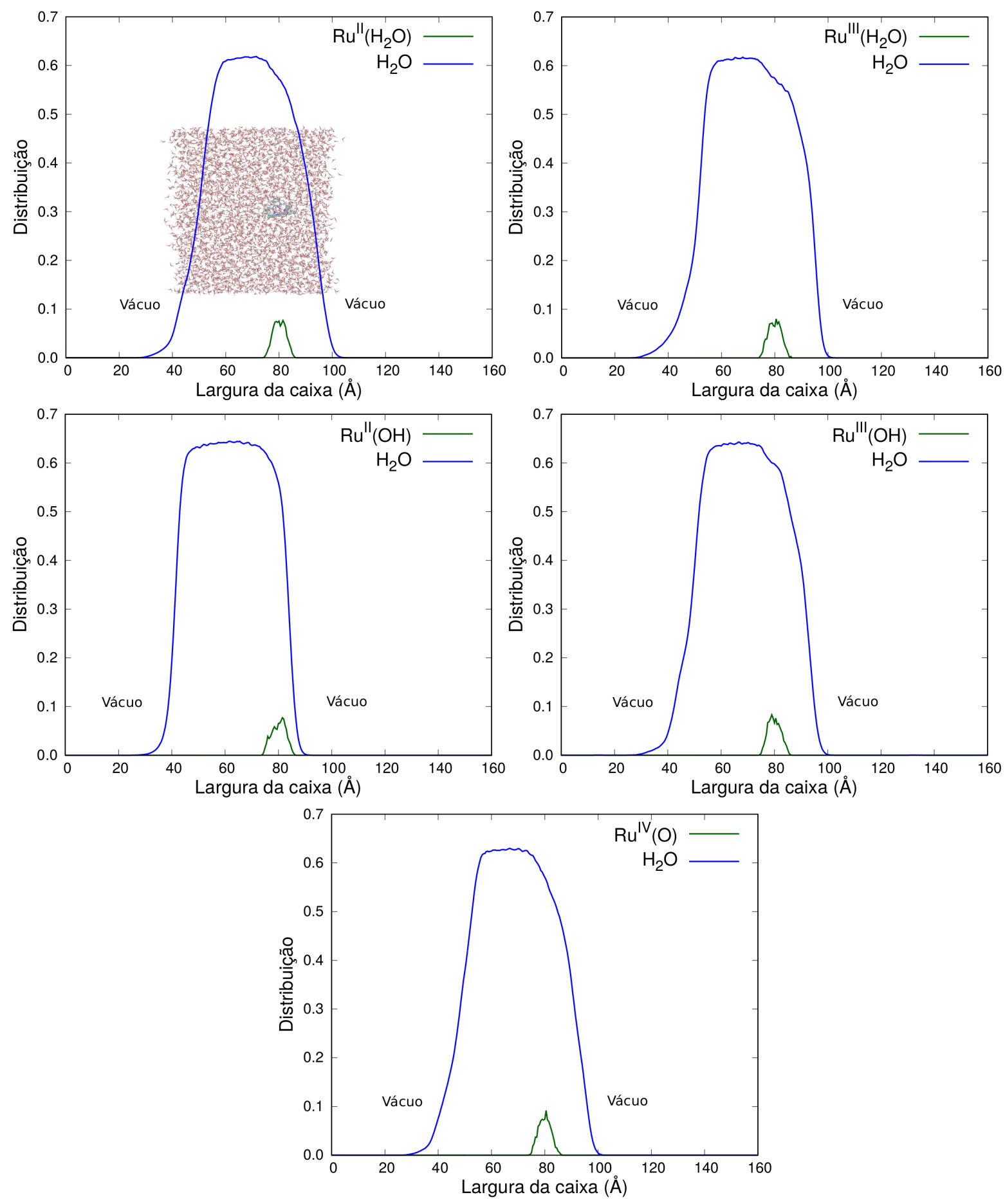

Figura 6.13 - Perfis de densidade das soluções de $R u$-Aqua/Oxo na interface água/vácuo.

átomos de $R u$ e $O$ e a interface, e entre a orientação angular dos complexos e a interface. Para responder a essas perguntas computamos a componente $z$ das posições de $R u$ e $O$ durante as simulações, e do ângulo formado pelo vetor que liga $R u$ a $O$ e o eixo de coordenadas $z$. Na figura 6.14 apresentamos essas quantidades para os complexos $R u^{I I}\left(\mathrm{H}_{2} \mathrm{O}\right)$ e $R u^{I I I}\left(\mathrm{H}_{2} \mathrm{O}\right)$. E nas figuras $6.15,6.16$ apresentamos essas quantidades para os complexos $R u^{I I}(O H), R u^{I I I}(O H)$ e $R u^{I V}(O)$. 

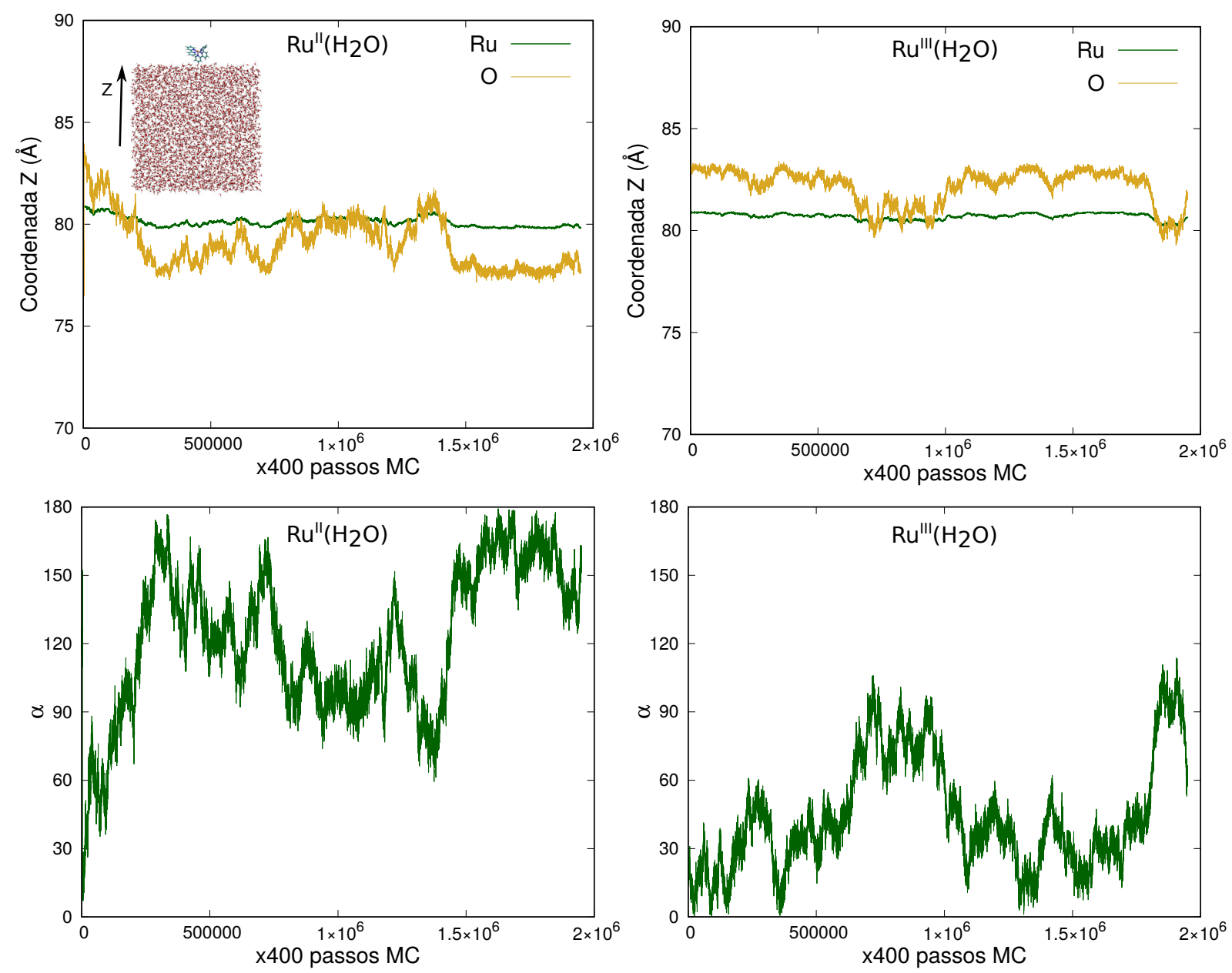

Figura 6.14 - Coordenada $z$ das posições dos átomos de $R u$ e $O$, e orientação angular do vetor que liga $R u$ a $O$ e o eixo de coordenadas $z$, nas simulações dos complexos de $R u$-Aqua em solução.

Nas simulações de interface, optamos por restaurar a posição do centro de massa do soluto a cada passo de MC. Como o centro de massa dos complexos de $R u$ encontra-se muito próximo da posição do átomo de $R u$, isso implica que a posição de $R u$ foi mantida aproximadamente constante durante as simulações. Essa escolha representa apenas uma mudança de referencial, onde ao invés de observarmos o soluto penetrando na caixa com água, observamos a caixa com água se deslocando na direção do soluto, a fim de solvatá-lo. Como mostrado nas figuras 6.14, 6.15 e 6.16, a posição do átomo de $R u$ encontra-se apenas flutuando em torno do equilíbrio. Já a posição do átomo de oxigênio é variável. No começo de cada simulação, iniciamos com a ligação $R u-O$ paralela ao eixo de coordenadas $z$, com $R u$ mais próximo da água e $O$ mais próximo do vácuo. Com a evolução das simulações, observamos diferentes padrões de posicionamento.

Uma Mudança na componente $z$ da posição de $O$ é naturalmente refletida no ângulo formado pelo vetor que liga $R u$ a $O$ e o eixo de coordenadas $z$. Se $R u$ e $O$ possuem a mesma coordenada $z$, então o ângulo $\alpha$ é de 90 graus, e, se a ligação $R u-O$ é colinear a $z$, então temos duas possibilidades: esse ângulo pode ser zero, se a coordenada $z$ de $R u$ for menor que 

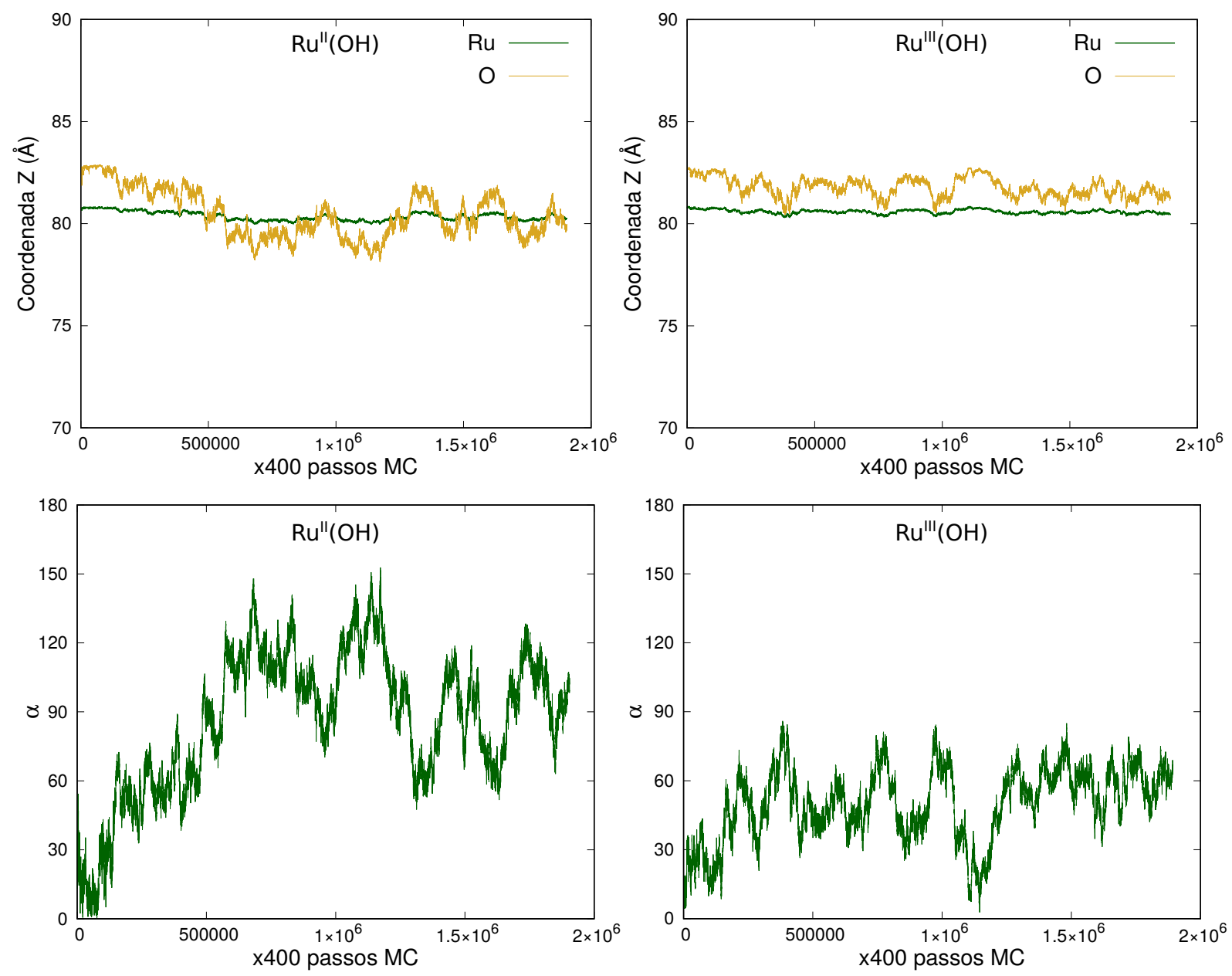

Figura 6.15 - Coordenada $z$ das posições dos átomos de $R u$ e $O$, e ângulo entre o vetor que liga $R u$ a $O$ e o eixo de coordenadas $z$, nas simulações dos complexos de $R u$-Hidróxido em solução.
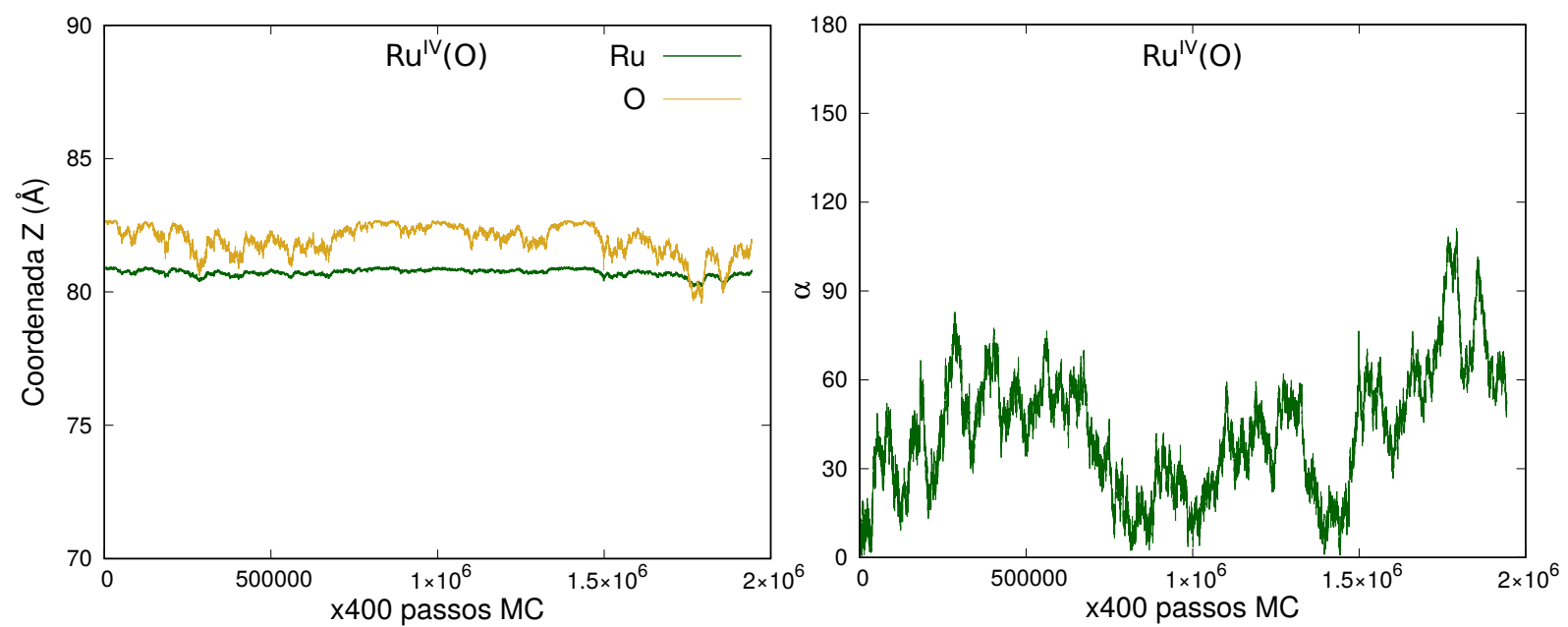

Figura 6.16 - Coordenada $z$ das posições dos átomos de $R u$ e $O$, e ângulo entre o vetor que liga $R u$ a $O$ e o eixo de coordenadas $z$, nas simulações dos complexos de $R u$-Óxido em solução. 
a de $O$; ou 180 graus, se a coordenada $z$ de $R u$ for maior que a de $O$. Dessa maneira, nos gráficos de evolução da coordenada $z$, sempre que observamos uma interseção entre as curvas de $R u$ e $O$, notamos que o ângulo $\alpha$ encontra-se em 90 graus. E sempre que observamos o ângulo $\alpha$ em zero ou em 180 graus, notamos que a diferença entre as coordenadas $z$ de $R u$ e $O$ é maximizada até um valor máximo, que corresponde justamente à distância de equilíbrio da ligação $R u-O$.

Seja pelos gráficos da componente $z$ de $R u$ e $O$ ou pelo gráfico de $\alpha$, notamos que na simulação do complexo $R u^{I I}\left(H_{2} \mathrm{O}\right)$, ocorre uma rápida inversão nos posicionamentos dos átomos de $R u$ e $O$ do complexo, que deixa os grupos polipiridínicos mais próximos da interface com o vácuo. No complexo $\mathrm{Ru}^{I I I}\left(\mathrm{H}_{2} \mathrm{O}\right)$, notamos a tendência contrária, e apenas em algumas partes da simulação, as componentes $z$ de $R u$ e $O$ flutuam próximas de valores similares, sem que ocorra uma completa inversão. No complexo $R u^{I I}(O H)$ observamos que após aproximadamente $1 / 3$ da simulação $\left(400 \times 5 \cdot 10^{5}\right.$ passos $\left.\mathrm{MC}\right)$, o ângulo $\alpha$ flutua em torno de 90 graus, o que corresponde ao fato de que nesse caso a coordenada $z$ de $R u$ e $O$ são similares em muitos pontos, sem que haja uma posicionamento preferencial. Já nos complexos $R u^{I I I}(O H)$ e $R u^{I V}(O)$ não observamos inversão nas coordenadas $z$ de $R u$ e $O$, e portanto, o grupos polipiridínicos, principalmente o grupo bpy1, tendem a ficar mais distantes da interface. A essa altura, cabe-nos tentar compreender porque os complexos apresentam comportamentos tão distintos quando estão próximos de uma interface água/vácuo.

A explicação mais simples está na observação da interação coulombiana soluto/solvente. As distribuições de cargas atômicas dos complexos revelam-nos porque algumas partes dos complexos tem mais afinidade por ambientes mais polares, e outras por ambientes menos polares. No caso em questão, basta que busquemos a resposta nas cargas dos grupos polipiridínicos, apresentadas na tabela 4 do capítulo anterior. Quando ocorre uma inversão das componentes $z$ de $R u$ e $O$, é notório, pela geometria dos complexos, que o grupo que tende a ficar mais próximo da interface é o grupo bpy1. Em ordem crescente, a carga total desse grupo em cada um dos complexos, levando em conta efeitos de polarização do solvente, é de 0.39 em $R u^{I I}\left(H_{2} O\right), 0.43$ em $R u^{I I}(O H), 0.58$ em $R u^{I V}(O), 0.63$ em $R u^{I I I}(O H)$ e 0.68 em $\mathrm{Ru}^{I I I}\left(\mathrm{H}_{2} \mathrm{O}\right)$. E justamente nessa ordem, temos: o complexo que passa pela rápida inversão nos posicionamentos de $R u$ e $O$; o complexo com a coordenada $z$ de $R u$ e $O$ similares; e os complexos que não sofrem inversão. Lembrando que, no caso de uma inversão, o complexo passa a expor mais o grupo bpy1, então, pelas respectivas distribuições de carga do grupo bpy1, entendemos que quanto menor for a carga total desse grupo, maior será a probabilidade de que encontremos o complexo com esse grupo apontando para a região interfacial. Ademais, vale destacar que a soma das cargas de todos os grupos polipiridínicos levam a mesma conclusão, na ordem citada teríamos cargas de 0.93, 1.28, 1.54, 1.56 e 1.64 . 



\section{Capítulo}

\section{Propriedades eletrônicas}

Neste capítulo, iremos apresentar os resultados do estudo das propriedades eletrônicas dos complexos de Ru-Aqua/Oxo em solução. Começaremos com a descrição dos orbitais de fronteira dos complexos no vácuo e em solução, passaremos aos espectros de absorção UV-Vis e, por fim, falaremos da espectroscopia de fotoelétrons de raios-X. Na parte de espectroscopia UV-Vis, trataremos de aspectos teóricos fundamentais, como: os efeitos da escolha do método QM e do conjunto de funções base na descrição dos espectros; os efeitos globais do solvente e de ligações de hidrogênio nas bandas de absorção; caracterização das excitações eletrônicas.

\subsection{Orbitais de fronteira}

O orbital molecular duplamente ocupado mais alto em energia (HOMO), ou singularmente ocupado (SOMO), e o orbital molecular não ocupado mais baixo em energia (LUMO) são conhecidos na Literatura como orbitais de fronteira ${ }^{\dagger}$. Devido a sua natureza e importância, os orbitais de fronteira são uma peça fundamental na compreensão de reações químicas e seus mecanismos. A diferença de energia entre os orbitais HOMO (ou SOMO) e LUMO, denominada salto de banda, ou simplesmente gap $\mathrm{H}(\mathrm{S}) \mathrm{OMO}-\mathrm{LUMO}$, pode servir como uma medida da excitabilidade da molécula, e quanto menor for essa energia, mais facilmente a molécula poderá ser excitada. Em reações químicas que envolvem a troca de elétrons, o HOMO é o orbital energeticamente mais favorável a perder elétrons (oxidação) e o LUMO é o orbital mais favorável a receber elétrons (redução). Analogamente, o HOMO e o LUMO são para os sistemas moleculares orgânicos, o que a banda de valência e a banda de condução são para os semicondutores inorgânicos. Nesse caso, a diferença de energia entre o HOMO e LUMO pode também representar a energia da banda proibida.

Na figura 7.1, apresentamos o diagrama de energia dos orbitais de fronteira dos complexos

\footnotetext{
† Os orbitais de fronteira foram gerados a partir do cálculo da energia eletrônica, via convergência da função de onda eletrônica B3LYP/(aug)-cc-pVDZ/(PP-Ru), nas geometrias otimizadas no vácuo e em solução. Para os complexos de camada aberta, utilizamos a funções de onda restrita ROB3LYP, a fim de obtermos um único conjunto de spin-orbitais
} 
de $R u$-Aqua/Oxo, no vácuo e em solução aquosa, e, na figura 7.2, temos uma ilustração dos orbitais HOMO-2 ao LUMO+2. Como 3 dos complexos tem spin não nulo, ao invés de HOMO temos orbitais SOMO. Em geral, os orbitais HOMO ou SOMO são orbitais do tipo $d$ do átomo de $R u$, e os orbitais LUMO são do tipo $\pi^{*}$, com densidade eletrônica distribuída nos grupos bipiridínicos. Portanto, uma transição eletrônica do tipo HOMO-LUMO teria um caráter de transferência de carga do tipo metal-ligante, tema da próxima seção.

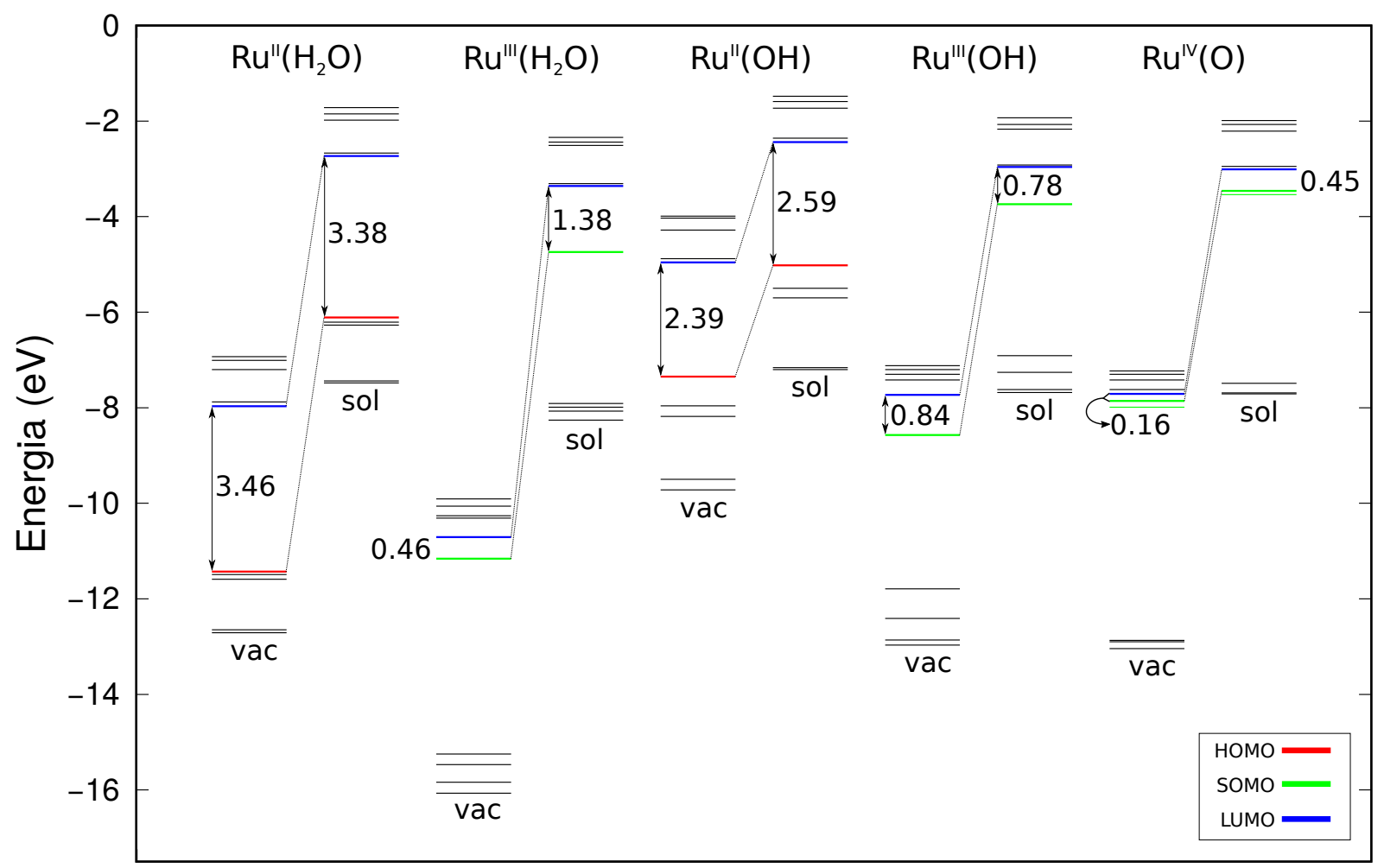

Figura 7.1 - Diagrama de energia dos orbitais de fronteira dos complexos de $R u$-Aqua/Oxo, no vácuo e em solução aquosa (por PCM). Energias obtidas das geometrias otimizadas no vácuo e em solução (por PCM), utilizando o funcional B3LYP e o conjunto de funções base (aug)-cc-PVDZ/(PP-Ru).

Por efeitos do solvente, todos os orbitais de fronteira são desestabilizados em solução. Essa desestabilização, medida por $\triangle E_{H S}^{V A C / S O L}$ para os orbitais $\mathrm{HOMO}$ e SOMO e por $\triangle E_{L}^{V A C / S O L}$ para os orbitais LUMO, como apresentado na tabela 7.1, é maior para os orbitais HOMO e SOMO nos complexos $R u^{I I}\left(H_{2} O\right)$ (5.31 eV) e $R u^{I I I}(O H)$ (4.83 eV), e maior para o orbital LUMO nos complexos $R u^{I I}\left(\mathrm{H}_{2} \mathrm{O}\right)$ (7.35 eV), $R u^{I I}(O H)(2.52 \mathrm{eV})$ e $R u^{I V}(O)$ $(4.70 \mathrm{eV})$. A desestabilização dos orbitais de fronteira, por efeitos do solvente, pode ser associada às cargas totais dos complexos: quanto maior a carga, maior a desestabilização. O complexo $R u^{I I I}\left(H_{2} O\right)$, com carga +3 , é o que tem os orbitais SOMO e LUMO mais desestabilizados $\left(\triangle E_{H S}^{V A C / S O L}=6.42 \mathrm{eV}, \Delta E_{L}^{V A C / S O L}=7.35 \mathrm{eV}\right)$, na sequência temos os complexos com carga $+2: R u^{I I}\left(H_{2} O\right)\left(\Delta E_{H S}^{V A C / S O L}=5.31 \mathrm{eV}, \Delta E_{L}^{V A C / S O L}=5.24 \mathrm{eV}\right)$, $R u^{I I I}(O H)\left(\triangle E_{H S}^{V A C / S O L}=4.83 \mathrm{eV}, \Delta E_{L}^{V A C / S O L}=4.77 \mathrm{eV}\right), R u^{I V}(O)\left(\Delta E_{H S}^{V A C / S O L}=\right.$ $\left.4.40 \mathrm{eV}, \Delta E_{L}^{V A C / S O L}=4.70 \mathrm{eV}\right)$. E, por último, o complexo $R u^{I I}(O H)$, com carga +1 , $\left(\Delta E_{H S}^{V A C / S O L}=2.32 \mathrm{eV}, \Delta E_{L}^{V A C / S O L}=2.52 \mathrm{eV}\right)$. 


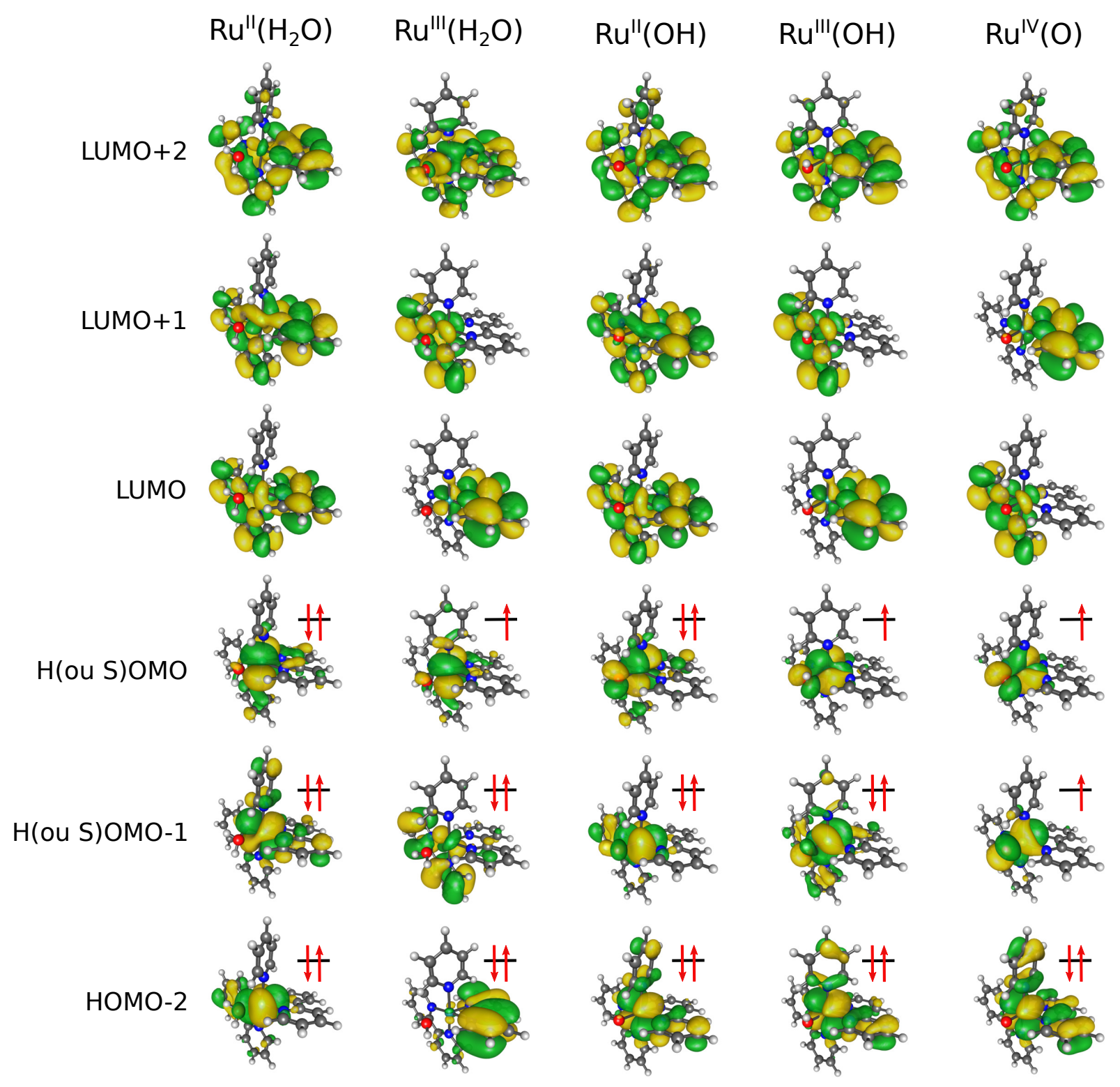

Figura 7.2 - Orbitais moleculares HOMO-2 ao LUMO+2 dos complexos de $R u$-Aqua/Oxo. Orbitais obtidos a partir da função de onda B3LYP e conjunto de funções base (aug)-cc-PVDZ/(PP-Ru), utilizando o formalismo com restrição de spin (ROB3LYP) para os complexos de camada aberta. Figuras plotadas utilizando um isovalue de 0.04 no programa IQMOL.

Os valores do gap $\mathrm{H}(\mathrm{S}) \mathrm{OMO}$-LUMO $\left(\Delta E_{H S L}\right)$ no vácuo crescem na ordem $0.16,0.46$, 0.84, 2.39 e $3.46 \mathrm{eV}$ para os complexos $R u^{I V}(O), R u^{I I I}\left(H_{2} O\right), R u^{I I I}(O H), R u^{I I}(O H)$ e $R u^{I I}\left(H_{2} \mathrm{O}\right)$, respectivamente. Os valores de $\Delta E_{H S L}$ em solução (PCM) crescem na ordem $0.45,0.78,1.38,2.59$ e $3.38 \mathrm{eV}$ para os complexos $R u^{I V}(\mathrm{O}), \mathrm{Ru}^{I I I}(\mathrm{OH}), \mathrm{Ru}^{I I I}\left(\mathrm{H}_{2} \mathrm{O}\right)$, $R u^{I I}(\mathrm{OH})$ e $R u^{I I}\left(\mathrm{H}_{2} \mathrm{O}\right)$, respectivamente. Portanto, por efeito do solvente, temos uma inversão na ordem de crescimento de $\Delta E_{H S L}$ entre os complexos $R u^{I I I}\left(H_{2} O\right)$ e $R u^{I I I}(O H)$, confirmando mais uma vez a maior sensibilidade de $R u^{I I I}\left(H_{2} O\right)$ ao solvente.

O gap H(S)OMO-LUMO de uma molécula é sensível a troca de prótons e elétrons com 
o meio. Intuitivamente, e tendo em mente apenas a Lei de Coulomb, a perda de um próton por uma molécula a deixaria menos positiva e tão logo mais propensa a perder, ou ter um elétron excitado (menor energia de ionização ou excitação). Em contrapartida, a perda de um elétron deveria dificultar a mobilidade dos demais elétrons do sistema (maior energia de ionização ou excitação). Quimicamente, a perda do próton não altera o estado de spin da molécula, mas apenas a sua carga total. Na desprotonação do complexo $R u^{I I}\left(H_{2} O\right)$, a intuição coulombiana não falha para os orbitais de fronteira, donde a perda de 1 próton da molécula de água coordenada leva a uma redução de $\Delta E_{H S L}$, de 3.46 para $2.39 \mathrm{eV}$ no vácuo e de 3.38 para $2.59 \mathrm{eV}$ em solução. Mas, na desprotonação do complexo $R u^{I I I}\left(H_{2} O\right)$, a perda de 1 próton da molécula de água coordenada leva à resultados não intuitivos (no vácuo), pois $\Delta E_{H S L}$ aumenta de 0.46 para $0.84 \mathrm{eV}$ no vácuo, e diminui de 1.38 para $0.78 \mathrm{eV}$ em solução.

Tabela 7.1 - Energias, em $e V$, dos orbitais HOMO ou SOMO $\left(E_{H S}\right)$ e LUMO $\left(E_{L}\right)$ dos complexos de $R u$-Aqua/Oxo, no vácuo e em solução aquosa. $\triangle E_{H S}^{V A C / S O L}$ e $\triangle E_{L}^{V A C / S O L}$ representam as variações energéticas de $E_{H S}$ e $E_{L}$ devido ao efeito solvente. $\Delta E_{H S L}$ representa o gap $\mathrm{HOMO}$ (ou SOMO)-LUMO. Energias obtidas das geometrias otimizadas no vácuo e em solução (por PCM), utilizando o funcional B3LYP e o conjunto de funções base (aug)-cc-PVDZ/(PP-Ru). Valores apresentados entre parênteses foram obtidos tratando-se o solvente como cargas pontuais, e valores entre colchetes foram obtidos tratando-se o solvente como cargas pontuais mas explicitando as ligações de hidrogênio no cálculo quântico. O desvio padrão de $E_{H S}$ ou $E_{L}$ é inferior a $0.2 \mathrm{eV}$.

\begin{tabular}{ccccccccc}
\hline & \multicolumn{2}{c}{$E_{H S}$} & \multicolumn{2}{c}{$E_{L}$} & \multicolumn{2}{c}{$\Delta E_{H S L}$} \\
& $\mathrm{VAC}$ & $\mathrm{SOL}$ & $\Delta E_{H S}^{V A C / S O L}$ & $\mathrm{VAC}$ & $\mathrm{SOL}$ & $\Delta E_{L}^{V A C / S O L}$ & $\mathrm{VAC}$ & SOL \\
\hline \multirow{2}{*}{$R u^{I I}\left(H_{2} O\right)$} & -11.43 & -6.11 & 5.31 & & -2.73 & 5.24 & & 3.38 \\
& & {$[-7.36)$} & $(4.07)$ & -7.97 & $(-4.02)$ & $(3.95)$ & 3.46 & $(3.34 \pm 0.2)$ \\
$R u^{I I I}\left(H_{2} O\right)$ & -11.16 & -4.74 & 6.42 & -10.71 & -3.36 & 7.35 & 0.46 & 1.38 \\
& & -5.02 & 2.32 & & -2.44 & 2.52 & & 2.59 \\
$R u^{I I}(\mathrm{OH})$ & -7.35 & $(-5.97)$ & $(1.38)$ & -4.96 & $(-3.28)$ & $(1.68)$ & 2.39 & $(2.69 \pm 0.3)$ \\
& & {$[-6.11]$} & {$[1.24]$} & & {$[-3.36]$} & {$[1.60]$} & & {$[2.75 \pm 0.4]$} \\
$R u^{I I I}(\mathrm{OH})$ & -8.57 & -3.74 & 4.83 & -7.73 & -2.96 & 4.77 & 0.84 & 0.78 \\
$R u^{I V}(\mathrm{O})$ & -7.86 & -3.46 & 4.40 & -7.71 & -3.01 & 4.70 & 0.16 & 0.45 \\
\hline
\end{tabular}

Por outro lado, a troca de elétrons entre uma molécula e seu meio causa mudanças no seu estado de spin. Uma molécula de camada fechada pode se tornar um dubleto caso perca um elétron, ou uma molécula de spin $1 / 2$ pode se estabilizar como um singleto caso receba um elétron. Nesses casos, a comparação energética entre os gap HOMO-LUMO e SOMOLUMO não faria sentido quimicamente, por causa dos diferentes números de ocupação dos orbitais ocupados mais altos. Todavia, nada impede que analisemos os efeitos da oxidação dos complexos no gap $\mathrm{HOMO}^{-1}$-LUMO. O que se extrai rapidamente, apenas olhando o diagrama da figura 7.1, é que a mono oxidação de $R u^{I I}\left(H_{2} O\right)$ ou de $R u^{I I}(O H)$ causa um aumento do 
gap $\mathrm{HOMO}^{-1}$-LUMO. Em solução, $\Delta E_{H^{-1} L}$ vale 3.48 e $3.06 \mathrm{eV}$ nos complexos $R u^{I I}\left(H_{2} O\right)$ e $R u^{I I}(O H)$, e passam a valer 4.55 e $3.95 \mathrm{eV}$ nos complexos $R u^{I I I}\left(\mathrm{H}_{2} \mathrm{O}\right)$ e $R u^{I I I}(\mathrm{OH})$, nessa ordem. Isso está de acordo com a ideia de que a perda de um elétron deveria dificultar a mobilidade dos demais elétrons do sistema (maior energia de ionização ou excitação).

Por fim, verificamos os efeitos nas energias dos orbitais de fronteira ao se tratar as interações soluto-solvente de forma mais realística. Dentro do escopo do método S-QM/MM, selecionamos uma centena de configurações estatisticamente descorrelacionadas do sistema soluto/solvente para os complexos de camada fechada. Para cada configuração, calculamos as energias dos orbitais de fronteira: (i) tratando as moléculas de água do solvente como cargas pontuais; (ii) tratando quanticamente as moléculas de água que realizam ligações de hidrogênio com os complexos e as demais como cargas pontuais. Os resultados são apresentados na tabela 7.1. Observa-se, por essas aproximações: (1) uma menor desestabilização energética dos orbitais de fronteira, em aproximadamente $1 \mathrm{eV}$; (2) Uma redução no valor de $\Delta E_{H S L}$ para $\operatorname{Ru}^{I I}\left(\mathrm{H}_{2} \mathrm{O}\right)$, em até $0.08 \mathrm{eV}$; (3) Um aumento no valor de $\Delta E_{H S L}$ para $R u^{I I}(O H)$, em até $0.15 \mathrm{eV}$. Essas observações podem ser relevantes num contexto em que o gap HOMO-LUMO é utilizado como medida da excitabilidade da molécula. Aproximações simplificadas da interação soluto-solvente podem superestimar ou subestimar o valor do gap.

\subsubsection{Reatividade eletrônica}

O potencial químico $\mu$ e a dureza química $\eta$ são propriedades eletrônicas que caracterizam a reatividade de um sistema molecular. As definições de $\mu$ e de $\eta$ foram dadas por Parr e Pearson ${ }^{[245]}$ como:

$$
\begin{gathered}
\mu=-\frac{1}{2}(I P+E A) \\
\eta=\frac{1}{2}(I P-E A)
\end{gathered}
$$

onde IP e EA são o primeiro potencial de ionização vertical e a afinidade eletrônica da molécula neutra, respectivamente. Pelo teorema de Koopmans $\left(I P \approx-E_{H}\right.$ e $\left.E A \approx-E_{L}\right)$, $\mu$ e $\eta$ podem ser determinados em termos das energias dos orbitais de fronteira HOMO e LUMO, como segue:

$$
\begin{gathered}
\mu=\frac{1}{2}\left(E_{L}+E_{H}\right) \\
\eta=\frac{1}{2}\left(E_{L}-E_{H}\right)
\end{gathered}
$$

Fisicamente, o potencial químico $\mu$ caracteriza a tendência de escape dos elétrons do sistema de equilíbrio, sendo então relacionado ao rearranjo de carga eletrônica associado a qualquer processo químico. Já a dureza química $\eta$ pode ser entendida como uma resistência 
à transferência de carga ${ }^{[245-248]}$. Ambos, $\mu$ e $\eta$, são propriedades globais do sistema e tem sido abordados na literatura como descritores da reatividade química. Segundo o Princípio da Dureza Máxima, sistemas moleculares em equilíbrio devem estar em um estado de dureza máxima ${ }^{[247-249]}$, e estados de transição devem estar em um estado de dureza mínima ${ }^{[250]}$.

Na tabela 7.2 apresentamos os valores de $\mu$ e $\eta$ para os complexos de $R u$-Aqua/Oxo de camada fechada, no vácuo e em solução, utilizando PCM e também por cargas pontuais (com e sem as ligações de hidrogênio explícitas).

Tabela 7.2 - Potencial químico $\mu$ e dureza química $\eta$ dos complexos $R u^{I I}\left(H_{2} O\right)$ e $R u^{I I}(O H)$ no vácuo e em solução, utilizando PCM e também por cargas pontuais, com $(\mathrm{HB}+\mathrm{PC})$ e sem $(\mathrm{CP})$ as ligações de hidrogênio explícitas.

\begin{tabular}{ccccccccccc}
\hline & \multicolumn{4}{c}{$\mu$} & \multicolumn{4}{c}{$\eta$} \\
& \multicolumn{4}{c}{ SOL } & & \multicolumn{3}{c}{ SOL } \\
& VAC & PCM & PC & HB +PC & VAC & PCM & PC & HB+PC \\
$R u^{I I}\left(H_{2} O\right)$ & -9.70 & -4.42 & -5.69 & -5.62 & 1.73 & 1.69 & 1.67 & 1.65 \\
$R u^{I I}(\mathrm{OH})$ & -6.15 & -3.73 & -4.63 & -4.74 & 1.19 & 1.29 & 1.35 & 1.38 \\
\hline
\end{tabular}

Seja no vácuo, ou em solução, o potencial químico de $R u^{I I}\left(H_{2} O\right)$ é o mais negativo, e a dureza química de $\mathrm{Ru}^{I I}\left(\mathrm{H}_{2} \mathrm{O}\right)$ é a de maior valor. Portanto, tanto a mobilidade eletrônica, em processos internos de transferência de carga, quanto a tendência de escape de elétrons, em processos de oxidação, são menores no complexo com maior carga total, $R u^{I I}\left(H_{2} \mathrm{O}\right)$ com carga $2+$. Independente do modelo adotado para representar as interações soluto-solvente, o solvente atua para deixar $\mu$ menos negativo e $\eta$ menos positivo, e portanto, o solvente viabiliza a mobilidade eletrônica entre os átomos dos complexos e entre os complexos e o ambiente. Comparando $R u^{I I}\left(\mathrm{H}_{2} \mathrm{O}\right)$ e $R u^{I I}(\mathrm{OH})$, notamos que a perda de um próton faz com que o potencial químico aumente, ficando menos negativo, e a dureza química diminua. Portanto, a desprotonação causa os mesmos efeitos que a solvatação, mas em maior escala. No mais, os resultados obtidos com solvente explícito ( $\mathrm{PC}$ e $\mathrm{HB}+\mathrm{PC})$ não levam a conclusões diferentes.

\subsection{Espectroscopia de absorção UV-Vis}

Nesta seção apresentaremos os resultados do nosso estudo sobre a espectroscopia de absorção dos complexos de Ru-Aqua/Oxo em solução aquosa. A exposição encontra-se dividida em 4 tópicos, são eles: descrição dos espectros experimentais; efeitos da escolha do método QM e do conjunto de funções base na descrição dos espectros; efeitos do solvente; e caracterização das transições eletrônicas. 

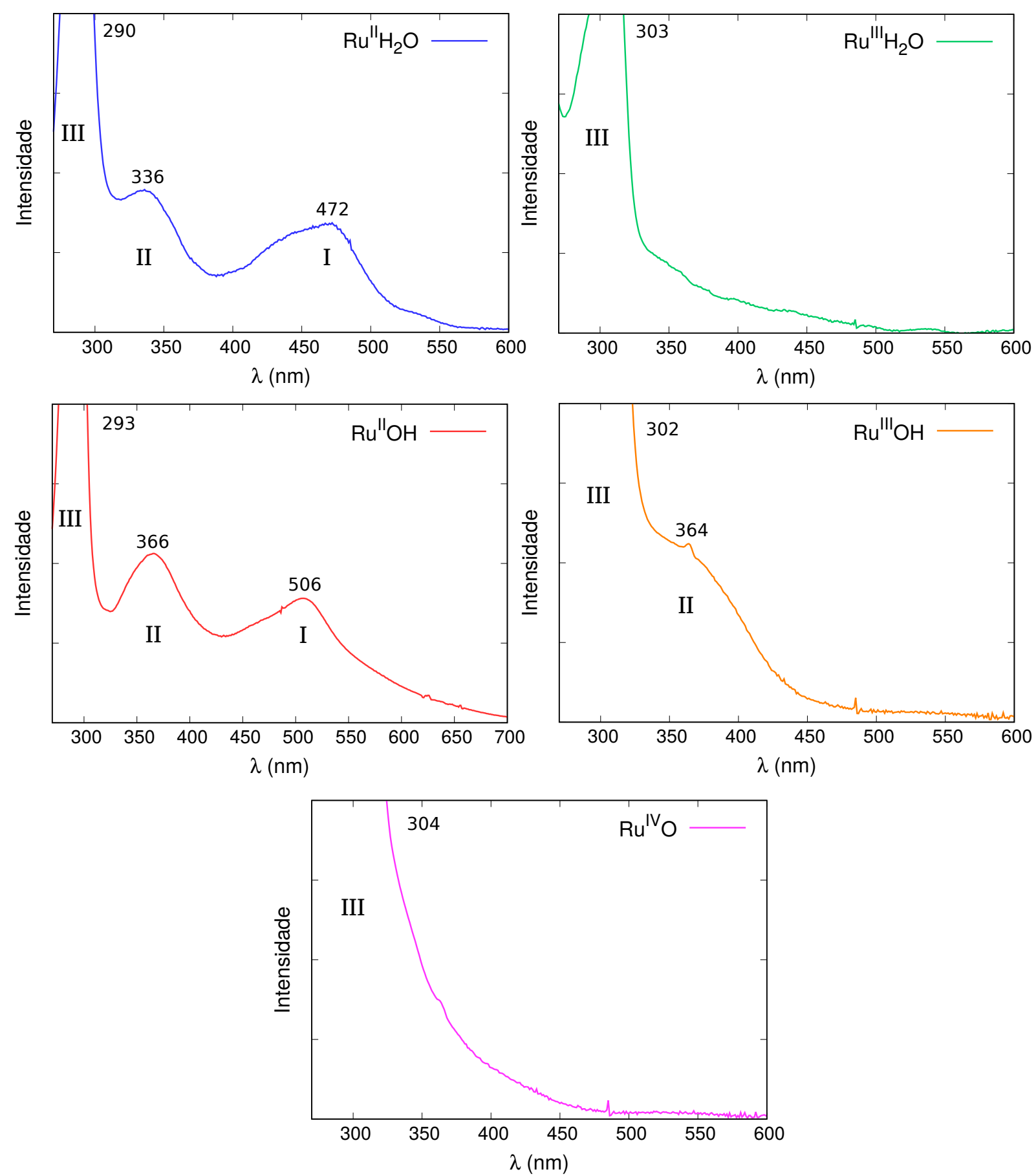

Figura 7.3 - Espectros de absorção UV-Vis experimentais dos complexos de Ru-Aqua/Oxo em solução aquosa. Picos de absorção designados por I, II e III, acompanhados por seus respectivos comprimentos de onda, na unidade de $n m$. Os espectros foram obtidos usando uma concentração de $0.1 \mathrm{mM}$ de solução do complexo em $0.10 \mathrm{M}$ de nitrato de potássio.

\subsubsection{Espectros UV-Vis experimentais}

Os espectros de absorção ultravioleta-visível (UV-Vis) dos complexos de $R u$-Aqua/Oxo em solução aquosa, mostrados na figura 7.3 , apresentam bandas de absorção na região do 
ultravioleta $(\lambda<400 \mathrm{~nm})$ e do visível $(400<\lambda<700 \mathrm{~nm})$, com intensidades que crescem no sentido de aumento da energia de absorção. Para os complexos na oxidação $I I$, observamos três bandas com máximos bem definidos: em 472, 336, $290 \mathrm{~nm}$ para $\mathrm{Ru}^{I I}\left(\mathrm{H}_{2} \mathrm{O}\right)$; em 506, 366, $293 \mathrm{~nm}$ para $R u^{I I}(O H)$ ). Portanto, a desprotonação da molécula de água coordenada leva a um deslocamento das bandas de maior comprimento de onda, em aproximadamente 30 $n m$, para a região do vermelho. Nas oxidações $I I I$ e $I V$, as bandas de absorção na região do visível perdem intensidade, ou desaparecem. O pico de absorção da banda mais intensa, na região do ultravioleta, é pouco afetado pelos processos de oxidação ou desprotonação, e tem a posição do seu máximo variando entre 290 e $304 \mathrm{~nm}$ em todos os complexos.

A forma desses espectros, com uma banda mais intensa no ultravioleta e com bandas menos intensas nas regiões de maior comprimento de onda, é bem conhecida na literatura. ${ }^{[251]}$ As bandas na região do visível são geralmente caracterizadas como bandas do tipo MLCT (do inglês metal ligand charge transfer), que envolvem a transferência de elétrons de orbitais $d$ do metal para orbitais $\pi$ dos ligantes. Ainda na região do visível devemos encontrar bandas do tipo MC (do inglês metal centered), que envolvem a transferência de elétrons entre orbitais $d$ do metal, e são por isso também conhecidas por bandas $d-d$. Já na região do ultravioleta é esperado que encontremos bandas do tipo LMCT (do inglês ligand metal charge transfer), as quais devem envolver a transferência de elétrons de orbitais $\pi$ ou $\sigma$ dos ligantes para orbitais $d$ do metal, e também bandas do tipo LC (do inglêsligand centered), que envolvem a transferência de elétrons entre orbitais $\pi$ dos ligantes. Em seção seguinte, iremos caracterizar completamente os espectros calculados.

\subsubsection{Efeitos da escolha do método QM e do conjunto de funções base na descrição teórica dos espectros UV-Vis}

Para realizar a descrição teórica dos espectros de absorção UV-Vis dos complexos de $R u$-Aqua/Oxo, optamos inicialmente por testar algums métodos de cálculo de excitações eletrônicas e também alguns conjuntos de funções base. Por economia, realizamos esses testes apenas para o complexo $\mathrm{Ru}^{I I}\left(\mathrm{H}_{2} \mathrm{O}\right)$. Inicialmente, fixamos o conjunto de funções base de Dunning aqui denotado por (aug)-cc-pVDZ/(PP-Ru), que significa aug-cc-pVDZ para átomos de $C, N, O$; cc-pVDZ para átomos de $H$; e aug-cc-pVDZ/PP para o átomo de $R u$. Calculamos as 50 primeiras excitações eletrônicas utilizando o método de interação de configurações de excitações simples (CIS); e utilizando a Teoria do Funcional da Densidade Dependente do Tempo (TD-DFT) para seis funcionais diferentes: M06-2X, BHANDH, CAM-B3LYP, LC-wPBE, PBE0 e B3LYP. Testamos também a variação TD-Hartree Fock.

Apresentamos na figura 7.4 o espectro de absorção UV-Vis teórico do complexo $R u^{I I}\left(H_{2} O\right)$ em solução aquosa, obtido pelos diferentes métodos mencionados. Em cada caso, calculamos as 50 primeiras excitações eletrônicas e obtivemos o espectro teórico a partir da convolução por funções lorentzianas de largura $0.15 \mathrm{eV}$ centradas em cada excitação. A escolha da largura 

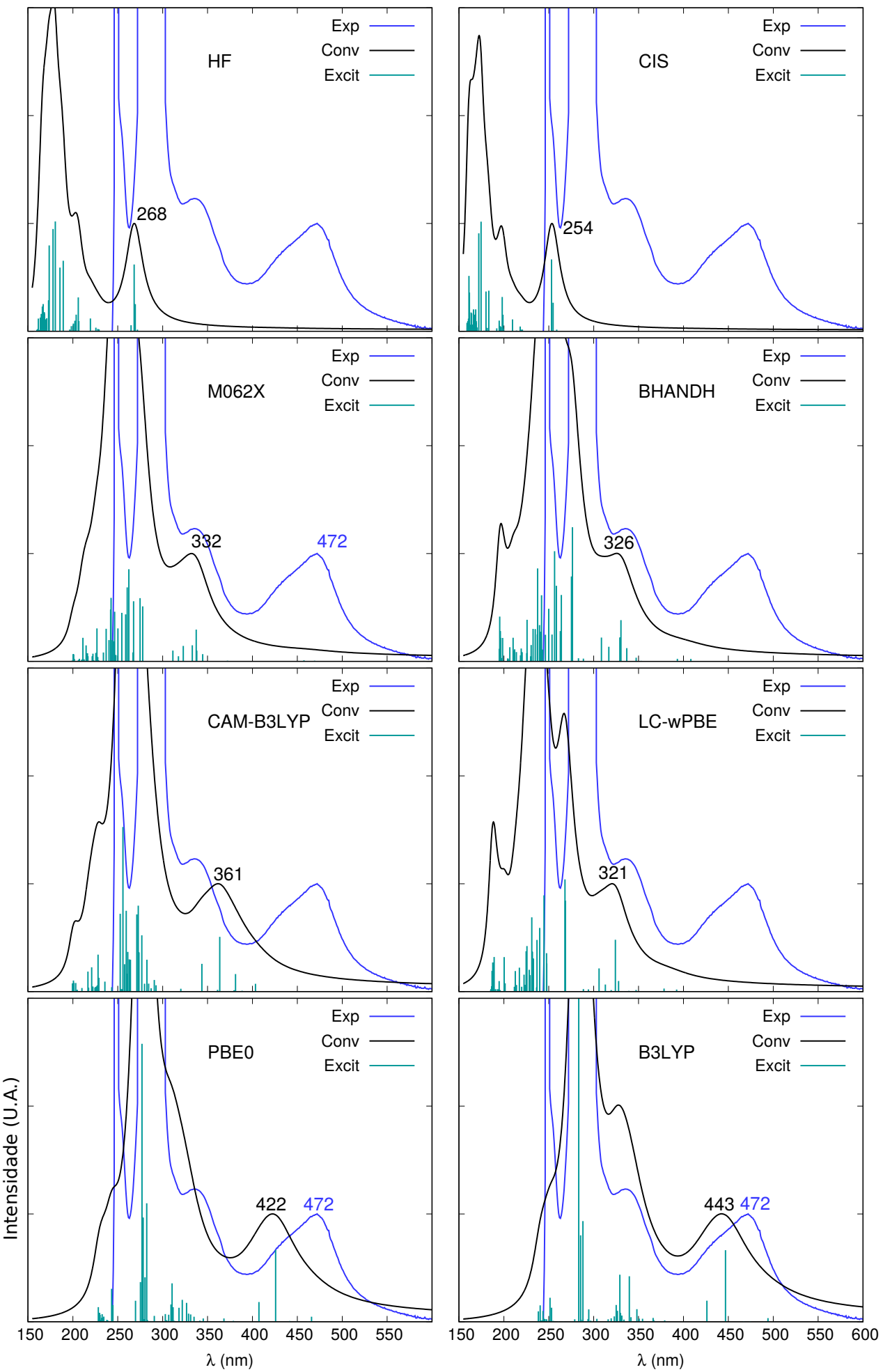

Figura 7.4 - Espectro de absorção UV-Vis teórico do complexo $R u^{I I}\left(H_{2} O\right)$ em solução aquosa, obtido por diferentes métodos, e utilizando o conjunto de funções base (aug)cc-pVDZ/PP. As 50 primeiras excitações eletrônicas calculadas encontram-se representadas pelas barras verticais, e o espectro convoluído foi obtido a partir da soma de funções lorentzianas de largura $0.15 \mathrm{eV}$ centradas em cada excitação. Efeitos do solvente incluídos nos cálculos por meio do modelo contínuo PCM. Espectro experimental apresentado para comparação. 
de linha foi feita de forma arbitrária. O espectro experimental é apresentado em cada gráfico para uma comparação direta.

Nos espectros téoricos obtidos a partir dos métodos TD-Hartree Fock e CIS, encontramos a primeira banda de absorção, na região de menor energia, com picos em 268 e $254 \mathrm{~nm}$, respectivamente. Por qualquer um dos dois métodos, isso representa um desvio superior a $200 \mathrm{~nm}$ em relação ao valor experimental. Pelo método TD-DFT, calculamos essa banda em uma região mais ao vermelho. Utilizando os funcionais M06-2X, BHANDH, CAM-B3LYP e LC-wPBE, obtemos o pico dessa banda em 332, 326, 361 e $321 \mathrm{~nm}$, respectivamente. Isso ainda representa um desvio entre 111 e $151 \mathrm{~nm}$ do valor experimental. Utilizando o funcional PBE0 esse desvio cai para $50 \mathrm{~nm}$, e utilizando o funcional B3LYP, cai para $29 \mathrm{~nm}$.

Além de fornecer uma boa descrição do posicionamento do máximo de absorção da banda em menor energia, o funcional B3LYP também fornece uma boa descrição das bandas na região do ultravioleta, com picos calculados em 328 e $284 \mathrm{~nm}$, muito próximos dos valores experimentais, que são de 336 e $290 \mathrm{~nm}$. Além do mais, o B3LYP também acerta a relação de intensidade entre as bandas, apesar da banda intermediária apresentar um valor de intensidade superestimado em aproximadamente $60 \%$.

Uma vez definido o funcional B3LYP, realizamos testes para escolher um conjunto de funções base com bom custo-benefício para os cálculos das excitações eletrônicas. Como os complexos de $R u$-Aqua/Oxo contem em sua estrutura um metal de transição, tivemos o cuidado de avaliar três tipos de combinações de bases: (i) bases com todos os elétrons explícitos (All-electron) para os átomos não metálicos, combinadas à bases com potencial efetivo de caroço (ECP) para o átomo de $R u$ (do inglês effective core potential); (ii) bases com todos os elétrons explícitos (All-electron); (iii) bases com todos os elétrons explícitos e com correção relativística do tipo Douglas-Kroll-Hess de ordem zero (All-electron DKH). É importante salientar que nos cálculos com correção relativística, foram adotadas as bases corrigidas e o Hamiltoniano eletrônico com o termo de correção DKH. Calculamos as 50 primeiras excitações eletrônicas do complexo $R u^{I I}\left(H_{2} O\right)$ em solução aquosa, utilizando o modelo contínuo PCM para tratar as interações soluto-solvente. Na tabela 7.3 trazemos o valor do comprimento de onda do pico de absorção da banda em menor energia, para 16 conjuntos de funções base diferentes. E apresentamos também o tempo de processamento (em horas) que foi gasto para a realização de cada cálculo, considerando a utilização de 10 processadores Intel(R) Xeon(R) CPU E7-2870 de 2.40GHz e 100GB de memória RAM para cada cálculo.

Dentre os conjuntos de funções base testados, o maior e menor desvio de $\lambda$ em relação ao valor experimental são curiosamente obtidos com as bases Jorge-ADZP e Jorge-ATZP, respectivamente. Apesar da base Jorge-ATZP oferecer um bom custo computacional (26.4 h) e fornecer um valor de $\lambda$ próximo do experimental $(\Delta \lambda=13.06)$, observamos que inconsistentemente, a base Jorge-AQZP leva a um distanciamento do valor experimental $(\Delta \lambda=21.69)$. Dentre os demais conjuntos de funções base, observamos que as bases (aug)-cc-pVTZ/(PP- $R u$ ), DEF2QZVPP e ANO-RCC-VDZP levam a $\Delta \lambda$ 's de 20.74, 24.24 e $31.33 \mathrm{~nm}$, mas com custos 
Tabela 7.3 - Valor do comprimento de onda $\lambda(\mathrm{nm})$ do pico de absorção da banda em menor energia do complexo $R u^{I I}\left(\mathrm{H}_{2} \mathrm{O}\right)$ em solução aquosa, utilizando o funcional B3LYP e diversos conjuntos de funções base. Interações soluto-solvente tratadas com o modelo PCM. Desvio de $\lambda$ em relação ao valor experimental $\left(\Delta \lambda=\lambda^{e x p}-\lambda^{t e o}\right)$, e tempo de processamento real (em horas) utilizando 10 processadores Intel(R) Xeon(R) CPU E7-2870 de 2.40GHz e 100GB de memória RAM.

\begin{tabular}{llccc}
\hline Tipo & Base & $\lambda(\mathrm{nm})$ & $\Delta \lambda(\mathrm{nm})$ & Tempo $(\mathrm{h})$ \\
\hline & cc-pVDZ/(PP- $R u)$ & 438.36 & 33.64 & 0.7 \\
& cc-pVTZ/(PP- $R u)$ & 448.26 & 23.74 & 24.4 \\
& cc-pVQZ/(PP- $R u)$ & 450.89 & 21.11 & 91.2 \\
& $($ aug)-cc-pVDZ/(PP- $R u)$ & 446.80 & 25.20 & 16.8 \\
All-electron/ECP & (aug)-cc-pVTZ/(PP- $R u)$ & 451.26 & 20.74 & 182.4 \\
& LANL2DZ & 435.95 & 36.05 & 0.4 \\
& DEF2TZVP & 442.73 & 35.31 & 19.2 \\
& DEF2QZVP & 447.76 & 29.27 & 379.2 \\
& DEF2QZVPP & 447.92 & 24.24 & 412.8 \\
& Sapporo-DZP-2012 & 422.00 & 50.0 & 4.8 \\
All-electron & Sapporo-TZP-2012 & 431.84 & 40.16 & 45.6 \\
& Sapporo-QZP-2012 & 433.49 & 38.51 & 278.4 \\
& Jorge-ADZP & 517.96 & -45.96 & 2.1 \\
& Jorge-ATZP & 458.94 & 13.06 & 26.4 \\
All-electron DKH & Jorge-AQZP & 450.31 & 21.69 & 340.8 \\
& ANO-RCC-VDZP & 440.67 & 31.33 & 45.6 \\
& Experimental & 472.0 & & \\
\hline
\end{tabular}

computacionais de $182.4,412.8$ e 45.6 horas. O melhor custo benefício é alcançado com a base (aug)-cc-pVDZ/(PP-Ru), que fornece $\Delta \lambda$ de 25.20 com um custo computacional de 16.8 horas.

Ademais, observamos também que a inclusão de efeitos relativísticos nos cálculos das energias de excitação não cumprem um papel relevante na descrição do espectro de absorção dos complexos de $R u$-Aqua/Oxo. A simples utilização de um potencial efetivo para representar os elétrons de caroço do átomo de $R u$ mostra ser uma opção consistente e computacionalmente mais barata. Nessa ordem, aprofundaremos agora no estudo da espectroscopia de absorção de todos os complexos de Ru-Aqua/Oxo utilizando o funcional B3LYP combinado ao conjunto de funções base (aug)-cc-pVDZ/(PP-Ru). Vale lembrar que as estruturas moleculares dos complexos foram obtidas nesse mesmo nível de cálculo. Na próxima seção iremos apresentar os espectros de absorção calculados para todos os complexos e discutir os efeitos do solvente nas 
excitações eletrônicas.

\subsubsection{Espectros UV-Vis teóricos e efeitos do solvente}

Uma vez estabelecidos método e conjunto de funções base com melhor custo benefício, passamos agora ao estudo da espectroscopia de absorção em todos os complexos de $R u$ Aqua/Oxo. Vale recapitular que, para cada complexo, calculamos as 50 primeiras excitações eletrônicas no vácuo e em solução aquosa. Para ir além do modelo contínuo PCM, e introduzir efeitos explícitos do solvente, adotamos o protocolo S-QM/MM. Das simulações clássicas de Monte Carlo, selecionamos uma centena de configurações estatisticamente descorrelacionadas do sistema soluto/solvente. Para cada configuração, calculamos as 50 primeiras excitações eletrônicas em dois níveis de aproximação: (i) tratando as moléculas de água do solvente como cargas pontuais (que denotaremos por PC); (ii) tratando quanticamente as moléculas de água que realizam ligações de hidrogênio com os complexos e as demais como cargas pontuais (que denotaremos por HB+PC). Nas figuras 7.5, 7.6 e 7.7, apresentamos os espectros de absorção teóricos de todos os complexos de $R u$-Aqua/Oxo na condição de vácuo e em solução aquosa (obtidos via PCM, PC e HB+PC), e na tabela 7.4 sumarizamos os picos de absorção de todas as bandas teóricas e experimentais.

Os espectros de absorção UV-Vis dos complexos de $R u$-Aqua/Oxo são mais sensíveis aos efeitos do solvente na região do visível e menos sensíveis na região do ultra-violeta. Considerando a melhor descrição teórica (PC+HB), a banda experimental com picos de absorção entre 290 a $305 \mathrm{~nm}$ é calculada com um desvio solvatocrômico de no máximo $5 \mathrm{~nm}$ em relação ao vácuo (pico III na tabela 7.4). A banda experimental com picos em $336 \mathrm{~nm}\left(\mathrm{Ru}^{I I}\left(\mathrm{H}_{2} \mathrm{O}\right)\right.$ ) $364 \mathrm{~nm}\left(R u^{I I}(O H)\right)$ e $366 \mathrm{~nm}\left(R u^{I I I}(O H)\right)$ é calculada com um desvio solvatocrômico de $18 \mathrm{~nm}$ (para o vermelho), $6 \mathrm{~nm}$ (para o azul) e $13 \mathrm{~nm}$ para o azul, em relação ao vácuo, respectivamente (pico II na tabela 7.4). Já na região do visível, as bandas com picos em 472 e $506 \mathrm{~nm}$ nos complexos $R u^{I I}\left(\mathrm{H}_{2} \mathrm{O}\right)$ e $R u^{I I}(\mathrm{OH})$ são calculadas com desvios solvatocrômicos de $24 \mathrm{~nm}$ (para o vermelho) e $29 \mathrm{~nm}$ (para o azul), em relação ao vácuo (pico I na tabela 7.4), nessa ordem.

No global, a contabilização de efeitos do solvente favorece a descrição dos espectros experimentais. Nos complexos com estado de spin nulo temos o cenário onde os efeitos do solvente são mais importantes. Para os complexos $R u^{I I}\left(H_{2} O\right)$ e $R u^{I I}(O H)$, o tratamento explícito das interações soluto-solvente, via PC ou PC+HB, levam a um melhor acordo teórico/experimental. Isso pode ser notado apenas por uma inspeção visual dos espectros de absorção, nas figuras 7.5 e 7.6, ou também por uma comparação entre os valores absolutos dos picos de absorção teóricos e experimentais, na tabela 7.4. Para o complexo $R u^{I I}\left(H_{2} O\right)$, os comprimentos de onda dos picos I e II são continuamente deslocados para o vermelho, de 432 e $320 \mathrm{~nm}$ no vácuo, para 442 e $330 \mathrm{~nm}$ (via PC), para 456 e $338 \mathrm{~nm}$ (via $\mathrm{PC}+\mathrm{HB}$ ), sendo cada vez mais próximos dos valores experimentais (472 e $336 \mathrm{~nm}$ ). Para o complexo $R u^{I I}(O H)$, 


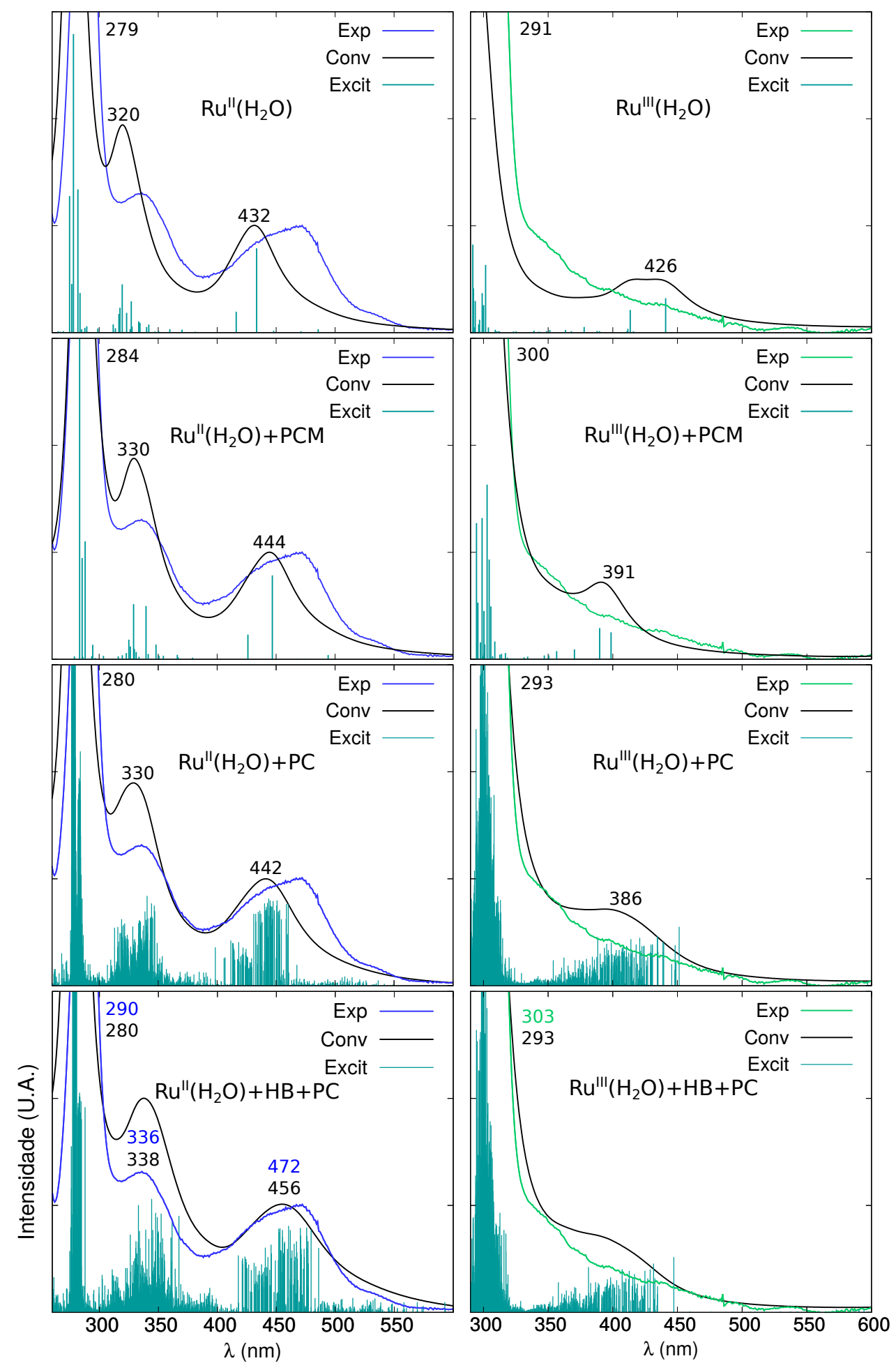

Figura 7.5 - Espectros de absorção UV-Vis teóricos dos complexos de $\mathrm{Ru}\left(\mathrm{H}_{2} \mathrm{O}\right)$ no vácuo e em solução aquosa. Excitações eletrônicas, representadas pelas barras verticais, calculadas com o método TD-DFT e utilizando B3LYP/(aug)-cc-pVDZ(PP). Espectros teóricos gerados a partir da convolução de Lorentzianas de largura $0.15 \mathrm{eV}$ centradas em cada excitação. Interações soluto-solvente tratadas com os modelos PCM, PC e PC+HB. Espectros experimentais apresentados para comparação. 


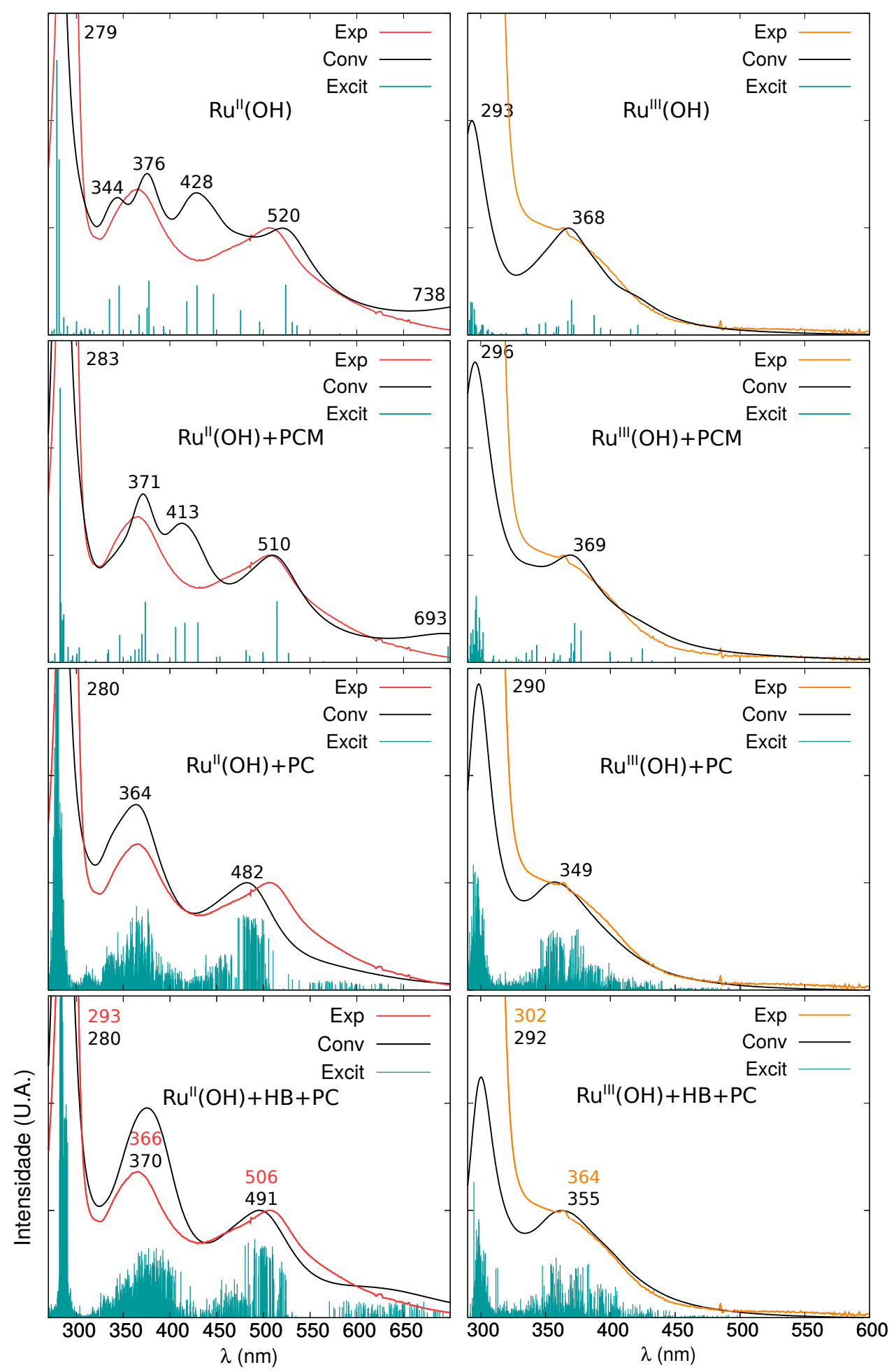

Figura 7.6 - Espectros de absorção UV-Vis teóricos dos complexos de $R u(O H)$, no vácuo e em solução aquosa. Excitações eletrônicas (primeiras 50) calculadas com o método TD-DFT, utilizando B3LYP/(aug)-cc-pVDZ(PP). Interações soluto-solvente tratadas com os modelos $\mathrm{PCM}, \mathrm{PC}$ e $\mathrm{PC}+\mathrm{HB}$. Os dois últimos, dentro do escopo do método $\mathrm{QM} / \mathrm{MM}$ sequencial, e utilizando configurações do solvente geradas a partir das simulações de MC. Os espectros experimentais são apresentados para comparação. 


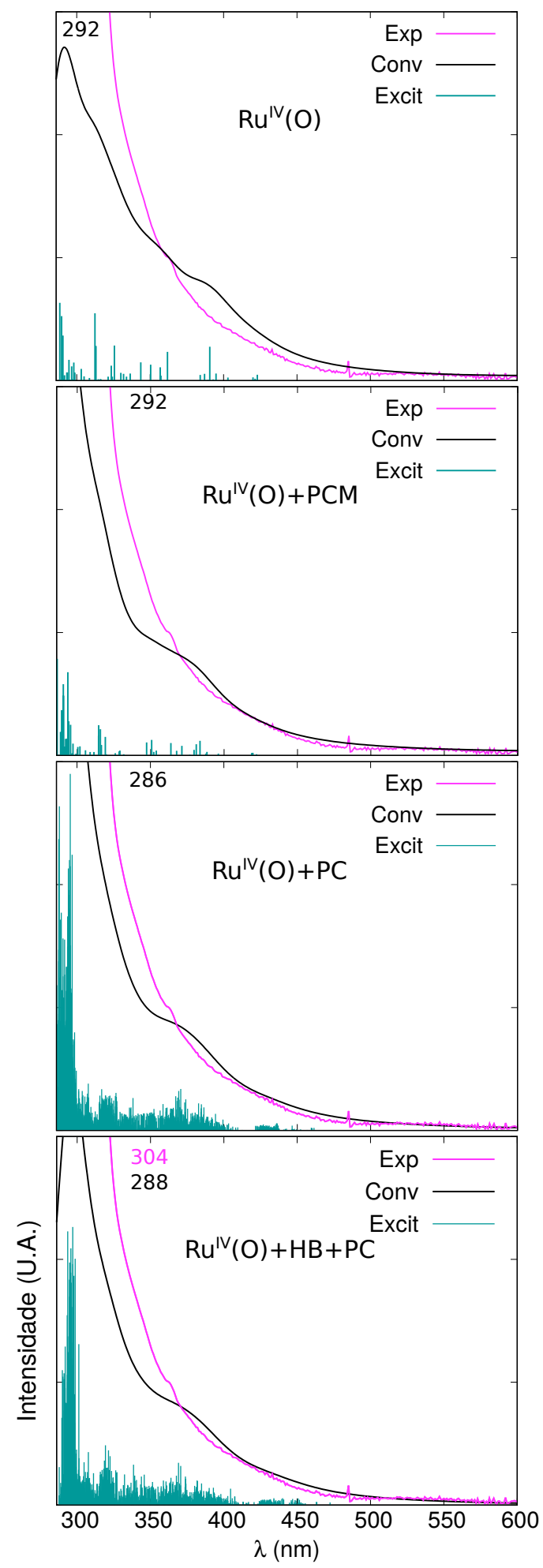

Figura 7.7 - Espectros de absorção UV-Vis teóricos dos complexos de $R u(O)$, no vácuo e em solução aquosa. Excitações eletrônicas (primeiras 50) calculadas com o método TD-DFT, utilizando B3LYP/(aug)-cc-pVDZ(PP). Interações solutosolvente tratadas com os modelos $\mathrm{PCM}, \mathrm{PC}$ e $\mathrm{PC}+\mathrm{HB}$. Os dois últimos, dentro do escopo do método QM/MM sequencial, e utilizando configurações do solvente geradas a partir das simulações de MC. Espectros experimentais apresentados para comparação. 
Tabela 7.4 - Valor do comprimento de onda $\lambda(\mathrm{nm})$ dos picos de absorção UV-Vis dos complexos de $R u$-Aqua/Oxo no vácuo e em solução aquosa, utilizando B3LYP/(aug)cc-pVDZ/(PP-Ru) e diferentes aproximações para a interação soluto-solvente (PCM, PC, $\mathrm{HB}+\mathrm{PC})$.

\begin{tabular}{ccccccccccccc}
\hline & \multicolumn{2}{c}{$R u^{I I}\left(\mathrm{H}_{2} \mathrm{O}\right)$} & \multicolumn{2}{c}{$R u^{I I}(\mathrm{OH})$} & \multicolumn{2}{c}{$R u^{I I I}\left(\mathrm{H}_{2} \mathrm{O}\right)$} & \multicolumn{2}{c}{$R u^{I I I}(\mathrm{OH})$} & \multicolumn{2}{c}{$R u^{I V}(\mathrm{O})$} \\
& \multicolumn{3}{c}{ picos } & \multicolumn{2}{c}{ picos } & \multicolumn{2}{c}{ picos } & \multicolumn{2}{c}{ picos } & picos \\
& I & II & III & I & II & III & II & III & II & III & III \\
\hline VAC & 432 & 320 & 279 & 520 & 376 & 279 & 426 & 291 & 368 & 293 & 292 \\
PCM & 444 & 330 & 284 & 510 & 371 & 283 & 391 & 300 & 369 & 296 & 292 \\
PC & 442 & 330 & 280 & 482 & 364 & 280 & 386 & 293 & 349 & 290 & 286 \\
HB+PC & 456 & 338 & 280 & 491 & 370 & 280 & - & 293 & 355 & 292 & 288 \\
EXP & 472 & 336 & 290 & 506 & 366 & 293 & - & 303 & 364 & 302 & 304 \\
\hline
\end{tabular}

os comprimentos de onda dos picos I e II são deslocados para o azul, de 520 e $376 \mathrm{~nm}$ no vácuo, para 482 e 364 nm (via PC), para 491 e 370 nm (via PC+HB), sendo também mais próximos dos valores experimentais (506 e $366 \mathrm{~nm}$ ). Isso revela a importância de se considerar explicitamente a participação das ligações de hidrogênio no processso de excitação eletrônica desses complexos.

A descrição teórica dos espectros por meio da aproximação $\mathrm{PC}+\mathrm{HB}$ é assim satisfatória. Além de levar a uma melhor concordância teórico/experimental em termos do posicionamento dos picos de absorção nos espectros, ainda permite a descrição do alargamento não-homogêneo provocado pela dinâmica do solvente. Conforme visualizamos nas figuras 7.5, 7.6 e 7.7, as excitações eletrônicas calculadas para cada espectro via PC+HB (ou PC), num total de 5000 excitações, considerando o produto do número de excitações calculadas por configuração (50) e o número de configurações utilizadas (100), cobrem grande parte do intervalo visível/ultravioleta dos espectros experimentais. Como se não bastasse a boa concordância entre os picos teóricos, obtidos a partir da convolução dessas excitações, e os picos experimentais, há também uma excelente concordância entre o posicionamento dessas excitações, suas intensidades e as bandas de absorção nos espectros experimentais.

Utilizando o modelo contínuo PCM alcançamos também uma boa descrição teórica dos espectros experimentais. Há naturalmente a perda do alargamento não-homogêneo das bandas, já que o solvente é tratado de forma implícita, e realizamos apenas o cálculo das 50 primeiras excitações eletrônicas na geometria otimizada do soluto. Utilizando o modelo PCM conseguimos uma boa descrição de todos os picos na região do ultra-violeta. Entre os 5 complexos, o comprimento de onda do pico III desvia-se dos valores experimentais de 3 a $12 \mathrm{~nm}$, similar ao que obtemos via PC (de 8 a $13 \mathrm{~nm}$ ) ou via PC+HB (de 6 a $13 \mathrm{~nm}$ ). O comprimento de onda do pico II desvia-se dos valores experimentais de 5 a $6 \mathrm{~nm}$ via PCM; de 2 a $15 \mathrm{~nm}$ via PC e de 2 a $9 \mathrm{~nm}$ via HB+PC. Já na região do visível, o modelo PCM fornece uma boa descrição 
do pico I para o complexo $R u^{I I}(O H)$ (pico I obtido em $510 \mathrm{~nm}$ e experimental em $506 \mathrm{~nm}$ ) e uma descrição menos precisa desse pico para o complexo $R u^{I I}\left(H_{2} O\right)$ (pico I obtido em 444 $\mathrm{nm}$ e experimental em $472 \mathrm{~nm}$ ).

Nos cálculos das excitações eletrônicas com solvente explícito, utilizando as aproximações $\mathrm{PC}$ ou $\mathrm{HB}+\mathrm{PC}$, a estrutura molecular dos complexos foi mantida fixa na geometria otimizada em solução (apenas a molécula de água nos complexos $R u^{I I}\left(\mathrm{H}_{2} \mathrm{O}\right)$ e $R u^{I I I}\left(\mathrm{H}_{2} \mathrm{O}\right)$ foi deixada livre para rotacionar e transladar) durante as simulações de Monte Carlo. Por isso, quando falamos em alargamento das bandas citamos apenas o alargamento proveniente das mudanças na estrutura do solvente, que chamamos de alargamento não homogêneo. Como esses cálculos foram feitos numa geometria rígida, então não temos o alargamento espectral proveniente de movimentos internos da molécula. Chamamos esse tipo de alargamento de alargamento homogêneo. Apesar de termos obtido uma boa descrição dos espectros de absorção dos complexos, ainda restaria um questionamento: qual seria o efeito nos espectros de se considerar os complexos de $R u$ Aqua/Oxo flexíveis, e não rígidos? Para responder a essa pergunta, escolhemos o complexo $R u^{I I}\left(\mathrm{H}_{2} \mathrm{O}\right)$ como modelo e realizamos a simulação de Dinâmica Molecular clássica desse complexo em solução aquosa (mais detalhes no capítulo de metodologia), permitindo assim os movimentos internos do complexo. Seguimos o protocolo S-QM/MM, e selecionamos uma centena de configurações da simulação para a realização dos cálculos das excitações eletrônicas, dessa vez utilizando apenas a aproximãção PC. O resultado se confere na figura 7.8.

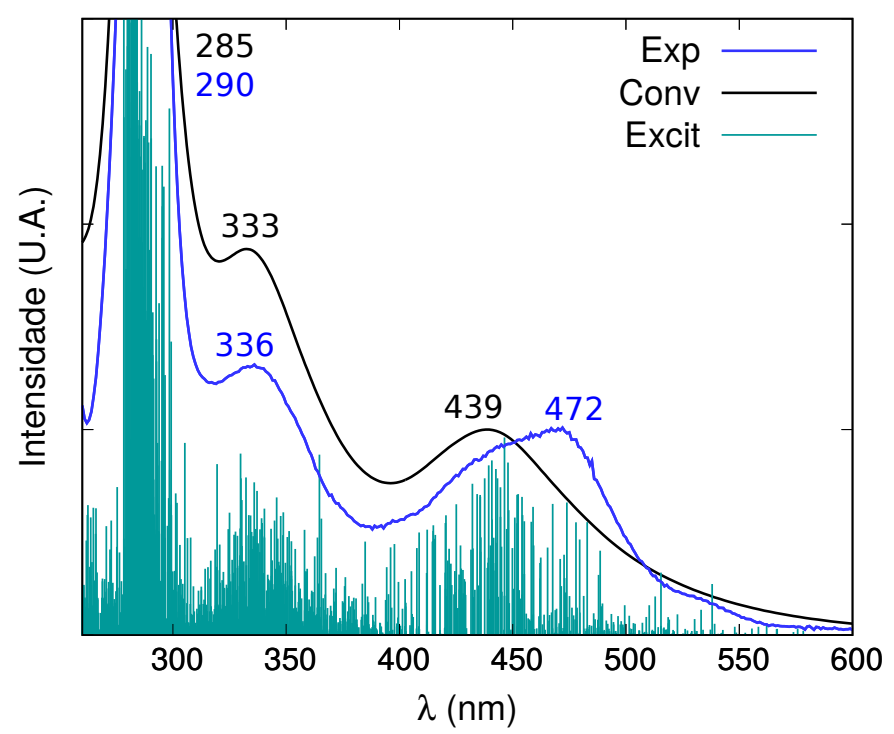

Figura 7.8 - Espectro de absorção UV-Vis teórico do complexo $R u^{I I}\left(H_{2} O\right)$ em solução aquosa, obtido via QM/MM sequencial utilizando Dinâmica Molecular. Excitações eletrônicas (primeiras 50) calculadas com o método TD-DFT, utilizando B3LYP/(aug)-cc-pVDZ(PP). Interações soluto-solvente tratadas com o modelo $\mathrm{CP}$, dentro do escopo do método $\mathrm{QM} / \mathrm{MM}$ sequencial, e utilizando configurações do solvente geradas a partir das simulações de Dinâmica Molecular. Espectro experimental apresentado para comparação.

O espectro de absorção obtido para o complexo $R u^{I I}\left(H_{2} O\right)$ em solução por meio do 
protocolo S-QM/MM, mas permitindo a flexibilidade interna do complexo, é semelhante ao complexo calculado com a geometria rígida, desde o posicionamento dos picos de absorção até o alargamento das bandas. Posto que para esse teste aplicamos apenas a aproximação PC, nada mais justo que compararmos esse espectro diretamente com o espectro calculado por meio de simulação de Monte Carlo e utilizando a aproximação PC. Por Monte Carlo, obtivemos os picos de absorção I, II e III em 442, 330 e $280 \mathrm{~nm}$. Agora, por Dinâmica Molecular, obtivemos esses picos em 439, 336 e $285 \mathrm{~nm}$. Esse resultado permite-nos chegar a duas conclusões importantes: (i) a flexibilidade interna dos complexos de $R u$-Aqua/Oxo tem pouca importância para a descrição de seus espectros de absorção; (ii) o alargamento espectral das bandas de absorção desses complexos tem um caráter principalmente não-homogêneo.

\subsubsection{Caracterização das excitações eletrônicas}

Para avançar na compreensão dos espectros de absorção dos complexos de $R u$-Aqua/Oxo analisamos o caráter das excitações eletrônicas utilizando as ferramentas de análise do programa Theodore. ${ }^{[252]}$ Separamos cada complexo em 5 grupos de átomos: Ru, bpy1, bpy2, py e grupo Aqua/Oxo. Analisamos as matrizes de densidade de transição geradas a partir dos cálculos TD-DFT, dentro da aproximação TDA. Caracterizamos as excitações eletrônicas em 5 tipos de contribuição:

- MLCT - Excitação com transferência de carga do metal para os grupos ligantes.

- MC - Excitação local entre orbitais $d$ do metal.

- LMCT - Excitação com transferência de carga dos grupos ligantes para o metal.

- LLCT - Excitação com transferência de carga entre os grupos ligantes.

- LC - Excitação local dos ligantes.

Nas figuras 7.9 e 7.10, reapresentamos os espectros de absorção (teórico - HB+PC e experimental) dos complexos de $R u$-Aqua/Oxo e o mapeamento das excitações eletrônicas. Pela legenda do espectro de absorção identificamos o conjunto de excitações eletrônicas que predomina em cada parte do espectro. Seguindo para o mapa de contribuição/excitação, identificamos o caráter de cada excitação pelo percentual das contribuições MC, MLCT, LMCT, LLCT e LC. Nas figuras 7.11, 7.12 e 7.13, reapresentamos esses mapas de contribuição/excitação numa versão mais detalhada. E na tabela 7.5 , apresentamos de forma resumida o percentual de cada contribuição por 2 grupos de excitações eletrônicas, onde consideramos as 30 primeiras excitações no primeiro grupo (1-30) e as demais excitações no segundo grupo (31-50).

Nos complexos $R u^{I I}\left(H_{2} O\right)$ e $R u^{I I}(O H)$, as bandas com picos de absorção em 472, 336 $\mathrm{nm}$ e 506, $366 \mathrm{~nm}$, respectivamente, são constituídas principalmente por excitações do tipo MLCT, em torno de 60\%, e, em menor grau, por excitações LLCT e LC, aproximadamente $30 \%$. Abaixo dos $300 \mathrm{~nm}$, observamos um aumento das contribuições LLCT e LC, para 56\%, 
(a)
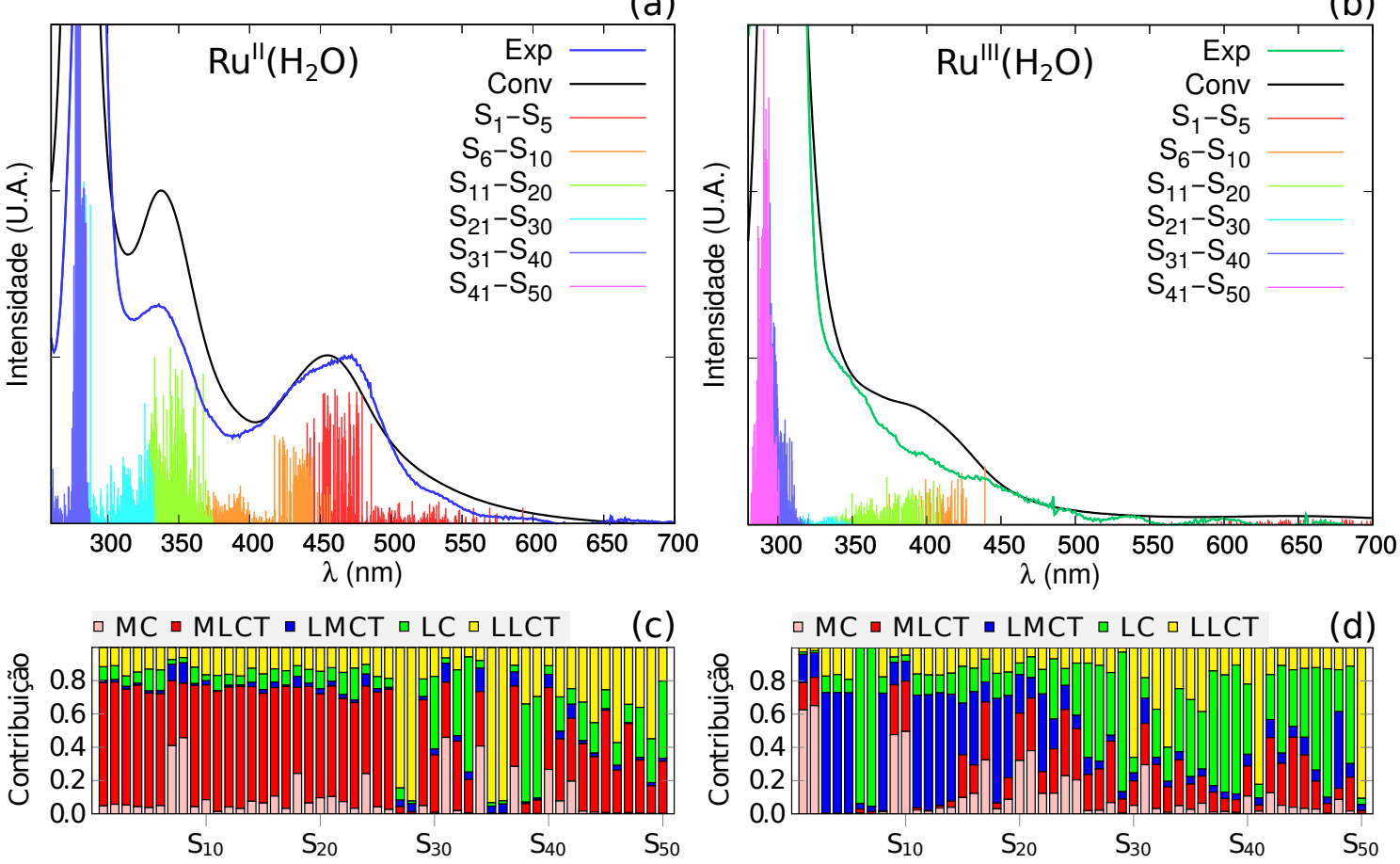

(e)
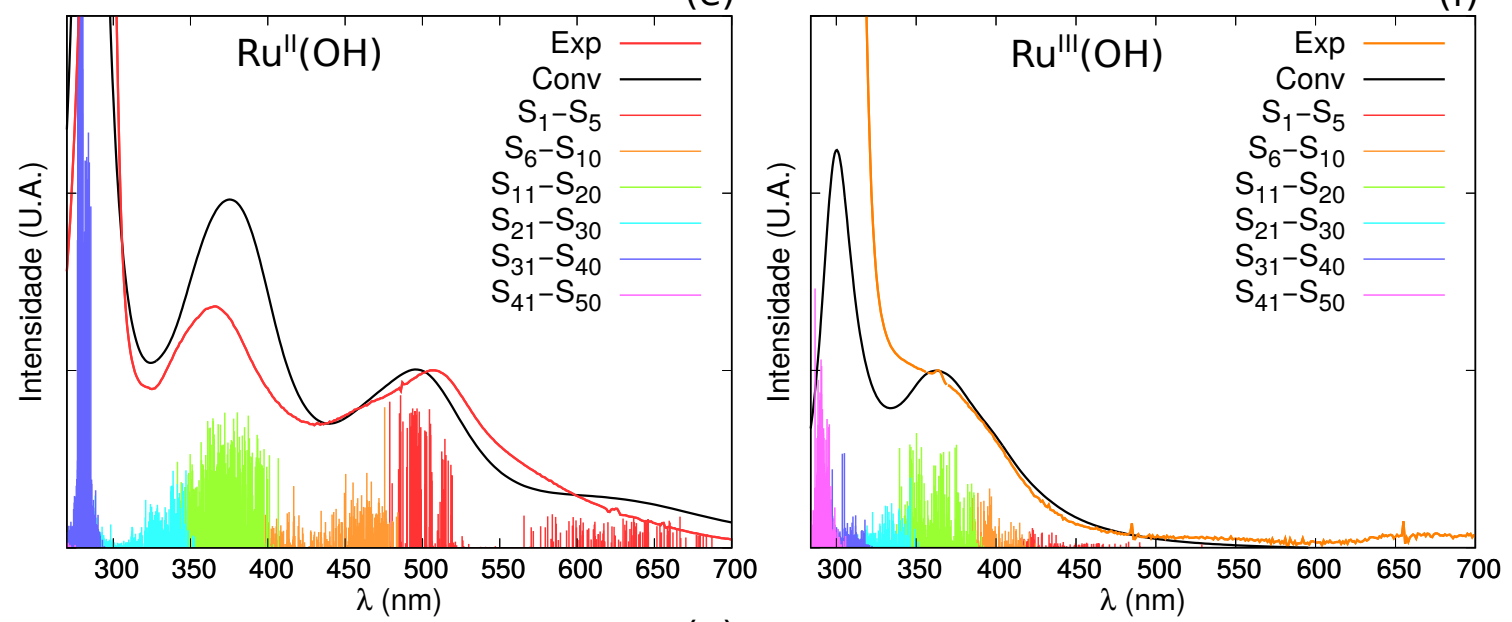

$\square \mathrm{MC} \backsim \mathrm{MLCT} \backsim \mathrm{LMCT} \square \mathrm{LC} \square \mathrm{LLCT} \quad(\mathrm{g})$

$\square \mathrm{MC} \square \mathrm{MLCT} \backsim \mathrm{LMCT} \square \mathrm{LC} \square \mathrm{LLCT}$

(h)
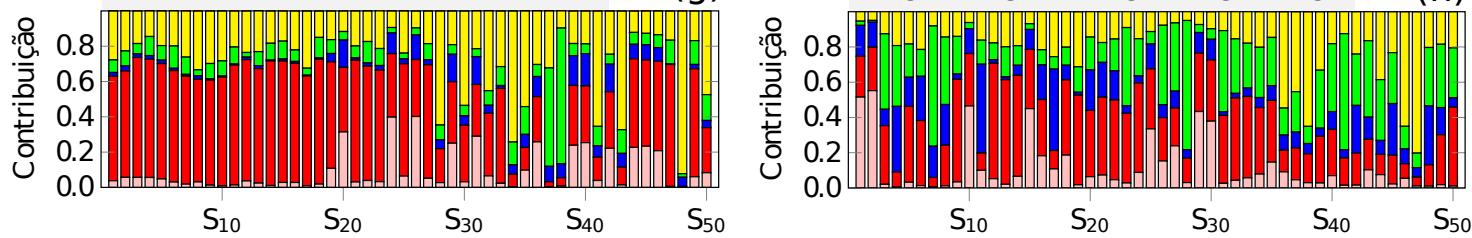

Figura 7.9 - Espectros de absorção UV-Vis teóricos (a, b, e, f) dos complexos de Ru-Aqua/Oxo em solução aquosa e mapa das contribuições MC, MLCT, LMCT, LLCT e LC das excitações eletrônicas (c, d, g, h). Excitações eletrônicas calculadas via protocolo S-QM/MM/TD-DFT utilizando B3LYP/(aug)-cc-pVDZ(PP). Efeitos do solvente incluídos via aproximação HB+PC. Excitações eletrônicas representadas pelas barras verticais coloridas, e espectro teórico obtido a partir da convolução por lorentzianas de largura $0.15 \mathrm{eV}$. Mapas das contribuições gerados pelo programa Theodore ${ }^{[252]}$, utilizando a aproximação TDA. 
(a)
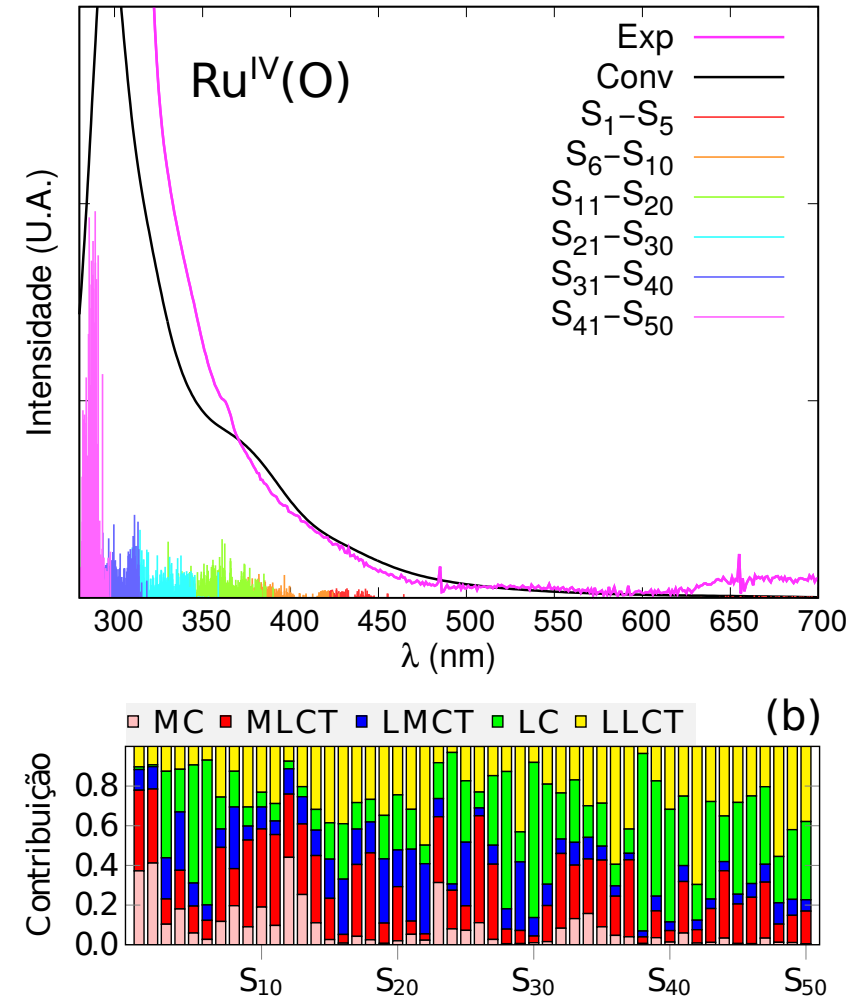

Figura 7.10 - Espectro de absorção UV-Vis teórico (a) dos complexos $R u^{I V}(O)$ em solução aquosa e mapa das contribuições MC, MLCT, LMCT, LLCT e LC das excitações eletrônicas (b). Excitações eletrônicas calculadas via protocolo S-QM/MM/TDDFT utilizando B3LYP/(aug)-cc-pVDZ(PP). Efeitos do solvente incluídos via aproximação $\mathrm{HB}+\mathrm{PC}$. Excitações eletrônicas representadas pelas barras verticais coloridas, e espectro teórico obtido a partir da convolução por lorentzianas de largura $0.15 \mathrm{eV}$. Mapas das contribuições gerados pelo programa Theodore ${ }^{[252]}$, utilizando a aproximação TDA.

Tabela 7.5 - Percentual das contribuições MC, MLCT, LMCT, LC e LLCT por grupos de excitações eletrônicas (1-30 e 31-50).

\begin{tabular}{lllllllllll}
\hline & \multicolumn{2}{l}{$R u^{I I}\left(\mathrm{H}_{2} \mathrm{O}\right)$} & \multicolumn{2}{l}{$R u^{I I I}\left(\mathrm{H}_{2} \mathrm{O}\right)$} & \multicolumn{2}{l}{$R u^{I I}(\mathrm{OH})$} & \multicolumn{2}{l}{$R u^{I I I}(\mathrm{OH})$} & \multicolumn{2}{l}{$R u^{I V}(\mathrm{O})$} \\
& $1-30$ & $31-50$ & $1-30$ & $31-50$ & $1-30$ & $31-50$ & $1-30$ & $31-50$ & $1-30$ & $31-50$ \\
\hline MC & 9 & 9 & 15 & 5 & 8 & 12 & 16 & 5 & 11 & 4 \\
MLCT & 60 & 30 & 16 & 18 & 58 & 30 & 34 & 24 & 25 & 21 \\
LMCT & 3 & 5 & 32 & 8 & 4 & 8 & 15 & 10 & 17 & 7 \\
LC & 9 & 23 & 24 & 41 & 7 & 15 & 21 & 30 & 25 & 36 \\
LLCT & 19 & 33 & 13 & 28 & 23 & 35 & 14 & 31 & 22 & 32 \\
\hline
\end{tabular}

e uma redução da MCLT para 30\%, indicando que a banda em torno dos $290 \mathrm{~nm}$ é constituída principalmente por excitações envolvendo os ligantes.

A oxidação do complexo $R u^{I I}\left(H_{2} O\right)$ provoca uma drástica redução da contribuição MLCT 
em todo o espectro. Com 1 elétron a menos, o átomo de $R u$ em $R u^{I I I}\left(H_{2} O\right)$ transforma-se num forte aceitador de elétrons, levando a uma redução da contribuição MCLT para 16\% e a um aumento da contribuição LMCT para $32 \%$ entre as 30 primeiras excitações eletrônicas. $\mathrm{Na}$ região dos $300 \mathrm{~nm}$, a contribuição MLCT cai para $18 \%$ e as contribuições LC e LLCT sobem para quase $70 \%$.

Considerando a perda de 1 elétron e 1 próton acoplados, $R u^{I I}\left(H_{2} O\right) \rightarrow R u^{I I I}(O H)+$ $e^{-}+H^{+}$, o caráter de aceitador do átomo de $R u$ é reequilibrado, e a contribuição MCLT volta a ter um papel importante até os $300 \mathrm{~nm}, 34 \%$, competindo assim com as contribuições LC e LLCT, que somam 35\%, e a contribuição LMCT com 15\%. Na região dos $300 \mathrm{~nm}$, a contribuição MLCT sobe para $24 \%$ e as contribuições LC, LLCT e LMCT somam $71 \%$.

No caso do complexo $R u^{I V}(O)$, as contribuições LC e LLCT correspondem a $47 \%$ de todas as contribuições entre as primeiras 30 excitações eletrônicas, e esse número sobe para $69 \%$ entre as últimas 20 excitações. A contribuição MLCT é de $25 \%$ no primeiro grupo de excitações e de $21 \%$ no segundo grupo. Um dado interessante é a contribuição LMCT, que corresponde a $17 \%$ das contribuições no primeiro grupo e a $7 \%$ das contribuições no segundo. Portanto, o complexo $R u^{I V}(O)$ apresenta o segundo maior percentual de contribuição LMCT entre as 30 primeiras excitações, ficando atrás apenas do complexo $R u^{I I I}\left(\mathrm{H}_{2} \mathrm{O}\right)$.

Num contexto geral, a contribuição $\mathrm{MC}$ tem baixo percentual entre todas as contribuições. Nos complexos $R u^{I I}\left(\mathrm{H}_{2} \mathrm{O}\right)$ e $R u^{I I}(\mathrm{OH})$, as 30 primeiras excitações tem 9 e $8 \%$ de contribuição MC, e as 20 últimas excitações tem 9 e 12\%, respectivamente. Com a mono oxidação dos complexos, as excitações do primeiro grupo tem um aumento da contribuição MC, passando a $15 \%$ em $R u^{I I I}\left(\mathrm{H}_{2} \mathrm{O}\right)$ e $16 \%$ em $R u^{I I I}(\mathrm{OH})$. Já as excitações do segundo grupo tem uma redução da contribuição $\mathrm{MC}$, passando a $5 \%$ em ambos os complexos. A redução da contribuição MC após a oxidação é um fato intuitivo, uma vez que a redução da densidade eletrônica do átomo deveria levar a uma redução das excitações locais. Já o aumento dessa contribuição é um fato contra intuitivo. À nível de hipótese formulamos a explicação que segue. Sabemos que antes da oxidação, a contribuição MCLT predomina no primeiro grupo de excitações eletrônicas, e tem um papel menos importante no segundo grupo, e, após uma oxidação, grande parte dessas transições desaparecem. Entendemos que possíveis excitações MLCT podem não desaparecer completamente, entretanto, essas que sobram podem não alcançar o estado de transferência de carga, necessário para serem caracterizadas como MLCT, tão logo são caracterizadas como MC. Como havia antes da oxidação uma maior abundância de excitações MLCT no primeiro grupo, é natural que tenhamos então um aumento dessas excitações MLCT "frustradas", agora caracterizadas por MC.

Quando caracterizamos uma excitação como sendo do tipo MLCT ou LMCT, por exemplo, não informamos com precisão a localização do par elétron-buraco. Numa excitação MLCT, sabemos que o buraco se localiza em algum orbital do metal mas não sabemos para qual ligante se destinou o elétron, e o oposto vale para uma excitação LMCT. Para dar um maior profundidade na compreensão das excitações eletrônicas dos complexos de $R u$-Aqua/Oxo, 


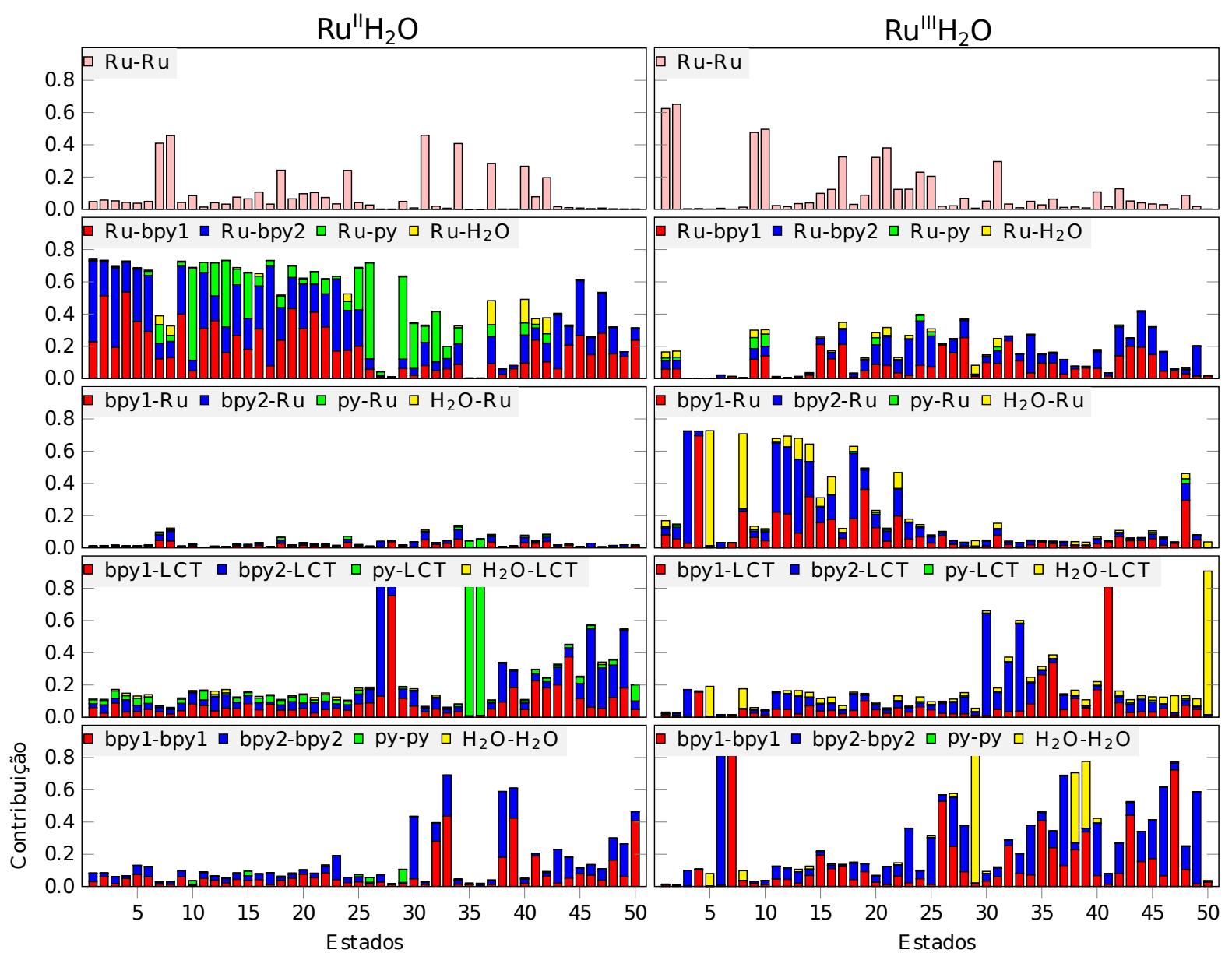

Figura 7.11 - Mapa detalhado das contribuições MC, MLCT, LMCT, LLCT e LC nas excitações eletrônicas dos complexos $\mathrm{Ru}^{I I}\left(\mathrm{H}_{2} \mathrm{O}\right)$ e $\mathrm{Ru} u^{I I I}\left(\mathrm{H}_{2} \mathrm{O}\right)$ em solução aquosa.

realizamos uma análise mais detalhada, explicitando os ligantes envolvidos nas excitações. Os mapas de contribuições detalhados são apresentados nas figuras 7.11, 7.12 e 7.13.

De modo geral, nas contribuições MLCT há predominantemente a transferência de densidade eletrônica do metal para os grupos bipiridínicos (bpy1 e bpy2), e em menor parte, do metal para a piridina. De outra parte, nas contribuições LMCT predomina a transferência de densidade eletrônica dos grupos bipiridínicos para o metal. Em menor percentual, tanto para MLCT quanto para LMCT, há também a contribuição de transferências eletrônicas envolvendo os grupos piridina e Aqua/Oxo.

Nas contribuições LLCT, os brupos bipiridínicos doam a maior parte da densidade eletrônica em excitações envolvendo os ligantes piridínicos bpy1, bpy2 e py. Especificamente nos complexos $R u^{I I}(O H)$ e $R u^{I V}(O)$ (figura 7.13) observamos também que os íons hidróxido e óxido doam uma parcela importante de densidade eletrônica para os ligantes piridínicos. Em todo o espectro calculado, as contribuições OH-LCT e O-LCT foram computadas em 20 e $20 \%$, respectivamente. Considerando a oxidação de $R u^{I I}(O H)$, observamos a contribuição OH-LCT cair para $12 \%$. 


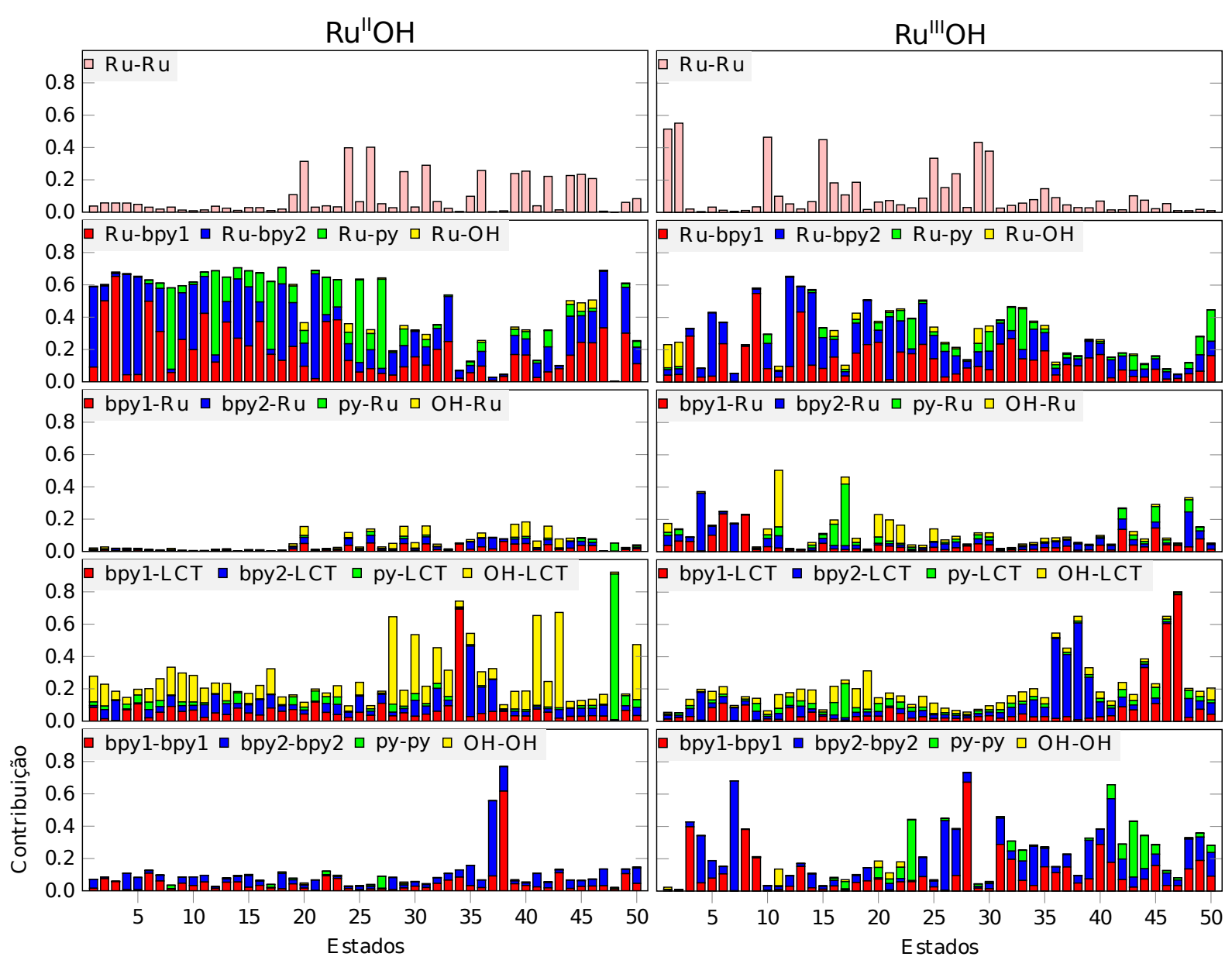

Figura 7.12 - Mapa detalhado das contribuições MC, MLCT, LMCT, LLCT e LC nas excitações eletrônicas dos complexos $R u^{I I}(O H)$ e $R u^{I I I}(O H)$ em solução aquosa.

\subsection{Espectroscopia de fotoelétrons de raios-X (XPS)}

O desenvolvimento de novos eletrocatalisadores moleculares, mais eficientes e mais estáveis, para a realização de fotossíntese artificial, depende de uma profunda compreensão em nível atomístico das reações eletroquímicas que envolvem o catalisador e a solução. Em iniciativas recentes, pesquisadores tem direcionado seus esforços na aplicação de técnicas experimentais como ressonância paramagnética eletrônica e espectroscopia de raios-X para estudar reações eletroquímicas em condições fisico-químicas realísticas. ${ }^{[253-255]}$ Essas técnicas tem demonstrado ser poderosas abordagens, de alta resolução, para sondar a estrutura eletrônica de moléculas em diferentes ambientes químicos.

A espectroscopia de fotoelétrons de raios-X (XPS) é uma técnica de análise usada para obter informações químicas sobre as superfícies de materiais sólidos ou líquidos. Tanto a composição quanto o estado químico dos constituintes da superfície podem ser determinados até alguns nanômetros de espessura. A amostra é colocada em um ambiente de ultra-vácuo e exposta a uma fonte de raios- $X$ monocromática e de baixa energia. Os raios- $X$ incidentes 


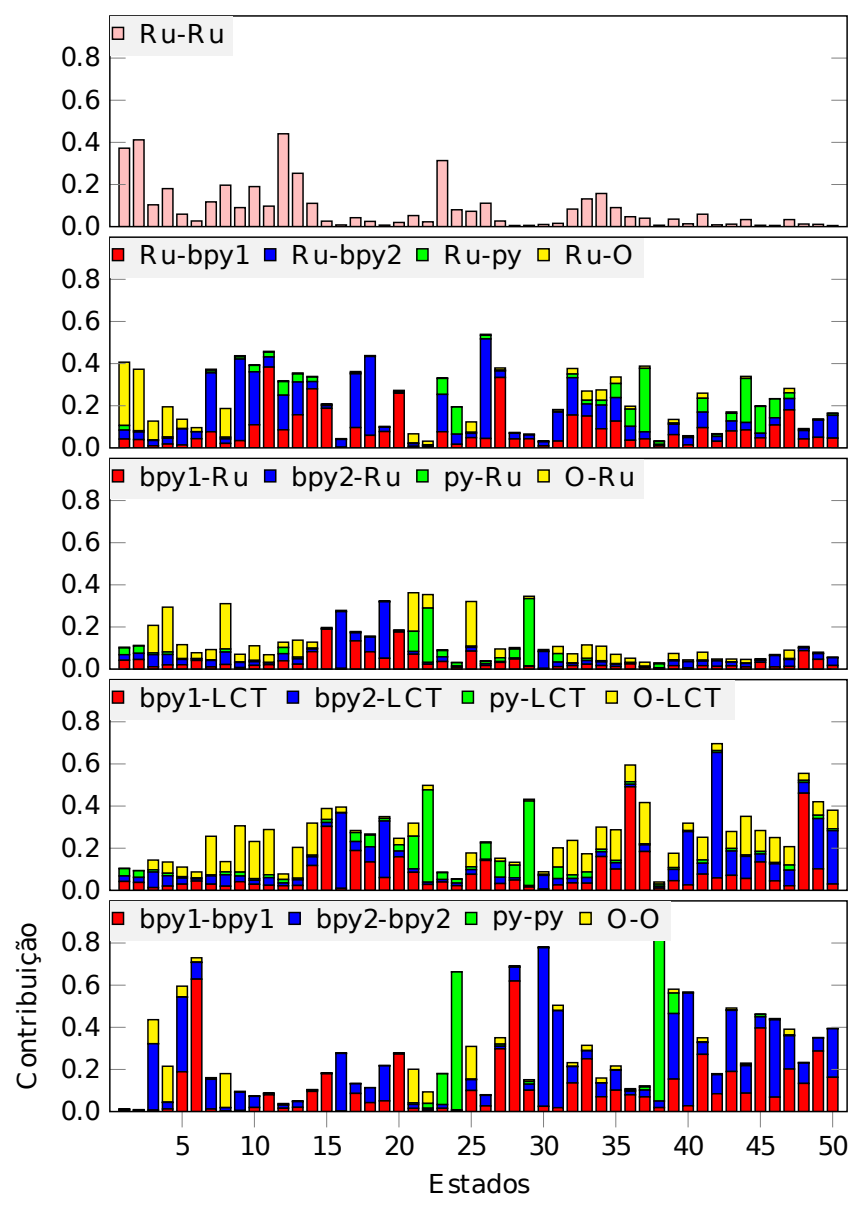

Figura 7.13 - Mapa detalhado das contribuições MC, MLCT, LMCT, LLCT e LC nas excitações eletrônicas do complexo $R u^{I V}(O)$ em solução aquosa.

causam a ejeção de elétrons próximos ao núcleo atômico. A energia do elétron foto-emitido é uma função de sua energia de ligação e portanto caracteriza o elemento a partir do qual o elétron foi ejetado. A análise de energia dos fotoelétrons emitidos é o principal dado usado pelo XPS. Quando um elétron próximo ao núcleo é ejetado pelo raio-X incidente, um elétron externo preenche a lacuna deixada pelo elétron ejetado. A energia dessa transição é equilibrada pela emissão de um elétron Auger ou um raio-X característico. Os fotoelétrons e os elétrons Auger emitidos a partir da amostra são detectados por um analisador de energia eletrônica, e sua energia é determinada em função da velocidade que eles entram no detector. Contando-se o número de fotoelétrons em função de sua energia, é obtido um espectro de XPS que representa a composição da superfície. A energia correspondente a cada pico é característica de cada elemento químico presente na amostra. A forma do pico e sua posição indicam o estado químico do elemento. O XPS é uma técnica sensível à superfície porque apenas os elétrons gerados perto da superfície escapam e são detectados. Os fotoelétrons de interesse possuem energia cinética relativamente baixa. Devido a colisões inelásticas na estrutura atômica da amostra, os fotoelétrons originários de regiões muito abaixo da superfície não podem escapar com energia suficiente para serem detectados.

A espectroscopia de fotoelétrons de raios-X (XPS) aliada à técnica de micro-jato líquido foi 
recentemente utilizada na investigação de reações redox próton-acoplados dos complexos de $R u$-Aqua/Oxo aqui estudados. ${ }^{[69]}$ De forma colaborativa, participamos desse estudo realizando a modelagem teórica QM/MM desses complexos em solução. Nesta seção, abordaremos os resultados experimentais e teóricos de XPS alcançados nesse estudo.

Na figura 7.14 apresentamos os espectros de XPS experimentais e teóricos, no vácuo e em solução aquosa, para elétrons ionizados dos orbitais $R u(3 d)$ e $C(1 s)$. Nos espectros experimentais, observamos predominantemente a formação de uma primeira banda de energia referente à ionização de elétrons do orbital $R u\left(3 d_{5 / 2}\right)$ (em menores energias), e uma segunda banda referente à ionização de elétrons dos orbitais $C(1 s)$ e $R u\left(3 d_{3 / 2}\right)$ (em maiores energias). E para determinadas condições de $p H$ e de concentração de agentes oxidativos, observamos o surgimento de uma terceira banda com energia intermediária. No complexo $\mathrm{Ru}^{I I}\left(\mathrm{H}_{2} \mathrm{O}\right)$, a banda referente a $R u\left(3 d_{5 / 2}\right)$ tem pico em $293 \mathrm{eV}$ (pico I), e a banda referente a $C(1 s)$ e $R u\left(3 d_{3 / 2}\right)$ tem pico em 290-291 eV (pico II). Esses valores representam o que figurativamente denominamos por impressão digital desse complexo em solução aquosa no $p H 2.8$.

Considerando a reação de mono-desprotonação do complexo $R u^{I I}\left(H_{2} O\right)$ obtemos o complexo $R u^{I I}(O H)$, espectro na figura 7.14-d. O $p K a$ dessa reação foi primeiramente medido por Moyer e Meyer ${ }^{[256]}, p K a^{1}=10.26$, e as novas medidas indicaram $p K a^{1}=10.8$. O pico de $R u\left(3 d_{5 / 2}\right)$ no complexo $R u^{I I}(O H)$ (pico VIII) encontra-se deslocado para uma energia de ligação mais baixa em aproximadamente $0.3 \mathrm{eV}$ em comparação com o pico I, em $\mathrm{Ru}^{I I}\left(\mathrm{H}_{2} \mathrm{O}\right)$. Esse comportamento é esperado, dado que nesse composto, observa-se uma maior densidade de elétrons no centro metálico, em comparação com $R u^{I I}\left(H_{2} O\right)$. Recordemos os valores de cargas atômicas calculadas para o átomo de $R u$ para cada complexo em solução aquosa (em unidades de carga elementar): 0.33, 0.72, 0.94, 1.01, $1.30 \mathrm{em} R u^{I I}(O H), R u^{I I I}(O H)$, $R u^{I I}\left(H_{2} \mathrm{O}\right), R u^{I V}(\mathrm{O})$ e $R u^{I I I}\left(\mathrm{H}_{2} \mathrm{O}\right)$, respectivamente. A carga de $R u$ é portanto 2.85 vezes menos positiva em $R u^{I I}(O H)$ do que em $R u^{I I}\left(H_{2} O\right)$, justificando assim o menor valor na energia de ligação de $R u\left(3 d_{5 / 2}\right)$ em $R u^{I I}(O H)$.

Considerando a mono-oxidação do complexo $R u^{I I}\left(H_{2} \mathrm{O}\right)$, podemos obter o composto $R u^{I I I}\left(\mathrm{H}_{2} \mathrm{O}\right)$ ou ainda, $R u^{I I I}(\mathrm{OH})$, caso a perda do elétron seja acompanhada da perda de um próton, o que denominamos por reação redox próton-acoplado. As medidas realizadas por Moyer e Meyer ${ }^{[256]}$ indicaram $p K a^{2}=0.85$, para o equilíbrio $R u^{I I I}\left(H_{2} O\right) / R u^{I I I}(O H)$, e as novas medidas indicaram $p K a^{2}=1.3$. Portanto, indo para $p H s$ acima de 1.3 devemos observar um aumento na concentração de $R u^{I I I}(O H)$, e, indo para $p H s$ abaixo de 1.3, devemos observar um aumento na concentração de $R u^{I I I}\left(H_{2} O\right)$. Os espectros experimentais de XPS dos complexos no estado de oxidação $I I I$ são apresentados na figura 7.14-(b e b'), nos $p H s 3$ e 1.3, respectivamente. Nesses espectros, a intensidade dos picos de energia refletem as concentrações das espécies protonada e desprotonada em cada $\mathrm{pH}$. A redução no $p H$ de 3 para 1.3 leva a uma redução na intensidade do pico III e a um aumento na intensidade do pico IV. Portanto, isso só pode nos levar a concluir que os picos III e IV' surgem da ionização de elétrons do orbital $R u\left(3 d_{5 / 2}\right)$ nos complexos $R u^{I I I}(O H)$ e $R u^{I I I}\left(H_{2} O\right)$, respectivamente. 

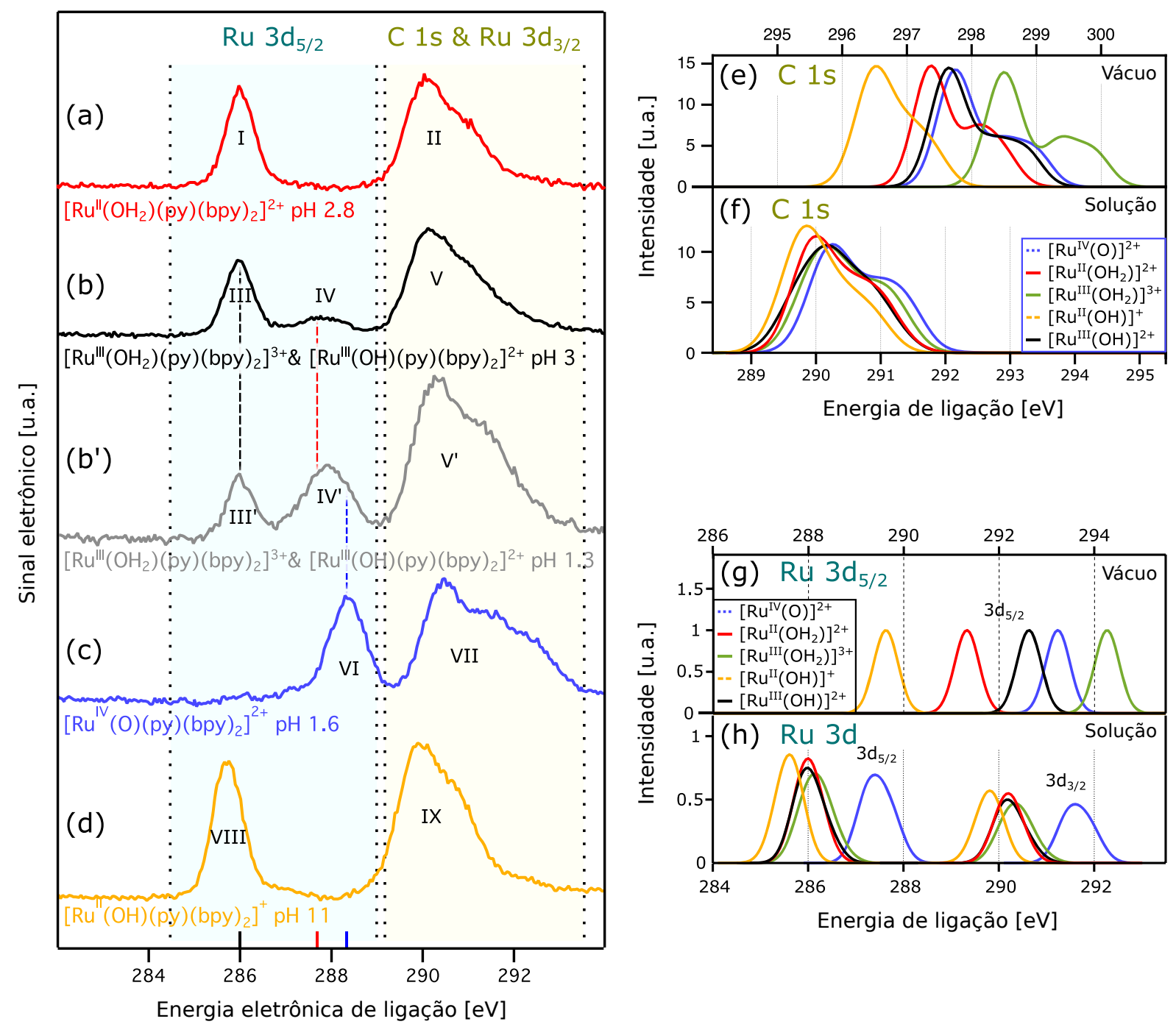

Figura 7.14 - (a-d) Espectro de XPS experimental de $R u(3 d)$ e $C(1 s)$ utilizando a técnica de micro-jato líquido. (e,f) Espectro de XPS teórico de $C 1 s$ no vácuo e em solução aquosa, respectivamente. (g,h) Espectro de XPS teórico de $R u 3 d_{5 / 2}$ no vácuo e em solução aquosa, respectivamente. Figura retirada da referência ${ }^{[69]}$.

As semelhanças dos espectros $R u^{I I}\left(\mathrm{H}_{2} \mathrm{O}\right)$ e $R u^{I I I}(\mathrm{OH})$ (os principais picos na figura 7.14-(a e b) podem ser entendidas considerando-se a interação de dois efeitos contrários. Por um lado, a remoção de um elétron aumenta a carga positiva no centro do metal, aumentando a energia de ligação dos elétrons ao núcleo. Por outro lado, uma vez que o centro metálico é oxidado, o ligante hidróxido transfere mais densidade de elétrons para o centro do metal, o que tende a diminuir a energia de ligação dos elétrons. Esses efeitos parecem se cancelar amplamente em solução aquosa.

Em uma análise mais criteriosa, realizando-se a deconvolução dos espectros experimentais dos complexos $R u^{I I I}\left(\mathrm{H}_{2} \mathrm{O}\right)$ e $R u^{I I I}(\mathrm{OH})$, por funções Lorentzianas, figura 7.15 , detectamos que o melhor ajuste dos espectros só é alcançado considerando-se a deconvolução dos picos IV ou IV' $\left(R u\left(3 d_{5 / 2}\right)\right)$ por duas funções Lorentzianas, centradas em 287.7 e $288.2 \mathrm{eV}$. Isso significa 


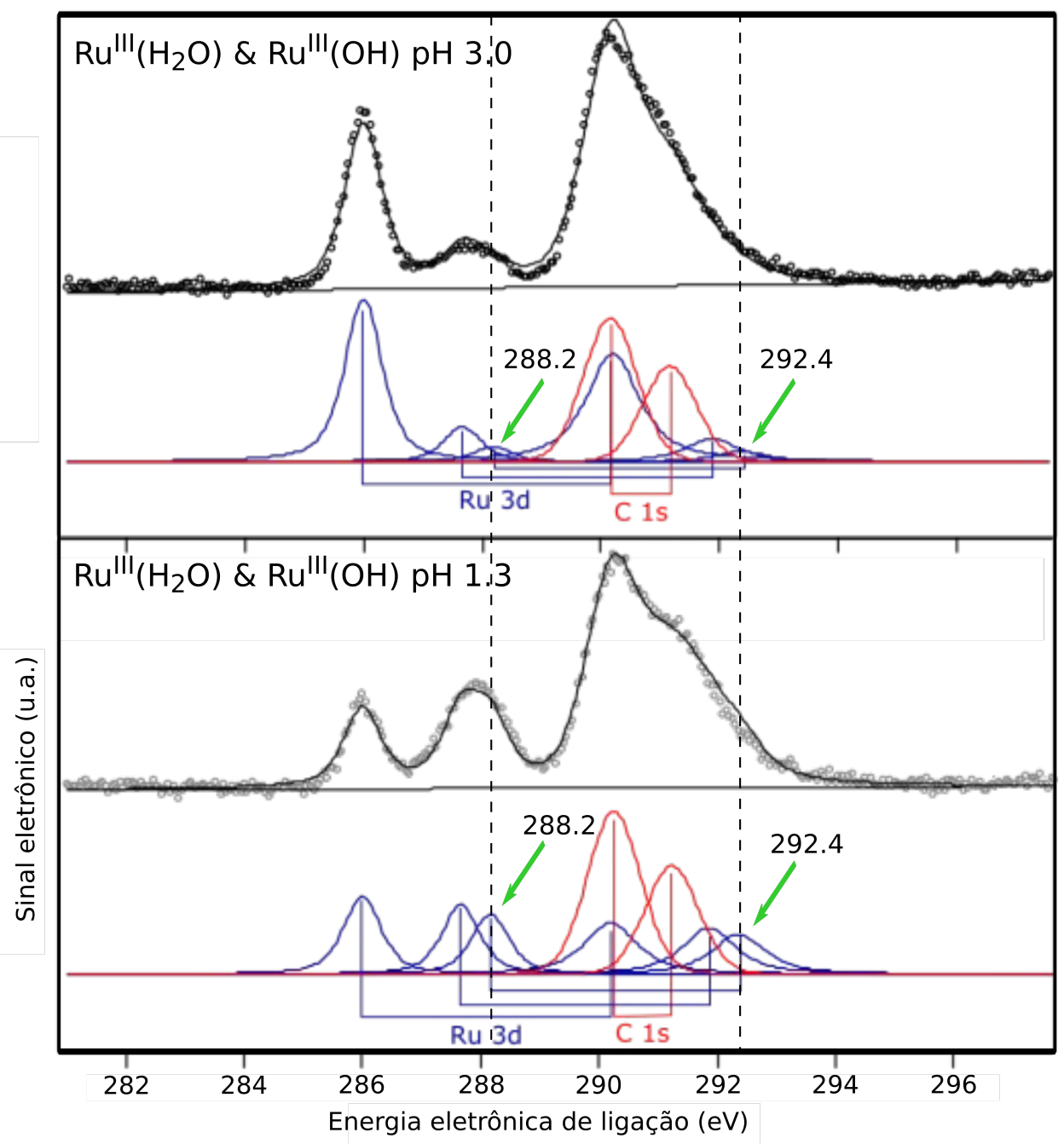

Figura 7.15 - Deconvolução dos espectros experimentais dos complexos $R u^{I I I}\left(\mathrm{H}_{2} \mathrm{O}\right)$ e $R u^{I I I}(O H)$. As setas em verde apontam para os picos extras de $R u\left(3 d_{5 / 2}\right)$ e $R u\left(3 d_{3 / 2}\right)$ relacionados à espécie desconhecida. Figura retirada da referência ${ }^{[69]}$.

dizer que uma terceira espécie deve estar presente nessa solução, com maior concentração no pH 1.3. De acordo com os ajustes realizados, essa nova espécie deve apresentar os picos de energia dos orbitais $R u\left(3 d_{5 / 2}\right)$ e $R u\left(3 d_{3 / 2}\right)$ em 288.2 e $292.4 \mathrm{eV}$, respectivamente. Considerando-se o baixo $\mathrm{pH}$ da solução, essa espécie não poderia ser $R u^{I V}(O H)$, e a busca por uma resposta para essa questão deverá ser tema de pesquisas futuras.

O espectro de XPS da espécie $R u^{I V}(O)$ é apresentado na figura 7.14-c, picos VI e VII. Nesse caso, os estados $R u\left(3 d_{5 / 2}\right)$ e $R u\left(3 d_{3 / 2}\right)$, e em menor grau $C(1 s)$, são deslocados para energias mais altas, em comparação com as espécies discutidas anteriormente. Consequentemente, o pico VII se torna mais alargado porque a sobreposição espectral dos estados $C(1 s)$ e $R u\left(3 d_{3 / 2}\right)$ diminui. Portanto, para o complexo $R u^{I V}(O)$, precisamos fornecer mais energia para arrancar elétrons do caroço de $R u$. Em comparação com o complexo $R u^{I I}\left(H_{2} O\right)$, em $R u^{I V}(O)$ são necessários $2.2 \mathrm{eV}$ a mais de energia para ionizar um elétron do orbital $R u\left(3 d_{5 / 2}\right)$. Se olharmos para as cargas atômicas de $R u$ nesses dois complexos, em solução aquosa, veremos que $R u$ 
é ligeiramente mais positivo em $R u^{I V}(O)\left(q_{R u}=1.01\right)$ que em $R u^{I I}\left(H_{2} O\right)\left(q_{R u}=0.94\right)$. E portanto, tendo $R u^{I I}\left(H_{2} O\right)$ como referência, conseguimos entender olhando apenas para as cargas atômicas de $R u$, porque as energias dos orbitais $R u(3 d)$ são menores no complexo $R u^{I I}(O H)$ e agora maiores no complexo $R u^{I V}(O)$. Nessa linha de raciocínio, deveríamos esperar que a ionização de elétrons dos orbitais $R u\left(3 d_{5 / 2}\right)$ e $R u\left(3 d_{3 / 2}\right)$ no complexo $R u^{I I I}\left(H_{2} O\right)$ fosse mais difífil que em $R u^{I V}(O)$, já que a carga de $R u$ nesse complexo, em solução, é ainda maior $\left(q_{R u}=1.30\right)$. Entretanto, não é isso o que acontece. A ordem experimental dos picos de XPS nos complexos de Ru-Aqua/Oxo não pode ser comprendida a partir da observação local do estado de oxidação ou da distribuição de carga do átomo de $R u$.

A modelagem teórica dos espectros de XPS foi realizada dentro do protocolo S-QM/MM, utilizando-se a teoria de Slater-Janak ${ }^{[100,101]}$ no cálculo das energias de ligação dos orbitais de caroço $R u(3 d)$ e $C(1 s)$ dos complexos de $R u$-Aqua/Oxo, no vácuo e em solução aquosa. Para uma comparação direta com os resultados experimentais, os picos teóricos para os orbitais $C(1 s)$ estão apresentados na figura 7.14-(e,f), e os picos teóricos para os orbitais $R u(3 d)$ na figura 7.14-(g,h). No vácuo, os picos teóricos referentes à cada complexo seguem a ordem das cargas totais. Nos dois extremos, temos o complexo $R u^{I I}(O H)$ (carga total +1 ) com os picos de XPS nas menores energias, e o complexo $R u^{I I I}\left(H_{2} O\right)$ com os picos de XPS nas maiores energias. Experimentalmente, observamos essa tendência para os complexos $R u^{I I}(O H)$ (carga total +1$), R u^{I I}\left(\mathrm{H}_{2} \mathrm{O}\right)$ (carga total +2$), R u^{I I I}(\mathrm{OH})($ carga total +2$)$, mas, para os complexos $R u^{I I I}\left(\mathrm{H}_{2} \mathrm{O}\right)$ (carga total +3 ) e $R u^{I V}(O)$ (carga total +2 ), temos uma inversão. Fica assim destacada a necessidade de se contabilizar os efeitos do solvente na modelagem teórica do XPS desses complexos.

No estudo de inclusão dos efeitos do solvente, testamos inicialmente o efeito de se contabilizar apenas a inclusão das moléculas de água da solução que realizam ligações de hidrogênio com os complexos. Dentro da filosofia do método S-QM/MM, realizamos as simulações clássicas de Monte Carlo dos complexos em solução e extraímos configurações do soluto e suas ligações de hidrogênio. Os cálculos de XPS para esse teste foram realizados para os complexos $R u^{I I}\left(H_{2} O\right)$, $R u^{I I I}\left(H_{2} O\right)$ e $R u^{I V}(O)$, e os espectros do orbital $R u\left(3 d_{5 / 2}\right)$ são apresentados na figura 7.16-b. Conforme verificamos, a simples inclusão das ligações de hidrogênio nos cálculos de XPS não é suficiente para descrever os efeitos do solvente nos espectros experimentais. Nessa aproximação, verificou-se apenas pequenos desvios para menores energias, inferiores a $0.5 \mathrm{eV}$, em relação aos cálculos de vácuo.

Fazendo-se a inclusão explícita de todas as moléculas de água que compõem a primeira camada de solvatação, um total aproximado de 70 moléculas, nos cálculos de XPS, alcançamos a saturação dos espectros teóricos e a melhor descrição possível dentro das aproximações adotadas, figura 7.16 -c para o orbital $R u\left(3 d_{5 / 2}\right)$, e figura $7.14-(\mathrm{f}, \mathrm{h})$ para todos os orbitais. Nessa abordagem, conseguimos descrever a ordem dos picos de $R u(3 d)$ e $C(1 s)$ nos espectros experimentais. Na tabela 7.6 sumarizamos os valores de $B E$, experimentais e teóricos (no vácuo e em solução aquosa), dos orbitais $R u\left(3 d_{5 / 2}\right)$. 


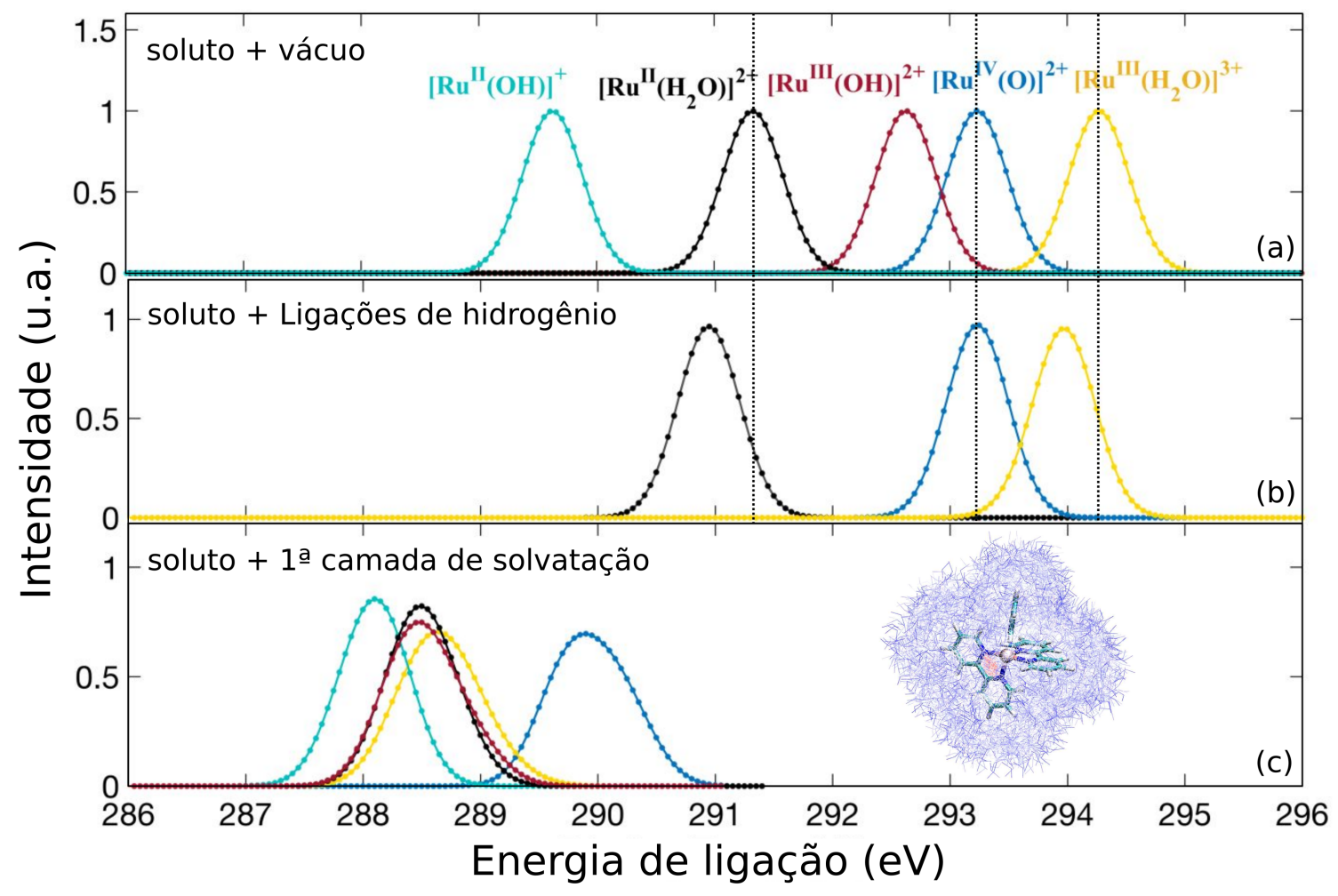

Figura 7.16 - Espectro de XPS do orbital $R u\left(3 d_{5 / 2}\right)$ (a) no vácuo, (b) incluindo apenas as moléculas de água que realizam ligações de hidrogênio com os complexos e (c) incluindo todas as moléculas de água que compõem a primeira camada de solvatação. Figura retirada da referência ${ }^{[69]}$.

Tabela 7.6 - Valores experimentais e teóricos (no vácuo e em solução aquosa) de BE dos orbitais $R u\left(3 d_{5 / 2}\right)$ nos complexos de $R u$-Aqua/Oxo. Entre colchetes encontramse os valores de BE levando-se em conta apenas as ligações de hidrogênio. A quantidade $\triangle \mathrm{BE}$ representa a variação de BE em relação ao complexo $R u^{I I}\left(\mathrm{H}_{2} \mathrm{O}\right)$. Tabela retirada da referência ${ }^{[69]}$.

\begin{tabular}{|c|c|c|c|c|c|c|}
\hline \multirow[b]{3}{*}{$R u\left(3 d_{5 / 2}\right)$} & & & \multicolumn{4}{|c|}{ teórico } \\
\hline & \multicolumn{2}{|c|}{ experimental } & \multicolumn{2}{|c|}{ vácuo } & \multicolumn{2}{|c|}{ solução } \\
\hline & $\mathrm{BE}$ & $\Delta \mathrm{BE}$ & $\mathrm{BE}$ & $\Delta \mathrm{BE}$ & $\mathrm{BE}$ & $\Delta \mathrm{BE}$ \\
\hline Rull(OH) & 285.7 (VIII) & -0.3 & 289.6 & -1.7 & 285.6 & -0.4 \\
\hline Rull(H2O) & $286.0(\mathrm{I})$ & 0.0 & 291.3 [290.9] & $0.0[0.0]$ & 286.0 & 0.0 \\
\hline RullI(OH) & 286.0 (III) & 0.0 & 292.6 & 1.3 & 286.0 & 0.0 \\
\hline RullI(H2O) & 287.7 (IV) & 1.7 & 294.2 [294.0] & 2.9 [3.0] & 286.3 & 0.3 \\
\hline $\operatorname{RuIV(O)}$ & $288.2(\mathrm{VI})$ & 2.2 & $293.2[293.2]$ & 1.9 [2.3] & 287.5 & 1.5 \\
\hline
\end{tabular}

Conforme já mencionamos, para alguns complexos, os valores experimentais de BE dos orbitais $R u\left(3 d_{5 / 2}\right)$ seguem a ordem de crescimento da carga total do complexo, ou mesmo da carga atômica do átomo de $R u$, são eles: $R u^{I I}(O H)$ (carga total $+1, q_{R u}=0.33, \mathrm{BE}=285.7$ $e V), R u^{I I}(O H)$ (carga total $\left.+2, q_{R u}=0.72, \mathrm{BE}=286.0 \mathrm{eV}\right), R u^{I I}\left(\mathrm{H}_{2} \mathrm{O}\right)$ (carga total +2 , 
$\left.q_{R u}=0.94, \mathrm{BE}=286.0 \mathrm{eV}\right)$. Mas, para os demais complexos, isso não é observado: $R u^{I V}(O)$ (carga total $\left.+2, q_{R u}=1.01, \mathrm{BE}=288.2 \mathrm{eV}\right)$ e $R u^{I I I}\left(\mathrm{H}_{2} \mathrm{O}\right)\left(\right.$ carga total $+3, q_{R u}=1.30$, $\mathrm{BE}=287.7 \mathrm{eV})$. Essa tendência não é descrita nos cálculos de vácuo, e nem mesmo com a simples inclusão das ligações de hidrogênio. Entretanto, considerando-se os efeitos de solvente até a primeira camada de solvatação, conseguimos reprozudir essa tendência experimental. Na tabela 7.6, a quantidade $\triangle \mathrm{BE}$, que representa a variação de $\mathrm{BE}$ em relação ao complexo $R u^{I I}\left(H_{2} \mathrm{O}\right)$, serve de parâmetro para identificarmos a tendência de crescimento de BE. $\mathrm{O}$ complexo $R u^{I I}(O H)$ tem $\triangle \mathrm{BE}$ negativo de $-0.3 \mathrm{eV}$, e o resultado teórico foi de $-0.4 \mathrm{eV}$. $\mathrm{O}$ complexo $R u^{I I I}(O H)$ tem $\triangle \mathrm{BE}$ nulo, o resultado teórico é também nulo. O complexo $R u^{I I I}\left(\mathrm{H}_{2} \mathrm{O}\right)$ tem $\Delta$ BE positivo de 1.7 , e o resultado teórico foi de $0.3 \mathrm{eV}$. Por fim, o complexo $R u^{I V}(O)$ tem $\triangle \mathrm{BE}$ positivo de 2.2, e o resultado teórico foi de $1.5 \mathrm{eV}$. É notório que os resultados teóricos reproduzem a tendência experimental, todavia, percebemos também que a descrição de $\Delta \mathrm{BE}$ para os complexos $R u^{I I I}\left(\mathrm{H}_{2} \mathrm{O}\right)$ e $R u^{I V}(O)$ é menos precisa que nos demais complexos.

Apesar de ser um processo que acontece a nível eletrônico, e muito próximo do núcleo atômico, a energia de ligação dos elétrons sofre deslocamentos que são governados principalmente pela interação soluto-solvente até a primeira camada de solvatação. Dessa parte, a correta descrição do solvente é necessária para se reproduzir os valores de BE dos orbitais de camada profunda e tão logo as tendências de aumento ou redução de BE conforme a molécula passa por processos de oxidação, desprotonação, ou ambos. 
cormut 8

\section{Propriedades eletroquímicas}

Neste capítulo iremos tratar da predição teórica da energia livre de solvatação e de propriedades eletroquímicas dos complexos de $R u$-Aqua/Oxo em solução aquosa, $p K a$ e potencial redox $\left(V^{o x}\right)$, a partir da aproximação de ciclos termodinâmicos. Destacaremos os efeitos da escolha do método QM e do conjunto de funções base no cálculo da energia livre de vácuo. Destacaremos os efeitos da escolha do método, QM ou MM, no cálculo da energia livre de solvatação, considerando os efeitos de polarização do solvente descritos por diferentes métodos. Apresentaremos diferentes predições teóricas para os valores de $p K a$ e $V^{o x}$ dos complexos de $R u$-Aqua/Oxo, em comparação com resultados experimentais da literatura.

\subsection{Eletroquímica dos complexos de Ru-Aqua/Oxo}

A eletroquímica dos complexos de $R u$-Aqua/Oxo em solução aquosa foi primeiramente descrita por Moyer e Meyer em 1981. ${ }^{[256]} \mathrm{Na}$ figura 8.1, ilustramos as reações descritas por Moyer e Meyer e na tabela 8.1 apresentamos os valores experimentais de $p K a$ e $V^{o x}$ relacionados a cada caminho de reação. Originalmente, os potenciais de redox foram obtidos utilizando como referência o eletrodo saturado de calomelano (SCE) (do inglês Saturated Calomel Electrode). Para converter para a referência do eletrodo padrão de hidrogênio (SHE) (do inglês standard hydrogen electrode), somamos à todos os valores de $V^{o x}$ a quantia de $0.244 V^{[257]}$

Os valores experimentais de $p K a$ e $V^{o x}$ dessas reações são obtidos em condições muito específicas do meio. Inicialmente, parte-se do complexo $R u^{I I}\left(H_{2} O\right)$ isolado na forma de perclorato $\left(\left[\mathrm{Ru}^{I I}\left(\mathrm{H}_{2} \mathrm{O}\right)(\mathrm{py})(\mathrm{bpy})_{2}\right]\left[\left(\mathrm{ClO}_{4}\right)_{2}\right]\right)$ ou nitrato $\left(\left[\mathrm{Ru}^{\mathrm{II}}\left(\mathrm{H}_{2} \mathrm{O}\right)(\mathrm{py})(\text { bpy })_{2}\right]\left[\left(\mathrm{NO}_{3}\right)_{2}\right]\right)$. Adicionando-se agentes oxidativos, tal como o nitrato de amônio-cério(IV), produz-se os complexos em estados de oxidação mais altos. Adicionando-se bases (ex.: $\mathrm{KOH}, \mathrm{NaOH}$ ) ou ácidos (ex.: $\mathrm{HNO}_{3}, \mathrm{HCl}$ ), ajusta-se o $\mathrm{pH}$ da solução e produz-se os complexos nas formas desprotonadas. Portanto, ajustando-se a concentração do oxidante e o $p H$ da solução, produz-se todas as formas dos complexos de $R u$-Aqua/Oxo. ${ }^{[69,256]}$ 


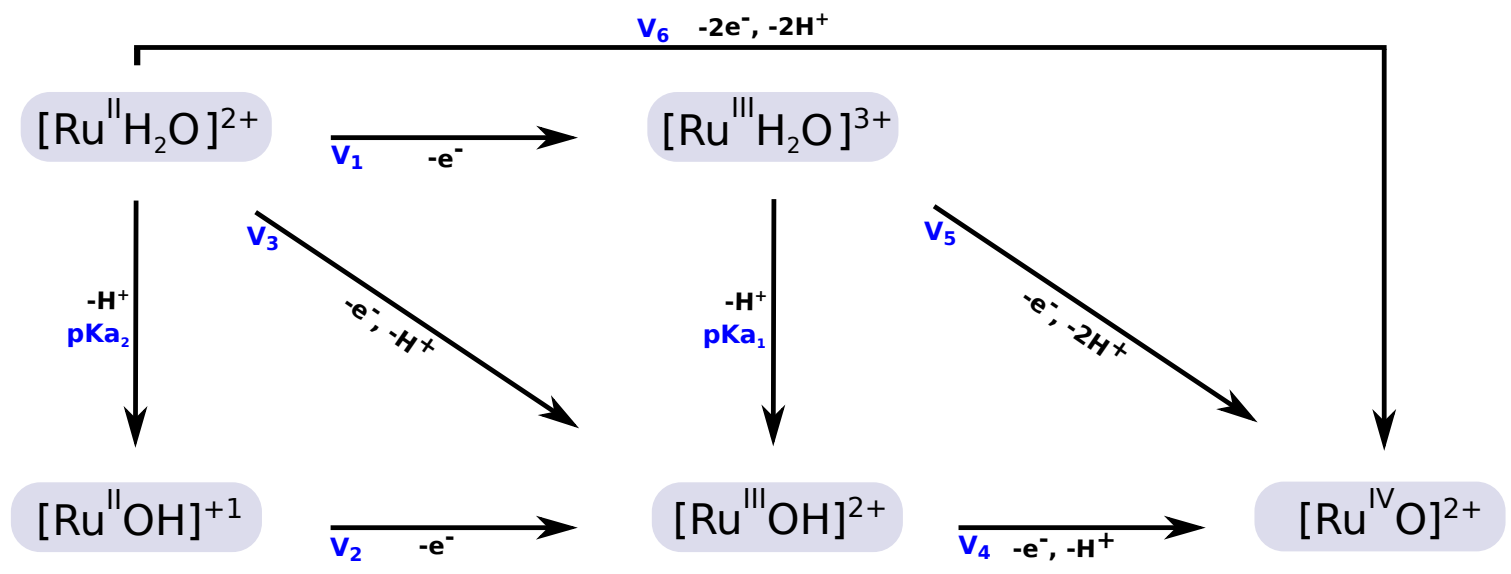

Figura 8.1 - Caminhos de reação para a transferência de prótons e elétrons dos complexos de $R u$-Aqua/Oxo em solução aquosa.

Tabela 8.1 - Valores experimentais de $p K a$ e $V^{o x}$ relacionados às reações de transferência de prótons e elétrons dos complexos de $R u$-Aqua/Oxo em solução aquosa, na referência do eletrodo saturado de calomelano (SCE) e do eletrodo padrão de hidrogênio (SHE).

\begin{tabular}{ccc}
\hline$V^{o x}$ & $\operatorname{SCE}(V)$ & $\operatorname{SHE}(V)$ \\
\hline$V_{1}^{o x}$ & $0.78^{[256]}$ & $1.02^{[256]}$ \\
$V_{2}^{o x}$ & - & - \\
$V_{3}^{o x}$ & $0.42^{[256]}$ & $0.66^{[256]}$ \\
$V_{4}^{o x}$ & $0.53^{[256]}$ & $0.77^{[256]}$ \\
$V_{5}^{o x}$ & $0.99^{[256]}$ & $1.23^{[256]}$ \\
$V_{6}^{o x}$ & $0.89^{[256]}$ & $1.13^{[256]}$ \\
\hline
\end{tabular}

\begin{tabular}{lc}
\hline$p K a_{i}$ & Valor \\
\hline$p K a_{1}$ & $0.85^{[256]}, 1.3^{[69]}$ \\
$p K a_{2}$ & $10.26^{[256]}, 10.8^{[69]}$ \\
\hline
\end{tabular}

\subsection{Energia livre de vácuo}

Conforme já descrevemos, as quantidades $p K a$ e $V^{o x}$ podem ser expressas em termos da variação de energia livre em solução $\left(\Delta G_{\text {sol }}\right)$, equações 3.56 e 3.60. Dentro da aproximação de ciclos termodinâmicos, $\Delta G_{\text {sol }}$ depende das variações da energia livre de vácuo $\left(\Delta G_{v a c}\right)$ e da energia livre de solvatação $\left(\Delta G_{\text {solv }}\right)$ dos produtos e reagentes da reação. A precisão nos cálculos de $\Delta G_{v a c}$ é tão importante quanto nos cálculos de $\Delta G_{s o l v}$, e por isso nos atentamos aos efeitos causados pela escolha do método QM nos cálculos de $G_{v a c}$ dos reagentes e produtos. Na tabela 8.2, apresentamos os valores de $\Delta G_{v a c}$ para todas as reações de troca de prótons e elétrons, utilizando diferentes métodos QM.

Sem a pretenção de fazer dessa comparação de métodos um estudo completo sobre o 
Tabela 8.2 - Variação da energia livre de vácuo $\left(\Delta G_{v a c}\right)$ em reações de troca de prótons e elétrons dos complexos de $R u$-Aqua/Oxo (nas geometrias otimizadas B3LYP/(aug)cc-pVDZ/(PP-Ru)), utilizando diferentes métodos QM. Valores apresentados em módulo.

\begin{tabular}{cccccccccc}
\hline & \multicolumn{8}{c}{ Reações identificadas por seus $p K a$ ou $V$} \\
Método & $p K a_{1}$ & $p K a_{2}$ & $V_{1}^{o x}$ & $V_{2}^{o x}$ & $V_{3}^{o x}$ & $V_{4}^{o x}$ & $V_{5}^{o x}$ & $V_{6}^{o x}$ \\
\hline M06-2X $^{1}$ & 111.6 & 208.2 & 288.0 & 191.4 & 399.6 & 402.2 & 801.8 & 513.8 \\
PBE0 $^{1}$ & 108.6 & 201.2 & 285.5 & 192.9 & 394.1 & 396.8 & 790.9 & 505.4 \\
B3LYP $^{1}$ & 108.4 & 200.7 & 286.1 & 193.8 & 394.5 & 397.3 & 791.7 & 505.6 \\
MP2 $^{1}$ & 109.0 & 200.5 & 289.3 & 197.9 & 398.4 & 390.9 & 789.3 & 499.9 \\
MP4(SDQ $^{2}$ & - & 206.4 & - & 190.3 & 396.7 & 395.4 & 792.1 & - \\
\hline
\end{tabular}

(1) Conjunto de funções base utilizado: aug-cc-pVDZ/PP para $R u$, aug-cc-pVDZ para $C$ e $N$, e ccpVDZ/PP para $H$. (2) Conjunto de funções base utilizado: aug-cc-pVDZ/PP para $R u$, aug-cc-pVDZ para $N$ e cc-pVDZ/PP para $C$ e $H$.

assunto, testamos apenas alguns funcionais da DFT (PBE0, M06-2X e B3LYP) e adicionalmente testamos os métodos MP2 e MP4(SDQ). O custo computacional envolvido nos cálculos MP4 é extremamente alto e por conta disso reduzimos o conjunto de funções base, retirando as funções difusas de todos os carbonos e hidrogênios. O cálculo MP4 para o complexo $R u^{I I I}\left(H_{2} O\right)$ não foi realizado com sucesso e por conta disso existem as lacunas nas reações que envolvem esse complexo.

Para um sistema com 55 átomos, a função de onda MP4(SDQ) deve ser considerada o estado da arte para a descrição da energia eletrônica. E abaixo disso, deve vir a função de onda MP2. Comparando os valores de $\Delta G_{v a c}$ calculado à nível DFT, notamos que os funcionais B3LYP e M06-2X são os que mais se aproximam do métodos MP4(SDQ) e MP2 (no caso das reações que envolvem o complexo $R u^{I I I}\left(H_{2} O\right)$ ). Em relação aos métodos MP, os valores DFT de $\Delta G_{v a c}$ se distanciam em até $13.9 \mathrm{kcal} / \mathrm{mol}$ (para a reação com potencial $\left.V_{6}^{o x}\right)$. Comparando $\Delta G_{v a c}$ nos níveis MP2 e MP4(SDQ), notamos que em geral há diferenças não desprezíveis entre os valores obtidos, em $\mathrm{kcal} / \mathrm{mol}$ : 5.9 para a reação com $\mathrm{pka}_{2}$ e $7.6,1.7$, 4.5, 2.8 para as reações com $V_{2}^{o x}, V_{3}^{o x}, V_{4}^{o x}$ e $V_{5}^{o x}$, respectivamente. No cálculo do $p K a$, uma variação de 5.9 no $\Delta G_{v a c}$ da reação leva a uma variação de $5.9 / R T \cdot \ln 10=4.3$ unidades de $p K a$. Já no cálculo de $V^{o x}$, uma variação de 7.6 no $\Delta G_{v a c}$ da reação leva a uma variação de $7.6 / n F=0.3$ unidades de $V^{o x}$, para $n=1$. $F$ é constante de Faraday, $R$ é a constante dos gases ideais, e $n$ é o número de elétrons envolvidos na reação.

Além da influência do método QM, exploramos também os efeitos causados pela escolha do conjunto de funções base em $\Delta G_{v a c}$. Fixando o método B3LYP, testamos bases all-electron com potencial efetivo de caroço para $R u$ ((aug)-cc-pVDZ/(PP-Ru), (aug)-cc-pVTZ/(PP-Ru), (aug)-cc-pVQZ/(PP-Ru) e DEF2-QZVPP), a base com correção relativística ANO-RCC-VDZP e a base all-electron Jorge-AQZP. Os resultados são apresentados na tabela 8.3. A principal observação a ser feita é que enquanto a mudança de método pode levar a valores de $\Delta G_{v a c}$ 
diferentes em até $7.6 \mathrm{kcal} / \mathrm{mol}$, mudanças no conjunto de funções base não são tão influentes, levando a valores de $\Delta G_{v a c}$ diferentes em até $3.0 \mathrm{kcal} / \mathrm{mol}$. Isso pode representar uma variação de 2.2 unidades de $p K a$ ou 0.13 unidades de $V^{o x}$.

Tabela 8.3 - Variação da energia livre de vácuo $\left(\Delta G_{v a c}\right)$ em reações de troca de prótons e elétrons dos complexos de $R u$-Aqua/Oxo, utilizando o funcional B3LYP e diferentes conjuntos de funções base. Valores apresentados em módulo.

\begin{tabular}{cccccccccc}
\hline & \multicolumn{8}{c}{ Reações identificadas por seus $p K a$ ou $V$} \\
Funções de base & $p K a_{1}$ & $p K a_{2}$ & $V_{1}^{o x}$ & $V_{2}^{o x}$ & $V_{3}^{o x}$ & $V_{4}^{o x}$ & $V_{5}^{o x}$ & $V_{6}^{o x}$ \\
\hline (aug)-cc-pVDZ/(PP- $R u)$ & 108.4 & 200.7 & 286.1 & 193.8 & 394.5 & 397.3 & 791.7 & 505.6 \\
(aug)-cc-pVTZ/(PP- $R u)$ & 109.0 & 201.8 & 286.0 & 193.2 & 395.0 & 398.3 & 793.4 & 507.4 \\
(aug)-cc-pVQZ/(PP-Ru) & 109.2 & 202.0 & 285.8 & 193.0 & 395.0 & 398.4 & 793.4 & 507.6 \\
DEF2-QZVPP & 109.1 & 202.1 & 286.7 & 193.7 & 395.8 & 398.4 & 791.7 & 506.5 \\
ANO-RCC-VDZP & 109.1 & 203.5 & 285.2 & 190.8 & 394.3 & 397.5 & 794.1 & 507.5 \\
Jorge-AQZP & 109.1 & 202.3 & 286.4 & 193.2 & 395.5 & 398.5 & 794.1 & 507.7 \\
\hline
\end{tabular}

\subsection{Energia livre de solvatação}

A energia livre de solvatação $\left(\Delta G_{\text {solv }}\right)$ é constituída pela soma de duas contribuições: eletrostática $\left(\Delta G_{\text {ele }}\right)$ e não-eletrostática $\Delta G_{\text {nele }}$. A primeira se deve às interações coulombianas e a segunda às interações de van der Walls. Ingrediente fundamental no cálculo de propriedades eletroquímicas, a energia livre de solvatação, por si só, é uma medida da espontaneidade com que um dado sistema pode ser solvatado. Valores negativos de $\Delta G_{\text {solv }}$ indicam que esse processo é espontâneo, e tão mais espontâneo quanto mais negativo for $\Delta G_{\text {solv }}$. Valores positivos indicam o contrário, e são normalmente encontrados para sistemas insolúveis.

Calculamos $\Delta G_{\text {solv }}$ para os complexos de $R u$-Aqua/Oxo utilizando diferentes abordagens, tratando as interações soluto-solvente via modelos contínuos de solvente (SMD e PCM), e via mecânica molecular (MC e MD). Por MC, utilizamos o método FEP-MC, e por MD utilizamos o método BAR, para obter $\Delta G_{\text {solv }}$. Nos cálculos BAR-MD, testamos os efeitos de polarização do solvente via PCM e ASEC, e também testamos o cálculo de cargas atômicas via CHELPG (CPG) e Hirshfeld CM5 (HFD). Adicionalmente, verificamos o efeito causado em $\Delta G_{\text {solv }}$, quando há na solução uma concentração específica de nitrato de potássio (0.1 molar). Os resultados se confere na tabela 8.4 .

Seja por qualquer um dos métodos utilizados, a contribuição eletrostática é predominantemente a mais importante, variando de: -49.9 a -314.0 pelo modelo SMD; -42.9 a -285.0 pelo modelo PCM; -42.4 a -260.2 pelo método FEP-MC; -27.9 a -255.0 pelo método BAR-MD. Menos importante, a contribuição não-eletrostática varia de: 11.7 a 12.6 pelo modelo SMD; 16.6 a 18.2 pelo modelo PCM; -8.0 a -8.8 pelo método FEP-MC; 1.0 a 1.4 pelo método BAR-MD. A contribuição não-eletrostática pode ser dividida na soma de duas energias: cavitação (sempre 
Tabela 8.4 - Energia livre de solvatação $\left(\Delta G_{\text {solv }}\right)$, e suas contribuições eletrostática $\left(\Delta G_{\text {solv }}^{\text {ele }}\right)$ e não-eletrostática $\left(\Delta G_{\text {solv }}^{\text {nele }}\right)$, dos complexos de $R u$-Aqua/Oxo, por diferentes métodos QM (SMD e PCM) e MM (FEP-MC e BAR-MD). Na primeira coluna, siglas em superescrito indicam o método utilizado para representar efeitos de polarização do solvente (PCM ou ASEC) e o método utilizado para gerar as cargas atômicas (CPG e HFD). $0.1 \mathrm{M} \mathrm{KNO}_{3}$ indica que as simulações MD foram realizadas num concentração de 0.1 molar de $\mathrm{KNO}_{3}$.

\begin{tabular}{|c|c|c|c|c|c|c|}
\hline \multirow[b]{2}{*}{ Método } & \multirow[b]{2}{*}{ Energia } & \multicolumn{5}{|c|}{ Complexos } \\
\hline & & $R u^{I I}\left(H_{2} \mathrm{O}\right)$ & $\mathrm{Ru}^{I I I}\left(\mathrm{H}_{2} \mathrm{O}\right)$ & $R u^{I I}(O H)$ & $R u^{I I I}(O H)$ & $R u^{I V}(O)$ \\
\hline \multirow{3}{*}{ SMD-M05-2X } & $\Delta G_{\text {solv }}^{\text {ele }}$ & -146.7 & -314.0 & -54.1 & -149.3 & -146.0 \\
\hline & $\Delta G_{\text {solv }}^{\text {nele }}$ & 12.5 & 12.6 & 12.2 & 11.7 & 11.7 \\
\hline & $\Delta G_{\text {solv }}$ & -134.2 & -301.5 & -41.9 & -137.6 & -134.3 \\
\hline \multirow{3}{*}{ SMD-B3LYP } & $\Delta G_{\text {solv }}^{\text {ele }}$ & -145.6 & -313.2 & -49.9 & -146.6 & -144.0 \\
\hline & $\Delta G_{\text {solv }}^{\text {nele }}$ & 12.5 & 12.6 & 12.2 & 11.7 & 11.7 \\
\hline & $\Delta G_{\text {solv }}$ & -133.1 & -300.6 & -37.7 & -134.9 & -132.3 \\
\hline \multirow{3}{*}{ PCM-HF } & $\Delta G_{\text {solv }}^{\text {ele }}$ & -131.6 & -285.0 & -42.9 & -130.4 & -125.4 \\
\hline & $\Delta G_{\text {solv }}^{\text {nele }}$ & 16.6 & 16.6 & 16.7 & 17.2 & 18.2 \\
\hline & $\Delta G_{\text {solv }}$ & -114.9 & -268.4 & -26.2 & -113.2 & -107.2 \\
\hline \multirow{3}{*}{ FEP-MC ${ }^{\mathrm{PCM} / \mathrm{CPG}}$} & $\Delta G_{\text {solv }}^{\text {ele }}$ & -121.5 & -260.2 & -42.4 & -118.2 & -119.1 \\
\hline & $\Delta G_{\text {solv }}^{\text {nele }}$ & -8.6 & -8.0 & -8.4 & -8.6 & -8.8 \\
\hline & $\Delta G_{\text {solv }}$ & -130.1 & -268.2 & -50.8 & -126.7 & -127.9 \\
\hline \multirow{3}{*}{ BAR-MD ${ }^{\mathrm{PCM} / \mathrm{CPG}}$} & $\Delta G_{\text {solv }}^{\text {ele }}$ & -106.5 & -254.2 & -33.5 & -106.7 & -107.8 \\
\hline & $\Delta G_{\text {solv }}^{\text {nele }}$ & 1.0 & 1.2 & 1.2 & 1.0 & 1.2 \\
\hline & $\Delta G_{\text {solv }}$ & -105.5 & -253.0 & -32.4 & -105.7 & -106.6 \\
\hline \multirow{3}{*}{ 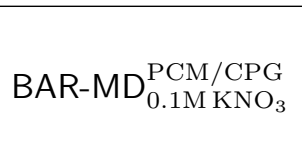 } & $\Delta G_{\text {solv }}^{\text {ele }}$ & -106.9 & -255.0 & -33.7 & -107.2 & -108.2 \\
\hline & $\Delta G_{\text {solv }}^{\text {nele }}$ & 1.4 & 1.3 & 1.3 & 1.4 & 1.1 \\
\hline & $\Delta G_{\text {solv }}$ & -105.5 & -253.7 & -32.4 & -105.8 & -107.0 \\
\hline \multirow{3}{*}{ BAR-MDASEC/CPG } & $\Delta G_{\text {solv }}^{\text {ele }}$ & -107.5 & -254.6 & -40.6 & -108.0 & -112.4 \\
\hline & $\Delta G_{\text {solv }}^{\text {nele }}$ & 1.0 & 1.2 & 1.2 & 1.0 & 1.2 \\
\hline & $\Delta G_{\text {solv }}$ & -106.5 & -253.4 & -39.5 & -107.0 & -111.3 \\
\hline \multirow{3}{*}{ BAR-MD ${ }^{\mathrm{PCM} / \mathrm{HFD}}$} & $\Delta G_{\text {solv }}^{\text {ele }}$ & -106.0 & -253.3 & -27.9 & -103.8 & -105.3 \\
\hline & $\Delta G_{\text {solv }}^{\text {nele }}$ & 1.0 & 1.2 & 1.2 & 1.0 & 1.2 \\
\hline & $\Delta G_{\text {solv }}$ & -105.0 & -252.1 & -26.8 & -102.7 & -104.1 \\
\hline
\end{tabular}

positiva) e dispersão (sempre negativa). Portanto, $\Delta G_{\text {solv }}^{\text {nele }}$ positivo indica que a energia de cavitação é maior, em módulo, que a energia de dispersão, e vice versa, caso contrário. Tanto pelos modelos PCM e SMD, quanto pelo método BAR-MD, os valores obtidos de $\Delta G_{\text {solv }}^{\text {nele }}$ são positivos. Apenas o método FEP-MC fornece uma energia de dispersão maior, em módulo, que a energia de cavitação.

Como a contribuição eletrostática é sempre negativa e maior em módulo, os complexos de $R u$-Aqua/Oxo possuem $\Delta G_{\text {solv }}$ sempre negativo, independentemente do método utilizado para o cálculo. Isso significa que a hidratação desses complexos é um processo espontâneo. A magnitude de $\Delta G_{\text {solv }}$, por sua vez, segue a ordem das cargas totais de cada complexo. 
Tabela 8.5 - Variação da energia livre de solvatação $\left(\Delta \Delta G_{\text {solv }}^{\text {ele }}, \Delta \Delta G_{\text {solv }}^{\text {nele }}, \Delta \Delta G_{\text {solv }}\right)$ em reações de troca de prótons e elétrons dos complexos de $R u$-Aqua/Oxo, por diferentes métodos QM (SMD e PCM) e MM (FEP-MC e BAR-MD). Na primeira coluna, siglas em superescrito indicam o método utilizado para representar efeitos de polarização do solvente (PCM ou ASEC) e o método utilizado para gerar as cargas atômicas (CPG, HFD). $0.1 \mathrm{M} \mathrm{KNO}_{3}$ indica que as simulações MD foram realizadas num concentração de 0.1 molar de $\mathrm{KNO}_{3}$.

\begin{tabular}{|c|c|c|c|c|c|c|c|c|c|}
\hline \multirow[b]{2}{*}{ Método } & \multirow[b]{2}{*}{ Energia } & \multicolumn{8}{|c|}{ Reações identificadas por seus $p K a$ ou $V$} \\
\hline & & $p K a_{1}$ & $p K a_{2}$ & $V_{1}^{o x}$ & $V_{2}^{o x}$ & $V_{3}^{o x}$ & $V_{4}^{o x}$ & $V_{5}^{o x}$ & $V_{6}^{o x}$ \\
\hline \multirow{3}{*}{ SMD-M05-2X } & $\Delta \Delta G_{\text {solv }}^{\text {ele }}$ & 164.8 & 92.6 & -167.4 & -95.2 & -2.6 & 3.3 & 168.0 & 0.7 \\
\hline & $\Delta \Delta G_{\text {solv }}^{\text {nele }}$ & -0.9 & -0.3 & 0.1 & -0.4 & -0.8 & 0.0 & -0.9 & -0.8 \\
\hline & $\Delta \Delta G_{\text {solv }}$ & 163.9 & 92.3 & -167.3 & -95.6 & -3.4 & 3.2 & 167.1 & -0.1 \\
\hline \multirow{3}{*}{ SMD-B3LYP } & $\Delta \Delta G_{\text {solv }}^{\text {ele }}$ & 166.6 & 95.7 & -167.7 & -96.7 & -1.1 & 2.7 & 169.2 & 1.6 \\
\hline & $\Delta \Delta G_{\text {solv }}^{\text {nele }}$ & -0.9 & -0.3 & 0.1 & -0.4 & -0.8 & 0.0 & -0.9 & -0.8 \\
\hline & $\Delta \Delta G_{\text {solv }}$ & 165.7 & 95.4 & -167.6 & -97.2 & -1.8 & 2.6 & 168.3 & 0.8 \\
\hline \multirow{3}{*}{ PCM-HF } & $\Delta \Delta G_{\text {solv }}^{\text {ele }}$ & 154.7 & 88.6 & -153.5 & -87.4 & 1.2 & 5.0 & 159.7 & 6.2 \\
\hline & $\Delta \Delta G_{\text {solv }}^{\text {nele }}$ & 0.6 & 0.1 & 0.0 & 0.5 & 0.6 & 1.0 & 1.6 & 1.6 \\
\hline & $\Delta \Delta G_{\text {solv }}$ & 155.3 & 88.7 & -153.5 & -87.0 & 1.8 & 6.0 & 161.3 & 7.8 \\
\hline \multirow{3}{*}{ FEP-MC ${ }^{\mathrm{PCM} / \mathrm{CPG}}$} & $\Delta \Delta G_{\text {solv }}^{\text {ele }}$ & 142.0 & 79.1 & -138.7 & -75.8 & 3.3 & -1.0 & 141.0 & 2.4 \\
\hline & $\Delta \Delta G_{\text {solv }}^{\text {nele }}$ & -0.6 & 0.2 & 0.6 & -0.2 & 0.0 & -0.2 & -0.8 & -0.2 \\
\hline & $\Delta \Delta G_{\text {solv }}$ & 141.4 & 79.3 & -138.1 & -75.9 & 3.3 & -1.2 & 140.2 & 2.1 \\
\hline \multirow{3}{*}{ BAR-MD ${ }^{\mathrm{PCM} / \mathrm{CPG}}$} & $\Delta \Delta G_{\text {solv }}^{\text {ele }}$ & 147.5 & 72.9 & -147.7 & -73.2 & -0.2 & -1.1 & 146.4 & -1.3 \\
\hline & $\Delta \Delta G_{\text {solv }}^{\text {nele }}$ & -0.1 & 0.2 & 0.2 & -0.1 & 0.0 & 0.1 & 0.0 & 0.2 \\
\hline & $\Delta \Delta G_{\text {solv }}$ & 147.3 & 73.1 & -147.5 & -73.3 & -0.2 & -1.0 & 146.4 & -1.2 \\
\hline \multirow{3}{*}{ BAR-MD $\mathrm{MCM}_{0.1 \mathrm{MNNO}}^{\mathrm{PCP}}$} & $\Delta \Delta G_{\text {solv }}^{\text {ele }}$ & 147.8 & 73.1 & -148.1 & -73.5 & -0.3 & -1.0 & 146.8 & -1.3 \\
\hline & $\Delta \Delta G_{\text {solv }}^{\text {nele }}$ & 0.1 & -0.1 & -0.1 & 0.1 & 0.0 & -0.3 & -0.2 & -0.3 \\
\hline & $\Delta \Delta G_{\text {solv }}$ & 147.9 & 73.0 & -148.2 & -73.4 & -0.3 & -1.2 & 146.7 & -1.5 \\
\hline \multirow{3}{*}{ BAR-MD ASEC/CPG } & $\Delta \Delta G_{\text {solv }}^{\text {ele }}$ & 146.6 & 66.9 & -147.1 & -67.4 & -0.5 & -4.4 & 142.2 & -4.9 \\
\hline & $\Delta \Delta G_{\text {solv }}^{\text {nele }}$ & -0.1 & 0.2 & 0.2 & -0.1 & 0.0 & 0.1 & 0.0 & 0.2 \\
\hline & $\Delta \Delta G_{\text {solv }}$ & 146.4 & 67.0 & -146.9 & -67.5 & -0.5 & -4.3 & 142.1 & -4.8 \\
\hline \multirow{3}{*}{ BAR-MD ${ }^{\mathrm{PCM} / \mathrm{HFD}}$} & $\Delta \Delta G_{\text {solv }}^{\text {ele }}$ & 149.5 & 78.1 & -147.3 & -75.8 & 2.2 & -1.5 & 148.0 & 0.7 \\
\hline & $\Delta \Delta G_{\text {solv }}^{\text {nele }}$ & -0.1 & 0.2 & 0.2 & -0.1 & 0.0 & 0.1 & 0.0 & 0.2 \\
\hline & $\Delta \Delta G_{\text {solv }}$ & 149.4 & 78.2 & -147.1 & -76.0 & 2.3 & -1.4 & 148.0 & 0.9 \\
\hline
\end{tabular}

O complexo de menor carga, $R u^{I I}(O H)$ com carga +1 , é o complexo com $\Delta G_{\text {solv }}$ menos negativo, e o complexo de maior carga , $R u^{I I I}\left(H_{2} O\right)$ com carga +3 , é o complexo com $\Delta G_{\text {solv }}$ mais negativo. Os complexos com carga intermediária, $R u^{I I}\left(H_{2} O\right), R u^{I I I}(O H)$ e $R u^{I V}(O)$, todos com carga +2 , possuem $\Delta G_{\text {solv }}$ muito parecidos, e a ordem de solvatação entre eles depende do método utilizado.

No cálculo de $p K a$ e $V^{o x}$, a diferença de energia livre entre produtos e reagentes $\left(\Delta \Delta G_{\text {solv }}\right)$ é tão importante quanto a variação de energia livre de vácuo. Na tabela 8.5 , apresentamos as contribuições eletrostática e não-eletrostática, e também o valor total, de $\Delta \Delta G_{\text {solv }}$ nas reações de troca de prótons e elétrons dos complexos de $R u$-Aqua/Oxo. Os valores, em módulo, de 
$\Delta \Delta G_{\text {solv }}^{\text {nele }}$ são inferiores a $1 \mathrm{kcal} / \mathrm{mol}$ entre os métodos $\mathrm{MM}$ e inferiores a $1.6 \mathrm{kcal} / \mathrm{mol}$ entre os modelos contínuos. Portanto, $\Delta \Delta G_{\text {solv }}$ tem um caráter quase que puramente eletrostático. À propósito, foi a partir dessa observação que decidimos investigar como a polarização do solvente e o cálculo de cargas atômicas do soluto poderiam afetar $\Delta G_{\text {solv }}, \Delta \Delta G_{\text {solv }}$ e tão logo os valores de $p K a$ e $V^{o x}$. Como já mencionamos, esses testes foram feitos apenas à nível BAR-MD, trocando o modelo de polarização PCM pelo ASEC e trocando o método de cálculo de cargas atômicas CHELPG pelo Hirshfeld.

Tabela 8.6 - Cargas atômicas de $R u, N$ e $O$ dos complexos de $R u$-Aqua/Oxo, utilizando PCM ou ASEC para representar efeitos de polarização do solvente e CHELPG (CPG) ou Hirshfeld (HFD) para gerar as cargas atômicas.

\begin{tabular}{|c|c|c|c|c|c|c|c|c|}
\hline & & $\mathrm{Ru}$ & 0 & N3 & N11 & N19 & $\mathrm{N} 25$ & N45 \\
\hline \multirow{5}{*}{ Rull(H2O) } & $\mathrm{PCM} / \mathrm{CPG}$ & 0.94 & -0.65 & -0.23 & -0.42 & -0.37 & -0.35 & -0.37 \\
\hline & ASEC/CPG & 0.91 & -0.73 & -0.22 & -0.46 & -0.40 & -0.22 & -0.39 \\
\hline & PCM/HFD & 0.85 & -0.54 & -0.35 & -0.35 & -0.35 & -0.35 & -0.35 \\
\hline & $\Delta^{P C M / A S E C}$ & -0.03 & -0.08 & 0.01 & -0.05 & -0.03 & 0.13 & -0.02 \\
\hline & $\Delta^{C P G / H F D}$ & -0.09 & 0.11 & -0.12 & 0.07 & 0.02 & 0.01 & 0.02 \\
\hline \multirow{5}{*}{ RullI(H2O) } & $\mathrm{PCM} / \mathrm{CPG}$ & 1.30 & -0.77 & -0.36 & -0.27 & -0.33 & -0.45 & -0.46 \\
\hline & ASEC/CPG & 1.38 & -1.07 & -0.31 & -0.54 & -0.34 & -0.29 & -0.54 \\
\hline & PCM/HFD & 1.08 & -0.52 & -0.35 & -0.35 & -0.35 & -0.35 & -0.35 \\
\hline & $\Delta^{P C M / A S E C}$ & 0.08 & -0.30 & 0.05 & -0.27 & -0.02 & 0.16 & -0.08 \\
\hline & $\Delta^{C P G / H F D}$ & -0.22 & 0.25 & 0.02 & -0.08 & -0.02 & 0.10 & 0.11 \\
\hline \multirow{5}{*}{ Rull(OH) } & & 0.33 & -0.89 & 0.07 & -0.37 & 13 & 13 & -0.09 \\
\hline & ASEC/CPG & 0.54 & -1.11 & 0.11 & -0.52 & 0.01 & -0.16 & -0.25 \\
\hline & PCM/HFD & 0.88 & -0.68 & -0.35 & -0.35 & -0.35 & -0.35 & -0.35 \\
\hline & $\Delta^{P C M / A S E C}$ & 0.21 & -0.22 & 0.05 & -0.15 & -0.12 & -0.03 & -0.16 \\
\hline & $\Delta^{C P G / H F D}$ & 0.55 & 0.22 & -0.42 & 0.02 & -0.48 & -0.22 & -0.25 \\
\hline \multirow{5}{*}{ RullI(OH) } & $\mathrm{PCM} / \mathrm{CPG}$ & 0.72 & -0.76 & -0.14 & -0.31 & -0.04 & -0.25 & -0.30 \\
\hline & ASEC/CPG & 0.88 & -0.83 & -0.12 & -0.39 & -0.13 & -0.32 & -0.21 \\
\hline & PCM/HFD & 1.02 & -0.60 & -0.35 & -0.35 & -0.35 & -0.34 & -0.35 \\
\hline & $\Delta^{P C M / A S E C}$ & 0.16 & -0.06 & 0.01 & -0.09 & -0.09 & -0.08 & 0.09 \\
\hline & $\Delta^{C P G / H F D}$ & 0.30 & 0.17 & -0.21 & -0.04 & -0.31 & -0.10 & -0.05 \\
\hline \multirow{5}{*}{ RulV(O) } & PCM/CPG & 1.01 & -0.57 & -0.20 & -0.36 & -0.21 & -0.19 & -0.28 \\
\hline & ASEC/CPG & 1.08 & -0.71 & -0.18 & -0.42 & -0.22 & -0.29 & -0.25 \\
\hline & PCM/HFD & 1.08 & -0.44 & -0.34 & -0.35 & -0.34 & -0.34 & -0.34 \\
\hline & $\Delta^{P C M / A S E C}$ & 0.07 & -0.14 & 0.02 & -0.06 & -0.02 & -0.10 & 0.03 \\
\hline & $\Delta^{C P G / H F D}$ & 0.07 & 0.13 & -0.14 & 0.01 & -0.14 & -0.15 & -0.06 \\
\hline
\end{tabular}

$\mathrm{O}$ valor de $\Delta G_{\text {solv }}$ dos complexos $R u^{I I}\left(\mathrm{H}_{2} \mathrm{O}\right)$ e $R u^{I I I}\left(\mathrm{H}_{2} \mathrm{O}\right)$ é pouco sensível à troca de PCM para ASEC na polarização e também pouco sensível a troca de CPG para HFD no cálculo de cargas atômicas. Como mostrado na tabela 8.4, os valores obtidos para $\Delta G_{\text {solv }}$, por qualquer combinação de métodos, variam em no máximo $1.3 \mathrm{kcal} / \mathrm{mol}$. Os outros complexos são mais sensíveis ao tipo de polarização empregado e ao tipo de cálculo de cargas atômicas. A polarização ASEC leva a um $\Delta G_{\text {solv }}$ mais negativo que a polarização PCM: em 7.1, 1.3 e 
$4.7 \mathrm{kcal} / \mathrm{mol}$ para os complexos $R u^{I I}(O H), R u^{I I I}(O H)$ e $R u^{I V}(O)$. E o método Hirshfeld leva a um $\Delta G_{\text {solv }}$ menos negativo que o método CHELPG: em 5.6, 3.0 e $2.5 \mathrm{kcal} / \mathrm{mol}$ para os complexos $R u^{I I}(O H)$, $R u^{I I I}(O H)$ e $R u^{I V}(O)$. Essas diferenças são provenientes das mudanças nas cargas atômicas dos complexos. Na tabela 8.6 trazemos as cargas atômicas de alguns átomos dos complexos $(R u, N$ e $O$ ) calculadas via PCM/CPG, ASEC/CPG e $\mathrm{PCM} / \mathrm{HFD}$. Podemos observar que a carga de $R u$ sofre mudanças de até 0.21 quando se troca PCM por ASEC, e de até 0.55 quando se troca CPG por HFD. A carga de $O$ sofre mudanças de até 0.30 quando se troca PCM por ASEC, e de até 0.25 quando se troca CPG por HFD. As cargas dos $N$ sofrem mudanças de até 0.27 quando se troca PCM por ASEC, e de até 0.48 quando se troca CPG por HFD. E as principais mudanças são para o complexo $R u^{I I}(O H)$, justamente o que apresenta os valores de $\Delta G_{\text {solv }}$ mais sensíveis às trocas de métodos na polarização e no cálculo de cargas.
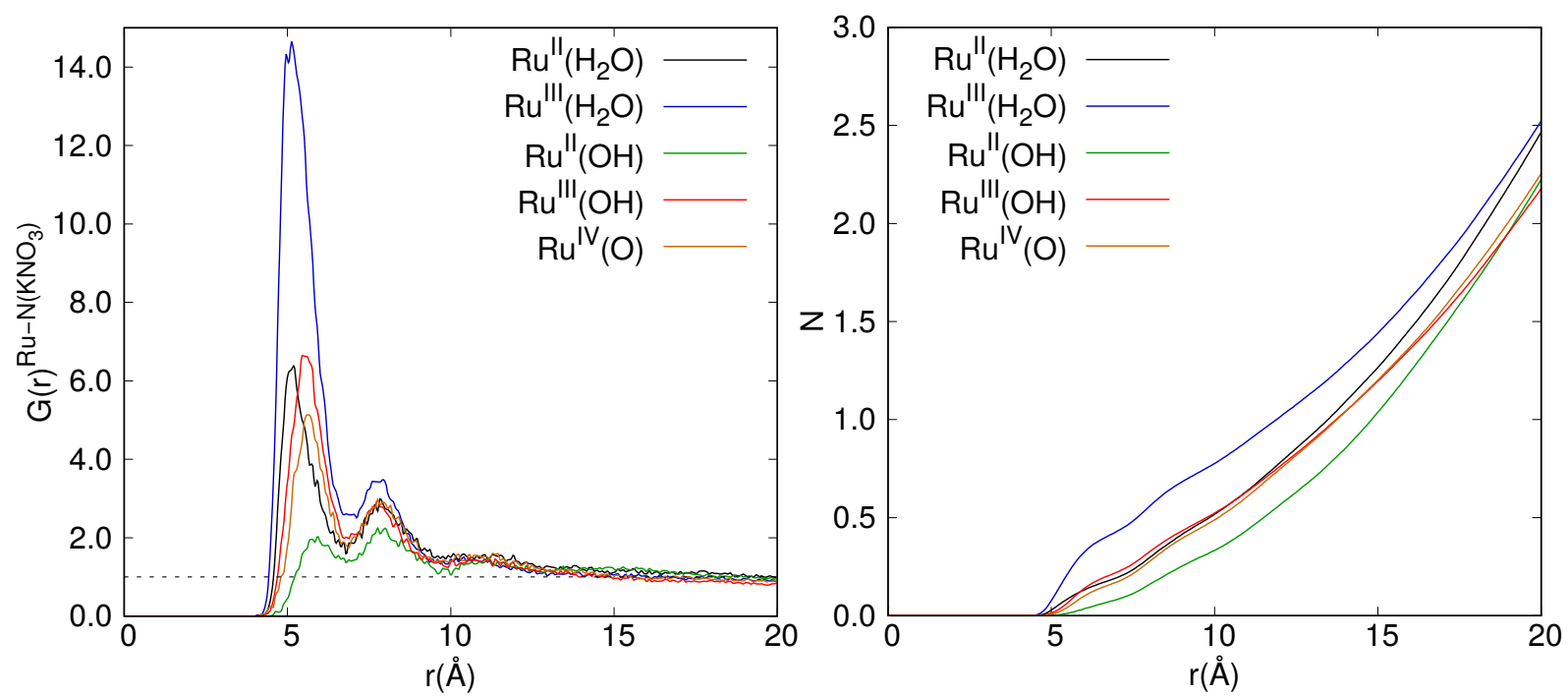

Figura 8.2 - À esquerda: função de distribuição radial entre o átomo de $R u$ dos complexos e o átomo de $N$ das moléculas de $\mathrm{KNO}_{3}\left(G(r)^{R u-N\left(N O_{3}\right)}\right)$. À direita: número de coordenação correspondente à integral de $G(r)^{R u-N\left(N O_{3}\right)}$.

Por fim, como as medidas experimentais de $p K a$ e $V^{o x}$ mais recentes ${ }^{[69]}$ foram realizadas em soluções aquosas a 0.1 molar de $\mathrm{KNO}_{3}$, logo também verificamos o efeito que a presença desse sal poderia levar às propriedades eletroquímicas dos complexos. Na figura 8.2 apresentamos a função de distribuição radial entre o átomo de $R u$ dos complexos e o átomo de $N$ dos íons $\mathrm{NO}_{3}\left(G(r)^{R u-N\left(\mathrm{NO}_{3}\right)}\right)$, e também o número de coordenação correspondente à integral de $G(r)^{R u-N\left(\mathrm{NO}_{3}\right)}$. As $G(r)^{R u-N\left(\mathrm{NO}_{3}\right)}$ podem ser separadas segundo as cargas dos complexos. A $G(r)^{R u-N\left(\mathrm{NO}_{3}\right)}$ do complexo de carga +1 tem a menor intensidade, as $G(r)^{R u-N\left(N O_{3}\right)}$ dos complexos com carga +2 são muito semelhantes, e a $G(r)^{R u-N\left(N_{3}\right)}$ do complexo com carga +3 é a mais intensa. A intensidade da $G(r)^{R u-N\left(N O_{3}\right)}$, nesse caso, reflete-se no número de coordenação. Numa distância de aproximadamente $12 \AA$ do átomo de $R u$ contabilizamos em média 1 íon de $\mathrm{NO}_{3}$ na solução de $R u^{I I I}\left(\mathrm{H}_{2} \mathrm{O}\right)$ e 0.5 na solução de $R u^{I I}(O H)$. Uma esfera de $12 \AA$ de raio ocupa um volume de aproximadamente $7 \%$ do volume total da caixa 
de simulação, que tem arestas de 50 Å. Portanto, existe uma proximidade considerável entre os íons de $\mathrm{NO}_{3}^{-}$e os complexos. Todavia, comparando os valores de $\Delta G_{\text {solv }}$ calculados via BAR-MD, com e sem a concentração de 0.1 molar de $\mathrm{KNO}_{3}$, notamos que a contribuição eletrostática $\Delta G_{\text {solv }}^{\text {ele }}$ é ligeiramente mais negativa para os complexos na presença do $\mathrm{KNO}_{3}$, em quantidades inferiores a $1 \mathrm{kcal} / \mathrm{mol}$, e portanto desprezíveis.

\subsection{Energia de polarização e de mudanças geométricas}

A energia de polarização, definida como $\Delta E^{\text {pol }}=\left\langle\psi^{\text {pol }}\left|H_{0}\right| \psi^{\text {pol }}\right\rangle-\left\langle\psi^{0}\left|H_{0}\right| \psi^{0}\right\rangle$, onde $H^{0}$ é o hamiltoniano do soluto isolado, $\psi^{\text {pol }}$ e $\psi^{0}$ são as funções de onda polarizada em solução e no vácuo, é mais uma quantidade importante no cálculo de $p K a$ e $V^{o x}$. Essa, por sua vez, também depende do método utilizado para representar os efeitos de polarização do solvente, PCM ou ASEC, como temos adotado. Na tabela 8.7, apresentamos as energias de polarização dos complexos de $R u$-Aqua/Oxo, utilizando a função de onda B3LYP/(aug)-cc-pVDZ/(PP-Ru) e os métodos de polarização PCM e ASEC.

Tabela 8.7 - Energia de polarização da função de onda B3LYP/(aug)-cc-pVDZ/(PP-Ru), $\Delta E^{\text {pol }}$, utilizando $\mathrm{PCM}$ e $\mathrm{ASEC}$, em $\mathrm{kcal} / \mathrm{mol}$. Energia relacionada à mudança de geometria de vácuo para solução, $\Delta E^{g e o m}(\mathrm{VAC} / \mathrm{PCM})$, em $\mathrm{kcal} / \mathrm{mol}$.

\begin{tabular}{cccc}
\hline & $\Delta E^{\text {pol }}(\mathrm{PCM})$ & $\Delta E^{\text {pol }}(\mathrm{ASEC})$ & $\Delta E^{\text {geom }}(\mathrm{VAC} / \mathrm{PCM})$ \\
\hline$R u^{I I}\left(\mathrm{H}_{2} \mathrm{O}\right)$ & 2.53 & 4.00 & 0.25 \\
$R u^{I I I}\left(\mathrm{H}_{2} \mathrm{O}\right)$ & 6.19 & 7.29 & 0.72 \\
$R u^{I I}(\mathrm{OH})$ & 1.51 & 16.18 & 0.78 \\
$R u^{I I I}(\mathrm{OH})$ & 2.05 & 2.50 & 0.27 \\
$R u^{I V}(\mathrm{O})$ & 2.31 & 6.32 & 0.24 \\
\hline
\end{tabular}

A energia de polarização dos complexos varia de 1.51 a $6.19 \mathrm{kcal} / \mathrm{mol}$ por PCM, e de 2.50 a $16.18 \mathrm{kcal} / \mathrm{mol}$ por ASEC. A ordem de crescimento de $\Delta E^{\mathrm{pol}}(\mathrm{PCM})$ segue a ordem de crescimento da carga total dos complexos, mas o mesmo não é verdade para $\Delta E^{\text {pol }}$ (ASEC). Curiosamente, o complexo $R u^{I I}(O H)$ possui a maior energia de polarização dentro da aproximação ASEC $(16.18 \mathrm{kcal} / \mathrm{mol})$, e a menor energia de polarização dentro da aproximação PCM $(1.51 \mathrm{kcal} / \mathrm{mol})$. Isso é mais uma demonstração de que a contabilização dos detalhes atomísticos do solvente, principalmente na região de micro-solvatação dos complexos, pode causar mudanças drásticas na polarização do soluto. A seguir, iremos contabilizar todos esses efeitos nos valores finais de $p K a$ e $V^{o x}$ dos complexos em solução.

Por fim, a última quantidade a ser considerada é a variação da energia eletrônica do soluto devido à otimização de geometria em solução $\left(\Delta E^{\text {geom }}(\mathrm{VAC} / \mathrm{PCM})\right)$, a qual também está apresentada na tabela 8.7. Os valores de $\Delta E^{\text {geom }}(\mathrm{VAC} / \mathrm{PCM})$ são inferiores a $1 \mathrm{kcal} / \mathrm{mol}$, e portanto tem um impacto pequeno na predição de propriedades eletroquímicas. Ainda assim, é notável que os maiores valores de $\Delta E^{\text {geom }}(\mathrm{VAC} / \mathrm{PCM})$ correspondem aos complexos com maior 
$R M S D^{V A C / S O L}$ (0.16 para $R u^{I I I}\left(H_{2} O\right)$ e 0.14 para $R u^{I I}(O H)$ ), e que os menores valores de $\triangle E^{\text {geom }}(\mathrm{VAC} / \mathrm{PCM})$ correspondem aos complexos com menor $R M S D^{V A C / S O L}$ (0.01 para $R u^{I I}\left(H_{2} O\right)$, 0.09 para $R u^{I I I}(O H)$ e 0.11 para $R u^{I V}(O)$ ), mas não seguem necessariamente a mesma ordem.

\section{5 pKa e potencial redox}

Na tabela 8.8, apresentamos os valores calculados de $p K a$ e $V^{o x}$ para todas as reações de troca de prótons e elétrons dos complexos de $R u$-Aqua/Oxo. Na primeira coluna, listamos os métodos utilizados no cálculo da energia livre de solvatação, e explicitamos os métodos utilizados para representar os efeitos de polarização do solvente (PCM ou ASEC) e para o cálculo das cargas atômicas (CPG ou HFD). Na segunda coluna, listamos os métodos utilizados no cálculo da energia eletrônica $\left(E^{0}\right)$. Para comparação, resultados experimentais da Literatura são apresentados nas últimas linhas da tabela.

À começar pelo $p K a_{1}$, as medidas experimentais apontam para um equilíbrio entre as formas protonada $R u^{I I I}\left(H_{2} O\right)$ e desprotonada $R u^{I I I}(O H)$ num $p H$ de $0.85^{[256]}$ ou $1.3^{[69]}$. Os resultados obtidos utilizando o modelo contínuo SMD são os mais próximos do experimental, sendo que a escolha do método M06-2X para o cálculo da energia eletrônica apresenta-se como a melhor opção, fornecendo $p K a_{1}$ em -1.58 (para $\Delta G_{\text {solv }}$ calculado por SMD-B3LYP) e -2.93 (para $\Delta G_{\text {solv }}$ calculado por SMD-M05-2X). Os outros métodos fornecem valores também negativos de $p K a$, porem mais distantes do experimental: entre -9.25 e -11.65 utilizando PCM; entre -13.58 e -20.11 utilizando os métodos MM.

$\mathrm{O} p K a_{2}$ experimental indica um equilíbrio entre as formas protonada $R u^{I I}\left(H_{2} \mathrm{O}\right)$ e desprotonada $R u^{I I}(O H)$ num $p H$ de $10.26^{[256]}$ ou $10.8^{[69]}$. Contraditoriamente, as combinações de métodos que fornecem a melhor descrição do $p K a_{1}\left(\Delta G_{\text {solv }}\right.$ via SMD e $E^{0}$ via M06-2X), levam a pior descrição do $p K a_{2}$ (16.06 e 18.31), superestimando-o em mais de 50\%. Por outro lado, ainda com o SMD e considerando o cálculo de $E^{0}$ utilizando o funcional B3LYP ou o método MP2, esses valores caem para 12.79 e 13.12, respectivamente. Utilizando o método PCM, obtemos valores no intervalo de 7.93 a 13.45. Considerando os métodos MM, os melhores resultados são obtidos utilizando M06-2X e MP4(SDQ) no cálculo de $E^{0}$. As combinações FEP-MC/M06-2X e FEP-MC/MP4(SDQ), considerando a polarização PCM e cargas atômicas CHELPG, fornecem valores de $p K a_{2}$ de 9.02 e 7.68, respectivamente. Em contrapartida, apenas trocando FEP-MC por BAR-MD, esses valores caem para 1.99 e 0.66 . Os valores de $p K a_{2}$ obtidos por BAR-MD ficam mais próximos do experimental quando consideramos a polarização ASEC com cargas CHELPG (7.24), ou a polarização PCM com cargas Hirshfeld (5.76).

Dentre os potenciais redox relacionados à troca de apenas um elétron, $V_{1}^{o x}$ (entre o par $\left.R u^{I I}\left(H_{2} O\right) / R u^{I I I}\left(H_{2} O\right)\right)$ e $V_{2}^{o x}$ (entre o par $R u^{I I}(O H) / R u^{I I I}(O H)$ ), apenas $V_{1}^{o x}$ é conhecido experimentalmente $\left(V_{1}^{o x}=1.02\right)$. Os resultados teóricos para $V_{1}^{o x}$ mais próximos do 
Tabela 8.8 - $p K a$ e potenciais redox $(V)$ em reações de troca de prótons e elétrons dos complexos de $R u$-Aqua/Oxo, por diferentes métodos QM (SMD e PCM) e MM (FEP-MC e BAR-MD). Na primeira coluna, siglas em superescrito indicam o método utilizado para representar efeitos de polarização do solvente (PCM ou ASEC) e o método utilizado para gerar as cargas atômicas (CHELPG-CPG, Hirshfeld-HFD). $0.1 \mathrm{M} \mathrm{KNO}_{3}$ indica que as simulações $\mathrm{MD}$ foram realizadas num concentração de 0.1 molar de $\mathrm{KNO}_{3}$. Na segunda coluna, os métodos QM utilizados para calcular a energia eletrônica $E^{0}$, com o conjunto de funções base (aug)-cc-pVDZ(PP-Ru).

\begin{tabular}{|c|c|c|c|c|c|c|c|c|c|}
\hline \multirow[b]{2}{*}{ Método $\left(\Delta G_{\text {solv }}\right)$} & \multirow[b]{2}{*}{ Método $\left(E^{0}\right)$} & \multicolumn{8}{|c|}{ Reações identificadas por seus $p K a$ ou $V$} \\
\hline & & $p K a_{1}$ & $p K a_{2}$ & $V_{1}^{o x}$ & $V_{2}^{o x}$ & $V_{3}^{o x}$ & $V_{4}^{o x}$ & $V_{5}^{o x}$ & $V_{6}^{o x}$ \\
\hline SMD-M05-2X & M06-2X & -2.93 & 16.06 & 0.87 & -0.25 & 0.70 & 1.18 & 0.94 & 1.00 \\
\hline \multirow{4}{*}{ SMD-B3LYP } & B3LYP & -3.98 & 12.79 & 0.78 & -0.21 & 0.54 & 0.93 & 0.74 & 0.89 \\
\hline & M06-2X & -1.58 & 18.31 & 0.86 & -0.31 & 0.77 & 1.15 & 0.96 & 1.25 \\
\hline & MP2 & -3.66 & 13.12 & 0.92 & -0.07 & 0.70 & 0.67 & 0.69 & 0.64 \\
\hline & $\mathrm{MP} 4(\mathrm{SDQ})$ & - & 16.97 & - & -0.36 & 0.64 & 0.85 & 0.75 & - \\
\hline \multirow{4}{*}{ PCM-HF } & B3LYP & -11.65 & 7.93 & 1.39 & 0.23 & 0.70 & 1.08 & 0.89 & 0.59 \\
\hline & M06-2X & -9.25 & 13.45 & 1.47 & 0.13 & 0.93 & 1.30 & 1.11 & 0.94 \\
\hline & MP2 & -11.33 & 8.26 & 1.53 & 0.37 & 0.86 & 0.81 & 0.84 & 0.34 \\
\hline & $\mathrm{MP4}(\mathrm{SDQ})$ & - & 12.11 & - & 0.08 & 0.80 & 1.00 & 0.90 & - \\
\hline \multirow{4}{*}{ FEP-MCPCM/CPG } & B3LYP & -20.11 & 3.50 & 2.06 & 0.66 & 0.87 & 0.67 & 0.77 & -0.33 \\
\hline & M06-2X & -17.71 & 9.02 & 2.14 & 0.56 & 1.09 & 0.88 & 0.99 & 0.03 \\
\hline & MP2 & -19.79 & 3.83 & 2.20 & 0.80 & 1.03 & 0.40 & 0.72 & -0.58 \\
\hline & $\mathrm{MP4}(\mathrm{SDQ})$ & - & 7.68 & - & 0.51 & 0.97 & 0.59 & 0.78 & - \\
\hline \multirow{4}{*}{ BAR-MDPCM/CPG } & B3LYP & -17.47 & -3.53 & 1.65 & 0.82 & 0.62 & 0.78 & 0.70 & -0.06 \\
\hline & M06-2X & -15.07 & 1.99 & 1.73 & 0.72 & 0.84 & 0.99 & 0.92 & 0.30 \\
\hline & MP2 & -17.15 & -3.20 & 1.79 & 0.96 & 0.78 & 0.51 & 0.64 & -0.31 \\
\hline & $\mathrm{MP4}(\mathrm{SDQ})$ & - & 0.66 & - & 0.68 & 0.71 & 0.70 & 0.71 & - \\
\hline \multirow{4}{*}{ BAR-MDASEC/CPG } & B3LYP & -18.58 & 1.72 & 1.66 & 0.46 & 0.56 & 0.79 & 0.67 & -0.12 \\
\hline & M06-2X & -16.18 & 7.24 & 1.74 & 0.36 & 0.78 & 1.00 & 0.89 & 0.24 \\
\hline & MP2 & -18.26 & 2.06 & 1.80 & 0.60 & 0.72 & 0.52 & 0.62 & -0.37 \\
\hline & $\mathrm{MP} 4(\mathrm{SDQ})$ & - & 5.91 & - & 0.31 & 0.66 & 0.71 & 0.68 & - \\
\hline \multirow{4}{*}{ BAR-MDPCM/HFD } & B3LYP & -15.98 & 0.24 & 1.67 & 0.71 & 0.72 & 0.76 & 0.74 & 0.01 \\
\hline & M06-2X & -13.58 & 5.76 & 1.75 & 0.61 & 0.95 & 0.98 & 0.96 & 0.37 \\
\hline & MP2 & -15.66 & 0.57 & 1.81 & 0.85 & 0.88 & 0.49 & 0.69 & -0.24 \\
\hline & $\mathrm{MP} 4(\mathrm{SDQ})$ & - & 4.42 & - & 0.56 & 0.82 & 0.68 & 0.75 & - \\
\hline \multirow{2}{*}{\multicolumn{2}{|c|}{ Experimental ${ }^{[256]}\left(V^{o x}\right.$ no SHE $)$}} & 0.85 & 10.26 & 1.02 & - & 0.66 & 0.77 & 1.23 & 1.13 \\
\hline & & 1.3 & 10.8 & & & & & & \\
\hline
\end{tabular}

experimental são obtidos utilizando o método $S M D$, e variam de 0.78 (para $E^{0}$ calculado via B3LYP) a 0.92 (para $E^{0}$ calculado via MP2). Os valores calculados via PCM variam de 1.39 a 1.53. E os valores calculados utilizando os métodos $M M$ variam de 1.65 a 2.20. Os erros cometidos nos cálculos MM de $V_{1}^{o x}$ superam a margem de $50 \%$ em todas as combinações de métodos QM e BAR-MD e batem a margem dos $100 \%$ nas combinações QM e FEP-MC. Para 
$V_{2}^{o x}$, os resultados obtidos variam: de -0.07 a -0.36 por SMD; de 0.08 a 0.37 por FEP-MC; de 0.31 a 0.96 por BAR-MD.

Os potenciais $V_{3}^{o x}\left(R u^{I I}\left(H_{2} O\right) / R u^{I I I}(O H)\right)$ e $V_{4}^{o x}\left(R u^{I I I}(O H) / R u^{I V}(O)\right)$, relativos às trocas de 1 par elétron/próton ocorrem nos potenciais de 0.66 e $0.77 \mathrm{~V}$. Para $V_{3}^{o x}$, os resultados teóricos variam: de 0.54 a $0.77 \mathrm{~V}$ por SMD; de 0.70 a $0.93 \mathrm{~V}$ por PCM; de 0.87 a $1.09 \mathrm{~V}$ por FEP-MC; de 0.56 a $0.95 \mathrm{~V}$ por BAR-MD. E para $V_{4}^{o x}$, os resultados teóricos variam: de 0.67 a $1.18 \mathrm{~V}$ por SMD; de 0.81 a $1.30 \mathrm{~V}$ por PCM; de 0.40 a $0.88 \mathrm{~V}$ por FEP-MC; de 0.51 a $1.00 \mathrm{~V}$ por BAR-MD. É possível perceber que o FEP-MC fornece valores de $V_{3}^{o x}$ maiores que $V_{4}^{o x}$, em contradição com os resultados experimentais. E dentre todos os resultados teóricos obtidos aqueles que mais se ajustam aos resultados experimentais são: $V_{3}^{o x}=0.64 \mathrm{~V}$ e $V_{4}^{o x}=0.85 V\left(\right.$ com $\Delta G_{\text {solv }}$ dado por SMD-B3LYP e $E^{0}$ por MP4(SDQ)); $V_{3}^{o x}=0.62 \mathrm{~V}$ e $V_{4}^{o x}=0.78 \mathrm{~V}$ (com $\triangle G_{\text {solv }}$ dado por BAR-MD ${ }^{P C M / C P G}$ e $E^{0}$ por B3LYP); $V_{3}^{o x}=0.66 \mathrm{~V}$ e $V_{4}^{o x}=0.71 V$ (com $\Delta G_{\text {solv }}$ dado por BAR-MD ${ }^{A S E C / C P G}$ e $E^{0}$ por MP4(SDQ)). No entanto, essas combinações de métodos não fornecem uma descrição adequada de $V_{1}^{o x}$ ou dos $p K a$.

$\mathrm{O}$ potencial $V_{5}^{o x}$, relativo à troca de 1 elétron e dois prótons entre os complexos $R u^{I I I}\left(\mathrm{H}_{2} \mathrm{O}\right)$ e $R u^{I V}(O)$ é medido experimentalmente em $1.23 \mathrm{~V}$. O resultado teórico mais próximo desse valor é obtido com $\Delta G_{\text {solv }}$ dado por PCM e $E^{0}$ por M06-2X, de $1.11 \mathrm{~V}$. As demais combinações de método fornecem valores nos intervalos: de 0.69 a 0.96 por SMD; de 0.84 a 1.11 por PCM; de 0.72 a 0.99 por FEP-MC; de 0.62 a 0.96 por BAR-MD.

Por fim, o potencial $V_{6}^{o x}$, relativo à troca de 2 pares elétron/próton entre os complexos $R u^{I I}\left(H_{2} O\right)$ e $R u^{I V}(O)$ é medido experimentalmente em $1.13 \mathrm{~V}$. Os resultados teóricos mais próximos desse valor são obtidos com $\Delta G_{\text {solv }}$ dado por SMD e $E^{0}$ dado por M06-2X: 1.00 e $1.25 V$. O método PCM fornece um valor razoável de $V_{6}^{o x}$, para $E^{0}$ calculado por M06-2X, de $0.94 \mathrm{~V}$. Esse valor, junto aos $1.11 \mathrm{~V}$ obtidos para $V_{5}^{o x}$, utilizando os mesmos métodos para os cálculos de $\Delta G_{\text {solv }}$ e $E^{0}$, seguem a tendência experimental que aponta $V_{5}^{o x}$ maior que $V_{6}^{o x}$. Os demais resultados obtidos para $V_{6}^{o x}$, utilizando os métodos $\mathrm{MM}$, são muito distantes do valor experimental, variando de -0.58 a $0.37 \mathrm{~V}$.

Concluímos que os valores experimentais de $p K a$ ou $V^{o x}$ dos complexos de $R u$-Aqua/Oxo são reprodutíveis teoricamente, mas isoladamente. O grande desafio está em determinar um protocolo teórico que permita a descrição de todos os $p K a$ e de todos os potenciais redox utilizando os mesmos métodos QM e, ou, MM. Dentro da aproximação de ciclos termodinâmicos, as duas principais fontes de erro são o cálculo de $G_{v a c}$ e de $\Delta G_{\text {solv }}$. A princípio, questionamos a necessidade de se incluir correções relativísticas nos cálculos de energia eletrônica, e por isso testamos o hamiltoniano de Douglas-Kroll-Hess de ordem 0 combinado às bases com correções relativísticas ANO-RCC-VDZP. Por fim, demonstramos que as variações de $\Delta G_{v a c}$ são basicamente as mesmas que aquelas calculadas utilizando potencial efetivo de caroço para o átomo de $R u$. Adicionalmente, questionamos a própria descrição DFT da energia eletrônica, e por isso realizamos os cálculos de $E^{0}$ a nível MP2 e MP4(SDQ). Como o custo computacional do método MP4 cresce com $N^{7}$, onde $N$ é o número de elétrons, o cálculo MP4(SDTQ) é 
infactível, e por isso nos limitamos ao MP4(SDQ). Como nem todos os resultados com a função de onda MP4(SDQ) foram satisfatórios, talvez ainda possamos nos apoiar na hipótese de que a falta de inclusão das substituições triplas no cálculo MP4 poderia estar levando a algum resultado ainda impreciso da energia eletrônica dos complexos.

Em relação à descrição de $\Delta G_{\text {solv }}$, fizemos vários testes. Como os modelos contínuos de solvente PCM e SMD não foram parametrizados para sistemas atômicos à base de rutênio, fomos além desses métodos e testamos dois dos mais sofisticados métodos existentes para o cálculo da energia livre de solvatação (FEP-MC e BAR-MD). Em seguida, questionamos a necessidade de se tratar os efeitos de polarização do solvente com uma abordagem mais realística, que fosse além dos modelos contínuos de solvente. Logo, testamos o método atomístico ASEC, já conhecido na Literatura por sua superioridade em relação aos modelos contínuos em descrever interações específicas entre soluto e solvente. Questionamos também a influência do método utilizado no cálculos das cargas atômicas do soluto, e por isso testamos o CHELPG e o Hirshfeld. Por fim, questionamos a possível influência do nitrato de potássio (utilizado nos experimentos de $p K a$ e $V^{o x}$ ) no valor de $\Delta G_{\text {solv }}$, e demonstramos pelos cálculos BAR-MD que a presença desse sal na solução influencia minimamente os valores de $\Delta G_{\text {solv }}$ dos complexos.

Por fim, para facilitar a visualização da performance alcançada com cada um dos protocolos testados, calculamos o erro quadrático médio $\chi$ para cada combinação de método $\mathrm{QM}$ e $\mathrm{MM}$, figura 8.3. O erro quadrático médio $\chi$ é definido como:

$$
\chi=\sqrt{\frac{1}{N} \sum_{i=1}^{N}\left(X_{i}^{t e o}-X_{i}^{e x p}\right)^{2}}
$$

onde $X_{i}^{t e o}$ e $X_{i}^{e x p}$ são os valores teórico e experimental da propriedade, $p K a$ ou $V_{o x}$, e $N$ o número de parâmetros considerados. Para $p K a$ utilizamos os valores experimentais fornecidos pela referência ${ }^{[69]}$ e para $V_{o x}$ utilizamos os valores fornecidos pela referência ${ }^{[256]}$. Em suma, observamos que os métodos DFT conduzem aos menores valores de $\chi$, comparados aos métodos MM. Os métodos MM levam a valores mais elevados de $\chi$, no entanto, há notoriamente um melhoramento da descrição do $p K a$ e $V_{o x}$ quando consideramos o tratamento da função de onda no melhor nível de cálculo, MP4(SDQ), dando indícios de que a predição teórica dessas propriedades depende de uma descrição robusta da estrutura eletrônica dos produtos e reagentes na fase gasosa. 
Erro Quadrático Médio (pKa)

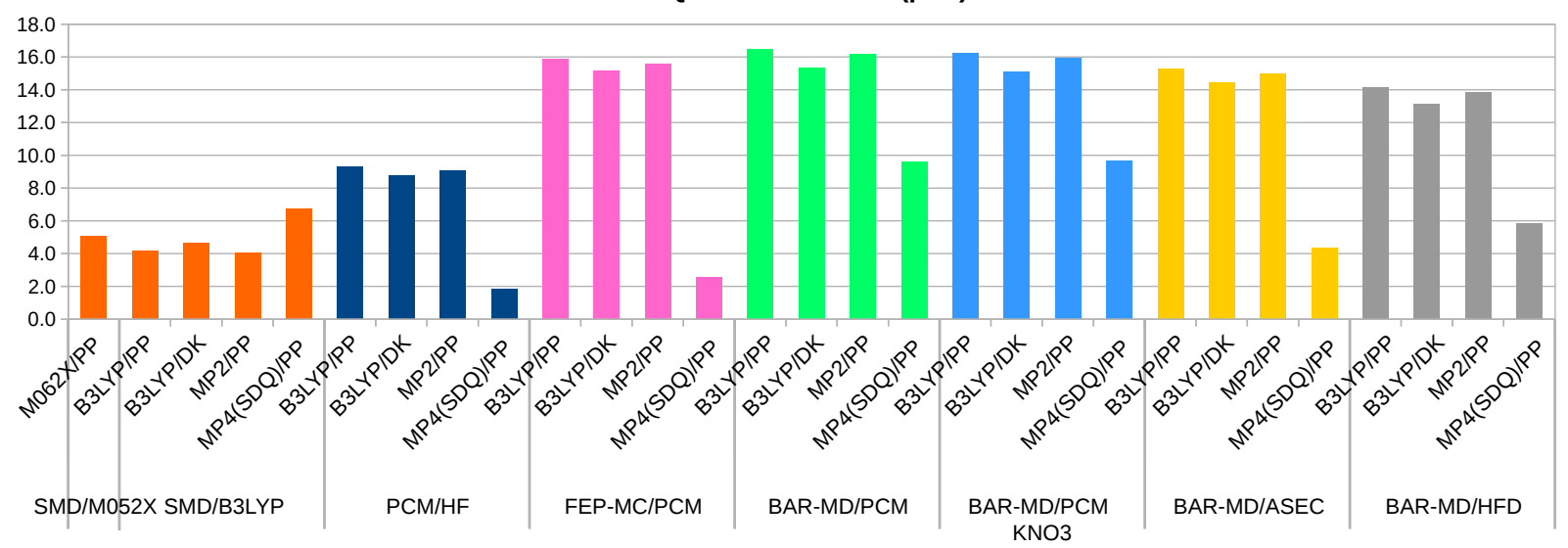

Erro Quadrático Médio (redox [eV])

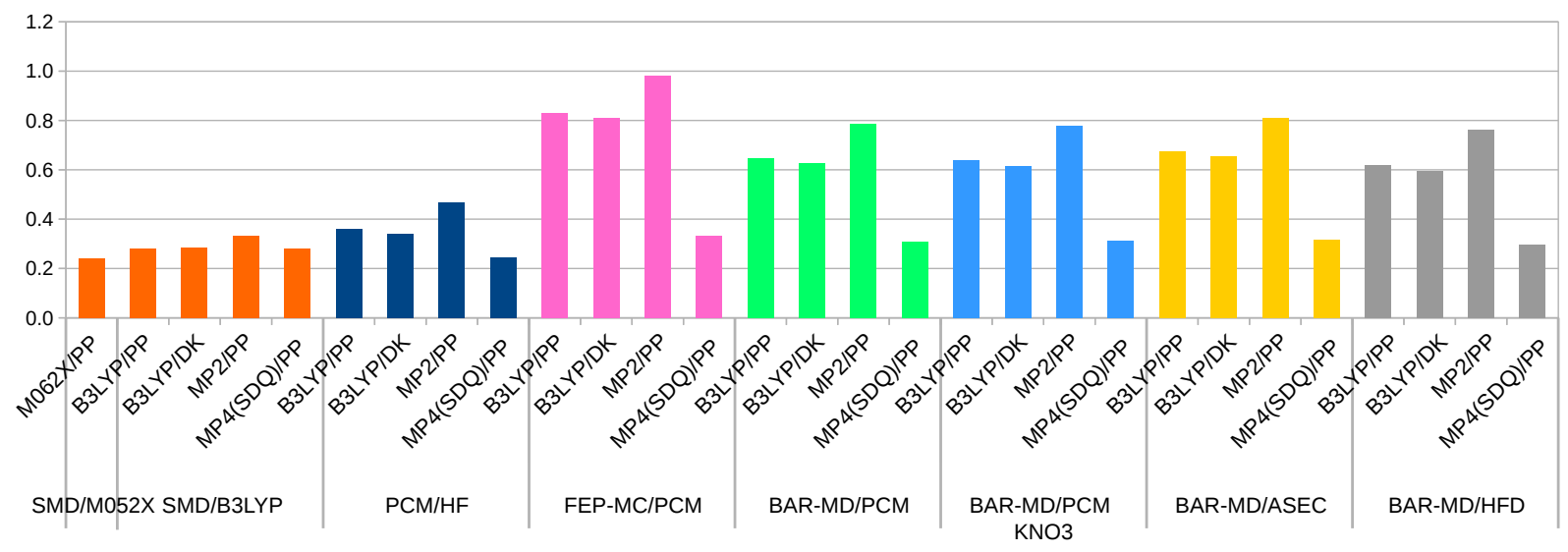

Figura 8.3 - Erro quadrático médio relacionado ao cálculo dos pKa e potenciais redox dos complexos de $R u$-Aqua/Oxo em solução aquosa, utilizando diferentes combinações de métodos e conjuntos de funções base. 


\section{Capítulo}

\section{Conclusão}

Neste trabalho, realizamos o estudo de 5 complexos de $R u$-Aqua/Oxo no vácuo e em solução aquosa. Investigamos propriedades estruturais, eletrônicas e eletroquímicas, tratando os efeitos de solvente de forma implícita (por modelos contínuos de solvente) e explícita (pelo método S-QM/MM). Os resultados foram alcançados realizando-se simulações clássicas de Monte Carlo e de Dinâmica Molecular, e cálculos quânticos DFT e pós-Hartree-Fock. Elucidamos a estrutura e dinâmica de soluções de complexos de $R u$-Aqua/Oxo, elucidamos processos de absorção de luz (UV-Vis e raios-X) dos complexos em solução, e colaboramos no entendimento das reações químicas envolvendo a troca de prótons e elétrons desses complexos em solução.

A estrutura conformacional dos complexos é similar à geometria cristalográfica do composto octaédrico $\operatorname{Ru} u^{I I} \operatorname{Tris}\left(2,2^{\prime}-b p y\right)$. A solvatação, a oxidação e a desprotonação (no grupo Aqua/Oxo) dos complexos causam pertubações estruturais principalmente na esfera de coordenação de $R u$, sendo que as distâncias $R u-N, R u-O$ e os ângulos e diedros envolvendo o grupo Aqua/Oxo ou a piridina são os parâmetros mais sensíveis. A solvatação leva a mudanças geométricas globais que não seguem as cargas totais dos complexos, e, localmente, temos a redução das ligações $R u-N$ e redução de $R u-O$ (nos complexos com água) ou aumento de $R u-O$ (nos complexos com hidróxido e óxido). A oxidação dos complexos provoca aumento das ligações $R u-N$ (principalmente para a ligação oposta ao oxigênio) e redução de $R u-O$, de forma mais exacerbada nos complexos com hidróxido. A desprotonação do grupo Aqua/Oxo sempre leva a uma redução de $R u-O$ e mudanças diversas de $R u-N$. O posicionamento da piridina é mais estável à perda de prótons que a perda de elétrons, e as bipiridinas são bastante rígidas. A oxidação dos complexos e a desprotonação do grupo Aqua/Oxo tem efeitos contrários na densidade eletrônica do átomo $R u$, donde a oxidação deixa $R u$ mais positivo e a desprotonação deixa $R u$ menos positivo. Átomo por átomo, o átomo $R u$ é quem sofre as maiores mudanças de carga quando ocorre a perda de prótons e ou elétrons. No mais, nos complexos de camada aberta, a densidade de spin encontra-se localizada no átomo de $R u$ ou delocalizada entre $R u$ e $O$.

Em solução, os complexos possuem camadas de solvatação semelhantes, que se diferenciam 
apenas na região de microsolvatação, onde acontecem as ligações de hidrogênio intermoleculares. Nos complexos com uma molécula de água, a distância $R u-O$ é regida pelas ligações de hidrogênio e não pelo estado de oxidação dos complexos. Os complexos com íon hidróxido formam mais ligações de hidrogênio que os demais, mas, as ligações mais intensas são formadas pelos complexos com maior carga total. Em qualquer complexo, o átomo $R u$ não forma ligações de hidrogênio com a solução. As ligações de hidrogênio complexo/solvente e solvente/solvente, na primeira camada de solvatação, tem altos tempos de vida. Esses, justificados, no primeiro caso, pela baixa mobilidade dos complexos em solução (coeficiente de difusão inferior a metade do coeficiente de difusão de uma molécula de água) e por maiores energias de interação das ligações de hidrogênio, e, no segundo caso, pela redução entrópica e aumento da energia interna do sistema soluto/solvente devido a formação de clatratos no entorno do soluto. $\mathrm{Na}$ interface água/vácuo, a posição do centro de massa dos complexos em relação a interface encontra-se correlacionada com a carga total de cada complexo: quanto menor a carga total, mais próximo da superfície. A direcionalidade da ligação $R u-O$ em relação a interface se correlaciona com a carga total dos grupos piridínicos, sendo que $R u$ encontra-se mais distante da interface quanto menor for a carga total desses grupos (menor polaridade implica em maior afinidade pelo vácuo).

Os orbitais de fronteira $\mathrm{H}(\mathrm{S}) \mathrm{OMO}$ e LUMO são do tipo $d$ (metal) e $\pi^{*}$ (bipiridinas), respectivamente. Isso implica que transições eletrônicas H(S)OMO-LUMO tem caráter MLCT. Em relação ao vácuo, o solvente causa desestabilização dos orbitais de fronteira, que é maior para os complexos de maior carga total. Essa desestabilização é menor quando se trata o solvente como cargas pontuais interagentes. Do gap HOMO-LUMO extrai-se que a mobilidade eletrônica é menor nos complexos de maior carga e tende a aumentar quando o sistema desprotona. Na descrição dos espectros de absorção UV-Vis, a combinação B3LYP/(aug)-cc$\mathrm{pVDZ/(PP-Ru)} \mathrm{traz} \mathrm{os} \mathrm{melhores} \mathrm{resultados} \mathrm{com} \mathrm{o} \mathrm{menor} \mathrm{custo} \mathrm{computacional,} \mathrm{e} \mathrm{a} \mathrm{inclusão} \mathrm{de}$ efeitos relativísticos não leva a resultados melhores. Os espectros UV-Vis são mais sensíveis aos efeitos do solvente na região do visível, onde os complexos de camada fechada tem bandas de absorção MLCT alargadas e com picos sensíveis ao pH da solução. Essas bandas perdem intensidade ou desaparecem quando os complexos oxidam, e prevalecem bandas LC e LLCT na região do ultra-violeta. As bandas MLCT no visível tem contribuição predominante de transferência de carga do metal para as bipiridinas, e são melhor descritas quando as ligações de hidrogênio complexo/solvente são tratadas quanticamente e as demais moléculas de água como cargas pontuais. A flexibilidade interna dos complexos tem pouca importância para a descrição dos espectros UV-Vis. Em relação aos espectros de XPS, o posicionamento dos picos de XPS podem ser associados à natureza química do complexo, indicando seu estado de oxidação e protonação. Considerando-se os efeitos do solvente explicitamente e por QM até a primeira camada de solvatação, conseguimos descrever a ordem experimental dos picos de $R u(3 d)$ e $C(1 s)$, que não se correlaciona com o estado de oxidação ou a carga atômica de $R u$. A energia de ligação de elétrons de camadas profundas é uma propriedade governada principalmente pela interação soluto-solvente, que deve ser contabilizada explicitamente e 
muito além das ligações de hidrogênio complexo/solvente.

As conversões internas entre os complexos de $R u$-Aqua/Oxo, a partir da troca de prótons e elétrons com a solução acontecem em condições específicas de $p K a$ e $V^{o x}$. A predição teórica dessas quantidades depende de cálculos acurados das energias livre de vácuo e de solvatação das espécies envolvidas nas reações químicas. À nível DFT, os funcionais B3LYP e M062X fornecem variações de energia livre de vácuo em bom acordo com os métodos MP2 e MP4(SDQ), e a utilização de conjuntos de funções base maiores que (aug)-cc-pVDZ/(PP-Ru) ou com correção relativística introduz pequenas mudanças nas variações de energia livre de vácuo. A energia livre de solvatação dos complexos tem grande contribuição eletrostática e tem valores negativos, indicando que a hidratação dos complexos trata-se de um processo espontâneo (e tão mais espontâneo quanto maior for a carga total do complexo). Em soluções com nitrato de potássio, há interação entre os complexos e os íons $\mathrm{NO}_{3}^{-}$na primeira e segunda camada de solvatação dos complexos, entretanto, a presença desse sal na solução altera minimamente a energia livre de solvatação dos complexos. A energia relativa às mudanças geométricas entre as geometrias otimizadas no vácuo e em solução é desprezível, e a energia relativa à polarização da função de onda pelo solvente pode ser relevante em algumas reações químicas e portanto não pode ser desprezada. O modelo de solvente, contínuo (PCM) ou atomístico (ASEC), tem grande impacto no cálculo da energia livre de solvatação, e o método de cálculo das cargas atômicas (CHELPG ou Hirshfeld, por exemplo) também segue o mesmo caminho. Dentre todos os testes realizados, algumas combinações de métodos QM e MM mostraram-se bastante acuradas na predição de algum $p K a$ ou de um ou mais potenciais redox, entretanto, não encontramos um protocolo único que forneça resultados coerentes com as medidas experimentais de todos as propriedades eletroquímicas. Novos estudos deverão ser realizados para que tal protocolo seja desenvolvido.

Por fim, restam ainda algumas considerações:

- Os parâmetros de LJC desenvolvidos para o átomo de $R u$ foram validados nos cálculos de espectros de absorção UV-Vis em solução, e nos cálculos de excitação de elétrons de camadas profundas. O bom acordo entre os resultados teóricos e experimentais demonstram que a obtenção de parâmetros LJC a partir do melhor ajuste entre as curvas QM e MM do potencial de interação entre a molécula de água coordenada e o complexo é um protocolo confiável.

- A técnica experimental de XPS aliada à cálculos quânticos DFT demonstra ser uma estratégia promissora na caracterização das espécies químicas envolvidas em reações químicas de troca de prótons e elétrons. Esse é uma tema de grande importância no desenvolvimento de novas tecnologias baseadas em fotossíntese artificial para a produção de combustível limpo e sustentável, e pode vir a ter uma importância fundamental no design de novos complexos, mais eficientes e estáveis.

- Na deconvolução dos espectros experimentais de XPS dos complexos $R u^{I I I}\left(\mathrm{H}_{2} \mathrm{O}\right)$ e 
$R u^{I I I}(O H)$, detectou-se picos extras de $R u\left(3 d_{5 / 2}\right)$ e $R u\left(3 d_{3 / 2}\right)$ possivelmente relacionados à alguma espécie desconhecida. Novos estudos deverão ser conduzidos a fim de compreender esse sinal de XPS, que pode de fato estar relacionado a alguma espécie intermediária, mas que também pode estar relacionado à formação de dímeros de complexos de $R u$-Aqua/Oxo em solução.

- A simulação MM de várias unidades de complexos de $R u$-Aqua/Oxo deverá ser realizada em pesquisas futuras, pois em altas concentrações de complexos em solução, é possível que haja uma predisposição dos complexos em formar dímeros e talvez trímeros, pela interação entre os grupos apolares dos complexos.

Nesta última oportunidade, acreditamos que este estudo poderá ao menos servir de inspiração para novos estudos e quiça novas descobertas no campo da aplicação de complexos de $R u$ Aqua/Oxo como eletro-catalisadores de reações químicas para a realização de fotossíntese artificial. 


\section{Referências}

1 BRUNEAU, C.; DIXNEUF, P. H. Ruthenium catalysts and fine chemistry. [S.I.]:

Springer Science \& Business Media, 2004. v. 11.

2 BOUBEKEUR-LECAQUE, L.; COE, B. J.; CLAYS, K.; FOERIER, S.; VERBIEST, T.; ASSELBERGHS, I. Redox-switching of nonlinear optical behavior in langmuir- blodgett thin films containing a ruthenium (ii) ammine complex. Journal of the American Chemical Society, ACS Publications, v. 130, n. 11, p. 3286-3287, 2008.

3 WHITTALL, I.; MCDONAGH, A. M.; HUMPHREY, M.; SAMOC, M. Organometallic complexes in nonlinear optics ii: third-order nonlinearities and optical limiting studies.

Advances in organometallic chemistry, Academic Press, v. 43, p. 349-405, 1999.

4 MIKURIYA, M.; YOSHIOKA, D.; HANDA, M. Magnetic interactions in one-, two-, and three-dimensional assemblies of dinuclear ruthenium carboxylates. Coordination chemistry reviews, Elsevier, v. 250, n. 17-18, p. 2194-2211, 2006.

5 LARIONOVA, J.; MOMBELLI, B.; SANCHIZ, J.; KAHN, O. Magnetic properties of the two-dimensional bimetallic compounds (nbu4)[miiruiii (ox) 3] (nbu4= tetra-n-butylammonium; $\mathrm{m}=\mathrm{mn}, \mathrm{fe}, \mathrm{cu} ; \mathrm{ox}=$ oxalate). Inorganic Chemistry, ACS Publications, v. 37, n. 4, p. 679-684, 1998.

6 AQUINO, M. A. Diruthenium and diosmium tetracarboxylates: synthesis, physical properties and applications. Coordination chemistry reviews, Elsevier, v. 170, n. 1, p. 141-202, 1998.

7 HUDSON, S. A.; MAITLIS, P. M. Calamitic metallomesogens: metal-containing liquid crystals with rodlike shapes. Chemical reviews, ACS Publications, v. 93, n. 3, p. 861-885, 1993.

$8 \mathrm{KIZAKI}, \mathrm{T}$.; ABE, T.; MATSUMOTO, T.; OGO, S. A ph-stable ruthenium (ii)-based sensing system for dissolved dinitrogen. Chemistry letters, The Chemical Society of Japan, v. 39, n. 2, p. 128-129, 2010.

9 FILLAUT, J.-L.; ANDRIES, J.; MARWAHA, R. D.; LANOË, P.-H.; LOHIO, O.; TOUPET, L.; WILLIAMS, J. G. Flavonol based ruthenium acetylides as fluorescent chemosensors for lead ions. Journal of Organometallic Chemistry, Elsevier, v. 693, n. 2, p. 228-234, 2008.

10 SILVA, D. de O. Perspectives for novel mixed diruthenium-organic drugs as metallopharmaceuticals in cancer therapy. Anti-Cancer Agents in Medicinal Chemistry (Formerly Current Medicinal Chemistry-Anti-Cancer Agents), Bentham Science Publishers, v. 10, n. 4, p. 312-323, 2010. 
11 LIU, Y.-J.; ZENG, C.-H.; YAO, J.-H.; WU, F.-H.; HE, L.-X.; HUANG, H.-L. Synthesis, structure, dna-binding properties, and cytotoxicity of ruthenium (ii) polypyridyl complexes. Chemistry \& biodiversity, Wiley Online Library, v. 7, n. 7, p. 1770-1783, 2010.

12 SIRIMANNE, P.; WINTHER-JENSEN, B.; WEERASINGHE, H.; CHENG, Y.-B. Towards an all-polymer cathode for dye sensitized photovoltaic cells. Thin solid films, Elsevier, v. 518, n. 10, p. $2871-2875,2010$.

13 CHEN, C.-Y.; POOTRAKULCHOTE, N.; WU, S.-J.; WANG, M.; LI, J.-Y.; TSAI, J.-H.; WU, C.-G.; ZAKEERUDDIN, S. M.; GRATZEL, M. New ruthenium sensitizer with carbazole antennas for efficient and stable thin-film dye-sensitized solar cells. The Journal of Physical Chemistry C, ACS Publications, v. 113, n. 48, p. 20752-20757, 2009.

14 LYON, J.; RAYAN, M.; BEERBOM, M.; SCHLAF, R. Electronic structure of the indium tin oxide/nanocrystalline anatase (tio 2)/ruthenium-dye interfaces in dye-sensitized solar cells. Journal of Applied Physics, AIP, v. 104, n. 7, p. 073714, 2008.

15 KREBS, F. C.; BIANCARDO, M. Dye sensitized photovoltaic cells: Attaching conjugated polymers to zwitterionic ruthenium dyes. Solar energy materials and solar cells, Elsevier, v. 90 , n. 2, p. 142-165, 2006.

16 GRÄTZEL, M. Solar energy conversion by dye-sensitized photovoltaic cells. Inorganic chemistry, ACS Publications, v. 44, n. 20, p. 6841-6851, 2005.

17 KARKAS, M. D.; VERHO, O.; JOHNSTON, E. V.; ÅKERMARK, B. Artificial photosynthesis: molecular systems for catalytic water oxidation. Chemical reviews, ACS Publications, v. 114, n. 24, p. 11863-12001, 2014.

18 FALK, J.; PHILLIPS, J.; DWYER, F.; MELLOR, D. Chelating agents and metal chelates. Academic Press, New York, NY, p. 441, 1964.

19 CALLAHAN, R. W.; BROWN, G. M.; MEYER, T. J. Effects of weak metal-metal interactions in ligand-bridged complexes of ruthenium. dimeric complexes containing ruthenium ions in different coordination environments. Inorganic Chemistry, ACS Publications, v. 14, n. 7, p. 1443-1453, 1975.

20 BROWN, G. M.; CALLAHAN, R. W.; MEYER, T. J. Thermal and light-induced decomposition of azido (bis-2, 2'-bipyridine) complexes of ruthenium (iii). Inorganic Chemistry, ACS Publications, v. 14, n. 8, p. 1915-1921, 1975.

21 SULLIVAN, B.; SALMON, D.; MEYER, T. Mixed phosphine 2, 2'-bipyridine complexes of ruthenium. Inorganic Chemistry, ACS Publications, v. 17, n. 12, p. 3334-3341, 1978.

22 CONSTABLE, E. C. The coordination chemistry of 2,2:6,2-terpyridine and higher oligopyridines. In: Advances in Inorganic Chemistry. [S.I.]: Elsevier, 1986. v. 30, p. 69-121.

23 KAES, C.; KATZ, A.; HOSSEINI, M. W. Bipyridine: the most widely used ligand. a review of molecules comprising at least two 2, 2 '-bipyridine units. Chemical reviews, ACS Publications, v. 100, n. 10, p. 3553-3590, 2000.

24 GISPERT, J. R. Coordination chemistry. [S.I.]: Wiley-VCH Weinheim, 2008. v. 483. 
25 JURIS, A.; BALZANI, V.; BARIGELLETTI, F.; CAMPAGNA, S.; BELSER, P. I.; ZELEWSKY, A. v. von. Ru (ii) polypyridine complexes: photophysics, photochemistry, eletrochemistry, and chemiluminescence. Coordination Chemistry Reviews, Elsevier, v. 84, p. 85-277, 1988.

26 BALZANI, V.; JURIS, A.; VENTURI, M.; CAMPAGNA, S.; SERRONI, S. Luminescent and redox-active polynuclear transition metal complexes. Chemical Reviews, ACS Publications, v. 96, n. 2 , p. $759-834,1996$.

27 MAESTRI, M.; ARMAROLI, N.; BALZANI, V.; CONSTABLE, E. C.; THOMPSON, A. M. C. Complexes of the ruthenium (ii)-2, 2': 6', 2"-terpyridine family. effect of electron-accepting and-donating substituents on the photophysical and electrochemical properties. Inorganic Chemistry, ACS Publications, v. 34, n. 10, p. 2759-2767, 1995.

28 HOFMEIER, H.; SCHUBERT, U. S. Recent developments in the supramolecular chemistry of terpyridine-metal complexes. Chemical Society Reviews, Royal Society of Chemistry, v. 33, n. 6, p. 373-399, 2004.

29 MAGNUSON, A.; ANDERLUND, M.; JOHANSSON, O.; LINDBLAD, P.; LOMOTH, R.; POLIVKA, T.; OTT, S.; STENSJÖ, K.; STYRING, S.; SUNDSTRÖM, V. et al. Biomimetic and microbial approaches to solar fuel generation. Accounts of chemical research, ACS Publications, v. 42, n. 12, p. 1899-1909, 2009.

30 LLOBET, A. Molecular water oxidation catalysis: a key topic for new sustainable energy conversion schemes. [S.I.]: John Wiley \& Sons, 2014.

31 STIEBRITZ, M. T.; REIHER, M. Hydrogenases and oxygen. Chemical science, Royal Society of Chemistry, v. 3, n. 6, p. 1739-1751, 2012.

32 PERSHAD, H. R.; DUFF, J. L.; HEERING, H. A.; DUIN, E. C.; ALBRACHT, S. P.; ARMSTRONG, F. A. Catalytic electron transport in chromatium vinosum [nife]-hydrogenase: application of voltammetry in detecting redox-active centers and establishing that hydrogen oxidation is very fast even at potentials close to the reversible $\mathrm{h}+/ \mathrm{h} 2$ value. Biochemistry, ACS Publications, v. 38, n. 28, p. 8992-8999, 1999.

33 FUKUZUMI, S.; YAMADA, Y.; SUENOBU, T.; OHKUBO, K.; KOTANI, H. Catalytic mechanisms of hydrogen evolution with homogeneous and heterogeneous catalysts. Energy \& Environmental Science, Royal Society of Chemistry, v. 4, n. 8, p. 2754-2766, 2011.

34 VALDEZ, C. N.; DEMPSEY, J. L.; BRUNSCHWIG, B. S.; WINKLER, J. R.; GRAY, H. B. Catalytic hydrogen evolution from a covalently linked dicobaloxime. Proceedings of the National Academy of Sciences, National Acad Sciences, v. 109, n. 39, p. 15589-15593, 2012.

35 CALLEJAS, J. F.; READ, C. G.; ROSKE, C. W.; LEWIS, N. S.; SCHAAK, R. E. Synthesis, characterization, and properties of metal phosphide catalysts for the hydrogen-evolution reaction. Chemistry of Materials, ACS Publications, v. 28, n. 17, p. 6017-6044, 2016.

36 PRIER, C. K.; RANKIC, D. A.; MACMILLAN, D. W. Visible light photoredox catalysis with transition metal complexes: applications in organic synthesis. Chemical reviews, ACS Publications, v. 113, n. 7, p. 5322-5363, 2013. 
37 NARAYANAM, J. M.; STEPHENSON, C. R. Visible light photoredox catalysis: applications in organic synthesis. Chemical Society Reviews, Royal Society of Chemistry, v. 40 , n. 1 , p. $102-113,2011$.

38 XUAN, J.; XIAO, W.-J. Visible-light photoredox catalysis. Angewandte Chemie International Edition, Wiley Online Library, v. 51, n. 28, p. 6828-6838, 2012.

$39 \mathrm{XI}, \mathrm{Y}$.; YI, H.; LEI, A. Synthetic applications of photoredox catalysis with visible light. Organic \& biomolecular chemistry, Royal Society of Chemistry, v. 11, n. 15, p. 2387-2403, 2013.

40 GERSTEN, S. W.; SAMUELS, G. J.; MEYER, T. J. Catalytic oxidation of water by an oxo-bridged ruthenium dimer. Journal of the American Chemical Society, ACS Publications, v. 104, n. 14, p. 4029-4030, 1982.

41 COLLIN, J.; SAUVAGE, J. P. Synthesis and study of mononuclear ruthenium (ii) complexes of sterically hindering diimine chelates. implications for the catalytic oxidation of water to molecular oxygen. Inorganic Chemistry, ACS Publications, v. 25, n. 2, p. 135-141, 1986.

42 NAGOSHI, K.; YAMASHITA, S.; YAGI, M.; KANEKO, M. Catalytic activity of [(bpy) 2 (h2o) ru-o-ru (h2o)(bpy) 2] 4+ for four-electron water oxidation. Journal of Molecular

Catalysis A: Chemical, Elsevier, v. 144, n. 1, p. 71-76, 1999.

43 LIU, F.; CONCEPCION, J. J.; JURSS, J. W.; CARDOLACCIA, T.; TEMPLETON, J. L.; MEYER, T. J. Mechanisms of water oxidation from the blue dimer to photosystem ii. Inorganic Chemistry, ACS Publications, v. 47, n. 6, p. 1727-1752, 2008.

44 SENS, C.; ROMERO, I.; ROdRÍGueZ, M.; LLOBET, A.; PARELLA, T.; BENETBUCHHOLZ, J. A new ru complex capable of catalytically oxidizing water to molecular dioxygen. Journal of the American Chemical Society, ACS Publications, v. 126, n. 25, p. 7798-7799, 2004.

45 ROMAIN, S.; BOZOGLIAN, F.; SALA, X.; LLOBET, A. Oxygen- oxygen bond formation by the ru-hbpp water oxidation catalyst occurs solely via an intramolecular reaction pathway. Journal of the American Chemical Society, ACS Publications, v. 131, n. 8, p. 2768-2769, 2009.

46 ZONG, R.; THUMMEL, R. P. A new family of ru complexes for water oxidation. Journal of the American Chemical Society, v. 127, n. 37, p. 12802-12803, 2005.

47 TSENG, H.-W.; ZONG, R.; MUCKERMAN, J. T.; THUMMEL, R. Mononuclear ruthenium (ii) complexes that catalyze water oxidation. Inorganic chemistry, ACS Publications, v. 47, n. 24 , p. $11763-11773,2008$.

48 POLYANSKY, D. E.; MUCKERMAN, J. T.; ROCHFORD, J.; ZONG, R.; THUMMEL, R. P.; FUJITA, E. Water oxidation by a mononuclear ruthenium catalyst: characterization of the intermediates. Journal of the American Chemical Society, ACS Publications, v. 133, n. 37, p. 14649-14665, 2011.

49 DUAN, L.; ARAUJO, C. M.; AHLQUIST, M. S.; SUN, L. Highly efficient and robust molecular ruthenium catalysts for water oxidation. Proceedings of the National Academy of Sciences, National Acad Sciences, v. 109, n. 39, p. 15584-15588, 2012. 
50 ANDERSON, T. R.; HAWKINS, E.; JONES, P. D. Co2, the greenhouse effect and global warming: from the pioneering work of arrhenius and callendar to today's earth system models. Endeavour, Elsevier, v. 40, n. 3, p. 178-187, 2016.

51 CHEN, Z.; CONCEPCION, J. J.; HU, X.; YANG, W.; HOERTZ, P. G.; MEYER, T. J. Concerted o atom-proton transfer in the o-o bond forming step in water oxidation. Proceedings of the National Academy of Sciences, National Acad Sciences, v. 107, n. 16, p. 7225-7229, 2010.

52 RUITER, J. M. de; GROOT, H. J. de; BUDA, F. Energetic effects of a closed system approach including explicit proton and electron acceptors as demonstrated by a mononuclear ruthenium water oxidation catalyst. ChemCatChem, Wiley Online Library, v. 10, n. 20, p. 4594-4601, 2018.

53 GOVINDARAJAN, N.; MEIJER, E. J. Modeling the catalyst activation step in a metal-ligand radical mechanism based water oxidation system. Inorganics, Multidisciplinary Digital Publishing Institute, v. 7, n. 5, p. 62, 2019.

54 ZHAN, S.; TRIVINO, J. A. D. G.; AHLQUIST, M. S. The carboxylate ligand as an oxide relay in catalytic water oxidation. Journal of the American Chemical Society, ACS Publications, v. 141, n. 26, p. 10247-10252, 2019.

55 ZHAN, S.; ZOU, R.; AHLQUIST, M. S. Dynamics with explicit solvation reveals formation of the prereactive dimer as sole determining factor for the efficiency of ru (bda) I2 catalysts. ACS Catalysis, ACS Publications, v. 8, n. 9, p. 8642-8648, 2018.

56 BIANCO, R.; HAY, P. J.; HYNES, J. T. Theoretical study of o-o single bond formation in the oxidation of water by the ruthenium blue dimer. The Journal of Physical Chemistry A, ACS Publications, v. 115, n. 27, p. 8003-8016, 2011.

57 BIANCO, R.; HAY, P. J.; HYNES, J. T. Theoretical study of water oxidation by the ruthenium blue dimer. ii. proton relay chain mechanism for the step [bpy2 (hoo) ruivoruiv (oh) bpy2] $4+\rightarrow$ [bpy2 (o2-) ruivoruiii (oh2) bpy2] 4+. The Journal of Physical Chemistry B, ACS Publications, v. 117, n. 49, p. 15761-15773, 2013.

58 KUNZ, V.; LINDNER, J. O.; SCHULZE, M.; RÖHR, M. I.; SCHMIDT, D.; MITRIĆ, R.; WÜRTHNER, F. Cooperative water oxidation catalysis in a series of trinuclear metallosupramolecular ruthenium macrocycles. Energy \& Environmental Science, Royal Society of Chemistry, v. 10, n. 10, p. 2137-2153, 2017.

59 GOVINDARAJAN, N.; SINHA, V.; TRINCADO, M.; GRÜTZMACHER, H.; MEIJER, E. J.; BRUIN, B. de. An in-depth mechanistic study of ru catalysed aqueous methanol dehydrogenation and prospects for future catalyst design. ChemCatChem, Wiley Online Library, 2020.

60 BASRI, S.; KAMARUDIN, S.; DAUD, W.; YAAKUB, Z. Nanocatalyst for direct methanol fuel cell (dmfc). International Journal of Hydrogen Energy, Elsevier, v. 35, n. 15, p. 7957-7970, 2010.

61 SINHA, V.; GOVINDARAJAN, N.; BRUIN, B. de; MEIJER, E. J. How solvent affects $\mathrm{c}-\mathrm{h}$ activation and hydrogen production pathways in homogeneous ru-catalyzed methanol dehydrogenation reactions. ACS catalysis, ACS Publications, v. 8, n. 8, p. 6908-6913, 2018. 
$62 \mathrm{MEI}, \mathrm{D} . ;$ K. O.; GERBER, M.; ROUSSEAU, R.; DAGLE, R. A. Highly active and stable mgal2o4supported $r$ and ir catalysts for methane steam reforming: A combined experimental and theoretical study. Journal of catalysis, Elsevier, v. 316, p. 11-23, 2014.

63 HÖLSCHER, M.; LEITNER, W. Dft investigation of the potential of [h-m $\{(\mathrm{NHCH} 2 \mathrm{CH} 2)$ $3 X\}$ ] catalysts $(m=m o, r u, o s ; x=n, p)$ for the reduction of $n 2$ to $n h 3$ by h2. European journal of inorganic chemistry, Wiley Online Library, v. 2006, n. 21, p. 4407-4417, 2006.

64 CAO, Y.; GAO, Y.; ZHOU, H.; CHEN, X.; HU, H.; DENG, S.; ZHONG, X.; ZHUANG, G.; WANG, J. Highly efficient ammonia synthesis electrocatalyst: single ru atom on naturally nanoporous carbon materials. Advanced Theory and Simulations, Wiley Online Library, v. 1, n. 5, p. 1800018, 2018.

65 AKPA, B.; D'AGOSTINO, C.; GLADDEN, L.; HINDLE, K.; MANYAR, H.; MCGREGOR, J.; LI, R.; NEUROCK, M.; SINHA, N.; STITT, E. et al. Solvent effects in the hydrogenation of 2-butanone. Journal of Catalysis, Elsevier, v. 289, p. 30-41, 2012.

66 DIAMANTIS, P.; GONTHIER, J. F.; TAVERNELLI, I.; ROTHLISBERGER, U. Study of the redox properties of singlet and triplet tris (2,2'-bipyridine) ruthenium (ii)([ru(bpy)3]2+) in aqueous solution by full quantum and mixed quantum/classical molecular dynamics simulations. The Journal of Physical Chemistry B, ACS Publications, v. 118, n. 14, p. 3950-3959, 2014.

67 ZENG, X.; HU, H.; HU, X.; COHEN, A. J.; YANG, W. Ab initio quantum mechanical/molecular mechanical simulation of electron transfer process: Fractional electron approach. The Journal of chemical physics, American Institute of Physics, v. 128, n. 12, p. 124510, 2008.

68 BANDARU, S.; ENGLISH, N. J.; MACELROY, J. Implicit and explicit solvent models for modeling a bifunctional arene ruthenium hydrogen-storage catalyst: A classical and ab initio molecular simulation study. Journal of Computational Chemistry, Wiley Online Library, v. 35, n. 9, p. 683-691, 2014.

69 SILVA, J. L.; UNGER, I.; MATIAS, T. A.; FRANCO, L. R.; DAMAS, G.; COSTA, L. T.; TOLEDO, K. C.; ROCHA, T. C.; BRITO, A. N. de; SAAK, C.-M. et al. X-ray photoelectron fingerprints of high-valence ruthenium-oxo complexes along the oxidation reaction pathway in an aqueous environment. The journal of physical chemistry letters, ACS Publications, v. 10, n. 24, p. $7636-7643,2019$.

70 PARK, P.; FRANCO, L. R.; CHAIMOVICH, H.; COUTINHO, K.; CUCCOVIA, I. M.; LIMA, F. S. Binding and flip as initial steps for bp-100 antimicrobial actions. Scientific reports, Nature Publishing Group, v. 9, n. 1, p. 1-14, 2019.

71 COUTINHO, K.; CANUTO, S. Solvent effects from a sequential monte carlo-quantum mechanical approach. In: Advances in quantum chemistry. [S.I.]: Elsevier, 1997. v. 28, p. 89-105.

72 BRANDT, P.; NORRBY, T.; ÅKERMARK, B.; NORRBY, P.-O. Molecular mechanics (mm3*) parameters for ruthenium (ii)- polypyridyl complexes. Inorganic chemistry, ACS Publications, v. 37, n. 16, p. 4120-4127, 1998. 
73 MOYER, B. A.; MEYER, T. J. Properties of the oxo/aqua system (bpy) 2 (py) ruo2 $+/$ (bpy) 2 (py) ru (oh2) $2+$. Inorganic Chemistry, ACS Publications, v. 20, n. 2, p. 436-444, 1981.

74 CONCEPCION, J. J.; JURSS, J. W.; TEMPLETON, J. L.; MEYER, T. J. One site is enough. catalytic water oxidation by [ru (tpy)(bpm)(oh2)] 2+ and [ru (tpy)(bpz)(oh2)] $2+$. Journal of the American Chemical Society, ACS Publications, v. 130, n. 49, p. 16462-16463, 2008.

75 WASYLENKO, D. J.; GANESAMOORTHY, C.; KOIVISTO, B. D.; HENDERSON, M. A.; BERLINGUETTE, C. P. Insight into water oxidation by mononuclear polypyridyl ru catalysts. Inorganic chemistry, ACS Publications, v. 49, n. 5, p. 2202-2209, 2010.

76 KUTZELNIGG, W. The adiabatic approximation: The physical background of the born-handy ansatz. Molecular Physics, v. 90, n. 6, p. 909-916, 1997.

77 SZABO, A.; OSTLUND, N. S. Modern Quantum Chemistry. [S.I.]: Courier Corporation. 480 p. ISBN 0-486-13459-8.

78 SPRINGBORG, M. Methods of electronic-structure calculations. [S.I.]: Wiley-Chichester, 2000.

79 HIRSCHFELDER, J. O. Formal rayleigh-schrödinger perturbation theory for both degenerate and non-degenerate energy states. International Journal of Quantum Chemistry, Wiley Online Library, v. 3, n. 5, p. 731-748, 1969.

80 CREMER, D. Møller-plesset perturbation theory: from small molecule methods to methods for thousands of atoms. Wiley Interdisciplinary Reviews: Computational Molecular Science, Wiley Online Library, v. 1, n. 4, p. 509-530, 2011.

81 HOHENBERG, P.; KOHN, W. Inhomogeneous electron gas. Physical Review, American Physical Society, v. 136, p. B864-B871, Nov 1964.

82 MORGON, N. H.; CUSTODIO, R. Teoria do funcional de densidade. Química Nova, v. 18, p. $44-55,1995$.

$83 \mathrm{KOHN}$, W.; SHAM, L. J. Self-consistent equations including exchange and correlation effects. Physical Review, American Physical Society, v. 140, p. A1133-A1138, Nov 1965.

84 SHAM, L. J.; KOHN, W. One-particle properties of an inhomogeneous interacting electron gas. Physical Review, American Physical Society, v. 145, p. 561-567, May 1966.

85 GUNNARSSON, O.; LUNDQVIST, B. I. Exchange and correlation in atoms, molecules, and solids by the spin-density-functional formalism. Physical Review B, American Physical Society, v. 13, p. 4274-4298, May 1976.

86 PERDEW, J. P.; YUE, W. Accurate and simple density functional for the electronic exchange energy: Generalized gradient approximation. Physical Review B, American Physical Society, v. 33, p. 8800-8802, Jun 1986.

87 ZAHARIEV, F.; LEANG, S.; GORDON, M. S. Functional derivatives of meta-generalized gradient approximation (meta-gga) type exchange-correlation density functionals. The Journal of Chemical Physics, AIP Publishing, v. 138, n. 24, p. 244108, 2013. 
88 BECKE, A. D. Density-functional exchange-energy approximation with correct asymptotic behavior. Physical Review A, APS, v. 38, n. 6, p. 3098, 1988.

89 LEE, C.; YANG, W.; PARR, R. G. Development of the colle-salvetti correlation-energy formula into a functional of the electron density. Physical Review B, APS, v. 37, n. 2, p. $785,1988$.

90 YANAI, T.; TEW, D. P.; HANDY, N. C. A new hybrid exchange-correlation functional using the coulomb-attenuating method (cam-b3lyp). Chemical Physics Letters, v. 393, n. $1-3$, p. $51-57,2004$. ISSN 0009-2614.

91 TAWADA, Y.; TSUNEDA, T.; YANAGISAWA, S.; YANAI, T.; HIRAO, K. A long-range-corrected time-dependent density functional theory. The Journal of Chemical Physics, AIP Publishing, v. 120, n. 18, p. 8425-8433, 2004.

92 FRISCH, M. J. et al. Gaussian 09 Revision E.01. Gaussian Inc. Wallingford CT 2009.

93 RUNGE, E.; GROSS, E. K. U. Density-functional theory for time-dependent systems.

Physical Review Letters, American Physical Society, v. 52, p. 997-1000, Mar 1984.

94 MARQUES, M.; GROSS, E. Time-dependent density functional thoery. Annual Review of Physical Chemistry, v. 55, n. 1, p. 427-455, 2004.

95 DAHLEN, N. E.; LEEUWEN, R. van. Self-consistent solution of the dyson equation for atoms and molecules within a conserving approximation. The Journal of Chemical Physics, v. 122, n. 16, 2005.

96 DREUW, A.; HEAD-GORDON, M. Single-reference ab initio methods for the calculation of excited states of large molecules. Chemical reviews, ACS Publications, v. 105, n. 11, p. 4009-4037, 2005.

97 FURCHE, F.; AHLRICHS, R. Adiabatic time-dependent density functional methods for excited state properties. The Journal of chemical physics, American Institute of Physics, v. 117, n. 16, p. 7433-7447, 2002.

98 HIRATA, S.; HEAD-GORDON, M. Time-dependent density functional theory within the tamm-dancoff approximation. Chemical Physics Letters, Elsevier, v. 314, n. 3-4, p. 291-299, 1999.

99 PEACH, M. J.; TOZER, D. J. Overcoming low orbital overlap and triplet instability problems in tddft. The Journal of Physical Chemistry A, ACS Publications, v. 116, n. 39, p. 9783-9789, 2012.

100 JANAK, J. Proof that $\frac{\partial e}{\partial n_{i}}=\varepsilon_{i}$ in density-functional theory. Physical Review B, APS, v. 18, n. 12, p. $7165,1978$.

101 OLOVSSON, W.; GÖRANSSON, C.; POUROVSKII, L.; JOHANSSON, B.; ABRIKOSOV, I. A. Core-level shifts in fcc random alloys: A first-principles approach. Physical Review B, APS, v. 72, n. 6, p. 064203, 2005.

102 LI, Y.; SANNA, S.; SCHMIDT, W. G. Modeling intrinsic defects in linbo3 within the slater-janak transition state model. The Journal of Chemical Physics, American Institute of Physics, v. 140, n. 23, p. 234113, 2014. 
103 GÖRANSSON, C.; OLOVSSON, W.; ABRIKOSOV, I. A. Numerical investigation of the validity of the slater-janak transition-state model in metallic systems. Physical Review B, APS, v. 72, n. 13, p. 134203, 2005.

104 BAERENDS, E. J. On derivatives of the energy with respect to total electron number and orbital occupation numbers. a critique of janak's theorem. Molecular Physics, Taylor \& Francis, v. 118, n. 5, p. e1612955, 2020.

105 BOYS, S. F. The integral formulae for the variational solution of the molecular many-electron wave equation in terms of gaussian functions with direct electronic correlation. Proceedings of the Royal Society of London. Series A. Mathematical and Physical Sciences, The Royal Society London, v. 258, n. 1294, p. 402-411, 1960.

106 PETERSON, K. A.; FIGGEN, D.; DOLG, M.; STOLL, H. Energy-consistent relativistic pseudopotentials and correlation consistent basis sets for the $4 \mathrm{~d}$ elements $\mathrm{y}-\mathrm{pd}$. The Journal of chemical physics, AIP, v. 126, n. 12, p. 124101, 2007.

107 XU, X.; TRUHLAR, D. G. Accuracy of effective core potentials and basis sets for density functional calculations, including relativistic effects, as illustrated by calculations on arsenic compounds. Journal of chemical theory and computation, ACS Publications, v. 7, n. 9, p. 2766-2779, 2011.

108 BOYS, S. F.; BERNARDI, F. The calculation of small molecular interactions by the differences of separate total energies. some procedures with reduced errors. Molecular Physics, Taylor \& Francis, v. 19, n. 4, p. 553-566, 1970.

109 CARBÓ-DORCA, R.; BULTINCK, P. Quantum mechanical basis for mulliken population analysis. Journal of mathematical chemistry, Springer, v. 36, n. 3, p. 231-239, 2004.

110 MULLIKEN, R. Criteria for the construction of good self-consistent-field molecular orbital wave functions, and the significance of Icao-mo population analysis. The Journal of Chemical Physics, AIP Publishing, v. 36, n. 12, p. 3428-3439, 1962.

111 HIRSHFELD, F. L. Bonded-atom fragments for describing molecular charge densities. Theoretica chimica acta, Springer, v. 44, n. 2, p. 129-138, 1977.

112 SINGH, U. C.; KOLLMAN, P. A. An approach to computing electrostatic charges for molecules. Journal of Computational Chemistry, Wiley Online Library, v. 5, n. 2, p. 129-145, 1984.

113 BRENEMAN, C. M.; WIBERG, K. B. Determining atom-centered monopoles from molecular electrostatic potentials. the need for high sampling density in formamide conformational analysis. Journal of Computational Chemistry, Wiley Online Library, v. 11, n. 3, p. 361-373, 1990.

114 LILLESTOLEN, T. C.; WHEATLEY, R. J. Atomic charge densities generated using an iterative stockholder procedure. The Journal of chemical physics, American Institute of Physics, v. 131, n. 14, p. 144101, 2009.

115 MARENICH, A. V.; JEROME, S. V.; CRAMER, C. J.; TRUHLAR, D. G. Charge model 5: An extension of hirshfeld population analysis for the accurate description of molecular interactions in gaseous and condensed phases. Journal of chemical theory and computation, ACS Publications, v. 8, n. 2, p. 527-541, 2012. 
116 MANZ, T. A.; SHOLL, D. S. Improved atoms-in-molecule charge partitioning functional for simultaneously reproducing the electrostatic potential and chemical states in periodic and nonperiodic materials. Journal of chemical theory and computation, ACS Publications, v. 8, n. 8, p. 2844-2867, 2012.

117 HEIDAR-ZADEH, F.; AYERS, P. W.; BULTINCK, P. Fractional nuclear charge approach to isolated anion densities for hirshfeld partitioning methods. Journal of Molecular Modeling, Springer, v. 23, n. 12, p. 348, 2017.

118 ZHAO, Y.; TRUHLAR, D. G. Density functionals with broad applicability in chemistry. Accounts of chemical research, ACS Publications, v. 41, n. 2, p. 157-167, 2008.

119 ADAMO, C.; BARONE, V. Exchange functionals with improved long-range behavior and adiabatic connection methods without adjustable parameters: The $\mathrm{m}$ pw and $\mathrm{m}$ pw1pw models. The Journal of chemical physics, American Institute of Physics, v. 108, n. 2, p. 664-675, 1998.

120 METROPOLIS, N.; ULAM, S. The monte carlo method. Journal of the American Statistical Association, Taylor \& Francis Group, v. 44, n. 247, p. 335-341, 1949.

121 Metropolis, N.; ROSENBluTH, A. W.; ROSENBLUTH, M. N.; TELLER, A. H.; TELLER, E. Equation of state calculations by fast computing machines. The journal of chemical physics, American Institute of Physics, v. 21, n. 6, p. 1087-1092, 1953.

122 ALLEN, M. P.; TILDESLEY, D. J. Computer Simulation of Liquids. [S.I.]: Oxford, Nova York, 1989.

123 COUTINHO, K. Modelo discreto de solvente. Solvatocromismo no espectro de absorção molecular. 1997. Tese (Doutorado) — Instituto de Fisica, Universidade de Sao Paulo, doi:10.11606/T.43.1997.tde-22062012-154558, 1997.

124 CEZAR, H. M. Implementação e desenvolvimento de algoritmo eficiente para deformação intramolecular com o método Monte Carlo. 2018. Tese (Doutorado) Instituto de Fisica, Universidade de Sao Paulo, doi:10.11606/T.43.2018.tde-19102018-165856, 2018.

125 RAHMAN, A. Correlations in the motion of atoms in liquid argon. Physical review, APS, v. 136, n. 2A, p. A405, 1964.

126 HOCKNEY, R. W.; GOEL, S.; EASTWOOD, J. W. Quiet high-resolution computer models of a plasma. Journal of Computational Physics, v. 14, n. 2, p. $148-158,1974$.

127 HESS, B.; BEKKER, H.; BERENDSEN, H. J. C.; FRAAIJE, J. G. E. M. Lincs: a linear constraint solver for molecular simulations. Journal of Computational Chemistry, Wiley Online Library, v. 18, n. 12, p. 1463-1472, 1997.

128 RYCKAERT, J.-P.; CICCOTTI, G.; BERENDSEN, H. J. Numerical integration of the cartesian equations of motion of a system with constraints: molecular dynamics of n-alkanes. Journal of computational physics, Academic Press, v. 23, n. 3, p. 327-341, 1977.

129 CICCOTTI, G.; RYCKAERT, J.-P. Molecular dynamics simulation of rigid molecules.

Computer Physics Reports, Elsevier, v. 4, n. 6, p. 346-392, 1986. 
130 WOODCOCK, L.-V. Isothermal molecular dynamics calculations for liquid salts.

Chemical Physics Letters, Elsevier, v. 10, n. 3, p. 257-261, 1971.

131 BUSSI, G.; DONADIO, D.; PARRINELLO, M. Canonical sampling through velocity rescaling. The Journal of chemical physics, American Institute of Physics, v. 126, n. 1, p. 014101, 2007.

132 GOGA, N.; RZEPIELA, A.; VRIES, A. D.; MARRINK, S.; BERENDSEN, H. Efficient algorithms for langevin and dpd dynamics. Journal of chemical theory and computation, ACS Publications, v. 8, n. 10, p. 3637-3649, 2012.

133 SPOEL, D. V. D.; LINDAHL, E.; HESS, B.; GROENHOF, G.; MARK, A. E.; BERENDSEN, H. J. Gromacs: fast, flexible, and free. Journal of computational chemistry, Wiley Online Library, v. 26, n. 16, p. 1701-1718, 2005.

134 BERENDSEN, H. J.; POSTMA, J. v.; GUNSTEREN, W. F. van; DINOLA, A.; HAAK, J. R. Molecular dynamics with coupling to an external bath. The Journal of chemical physics, American Institute of Physics, v. 81, n. 8, p. 3684-3690, 1984.

135 CICCOTTI, G. Molecular-dynamics simulation of statistical-mechanical systems: Varenna on lake como, villa monastero, 23 july-2 august 1985. North-Holland, 1986.

136 BARKER, J. A.; WATTS, R. O. Monte carlo studies of the dielectric properties of water-like models. Molecular Physics, Taylor \& Francis, v. 26, n. 3, p. 789-792, 1973.

137 BENEDETTO, J. J.; ZIMMERMANN, G. Sampling multipliers and the poisson summation formula. Journal of Fourier Analysis and Applications, Springer, v. 3, n. 5, p. 505-523, 1997.

138 GEORG, H. C.; CANUTO, S. Métodos híbridos para modelagem do ambiente molecular. In: MORGON, N. H.; COUTINHO, K. (Ed.). Métodos de Química Teórica e Modelagem Molecular. [S.I.]: Livraria da Física, São Paulo, 2007. p. 453-488.

139 LENNARD-JONES, J. The equation of state of gases and critical phenomena. Physica, Elsevier, v. 4, n. 10, p. 941-956, 1937.

140 LORENTZ, H. Ueber die anwendung des satzes vom virial in der kinetischen theorie der gase. Annalen der physik, Wiley Online Library, v. 248, n. 1, p. 127-136, 1881.

141 GOOD, R. J.; HOPE, C. J. New combining rule for intermolecular distances in intermolecular potential functions. The Journal of Chemical Physics, American Institute of Physics, v. 53, n. 2, p. 540-543, 1970.

142 BERTHELOT, D. Sur le mélange des gaz. Compt. Rendus, v. 126, p. 1703-1706, 1898.

143 CEZAR, H. M.; CANUTO, S.; COUTINHO, K. Dice: A monte carlo code for molecular simulation including configurational bias monte carlo method. Journal of Chemical Information and Modeling, ACS Publications, 2020.

144 TOMASI, J.; MENNUCCI, B.; CAMMI, R. Quantum mechanical continuum solvation models. Chemical reviews, ACS Publications, v. 105, n. 8, p. 2999-3094, 2005. 
145 MENNUCCI, B.; TOMASI, J.; CAMMI, R.; CHEESEMAN, J.; FRISCH, M.; DEVLIN, F.; GABRIEL, S.; STEPHENS, P. Polarizable continuum model $(\mathrm{pcm})$ calculations of solvent effects on optical rotations of chiral molecules. The Journal of Physical Chemistry A, ACS Publications, v. 106, n. 25, p. 6102-6113, 2002.

146 MARENICH, A. V.; CRAMER, C. J.; TRUHLAR, D. G. Universal solvation model based on solute electron density and on a continuum model of the solvent defined by the bulk dielectric constant and atomic surface tensions. The Journal of Physical Chemistry B, ACS Publications, v. 113, n. 18, p. 6378-6396, 2009.

147 SANCHEZ, M. L.; AGUILAR, M.; VALLE, F. Olivares del. Study of solvent effects by means of averaged solvent electrostatic potentials obtained from molecular dynamics data. Journal of computational chemistry, Wiley Online Library, v. 18, n. 3, p. 313-322, 1997.

148 COUTINHO, K.; GEORG, H.; FONSECA, T.; LUDWIG, V.; CANUTO, S. An efficient statistically converged average configuration for solvent effects. Chemical Physics Letters, Elsevier, v. 437, n. 1, p. 148-152, 2007.

149 CONSTANCIEL, R. Theoretical basis of the empirical reaction field approximations through continuum model. Theoretica Chimica Acta, Springer, v. 69, n. 5-6, p. 505-523, 1986.

150 TOMASI, J.; MENNUCCI, B.; CAMMI, R. Quantum mechanical continuum solvation models. Chemical Reviews, ACS Publications, v. 105, n. 8, p. 2999-3094, 2005.

151 CANUTO, S. Solvation effects on molecules and biomolecules: computational methods and applications. [S.I.]: Springer Science \& Business Media, 2010. v. 6.

152 GEORG, H.; FERNANDES, T.; CANUTO, S.; TAKENAKA, N.; KITAMURA, Y.; NAGAOKA, M. A combination of the sequential $\mathrm{qm} / \mathrm{mm}$ and the free energy gradient methodologies with applications. In: Practical Aspects of Computational Chemistry III. [S.I.]: Springer, 2014. p. 231-247.

153 OKUYAMA-YOSHIDA, N.; NAGAOKA, M.; YAMABE, T. Transition-state optimization on free energy surface: Toward solution chemical reaction ergodography. International journal of quantum chemistry, Wiley Online Library, v. 70, n. 1, p. 95-103, 1998.

154 GEORG, H. C.; CANUTO, S. Electronic properties of water in liquid environment. a sequential $\mathrm{qm} / \mathrm{mm}$ study using the free energy gradient method. The Journal of Physical Chemistry B, ACS Publications, v. 116, n. 36, p. 11247-11254, 2012.

155 FRANCO, L. R.; BRANDÃO, I.; FONSECA, T. L.; GEORG, H. C. Elucidating the structure of merocyanine dyes with the asec-feg method. phenol blue in solution. The Journal of chemical physics, American Institute of Physics, v. 145, n. 19, p. 194301, 2016.

156 BRANDÃO, I.; FRANCO, L. R.; FONSECA, T. L.; CASTRO, M. A.; GEORG, H. C. Confirming the relationship between first hyperpolarizability and the bond length alternation coordinate for merocyanine dyes. The Journal of Chemical Physics, AIP Publishing LLC, v. 146, n. 22, p. $224505,2017$.

157 HAILE, J. Molecular dynamics simulation-elementary methods, john willey \& sons. Inc., New York, 1992. 
158 ELLIOTT, S. R. Physics of Amorphous Materials. 2. ed. [S.I.]: Longman Scientific, Nova York, 1990.

159 DESIRAJU, G. R.; STEINER, T. The Weak Hydrogen Bond: In Structural Chemistry and Biology. [S.I.]: Oxford University Press, 1999.

160 LUZAR, A.; CHANDLER, D. Hydrogen-bond kinetics in liquid water. Nature, Nature Publishing Group, v. 379, n. 6560, p. 55-57, 1996.

161 ZWANZIG, R. W. High-temperature equation of state by a perturbation method. i. nonpolar gases. The Journal of Chemical Physics, American Institute of Physics, v. 22, n. 8, p. 1420-1426, 1954.

162 KIRKWOOD, J. G. Statistical mechanics of fluid mixtures. The Journal of chemical physics, American Institute of Physics, v. 3, n. 5, p. 300-313, 1935.

163 BENNETT, C. H. Efficient estimation of free energy differences from monte carlo data. Journal of Computational Physics, Elsevier, v. 22, n. 2, p. 245-268, 1976.

164 STEINBRECHER, T.; JOUNG, I.; CASE, D. A. Soft-core potentials in thermodynamic integration: Comparing one-and two-step transformations. Journal of computational chemistry, Wiley Online Library, v. 32, n. 15, p. 3253-3263, 2011.

165 PHAM, T. T.; SHIRTS, M. R. Identifying low variance pathways for free energy calculations of molecular transformations in solution phase. The Journal of chemical physics, American Institute of Physics, v. 135, n. 3, p. 034114, 2011.

166 KOFKE, D. A.; CUMMINGS, P. T. Quantitative comparison and optimization of methods for evaluating the chemical potential by molecular simulation. Molecular Physics, Taylor \& Francis, v. 92, n. 6, p. 973-996, 1997.

167 LU, N.; SINGH, J. K.; KOFKE, D. A. Appropriate methods to combine forward and reverse free-energy perturbation averages. The Journal of Chemical Physics, American Institute of Physics, v. 118, n. 7, p. 2977-2984, 2003.

168 LU, N.; KOFKE, D. A.; WOOLF, T. B. Improving the efficiency and reliability of free energy perturbation calculations using overlap sampling methods. Journal of computational chemistry, Wiley Online Library, v. 25, n. 1, p. 28-40, 2004.

169 CUNHA, A. R. da; DUARTE, E. L.; LAMY, M. T.; COUTINHO, K. Protonation/deprotonation process of emodin in aqueous solution and pka determination: Uv/visible spectrophotometric titration and quantum/molecular mechanics calculations. Chemical Physics, Elsevier, v. 440, p. 69-79, 2014.

170 TISSANDIER, M. D.; COWEN, K. A.; FENG, W. Y.; GUNDLACH, E.; COHEN, M. H.; EARHART, A. D.; COE, J. V.; TUTTLE, T. R. The proton's absolute aqueous enthalpy and gibbs free energy of solvation from cluster-ion solvation data. The Journal of Physical Chemistry A, ACS Publications, v. 102, n. 40, p. 7787-7794, 1998.

171 TAVERNELLI, I.; VUILLEUMIER, R.; SPRIK, M. Ab initio molecular dynamics for molecules with variable numbers of electrons. Physical review letters, APS, v. 88, n. 21, p. 213002, 2002. 
172 LI, J.; FISHER, C. L.; CHEN, J. L.; BASHFORD, D.; NOODLEMAN, L. Calculation of redox potentials and $\mathrm{p} \mathrm{k}$ a values of hydrated transition metal cations by a combined density functional and continuum dielectric theory. Inorganic Chemistry, ACS Publications, v. 35, n. 16, p. 4694-4702, 1996.

173 PATTERSON, E. V.; CRAMER, C. J.; TRUHLAR, D. G. Reductive dechlorination of hexachloroethane in the environment: mechanistic studies via computational electrochemistry. Journal of the American Chemical Society, ACS Publications, v. 123, n. 9, p. 2025-2031, 2001.

174 WINGET, P.; WEBER, E. J.; CRAMER, C. J.; TRUHLAR, D. G. Computational electrochemistry: aqueous one-electron oxidation potentials for substituted anilines. Physical Chemistry Chemical Physics, Royal Society of Chemistry, v. 2, n. 6, p. 1231-1239, 2000.

175 SAWYER, D. T.; SOBKOWIAK, A.; ROBERTS, J. L. Electrochemistry for chemists. [S.I.]: Wiley, 1995.

176 MANZONI, V.; LYRA, M. L.; GESTER, R. M.; COUTINHO, K.; CANUTO, S. Study of the optical and magnetic properties of pyrimidine in water combining $\mathrm{pcm}$ and $\mathrm{qm} / \mathrm{mm}$ methodologies. Physical Chemistry Chemical Physics, Royal Society of Chemistry, v. 12, n. 42, p. 14023-14033, 2010.

177 GESTER, R. M.; GEORG, H. C.; CANUTO, S.; CAPUTO, M. C.; PROVASI, P. F. $\mathrm{Nmr}$ chemical shielding and spin- spin coupling constants of liquid nh3: A systematic investigation using the sequential $\mathrm{qm} / \mathrm{mm}$ method. The Journal of Physical Chemistry A, ACS Publications, v. 113, n. 52, p. 14936-14942, 2009.

178 BISTAFA, C.; CANUTO, S. Solvent effects on the two lowest-lying singlet excited states of 5-fluorouracil. Theoretical Chemistry Accounts, Springer, v. 132, n. 1, p. 1299, 2013.

179 JR, T. H. D. Gaussian basis sets for use in correlated molecular calculations. i. the atoms boron through neon and hydrogen. The Journal of chemical physics, American Institute of Physics, v. 90, n. 2, p. 1007-1023, 1989.

180 ALLEN, M. P.; TILDESLEY, D. J. Computer simulation of liquids. [S.I.]: Oxford university press, 2017.

181 ESSMANN, U.; PERERA, L.; BERKOWITZ, M. L.; DARDEN, T.; LEE, H.; PEDERSEN, L. G. A smooth particle mesh ewald method. The Journal of chemical physics, AIP, v. 103, n. 19, p. 8577-8593, 1995.

182 FRENKEL, D.; SMIT, B. Understanding molecular simulation academic press. San Diego, p. 27-33, 1996.

183 GOWERS, R. J.; CARBONE, P. A multiscale approach to model hydrogen bonding: The case of polyamide. The Journal of Chemical Physics, AIP Publishing LLC, v. 142, n. 22, p. 224907, 2015.

184 LUZAR, A. Resolving the hydrogen bond dynamics conundrum. The Journal of Chemical Physics, American Institute of Physics, v. 113, n. 23, p. 10663-10675, 2000.

185 BERTHELOT, D. Sur le mélange des gaz. Compt. Rendus, v. 126, p. 1703-1706, 1898. 
186 GOOD, R. J.; HOPE, C. J. New combining rule for intermolecular distances in intermolecular potential functions. The Journal of Chemical Physics, AIP, v. 53, n. 2, p. 540-543, 1970.

187 JORGENSEN, W. L.; MAXWELL, D. S.; TIRADO-RIVES, J. Development and testing of the opls all-atom force field on conformational energetics and properties of organic liquids. Journal of the American Chemical Society, v. 118, n. 45, p. 11225-11236, 1996.

188 JORGENSEN, W. L.; CHANDRASEKHAR, J.; MADURA, J. D.; IMPEY, R. W.; KLEIN, M. L. Comparison of simple potential functions for simulating liquid water. The Journal of chemical physics, AIP, v. 79, n. 2, p. 926-935, 1983.

189 BRENEMAN, C. M.; WIBERG, K. B. Determining atom-centered monopoles from molecular electrostatic potentials. the need for high sampling density in formamide conformational analysis. Journal of Computational Chemistry, Wiley Online Library, v. 11, n. 3, p. 361-373, 1990.

190 SEBESTA, F.; SLMA, V.; MELCR, J.; FUTERA, Z.; BURDA, J. V. Estimation of transition-metal empirical parameters for molecular mechanical force fields. Journal of chemical theory and computation, ACS Publications, v. 12, n. 8, p. 3681-3688, 2016.

191 SIMON, S.; DURAN, M.; DANNENBERG, J. How does basis set superposition error change the potential surfaces for hydrogen-bonded dimers? The Journal of chemical physics, AIP, v. 105, n. 24, p. 11024-11031, 1996.

192 GARBEROGLIO, G. Obgmx: A web-based generator of gromacs topologies for molecular and periodic systems using the universal force field. Journal of computational chemistry, Wiley Online Library, v. 33, n. 27, p. 2204-2208, 2012.

193 ZWANZIG, R. W. High-temperature equation of state by a perturbation method. i. nonpolar gases. The Journal of Chemical Physics, AIP, v. 22, n. 8, p. 1420-1426, 1954.

194 JORGENSEN, W. L.; BUCKNER, J. K.; BOUDON, S.; TIRADO-RIVES, J. Efficient computation of absolute free energies of binding by computer simulations. application to the methane dimer in water. The Journal of chemical physics, AIP, v. 89, n. 6, p. 3742-3746, 1988.

195 GUEDES, R.; COUTINHO, K.; CABRAL, B. C.; CANUTO, S. Differential hydration of phenol and phenoxy radical and the energetics of the phenol o- $h$ bond in solution. The Journal of Physical Chemistry B, ACS Publications, v. 107, n. 18, p. 4304-4310, 2003.

196 CIEPLAK, P.; KOLLMAN, P. A. Calculation of the free energy of association of nucleic acid bases in vacuo and water solution. Journal of the American Chemical Society, ACS Publications, v. 110, n. 12, p. 3734-3739, 1988.

197 GUNSTEREN, W. F. V.; BERENDSEN, H. J. A leap-frog algorithm for stochastic dynamics. Molecular Simulation, Taylor \& Francis, v. 1, n. 3, p. 173-185, 1988.

198 SMITH, D. E.; DANG, L. X. Computer simulations of nacl association in polarizable water. The Journal of Chemical Physics, American Institute of Physics, v. 100, n. 5, p. 3757-3766, 1994. 
199 ZHAO, Y.; SCHULTZ, N. E.; TRUHLAR, D. G. Design of density functionals by combining the method of constraint satisfaction with parametrization for thermochemistry, thermochemical kinetics, and noncovalent interactions. Journal of Chemical Theory and Computation, ACS Publications, v. 2, n. 2, p. 364-382, 2006.

200 DITCHFIELD, R.; HEHRE, W. J.; POPLE, J. A. Self-consistent molecular-orbital methods. ix. an extended gaussian-type basis for molecular-orbital studies of organic molecules. The Journal of Chemical Physics, American Institute of Physics, v. 54, n. 2, p. 724-728, 1971.

201 BARONE, V.; COSSI, M.; TOMASI, J. A new definition of cavities for the computation of solvation free energies by the polarizable continuum model. The Journal of chemical physics, AIP, v. 107, n. 8, p. 3210-3221, 1997.

202 BECKE, A. D. A new mixing of hartree-fock and local density-functional theories. The Journal of chemical physics, American Institute of Physics, v. 98, n. 2, p. 1372-1377, 1993.

203 DELLEY, B. From molecules to solids with the dmol 3 approach. The Journal of chemical physics, American Institute of Physics, v. 113, n. 18, p. 7756-7764, 2000.

204 ADAMO, C.; BARONE, V. Toward reliable density functional methods without adjustable parameters: The pbe 0 model. The Journal of chemical physics, AIP, v. $110, n .13$, p. 6158-6170, 1999.

205 BAUERNSCHMITT, R.; AHLRICHS, R. Treatment of electronic excitations within the adiabatic approximation of time dependent density functional theory. Chemical Physics Letters, North-Holland, v. 256, n. 4-5, p. 454-464, 1996.

206 FORESMAN, J. B.; HEAD-GORDON, M.; POPLE, J. A.; FRISCH, M. J. Toward a systematic molecular orbital theory for excited states. The Journal of Physical Chemistry, ACS Publications, v. 96, n. 1, p. 135-149, 1992.

207 DOUGLAS, M.; KROLL, N. M. Quantum electrodynamical corrections to the fine structure of helium. Annals of Physics, Academic Press, v. 82, n. 1, p. 89-155, 1974.

208 HESS, B. A. Applicability of the no-pair equation with free-particle projection operators to atomic and molecular structure calculations. Physical Review A, APS, v. 32, n. 2, p. 756, 1985.

209 KENDALL, R. A.; JR, T. H. D.; HARRISON, R. J. Electron affinities of the first-row atoms revisited. systematic basis sets and wave functions. The Journal of chemical physics, American Institute of Physics, v. 96, n. 9, p. 6796-6806, 1992.

210 WOON, D. E.; JR, T. H. D. Gaussian basis sets for use in correlated molecular calculations. iii. the atoms aluminum through argon. The Journal of chemical physics, American Institute of Physics, v. 98, n. 2, p. 1358-1371, 1993.

211 HAY, P. J.; WADT, W. R. Ab initio effective core potentials for molecular calculations. potentials for the transition metal atoms sc to hg. The Journal of chemical physics, American Institute of Physics, v. 82, n. 1, p. 270-283, 1985. 
212 WEIGEND, F.; AHLRICHS, R. Balanced basis sets of split valence, triple zeta valence and quadruple zeta valence quality for $h$ to $\mathrm{rn}$ : Design and assessment of accuracy. Physical Chemistry Chemical Physics, The Royal Society of Chemistry, v. 7, n. 18, p. 3297-3305, 2005.

213 NORO, T.; SEKIYA, M.; KOGA, T. Segmented contracted basis sets for atoms $h$ through xe: Sapporo-(dk)-nzp sets $(n=d, t, q)$. Theoretical Chemistry Accounts, Springer, v. 131, n. 2, p. 1124, 2012.

214 JORGE, F.; NETO, A. C.; CAMILETTI, G.; MACHADO, S. Contracted gaussian basis sets for douglas-kroll-hess calculations: estimating scalar relativistic effects of some atomic and molecular properties. The Journal of chemical physics, American Institute of Physics, v. 130, n. 6 , p. $064108,2009$.

215 ROOS, B. O.; LINDH, R.; MALMQVIST, P.-Å.; VERYAZOV, V.; WIDMARK, P.-O. New relativistic ano basis sets for transition metal atoms. The Journal of Physical Chemistry A, ACS Publications, v. 109, n. 29, p. 6575-6579, 2005.

216 PERDEW, J. P.; BURKE, K.; ERNZERHOF, M. Generalized gradient approximation made simple. Physical review letters, APS, v. 77, n. 18, p. 3865, 1996.

217 BLÖCHL, P. E. Projector augmented-wave method. Physical review B, APS, v. 50, n. 24, p. $17953,1994$.

218 KRESSE, G.; FURTHMÜLLER, J. Efficient iterative schemes for ab initio total-energy calculations using a plane-wave basis set. Physical review B, APS, v. 54, n. 16, p. 11169, 1996.

219 FRISCH, M. J.; HEAD-GORDON, M.; POPLE, J. A. A direct mp2 gradient method. Chemical Physics Letters, Elsevier, v. 166, n. 3, p. 275-280, 1990.

220 HEAD-GORDON, M.; POPLE, J. A.; FRISCH, M. J. Mp2 energy evaluation by direct methods. Chemical physics letters, Elsevier, v. 153, n. 6, p. 503-506, 1988.

221 KRISHNAN, R.; POPLE, J. A. Approximate fourth-order perturbation theory of the electron correlation energy. International Journal of Quantum Chemistry, Wiley Online Library, v. 14, n. 1, p. 91-100, 1978.

222 III, G. D. P.; BARTLETT, R. J. A full coupled-cluster singles and doubles model: The inclusion of disconnected triples. The Journal of Chemical Physics, American Institute of Physics, v. 76, n. 4, p. 1910-1918, 1982.

223 PETERSON, K. A.; WOON, D. E.; JR, T. H. D. Benchmark calculations with correlated molecular wave functions. iv. the classical barrier height of the $h+h 2 \rightarrow h 2+h$ reaction. The Journal of chemical physics, American Institute of Physics, v. 100, n. 10, p. 7410-7415, 1994.

224 BARTMESS, J. E.; SCOTT, J. A.; JR, R. T. M. Substituent and solvation effects on gas-phase acidities. Journal of the American Chemical Society, ACS Publications, v. 101, n. 20, p. 6056-6063, 1979.

225 LINSTORM, P. Nist chemistry webbook, nist standard reference database number 69 . J.

Phys. Chem. Ref. Data, Monograph, v. 9, p. 1-1951, 1998. 
226 TISSANDIER, M. D.; COWEN, K. A.; FENG, W. Y.; GUNDLACH, E.; COHEN, M. H.; EARHART, A. D.; COE, J. V.; TUTTLE, T. R. The proton's absolute aqueous enthalpy and gibbs free energy of solvation from cluster-ion solvation data. The Journal of Physical Chemistry A, ACS Publications, v. 102, n. 40, p. 7787-7794, 1998.

227 KOBER, E. M.; MEYER, T. J. Concerning the absorption spectra of the ions $m$ (bpy) $32+\left(\mathrm{m}=\mathrm{fe}, \mathrm{ru}, \mathrm{os} ; \mathrm{bpy}=2,2^{\prime}\right.$-bipyridine $)$. Inorganic Chemistry, ACS Publications, v. 21, n. 11, p. 3967-3977, 1982.

228 HAGER, G.; CROSBY, G. Charge-transfer exited states of ruthenium (ii) complexes. i. quantum yield and decay measurements. Journal of the American Chemical Society, ACS Publications, v. 97, n. 24, p. 7031-7037, 1975.

229 FELIX, F.; FERGUSON, J.; GUEDEL, H. U.; LUDI, A. The electronic spectrum of tris (2, 2'-bipyridine) ruthenium (2+). Journal of the American Chemical Society, ACS Publications, v. 102, n. 12, p. 4096-4102, 1980.

230 GALLHUBER, E.; HENSLER, G.; YERSIN, H. Magnetic-field effects in the lowtemperature polarized emission and absorption spectra of single-crystal tris (2, 2'-bipyridine) ruthenium $(2+)$ bis (hexafluorophosphate)([ru (bpy) 3](pf6) 2). Journal of the American Chemical Society, ACS Publications, v. 109, n. 16, p. 4818-4822, 1987.

231 HARROWFIELD, J. M.; SOBOLEV, A. N. The crystal structure of tris (2, 2'-bipyridine) ruthenium (ii) perchlorate. Australian Journal of Chemistry, CSIRO, v. 47, n. 4, p. 763-767, 1994.

232 MATIAS, T. A.; REIN, F. N.; ROCHA, R. C.; FORMIGA, A. L. B.; TOMA, H. E.; ARAKI, K. Effects of a strong $\pi$-accepting ancillary ligand on the water oxidation activity of weakly coupled binuclear ruthenium catalysts. Dalton Transactions, Royal Society of Chemistry, v. 48, n. 9, p. 3009-3017, 2019.

233 ALLINGER, N. L.; ZHOU, X.; BERGSMA, J. Molecular mechanics parameters. Journal of Molecular Structure: THEOCHEM, Elsevier, v. 312, n. 1, p. 69-83, 1994.

234 ADLHART, C.; CHEN, P. Ligand rotation distinguishes first-and second-generation ruthenium metathesis catalysts. Angewandte Chemie International Edition, Wiley Online Library, v. 41, n. 23, p. 4484-4487, 2002.

235 RAPPÉ, A. K.; CASEWIT, C. J.; COLWELL, K.; III, W. A. G.; SKIFF, W. M. Uff, a full periodic table force field for molecular mechanics and molecular dynamics simulations. Journal of the American chemical society, ACS Publications, v. 114, n. 25, p. 10024-10035, 1992.

236 CLARK, M.; III, R. D. C.; OPDENBOSCH, N. V. Validation of the general purpose tripos 5.2 force field. Journal of Computational Chemistry, Wiley Online Library, v. 10, n. 8, p. 982-1012, 1989.

237 HOBZA, P.; ZAHRADNIK, R. Intermolecular complexes. [S.I.]: Elsevier, Amsterdam, 1988.

238 CANUTO, S.; COUTINHO, K.; TRZESNIAK, D. New developments in monte carlo/quantum mechanics methodology. the solvatochromism of $\beta$-carotene in different solvents. Elsevier, 2002. 
239 GEORG, H. C.; COUTINHO, K.; CANUTO, S. Solvent effects on the uv-visible absorption spectrum of benzophenone in water: A combined monte carlo quantum mechanics study including solute polarization. The Journal of chemical physics, American Institute of Physics, v. 126, n. 3, p. 034507, 2007.

240 ANTIPOVA, M.; PETRENKO, V. Hydrogen bond lifetime for water in classic and quantum molecular dynamics. Russian Journal of Physical Chemistry A, Springer, v. 87, n. 7, p. 1170-1174, 2013.

241 BERENDSEN, H.; POSTMA, J.; GUNSTEREN, W. V.; HERMANS, a. J. Intermolecular forces. [S.I.]: Reidel, Dordrecht Jerusalem, Israel, 1981.

242 JORGENSEN, W. L.; CHANDRASEKHAR, J.; MADURA, J. D.; IMPEY, R. W.; KLEIN, M. L. Comparison of simple potential functions for simulating liquid water. The Journal of chemical physics, AIP, v. 79, n. 2, p. 926-935, 1983.

243 CUSSLER, E. L.; CUSSLER, E. L. Diffusion: mass transfer in fluid systems. [S.I.]: Cambridge university press, 2009.

244 EASTEAL, A. J.; PRICE, W. E.; WOOLF, L. A. Diaphragm cell for high-temperature diffusion measurements. tracer diffusion coefficients for water to $363 \mathrm{k}$. Journal of the

Chemical Society, Faraday Transactions 1: Physical Chemistry in Condensed Phases, Royal Society of Chemistry, v. 85, n. 5, p. 1091-1097, 1989.

245 PARR, R. G.; PEARSON, R. G. Absolute hardness: companion parameter to absolute electronegativity. Journal of the American Chemical Society, ACS Publications, v. 105, n. 26, p. 7512-7516, 1983.

246 PARR, R. G. W. Yang Density-functional theory of atoms and molecules. [S.I.]: Oxford University Press, New York, 1989.

247 PEARSON, R. G. Chemical hardness. [S.I.]: Wiley Online Library, 1997.

248 PEARSON, R. G. Recent advances in the concept of hard and soft acids and bases. Journal of Chemical Education, ACS Publications, v. 64, n. 7, p. 561, 1987.

249 DATTA, D. "hardness profile"of a reaction path. The Journal of Physical Chemistry, ACS Publications, v. 96, n. 6, p. 2409-2410, 1992.

250 GUTIERREZ-OLIVA, S.; LETELIER, J. R.; TORO-LABBE, A. Energy, chemical potential and hardness profiles for the rotational isomerization of hooh, hsoh and hssh. Molecular Physics, Taylor \& Francis, v. 96, n. 1, p. 61-70, 1999.

251 SEDDON, E. A.; SEDDON, K. R. The chemistry of ruthenium. [S.I.]: Elsevier, 2013.

252 PLASSER, F. Theodore: A toolbox for a detailed and automated analysis of electronic excited state computations. The Journal of Chemical Physics, AIP Publishing LLC, v. 152, n. 8, p. 084108, 2020.

253 SEIDEL, R.; POHL, M. N.; ALI, H.; WINTER, B.; AZIZ, E. F. Advances in liquid phase soft-x-ray photoemission spectroscopy: A new experimental setup at bessy ii. Review of Scientific Instruments, AIP Publishing LLC, v. 88, n. 7, p. 073107, 2017. 
254 OGLeTREE, D. F.; BLUHM, H.; HEBENSTREIT, E. D.; SALMERON, M. Photoelectron spectroscopy under ambient pressure and temperature conditions. Nuclear Instruments and Methods in Physics Research Section A: Accelerators, Spectrometers, Detectors and Associated Equipment, Elsevier, v. 601, n. 1-2, p. 151-160, 2009.

255 KNUDSEN, J.; ANDERSEN, J. N.; SCHNADT, J. A versatile instrument for ambient pressure $\mathrm{x}$-ray photoelectron spectroscopy: The lund cell approach. Surface Science, Elsevier, v. 646, p. $160-169,2016$.

256 MOYER, B. A.; MEYER, T. J. Properties of the oxo/aqua system (bpy) 2 (py) ruo2 $+/$ (bpy) 2 (py) ru (oh2) $2+$. Inorganic Chemistry, ACS Publications, v. 20, n. 2, p. 436-444, 1981.

257 FAULKNER, L. R.; BARD, A. J. Electrochemical methods: fundamentals and applications. [S.I.]: John Wiley and Sons, 2002. 
Apêndices 



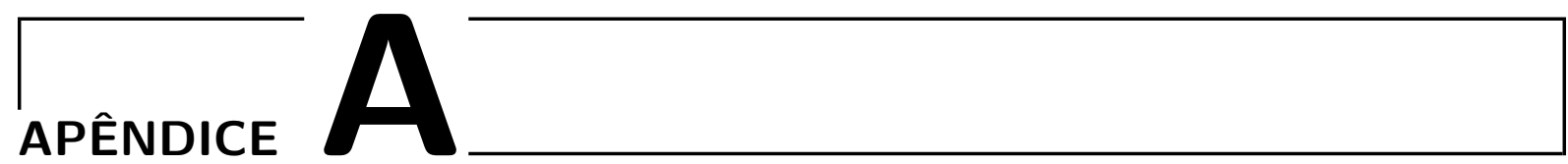

Excitações eletrônicas dos complexos de $R u$-Aqua/Oxo em solução aquosa. 
Tabela A.1 - Comprimento de onda $\lambda(\mathrm{em} \mathrm{nm})$ e intensidade $I\left(\times 10^{-3}\right)$ das 50 primeiras excitações eletrônicas dos complexos de $R u$-Aqua/Oxo na oxidação $I I$, calculadas com o método TD-DFT, utilizando B3LYP/(aug)-cc-pVDZ(PP). Interações soluto-solvente tratadas com os métodos $\mathrm{PCM}, \mathrm{CP}$ e $\mathrm{CP}+\mathrm{HB}$. Os dois últimos, dentro do escopo do método QM/MM sequencial, e utilizando configurações do solvente geradas a partir das simulações MC.

\begin{tabular}{|c|c|c|c|c|c|c|c|c|}
\hline \multirow[b]{3}{*}{ Estados } & \multicolumn{6}{|c|}{$R u^{I I}\left(H_{2} \mathrm{O}\right)$} & \multirow{2}{*}{\multicolumn{2}{|c|}{$\mathrm{HB}+\mathrm{PC}$}} \\
\hline & \multicolumn{2}{|c|}{ VAC } & \multicolumn{2}{|c|}{ PCM } & \multicolumn{2}{|c|}{ PC } & & \\
\hline & $\lambda(n m)$ & $I$ & $\lambda(n m)$ & $I$ & $\lambda(n m)$ & $I$ & $\lambda(n m)$ & $I$ \\
\hline 1 & 485.7 & 4 & 494.2 & 7 & 512.3 & 4 & 537.5 & 6 \\
\hline 2 & 471.1 & 2 & 489.9 & 1 & 493.0 & 2 & 516.4 & 4 \\
\hline 3 & 468.3 & 1 & 474.4 & 1 & 476.5 & 5 & 496.0 & 5 \\
\hline 4 & 448.0 & 2 & 467.2 & 1 & 456.2 & 19 & 74.8 & 20 \\
\hline 5 & 433.4 & 103 & 446.8 & 134 & 442.3 & 73 & 460.1 & 57 \\
\hline 6 & 416.2 & 25 & 426.1 & 40 & 421.3 & 31 & 435.9 & 38 \\
\hline 7 & 381.3 & 1 & 379.2 & 3 & 390.2 & 7 & 401.7 & 8 \\
\hline 8 & 370.2 & 4 & 367.0 & 3 & 376.5 & 5 & 388.2 & 7 \\
\hline 9 & 359.8 & 4 & 366.2 & 7 & 368.2 & 4 & 77.3 & 6 \\
\hline 10 & 350.3 & 2 & 362.1 & 0 & 362.0 & 4 & 70.9 & 7 \\
\hline 11 & 347.2 & 1 & 354.4 & 6 & 356.5 & 4 & 364.7 & 11 \\
\hline 12 & 342.0 & 10 & 350.6 & 6 & 351.5 & 9 & 358.7 & 13 \\
\hline 13 & 340.1 & 7 & 348.2 & 24 & 346.6 & 10 & 53.8 & 23 \\
\hline 14 & 334.5 & 12 & 341.5 & 9 & 342.4 & 29 & 349.3 & 28 \\
\hline 15 & 333.4 & 14 & 339.7 & 85 & 338.8 & 35 & 345.3 & 26 \\
\hline 16 & 327.8 & 7 & 333.8 & 4 & 335.1 & 21 & 41.8 & 17 \\
\hline 17 & 327.1 & 38 & 331.4 & 12 & 332.2 & 26 & 338.2 & 20 \\
\hline 18 & 326.2 & 4 & 329.9 & 17 & 329.9 & 17 & 35.1 & 21 \\
\hline 19 & 323.2 & 24 & 329.2 & 88 & 327.1 & 16 & 332.2 & 24 \\
\hline 20 & 319.5 & 59 & 326.4 & 21 & 324.6 & 16 & 329.2 & 16 \\
\hline 21 & 317.5 & 30 & 325.1 & 31 & 321.7 & 21 & 25.7 & 17 \\
\hline 22 & 316.7 & 23 & 323.0 & 10 & 319.0 & 25 & 21.0 & 11 \\
\hline 23 & 313.7 & 5 & 319.6 & 7 & 315.6 & 14 & 16.2 & 13 \\
\hline 24 & 3. & 10 & 316.2 & 5 & 1.0 & 7 & 0.8 & 13 \\
\hline 25 & 298.8 & 5 & 303.6 & 6 & 304.8 & 4 & 06.2 & 4 \\
\hline 26 & 297.2 & 0 & 296.7 & 2 & 300.5 & 4 & 01.7 & 4 \\
\hline 27 & 289.4 & 8 & 294.6 & 23 & 94.9 & 4 & .0 & 4 \\
\hline 28 & 287.8 & 6 & 293.8 & 5 & 291.9 & 6 & 93.9 & 3 \\
\hline 29 & 285.1 & 4 & 292.2 & 1 & 289.2 & 23 & 90.2 & 12 \\
\hline 30 & 283.7 & 48 & 288.1 & 189 & 286.2 & 52 & 86.0 & 52 \\
\hline 31 & 282.0 & 174 & 286.2 & 4 & 283.7 & 106 & 283.6 & 80 \\
\hline 32 & 278.1 & 363 & 285.6 & 162 & 280.7 & 176 & 281.3 & 165 \\
\hline 33 & 276.7 & 59 & 283.4 & 727 & 278.7 & 253 & 279.3 & 255 \\
\hline 34 & 274.8 & 166 & 278.9 & 5 & 276.6 & 207 & 276.8 & 180 \\
\hline 35 & 269.7 & 2 & 266.3 & 1 & 267.7 & 7 & 270.8 & 33 \\
\hline 36 & 267.1 & 1 & 260.7 & 1 & 53.3 & 7 & 65.6 & 7 \\
\hline 37 & 265.2 & 2 & 255.0 & 2 & 257.4 & 9 & 261.5 & 6 \\
\hline 38 & 259.6 & 2 & 253.1 & 26 & 254.9 & 17 & 58.8 & 10 \\
\hline 39 & 2 & 5 & 251.4 & 45 & 52.7 & 13 & 56.4 & 10 \\
\hline 40 & 252.2 & 30 & 250.0 & 2 & 251.0 & 17 & 254.4 & 13 \\
\hline 41 & 250.4 & 49 & 248.7 & 1 & 249.4 & 10 & 252.7 & 13 \\
\hline 42 & 245.6 & 3 & 247.9 & 2 & 248.0 & 9 & 251.2 & 12 \\
\hline 43 & 244.5 & 2 & 247.5 & 5 & 246.6 & 9 & 249.7 & 17 \\
\hline 44 & 242.3 & 2 & 245.6 & 5 & 244.9 & 11 & 248.3 & 12 \\
\hline 45 & 241.2 & 3 & 244.1 & 7 & 243.7 & 14 & 247.1 & 12 \\
\hline 46 & 240.7 & 8 & 243.6 & 20 & 242.5 & 12 & 245.8 & 10 \\
\hline 47 & 239.3 & 28 & 242.4 & 3 & 241.4 & 10 & 244.8 & 12 \\
\hline 48 & 237.8 & 13 & 240.9 & 2 & 240.3 & 12 & 243.4 & 10 \\
\hline 49 & 236.9 & 6 & 240.5 & 31 & 239.2 & 11 & 242.2 & 12 \\
\hline 50 & 236.5 & 11 & 238.4 & 19 & 238.1 & 12 & 241.3 & 8 \\
\hline
\end{tabular}

\begin{tabular}{|c|c|c|c|c|c|c|c|c|}
\hline \multirow[b]{3}{*}{ Estados } & \multicolumn{6}{|c|}{$R u^{I I}(O H)$} & \multirow{2}{*}{\multicolumn{2}{|c|}{$\mathrm{HB}+\mathrm{PC}$}} \\
\hline & \multicolumn{2}{|c|}{ VAC } & \multicolumn{2}{|c|}{ PCM } & \multicolumn{2}{|c|}{ PC } & & \\
\hline & $\lambda(n m)$ & $I$ & $\lambda(n m)$ & $I$ & $\lambda(n m)$ & $I$ & $\lambda(n m)$ & I \\
\hline 1 & 808.2 & 5 & 745.6 & 4 & 621.9 & 3 & 647.5 & 13 \\
\hline 2 & 738.3 & 21 & 697.8 & 25 & 576.7 & 7 & 605.4 & 10 \\
\hline 3 & 581.9 & 2 & 564.4 & 2 & 536.0 & 1 & 545.0 & 0 \\
\hline 4 & 536.0 & 10 & 526.9 & 15 & 506.2 & 8 & 509.1 & 16 \\
\hline 5 & 530.9 & 14 & 514.7 & 93 & 487.7 & 74 & 497.5 & 63 \\
\hline 6 & 523.9 & 53 & 499.6 & 16 & 457.3 & 28 & 469.9 & 22 \\
\hline 7 & 496.0 & 14 & 485.4 & 10 & 435.5 & 15 & 455.7 & 14 \\
\hline 8 & 489.1 & 1 & 481.6 & 19 & 416.4 & 12 & 438.4 & 9 \\
\hline 9 & 475.6 & 26 & 453.5 & 9 & 397.6 & 13 & 413.0 & 7 \\
\hline 10 & 446.6 & 43 & 430.1 & 61 & 392.1 & 9 & 402.1 & 6 \\
\hline 11 & 429.0 & 52 & 416.1 & 60 & 385.8 & 14 & 393.9 & 29 \\
\hline 12 & 418.2 & 35 & 406.2 & 54 & 379.0 & 20 & 387.3 & 33 \\
\hline 13 & 395.3 & 2 & 398.1 & 2 & 374.5 & 29 & 380.6 & 36 \\
\hline 14 & 393.3 & 9 & 387.1 & 13 & 370.4 & 24 & 375.3 & 44 \\
\hline 15 & 382.6 & 9 & 378.1 & 4 & 366.0 & 23 & 365.7 & 41 \\
\hline 16 & 377.6 & 57 & 373.8 & 92 & 360.2 & 24 & 360.6 & 25 \\
\hline 17 & 375.6 & 29 & 370.2 & 43 & 355.9 & 27 & 356.3 & 16 \\
\hline 18 & 370.8 & 3 & 366.8 & 21 & 350.7 & 17 & 353.7 & 14 \\
\hline 19 & 367.1 & 22 & 362.7 & 20 & 346.5 & 17 & 351.1 & 19 \\
\hline 20 & 359.7 & 0 & 358.2 & 10 & 342.7 & 16 & 347.4 & 15 \\
\hline 21 & 358.2 & 5 & 355.0 & 3 & 336.7 & 22 & 342.8 & 15 \\
\hline 22 & 345.7 & 52 & 346.3 & 42 & 331.7 & 19 & 336.4 & 13 \\
\hline 23 & 335.4 & 38 & 334.4 & 20 & 327.2 & 13 & 328.0 & 10 \\
\hline 24 & 334.9 & 1 & 333.5 & 14 & 319.2 & 5 & 324.8 & 10 \\
\hline 25 & 327.9 & 5 & 320.7 & 4 & 315.1 & 9 & 316.5 & 3 \\
\hline 26 & 318.8 & 3 & 314.3 & 1 & 307.8 & 6 & 310.7 & 2 \\
\hline 27 & 314.9 & 5 & 310.1 & 3 & 304.5 & 4 & 306.9 & 3 \\
\hline 28 & 314.0 & 7 & 309.5 & 3 & 300.8 & 3 & 300.4 & 2 \\
\hline 29 & 309.2 & 7 & 303.1 & 23 & 296.9 & 3 & 295.8 & 2 \\
\hline 30 & 306.0 & 3 & 300.6 & 14 & 293.7 & 4 & 291.2 & 6 \\
\hline 31 & 304.9 & 6 & 297.2 & 1 & 287.9 & 56 & 287.8 & 19 \\
\hline 32 & 304.5 & 3 & 295.9 & 11 & 283.3 & 116 & 285.0 & 28 \\
\hline 33 & 300.2 & 15 & 294.3 & 4 & 281.2 & 165 & 283.3 & 92 \\
\hline 34 & 297.2 & 2 & 291.2 & 24 & 279.7 & 197 & 281.6 & 143 \\
\hline 35 & 294.4 & 1 & 289.8 & 1 & 277.0 & 99 & 279.7 & 201 \\
\hline 36 & 290.4 & 10 & 286.6 & 73 & 274.4 & 62 & 277.7 & 113 \\
\hline 37 & 289.2 & 1 & 285.1 & 65 & 272.0 & 46 & 276.0 & 113 \\
\hline 38 & 286.6 & 19 & 284.6 & 32 & 269.2 & 23 & 273.0 & 39 \\
\hline 39 & 283.4 & 2 & 283.6 & 91 & 266.8 & 6 & 270.2 & 16 \\
\hline 40 & 281.6 & 185 & 282.7 & 416 & 264.3 & 6 & 267.5 & 6 \\
\hline 41 & 279.1 & 290 & 282.5 & 249 & 262.1 & 5 & 265.4 & 4 \\
\hline 42 & 276.2 & 6 & 276.9 & 14 & 260.1 & 6 & 263.5 & 4 \\
\hline 43 & 273.9 & 4 & 274.2 & 3 & 258.8 & 7 & 261.6 & 4 \\
\hline 44 & 270.4 & 1 & 272.4 & 1 & 257.5 & 10 & 260.0 & 5 \\
\hline 45 & 269.7 & 1 & 270.3 & 6 & 256.3 & 9 & 258.7 & 3 \\
\hline 46 & 268.8 & 190 & 268.6 & 3 & 255.1 & 8 & 257.4 & 5 \\
\hline 47 & 266.4 & 16 & 263.4 & 4 & 253.8 & 6 & 256.5 & 5 \\
\hline 48 & 265.5 & 31 & 263.4 & 0 & 252.4 & 11 & 255.1 & 5 \\
\hline 49 & 264.5 & 6 & 259.7 & 3 & 251.1 & 13 & 253.8 & 8 \\
\hline 50 & 262.1 & 5 & 258.6 & 1 & 250.0 & 13 & 252.4 & 13 \\
\hline
\end{tabular}


Tabela A.2 - Comprimento de onda $\lambda(\mathrm{em} \mathrm{nm})$ e intensidade $I\left(\times 10^{-3}\right)$ das 50 primeiras excitações eletrônicas dos complexos de $R u$-Aqua/Oxo na oxidação $I I I$, calculadas com o método TD-DFT, utilizando B3LYP/(aug)-cc-pVDZ(PP). Interações soluto-solvente tratadas com os métodos $\mathrm{PCM}, \mathrm{CP}$ e $\mathrm{CP}+\mathrm{HB}$. Os dois últimos, dentro do escopo do método QM/MM sequencial, e utilizando configurações do solvente geradas a partir das simulações MC.

\begin{tabular}{|c|c|c|c|c|c|c|c|c|c|c|c|c|c|c|c|c|c|}
\hline \multirow[b]{3}{*}{ Estados } & \multicolumn{8}{|c|}{$R u^{I I I}\left(\mathrm{H}_{2} \mathrm{O}\right)$} & \multicolumn{9}{|c|}{$R u^{I I I}(O H)$} \\
\hline & \multicolumn{2}{|l|}{ VAC } & \multicolumn{2}{|c|}{ PCM } & \multicolumn{2}{|l|}{ PC } & \multicolumn{2}{|c|}{$\mathrm{HB}+\mathrm{PC}$} & \multicolumn{3}{|c|}{ VAC } & \multicolumn{2}{|c|}{ PCM } & \multicolumn{2}{|l|}{ PC } & \multicolumn{2}{|c|}{$\mathrm{HB}+\mathrm{PC}$} \\
\hline & $\lambda(n m)$ & $I$ & $\lambda(n m)$ & $I$ & $\lambda(n m)$ & $I$ & $\lambda(n m)$ & $I$ & Estados & $\lambda(n m)$ & $I$ & $\lambda(n m)$ & $I$ & $\lambda(n m)$ & $I$ & $\lambda(n m)$ & I \\
\hline 1 & 746.1 & 1 & 677.5 & 1 & 717.6 & 0 & 698.4 & 0 & 1 & 470.9 & 1 & 459.6 & 1 & 473.8 & 0 & 476.4 & 1 \\
\hline 2 & 735.9 & 0 & 667.2 & 0 & 707.3 & 0 & 688.1 & 0 & 2 & 460.7 & 0 & 449.4 & 0 & 463.6 & 0 & 466.2 & 0 \\
\hline 3 & 725.6 & 2 & 657.0 & 3 & 697.1 & 2 & 677.9 & 2 & 3 & 450.4 & 1 & 439.1 & 0 & 453.3 & 1 & 455.9 & 1 \\
\hline 4 & 683.1 & 2 & 636.5 & 2 & 644.8 & 1 & 623.7 & 1 & 4 & 435.8 & 2 & 432.0 & 2 & 437.0 & 2 & 441.2 & 2 \\
\hline 5 & 603.6 & 0 & 532.9 & 0 & 549.7 & 0 & 534.4 & 0 & 5 & 421.2 & 10 & 424.7 & 13 & 417.0 & 3 & 422.7 & 3 \\
\hline 6 & 440.8 & 32 & 419.9 & 0 & 437.1 & 3 & 438.5 & 1 & 6 & 415.7 & 6 & 416.3 & 5 & 410.0 & 2 & 412.9 & 3 \\
\hline 7 & 425.2 & 0 & 417.3 & 0 & 429.2 & 4 & 425.7 & 2 & 7 & 406.2 & 1 & 405.9 & 2 & 401.9 & 4 & 406.1 & 3 \\
\hline 8 & 416.0 & 1 & 415.3 & 0 & 416.6 & 6 & 418.3 & 4 & 8 & 399.6 & 1 & 399.7 & 10 & 393.6 & 8 & 397.9 & 7 \\
\hline 9 & 413.5 & 21 & 412.4 & 0 & 411.8 & 3 & 411.6 & 4 & 9 & 395.4 & 0 & 393.4 & 0 & 387.2 & 3 & 391.3 & 6 \\
\hline 10 & 411.7 & 4 & 398.7 & 27 & 407.1 & 6 & 405.0 & 6 & 10 & 392.6 & 7 & 387.8 & 1 & 382.0 & 5 & 387.2 & 7 \\
\hline 11 & 410.7 & 1 & 389.8 & 31 & 393.9 & 14 & 395.5 & 8 & 11 & 387.5 & 19 & 377.4 & 30 & 377.6 & 11 & 382.5 & 9 \\
\hline 12 & 389.7 & 2 & 375.1 & 1 & 382.6 & 6 & 382.6 & 8 & 12 & 380.5 & 1 & 372.5 & 37 & 370.7 & 6 & 376.3 & 9 \\
\hline 13 & 387.8 & 2 & 370.3 & 10 & 372.8 & 5 & 372.8 & 7 & 13 & 371.7 & 10 & 371.8 & 10 & 365.2 & 8 & 369.9 & 10 \\
\hline 14 & 377.9 & 5 & 360.5 & 0 & 365.6 & 5 & 366.0 & 5 & 14 & 370.1 & 33 & 369.8 & 18 & 362.3 & 8 & 365.4 & 8 \\
\hline 15 & 368.0 & 2 & 356.6 & 8 & 360.0 & 3 & 361.3 & 4 & 15 & 367.2 & 13 & 368.6 & 4 & 359.5 & 9 & 362.2 & 9 \\
\hline 16 & 363.4 & 3 & 350.6 & 4 & 355.7 & 2 & 356.8 & 3 & 16 & 363.6 & 1 & 361.2 & 7 & 355.3 & 12 & 359.6 & 9 \\
\hline 17 & 359.4 & 3 & 348.7 & 1 & 352.2 & 2 & 353.1 & 3 & 17 & 360.0 & 8 & 359.6 & 3 & 351.1 & 21 & 355.8 & 12 \\
\hline 18 & 351.3 & 3 & 347.0 & 4 & 348.7 & 1 & 350.1 & 2 & 18 & 358.3 & 8 & 356.5 & 9 & 347.3 & 14 & 352.7 & 15 \\
\hline 19 & 348.8 & 2 & 343.7 & 0 & 345.2 & 1 & 347.1 & 2 & 19 & 356.4 & 2 & 355.9 & 3 & 342.7 & 8 & 349.1 & 11 \\
\hline 20 & 343.2 & 1 & 339.6 & 1 & 341.6 & 1 & 344.3 & 1 & 20 & 350.0 & 12 & 343.2 & 16 & 337.9 & 7 & 345.2 & 6 \\
\hline 21 & 342.5 & 1 & 337.6 & 0 & 338.1 & 1 & 341.3 & 1 & 21 & 345.1 & 11 & 339.6 & 12 & 333.8 & 4 & 341.3 & 7 \\
\hline 22 & 339.0 & 2 & 334.2 & 3 & 335.2 & 1 & 338.6 & 1 & 22 & 338.8 & 1 & 337.7 & 3 & 330.1 & 3 & 336.6 & 4 \\
\hline 23 & 334.3 & 0 & 331.4 & 2 & 332.3 & 2 & 335.3 & 1 & 23 & 336.3 & 2 & 335.1 & 9 & 327.6 & 3 & 333.3 & 5 \\
\hline 24 & 325.3 & 1 & 329.9 & 0 & 329.1 & 1 & 332.8 & 1 & 24 & 335.0 & 7 & 331.6 & 2 & 325.7 & 2 & 329.8 & 3 \\
\hline 25 & 323.3 & 1 & 324.0 & 1 & 325.1 & 1 & 329.6 & 1 & 25 & 332.9 & 2 & 329.2 & 3 & 323.9 & 3 & 327.5 & 4 \\
\hline 26 & 318.6 & 0 & 322.4 & 1 & 321.8 & 1 & 326.7 & 1 & 26 & 328.0 & 1 & 327.4 & 5 & 321.9 & 2 & 325.4 & 3 \\
\hline 27 & 317.5 & 0 & 320.4 & 1 & 319.4 & 1 & 323.7 & 1 & 27 & 323.7 & 1 & 323.4 & 1 & 320.1 & 2 & 323.0 & 2 \\
\hline 28 & 312.2 & 2 & 318.7 & 2 & 316.8 & 1 & 320.5 & 1 & 28 & 321.6 & 1 & 321.5 & 1 & 318.6 & 1 & 321.3 & 2 \\
\hline 29 & 311.4 & 1 & 317.0 & 6 & 314.9 & 1 & 318.5 & 1 & 29 & 319.5 & 2 & 319.5 & 3 & 316.9 & 2 & 319.5 & 2 \\
\hline 30 & 310.3 & 1 & 313.9 & 5 & 312.6 & 2 & 316.5 & 1 & 30 & 316.0 & 1 & 317.4 & 0 & 315.2 & 2 & 317.8 & 1 \\
\hline 31 & 309.1 & 3 & 312.6 & 5 & 310.1 & 3 & 314.6 & 1 & 31 & 315.6 & 1 & 314.3 & 3 & 312.3 & 3 & 316.1 & 2 \\
\hline 32 & 305.7 & 0 & 308.7 & 18 & 307.1 & 4 & 312.4 & 2 & 32 & 313.3 & 1 & 309.9 & 6 & 310.0 & 3 & 313.7 & 3 \\
\hline 33 & 303.8 & 5 & 307.1 & 3 & 304.6 & 13 & 309.8 & 6 & 33 & 309.8 & 1 & 309.1 & 3 & 307.5 & 3 & 311.6 & 4 \\
\hline 34 & 301.7 & 63 & 305.7 & 52 & 302.7 & 18 & 307.5 & 6 & 34 & 309.4 & 2 & 302.7 & 2 & 305.2 & 3 & 309.7 & 2 \\
\hline 35 & 300.1 & 26 & 304.4 & 98 & 300.9 & 24 & 305.3 & 11 & 35 & 308.5 & 3 & 301.9 & 28 & 303.3 & 3 & 307.4 & 3 \\
\hline 36 & 299.0 & 37 & 302.8 & 172 & 299.5 & 31 & 303.2 & 18 & 36 & 305.8 & 5 & 300.7 & 12 & 301.2 & 4 & 305.4 & 3 \\
\hline 37 & 297.0 & 2 & 301.0 & 15 & 298.2 & 32 & 301.2 & 24 & 37 & 304.9 & 4 & 299.3 & 21 & 299.5 & 4 & 303.3 & 3 \\
\hline 38 & 297.0 & 12 & 300.4 & 48 & 297.0 & 31 & 299.8 & 24 & 38 & 301.9 & 10 & 298.9 & 42 & 298.0 & 5 & 301.8 & 4 \\
\hline 39 & 296.3 & 8 & 299.6 & 3 & 295.8 & 35 & 298.6 & 29 & 39 & 300.9 & 10 & 298.3 & 11 & 296.5 & 10 & 300.1 & 6 \\
\hline 40 & 293.7 & 30 & 299.0 & 139 & 294.5 & 44 & 297.2 & 44 & 40 & 298.7 & 3 & 297.3 & 29 & 295.2 & 14 & 299.0 & 8 \\
\hline 41 & 292.9 & 5 & 297.7 & 17 & 293.0 & 47 & 296.1 & 29 & 41 & 296.7 & 8 & 296.6 & 62 & 293.9 & 19 & 297.6 & 9 \\
\hline 42 & 292.2 & 42 & 295.7 & 56 & 291.9 & 69 & 294.7 & 37 & 42 & 296.1 & 10 & 296.0 & 49 & 293.0 & 22 & 296.2 & 16 \\
\hline 43 & 291.8 & 82 & 294.6 & 134 & 290.6 & 69 & 293.3 & 49 & 43 & 295.1 & 24 & 295.0 & 17 & 291.9 & 20 & 295.2 & 13 \\
\hline 44 & 288.8 & 88 & 289.3 & 39 & 289.0 & 43 & 292.3 & 58 & 44 & 293.5 & 30 & 294.0 & 31 & 291.0 & 24 & 294.1 & 15 \\
\hline 45 & 287.3 & 29 & 287.7 & 4 & 287.7 & 31 & 291.1 & 57 & 45 & 292.6 & 19 & 293.3 & 8 & 290.1 & 34 & 293.2 & 19 \\
\hline 46 & 286.8 & 50 & 287.5 & 5 & 286.4 & 22 & 289.8 & 57 & 46 & 292.3 & 31 & 292.5 & 28 & 289.2 & 37 & 292.2 & 19 \\
\hline 47 & 286.1 & 6 & 286.6 & 4 & 285.3 & 19 & 288.5 & 51 & 47 & 291.3 & 14 & 291.9 & 16 & 288.3 & 28 & 291.4 & 28 \\
\hline 48 & 285.2 & 16 & 284.8 & 6 & 284.2 & 13 & 286.8 & 22 & 48 & 289.8 & 2 & 290.5 & 4 & 287.1 & 25 & 290.4 & 24 \\
\hline 49 & 285.0 & 48 & 283.3 & 19 & 283.2 & 11 & 285.4 & 21 & 49 & 289.2 & 8 & 289.9 & 50 & 286.0 & 15 & 289.5 & 21 \\
\hline 50 & 282.4 & 4 & 280.5 & 2 & 282.0 & 11 & 284.3 & 14 & 50 & 288.6 & 35 & 288.9 & 41 & 285.1 & 17 & 288.5 & 20 \\
\hline
\end{tabular}


Tabela A.3 - Comprimento de onda $\lambda(\mathrm{em} \mathrm{nm})$ e intensidade $I\left(\times 10^{-3}\right)$ das 50 primeiras excitações eletrônicas dos complexos de $R u$-Aqua/Oxo na oxidação $I V$, calculadas com o método TD-DFT, utilizando B3LYP/(aug)-cc-pVDZ(PP). Interações soluto-solvente tratadas com os métodos $\mathrm{PCM}, \mathrm{CP}$ e $\mathrm{CP}+\mathrm{HB}$. Os dois últimos, dentro do escopo do método $\mathrm{QM} / \mathrm{MM}$ sequencial, e utilizando configurações do solvente geradas a partir das simulações MC.

\begin{tabular}{|c|c|c|c|c|c|c|c|c|}
\hline \multicolumn{9}{|c|}{$R u^{I V}(O)$} \\
\hline \multirow[b]{2}{*}{ Estados } & \multicolumn{2}{|c|}{ VAC } & \multicolumn{2}{|c|}{ PCM } & \multicolumn{2}{|c|}{ PC } & \multicolumn{2}{|c|}{$\mathrm{HB}+\mathrm{PC}$} \\
\hline & $\lambda$ & $I$ & $\lambda$ & $I$ & $\lambda$ & $I$ & $\lambda$ & 1 \\
\hline 1 & 626.0 & 1 & 651.2 & 1 & 675.2 & 1 & 683.1 & 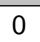 \\
\hline 2 & 606.4 & 0 & 628.1 & 0 & 637.2 & 0 & 646.9 & 0 \\
\hline 3 & 433.3 & 0 & 434.1 & 0 & 439.3 & 0 & 442.3 & 1 \\
\hline 4 & 423.0 & 3 & 422.1 & 1 & 425.4 & 1 & 427.9 & 1 \\
\hline 5 & 421.5 & 1 & 419.6 & 2 & 421.8 & 1 & 423.5 & 2 \\
\hline 6 & 420.1 & 1 & 418.8 & 2 & 418.1 & 2 & 419.4 & 2 \\
\hline 7 & 403.0 & 1 & 396.1 & 2 & 393.3 & 1 & 398.2 & 1 \\
\hline 8 & 394.9 & 3 & 388.4 & 3 & 389.1 & 2 & 392.6 & 2 \\
\hline 9 & 392.9 & 1 & 387.6 & 2 & 383.5 & 3 & 386.1 & 3 \\
\hline 10 & 390.6 & 15 & 383.6 & 12 & 379.7 & 3 & 381.5 & 3 \\
\hline 11 & 389.4 & 0 & 381.1 & 9 & 375.8 & 3 & 377.9 & 4 \\
\hline 12 & 387.0 & 3 & 379.6 & 5 & 373.3 & 5 & 374.8 & 4 \\
\hline 13 & 384.1 & 2 & 376.7 & 1 & 370.2 & 3 & 371.9 & 3 \\
\hline 14 & 378.9 & 3 & 371.3 & 8 & 366.9 & 3 & 369.1 & 3 \\
\hline 15 & 361.8 & 12 & 367.7 & 4 & 362.0 & 7 & 365.7 & 4 \\
\hline 16 & 357.4 & 2 & 363.8 & 10 & 358.2 & 5 & 361.7 & 4 \\
\hline 17 & 356.9 & 6 & 353.8 & 4 & 354.4 & 5 & 357.8 & 5 \\
\hline 18 & 350.3 & 7 & 352.1 & 3 & 350.3 & 4 & 354.0 & 5 \\
\hline 19 & 343.6 & 8 & 350.7 & 13 & 342.9 & 4 & 349.7 & 4 \\
\hline 20 & 336.4 & 3 & 347.3 & 11 & 338.0 & 3 & 345.1 & 4 \\
\hline 21 & 333.9 & 2 & 331.7 & 1 & 334.3 & 3 & 339.5 & 5 \\
\hline 22 & 331.9 & 3 & 329.1 & 4 & 328.7 & 4 & 335.6 & 4 \\
\hline 23 & 330.0 & 3 & 328.5 & 3 & 324.9 & 3 & 331.1 & 3 \\
\hline 24 & 325.6 & 15 & 325.9 & 2 & 322.6 & 3 & 327.9 & 3 \\
\hline 25 & 324.2 & 2 & 319.8 & 1 & 319.3 & 4 & 324.3 & 3 \\
\hline 26 & 323.5 & 6 & 319.1 & 15 & 316.6 & 7 & 322.1 & 3 \\
\hline 27 & 321.4 & 2 & 316.5 & 8 & 314.4 & 6 & 319.5 & 4 \\
\hline 28 & 316.6 & 1 & 315.8 & 21 & 312.5 & 7 & 316.9 & 7 \\
\hline 29 & 316.1 & 1 & 314.6 & 25 & 310.8 & 9 & 314.8 & 7 \\
\hline 30 & 314.7 & 1 & 314.5 & 16 & 309.0 & 7 & 312.8 & 8 \\
\hline 31 & 313.1 & 15 & 311.4 & 3 & 306.2 & 4 & 310.7 & 9 \\
\hline 32 & 312.4 & 29 & 308.8 & 3 & 304.1 & 3 & 308.7 & 7 \\
\hline 33 & 308.6 & 1 & 305.7 & 4 & 302.1 & 5 & 306.4 & 5 \\
\hline 34 & 305.0 & 2 & 301.9 & 7 & 300.2 & 4 & 304.4 & 4 \\
\hline 35 & 303.1 & 5 & 300.4 & 7 & 298.1 & 3 & 302.2 & 4 \\
\hline 36 & 298.7 & 3 & 299.1 & 1 & 296.5 & 4 & 300.4 & 4 \\
\hline 37 & 298.0 & 8 & 297.1 & 10 & 295.1 & 4 & 298.5 & 4 \\
\hline 38 & 297.0 & 1 & 296.5 & 2 & 293.8 & 4 & 297.2 & 5 \\
\hline 39 & 296.6 & 6 & 295.5 & 25 & 292.9 & 5 & 295.9 & 3 \\
\hline 40 & 295.5 & 0 & 294.2 & 28 & 291.9 & 6 & 294.8 & 4 \\
\hline 41 & 294.7 & 9 & 293.6 & 68 & 291.0 & 11 & 293.7 & 6 \\
\hline 42 & 293.5 & 4 & 292.9 & 14 & 289.9 & 13 & 292.9 & 8 \\
\hline 43 & 293.3 & 4 & 292.1 & 13 & 288.8 & 22 & 291.9 & 6 \\
\hline 44 & 291.7 & 2 & 291.4 & 7 & 287.9 & 36 & 290.8 & 17 \\
\hline 45 & 291.0 & 1 & 290.7 & 49 & 286.9 & 44 & 289.8 & 26 \\
\hline 46 & 290.6 & 19 & 290.5 & 58 & 285.7 & 50 & 288.7 & 23 \\
\hline 47 & 289.7 & 28 & 289.4 & 37 & 284.3 & 40 & 287.8 & 38 \\
\hline 48 & 288.5 & 33 & 288.6 & 19 & 282.7 & 27 & 286.8 & 40 \\
\hline 49 & 285.8 & 15 & 286.3 & 79 & 281.2 & 30 & 285.5 & 33 \\
\hline 50 & 285.6 & 11 & 285.4 & 7 & 280.0 & 35 & 284.2 & 30 \\
\hline
\end{tabular}




\section{APÊNDICE}

\section{B}

\section{Geometrias otimizadas e cargas atômicas polarizadas em solução aquosa (via PCM), e parâmetros de LJ dos complexos de $R u$-Aqua/Oxo}

\begin{tabular}{|c|c|c|c|c|c|c|}
\hline $\mathrm{X}$ & $\mathrm{Y}$ & $\mathrm{Z}$ & $Q(e)$ & \multicolumn{2}{|c|}{$\mathrm{E}(\mathrm{kcal} / \mathrm{mol})$} & S (Ang \\
\hline-3.241264 & -2.490441 & 0.270253 & -0.151 & 0.07 & 3.55 & \\
\hline-2.117089 & -1.662292 & 0.346317 & 0.122 & 0.07 & 3.55 & \\
\hline-1.577458 & -1.100252 & -0.772114 & -0.234 & 0.17 & 3.25 & \\
\hline-2.145056 & -1.351254 & -1.967101 & 0.099 & 0.07 & 3.55 & \\
\hline-3.264207 & -2.166825 & -2.109481 & -0.128 & 0.07 & 3.55 & \\
\hline-3.824039 & -2.746455 & -0.969261 & 0.042 & 0.07 & 3.55 & \\
\hline-3.682532 & -2.338070 & -3.100066 & 0.133 & 0.03 & 2.42 & \\
\hline-1.679183 & -0.881454 & -2.830618 & 0.095 & 0.03 & 2.42 & \\
\hline-1.767906 & -1.850075 & 2.848328 & -0.199 & 0.07 & 3.55 & \\
\hline-1.412783 & -1.334770 & 1.597776 & 0.249 & 0.07 & 3.55 & \\
\hline-0.351592 & -0.485176 & 1.459639 & -0.420 & 0.17 & 3.25 & \\
\hline 0.366001 & -0.161574 & 2.555520 & 0.233 & 0.07 & 3.55 & \\
\hline 0.063305 & -0.646694 & 3.823400 & -0.164 & 0.07 & 3.55 & \\
\hline-1.027047 & -1.505171 & 3.975796 & 0.072 & 0.07 & 3.55 & \\
\hline-2.617447 & -2.522417 & 2.940270 & 0.148 & 0.03 & 2.42 & \\
\hline 0.048736 & 0.148231 & -0.440563 & 0.944 & 0.40 & 1.80 & \\
\hline 4.177470 & 1.222272 & 0.100447 & -0.176 & 0.07 & 3.55 & \\
\hline 2.949626 & 0.584468 & -0.103696 & 0.197 & 0.07 & 3.55 & \\
\hline 1.775444 & 1.277776 & -0.055857 & -0.371 & 0.17 & 3.25 & \\
\hline 1.818845 & 2.605053 & 0.173897 & 0.220 & 0.07 & 3.55 & \\
\hline 3.007737 & 3.298052 & 0.382389 & -0.167 & 0.07 & 3.55 & \\
\hline 4.211355 & 2.592502 & 0.349454 & 0.076 & 0.07 & 3.55 & \\
\hline 3.901472 & -1.737327 & -0.452014 & -0.187 & 0.07 & 3.55 & \\
\hline 2.816665 & -0.856467 & -0.390443 & 0.207 & 0.07 & 3.55 & \\
\hline 1.541888 & -1.291571 & -0.603867 & -0.354 & 0.17 & 3.25 & \\
\hline 1.338267 & -2.594715 & -0.879237 & 0.170 & 0.07 & 3.55 & \\
\hline 2.375327 & -3.519559 & -0.955005 & -0.146 & 0.07 & 3.55 & \\
\hline 3.683006 & -3.083250 & -0.736397 & 0.065 & 0.07 & 3.55 & \\
\hline 1.204811 & 0.511774 & 2.402070 & 0.046 & 0.03 & 2.42 & \\
\hline-1.295162 & -1.903065 & 4.953878 & 0.107 & 0.03 & 2.42 & \\
\hline 0.678588 & -0.348764 & 4.670893 & 0.134 & 0.03 & 2.42 & \\
\hline-3.661812 & -2.933032 & 1.170179 & 0.139 & 0.03 & 2.42 & \\
\hline-4.700716 & -3.389265 & -1.041472 & 0.111 & 0.03 & 2.42 & \\
\hline 0.863826 & 3.123441 & 0.189520 & 0.047 & 0.03 & 2.42 & \\
\hline 2.978937 & 4.370986 & 0.565350 & 0.134 & 0.03 & 2.42 & \\
\hline
\end{tabular}




$\begin{array}{rrrrrrr}\mathrm{H} & 5.162689 & 3.098793 & 0.509858 & 0.105 & 0.03 & 2.42 \\ \mathrm{H} & 5.104240 & 0.655183 & 0.061715 & 0.141 & 0.03 & 2.42 \\ \mathrm{H} & 0.308190 & -2.898450 & -1.044659 & 0.060 & 0.03 & 2.42 \\ \mathrm{H} & 2.150749 & -4.560706 & -1.181230 & 0.131 & 0.03 & 2.42 \\ \mathrm{H} & 4.521045 & -3.777767 & -0.785679 & 0.109 & 0.03 & 2.42 \\ \mathrm{H} & 4.912266 & -1.376969 & -0.277646 & 0.145 & 0.03 & 2.42 \\ \mathrm{C} & -3.264599 & 3.818474 & -0.134445 & 0.073 & 0.07 & 3.55 \\ \mathrm{C} & -2.586100 & 3.382026 & 1.004608 & -0.185 & 0.07 & 3.55 \\ \mathrm{C} & -1.656003 & 2.352829 & 0.888223 & 0.222 & 0.07 & 3.55 \\ \mathrm{~N} & -1.369539 & 1.747772 & -0.286885 & -0.368 & 0.17 & 3.25 \\ \mathrm{C} & -2.036847 & 2.171091 & -1.384275 & 0.204 & 0.07 & 3.55 \\ \mathrm{C} & -2.979929 & 3.194966 & -1.350016 & -0.199 & 0.07 & 3.55 \\ \mathrm{H} & -3.997679 & 4.623118 & -0.075467 & 0.105 & 0.03 & 2.42 \\ \mathrm{H} & -2.768200 & 3.827718 & 1.981615 & 0.136 & 0.03 & 2.42 \\ \mathrm{H} & -1.122018 & 1.998208 & 1.765641 & 0.030 & 0.03 & 2.42 \\ \mathrm{H} & -1.797569 & 1.673043 & -2.320335 & 0.051 & 0.03 & 2.42 \\ \mathrm{H} & -3.479317 & 3.490485 & -2.271844 & 0.147 & 0.03 & 2.42 \\ \mathrm{O} & 0.337714 & 0.673429 & -2.571305 & -0.834 & 0.1521 & 3.1506 \\ \mathrm{H} & 0.818405 & 0.011311 & -3.089368 & 0.417 & 0.0000 & 0.0000 \\ \mathrm{H} & 0.803348 & 1.507281 & -2.734042 & 0.417 & 0.0000 & 0.0000\end{array}$

$\left[\mathrm{Ru}^{\mathrm{II}}(\mathrm{OH})(\text { py })(\mathrm{bpy})_{2}\right]^{1+}$

\begin{tabular}{|c|c|c|c|c|c|c|c|}
\hline & $\mathrm{X}$ & $\mathrm{Y}$ & $\mathrm{Z}$ & $Q(e)$ & \multicolumn{2}{|c|}{$\mathrm{E}(\mathrm{kcal} / \mathrm{mol})$} & S (Ang.) \\
\hline C & -3.292231 & -2.427922 & 0.129935 & -0.143 & 0.07 & 3.55 & \\
\hline $\mathrm{C}$ & -2.150358 & -1.631563 & 0.278874 & -0.010 & 0.07 & 3.55 & \\
\hline $\mathrm{N}$ & -1.535585 & -1.079177 & -0.805189 & 0.066 & 0.17 & 3.25 & \\
\hline $\mathrm{C}$ & -2.032972 & -1.308646 & -2.036023 & 0.032 & 0.07 & 3.55 & \\
\hline C & -3.163659 & -2.092254 & -2.247149 & -0.145 & 0.07 & 3.55 & \\
\hline $\mathrm{C}$ & -3.806942 & -2.660801 & -1.143452 & 0.020 & 0.07 & 3.55 & \\
\hline $\mathrm{H}$ & -3.529949 & -2.249354 & -3.260850 & 0.124 & 0.03 & 2.42 & \\
\hline $\mathrm{H}$ & -1.484579 & -0.836483 & -2.849878 & 0.103 & 0.03 & 2.42 & \\
\hline C & -1.929262 & -1.863119 & 2.791908 & -0.217 & 0.07 & 3.55 & \\
\hline $\mathrm{C}$ & -1.502469 & -1.333637 & 1.567894 & 0.291 & 0.07 & 3.55 & \\
\hline $\mathrm{N}$ & -0.415601 & -0.505294 & 1.489433 & -0.374 & 0.17 & 3.25 & \\
\hline $\mathrm{C}$ & 0.255698 & -0.223973 & 2.628468 & 0.234 & 0.07 & 3.55 & \\
\hline C & -0.115146 & -0.724555 & 3.871046 & -0.172 & 0.07 & 3.55 & \\
\hline $\mathrm{C}$ & -1.234752 & -1.558194 & 3.959194 & 0.033 & 0.07 & 3.55 & \\
\hline $\mathrm{H}$ & -2.797844 & -2.516984 & 2.831087 & 0.144 & 0.03 & 2.42 & \\
\hline $\mathrm{Ru}$ & 0.085104 & 0.144313 & -0.418512 & 0.331 & 0.40 & 1.80 & \\
\hline $\mathrm{C}$ & 4.196048 & 1.230052 & 0.104366 & -0.167 & 0.07 & 3.55 & \\
\hline $\mathrm{C}$ & 2.969951 & 0.583013 & -0.091841 & 0.072 & 0.07 & 3.55 & \\
\hline $\mathrm{N}$ & 1.786536 & 1.258817 & 0.000989 & 0.127 & 0.17 & 3.25 & \\
\hline C & 1.822674 & 2.579066 & 0.278767 & -0.016 & 0.07 & 3.55 & \\
\hline C & 3.007258 & 3.277726 & 0.485966 & -0.107 & 0.07 & 3.55 & \\
\hline C & 4.221110 & 2.590557 & 0.397898 & -0.003 & 0.07 & 3.55 & \\
\hline $\mathrm{C}$ & 3.926888 & -1.725182 & -0.510172 & -0.192 & 0.07 & 3.55 & \\
\hline C & 2.839325 & -0.850411 & -0.398327 & 0.166 & 0.07 & 3.55 & \\
\hline $\mathrm{N}$ & 1.557184 & -1.289244 & -0.561738 & -0.129 & 0.17 & 3.25 & \\
\hline C & 1.353321 & -2.594401 & -0.834436 & 0.047 & 0.07 & 3.55 & \\
\hline $\mathrm{C}$ & 2.391120 & -3.512107 & -0.956881 & -0.124 & 0.07 & 3.55 & \\
\hline $\mathrm{C}$ & 3.707000 & -3.070163 & -0.793417 & 0.026 & 0.07 & 3.55 & \\
\hline $\mathrm{H}$ & 1.117141 & 0.431852 & 2.524261 & -0.016 & 0.03 & 2.42 & \\
\hline $\mathrm{H}$ & -1.557166 & -1.966386 & 4.916577 & 0.098 & 0.03 & 2.42 & \\
\hline $\mathrm{H}$ & 0.467540 & -0.458998 & 4.752251 & 0.129 & 0.03 & 2.42 & \\
\hline $\mathrm{H}$ & -3.778051 & -2.862583 & 1.000652 & 0.127 & 0.03 & 2.42 & \\
\hline $\mathrm{H}$ & -4.696035 & -3.277892 & -1.271210 & 0.100 & 0.03 & 2.42 & \\
\hline
\end{tabular}




$\begin{array}{rrrrrrr}\mathrm{H} & 0.861789 & 3.083780 & 0.332338 & 0.084 & 0.03 & 2.42 \\ \mathrm{H} & 2.970173 & 4.343190 & 0.708667 & 0.116 & 0.03 & 2.42 \\ \mathrm{H} & 5.169580 & 3.104305 & 0.552019 & 0.108 & 0.03 & 2.42 \\ \mathrm{H} & 5.127596 & 0.674300 & 0.025075 & 0.139 & 0.03 & 2.42 \\ \mathrm{H} & 0.319097 & -2.903440 & -0.960225 & 0.082 & 0.03 & 2.42 \\ \mathrm{H} & 2.163036 & -4.553620 & -1.179400 & 0.115 & 0.03 & 2.42 \\ \mathrm{H} & 4.546021 & -3.759446 & -0.883899 & 0.102 & 0.03 & 2.42 \\ \mathrm{H} & 4.941502 & -1.357247 & -0.376324 & 0.138 & 0.03 & 2.42 \\ \mathrm{C} & -3.220616 & 3.838247 & -0.263974 & 0.028 & 0.07 & 3.55 \\ \mathrm{C} & -2.676703 & 3.335104 & 0.919774 & -0.139 & 0.07 & 3.55 \\ \mathrm{C} & -1.738805 & 2.307955 & 0.850992 & 0.069 & 0.07 & 3.55 \\ \mathrm{~N} & -1.319983 & 1.770433 & -0.316118 & -0.093 & 0.17 & 3.25 \\ \mathrm{C} & -1.848434 & 2.261154 & -1.459320 & 0.042 & 0.07 & 3.55 \\ \mathrm{C} & -2.793165 & 3.285789 & -1.472557 & -0.149 & 0.07 & 3.55 \\ \mathrm{H} & -3.958019 & 4.641311 & -0.243502 & 0.097 & 0.03 & 2.42 \\ \mathrm{H} & -2.969850 & 3.727657 & 1.892861 & 0.112 & 0.03 & 2.42 \\ \mathrm{H} & -1.302810 & 1.899524 & 1.759085 & 0.067 & 0.03 & 2.42 \\ \mathrm{H} & -1.457660 & 1.809331 & -2.369969 & 0.124 & 0.03 & 2.42 \\ \mathrm{H} & -3.182593 & 3.641232 & -2.426310 & 0.112 & 0.03 & 2.42 \\ \mathrm{O} & 0.324644 & 0.564824 & -2.434806 & -0.895 & 0.1521 & 3.1506 \\ \mathrm{H} & 1.072207 & 1.158418 & -2.577181 & 0.285 & 0.000 & 0.0000\end{array}$

$\left[\mathrm{Ru}^{\mathrm{III}}\left(\mathrm{H}_{2} \mathrm{O}\right)(\text { py })(\text { bpy })_{2}\right]^{3+}$

\begin{tabular}{|c|c|c|c|c|c|c|c|}
\hline & $\mathrm{X}$ & Y & Z & $Q(e)$ & \multicolumn{2}{|c|}{$\mathrm{E}(\mathrm{kcal} / \mathrm{mol})$} & $\mathrm{S}$ (Ang. ) \\
\hline C & -3.255285 & -2.502354 & 0.062112 & -0.171 & 0.07 & 3.55 & \\
\hline C & -2.131602 & -1.685629 & 0.204145 & 0.236 & 0.07 & 3.55 & \\
\hline $\mathrm{N}$ & -1.654657 & -0.958325 & -0.846484 & -0.365 & 0.17 & 3.25 & \\
\hline C & -2.294509 & -1.007323 & -2.028547 & 0.170 & 0.07 & 3.55 & \\
\hline C & -3.418997 & -1.800671 & -2.231940 & -0.120 & 0.07 & 3.55 & \\
\hline C & -3.902889 & -2.565971 & -1.170142 & 0.093 & 0.07 & 3.55 & \\
\hline $\mathrm{H}$ & -3.898950 & -1.808546 & -3.208664 & 0.148 & 0.03 & 2.42 & \\
\hline $\mathrm{H}$ & -1.902726 & -0.391031 & -2.833727 & 0.090 & 0.03 & 2.42 & \\
\hline C & -1.692496 & -2.167948 & 2.652551 & -0.108 & 0.07 & 3.55 & \\
\hline $\mathrm{C}$ & -1.392525 & -1.506232 & 1.461491 & 0.150 & 0.07 & 3.55 & \\
\hline $\mathrm{N}$ & -0.364528 & -0.604390 & 1.408900 & -0.270 & 0.17 & 3.25 & \\
\hline $\mathrm{C}$ & 0.361852 & -0.349223 & 2.517343 & 0.138 & 0.07 & 3.55 & \\
\hline C & 0.097127 & -0.973385 & 3.729660 & -0.088 & 0.07 & 3.55 & \\
\hline C & -0.943274 & -1.901446 & 3.797149 & 0.065 & 0.07 & 3.55 & \\
\hline $\mathrm{H}$ & -2.505906 & -2.887764 & 2.689219 & 0.144 & 0.03 & 2.42 & \\
\hline $\mathrm{Ru}$ & 0.033672 & 0.194549 & -0.422721 & 1.300 & 0.40 & 2.00 & \\
\hline C & 4.194471 & 1.089220 & 0.190084 & -0.146 & 0.07 & 3.55 & \\
\hline C & 2.950412 & 0.507945 & -0.061939 & 0.191 & 0.07 & 3.55 & \\
\hline $\mathrm{N}$ & 1.801758 & 1.234817 & 0.053904 & -0.325 & 0.17 & 3.25 & \\
\hline $\mathrm{C}$ & 1.871402 & 2.526939 & 0.427067 & 0.202 & 0.07 & 3.55 & \\
\hline $\mathrm{C}$ & 3.081666 & 3.158680 & 0.695526 & -0.116 & 0.07 & 3.55 & \\
\hline $\mathrm{C}$ & 4.263072 & 2.428069 & 0.571383 & 0.070 & 0.07 & 3.55 & \\
\hline $\mathrm{C}$ & 3.815801 & -1.805344 & -0.618675 & -0.160 & 0.07 & 3.55 & \\
\hline $\mathrm{C}$ & 2.766602 & -0.900508 & -0.452753 & 0.232 & 0.07 & 3.55 & \\
\hline N & 1.473539 & -1.295604 & -0.636596 & -0.449 & 0.17 & 3.25 & \\
\hline $\mathrm{C}$ & 1.205456 & -2.572486 & -0.973055 & 0.203 & 0.07 & 3.55 & \\
\hline $\mathrm{C}$ & 2.210440 & -3.515661 & -1.153408 & -0.133 & 0.07 & 3.55 & \\
\hline $\mathrm{C}$ & 3.537596 & -3.124252 & -0.974276 & 0.112 & 0.07 & 3.55 & \\
\hline $\mathrm{H}$ & 1.163006 & 0.376621 & 2.422941 & 0.066 & 0.03 & 2.42 & \\
\hline $\mathrm{H}$ & -1.172167 & -2.414227 & 4.730524 & 0.128 & 0.03 & 2.42 & \\
\hline $\mathrm{H}$ & 0.705176 & -0.730512 & 4.598841 & 0.146 & 0.03 & 2.42 & \\
\hline $\mathrm{H}$ & -3.628528 & -3.079012 & 0.904483 & 0.163 & 0.03 & 2.42 & \\
\hline $\mathrm{H}$ & -4.780088 & -3.199623 & -1.294411 & 0.120 & 0.03 & 2.42 & \\
\hline
\end{tabular}




$\begin{array}{rrrrrrr}\text { H } & 0.930346 & 3.061312 & 0.519046 & 0.050 & 0.03 & 2.42 \\ \mathrm{H} & 3.083810 & 4.204194 & 0.997643 & 0.144 & 0.03 & 2.42 \\ \mathrm{H} & 5.228789 & 2.890569 & 0.771636 & 0.126 & 0.03 & 2.42 \\ \mathrm{H} & 5.105345 & 0.504389 & 0.092870 & 0.152 & 0.03 & 2.42 \\ \mathrm{H} & 0.161691 & -2.839369 & -1.107067 & 0.067 & 0.03 & 2.42 \\ \mathrm{H} & 1.945670 & -4.534634 & -1.428849 & 0.150 & 0.03 & 2.42 \\ \mathrm{H} & 4.350795 & -3.837054 & -1.106041 & 0.117 & 0.03 & 2.42 \\ \mathrm{H} & 4.844609 & -1.487326 & -0.472611 & 0.154 & 0.03 & 2.42 \\ \mathrm{C} & -3.087111 & 3.989461 & 0.079615 & 0.112 & 0.07 & 3.55 \\ \mathrm{C} & -3.116186 & 2.927410 & 0.984507 & -0.158 & 0.07 & 3.55 \\ \mathrm{C} & -2.225851 & 1.873371 & 0.821248 & 0.224 & 0.07 & 3.55 \\ \mathrm{~N} & -1.318820 & 1.835751 & -0.182601 & -0.459 & 0.17 & 3.25 \\ \mathrm{C} & -1.292347 & 2.868888 & -1.059345 & 0.259 & 0.07 & 3.55 \\ \mathrm{C} & -2.156927 & 3.952194 & -0.960490 & -0.168 & 0.07 & 3.55 \\ \mathrm{H} & -3.775585 & 4.828124 & 0.182199 & 0.109 & 0.03 & 2.42 \\ \mathrm{H} & -3.819233 & 2.903931 & 1.815317 & 0.143 & 0.03 & 2.42 \\ \mathrm{H} & -2.233738 & 1.042601 & 1.518148 & 0.043 & 0.03 & 2.42 \\ \mathrm{H} & -0.567736 & 2.811202 & -1.865070 & 0.075 & 0.03 & 2.42 \\ \mathrm{H} & -2.091781 & 4.751287 & -1.697004 & 0.144 & 0.03 & 2.42 \\ \mathrm{O} & 0.449875 & 0.833762 & -2.431118 & -0.834 & 0.1521 & 3.1506 \\ \mathrm{H} & 0.208531 & 0.271426 & -3.182979 & 0.417 & 0.0000 & 0.0000 \\ \mathrm{H} & 1.331668 & 1.184979 & -2.633486 & 0.417 & 0.0000 & 0.0000\end{array}$

$\left[\mathrm{Ru}^{\mathrm{III}}(\mathrm{OH})(\text { py })(\text { bpy })_{2}\right]^{2+}$

\begin{tabular}{lr} 
& \multicolumn{1}{c}{$\mathrm{X}$} \\
$\mathrm{C}$ & -3.342197 \\
$\mathrm{C}$ & -2.196936 \\
$\mathrm{~N}$ & -1.654239 \\
$\mathrm{C}$ & -2.231138 \\
$\mathrm{C}$ & -3.372643 \\
$\mathrm{C}$ & -3.939461 \\
$\mathrm{H}$ & -3.798060 \\
$\mathrm{H}$ & -1.751214 \\
$\mathrm{C}$ & -1.888179 \\
$\mathrm{C}$ & -1.497629 \\
$\mathrm{~N}$ & -0.423210 \\
$\mathrm{C}$ & 0.265004 \\
$\mathrm{C}$ & -0.080142 \\
$\mathrm{C}$ & -1.173986 \\
$\mathrm{H}$ & -2.742859 \\
$\mathrm{Ru}$ & 0.066285 \\
$\mathrm{C}$ & 4.220380 \\
$\mathrm{C}$ & 2.967449 \\
$\mathrm{~N}$ & 1.829819 \\
$\mathrm{C}$ & 1.919331 \\
$\mathrm{C}$ & 3.136492 \\
$\mathrm{C}$ & 4.308957 \\
$\mathrm{C}$ & 3.810035 \\
$\mathrm{C}$ & 2.766080 \\
$\mathrm{~N}$ & 1.469231 \\
$\mathrm{C}$ & 1.191002 \\
$\mathrm{C}$ & 2.184690 \\
$\mathrm{C}$ & 3.518880 \\
$\mathrm{H}$ & 1.114528 \\
$\mathrm{H}$ & -1.469865 \\
$\mathrm{H}$ & 0.507574 \\
$\mathrm{H}$ & -3.768077 \\
& \\
\hline
\end{tabular}

$$
\begin{aligned}
& Y \\
& -2.397488 \\
& -1.607068 \\
& -0.973519 \\
& -1.118449 \\
& -1.889867 \\
& -2.540366 \\
& -1.974583 \\
& -0.611741 \\
& -1.976329 \\
& -1.388390 \\
& -0.553051 \\
& -0.289069 \\
& -0.834409 \\
& -1.697772 \\
& -2.646894 \\
& 0.184209 \\
& 0.984533 \\
& 0.428932 \\
& 1.166672 \\
& 2.439492 \\
& 3.044801 \\
& 2.305346 \\
& -1.874392 \\
& -0.967750 \\
& -1.345063 \\
& -2.609529 \\
& -3.560114 \\
& -3.183867 \\
& 0.381700 \\
& -2.150594 \\
& -0.584304 \\
& -2.898413 \\
&
\end{aligned}
$$

\section{Z}

0.131457

0.264183

$-0.813177$

$-2.020165$

$-2.215047$

$-1.118802$

$-3.213430$

$-2.852826$

2.751231

1.544803

1.487092

2. 613343

3.845810

3. 914641

2.786301

$-0.443483$

0.225388

$-0.047778$

0.095015

0.525539

0.820097

0.659354

$-0.676984$

$-0.470370$

$-0.634586$

$-0.995601$

$-1.210416$

$-1.052155$

2.519838

4.860341

4.727277

0.996911
$\mathrm{Q}(\mathrm{e})$

$-0.147$

0.141

$-0.138$

0.091

$-0.114$

0.042

0.133

0.093

$-0.151$

0.211

$-0.307$

0.173

$-0.124$

0.058

0.138

0.723

$-0.138$

0.101

$-0.041$

0.102

$-0.115$

0.035

$-0.196$

0.236

$-0.248$

0.156

$-0.152$

0.072

0.033

0.110

0.134

0.142

$\begin{array}{ll}\text { E (kcal/mol) } \\ 0.07 & 3.55 \\ 0.07 & 3.55 \\ 0.17 & 3.25 \\ 0.07 & 3.55 \\ 0.07 & 3.55 \\ 0.07 & 3.55 \\ 0.03 & 2.42 \\ 0.03 & 2.42 \\ 0.07 & 3.55 \\ 0.07 & 3.55 \\ 0.17 & 3.25 \\ 0.07 & 3.55 \\ 0.07 & 3.55 \\ 0.07 & 3.55 \\ 0.03 & 2.42 \\ 0.40 & 1.80 \\ 0.07 & 3.55 \\ 0.07 & 3.55 \\ 0.17 & 3.25 \\ 0.07 & 3.55 \\ 0.07 & 3.55 \\ 0.07 & 3.55 \\ 0.07 & 3.55 \\ 0.07 & 3.55 \\ 0.17 & 3.25 \\ 0.07 & 3.55 \\ 0.07 & 3.55 \\ 0.07 & 3.55 \\ 0.03 & 2.42 \\ 0.03 & 2.42 \\ 0.03 & 2.42 \\ 0.03 & 2.42 \\ & \\ 0.07\end{array}$

S (Ang . )

S(Ang.) 


$\begin{array}{rrrrrrr}\mathrm{H} & -4.832706 & -3.153532 & -1.232362 & 0.115 & 0.03 & 2.42 \\ \mathrm{H} & 0.985603 & 2.982025 & 0.640676 & 0.075 & 0.03 & 2.42 \\ \mathrm{H} & 3.153260 & 4.076629 & 1.166171 & 0.129 & 0.03 & 2.42 \\ \mathrm{H} & 5.281424 & 2.746816 & 0.874785 & 0.120 & 0.03 & 2.42 \\ \mathrm{H} & 5.123086 & 0.390759 & 0.106686 & 0.139 & 0.03 & 2.42 \\ \mathrm{H} & 0.142431 & -2.863093 & -1.122132 & 0.069 & 0.03 & 2.42 \\ \mathrm{H} & 1.906317 & -4.571391 & -1.501710 & 0.135 & 0.03 & 2.42 \\ \mathrm{H} & 4.324330 & -3.898560 & -1.217786 & 0.111 & 0.03 & 2.42 \\ \mathrm{H} & 4.843480 & -1.562543 & -0.549628 & 0.151 & 0.03 & 2.42 \\ \mathrm{C} & -2.911491 & 4.135201 & -0.252134 & 0.053 & 0.07 & 3.55 \\ \mathrm{C} & -3.139778 & 3.040704 & 0.582619 & -0.141 & 0.07 & 3.55 \\ \mathrm{C} & -2.282328 & 1.946760 & 0.516614 & 0.145 & 0.07 & 3.55 \\ \mathrm{~N} & -1.227982 & 1.892865 & -0.326208 & -0.301 & 0.17 & 3.25 \\ \mathrm{C} & -1.006013 & 2.960931 & -1.127313 & 0.210 & 0.07 & 3.55 \\ \mathrm{C} & -1.820292 & 4.088778 & -1.121063 & -0.154 & 0.07 & 3.55 \\ \mathrm{H} & -3.567012 & 5.005596 & -0.224310 & 0.107 & 0.03 & 2.42 \\ \mathrm{H} & -3.972171 & 3.022790 & 1.284481 & 0.126 & 0.03 & 2.42 \\ \mathrm{H} & -2.442333 & 1.091237 & 1.164911 & 0.061 & 0.03 & 2.42 \\ \mathrm{H} & -0.143738 & 2.903774 & -1.787630 & 0.037 & 0.03 & 2.42 \\ \mathrm{H} & -1.590092 & 4.915192 & -1.791713 & 0.131 & 0.03 & 2.42 \\ \mathrm{O} & 0.457317 & 0.546616 & -2.313170 & -0.764 & 0.1521 & 3.1506 \\ \mathrm{H} & -0.270837 & 0.961939 & -2.796714 & 0.391 & 0.0000 & 0.0000\end{array}$

$\left[\mathrm{Ru}^{\mathrm{IV}}(\mathrm{O})(\text { py })(\text { bpy })_{2}\right]^{2+}$

\begin{tabular}{|c|c|c|c|c|c|c|c|}
\hline & $\mathrm{X}$ & $\mathrm{Y}$ & Z & $Q(e)$ & \multicolumn{2}{|c|}{$\mathrm{E}(\mathrm{kcal} / \mathrm{mol})$} & S (Ang.) \\
\hline $\mathrm{C}$ & -3.194061 & -2.547517 & 0.189697 & -0.148 & 0.07 & 3.55 & \\
\hline $\mathrm{C}$ & -2.071924 & -1.720005 & 0.288314 & 0.144 & 0.07 & 3.55 & \\
\hline $\mathrm{N}$ & -1.592354 & -1.070576 & -0.807077 & -0.203 & 0.17 & 3.25 & \\
\hline $\mathrm{C}$ & -2.198767 & -1.229303 & -1.997599 & 0.096 & 0.07 & 3.55 & \\
\hline C & -3.316699 & -2.042599 & -2.156566 & -0.121 & 0.07 & 3.55 & \\
\hline $\mathrm{C}$ & -3.824728 & -2.710523 & -1.042295 & 0.066 & 0.07 & 3.55 & \\
\hline $\mathrm{H}$ & -3.773252 & -2.141767 & -3.139758 & 0.130 & 0.03 & 2.42 & \\
\hline $\mathrm{H}$ & -1.759098 & -0.685804 & -2.830986 & 0.118 & 0.03 & 2.42 & \\
\hline C & -1.630511 & -2.144898 & 2.747132 & -0.151 & 0.07 & 3.55 & \\
\hline C & -1.330466 & -1.493295 & 1.547392 & 0.205 & 0.07 & 3.55 & \\
\hline $\mathrm{N}$ & -0.306017 & -0.602960 & 1.473216 & -0.360 & 0.17 & 3.25 & \\
\hline C & 0.431845 & -0.351691 & 2.569536 & 0.200 & 0.07 & 3.55 & \\
\hline C & 0.186023 & -0.965807 & 3.793808 & -0.116 & 0.07 & 3.55 & \\
\hline C & -0.866018 & -1.878300 & 3.881872 & 0.058 & 0.07 & 3.55 & \\
\hline $\mathrm{H}$ & -2.447798 & -2.859316 & 2.800651 & 0.141 & 0.03 & 2.42 & \\
\hline $\mathrm{Ru}$ & 0.052136 & 0.215899 & -0.534871 & 1.013 & 0.40 & 1.80 & \\
\hline $\mathrm{C}$ & 4.152231 & 1.292992 & 0.129111 & -0.176 & 0.07 & 3.55 & \\
\hline C & 2.938318 & 0.651033 & -0.125501 & 0.213 & 0.07 & 3.55 & \\
\hline $\mathrm{N}$ & 1.763320 & 1.336781 & -0.060718 & -0.205 & 0.17 & 3.25 & \\
\hline $\mathrm{C}$ & 1.770745 & 2.646187 & 0.243542 & 0.108 & 0.07 & 3.55 & \\
\hline C & 2.947799 & 3.340061 & 0.507957 & -0.092 & 0.07 & 3.55 & \\
\hline $\mathrm{C}$ & 4.158429 & 2.649796 & 0.450158 & 0.057 & 0.07 & 3.55 & \\
\hline C & 3.920076 & -1.639330 & -0.582574 & -0.133 & 0.07 & 3.55 & \\
\hline C & 2.825374 & -0.777334 & -0.483699 & 0.123 & 0.07 & 3.55 & \\
\hline $\mathrm{N}$ & 1.563892 & -1.226662 & -0.726154 & -0.191 & 0.17 & 3.25 & \\
\hline C & 1.368638 & -2.507680 & -1.079728 & 0.074 & 0.07 & 3.55 & \\
\hline C & 2.419128 & -3.413014 & -1.199942 & -0.097 & 0.07 & 3.55 & \\
\hline C & 3.716436 & -2.970567 & -0.942774 & 0.059 & 0.07 & 3.55 & \\
\hline $\mathrm{H}$ & 1.239963 & 0.368044 & 2.459122 & 0.034 & 0.03 & 2.42 & \\
\hline $\mathrm{H}$ & -1.090338 & -2.381628 & 4.821840 & 0.112 & 0.03 & 2.42 & \\
\hline $\mathrm{H}$ & 0.810402 & -0.727851 & 4.653076 & 0.129 & 0.03 & 2.42 & \\
\hline $\mathrm{H}$ & -3.579371 & -3.059615 & 1.067560 & 0.138 & 0.03 & 2.42 & \\
\hline
\end{tabular}




$\begin{array}{rrrrrrr}\mathrm{H} & -4.700938 & -3.352379 & -1.127023 & 0.109 & 0.03 & 2.42 \\ \mathrm{H} & 0.806088 & 3.144422 & 0.273565 & 0.082 & 0.03 & 2.42 \\ \mathrm{H} & 2.904137 & 4.400034 & 0.751084 & 0.124 & 0.03 & 2.42 \\ \mathrm{H} & 5.100578 & 3.159258 & 0.649736 & 0.115 & 0.03 & 2.42 \\ \mathrm{H} & 5.088810 & 0.744105 & 0.074658 & 0.154 & 0.03 & 2.42 \\ \mathrm{H} & 0.343622 & -2.810969 & -1.273655 & 0.093 & 0.03 & 2.42 \\ \mathrm{H} & 2.211919 & -4.441421 & -1.490044 & 0.129 & 0.03 & 2.42 \\ \mathrm{H} & 4.563889 & -3.650546 & -1.023144 & 0.111 & 0.03 & 2.42 \\ \mathrm{H} & 4.925548 & -1.278859 & -0.382048 & 0.136 & 0.03 & 2.42 \\ \mathrm{C} & -3.285445 & 3.839164 & 0.038791 & 0.071 & 0.07 & 3.55 \\ \mathrm{C} & -2.816919 & 3.137724 & 1.150344 & -0.139 & 0.07 & 3.55 \\ \mathrm{C} & -1.875954 & 2.129164 & 0.968576 & 0.142 & 0.07 & 3.55 \\ \mathrm{~N} & -1.389695 & 1.797354 & -0.248387 & -0.281 & 0.17 & 3.25 \\ \mathrm{C} & -1.844764 & 2.478954 & -1.324021 & 0.119 & 0.07 & 3.55 \\ \mathrm{C} & -2.785592 & 3.498495 & -1.218713 & -0.133 & 0.07 & 3.55 \\ \mathrm{H} & -4.022744 & 4.634192 & 0.150739 & 0.099 & 0.03 & 2.42 \\ \mathrm{H} & -3.169220 & 3.360958 & 2.156201 & 0.123 & 0.03 & 2.42 \\ \mathrm{H} & -1.495327 & 1.574708 & 1.820633 & 0.065 & 0.03 & 2.42 \\ \mathrm{H} & -1.425663 & 2.189100 & -2.284242 & 0.110 & 0.03 & 2.42 \\ \mathrm{H} & -3.113972 & 4.013551 & -2.120251 & 0.120 & 0.03 & 2.42 \\ \mathrm{O} & 0.156952 & 0.629306 & -2.250805 & -0.570 & 0.21 & 2.96\end{array}$




\section{Exemplos de inputs para simulações de Dinâmica Molecular no GROMACS}

Topologia MD (*.top) para o complexo $R u^{I I}\left(H_{2} O\right)$ em solução aquosa

[ defaults ]

; nbfunc

comb-rule

3

gen-pairs

fudgeLJ

1.0

fudgeQQ

1.0

[ atomtypes ]

; name1 name2

C_2 C_2

mass

12.0107

charge

12.0107

0.0000

ptype

sigma

epsilon

C_R C_R

14.0067

0.0000

A

0.355

0.0000

0.355

0.29288

N_R N_R

12.0107

0.0000

0.325

0.29288

C_3 C_3

$\mathrm{H}_{-} \quad \mathrm{H}_{-}$

1.0079

0.0000

0.355

0.71128

Ru6 Ru6

101.0700

0.0000

$A$

0.242

0.29288

N_2 N_2

14.0067

0.0000

0.180

0.12552

0_3

0_3

15.9994

0.0000

0.325

1.67360

A

0.31506

0.71128

opls_111

opls_112

OW 8

9.95140

$-0.834$

4.03200

0.417

0.31506

0.63638

opls_401

$\begin{array}{lr}\text { HW } & 1 \\ \text { Cl } & 17\end{array}$

35.45300

$-1.000$

0.00000

0.636386

0.44172

0.000000

0.492833

\#include "ru.itp"

\#include "tip3p.itp"

\#include "ions.itp"

[ system ]

UFF MOLECULE in water

[ molecules ]

UFF 1

SOL 4000

CL 2 


\section{Topologia MD (*.itp) para o complexo $R u^{I I}\left(H_{2} O\right)$ em solução aquosa}

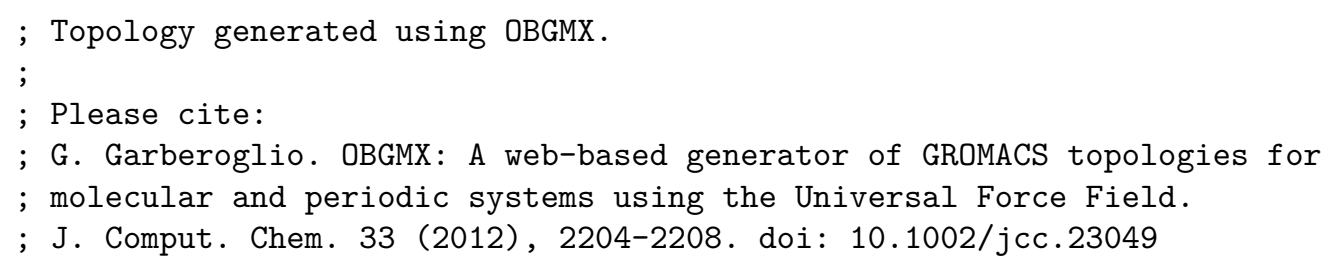

\begin{tabular}{lcrr} 
atom & cgnr & charge & \multicolumn{1}{l}{ mass } \\
C_2 & 1 & -0.151 & 12.0107 \\
C_R & 1 & 0.122 & 12.0107 \\
N_R & 1 & -0.234 & 14.0067 \\
C_2 & 1 & 0.099 & 12.0107 \\
C_2 & 1 & -0.128 & 12.0107 \\
C_3 & 1 & 0.042 & 12.0107 \\
H_ & 1 & 0.133 & 1.0079 \\
H_ & 1 & 0.095 & 1.0079 \\
C_2 & 1 & -0.199 & 12.0107 \\
C_R & 1 & 0.249 & 12.0107 \\
N_R & 1 & -0.420 & 14.0067 \\
C_2 & 1 & 0.233 & 12.0107 \\
C_2 & 1 & -0.164 & 12.0107 \\
C_3 & 1 & 0.072 & 12.0107 \\
H_ & 1 & 0.148 & 1.0079 \\
Ru6 & 1 & 0.944 & 101.0700 \\
C_2 & 1 & -0.176 & 12.0107 \\
C_R & 1 & 0.197 & 12.0107 \\
N_R & 1 & -0.371 & 14.0067 \\
C_2 & 1 & 0.220 & 12.0107 \\
C_2 & 1 & -0.167 & 12.0107 \\
C_3 & 1 & 0.076 & 12.0107 \\
C_2 & 1 & -0.187 & 12.0107 \\
C_R & 1 & 0.207 & 12.0107 \\
N_R & 1 & -0.354 & 14.0067 \\
C_2 & 1 & 0.170 & 12.0107 \\
C_2 & 1 & -0.146 & 12.0107 \\
C_3 & 1 & 0.065 & 12.0107 \\
H_ & 1 & 0.046 & 1.0079 \\
H_ & 1 & 0.107 & 1.0079 \\
H_ & 1 & 0.134 & 1.0079 \\
H_ & 1 & 0.139 & 1.0079 \\
H_ & 1 & 0.111 & 1.0079 \\
H_ & 1 & 0.047 & 1.0079 \\
H_ & 1 & 0.134 & 1.0079 \\
H_ & 1 & 0.105 & 1.0079 \\
H_- & 1 & 0.141 & 1.0079 \\
H_ & 1 & 0.060 & 1.0079 \\
H_ & 1 & 0.131 & 1.0079 \\
& 1 & 0.109 & 1.0079 \\
H_ & 1 & 0.145 & 1.0079
\end{tabular}




\begin{tabular}{|c|c|c|c|c|c|c|c|}
\hline 42 & C_3 & 1 & $\mathrm{UFF}$ & C_3 & 1 & 0.073 & 12.0107 \\
\hline 43 & C_2 & 1 & UFF & C_2 & 1 & -0.185 & 12.0107 \\
\hline 44 & C_2 & 1 & UFF & C_2 & 1 & 0.222 & 12.0107 \\
\hline 45 & N_2 & 1 & UFF & N_2 & 1 & -0.368 & 14.0067 \\
\hline 46 & C_2 & 1 & $\mathrm{UFF}$ & C_2 & 1 & 0.204 & 12.0107 \\
\hline 47 & C_2 & 1 & UFF & C_2 & 1 & -0.199 & 12.0107 \\
\hline 48 & $\mathrm{H}_{-}$ & 1 & UFF & $\mathrm{H}_{-}$ & 1 & 0.105 & 1.0079 \\
\hline 49 & $\mathrm{H}_{-}$ & 1 & UFF & $\mathrm{H}_{-}$ & 1 & 0.136 & 1.0079 \\
\hline 50 & $\mathrm{H}_{-}$ & 1 & UFF & $\mathrm{H}_{-}$ & 1 & 0.030 & 1.0079 \\
\hline 51 & $\mathrm{H}_{-}$ & 1 & $\mathrm{UFF}$ & $\mathrm{H}_{-}$ & 1 & 0.051 & 1.0079 \\
\hline 52 & $\mathrm{H}_{-}$ & 1 & UFF & $\mathrm{H}_{-}$ & 1 & 0.147 & 1.0079 \\
\hline 53 & $0 \_3$ & 1 & UFF & 0_3 & 1 & -0.834 & 15.9994 \\
\hline 54 & $\mathrm{H}_{-}$ & 1 & UFF & $\mathrm{H}_{-}$ & 1 & 0.417 & 1.0079 \\
\hline 55 & $\mathrm{H}_{-}$ & 1 & UFF & $\mathrm{H}_{-}$ & 1 & 0.417 & 1.0079 \\
\hline
\end{tabular}

[ bonds ]$$
7
$$
0.1089296830 .6400
$0.0968 \quad 468917.5853$
$0.1088 \quad 296830.6400$
$0.0969 \quad 468917.5853$
$0.2213 \quad 257670.4027$
$0.1087 \quad 296830.6400$
0.1089296830 .6400
$0.1392 \quad 433204.9028$
$0.1396 \quad 307907.6346$
$0.1347 \quad 467220.5256$
$0.1392 \quad 433204.9028$
$0.1352 \quad 481210.5024$
$0.1395 \quad 307907.6346$
0.1089296830 .6400
$0.1087 \quad 296830.6400$
$0.1089 \quad 277224.2634$
$0.1393 \quad 307907.6346$
$0.1392 \quad 433204.9028$
$0.1396 \quad 307907.6346$
$0.1347 \quad 467220.5256$
$0.1090 \quad 277224.2634$
$0.2077 \quad 251827.5702$
$0.1363 \quad 470170.3983$
$0.1393 \quad 307907.6346$
$0.2081 \quad 251827.5702$
$0.1364 \quad 470170.3983$
$0.1399 \quad 435878.9996$
$0.1087 \quad 296830.6400$
$0.2143 \quad 256665.3987$
$0.2099 \quad 251827.5702$
$0.2043 \quad 251827.5702$
$0.1475 \quad 327968.3830$
$0.1352 \quad 481210.5024$
$0.1090 \quad 277224.2634$
$0.1396 \quad 307907.6346$
$0.1364 \quad 470170.3983$
$0.1399 \quad 435878.9996$
$0.1348 \quad 467220.5256$
$0.1087 \quad 296830.6400$
$0.1393 \quad 307907.6346$
$0.1087 \quad 296830.6400$
$0.1392 \quad 433204.9028$
$0.1398 \quad 435878.9996$ 


$\begin{array}{lllll}1 & 32 & 1 & 0.1087 & 296830.6400 \\ 2 & 10 & 1 & 0.1473 & 327968.3830 \\ 22 & 21 & 1 & 0.1396 & 307907.6346 \\ 22 & 36 & 1 & 0.1090 & 277224.2634 \\ 21 & 35 & 1 & 0.1089 & 296830.6400 \\ 44 & 43 & 1 & 0.1392 & 433204.9028 \\ 44 & 50 & 1 & 0.1087 & 296830.6400 \\ 43 & 49 & 1 & 0.1089 & 296830.6400 \\ 11 & 10 & 1 & 0.1366 & 470170.3983 \\ 11 & 12 & 1 & 0.1349 & 467220.5256 \\ 10 & 9 & 1 & 0.1398 & 435878.9996 \\ 29 & 12 & 1 & 0.1087 & 296830.6400 \\ 12 & 13 & 1 & 0.1391 & 433204.9028 \\ 9 & 15 & 1 & 0.1087 & 296830.6400 \\ 9 & 14 & 1 & 0.1392 & 307907.6346 \\ 13 & 14 & 1 & 0.1396 & 307907.6346 \\ 13 & 31 & 1 & 0.1089 & 296830.6400 \\ 14 & 30 & 1 & 0.1089 & 277224.2634\end{array}$

[ angles ]

$\begin{array}{llllrr}2 & 1 & 6 & 2 & 119.5666 & 1505.3731 \\ 6 & 1 & 32 & 2 & 119.9751 & 713.7319 \\ 2 & 1 & 32 & 2 & 120.4583 & 885.1204 \\ 1 & 2 & 3 & 2 & 121.1870 & 2158.5603 \\ 3 & 2 & 10 & 2 & 114.5925 & 1878.0024 \\ 1 & 2 & 10 & 2 & 124.2167 & 1558.4550 \\ 4 & 3 & 16 & 2 & 125.7182 & 1278.6077 \\ 2 & 3 & 4 & 2 & 118.9753 & 1461.1132 \\ 2 & 3 & 16 & 2 & 115.2695 & 1281.1829 \\ 5 & 4 & 8 & 2 & 121.0717 & 881.8930 \\ 3 & 4 & 8 & 2 & 116.3227 & 1032.3413 \\ 3 & 4 & 5 & 2 & 122.6054 & 2145.1577 \\ 4 & 5 & 7 & 2 & 119.6073 & 881.8930 \\ 6 & 5 & 7 & 2 & 121.5746 & 713.7319 \\ 4 & 5 & 6 & 2 & 118.8181 & 1501.2419 \\ 5 & 6 & 33 & 2 & 120.8937 & 554.0843 \\ 1 & 6 & 5 & 2 & 118.8473 & 1028.6921 \\ 1 & 6 & 33 & 2 & 120.2590 & 554.0843 \\ 10 & 9 & 15 & 2 & 120.1258 & 885.1204 \\ 10 & 9 & 14 & 2 & 119.8473 & 1505.3731 \\ 14 & 9 & 15 & 2 & 120.0262 & 713.7319 \\ 2 & 10 & 11 & 2 & 115.0705 & 1878.0024 \\ 2 & 10 & 9 & 2 & 123.8104 & 1558.4550 \\ 9 & 10 & 11 & 2 & 121.1150 & 2158.5603 \\ 10 & 11 & 16 & 2 & 116.0448 & 1281.1829 \\ 12 & 11 & 16 & 2 & 125.2370 & 1278.6077 \\ 10 & 11 & 12 & 2 & 118.6886 & 1461.1132 \\ 11 & 12 & 29 & 2 & 116.3912 & 1032.3413 \\ 11 & 12 & 13 & 2 & 122.7503 & 2145.1577 \\ 13 & 12 & 29 & 2 & 120.8579 & 881.8930 \\ 12 & 13 & 14 & 2 & 118.9441 & 1501.2419 \\ 12 & 13 & 31 & 2 & 119.4133 & 881.8930 \\ 14 & 13 & 31 & 2 & 121.6426 & 713.7319 \\ 9 & 14 & 13 & 2 & 118.6494 & 1028.6921 \\ 9 & 14 & 30 & 2 & 120.3662 & 554.0843 \\ 13 & 14 & 30 & 2 & 120.9840 & 554.0843 \\ 3 & 16 & 53 & 2 & 95.2320 & 1860.3740 \\ 25 & 16 & 53 & 2 & 89.7106 & 1860.3740 \\ 45 & 16 & 53 & 2 & 88.7586 & 1879.2927\end{array}$




\begin{tabular}{|c|c|c|c|c|c|}
\hline 19 & 16 & 53 & 2 & 86.6373 & 1860.3740 \\
\hline 11 & 16 & 53 & 2 & 174.0898 & 1860.3740 \\
\hline 3 & 16 & 25 & 2 & 97.6661 & 1938.3757 \\
\hline 3 & 16 & 45 & 2 & 86.6715 & 1956.8076 \\
\hline 3 & 16 & 19 & 2 & 175.5242 & 1938.3757 \\
\hline 3 & 16 & 11 & 2 & 78.9675 & 1938.3757 \\
\hline 25 & 16 & 45 & 2 & 175.5162 & 1956.8076 \\
\hline 19 & 16 & 25 & 2 & 78.2532 & 1938.3757 \\
\hline 11 & 16 & 25 & 2 & 89.9472 & 1938.3757 \\
\hline 19 & 16 & 45 & 2 & 97.4473 & 1956.8076 \\
\hline 11 & 16 & 45 & 2 & 92.0076 & 1956.8076 \\
\hline 11 & 16 & 19 & 2 & 99.0680 & 1938.3757 \\
\hline 18 & 17 & 37 & 2 & 120.3512 & 885.1204 \\
\hline 18 & 17 & 22 & 2 & 119.7354 & 1505.3731 \\
\hline 22 & 17 & 37 & 2 & 119.9130 & 713.7319 \\
\hline 19 & 18 & 24 & 2 & 115.1875 & 1878.0024 \\
\hline 17 & 18 & 24 & 2 & 123.5690 & 1558.4550 \\
\hline 17 & 18 & 19 & 2 & 121.2424 & 2158.5603 \\
\hline 16 & 19 & 18 & 2 & 115.3459 & 1281.1829 \\
\hline 16 & 19 & 20 & 2 & 125.9967 & 1278.6077 \\
\hline 18 & 19 & 20 & 2 & 118.5998 & 1461.1132 \\
\hline 19 & 20 & 34 & 2 & 116.3545 & 1032.3413 \\
\hline 19 & 20 & 21 & 2 & 122.9154 & 2145.1577 \\
\hline 21 & 20 & 34 & 2 & 120.7301 & 881.8930 \\
\hline 20 & 21 & 22 & 2 & 118.7803 & 1501.2419 \\
\hline 20 & 21 & 35 & 2 & 119.5529 & 881.8930 \\
\hline 22 & 21 & 35 & 2 & 121.6668 & 713.7319 \\
\hline 17 & 22 & 21 & 2 & 118.7190 & 1028.6921 \\
\hline 17 & 22 & 36 & 2 & 120.3057 & 554.0843 \\
\hline 21 & 22 & 36 & 2 & 120.9746 & 554.0843 \\
\hline 24 & 23 & 28 & 2 & 119.7267 & 1505.3731 \\
\hline 28 & 23 & 41 & 2 & 119.9244 & 713.7319 \\
\hline 24 & 23 & 41 & 2 & 120.3489 & 885.1204 \\
\hline 23 & 24 & 25 & 2 & 121.1400 & 2158.5603 \\
\hline 18 & 24 & 25 & 2 & 115.2329 & 1878.0024 \\
\hline 18 & 24 & 23 & 2 & 123.6265 & 1558.4550 \\
\hline 16 & 25 & 26 & 2 & 125.2295 & 1278.6077 \\
\hline 24 & 25 & 26 & 2 & 118.8033 & 1461.1132 \\
\hline 16 & 25 & 24 & 2 & 115.9595 & 1281.1829 \\
\hline 27 & 26 & 38 & 2 & 120.8241 & 881.8930 \\
\hline 25 & 26 & 38 & 2 & 116.4058 & 1032.3413 \\
\hline 25 & 26 & 27 & 2 & 122.7700 & 2145.1577 \\
\hline 26 & 27 & 39 & 2 & 119.5431 & 881.8930 \\
\hline 28 & 27 & 39 & 2 & 121.6462 & 713.7319 \\
\hline 26 & 27 & 28 & 2 & 118.8107 & 1501.2419 \\
\hline 27 & 28 & 40 & 2 & 120.9493 & 554.084 \\
\hline 23 & 28 & 27 & 2 & 118.7493 & 1028.6921 \\
\hline 23 & 28 & 40 & 2 & 120.3013 & 554.0843 \\
\hline 47 & 42 & 48 & 2 & 120.9377 & 554.0843 \\
\hline 43 & 42 & 47 & 2 & 118.1621 & 1028.6921 \\
\hline 43 & 42 & 48 & 2 & 120.9001 & 554.0843 \\
\hline 42 & 43 & 44 & 2 & 119.1914 & 1501.2419 \\
\hline 42 & 43 & 49 & 2 & 121.5189 & 713.7319 \\
\hline 44 & 43 & 49 & 2 & 119.2897 & 881.8930 \\
\hline 43 & 44 & 45 & 2 & 123.0201 & 2178.9870 \\
\hline 45 & 44 & 50 & 2 & 116.8406 & 1051.5045 \\
\hline 43 & 44 & 50 & 2 & 120.1392 & 881.8930 \\
\hline 16 & 45 & 46 & 2 & 120.1302 & 1566.5622 \\
\hline 44 & 45 & 46 & 2 & 117.4212 & 1830.5395 \\
\hline
\end{tabular}




$\begin{array}{rrrrrr}16 & 45 & 44 & 2 & 122.4359 & 1566.5622 \\ 47 & 46 & 51 & 2 & 120.4772 & 881.8930 \\ 45 & 46 & 51 & 2 & 116.5364 & 1051.5045 \\ 45 & 46 & 47 & 2 & 122.9850 & 2178.9870 \\ 46 & 47 & 52 & 2 & 119.2868 & 881.8930 \\ 42 & 47 & 52 & 2 & 121.4956 & 713.7319 \\ 42 & 47 & 46 & 2 & 119.2176 & 1501.2419 \\ 54 & 53 & 55 & 2 & 105.0722 & 522.0894 \\ 16 & 53 & 54 & 2 & 114.6792 & 538.2431 \\ 16 & 53 & 55 & 2 & 115.3829 & 538.2431\end{array}$

[ dihedrals ]

\begin{tabular}{|c|c|c|c|c|c|c|}
\hline 7 & 5 & 4 & 8 & 1 & 179.8798 & 20.3968 \\
\hline 7 & 5 & 4 & 3 & 1 & -179.7912 & 20.3968 \\
\hline 6 & 5 & 4 & 8 & 1 & 179.9488 & 20.3968 \\
\hline 6 & 5 & 4 & 3 & 1 & -179.7156 & 20.3968 \\
\hline 7 & 5 & 6 & 33 & 1 & 179.7535 & 0.5233 \\
\hline 7 & 5 & 6 & 1 & 1 & 179.4356 & 0.5233 \\
\hline 4 & 5 & 6 & 33 & 1 & 179.8463 & 0.5233 \\
\hline 4 & 5 & 6 & 1 & 1 & 179.2043 & 0.5233 \\
\hline 8 & 4 & 3 & 16 & 1 & -175.2788 & 5.2335 \\
\hline 8 & 4 & 3 & 2 & 1 & -179.9488 & 5.2335 \\
\hline 5 & 4 & 3 & 16 & 1 & -175.5933 & 5.2335 \\
\hline 5 & 4 & 3 & 2 & 1 & 179.7587 & 5.2335 \\
\hline 51 & 46 & 47 & 52 & 1 & -179.5841 & 20.3968 \\
\hline 51 & 46 & 47 & 42 & 1 & -179.6980 & 20.3968 \\
\hline 45 & 46 & 47 & 52 & 1 & 179.5372 & 20.3968 \\
\hline 45 & 46 & 47 & 42 & 1 & 179.4233 & 20.3968 \\
\hline 51 & 46 & 45 & 16 & 1 & 177.8149 & 5.2335 \\
\hline 51 & 46 & 45 & 44 & 1 & -179.6530 & 5.2335 \\
\hline 47 & 46 & 45 & 16 & 1 & 178.6613 & 5.2335 \\
\hline 47 & 46 & 45 & 44 & 1 & -178.8065 & 5.2335 \\
\hline 52 & 47 & 42 & 48 & 1 & 179.5713 & 0.5233 \\
\hline 52 & 47 & 42 & 43 & 1 & 179.0069 & 0.5233 \\
\hline 46 & 47 & 42 & 48 & 1 & 179.8463 & 0.5233 \\
\hline 46 & 47 & 42 & 43 & 1 & 179.3563 & 0.5233 \\
\hline 5 & 6 & 1 & 2 & 1 & -179.3491 & 0.5233 \\
\hline 5 & 6 & 1 & 32 & 1 & -179.8463 & 0.5233 \\
\hline 33 & 6 & 1 & 2 & 1 & -179.8463 & 0.5233 \\
\hline 33 & 6 & 1 & 32 & 1 & 179.8463 & 0.5233 \\
\hline 39 & 27 & 26 & 38 & 1 & 179.7871 & 20.3968 \\
\hline 39 & 27 & 26 & 25 & 1 & 179.9488 & 20.3968 \\
\hline 28 & 27 & 26 & 38 & 1 & 179.9488 & 20.3968 \\
\hline 28 & 27 & 26 & 25 & 1 & -179.9194 & 20.3968 \\
\hline 39 & 27 & 28 & 40 & 1 & 179.6953 & 0.5233 \\
\hline 39 & 27 & 28 & 23 & 1 & 179.8463 & 0.5233 \\
\hline 26 & 27 & 28 & 40 & 1 & 179.4300 & 0.5233 \\
\hline 26 & 27 & 28 & 23 & 1 & 179.5327 & 0.5233 \\
\hline 38 & 26 & 25 & 16 & 1 & -177.6247 & 5.2335 \\
\hline 38 & 26 & 25 & 24 & 1 & -179.7327 & 5.2335 \\
\hline 27 & 26 & 25 & 16 & 1 & -177.8231 & 5.2335 \\
\hline 27 & 26 & 25 & 24 & 1 & -179.9311 & 5.2335 \\
\hline 4 & 3 & 16 & 53 & 1 & 177.1259 & 0.5233 \\
\hline 4 & 3 & 16 & 25 & 1 & -3.7000 & 0.0523 \\
\hline 4 & 3 & 16 & 45 & 1 & -5.9819 & 0.0052 \\
\hline 4 & 3 & 16 & 19 & 1 & -51.9177 & 0.0005 \\
\hline 4 & 3 & 16 & 11 & 1 & 179.4163 & 0.0001 \\
\hline 2 & 3 & 16 & 53 & 1 & -178.3777 & 0.0000 \\
\hline 2 & 3 & 16 & 25 & 1 & 0.7964 & 0.0000 \\
\hline
\end{tabular}




\begin{tabular}{|c|c|c|c|c|c|c|}
\hline 4 & 3 & 2 & 1 & 1 & -179.8149 & 5.2335 \\
\hline 4 & 3 & 2 & 10 & 1 & 178.8326 & 5.2335 \\
\hline 16 & 3 & 2 & 1 & 1 & 176.0123 & 5.2335 \\
\hline 16 & 3 & 2 & 10 & 1 & 174.6598 & 5.2335 \\
\hline 27 & 28 & 23 & 24 & 1 & -179.7390 & 0.5233 \\
\hline 27 & 28 & 23 & 41 & 1 & 179.8463 & 0.5233 \\
\hline 40 & 28 & 23 & 24 & 1 & -179.8463 & 0.5233 \\
\hline 40 & 28 & 23 & 41 & 1 & 179.7840 & 0.5233 \\
\hline 26 & 25 & 16 & 53 & 1 & -23.3299 & 0.0523 \\
\hline 26 & 25 & 16 & 3 & 1 & -171.8886 & 0.0052 \\
\hline 26 & 25 & 16 & 45 & 1 & -83.5027 & 0.0005 \\
\hline 26 & 25 & 16 & 19 & 1 & 176.9167 & 0.0001 \\
\hline 26 & 25 & 16 & 11 & 1 & -58.7318 & 0.0000 \\
\hline 24 & 25 & 16 & 53 & 1 & -17.1664 & 0.0000 \\
\hline 26 & 25 & 24 & 23 & 1 & 179.8590 & 5.2335 \\
\hline 26 & 25 & 24 & 18 & 1 & 179.2905 & 5.2335 \\
\hline 16 & 25 & 24 & 23 & 1 & 177.9439 & 5.2335 \\
\hline 16 & 25 & 24 & 18 & 1 & 177.3754 & 5.2335 \\
\hline 28 & 23 & 24 & 25 & 1 & -179.9367 & 20.3968 \\
\hline 28 & 23 & 24 & 18 & 1 & -179.3191 & 20.3968 \\
\hline 41 & 23 & 24 & 25 & 1 & -179.7428 & 20.3968 \\
\hline 41 & 23 & 24 & 18 & 1 & -179.1252 & 20.3968 \\
\hline 53 & 16 & 45 & 46 & 1 & -128.9041 & 2.0397 \\
\hline 53 & 16 & 45 & 44 & 1 & -131.5673 & 0.2040 \\
\hline 3 & 16 & 45 & 46 & 1 & 40.4667 & 0.0204 \\
\hline 3 & 16 & 45 & 44 & 1 & 37.8036 & 0.0020 \\
\hline 25 & 16 & 45 & 46 & 1 & 11.2235 & 0.0002 \\
\hline 25 & 16 & 45 & 44 & 1 & 8.5604 & 0.0000 \\
\hline 19 & 16 & 45 & 46 & 1 & 43.9865 & 0.0000 \\
\hline 19 & 16 & 45 & 44 & 1 & 41.3233 & 0.0000 \\
\hline 25 & 24 & 18 & 19 & 1 & -176.6363 & 5.2335 \\
\hline 25 & 24 & 18 & 17 & 1 & -175.8777 & 5.2335 \\
\hline 23 & 24 & 18 & 19 & 1 & -177.2206 & 5.2335 \\
\hline 23 & 24 & 18 & 17 & 1 & -176.4621 & 5.2335 \\
\hline 46 & 45 & 44 & 43 & 1 & 178.9432 & 5.2335 \\
\hline 46 & 45 & 44 & 50 & 1 & 178.7450 & 5.2335 \\
\hline 16 & 45 & 44 & 43 & 1 & -178.4620 & 5.2335 \\
\hline 16 & 45 & 44 & 50 & 1 & -178.6602 & 5.2335 \\
\hline 47 & 42 & 43 & 44 & 1 & -178.9752 & 0.5233 \\
\hline 47 & 42 & 43 & 49 & 1 & -178.7567 & 0.5233 \\
\hline 48 & 42 & 43 & 44 & 1 & -179.8463 & 0.5233 \\
\hline 48 & 42 & 43 & 49 & 1 & -179.3208 & 0.5233 \\
\hline 24 & 18 & 19 & 16 & 1 & 177.5252 & 5.2335 \\
\hline 24 & 18 & 19 & 20 & 1 & -177.2850 & 5.2335 \\
\hline 17 & 18 & 19 & 16 & 1 & 176.7859 & 5.2335 \\
\hline 17 & 18 & 19 & 20 & 1 & -178.0242 & 5.2335 \\
\hline 24 & 18 & 17 & 37 & 1 & 178.8698 & 20.3968 \\
\hline 24 & 18 & 17 & 22 & 1 & 178.3704 & 20.3968 \\
\hline 19 & 18 & 17 & 37 & 1 & 179.6727 & 20.3968 \\
\hline 19 & 18 & 17 & 22 & 1 & 179.1732 & 20.3968 \\
\hline 16 & 19 & 20 & 34 & 1 & -175.9968 & 5.2335 \\
\hline 16 & 19 & 20 & 21 & 1 & -175.9592 & 5.2335 \\
\hline 18 & 19 & 20 & 34 & 1 & 178.2055 & 5.2335 \\
\hline 18 & 19 & 20 & 21 & 1 & 178.2431 & 5.2335 \\
\hline 18 & 17 & 22 & 21 & 1 & 178.2380 & 0.5233 \\
\hline 18 & 17 & 22 & 36 & 1 & 179.8463 & 0.5233 \\
\hline 37 & 17 & 22 & 21 & 1 & 176.7462 & 0.5233 \\
\hline 37 & 17 & 22 & 36 & 1 & 178.4892 & 0.5233 \\
\hline 19 & 20 & 21 & 22 & 1 & -179.6385 & 20.3968 \\
\hline
\end{tabular}




$\begin{array}{llllrrrr}19 & 20 & 21 & 35 & 1 & -179.7522 & 20.3968 & 2 \\ 34 & 20 & 21 & 22 & 1 & -179.5993 & 20.3968 & 2 \\ 34 & 20 & 21 & 35 & 1 & -179.7129 & 20.3968 & 2 \\ 6 & 1 & 2 & 3 & 1 & 179.8221 & 20.3968 & 2 \\ 6 & 1 & 2 & 10 & 1 & -178.6906 & 20.3968 & 2 \\ 32 & 1 & 2 & 3 & 1 & 179.9488 & 20.3968 & 2 \\ 32 & 1 & 2 & 10 & 1 & -178.5660 & 20.3968 & 2 \\ 3 & 2 & 10 & 11 & 1 & -176.0641 & 5.2335 & 2 \\ 3 & 2 & 10 & 9 & 1 & -174.5935 & 5.2335 & 2 \\ 1 & 2 & 10 & 11 & 1 & -177.4633 & 5.2335 & 2 \\ 1 & 2 & 10 & 9 & 1 & -175.9927 & 5.2335 & 2 \\ 17 & 22 & 21 & 20 & 1 & -177.5447 & 0.5233 & 6 \\ 17 & 22 & 21 & 35 & 1 & -177.1962 & 0.5233 & 6 \\ 36 & 22 & 21 & 20 & 1 & -179.2997 & 0.5233 & 6 \\ 36 & 22 & 21 & 35 & 1 & -178.9513 & 0.5233 & 6 \\ 45 & 44 & 43 & 42 & 1 & -179.6934 & 20.3968 & 2 \\ 45 & 44 & 43 & 49 & 1 & -179.7645 & 20.3968 & 2 \\ 50 & 44 & 43 & 42 & 1 & -179.4889 & 20.3968 & 2 \\ 50 & 44 & 43 & 49 & 1 & -179.5601 & 20.3968 & 2 \\ 16 & 11 & 10 & 2 & 1 & 179.3995 & 5.2335 & 2 \\ 16 & 11 & 10 & 9 & 1 & 177.9723 & 5.2335 & 2 \\ 12 & 11 & 10 & 2 & 1 & -176.8485 & 5.2335 & 2 \\ 12 & 11 & 10 & 9 & 1 & -178.2757 & 5.2335 & 2 \\ 16 & 11 & 12 & 29 & 1 & -176.5657 & 5.2335 & 2 \\ 16 & 11 & 12 & 13 & 1 & -177.1257 & 5.2335 & 2 \\ 10 & 11 & 12 & 29 & 1 & 179.3069 & 5.2335 & 2 \\ 10 & 11 & 12 & 13 & 1 & 178.7469 & 5.2335 & 2 \\ 2 & 10 & 9 & 15 & 1 & 178.0416 & 20.3968 & 2 \\ 2 & 10 & 9 & 14 & 1 & 177.4447 & 20.3968 & 2 \\ 11 & 10 & 9 & 15 & 1 & 179.5975 & 20.3968 & 2 \\ 11 & 10 & 9 & 14 & 1 & 179.0006 & 20.3968 & 2 \\ 11 & 12 & 13 & 14 & 1 & -179.9488 & 20.3968 & 2 \\ 11 & 12 & 13 & 31 & 1 & -179.8196 & 20.3968 & 2 \\ 29 & 12 & 13 & 14 & 1 & 179.4562 & 20.3968 & 2 \\ 29 & 12 & 13 & 31 & 1 & 179.5961 & 20.3968 & 2 \\ 10 & 9 & 14 & 13 & 1 & 179.3024 & 0.5233 & 6 \\ 10 & 9 & 14 & 30 & 1 & -179.3640 & 0.5233 & 6 \\ 15 & 9 & 14 & 13 & 1 & 177.5134 & 0.5233 & 6 \\ 15 & 9 & 14 & 30 & 1 & 178.8470 & 0.5233 & 6 \\ 12 & 13 & 14 & 9 & 1 & -177.9008 & 0.5233 & 6 \\ & 13 & 14 & 30 & 1 & -179.2430 & 0.5233 & 6 \\ 31 & 13 & 14 & 30 & 1 & -179.6722 & 0.5233 & 6\end{array}$

[ dihedrals ]

; inversion terms (improper dihedrals)

$\begin{array}{lllllll}\text {; [0] } & \text { C_2 }_{-} & \text {C_R }_{-} & \text {C_3 }_{-} & \text {H } 2 & 0.0000 & 8.3736 \\ 1 & 6 & 2 & 32 & 2 & 0.0000 & 8.3736 \\ 1 & 32 & 2 & 6 & 2 & 0.0000 & 8.3736 \\ 1 & 6 & 32 & 2 & 2 & 0.0000 & 8.3736 \\ 2 & 3 & 1 & 10 & 2 & 0.0000 & 8.3736 \\ 2 & 10 & 1 & 3 & 2 & 0.0000 & 8.3736 \\ 2 & 3 & 10 & 1 & 2 & 0.0000 & 8.3736 \\ 3 & 4 & 16 & 2 & 2 & 0.0000 & 8.3736 \\ 3 & 2 & 16 & 4 & 2 & 0.0000 & 8.3736 \\ 3 & 4 & 2 & 16 & 2 & 0.0000 & 8.3736 \\ 4 & 8 & 5 & 3 & 2 & 0.0000 & 8.3736 \\ 4 & 3 & 5 & 8 & 2 & 0.0000 & 8.3736 \\ 4 & 8 & 3 & 5 & 2 & 0.0000 & 8.3736\end{array}$




\begin{tabular}{|c|c|c|c|c|c|c|}
\hline 5 & 7 & 4 & 6 & 2 & 0.0000 & 8.3736 \\
\hline 5 & 6 & 4 & 7 & 2 & 0.0000 & 8.3736 \\
\hline 5 & 7 & 6 & 4 & 2 & 0.0000 & 8.3736 \\
\hline 9 & 10 & 15 & 14 & 2 & 0.0000 & 8.3736 \\
\hline 9 & 14 & 15 & 10 & 2 & 0.0000 & 8.3736 \\
\hline 9 & 10 & 14 & 15 & 2 & 0.0000 & 8.3736 \\
\hline 10 & 2 & 11 & 9 & 2 & 0.0000 & 8.3736 \\
\hline 10 & 9 & 11 & 2 & 2 & 0.0000 & 8.3736 \\
\hline 10 & 2 & 9 & 11 & 2 & 0.0000 & 8.3736 \\
\hline 11 & 16 & 10 & 12 & 2 & 0.0000 & 8.3736 \\
\hline 11 & 12 & 10 & 16 & 2 & 0.0000 & 8.3736 \\
\hline 11 & 16 & 12 & 10 & 2 & 0.0000 & 8.3736 \\
\hline 12 & 11 & 29 & 13 & 2 & 0.0000 & 8.3736 \\
\hline 12 & 13 & 29 & 11 & 2 & 0.0000 & 8.3736 \\
\hline 12 & 11 & 13 & 29 & 2 & 0.0000 & 8.3736 \\
\hline 13 & 12 & 14 & 31 & 2 & 0.0000 & 8.3736 \\
\hline 13 & 31 & 14 & 12 & 2 & 0.0000 & 8.3736 \\
\hline 13 & 12 & 31 & 14 & 2 & 0.0000 & 8.3736 \\
\hline 17 & 18 & 37 & 22 & 2 & 0.0000 & 8.3736 \\
\hline 17 & 22 & 37 & 18 & 2 & 0.0000 & 8.3736 \\
\hline 17 & 18 & 22 & 37 & 2 & 0.0000 & 8.3736 \\
\hline 18 & 24 & 19 & 17 & 2 & 0.0000 & 8.3736 \\
\hline 18 & 17 & 19 & 24 & 2 & 0.0000 & 8.3736 \\
\hline 18 & 24 & 17 & 19 & 2 & 0.0000 & 8.3736 \\
\hline 19 & 16 & 18 & 20 & 2 & 0.0000 & 8.3736 \\
\hline 19 & 20 & 18 & 16 & 2 & 0.0000 & 8.3736 \\
\hline 19 & 16 & 20 & 18 & 2 & 0.0000 & 8.3736 \\
\hline 20 & 19 & 34 & 21 & 2 & 0.0000 & 8.3736 \\
\hline 20 & 21 & 34 & 19 & 2 & 0.0000 & 8.3736 \\
\hline 20 & 19 & 21 & 34 & 2 & 0.0000 & 8.3736 \\
\hline 21 & 20 & 22 & 35 & 2 & 0.0000 & 8.3736 \\
\hline 21 & 35 & 22 & 20 & 2 & 0.0000 & 8.3736 \\
\hline 21 & 20 & 35 & 22 & 2 & 0.0000 & 8.3736 \\
\hline 23 & 28 & 24 & 41 & 2 & 0.0000 & 8.3736 \\
\hline 23 & 41 & 24 & 28 & 2 & 0.0000 & 8.3736 \\
\hline 23 & 28 & 41 & 24 & 2 & 0.0000 & 8.3736 \\
\hline 24 & 25 & 23 & 18 & 2 & 0.0000 & 8.3736 \\
\hline 24 & 18 & 23 & 25 & 2 & 0.0000 & 8.3736 \\
\hline 24 & 25 & 18 & 23 & 2 & 0.0000 & 8.3736 \\
\hline 25 & 26 & 16 & 24 & 2 & 0.0000 & 8.3736 \\
\hline 25 & 24 & 16 & 26 & 2 & 0.0000 & 8.3736 \\
\hline 25 & 26 & 24 & 16 & 2 & 0.0000 & 8.3736 \\
\hline 26 & 38 & 27 & 25 & 2 & 0.0000 & 8.3736 \\
\hline 26 & 25 & 27 & 38 & 2 & 0.0000 & 8.3736 \\
\hline 26 & 38 & 25 & 27 & 2 & 0.0000 & 8.3736 \\
\hline 27 & 39 & 26 & 28 & 2 & 0.0000 & 8.3736 \\
\hline 27 & 28 & 26 & 39 & 2 & 0.0000 & 8.3736 \\
\hline 27 & 39 & 28 & 26 & 2 & 0.0000 & 8.3736 \\
\hline 43 & 42 & 44 & 49 & 2 & 0.0000 & 8.3736 \\
\hline 43 & 49 & 44 & 42 & 2 & 0.0000 & 8.3736 \\
\hline 43 & 42 & 49 & 44 & 2 & 0.0000 & 8.3736 \\
\hline 44 & 45 & 43 & 50 & 2 & 0.0000 & 8.3736 \\
\hline 44 & 50 & 43 & 45 & 2 & 0.0000 & 8.3736 \\
\hline 44 & 45 & 50 & 43 & 2 & 0.0000 & 8.3736 \\
\hline 45 & 46 & 16 & 44 & 2 & 0.0000 & 8.3736 \\
\hline 45 & 44 & 16 & 46 & 2 & 0.0000 & 8.3736 \\
\hline 45 & 46 & 44 & 16 & 2 & 0.0000 & 8.3736 \\
\hline 46 & 51 & 47 & 45 & 2 & 0.0000 & 8.3736 \\
\hline 46 & 45 & 47 & 51 & 2 & 0.0000 & 8.3736 \\
\hline
\end{tabular}




$\begin{array}{lllllll}46 & 51 & 45 & 47 & 2 & 0.0000 & 8.3736 \\ 47 & 52 & 46 & 42 & 2 & 0.0000 & 8.3736 \\ 47 & 42 & 46 & 52 & 2 & 0.0000 & 8.3736 \\ 47 & 52 & 42 & 46 & 2 & 0.0000 & 8.3736\end{array}$

\section{Exemplo de arquivo *.mdp para uma simulação MD de 1 complexo em uma caixa com água}

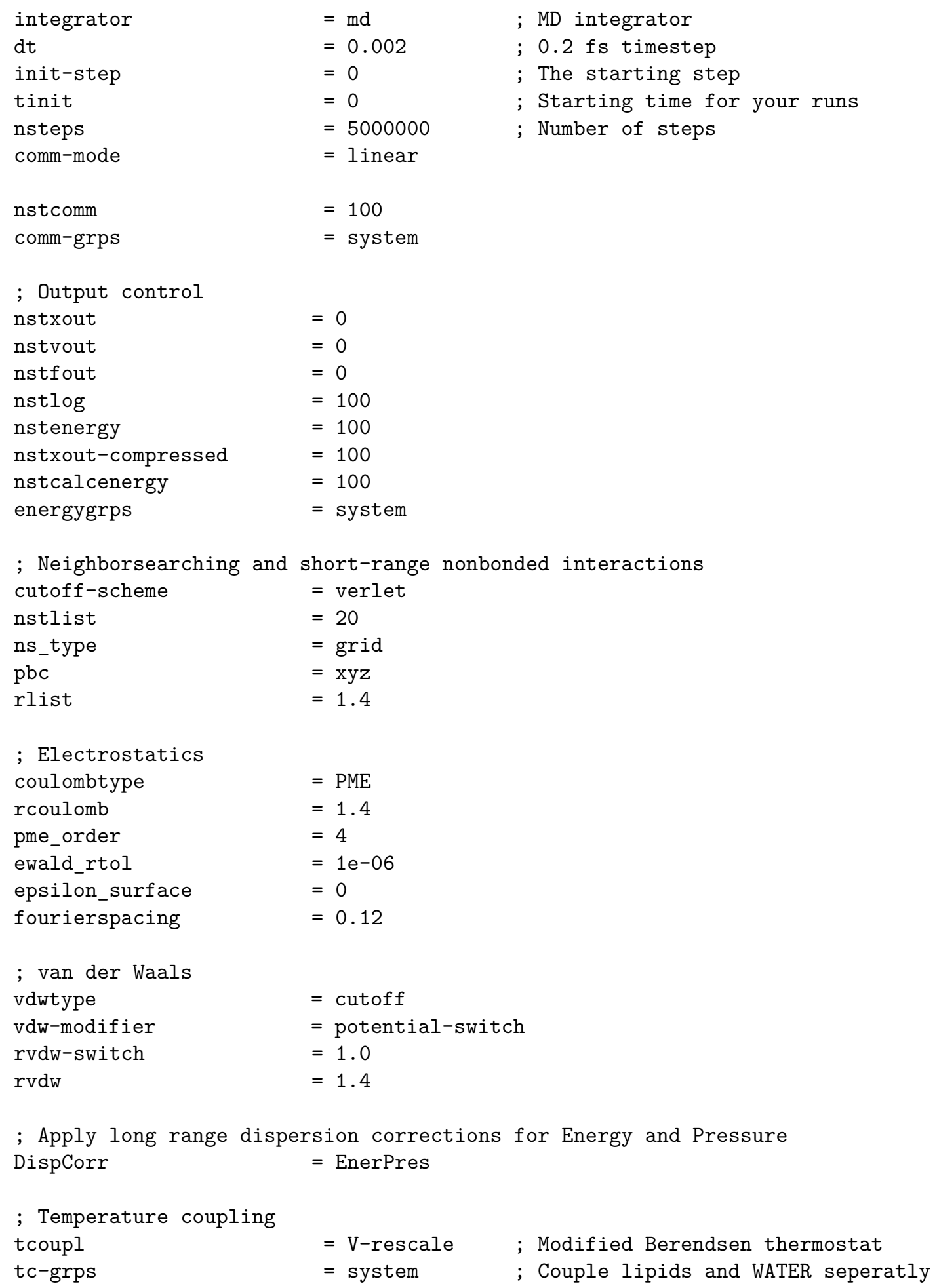




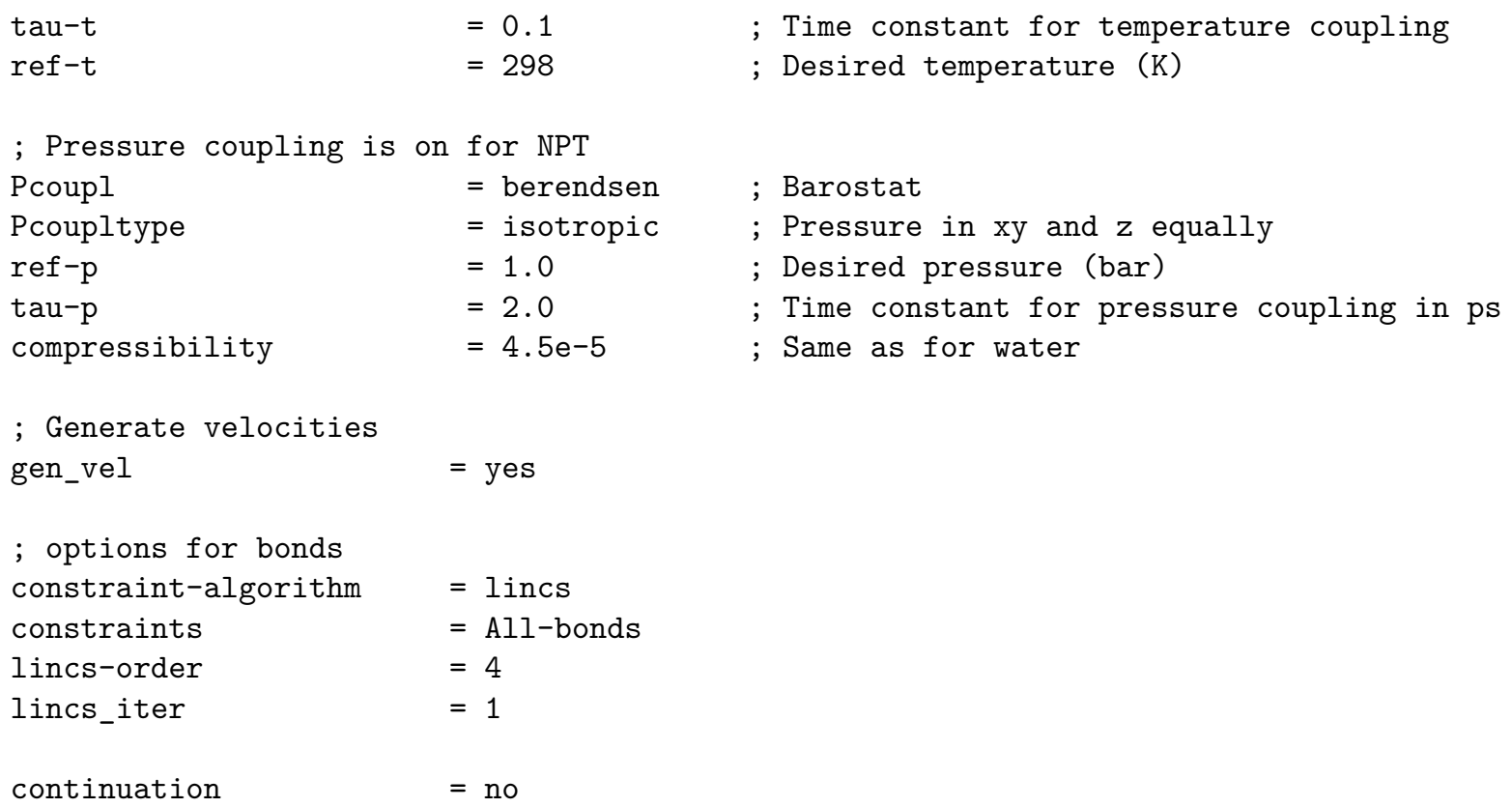

; Generate velocities gen_vel

$=$ yes

; options for bonds constraint-algorithm constraints

$=$ lincs

lincs-order

$=$ All-bonds

lincs_iter

$=4$

$=1$

continuation

$=$ no

\section{Exemplo de arquivo *.mdp utilizado no procedimento BAR-MD para o cálculo da contribuição eletrostática de $\Delta G$}

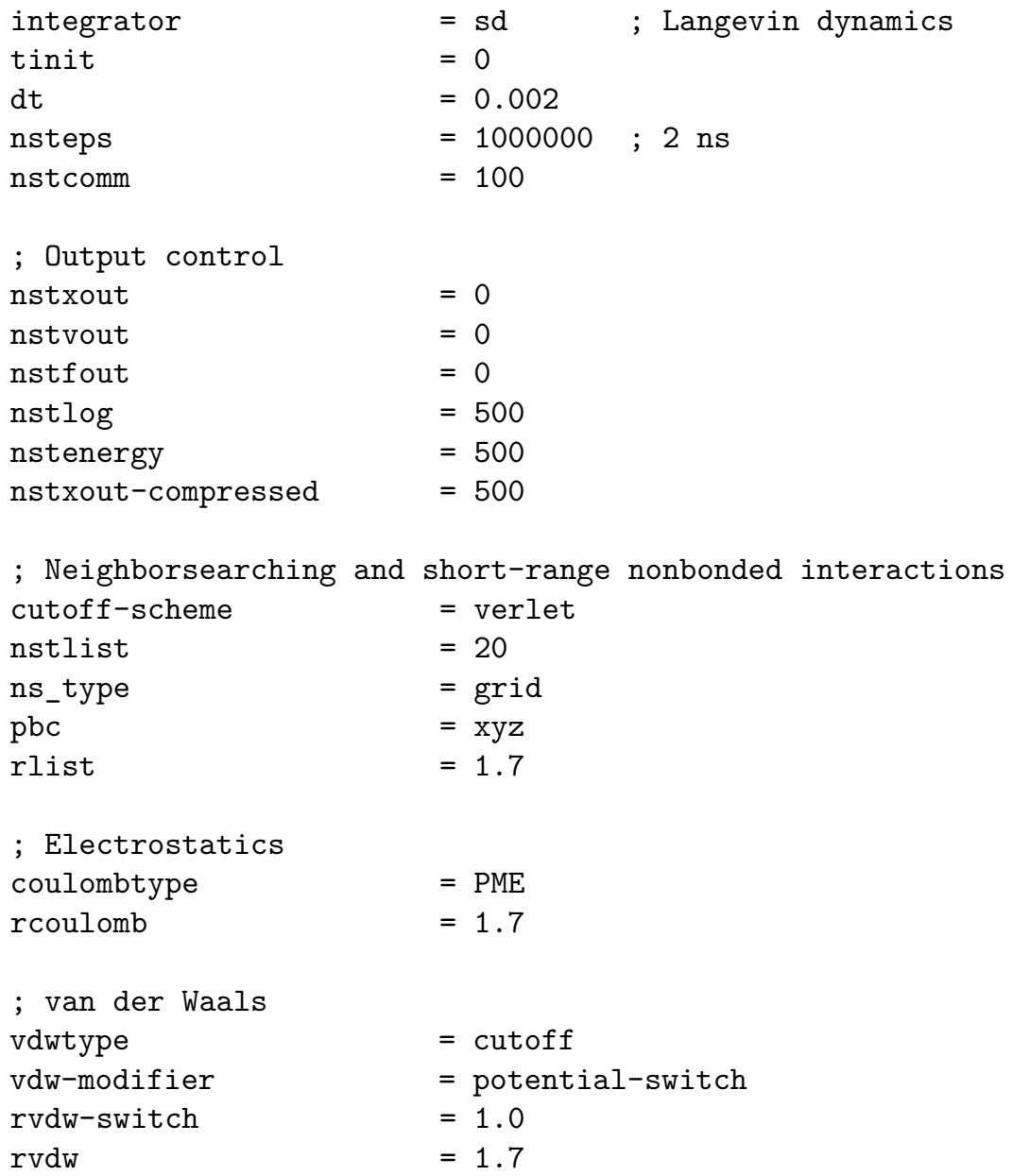


; Apply long range dispersion corrections for Energy and Pressure

DispCorr = EnerPres

; Spacing for the PME/PPPM FFT grid

fourierspacing $\quad=0.12$

; EWALD/PME/PPPM parameters

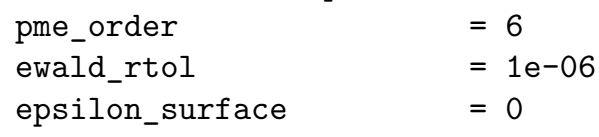

; Temperature coupling

; tcoupl is implicitly handled by the sd integrator

tc_grps = system

tau_t $\quad=1.0$

ref_t $\quad=298$

; Pressure coupling is on for NPT

Pcoupl = Berendsen ; Barostat

Pcoupltype $\quad$ = isotropic ; Pressure in $\mathrm{xy}$ and $\mathrm{z}$ equally

ref $-\mathrm{p} \quad=1.0 \quad$; Desired pressure (bar)

tau-p $\quad=1.0 \quad$; Time constant for pressure coupling in ps

compressibility $\quad=4.5 e-5 \quad$; Same as for water

; Free energy control stuff

free_energy $\quad=$ yes

init_lambda_state $\quad=0$

delta_lambda $\quad=0$

calc_lambda_neighbors $=1$; only immediate neighboring windows

couple-moltype $\quad$ UFF ; name of moleculetype to decouple

couple-lambda1 = vdwq

couple-lambda0 = vdw

couple-intramol $\quad=$ no

; Vectors of lambda specified here

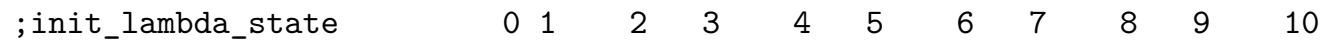

$\begin{array}{llllllllllllll}\text { coul_lambdas } \quad= & 0 & 0.05 & 0.1 & 0.15 & 0.2 & 0.25 & 0.3 & 0.35 & 0.4 & 0.45 & 0.5\end{array}$

$\begin{array}{llllllllll}11 & 12 & 13 & 14 & 15 & 16 & 17 & 18 & 19 & 20\end{array}$

$\begin{array}{llllllllllll}0.55 & 0.6 & 0.65 & 0.7 & 0.75 & 0.8 & 0.85 & 0.9 & 0.95 & 1\end{array}$

; Options for the decoupling

$\begin{array}{ll}\text { sc-alpha } & =0.5 \\ \text { sc-coul } & =\text { no } \\ \text { sc-power } & =1 \\ \text { sc-sigma } & =0.3 \\ \text { nstdhdl } & =10\end{array}$

; Do not generate velocities

gen_vel $\quad$ no

; options for bonds

constraints = all-bonds

; Type of constraint algorithm

constraint-algorithm = lincs

lincs-order $=4$

continuation $=$ yes 


\section{Exemplo de arquivo *.mdp utilizado no procedimento BAR-MD para o cálculo da contribuição não-eletrostática de $\Delta G$}

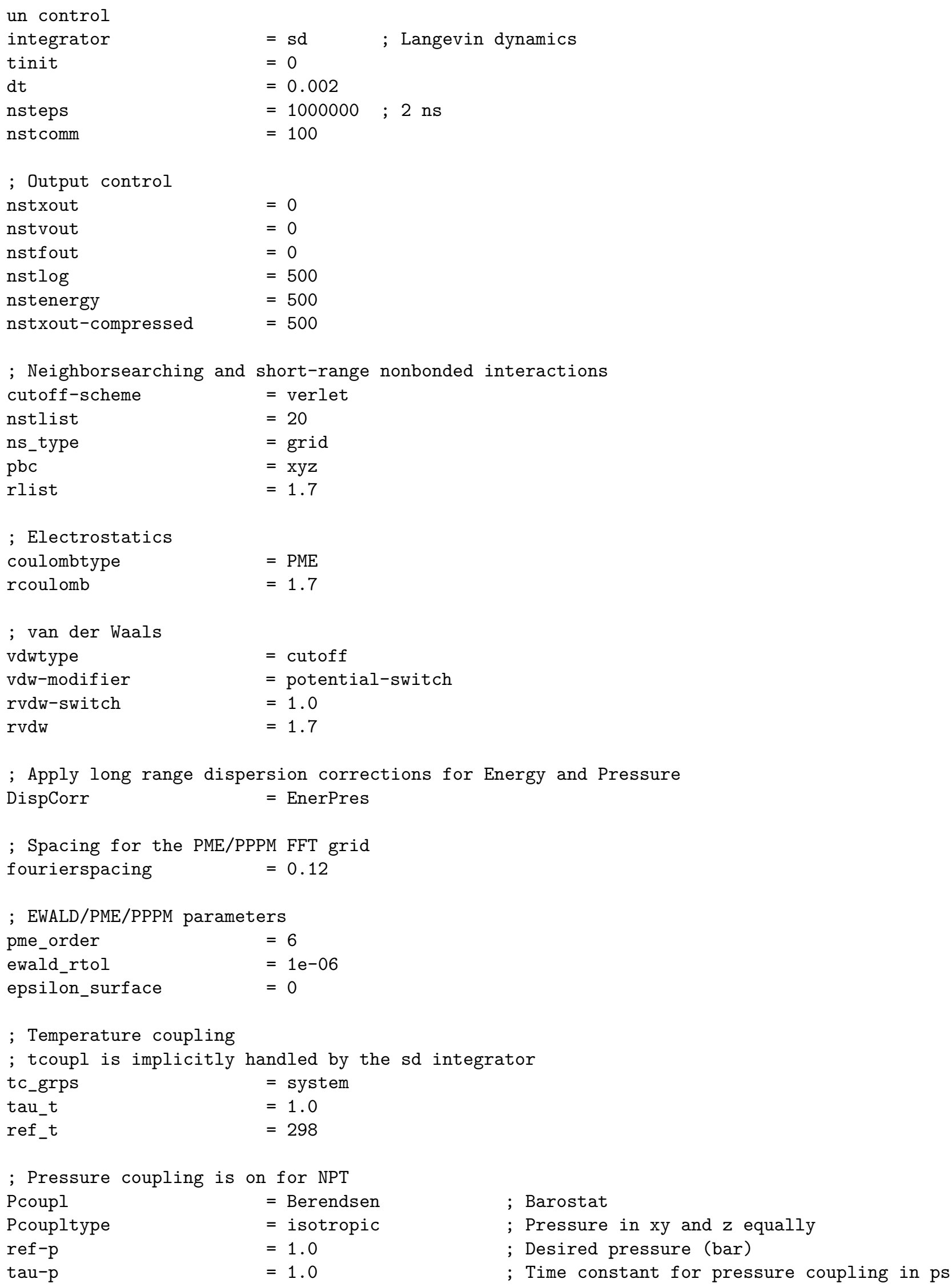




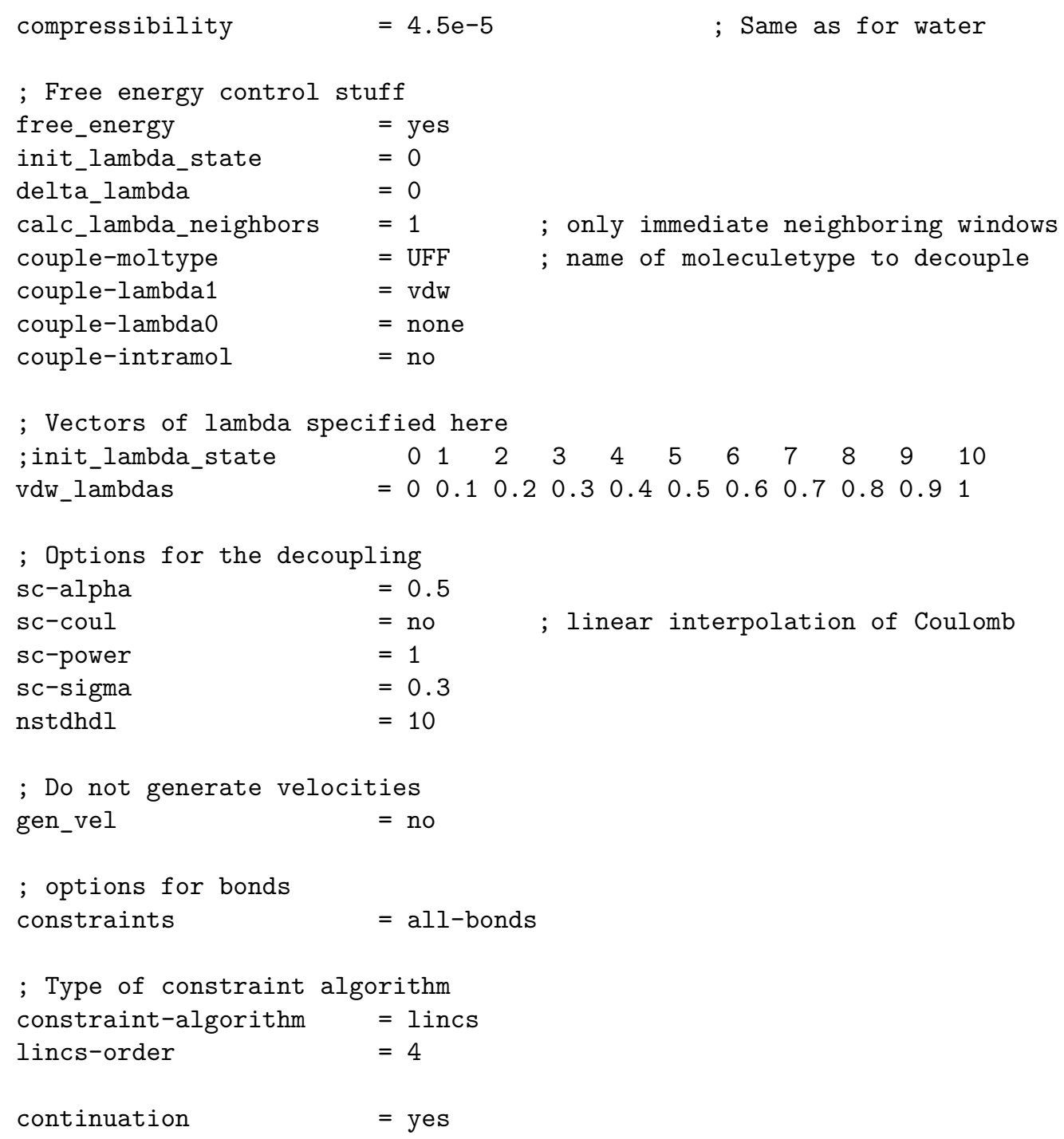




\title{
Exemplos de inputs para simulações de Monte Carlo no Dice
}

\author{
Input *.txt para simulação de equilíbrio NPT do complexo $\mathrm{Ru}^{I I}\left(\mathrm{H}_{2} \mathrm{O}\right)$ \\ no bulk
}

\begin{tabular}{rrrr}
\multicolumn{1}{r}{$*$} & \multicolumn{3}{l}{} \\
2 & \multicolumn{3}{l}{} \\
52 & \multicolumn{1}{c}{$\mathrm{X}$} \\
1 & 6 & -3.26509900 & \multicolumn{1}{l}{-2.46901800} \\
2 & 6 & -2.13290400 & -1.64970300 \\
3 & 7 & -1.57799800 & -1.11986700 \\
4 & 6 & -2.13761900 & -1.40269000 \\
5 & 6 & -3.26159500 & -2.21368900 \\
6 & 6 & -3.83952700 & -2.75542000 \\
7 & 1 & -3.67200600 & -2.41099900 \\
8 & 1 & -1.66090700 & -0.95854000 \\
9 & 6 & -1.80430800 & -1.78196300 \\
10 & 6 & -1.43519700 & -1.29973700 \\
11 & 7 & -0.36217400 & -0.46611500 \\
12 & 6 & 0.35146800 & -0.12874500 \\
13 & 6 & 0.03490200 & -0.58101400 \\
14 & 6 & -1.06820600 & -1.42182000 \\
15 & 1 & -2.66243200 & -2.44269500 \\
16 & 44 & 0.05219200 & 0.13761500 \\
17 & 6 & 4.18879900 & 1.22070500 \\
18 & 6 & 2.96052000 & 0.57896400 \\
19 & 7 & 1.78532900 & 1.27398700 \\
20 & 6 & 1.83306400 & 2.60487200 \\
21 & 6 & 3.02223300 & 3.30074900 \\
22 & 6 & 4.22602500 & 2.59397600 \\
23 & 6 & 3.91472100 & -1.74911300 \\
24 & 6 & 2.82906100 & -0.86703700 \\
25 & 7 & 1.55398000 & -1.30629100 \\
26 & 6 & 1.35649300 & -2.61562900 \\
27 & 6 & 2.39474100 & -3.54073600 \\
28 & 6 & 3.70131600 & -3.09965600 \\
29 & 1 & 1.20267400 & 0.52731100 \\
30 & 1 & -1.34799100 & -1.79457700 \\
31 & 1 & 0.64790400 & -0.27504600
\end{tabular}

Z

0.29604900

0.36251800

$-0.76502800$

$-1.95784100$

$-2.09154600$

$-0.94126300$

$-3.08123100$

$-2.83001600$

2.87365000

1.61303100

1. 46424000

2.55956500

3.83648200

3.99998900

2.97618400

$-0.44329700$

0.09319900

$-0.10369900$

$-0.06384800$

0.15427800

0.35506100

0.32798900

$-0.42179700$

$-0.37527900$

$-0.58912400$

$-0.84756100$

$-0.90904400$

$-0.69096200$

2. 39509500

4.98518700

4.68352400
Q $\mathrm{E}(\mathrm{Kcal} / \mathrm{mol})$

$-0.151$

0.122

$-0.234$

0.099

$-0.128$

0.042

0.133

0.095

$-0.199$

0.249

$-0.420$

0.233

$-0.164$

0.072

0.148

0.944

$-0.176$

0.197

$-0.371$

0.220

$-0.167$

0.076

$-0.187$

0.207

$-0.354$

0.170

$-0.146$

0.065

0.046

0.107

0.134
0.07

0.07

0.17

0.07

0.07

0.07

0.03

0.03

0.07

0.07

0.17

0.07

0.07

0.07

0.03

0.418

0.07

0.07

0.17

0.07

0.07

0.07

0.07

0.07

0.17

0.07

0.07

0.07

0.03

0.03

0.03
S (Ang)

3.55

3.55

3.25

3.55

3.55

3.55

2.42

2.42

3.55

3.55

3.25

3.55

3.55

3.55

2.42

1.80

3.55

3.55

3.25

3.55

3.55

3.55

3.55

3.55

3.25

3.55

3.55

3.55

2.42

2.42

2.42 


$\begin{array}{rrrrrrrr}32 & 1 & -3.70110100 & -2.88214900 & 1.20324500 & 0.139 & 0.03 & 2.42 \\ 33 & 1 & -4.72235300 & -3.39146000 & -1.00502200 & 0.111 & 0.03 & 2.42 \\ 34 & 1 & 0.87755800 & 3.12418900 & 0.16781900 & 0.047 & 0.03 & 2.42 \\ 35 & 1 & 2.99676100 & 4.37615500 & 0.52747800 & 0.134 & 0.03 & 2.42 \\ 36 & 1 & 5.17821500 & 3.10175800 & 0.48172000 & 0.105 & 0.03 & 2.42 \\ 37 & 1 & 5.11704100 & 0.65465500 & 0.05919400 & 0.141 & 0.03 & 2.42 \\ 38 & 1 & 0.32607000 & -2.92367100 & -1.00852200 & 0.060 & 0.03 & 2.42 \\ 39 & 1 & 2.17483300 & -4.58608600 & -1.12274900 & 0.131 & 0.03 & 2.42 \\ 40 & 1 & 4.54082200 & -3.79384800 & -0.72846400 & 0.109 & 0.03 & 2.42 \\ 41 & 1 & 4.92573200 & -1.38801100 & -0.24645200 & 0.145 & 0.03 & 2.42 \\ 42 & 6 & -3.26722800 & 3.82020100 & -0.18266700 & 0.073 & 0.07 & 3.55 \\ 43 & 6 & -2.53920300 & 3.44094100 & 0.94696800 & -0.185 & 0.07 & 3.55 \\ 44 & 6 & -1.61115500 & 2.40844500 & 0.84175300 & 0.222 & 0.07 & 3.55 \\ 45 & 7 & -1.37135900 & 1.74331300 & -0.31237100 & -0.368 & 0.17 & 3.25 \\ 46 & 6 & -2.09014800 & 2.11168400 & -1.39842600 & 0.204 & 0.07 & 3.55 \\ 47 & 6 & -3.03310900 & 3.13619700 & -1.37685000 & -0.199 & 0.07 & 3.55 \\ 48 & 1 & -3.99989800 & 4.62616200 & -0.13263600 & 0.105 & 0.03 & 2.42 \\ 49 & 1 & -2.68458400 & 3.93544000 & 1.90705800 & 0.136 & 0.03 & 2.42 \\ 50 & 1 & -1.03841100 & 2.09662200 & 1.71212800 & 0.030 & 0.03 & 2.42 \\ 51 & 1 & -1.89917700 & 1.56045200 & -2.31671800 & 0.051 & 0.03 & 2.42 \\ 52 & 1 & -3.57463900 & 3.38590100 & -2.28889300 & 0.142 & 0.03 & 2.42 \\ 3 & \text { solvent } \text { Water - tip3 } & & & & & \\ 1 & 8 & 0.62050961 & -1.46679902 & -2.34634898 & -0.834 & 0.1521 & 3.1506 \\ 2 & 1 & 0.79418961 & -2.38063902 & -2.07210898 & 0.417 & 0.0000 & 0.0000 \\ 2 & 1 & 1.21937961 & -1.20438902 & -3.06320898 & 0.417 & 0.0000 & 0.0000\end{array}$

Input *.in para simulação de equilíbrio NPT do complexo $R u^{I I}\left(H_{2} O\right)$ no bulk

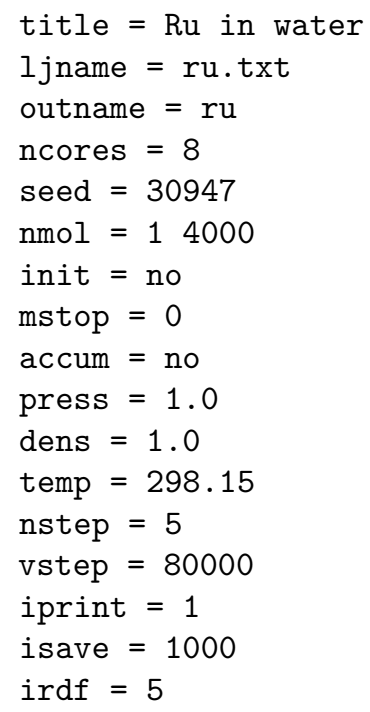

Input * in para simulação de termalização NVT do complexo $R u^{I I}\left(H_{2} O\right)$ na interface água/vácuo

title $=\mathrm{Ru}$ in water-vacuum (NVT)

ljname $=r u . t x t$ 


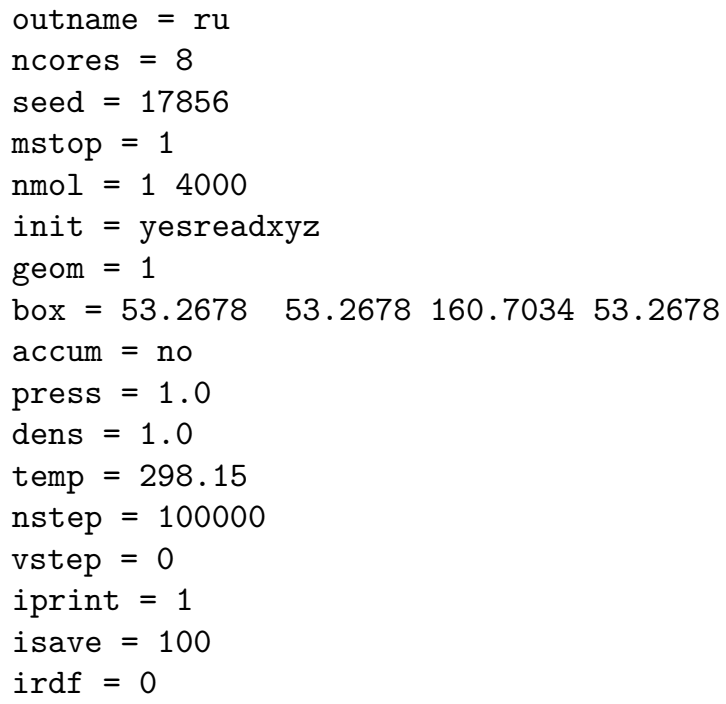





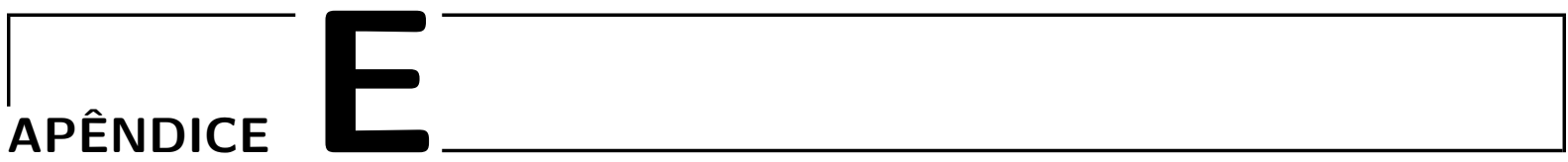

\title{
Exemplos de inputs para cálculos de mecânica quântica no Gaussian
}

\author{
Input para otimização de geometria \\ $\%$ chk $=1$.RuII_H2O_m1c2. chk \\ \#p B3LYP/gen SCF (XQC, NovarAcc, NoIncFock, MaxCycle=100) \\ Pseudo=Read OPT Geom=Check Guess=Read \\ Geometry optimization in vacuum \\ 21 \\ $\mathrm{C} O \mathrm{~N} O$ \\ Aug-cc-pVDZ \\ $* * * *$ \\ $\mathrm{H} O$ \\ cc-pVDZ \\ $* * * *$ \\ $\mathrm{Ru} 0$ \\ S 71.00 \\ $159.3720000 \quad 0.0006730$ \\ $20.9016000 \quad-0.0371610$ \\ $13.0741000 \quad 0.1665170$ \\ $4.7147400 \quad-0.6159540$ \\ $1.1361200 \quad 0.8428300$ \\ $0.5154640 \quad 0.4477630$ \\ $\begin{array}{ll}0.1067670 & 0.0184450\end{array}$ \\ S $7 \quad 1.00$ \\ $159.3720000 \quad-0.0001690$ \\ $\begin{array}{ll}20.9016000 & 0.0093920\end{array}$ \\ $13.0741000 \quad-0.0477130$ \\ $\begin{array}{lr}4.7147400 & 0.2011130\end{array}$ \\ $1.1361200 \quad-0.3734210$ \\ $\begin{array}{ll}0.5154640 & -0.2738590\end{array}$
}




$\begin{array}{rrr}\text { S } & 0.1067670 & 0.6093840 \\ 159.3720000 & \\ 20.9016000 & 0.0008950 \\ 13.0741000 & -0.0396350 \\ 4.7147400 & 0.1442430 \\ 1.1361200 & -0.5192870 \\ 0.5154640 & 1.5854040 \\ 0.1067670 & -0.9082030 \\ 1 & -1.4720020\end{array}$

S 11.00

$\begin{array}{ll}0.0392180 & 1.0000000\end{array}$

$\mathrm{S} \quad 1 \quad 1.00$

$\begin{array}{ll}0.0144000 & 1.0000000\end{array}$

P $6 \quad 1.00$

$\begin{array}{ll}12.8738000 & 0.0299680\end{array}$

$6.1475000 \quad-0.1879300$

$1.5652400 \quad 0.4999900$

$\begin{array}{ll}0.7361940 & 0.4957320\end{array}$

$0.3263170 \quad 0.1475150$

$0.1124070 \quad 0.0060880$

P $6 \quad 1.00$

$12.8738000 \quad-0.0078010$

$6.1475000 \quad 0.0536560$

$1.5652400 \quad-0.1719400$

$0.7361940 \quad-0.1991700$

$0.3263170 \quad 0.0744110$

$0.1124070 \quad 0.5971370$

P $6 \quad 1.00$

$12.8738000 \quad-0.0135020$

$\begin{array}{ll}6.1475000 & 0.0937330\end{array}$

$1.5652400 \quad-0.3159100$

$0.7361940 \quad-0.3618000$

$\begin{array}{ll}0.3263170 & 0.4008770\end{array}$

$\begin{array}{ll}0.1124070 & 0.7537660\end{array}$

P 11.00

$\begin{array}{ll}0.0391720 & 1.0000000\end{array}$

P 11.00

$\begin{array}{ll}0.0137000 & 1.0000000\end{array}$

D $5 \quad 1.00$

$6.2126500 \quad-0.0245970$

$2.7853900 \quad 0.1273340$

$\begin{array}{ll}1.2685100 & 0.3570810\end{array}$

$\begin{array}{ll}0.5517900 & 0.4082070\end{array}$

$0.2247310 \quad 0.2812400$

D $5 \quad 1.00$

$\begin{array}{ll}6.2126500 & 0.0261160\end{array}$

$2.7853900 \quad-0.1459400$

$1.2685100 \quad-0.4425210$

$0.5517900 \quad-0.1690200$ 


\begin{tabular}{|c|c|c|}
\hline \multicolumn{2}{|r|}{0.2247310} & 0.5052370 \\
\hline \multirow[t]{2}{*}{$\mathrm{D}$} & 1.00 & \\
\hline & 0.0824110 & 1.0000000 \\
\hline \multirow[t]{2}{*}{$\mathrm{D}$} & 1.00 & \\
\hline & 0.0302000 & 1.0000000 \\
\hline \multirow[t]{2}{*}{$\mathrm{F}$} & 1.00 & \\
\hline & 0.8500000 & 1.0000000 \\
\hline \multirow[t]{2}{*}{ F } & 1.00 & \\
\hline & 0.2719000 & 1.0000000 \\
\hline \multicolumn{3}{|l|}{$* * * *$} \\
\hline \multicolumn{3}{|c|}{ RU $\quad 0$} \\
\hline RU-ECP & 4 & \\
\hline \multicolumn{3}{|c|}{$\underset{1}{g-u l}$ potential } \\
\hline 2 & 1.0000000 & 0.0000000 \\
\hline \multicolumn{2}{|c|}{ s-ul potential } & \\
\hline 2 & 11.50059000 & 209.78649300 \\
\hline 2 & 5.06857500 & 30.21430700 \\
\hline
\end{tabular}

p-ul potential

4

$2 \quad 10.53263400$

48.75124400

$2 \quad 10.19201000$

97.49652900

24.73489200

7.86018800

24.50906500

15.32975100

d-ul potential

4

$\begin{array}{llr}2 & 8.87797700 & 26.96750600 \\ 2 & 8.76612200 & 40.43230300 \\ 2 & 3.17019600 & 3.34075800 \\ 2 & 3.22885100 & 5.25635200\end{array}$

f-ul potential

2

$\begin{array}{rrr}2 & 7.82024900 & -8.84752500 \\ 2 & 7.83964700 & -11.83551800\end{array}$

\section{Input para cálculo de cargas atômicas CHELPG em solução}

$\%$ chk $=1$.RuII_H2O_m1c2.chk

\#p B3LYP/gen SCF (XQC, NovarAcc, NoIncFock, MaxCycle=100)

Pseudo=Read SCRF (Solvent=Water) POP (Chelpg, ReadRadii) Geom=Check Guess=Read

CHELPG charges in solution

21 
Here comes the basis set

$\mathrm{Ru} 1.0$

Input para gerar orbitais de fronteira usando função de onda restrita

$\%$ chk=1.RuIII_H2O_m2c3.chk

\#p ROB3LYP/gen SCF (XQC, NovarAcc, NoIncFock, MaxCycle=100)

Pseudo=Read SCRF (Solvent=Water) Geom=Check Guess=Read

Frontier molecular orbitals

32

Here comes the basis set

Input para cálculo da energia de ligação com correção de Counterpoise

$\%$ chk $=1$.RuII_H2O_m1c2.chk

\#p B3LYP/gen Pseudo=Read Counterpoise=2 SCF (XQC, NoVarAcc,NoIncFock) Guess=Read

Counter Poise Correction

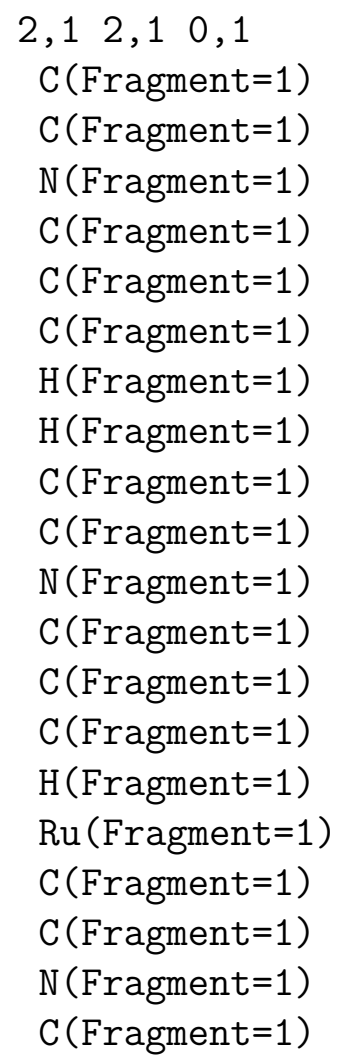

$-4.16100000$

$-2.78398000$

$-1.99684000$

$-2.56757000$

$-3.93051000$

$-4.74126000$

$-4.34469000$

$-1.90032000$

$-2.65957000$

$-2.06236000$

$-0.71049000$

0.03813000

$-0.51441000$

$-1.88684000$

$-3.71914000$

0.02831000

4.19962000

2.82313000

2.08432000

2.71444000
$-0.04305000$

0.18948000

$-0.54504000$

$-1.50527000$

$-1.77625000$

$-1.03113000$

$-2.55075000$

$-2.04622000$

1.98654000

1.18369000

1. 27269000

2. 13762000

2. 95051000

2.87839000

1.91433000

0.01132000

0.00014000

$-0.21263000$

0.52177000

1.44850000
0.18317000

0.11033000

$-0.74234000$

$-1.51155000$

$-1.46924000$

$-0.61021000$

$-2.09650000$

$-2.16323000$

1. 89378000

0.91694000

0.67168000

1. 40453000

2. 38649000

2.63364000

2.08222000

$-0.78956000$

0.35830000

0.22696000

$-0.67187000$

$-1.43929000$ 


\begin{tabular}{lrrr} 
C (Fragment=1) & 4.07967000 & 1.69342000 & -1.34366000 \\
C (Fragment=1) & 4.83546000 & 0.95918000 & -0.42775000 \\
C (Fragment=1) & 2.62804000 & -2.02088000 & 1.99378000 \\
C (Fragment=1) & 2.06731000 & -1.21042000 & 1.00125000 \\
N (Fragment=1) & 0.73236000 & -1.31388000 & 0.68777000 \\
C (Fragment=1) & -0.03514000 & -2.21424000 & 1.35381000 \\
C (Fragment=1) & 0.47961000 & -3.04102000 & 2.34547000 \\
C(Fragment=1) & 1.83329000 & -2.94272000 & 2.67227000 \\
H(Fragment=1) & 1.09171000 & 2.16015000 & 1.18108000 \\
H(Fragment=1) & -2.34453000 & 3.49929000 & 3.38908000 \\
H(Fragment=1) & 0.11944000 & 3.62305000 & 2.94400000 \\
H(Fragment=1) & -4.77932000 & 0.53853000 & 0.84877000 \\
H(Fragment=1) & -5.80398000 & -1.21507000 & -0.55900000 \\
H(Fragment=1) & 2.09288000 & 1.99057000 & -2.13236000 \\
H(Fragment=1) & 4.53674000 & 2.44085000 & -1.97402000 \\
H(Fragment=1) & 5.89776000 & 1.12602000 & -0.32983000 \\
H(Fragment=1) & 4.77639000 & -0.57813000 & 1.06270000 \\
H(Fragment=1) & -1.07379000 & -2.25216000 & 1.07010000 \\
H(Fragment=1) & -0.16760000 & -3.74264000 & 2.84909000 \\
H(Fragment=1) & 2.26180000 & -3.56953000 & 3.43995000 \\
H(Fragment=1) & 3.67427000 & -1.93591000 & 2.24158000 \\
C(Fragment=1) & -1.30606000 & 3.14772000 & -4.40433000 \\
C(Fragment=1) & -0.86417000 & 3.63794000 & -3.17363000 \\
C(Fragment=1) & -0.48414000 & 2.74320000 & -2.17931000 \\
N(Fragment=1) & -0.52495000 & 1.39294000 & -2.35706000 \\
C(Fragment=1) & -0.96491000 & 0.92198000 & -3.55802000 \\
C(Fragment=1) & -1.35474000 & 1.76511000 & -4.59278000 \\
H(Fragment=1) & -1.60587000 & 3.82304000 & -5.19195000 \\
H(Fragment=1) & -0.81506000 & 4.69943000 & -2.98244000 \\
H(Fragment=1) & -0.14448000 & 3.09111000 & -1.21782000 \\
H(Fragment=1) & -0.99867000 & -0.14948000 & -3.66654000 \\
H(Fragment=1) & -1.69349000 & 1.34212000 & -5.52659000 \\
O(Fragment=2) & 0.48754519 & -1.13492233 & -1.99680882 \\
H(Fragment=2) & -66122519 & -2.04876233 & -1.72256882 \\
H(Fragment=2) & -08641519 & -0.87251233 & -2.71366882 \\
& & & \\
\hline
\end{tabular}

Here comes the basis set

\section{Input para cálculo de excitações eletrônicas utilizando CIS}

$\%$ chk $=1$.RuII_H2O_m1c2.chk

\#p CIS (Nstates=50)/gen SCF (XQC, NovarAcc, NoIncFock, MaxCycle=100)

Pseudo=Read SCRF (PCM, Solvent=Water) Geom=Check Guess=Read

CIS excitations

21 
Here comes the basis set

Input para cálculo de excitações eletrônicas utilizando TD-DFT

$\%$ chk=1.RuII_H2O_m1c2.chk

\#p B3LYP/gen SCF (XQC, NovarAcc, NoIncFock, MaxCycle=100)

Pseudo=Read SCRF (PCM,Solvent=Water) TD (Nstates=50) Geom=Check Guess=Read

TD-DFT excitations

21

Here comes the basis set

Input para cálculo de energia eletrônica DFT com correção DKH de ordem zero

$\%$ chk=1.RuII_H2O_m1c2.chk

\#p B3LYP/gen SCF (XQC, NovarAcc, NoIncFock, MaxCycle=100)

$\operatorname{IOP}(3 / 91=3)$ Geom=Check Guess=Read

DKH Energy

21

Here comes the basis set (ANO-RCC-VDZP e.g.)

Input para cálculo de energia livre de vácuo com correções térmicas

$\%$ chk $=1$. RuII_H2O_m1c2.chk

\#p B3LYP/gen SCF (XQC, NovarAcc, NoIncFock, MaxCycle=100)

Pseudo=Read Freq Geom=Check Guess=Read

Harmonic Frequency calculation

21

Here comes the basis set 


\section{Input para cálculo de energia eletrônica usando MP4(SDQ)}

$\%$ chk $=1$.RuII_H2O_m1c2.chk

\#p MP4 (SDQ)/gen SCF (XQC, NovarAcc, NoIncFock, MaxCycle=100)

Pseudo=Read Geom=Check Guess $=$ Read

MP4 (SDQ) Energy

21

Here comes the basis set

Input para cálculo de energia livre de solvatação usando DFT/PCM no gaussian 03

$\%$ chk $=1$.RuII_H2O_m1c2.chk

\#p HF/gen SCF (XQC, NovarAcc,NoIncFock, MaxCycle=100) SCRF (Read, Solvent=Water)

Pseudo=Read Geom=Check Guess=Read

Solvation Free Energy PCM

21

Here comes the basis set

SCFVAC

radii=uahf

Input para cálculo de energia livre de solvatação usando DFT/SMD

$\%$ chk=1.RuII_H2O_m1c2.chk

\#p B3LYP/gen SCF (XQC,NovarAcc,NoIncFock, MaxCycle=100) Pseudo=Read

SCRF (SMD, SC, DoVacuum, Solvent=Water) Density Geom=Check Guess=Read

Solvation Free Energy SMD

21

Here comes the basis set

Input para cálculo da energia de polarização da função de onda

$\%$ chk $=1$. RuII_H2O_m1c2-pcm.chk 
\#p B3LYP/gen SCF (XQC, NovarAcc, NoIncFock, MaxCycle=100) Pseudo=Read Geom=Check

Single point in PCM geometry in vacuum

21

Here comes the basis set

--link1--

$\% c h k=1 . R u I I \_H 20 \_m 1 c 2$ pcm.chk

\#p B3LYP/gen SCF (XQC, NovarAcc, NoIncFock, MaxCycle=100)

Pseudo=Read SCRF (PCM, Solvent=Water) Geom=Check

Single point in PCM geometry in solution to generate the PMC polarized wave function

21

Here comes the basis set

--link1--

$\%$ oldchk $=1$.RuII_H2O_m1c2_pcm.chk

$\%$ chk $=1$.RuII_H2O_m1c2_1scf.chk

\#p B3LYP/gen SCF (MaxCycle=1, Conver=1) Pseudo=Read Geom=Check Guess=Read

1CSF Single point in PCM geometry in vacuum, reading

the PCM polarized wave function

21

Here comes the basis set 
Anexos 



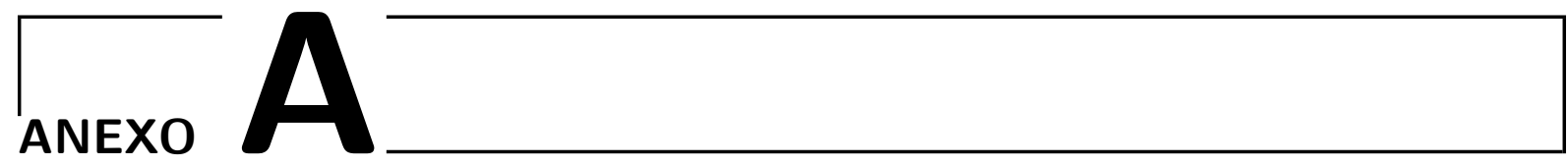

\section{Produção científica durante o doutorado}

\section{A.1 Artigos publicados}

- Leandro R. Franco, Idney Brandão, Tertius L. Fonseca, and Herbert C. Georg. "Elucidating the structure of merocyanine dyes with the ASEC-FEG method. Phenol blue in solution." The Journal of Chemical Physics 145, no. 19 (2016): 194301.

- Idney Brandão, Leandro R. Franco, Tertius L. Fonseca, Marcos A. Castro, and Herbert C. Georg. "Confirming the relationship between first hyperpolarizability and the bond length alternation coordinate for merocyanine dyes." The Journal of Chemical Physics 146, no. 22 (2017): 224505.

- Peter Park, Leandro R. Franco, Hernan Chaimovich, Kaline Coutinho, Iolanda M. Cuccovia, and Filipe S. Lima. "Binding and Flip as Initial Steps for BP-100 Antimicrobial Actions." Scientific Reports 9, no. 1 (2019): 1-14.

- Jose Luis Silva, Isaak Unger, Tiago Araujo Matias, Leandro R. Franco, Giane Damas, Luciano T. Costa, Kalil CF Toledo et al. "X-ray Photoelectron Fingerprints of HighValence Ruthenium-Oxo Complexes along the Oxidation Reaction Pathway in an Aqueous Environment." The Journal of Physical Chemistry Letters 10, no. 24 (2019): 7636-7643.

\section{A.2 Artigos submetidos}

- Leandro R. Franco, Andre Luiz Sehnem, Antonio Martins Figueiredo Neto and Kaline Coutinho. "The Temperature Dependence of the Gibbs Hydration Free Energy and the Thermodiffusion of lons." The Journal of Chemical Physics B (2020).

- Leandro R. Franco, Peter Park, Hernan Chaimovich, Kaline Coutinho, Iolanda M. Cuccovia, and Filipe S. Lima. "Structural and dynamic outcomes of a single antimicrobial peptide binding on a model membrane." Biophysical Journal (2020). 
- Idney Brandão, Tertius L. Fonseca, Leandro R. Franco, Herbert C. Georg and Marcos A. Castro. "Applicability of DFT functionals for evaluating the first hyperpolarizability of the phenol blue in solution." The Journal of Chemical Physics (2020).

\section{A.3 Manuscritos em preparação}

- Leandro R. Franco, Tiago Araujo Matias, Kalil CF Toledo, Moyses Araújo, Koiti Araki and Kaline Coutinho. "Electronic properties of a model of Ru-Aqua/Oxo complexes in water solution".

- Kalil CF Toledo, Leandro R. Franco, Tiago Araujo Matias, Moyses Araújo, Koiti Araki and Kaline Coutinho. "Understanding the structure and electronic properties of bis(2-pyridyl)-benzo-bis(imidazole) by theoretical-experimental approach".

- Leandro R. Franco, Henrique Musseli, Greice Saraiva, lolanda Cuccovia and Kaline Coutinho. "Theoretical and experimental determination of the pKa of 1,8-Naphthalimide in water solution". 